MASS.

EA 37.2:

F $45 / 2$

Arreld Guide to the Dragonflies and Damselflies

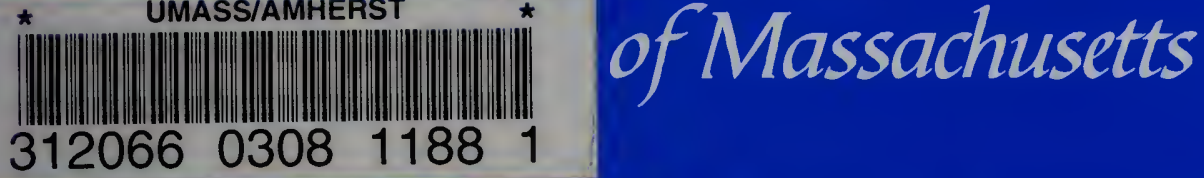

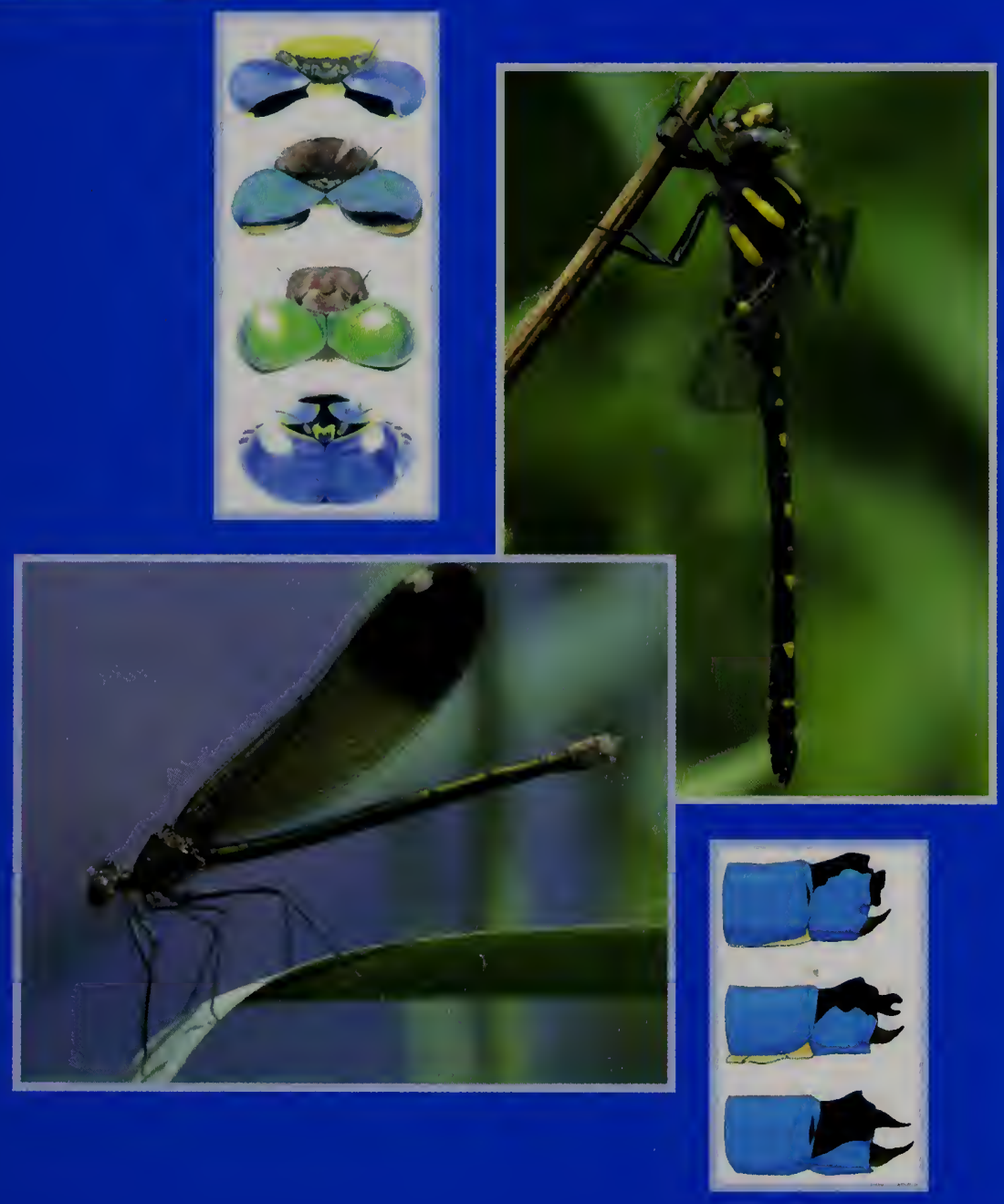

Blair Nikula

Jennifer L. Loose

Matthew R. Burne 
Dragonflies and damselflies are in the insect order Odonata, which has two suborders that occur in Massachusetts, the Anisoptera and Zygoptera, respectively. The Family Key below can be used to determine the taxonomic family, which narrows the number of species to consider and will help avoid misidentifications.

Key characteristics, described in detail in the species accounts, should be carefully examined to determine species identifications (see page 1

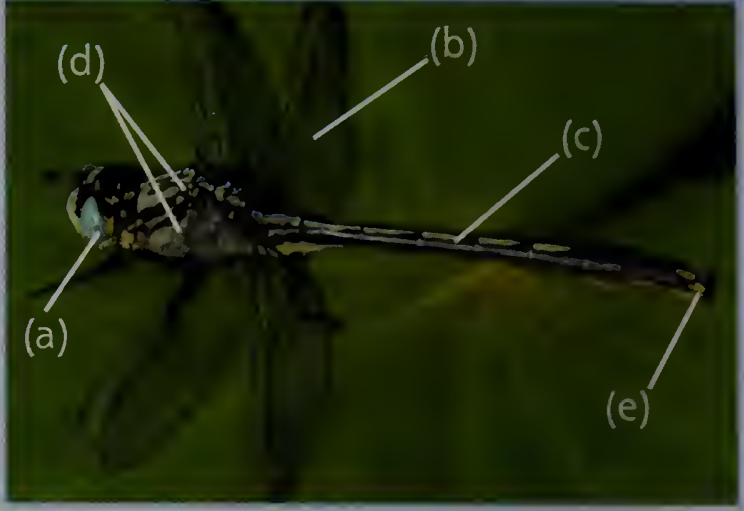
for a diagram of odonate anatomy and key terms). The photograph above illustrates the location of several important characters. The size and relative position of the eyes (a) is an important family characteristic, and eye color may also be helpful in species identification. Wing coloration and markings (b) are often very important in species identification, as are the shape, color, and markings of the abdomen (c). The thorax may be marked with antehumeral (shoulder) and/or lateral thoracic stripes (d) and other unique markings that facilitate field identification. For some species, identification is possible only with careful examination of the genitalia, or terminal appendages (e). Illustrations of male terminal appendages are presented for many species to aid in identification.

\section{FAMILY KEY}

\section{ZYGOPTERA: DAMSELFLIES}

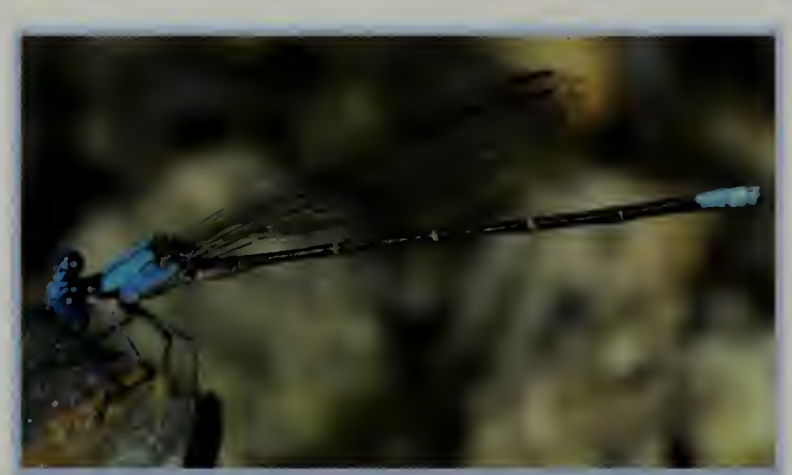

Damselflies: delicate and small bodied with narrow abdomen; head wider than long, with eyes separated by more than their own width; forewings and hind wings similar in shape, held either pressed above the body or only partially open at rest; weak fliers. 1a. Wings colored with amber, black or red, no "stalk" at base (a), body emerald green, blue or bronze:

Calopterygidae (p. 13)

1b. Wings clear or with amber wash with distinct "stalk" at base (b): 2

2a. Wings held partially open at rest (b), unless teneral: LESTIDAE (p. 19)

2b. Wings held pressed together over abdomen at rest (c): CoENAGRIONiDAE (p. 30)

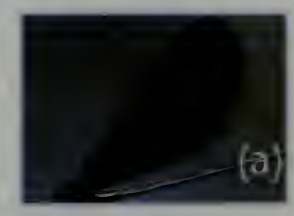

(a)
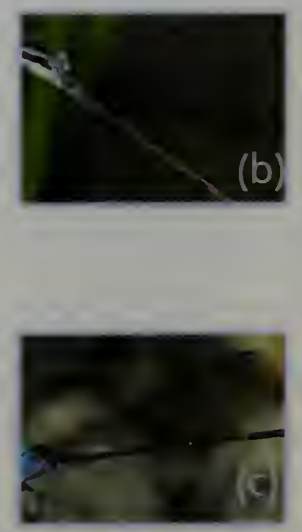


\section{ANISOPTERA: DRAGONFLIES}

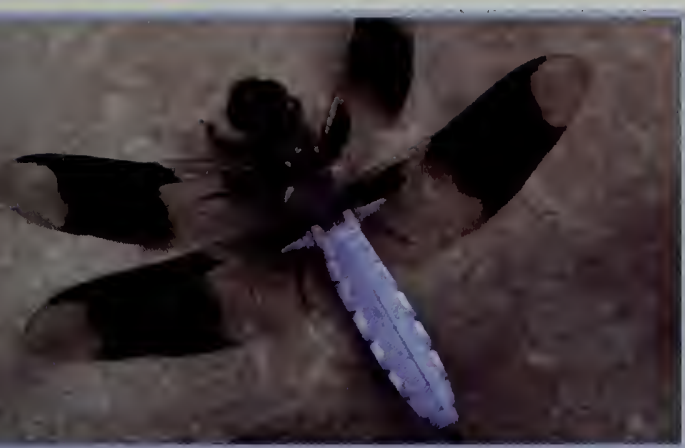

Dragonflies: stout and large bodied; head rounded, with eyes covering much of top and sides of head; forewings and hind wings different in shape, held straight out to the sides at rest; strong fliers. 1a. Eyes separated, not touching on top of head (a): 2

1b. Eyes touching either broadly in a seam on top of the head or just at a point $(b, c, d): 3$

2a. Large (3"), black and grey dragonflies; usually perch vertically: PetAluRIDAE (p. 68)

2b. Small to large dragonflies, black or brown with yellow, green or grey patterning, abdomen often noticeably clubbed on end; perch horizontally: GOMPHIDAE (p. 90)

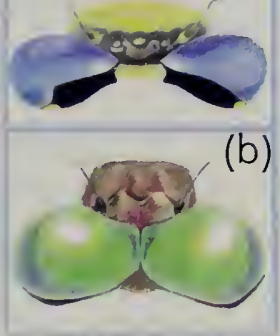

3a. Eyes touch at a single point on top of head (c); thorax dark brown or black with 2 yellow lateral thoracic stripes; perch vertically: CORDULEGASTRIDAE (p. 120)

3b. Eyes touch on top of head, forming a distinct seam (b, d): 4

4a. Eyes very large covering much of the head, meeting on top with long seam (d); large and often brightly colored bodies with blue, green, or yellow, and sometimes red or purple; wings clear or with amber wash; spend long periods on the wing; perch vertically: AESHNIDAE (p. 69)

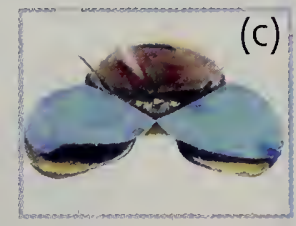


A publication of
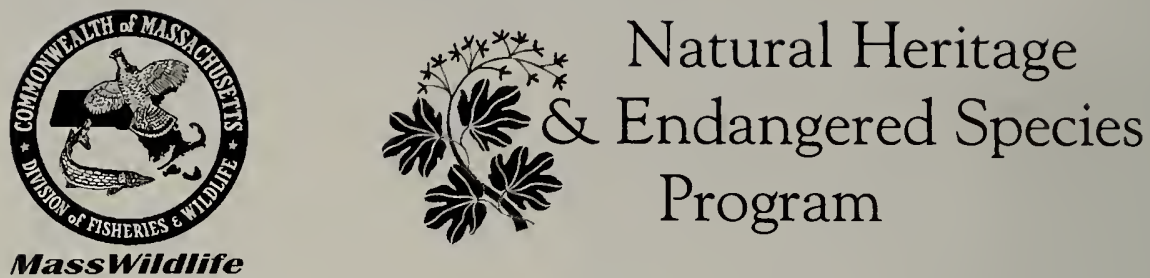

MA Division of Fisheries \& Wildlife

1 Rabbit Hill Road, Westborough, MA 01581

www.masswildlife.org

Funding for the printing of this publication was provided by:

Guy Tudor, President

New York City Butterfly Club

SWEET WATER

TRUST

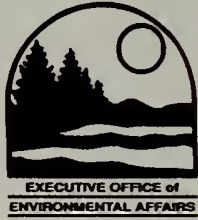

Executive Office of

Environmental Affairs

Commonwealth of

Massachusetts

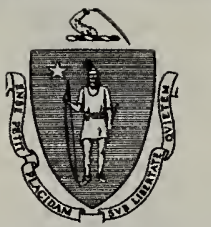

Mitt Romney GOVERNOR

Kerry Healey LIEUTENANT GOVERNOR

Ellen Roy Herzfelder SECRETARY
The Commonwealth of Massachusetts

Executive Office of Environmental Affairs

251 Causeway Street, Suite 900

Boston, $\mathcal{M}$ A 02114-2119

Dear Friend of the Environment,

June, 2003

Dragonflies and damselflies are a fascinating and beautiful component of Massachusetts' biodiversity. This field guide will raise public awareness and understanding of the state's dragonflies and damselflies by providing an excellent educational tool with identification, life history, and conservation information.

Educating people about the natural world helps them connect to it, and thereby increases their interest in our natural heritage. What people will learn from this book, and from spending time outside watching these fascinating creatures, will help to build an appreciation for biodiversity and support for its protection. As Secretary of Environmental Affairs, it is very important for me to build this support and see the great legacy of conservation in Massachusetts continue to grow.

Regards,

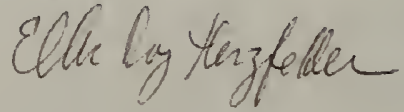

Ellen Roy Herzfelder 


\title{
A Field Guide to the \\ Dragonflies and Damselflies of Massachusetts
}

\author{
Blair Nikula \\ Jennifer L. Loose \\ Matthew R. Burne
}

Massachusetts Division of Fisheries $\&$ Wildlife

Natural Heritage $\&$ Endangered Species Program 


\section{Photographic Credits}

The photographs in this book are the work of Blair Nikula, except as noted below ( $T=$ top, $\mathrm{C}=$ center, $\mathrm{B}=$ bottom, $\mathrm{L}=$ left, $\mathrm{R}=$ right):

J. Bangma: 100B, 107L, 107R, 167T; R.A. Behrstock: 65T, 65B, 168B; M.R. Burne, MNH\&ESP: 6C, 6B, 7T, 7C, 8B, 9B; B. Byrne, MDFW: 11T; R.A. Cannings, Royal British Columbia Museum: 75L, 79R; R. Charlton: 3C; G.P. Doerksen, Royal British Columbia Museum: 25B, 180T; S. Dunkle: 21R, 27R, 35B, 36B, 37B, 39R, 40B, 41B, 43B, 44B, 45B, 48B, 49B, 51B, 53B, 54R, 59B, 73R, 84R, 88R, 110B, 115B, 116B, 118B, 134L, 134R, 136L, 136R, 139R; L.P. Kenney: 2C, 2B, 4C, 7B; R.S. Krotzer: 5C, 17B, 59T, 72L, 84L, 103B, 123L, 130L, 158B, 171B, 182T; J.L. Loose, MNH\&ESP: 151B; MNH\&ESP Files: 6T, 10B; J. Sones: 82R, 113B, 123R; B. Sorrie, MNH\&ESP: 9T; C. Stuart, MNH\&ESP: 10C, 11B; P. Swain, MHN\&ESP: 4B, 9C; J. Trimble: 192B; M.F. Veit: 71L, 108B, 150B; D. Westover: 105T, 105B, 142B, 184B, 187B; H.L. Woolsey, MNH\&ESP: 10T.

Front cover photos (River Jewelwing, Calopteryx aequabilis and Twin-spotted Spiketail, Cordulegaster maculata) by Blair Nikula. Rear cover photos by Matthew R. Burne.

All illustrations by Matthew R. Burne. Front cover illustrations: (upper left) the heads of four dragonfly adults; (lower right) terminal appendages of 3 Massachusetts bluets.

All photographs and illustrations are copyrighted. All rights are reserved.

\section{Acknowledgments}

We would like to thank Maria Aliberti; Bob Barber; Roy Beckemeyer; Paul-Michael Brunelle; Ginger Brown; Brian Cassie; Ralph Charlton; Betsy Colburn; Nick Donnelly; Sid Dunkle; Robert Durand; Dick Forster; David Gabriel; Leah Gibbons; Fred Goodwin; Patricia Huckery; Lynn Harper; Rick Heil; Richard Hildreth; Jeff Horton; Gail Howe; Diane Hinze Kanzler; Leo Kenney; Jim MacDougall; Dave McLain; Mark Mello; Peter Mirick; Fred Morrison; Dennis Paulson; Steve Roble; Fred SaintOurs; Laurie Sanders; Dave Small; Mike Thomas; Jeremiah Trimble; Peter Trimble; Christine Vaccaro; Michael Veit; Dave Wagner; Dick Walton; and Hal White. We would also like to thank Henry Woolsey for all of his support throughout this project.

We are grateful for the critical review of this manuscript provided by Christopher Leahy, Massachusetts Audubon Society; Joan Milam, Massachusetts Audubon Society; Mike Nelson, Massachusetts Natural Heritage \& Endangered Species Program; and Jackie Sones, Rhode Island Natural History Survey.

We would like to thank Alan, Janet and Mason Burne; Lisa Dennehy; Robert Hamersley; Mary, Leland and David Loose; and Jim and Maxine Nikula for all of their support. 


\section{CONTENTS}

Key characteristics for field identification ................................................ i

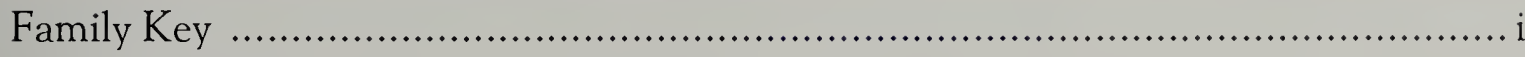

About this book ..................................................................................... vii

What are dragonflies and damselflies? .............................................. 1

Dragonfly anatomy

Adults

Larvae

Biology

Adults

Larvae

Observing odonates

Adults

Larvae

Collection

Field notes

Odonate conservation

Rare species

Identifying dragonflies and damselflies

Key to species accounts

Species Accounts: Zygoptera (Damselflies)

Calopterygidae: Broad-winged Damsels

Lestidae: Spreadwings

Coenagrionidae: Pond Damsels

Species Accounts: Anisoptera (Dragonflies)

Petaluridae: Petaltails 68

Aeshnidae: Darners

Gomphidae: Clubtails 90

Cordulegastridae: Spiketails

Macromiidae: Cruisers

Corduliidae: Emeralds

Libellulidae: Skimmers

Glossary

References

Index and Checklist 


\section{About this book}

This field guide is a product of the freshwater conservation initiative of the Massachusetts Division of Fisheries \& Wildlife's Natural Heritage \& Endangered Species Program. The conservation of freshwater ecosystems is critical to the protection of biodiversity in Massachusetts. Dragonflies and damselflies (Odonata) are an important component of aquatic biodiversity and, as such, are a focus of conservation efforts.

Dragonflies and damselflies are an exciting group of animals to study, being both beautiful and dramatic. Recent growth in the popularity of dragonfly watching and study was, in part, the inspiration for this field guide which is the first to cover the entire fauna of Massachusetts. Virginia Carpenter's Dragonflies and Damselflies of Cape Cod (Cape Cod Museum of Natural History, 1991; now out of print) is notable in that it was one of the first regional field guides to this fascinating insect order. Although odonates have been surveyed locally for over 100 years, and the statewide distribution of most species is fairly well known, many gaps in our knowledge remain, particularly on the islands of Martha's Vineyard and Nantucket. Although specific to Massachusetts, this book will be useful across a wider geographic area as the ranges of most species extend beyond Massachusetts.

This book will assist in the identification of the 166 species of dragonflies and damselflies that have been recorded in Massachusetts. For some groups of species we have included illustrations of characteristics such as male terminal appendages or thoracic stripes that are important for species identification. However, diagnosis of some species, and many females, is very difficult and may not be possible in the field. We have provided references and additional resources that are available for these cases (p. 194).

Odonate larvae present a fascinating study in identification, biology, and ecology. Larval sampling is one of the best ways to develop an understanding of species presence and population structure in a habitat. However, identifying larvae to species often requires examination under a microscope and the use of dichotomous keys, which is beyond the scope of this field guide. On the first page for each family (with the exception of Petaluridae: Petaltails, p. 68) we include an illustration of a typical larva of the family and point out some of the characters useful in diagnosing larvae of that family.

Copyright $\odot 2003$ Massachusetts Division of Fisheries \& Wildlife

Designed by Matthew R. Burne

Manufactured in the United States of America

Copies of this book are available through the Massachusetts Division of Fisheries \& Wildlife's Natural Heritage \& Endangered Species Program, Route 135, Westborough, MA 01581, (508) $792-7270$, ext. 200. 
Dragonflies and damselflies are insects of the taxonomic order Odonata, so named for their formidable biting mouthparts (odon meaning tooth in Greek) and predatory nature. Two suborders occur in North America, Anisoptera (dragonflies) and Zygoptera (damselflies). Though "dragonfly" refers to the Anisoptera, it is often used to refer to the entire order.

\section{Dragonfly anatomy}

A basic understanding of dragonfly anatomy is important in distinguishing odonates from other insects as well as in identifying species. Terms illustrated in the following diagram are used repeatedly in the keys and species accounts in this book. All insects have 3 major body sections: head ( $\tan )$, thorax (blue), and abdomen (green).
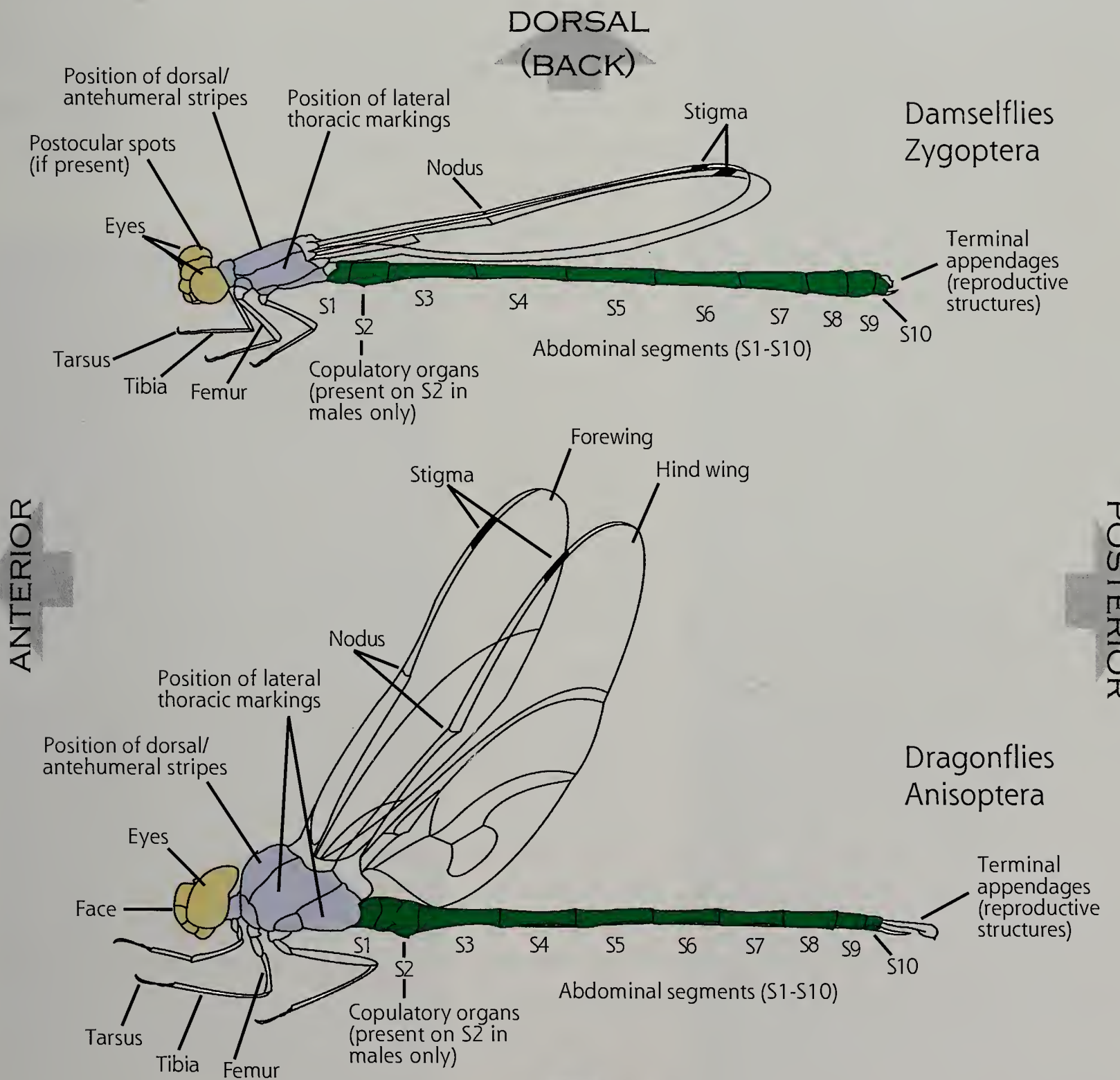

\section{VENTRAL \\ (UNDERSIDE)}


Odonates have highly developed, multifaceted compound eyes; in some families the eyes cover nearly the entire head, meeting in a broad seam along the top. The antennae are very small and inconspicuous, unlike those of many other insect orders. They have two pairs of densely veined wings. Odonates lack the hinge at the base of the wing that allows most other insects to fold them back against the body. They therefore hold their wings straight out to the sides (dragonflies) or pressed together vertically above the abdomen (most damselflies). The abdomen is very long, often accounting for more than two-thirds of the body length, and generally narrow in relation to overall body size. The abdomen has 10 segments and bears terminal appendages that are often important in species identification. Adult male dragonflies are distinguished from females (as well as other insects) by a secondary reproductive structure used during copulation that is located on the ventral side of the second abdominal segment (S2).

Dragonflies are generally large, stout animals while the damselflies are much smaller and delicate. However, a diagnostic character is the shape of the base of the wings. In the dragonflies the base of the hind wing is greatly broadened and different from the narrow base of the forewing. In the damseflies, the base of the hind wing is very similar to that of the forewing.

\section{Larvae}

Odonata are unique among aquatic insect larvae, having an articulated labium (lower jaw) that is extended outward for capturing prey. It is a long, jointed structure that is attached at the base of the head and folded under the thorax. When retracted, the labium fits mask-like over the face or flat against the bottom of the head. In lightning-quick action the larva shoots the labium outward, grasps prey, and draws it into the powerful mandibles. The presence of the articulated labium and vestigial antennae are unmistakable characteristics of odonate larvae.

Dragonfly larvae are generally more robust and larger than damselflies. The abdomens of dragonfly larvae are at least slightly flattened and are broader than the thoraxes. In damselfly larvae, the abdomens are narrow and cylindrical, as wide or only slightly narrower than the thoraxes. The diagnostic character differentiating the suborders is gill structure. Dragonflies have internal rectal gills, and a cluster of 5 short, stiff structures at the end of the abdomen. In contrast, damselfly larvae have a set of 3 external, feather-like gills called caudal lamellae at the end of the abdomen.

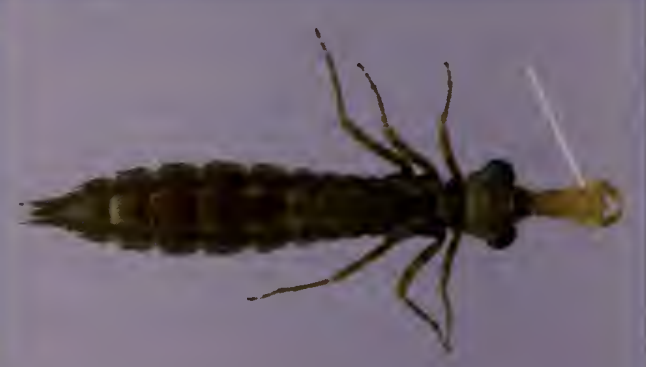

The articulated labium, or lower jaw, which in some species is nearly as long as the legs when extended, is unique to the Odonata.

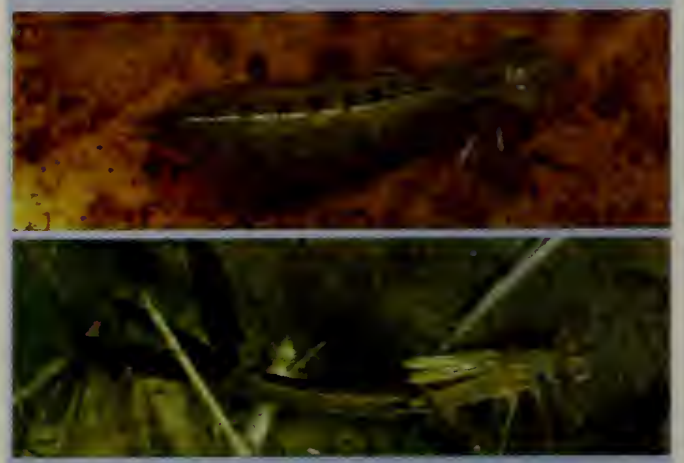

Dragonfly larvae (top) are stout with 5 short, stiff spines at the end of the abdomen. Damselfly larvae (bottom) are slender and have 3 feather-like gills at the end of the abdomen. 


\section{Adults}

After emergence from the aquatic larval stage, dragonflies begin what is essentially a terrestrial existence. They are initially called tenerals until the exoskeleton hardens and the wings lose their iridescent sheen. Tenerals are generally very weak in flight and are extremely vulnerable at this stage. Newly emerged dragonflies undergo a prereproductive period, sometimes straying far from water, while the reproductive organs mature. At this stage they are often seen hunting along forest edges, and in clearings and open fields. Adults typically live for about a month, though individuals of the larger species may survive for a couple of months.

As dragonflies mature they begin the reproductive stage of their lives. Males of some species are territorial, and after finding appropriate breeding habitat will attempt to establish and vigorously defend a territory. Some species will remain in flight for long periods, tirelessly patrolling a length of pond shore. Others perch on branches, stems, or rocks and make short forays away from the perches to defend their territories or capture a meal, then return to their perches. Females of most species frequent wetlands only when ready to mate.

Dragonfly mating is a unique spectacle. The pair forms a "mating wheel." The male grasps the female at the back of her head with the terminal appendages at the end of his abdomen. The female then curls her abdomen forward such that the opening at the end of her abdomen comes in contact with the male's sexual organs, located on the ventral side of the second abdominal segment at the base of his abdomen. Prior to forming a mating wheel with a female, the male transfers a packet of sperm (a spermatophore) from the end of his abdomen to the sexual organs. Before he transfers his spermatophore to the female, the male may remove spermatophores present in the female from any previous mating. After mating has occurred, the male may leave; fly with and guard the female while she oviposits; or guard by remaining in tandem (still grasping the female at the back of the head) while

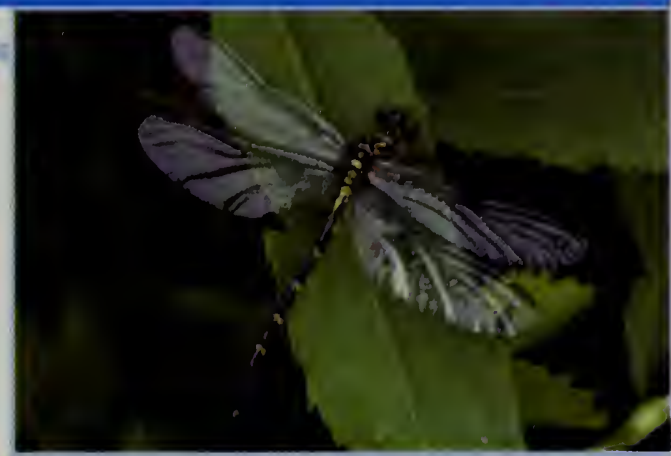

After emergence, the teneral adult's exoskeleton and wings are not yet hard and flight is weak.

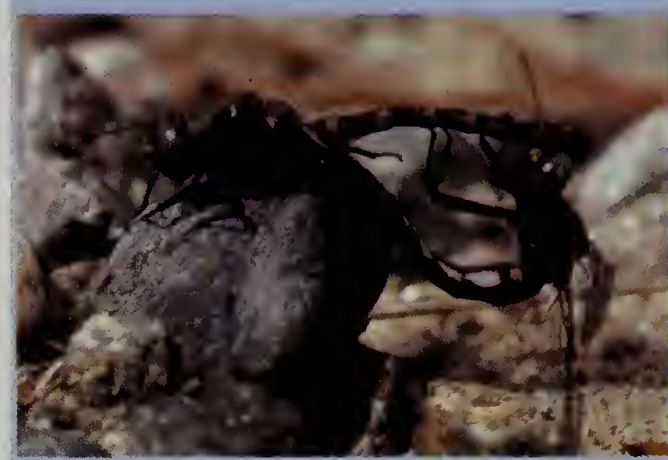

Odonates exhibit a unique mating behavior, copulating in a heart-shaped "mating wheel." The male grasps the female behind the head and the female then curls her abdomen forward and upward, joining the male on the underside of his abdomen.

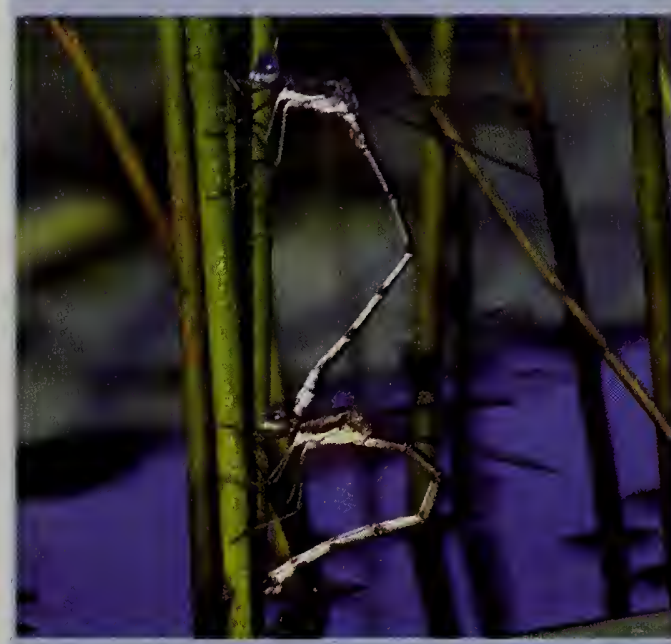

Many species oviposit while in tandem to reduce competition from other males, who have the ability to remove sperm from prior mating. 
eggs are deposited. Guarding allows a male to prevent the removal of his own sperm by competing males.

Females lay eggs (oviposit) in one of three methods, depending on the species. Eggs are either inserted into the stems of reeds and sedges, moss, rotten wood, or mud (endophytic oviposition); laid directly on the surface of leaves or stems (epiphytic oviposition); or directly into the water (exophytic oviposition). The shape of the ovipositor reflects the method of oviposition. Blade-shaped ovipositors are found in species that slice open plant stems to insert eggs; spoutshaped ovipositors are found in species that drive eggs into mud; species without distinct ovipositors generally oviposit directly into the water. In some species, eggs hatch soon after being laid, while other species may overwinter as eggs either in plant tissue or in dried mud.

\section{Larvae}

Larvae of all Massachusetts species are truly aquatic with the exception of the Gray Petaltail ( Tachopteryx thoreyi), which is thought to develop in wet, mossy seeps. The majority of an odonate's life is spent in the larval stage which lasts from several months in some species to $3-5$ years or longer in others, while the adult stage is much shorter (a few days to a few months). The wetland habitat that supports larval development is therefore the most critical factor regulating the persistence of populations.

Odonates are found in a great diversity of wetlands. They can be found in lakes and large rivers, small vernal pools and shrub swamps, and in nearly every other type of wetland and water body. The wide variety of conditions in which odonates breed (for example, the presence or absence of aquatic vegetation, woody debris, silt, mud, or cobble) has led to the evolution of different life styles among species (life histories), and to differences in larval body shape and structure. Dragonfly larvae can be classified by their body shape as claspers, sprawlers, hiders, or burrowers. Claspers are long and cylindrical and tend to cling to aquatic vegetation (e.g., Aeshnidae). Sprawlers have elongated legs and a flattened body and tend to be found among bottom debris (e.g.,
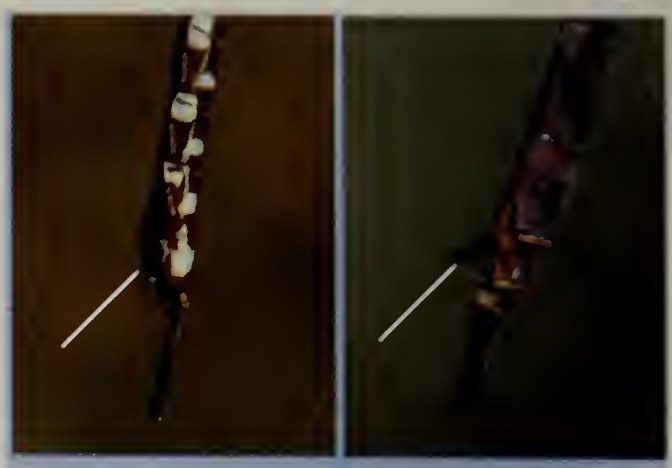

Blade-like ovipositors (left) are used to cut into plant tissue, allowing females to insert eggs. Spout-like ovipositors (right) are used to drive eggs into mud, moss, and other substrates.

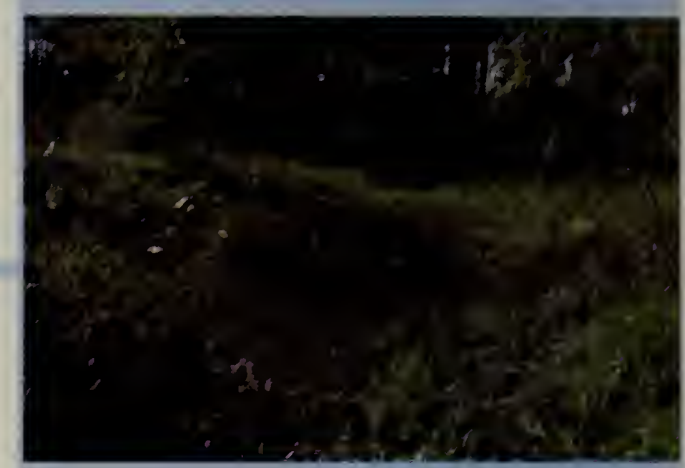

Some species may take advantage of temporary habitats, such as vernal pools. These are often fish-free, effectively reducing predation on odonate larvae.

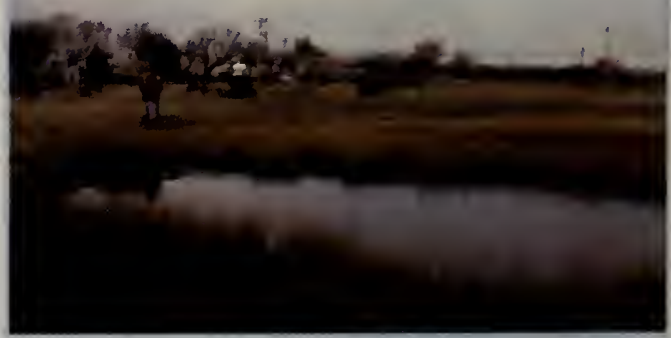

There are not many aquatic insects that develop in the saline water of salt marshes. One exception is the Seaside Dragonlet (Erythrodiplax berenice) which breeds in these saline wetlands. 
Corduliidae). Burrowers are stoutly shaped with legs that are adapted for digging into sand or mud (e.g., Gomphidae). Hiders are also flattened and tend to hide among flakes of bark and other debris (e.g., the Dragonhunter, Hagenius brevistylus).

Dragonfly larvae are voracious predators. Within fish-free habitats such as vernal pools, dragonfly larvae may become the top predators as their size increases. The larvae of large species (some of which reach nearly 3") are capable of catching tadpoles and small fish. As in the adults, the compound eyes are highly developed, and larvae are acute visual predators. Larvae that burrow or hide among bottom sediments will lie with only their eyes and antennae above the sediment, waiting for prey. Dragonflies are opportunistic predators, eating anything that they are able to grasp and subdue. Dragonfly larvae with streamlined bodies are fast swimmers and may actively hunt for prey; those with flattened bodies and widespread limbs hide among detritus at the bottom and wait for prey to happen by. Most damselflies are weak swimmers and hunt by hiding among aquatic vegetation, camouflaged by cryptic coloration, and waiting for prey.

At the end of the larval stage, an odonate undergoes metamorphosis. The adult, still in the skin of the last larval stage, crawls out of the water and then emerges (called eclosion) from the larval skin (the exuviae). Emergence takes place on bridge abutments, sandy shoals, vegetation, and other available substrates. Adults of many species emerge right at the water's edge, while some crawl considerable distances before eclosion. Exuviae of some species may be found 100 feet or more from the larval habitat. During eclosion, the larval skin is split along the back and head, and the adult dragonfly pulls itself free. The dragonfly pumps its body full of air, sends fluid into the wing veins, and expands into the familiar adult form. Initially the teneral adult is pale and soft, and the wings have a characteristic pearlescent sheen. Within a day or so, the wings lose their teneral sheen, the body becomes entirely hardened, and the colors characteristic of the species begin to develop.

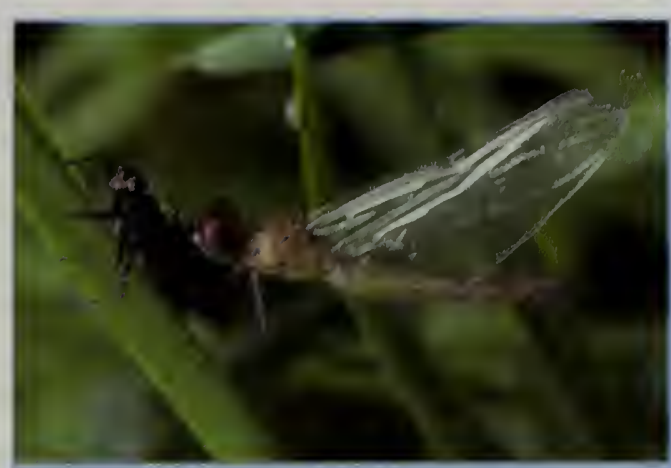

The pharate adult, still in the skin of the last larval stage, emerges from the water on grass stems, bridge abutments, or other suitable substrates and begins the process of eclosion. The larval skin is split along the back and the adult then pulls itself free. The shed larval skin (exuviae) remains after eclosion.

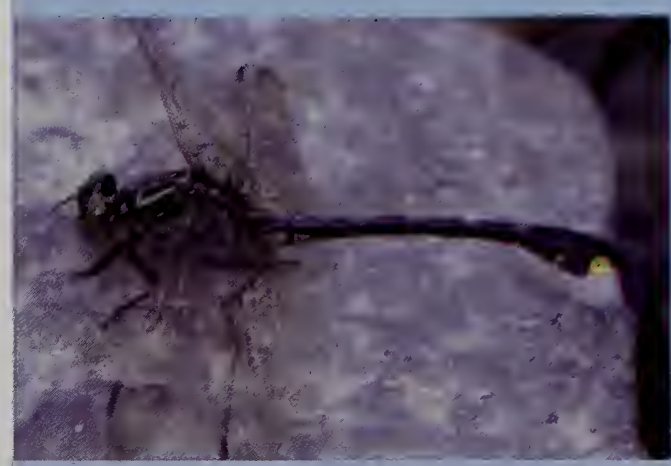

Initially a vibrant yellow, the thoracic markings of the Cobra Clubtail (Gomphus vastus) fade to a dull olive green as the adult ages.

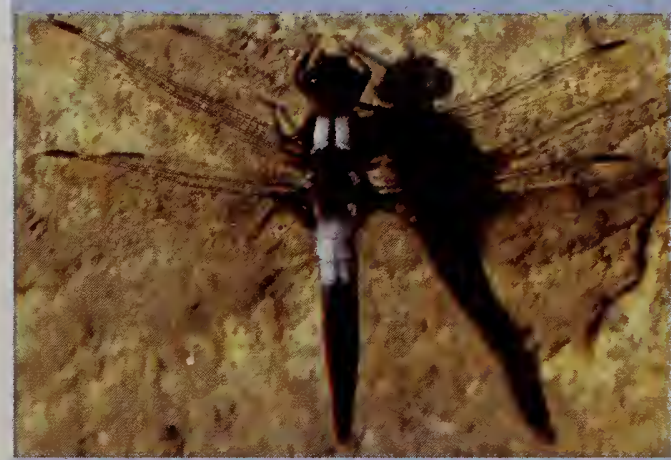

Over time, coloration may change in some species such as the Chalk-fronted Corporal (Libellula julia). A powdery coating called pruinosity develops, which imparts a chalky-white to frosty blue hue, depending on the species. 
Adults

Identifying the many species of odonates is challenging. Having the animal in-hand permits a close-up look at the colors, patterns, and other details that allow an accurate identification. Close-focus binoculars, a good insect net (preferably one with a long handle), and a small hand lens or loupe (10X or $14 \mathrm{X}$ ) are the tools of the trade, and will be invaluable in learning to identify Odonata.

Though challenging, especially for the fast and powerful fliers, catching dragonflies with an insect net is a sublime way to spend a hot summer's afternoon. Patience and practice will increase your success with even the most high-flying and aerobatic species. Always try to swing from behind or below the insect to reduce the chance it will see the net and evade your swing. Head-on swings are rarely successful and are more likely to damage the insect.

Once netted, a twist of the wrist will close the opening of the net and trap the dragonfly. Extracting a dragonfly from the net takes as much practice as getting one into it, and many will escape while you gain experience! After carefully reaching into the net, the dragonfly's wings can be brought together over its back, allowing you to hold the animal securely without harming it. A dragonfly can give your finger a strong nip, but their bite is harmless. The dragonfly can be held by the wings while the field guide is consulted, allowing easy comparisons between photographs, descriptions, and the animal in hand.

In general, dragonflies are most active from midmorning to mid-afternoon on sunny days. However, understanding the various habitat preferences and activity patterns of different species can increase the chance of encountering a greater variety of dragonflies. For example, shadowdragons (Neurocordulia) are active for only a brief period at dusk. During the height of summer some species will swarm during the late afternoon, well away from wetlands, hunting mosquitos and other flying insects. Walking power lines and climbing hilltops during the afternoon or evening can greatly increase the chances of encountering impressive

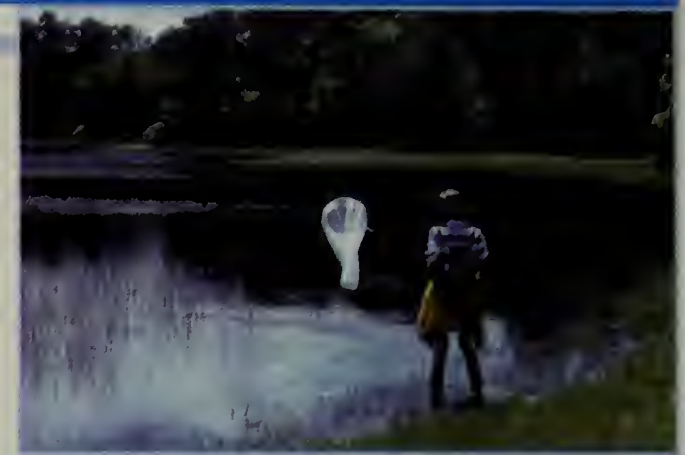

A long-handled insect net is essential for catching dragonflies. Once in the net, pinch the animal's wings together over its back to bring it out of the net for close inspection.

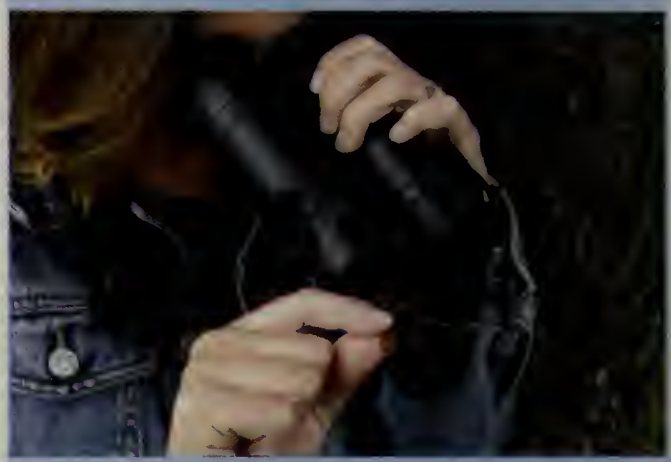

Using a small hand lens (or even looking the "wrong" way through a pair of binoculars), look at the terminal appendages and other details, that are important in identifying some species.

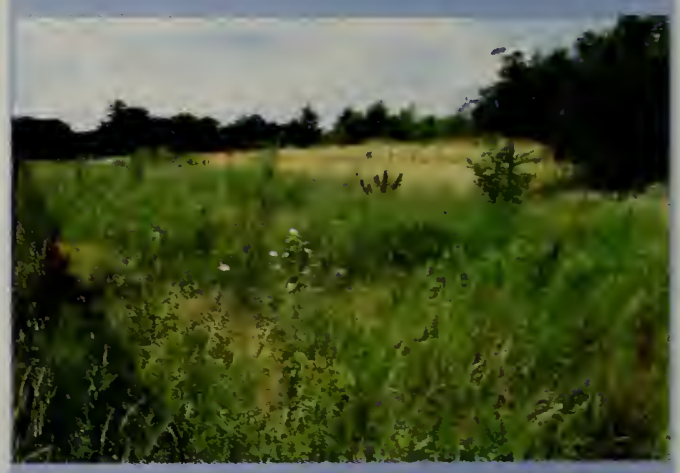

Power line cuts, fields, and other clearings are great places to observe the phenomenon of feeding swarms which may comprise several different species of dragonflies. 
swarms of big darners (Aeshna) and emeralds (Somatochlora). Patiently waiting along the banks of a stream, you may be rewarded with the sighting of an elusive riverine clubtail.

The odonate flight season in the Northeast typically extends from about mid-April to mid-November, though unusually warm or cold weather can extend or contract the season. In the Northeast, the greatest diversity of species is found during July. Although a few species have long adult flight periods, most are on the wing for just a month or two, and fall into one of three categories: "spring," "summer," or "fall" fliers. Spring fliers generally emerge in May and fly through June into early July. Summer fliers appear in June and are on the wing through August or early September. Fall fliers generally emerge in mid-summer and fly through early October, although a couple of species may linger into November.

\section{Larvae}

Finding larval dragonflies requires a good pair of boots or the willingness to get wet, a stout-handled dip net, and a plastic or metal tray into which a sample can be dumped. Since dragonflies breed in all types of wetlands and aquatic systems, searching for larvae in a variety of habitats such as marshes, kettlehole bogs, fast-flowing and boulder-strewn rivers, etc., will turn up a great diversity of species. Larvae are present throughout the year, but summer searches will typically yield the most species.

Collecting the cast skins (exuviae) of larvae is a great way to learn which species are found in an aquatic system. The exuviae may persist for quite some time after the adult has emerged, and in many cases can be used to identify the species with a taxonomic key. Searching for exuviae is less disruptive to the aquatic habitat than dip net sampling and provides confirmation of successful larval development. Collection of larvae and exuviae are the best ways to document successful reproduction at a site. Larval sampling is one of the best ways to measure species abundance and population structure.

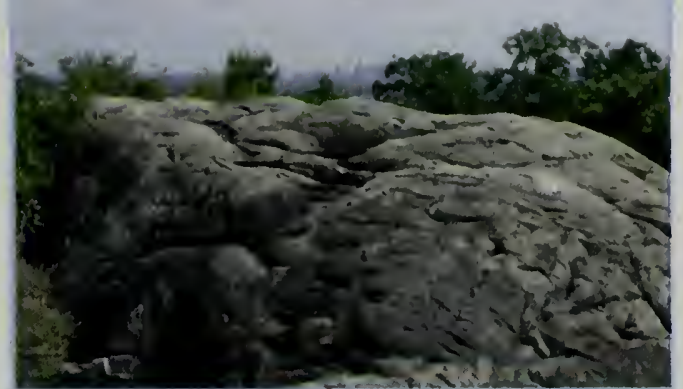

Many species of insects, including some odonates, gravitate to the highest point on the horizon, such as hill tops and ridges.

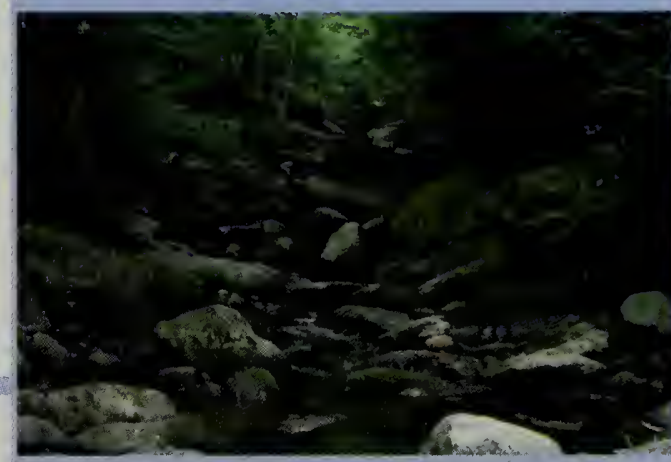

While many odonate species wander from their natal wetland habitats, others, especially many forest stream dwellers, apparently do not. These species are rarely encountered more than a few meters from their streams.

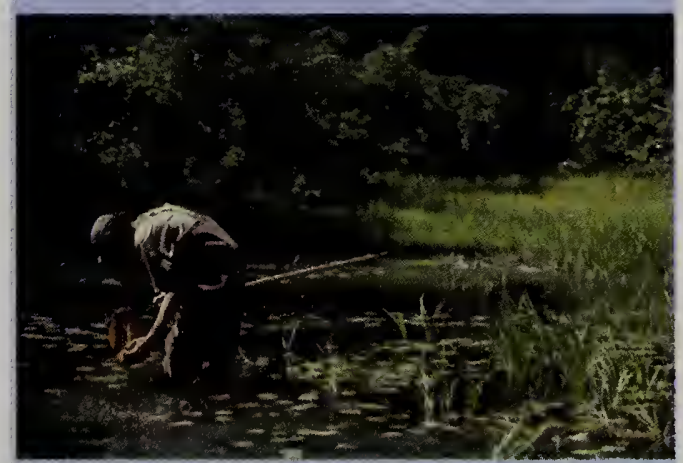

Search for larvae throughout the year in ponds, streams, and other wetlands using a sturdy aquatic dipnet. Searching for exuviae is also rewarding, and is a great way to prove that dragonflies successfully breed at a particular wetland. Many exuviae can be keyed out to determine species. 


\section{Collection}

For some species, examination under a microscope is the only way to be certain of identification, making collection necessary. Many scientists studying odonates maintain a collection of specimens, which are often a part of, or are donated to a museum or university collection. Collections are permanent and verifiable records of species distributions. Collection is also an excellent way to learn a group of organisms. Due to the high reproductive rates characteristic of insect populations, collection of a few individual dragonflies is unlikely to impact a population. If a collection is to be started and maintained, refer to an entomology text such as Westfall and May (1996) to learn the best way to collect and maintain specimens such that there will be long term utility to yourself and others. The advent of relatively cheap digital imaging capable of capturing high-quality images provides a good alternative.
Soyknomphus albisty lus

det. J. L. Loose

Massame, Sawasill River

9.5 $\mathrm{k}$ downurean from Feary Road

bridge crovsuag

20 Hesse 2001

Jeswifer Louse, Mat Burge

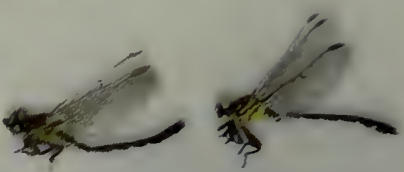

Proper curation ensures the quality and longevity of the data represented by a specimen.

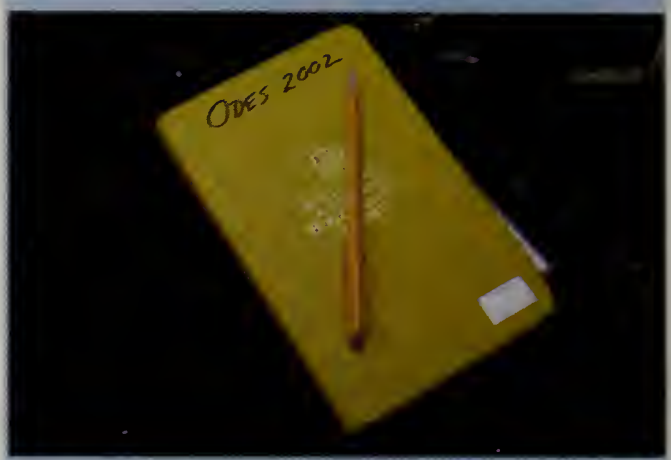

Taking field notes is an excellent way to hone observational skills and to track changes at a site over time.

\section{Field notes}

Taking clear and consistent field notes is an important skill. Noting identifying characteristics and behavior aids in learning species, and in tracking changes in abundance or species assemblages that might occur over the years. A small pocket notebook is ideal. Writing in pencil or waterproof pen is a good idea, as these won't run if they get wet.

Some useful notes include:

- Location (as specific as possible)

- Date

- Time of day, as some species are more active at different times of day

- Weather

- Habitat description

- Species present

- Identifying characteristics of the species

- Number and sex of individuals

- $\quad$ Evidence of reproductive activity (e.g., mating, oviposition, exuviae, teneral adults) 
There are approximately 445 species of Odonata found north of Mexico, and 166 (about 37\%) are found in Massachusetts. Habitats typical of the northern boreal zone, found in the Berkshires and the northern Worcester Plateau, fade into the northernmost extension of the Atlantic coastal plain in Plymouth County and Cape Cod. This habitat diversity is reflected in our fauna, with species that are common both well to the north and south of New England. Several species reach the northern or southern extents of their ranges, such as the Subarctic Darner (Aeshna subarctica), a northern species at the southern extent of its range, and the Attenuated Bluet (Enallagma daeckii), a southern species whose range extends north to southeastern Massachusetts. Both are more common to the north and south, respectively, but are rare here and therefore state-listed.

Stenotopic (inhabiting a narrow range of habitats) species of Odonata are found across the Commonwealth, from those inhabiting large rivers such as the Connecticut River, to those found in sphagnum bogs, to those that live in coastal plain ponds. Coastal New England is a center of endemism, having many species thought to have evolved here since the retreat of the last glacier. Some of the species that occur in Massachusetts are not found anywhere in the world outside the northeastern United States. The pitch pine barrens and the coastal plain ponds typical of Plymouth County and Cape Cod are home to many of these endemic species such as the Pine Barrens Bluet (Enallagma recurvatum), New England Bluet (E. laterale), and Scarlet Bluet (E. pictum), all of which are state-listed.

There are 32 state-listed odonates in Massachusetts, and many reasons for the rarity or imperilment of these species, but destruction and degradation of habitat is the most important. Stenotopic species face the greatest risk of extirpation, especially when they rely on rare or threatened habitats. Habitats considered to be most at risk in Massachusetts are coastal plain ponds, high quality streams, large rivers, bogs, and fens. Habitat destruction not only eliminates

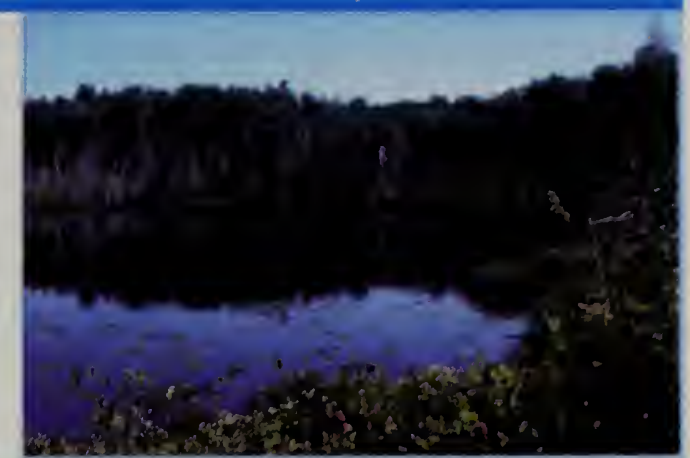

The boreal zone extends into northern Massachusetts and there are many species that can only be found in the habitats typical of this zone, such as sphagnum bogs, fens, and coniferous swamps.

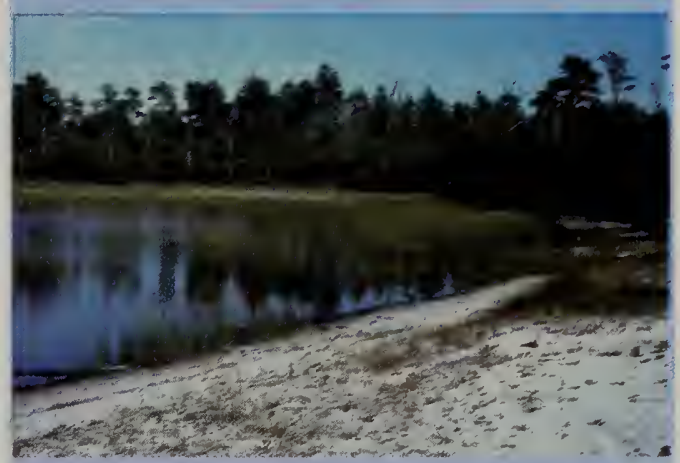

Coastal plain ponds have a limited global distribution, restricted to the northeastern coastal plain. They are habitat for several species endemic to this region, some of which are rare and not found anywhere else in the world.

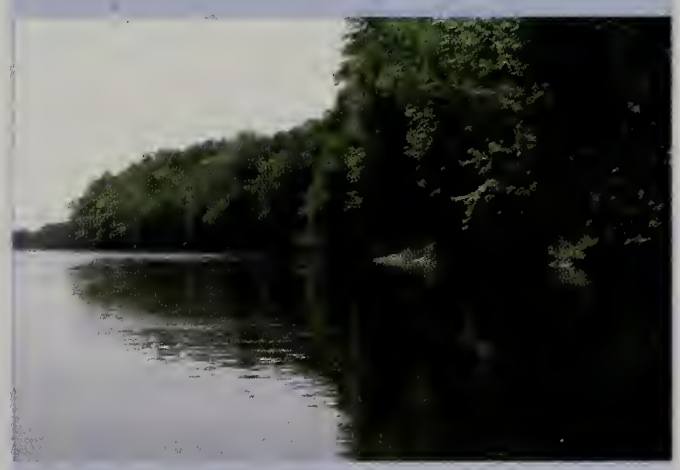

Within the Massachusetts landscape, the Connecticut River is an example of a rare habitat type. Several odonate species are specially adapted to large sand and silt-bottomed rivers. 
the local population, but also limits the dispersal ability of a species. Odonates use nearby habitat patches as "stepping-stones" for dispersal. These "steppingstones" allow expansion and recolonization. If abundance at one site is reduced by a catastrophic abiotic event (e.g., weather) or biotic pressures such as predation and disease, recolonization by populations in adjacent habitats may subsequently occur. Such population structure is called a "metapopulation," with several smaller populations linked by emigration and immigration. A viable metapopulation is better able to face random events through recolonization and genetic flexibility (movement between populations and subsequent mating increases the genetic diversity of a population).

Odonates have two distinct life stages (larva and adult), and populations are regulated by events in each. The larva is the most sensitive stage, as it is the longest and is confined to the wetland. Threats to Odonata are described below.

\section{Anthropogenic threats to larval odonates}

Odonates spend the majority of their lives as larvae and are integral components of aquatic ecosystems. They are major predators of invertebrates, especially in fishless water bodies, and are prey for many larger animals. Threats to larvae and their habitats are the most serious due to the sensitivity of the larval stage.

\section{Alteration of larval aquatic habitat}

- Direct loss of habitat by in-filling, construction, removal of substrate, trampling, and ORV use

- Increase in sediment load by destruction of vegetation cover in catchment area and subsequent erosion

- Destruction of heterogeneity of wetland margins and rate of flow by channelization

- Intermittent exposure of littoral zone (shoreline) by dam release, draining, drawdown from wells, or water diversion

- Eutrophication and subsequent changes in dissolved oxygen concentration

Driving off-road vehicles (ORVs) through delicate pond shores destroys the habitat for damselfly and dragonfly larvae that live among the sedges and grasses, and also may kill the eggs and larvae.

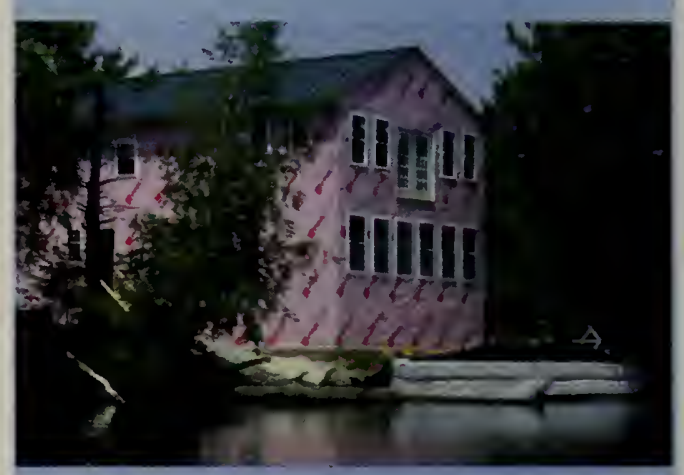

Pond shore development can cause eutrophication which leads to algal blooms and subsequent reduction in dissolved oxygen which suffocates aquatic life. Natural pond shore vegetation may also be impacted, affecting adult dragonflies that roost and hunt along the pond shore.

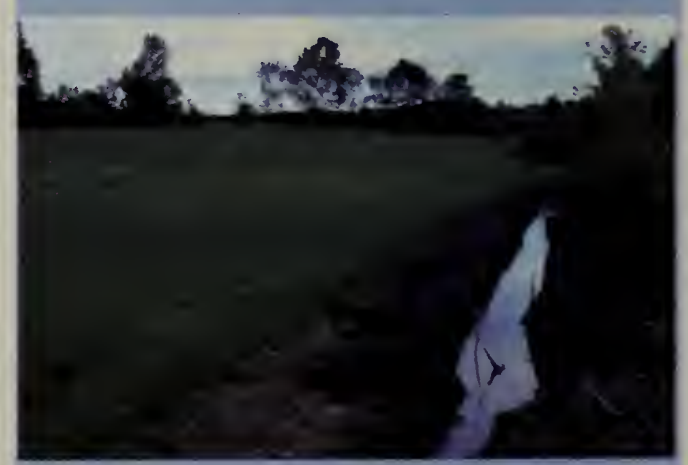

Pest controls, such as mosquito ditching and spraying, can alter habitat and directly kill non-target species, including odonates. 
- Direct and indirect effects of insecticides (e.g., mosquito control, agricultural runoff)

- Chemical or thermal contamination by runoff or discharge of agricultural, industrial, or urban effluent

- Major pollution event upstream

- Acidification of lakes by airborne industrial emissions

- Degradation by invasive exotic plants and animals Predation

- Increased predation of larvae due to stocking of fish, or by introduction of waterfowl

Anthropogenic threats to adult odonates

Adults are important components of the terrestrial ecosystem as they are voracious predators and are themselves prey for many animals.

Habitat destruction and degradation

- Destruction of uplands, forests, and meadows where adults hunt and roost

- Direct and indirect effects of insecticides

- Rapid water level rise (dam releases) and wave action from passing boats (both kill delicate emerging adults)

Other

- Road mortality

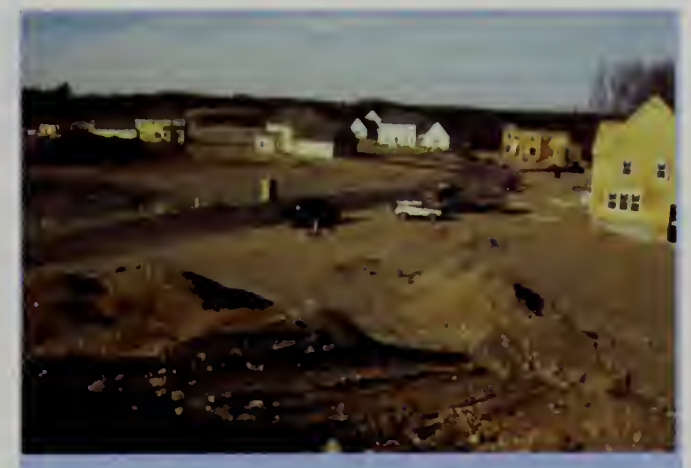

Suburban sprawl destroys and fragments terrestrial and aquatic habitats. It also increases degradation of nearby wetlands.

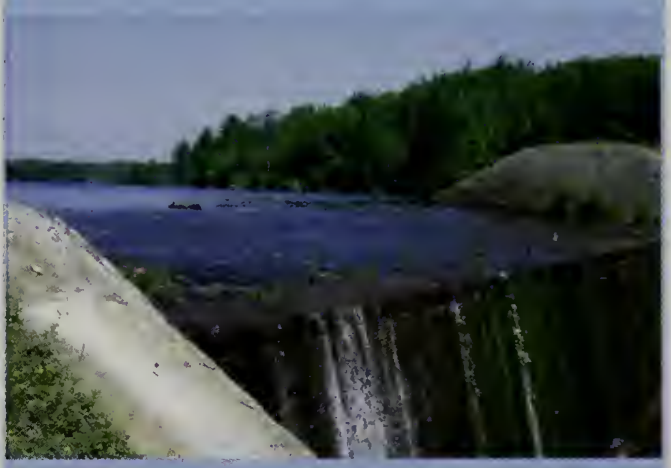

Damming fragments a river, impeding upstream movement of species and altering the temperature regime and nutrient dynamics of the river. Water releases scour emergence sites, killing delicate teneral adults.

\section{Rare species}

Massachusetts has a rich odonate fauna comprising 166 species, 32 of which are state-listed as Endangered, Threatened, or Species of Special Concern. The Massachusetts Natural Heritage \& Endangered Species Program (NHESP) maintains an extensive database of the occurrence of rare species across the state, which is used in conservation planning, land acquisition programs, and environmental review under the Massachusetts Wetlands Protection Act and Endangered Species Act.

The listed status is included in the species accounts of this book. It is important that observations of rare species are reported to the NHESP so that efforts to protect the state's biodiversity are based on the most accurate data available. The current state list of protected species and Rare Animal Observation Forms can be downloaded from the NHESP web site (www.state.ma.us/dfwele/dfw/nhesp) or by contacting the NHESP at the Westborough office of the Division of Fisheries \& Wildlife (508/792-7270 ext. 200). 


\section{Identifying dragonflies and damselflies}

Some species of dragonflies and damselflies can be reliably identified without in-hand inspection. However, many species require closer examination. These can be captured with a net and held by carefully pinching the wings together over the back of the animal. The animal can then be examined closely for field characteristics.

Identification begins by determining the family to which

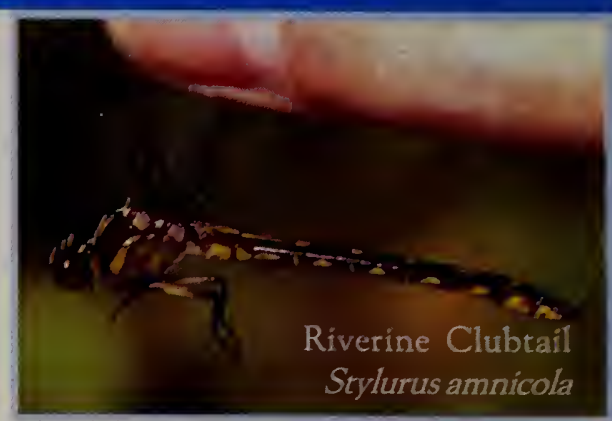
an individual belongs. Use the Family Key found inside the front cover. The book is divided into sections by family. Within the family sections, the accounts are grouped by appearance; similar-looking species are placed near each other. Pay particular attention to the size bar and phenology diagram (flight period, see the "Key to Species Accounts" below) which can give valuable clues and help eliminate some similarlooking species. Carefully read the text descriptions to confirm an identification. In some groups it will be necessary to examine the animal's terminal appendages or other characteristics that are presented in illustrations. There are species for which identification will require consultation with technical manuals, some of which are listed on page 194.

\section{Key to species accounts}

- Common and scientific names. If state-listed, status is in red box.

- Size bar shows average body length for the species, head to tip of abdomen (Westfall and May, 1996; Needham, Westfall, and May, 2000).

- Photographs of adults. Males $\left(o^{x}\right)$ generally on the left or above, females ( $q$ ) on the right or below.

- Text description of diagnostic characteristics and similar species.

- Range (Dunkle, 2000; NatureServe, 2003), status, habitat, and behavioral information.

- Phenology diagrams illustrate flight period (April-December). Darkest portion of diagram represents the period during which the species is most likely to be encountered in Massachusetts, and the lighter portions show times of lesser probability.

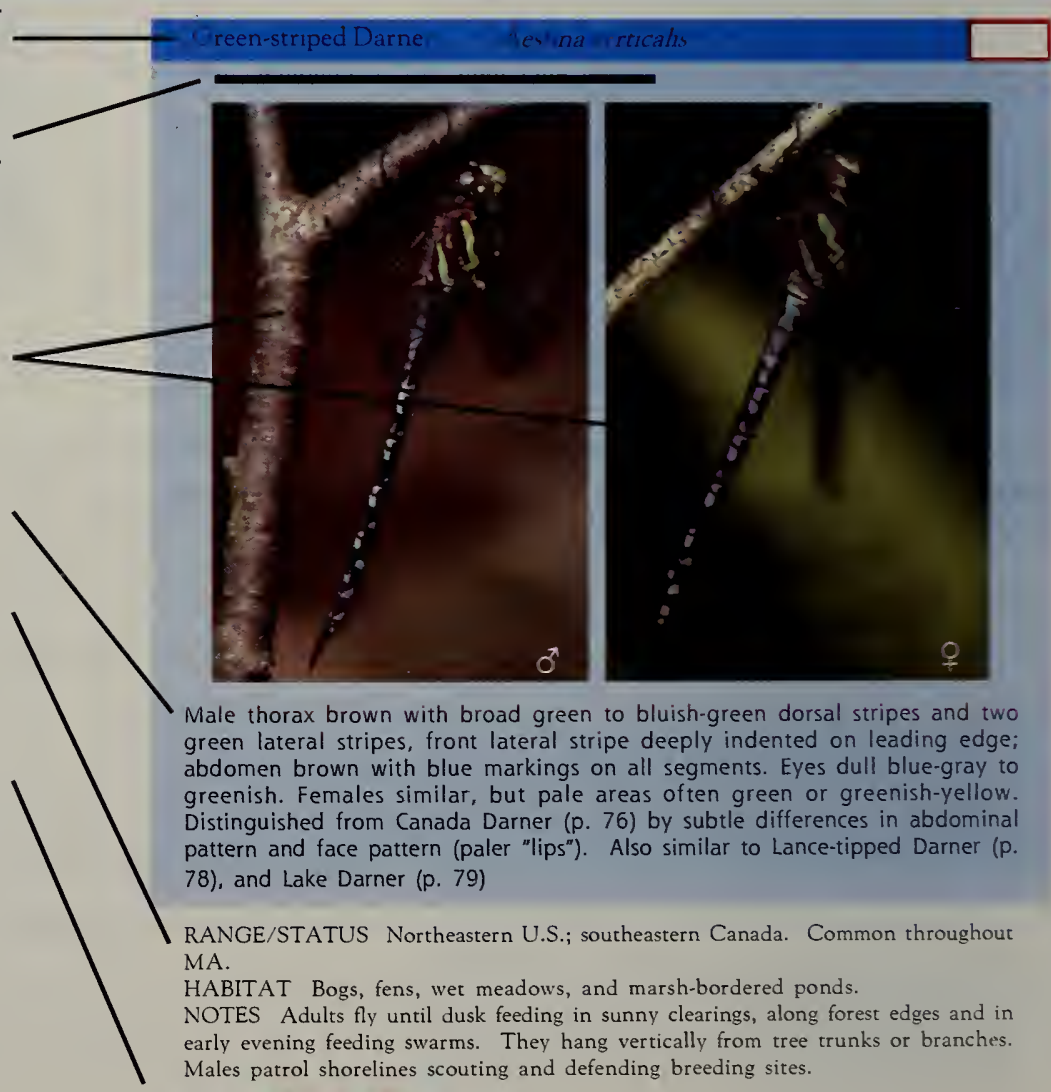

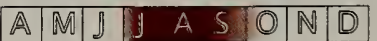




\section{CALOPTERYGIDAE: BROADWINGED DAMSELS}

Broad-winged Damsels are large and colorful and, as the common name suggests, the wings are broader than in other damselflies. Calopterygidae means "beautiful wing," a reference to the variably colored wings of most species. There are over 180 species in the family Calopterygidae worldwide, most occurring in the tropics. Nine species are known from North America, but only five are found as far north as Massachusetts.

Their large size, iridescent coloration, and distinctively shaped and patterned wings readily distinguish Broadwinged Damsels as a group. Male jewelwings (Calopteryx spp.) have brilliant, metallic green bodies (appearing blue in some light) with species-specific wing patterns that range in color from black to amber-tinted. Male rubyspots (Hetaerina) have bronze colored bodies and a bright red

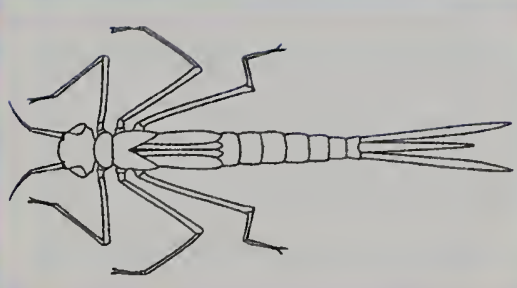

Broad-winged Damsel larvae are relatively large, with long antennae and long caudal gills. The first antennal segment is elongate. They are dark in coloration and spend much of their time climbing around and clinging to vegetation and detritus along the edges of streams. patch at the base of the wings. Females in both genera are bronzy with wings similar in general pattern to the males, though duller in coloration. In most species, the females have white stigmas. Although most females can be identified by sight, some require in-hand identification using technical keys. All species have long, spindly, black legs.

Members of this family breed exclusively in lotic (riverine) habitats. Some inhabit cold, rocky streams while others prefer sluggish, warmer rivers. Jewelwings are primarily early season fliers, flying from late May through July in Massachusetts. Rubyspots, in contrast, typically do not appear until early August, and fly through September. Broad wings and slow, bouncy flight give Broad-winged Damsels a unique, butterfly-like appearance on the wing. Teneral adults may wander a few hundred feet from the natal stream, perching in sunny spots in the woods. Sexually mature adults stay closer to the water, perching horizontally on streamside vegetation or rocks, usually $1-4 \mathrm{ft}$. above the water. Unlike other odonate families, females spend nearly as much time at the water as the males. Courtship behavior in the Calopterygidae is elaborate. Males defend small territories, often no more than $2-3 \mathrm{ft}$. wide along the river's edge. Various courtship displays are performed in front of females, both in flight and while perched. Unreceptive females curve their abdomens upward and spread their wings to indicate their unreceptiveness.

Females oviposit endophytically in partially or fully submerged vegetation. They curl their abdomens below the surface and use their ovipositors to slice into the plants and deposit their eggs. Typically the male hovers nearby, guarding the female against intrusion by competing males. The attenuated, long legged-larvae cling to vegetation and debris on the stream bottom. The larval stage lasts for about a year in the Ebony Jewelwing (Calopteryx maculata), and up to 2-3 years in the River Jewelwing (Calopteryx aequabilis). Emergence takes place on vegetation or other surfaces within a foot or so of the water's edge. 
The only northeastern odonate with entirely black wings. Male thorax and abdomen brilliant green (appearing blue when backlit). Wings black and broader than other jewelwings. Long black legs with prominent spines. Female more bronzy on body with thicker abdomen and dark brown wings with conspicuous white stigmas.
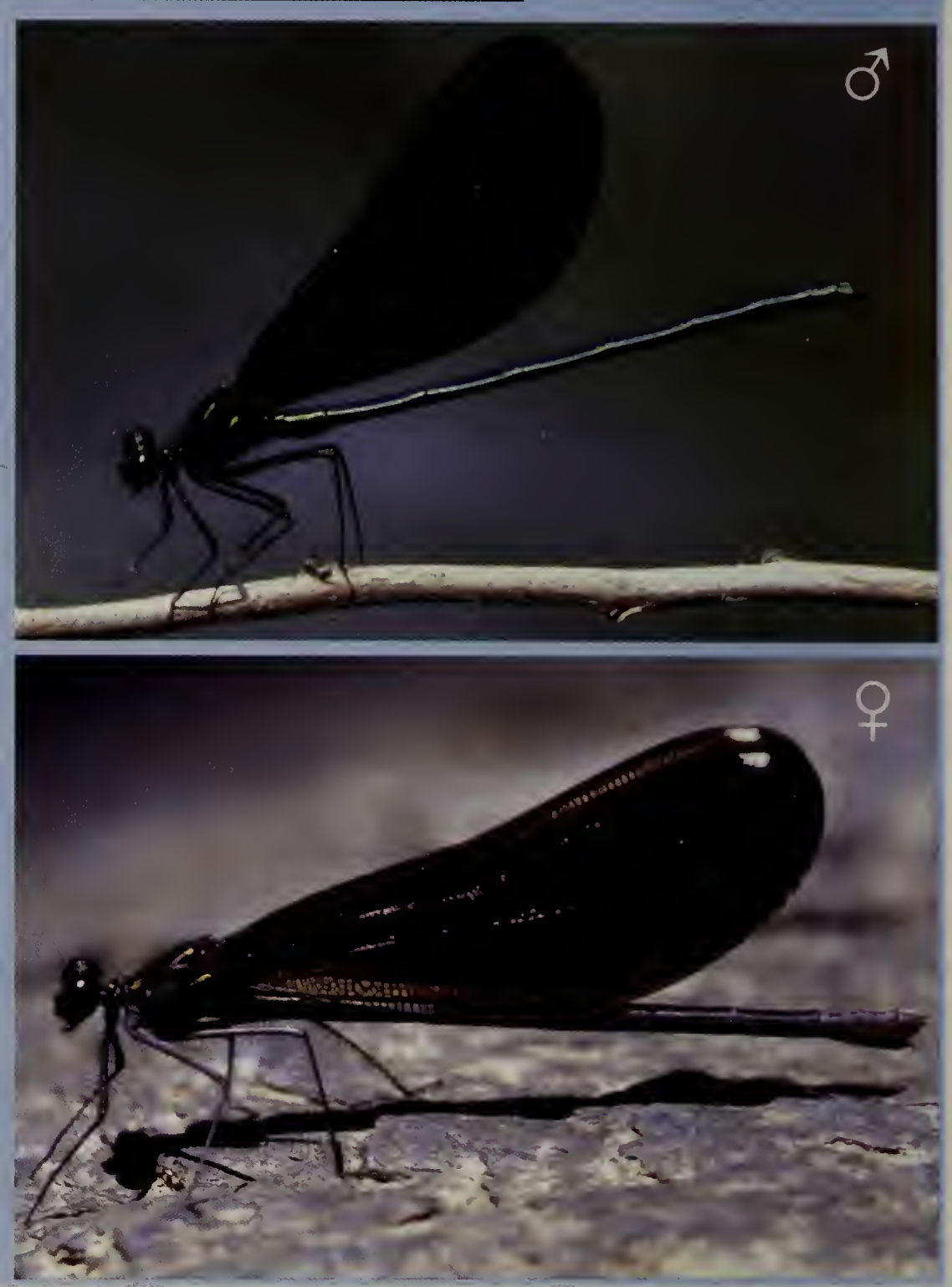

RANGE/STATUS Central to eastern U.S.; southeastern Canada. Common throughout MA.

HABITAT A variety of streams and small rivers but most common along shallow forested streams. Tends to be found on smaller, more forested streams than the River Jewelwing ( $C$. aequabilis).

NOTES Adults perch on streamside and emergent vegetation within a few feet of the water. They fly low over the water or along forest paths in a bouncy, butterfly-like manner. Males are territorial and perform fluttering courtship displays for females. Females oviposit in floating, emergent or submergent vegetation, often with the male guarding nearby.

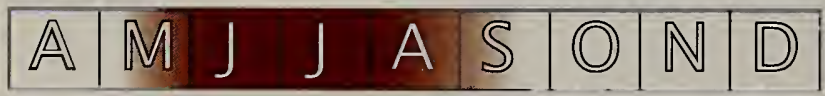


Largest of the jewelwings, with the narrowest wings. Male thorax and abdomen bright iridescent green (appearing blue in some light). Wings suffused with amber, with darker tips on hind wings. Long black legs with prominent spines. Female somewhat more bronzy on body with thicker abdomen. Variably sized white stigmas on wings and no dark tips on hind wings. Our only jewelwing in which the male has no black on wings.

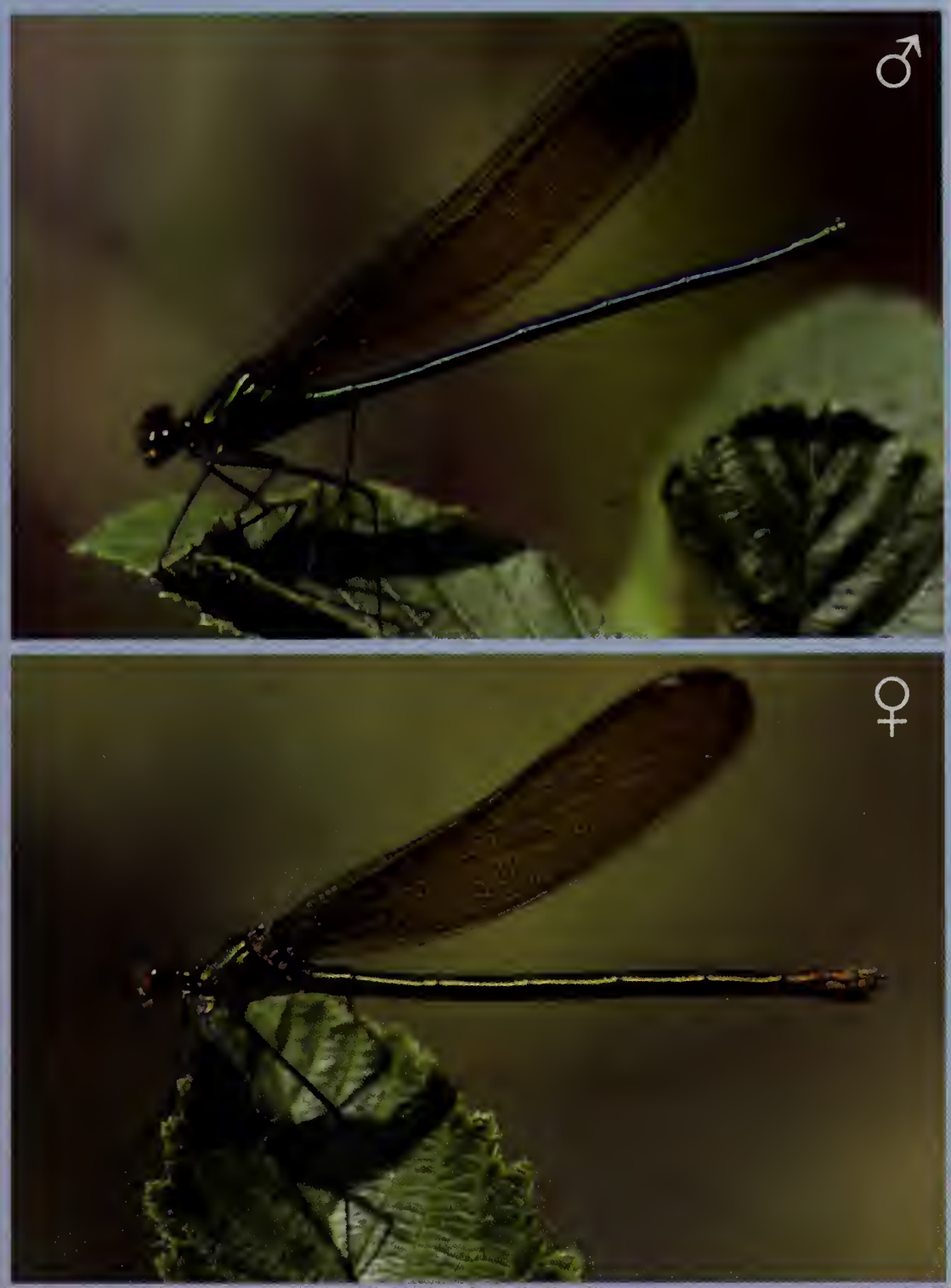

RANGE/STATUS Central to northeastern U.S.; eastern Canada. Uncommon, limited to north-central and western MA.

HABITAT Cold, rocky streams.

NOTES Adults perch on streamside and emergent vegetation or rocks close to the water. They fly within a few feet of the water in a bouncy, butterfly-like manner. Males perform fluttering courtship displays for females. Females oviposit in floating and emergent vegetation.

\begin{tabular}{|l|l|l|l|l|l|l|l|}
\hline $\mathbb{A}$ & $\mathbb{M}$ & $J$ & $\mathcal{A}$ & $\mathbb{S}$ & $\mathbb{O}$ & $\mathbb{N}$ & $\mathbb{D}$ \\
\hline
\end{tabular}


Thorax and abdomen bright metallic green (appearing blue in some light). Approximately outer third of wings black, with more black on hind wings than forewings. Long black legs with prominent spines. Female similar to male, but more bronzy in color with thicker abdomen; wings with conspicuous white stigmas and dark brown tips (brown absent in some individuals). Similar to the Sparkling Jewelwing ( $p$. 17), but black on tips of wings more extensive (outer third vs. outer fifth) and more extensive on hind wings than forewings (equal amounts of black in Sparkling Jewelwing).

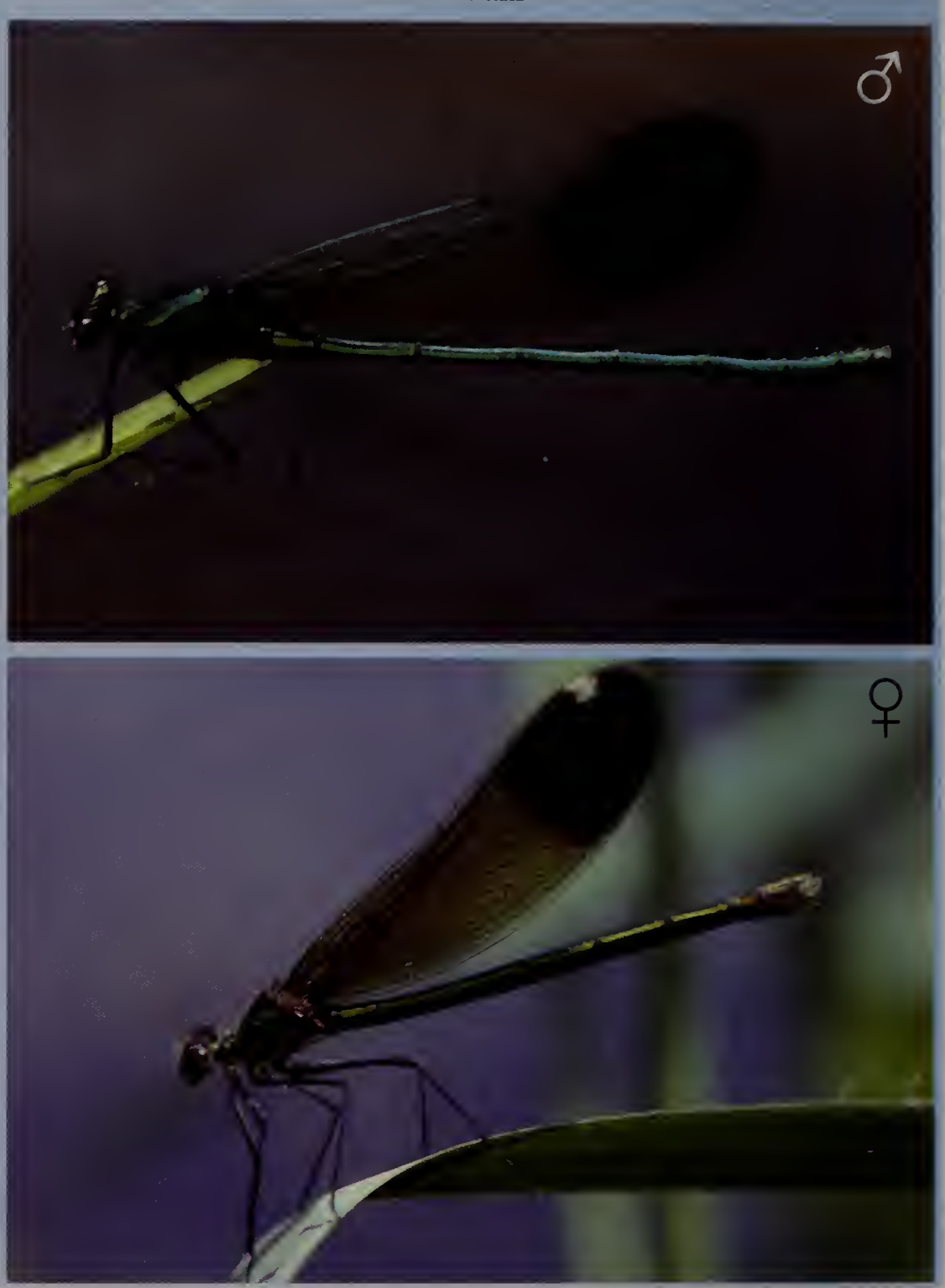

RANGE/STATUS Central to northern U.S.; southern Canada. Common throughout interior MA, but absent from the southeast coastal plain.

HABITAT A wide range of streams and small rivers; especially common along swiftly flowing riffle segments. Tends to be found on larger, more open streams and rivers than the Ebony Jewelwing (C. maculata).

NOTES Adults perch on streamside and emergent vegetation within a few feet of the shoreline. They fly low over the water in a bouncy, butterfly-like manner. Males are territorial and perform fluttering courtship displays for females.

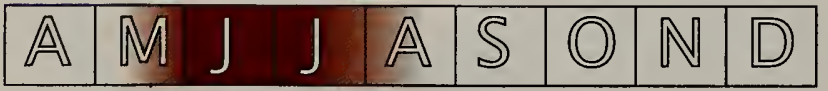


The smallest of the jewelwings. Male thorax and abdomen bright metallic green. Wings tipped with black (outer fifth). Long black legs with prominent spines. Female more bronzy on body with stockier abdomen; smoky brown wash on wings, no black tips, with small white stigmas (occasionally lacking). Similar to the River Jewelwing (p. 16), but black wing tips limited to outer fifth (vs. outer third in River Jewelwing), and black tips equal in extent on all four wings.

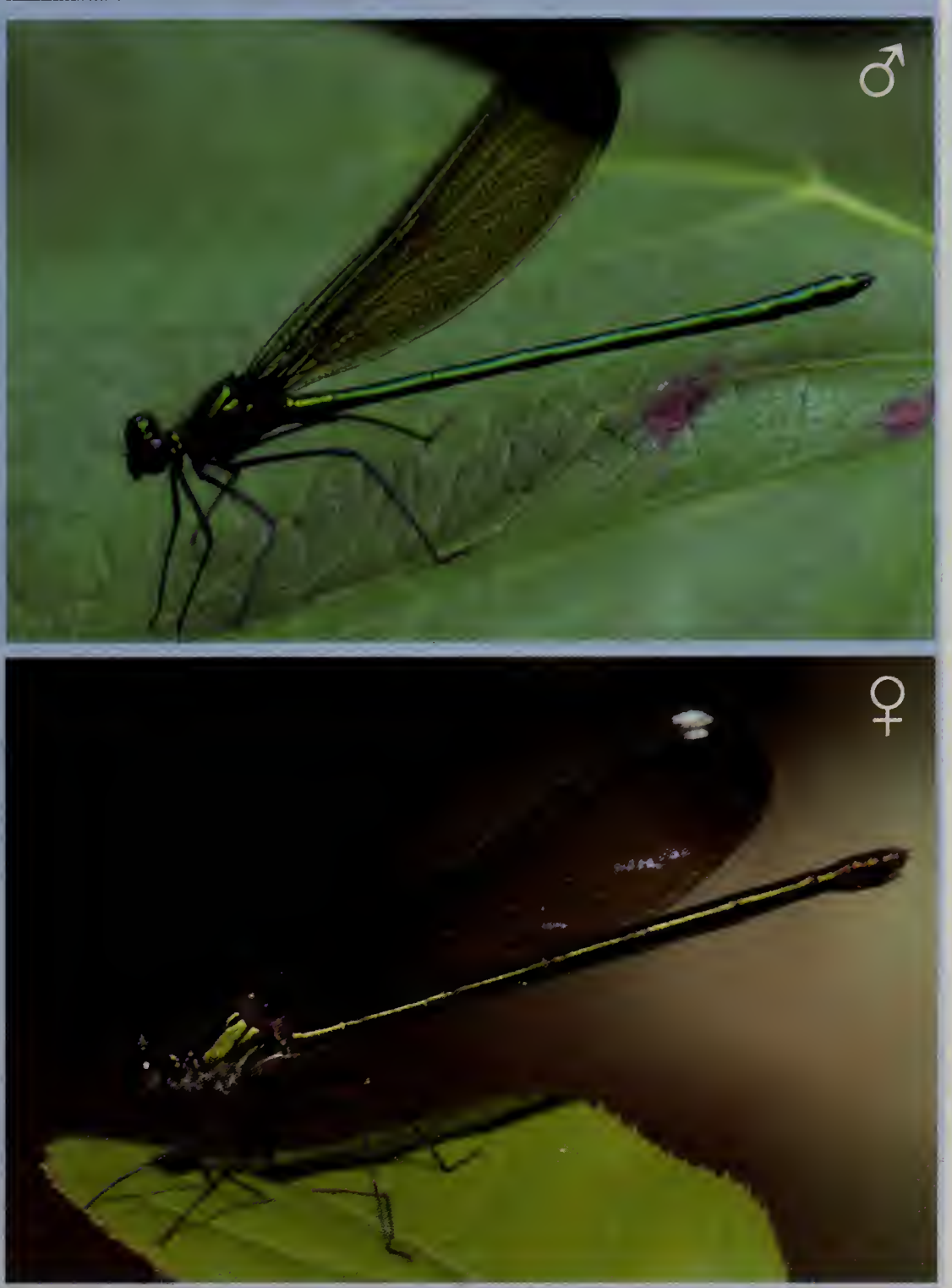

RANGE/STATUS Coastal central to southeastern U.S., north to southern NH. Uncommon in MA, limited to south-central and eastern portions of the Commonwealth, except absent on Cape Cod and the Islands.

HABITAT Slow-flowing streams and rivers with emergent vegetation. NOTES Adults perch on streamside and emergent vegetation. They fly within a few feet of the water in a bouncy, butterfly-like manner. Males perform fluttering courtship displays in front of females. Females oviposit on floating and emergent vegetation, often while the male guards nearby.

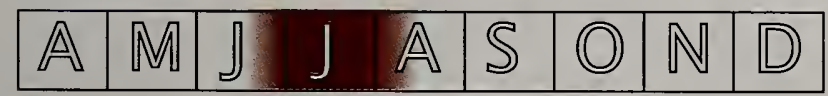


A strikingly colored, large damselfly. Male thorax dark, reddish-bronze above with thin, pale shoulder stripes and pale yellowish lower sides; abdomen dark green to brown above (appearing blackish in poor light) with thin, pale rings. Wings with large red basal patch. Eyes brownish. Female similar to male, but wings suffused with amber at base and along leading edges, with tiny white stigmas; thorax with green (rather than red) iridescence above, abdomen stockier. Red patch in wings distinctive among northeastern damselflies.
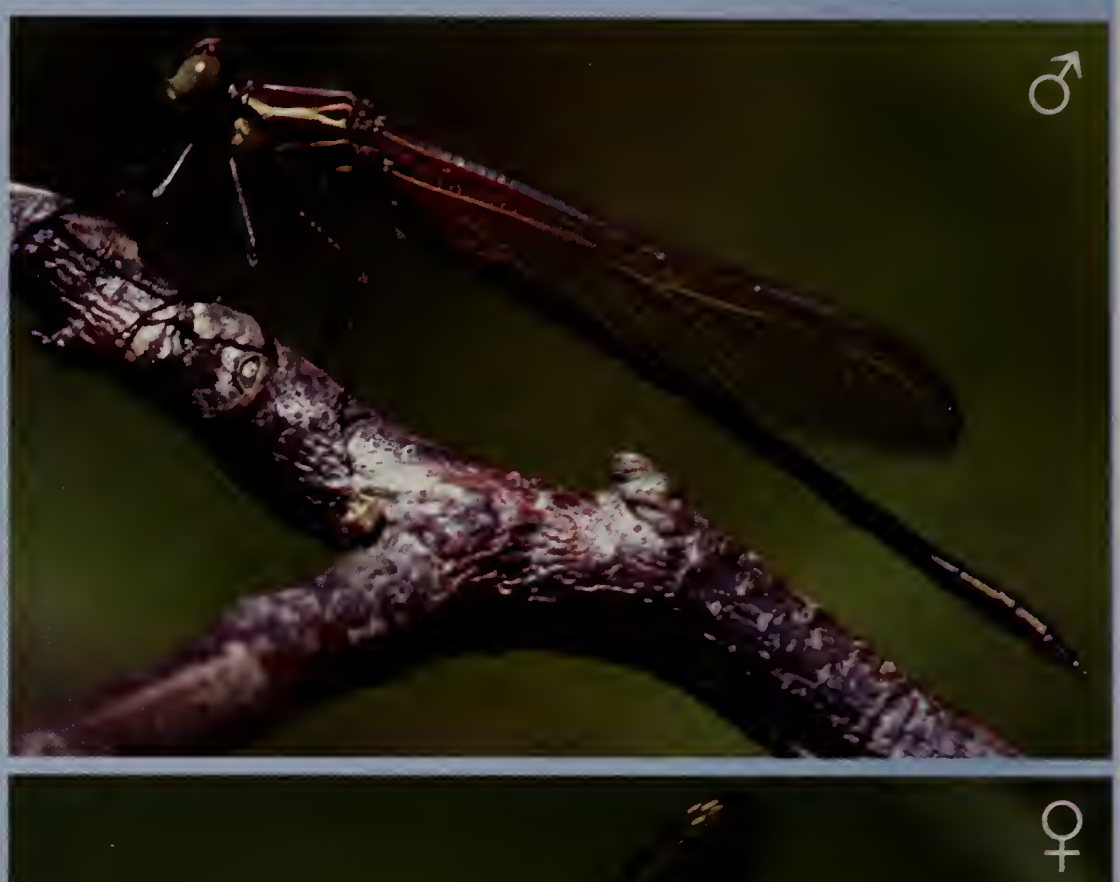

RANGE/STATUS The majority of the U.S., but more common to the south, and extending into the Canadian Great Lakes region. Uncommon in MA and most often reported from the north-central rivers, including Millers and Connecticut Rivers; there are a few historic records along the southeast coastal plain.

HABITAT Moderately flowing streams and rivers with emergent vegetation. NOTES Adults perch along the shoreline on vegetation and rocks. Flight is slow and lilting, like that of a butterfly. Males perform mating displays and guard the female as she oviposits in emergent vegetation or submerged, decaying wood.

\begin{tabular}{|l|l|l|l|l|l|l|l|l|}
\hline $\mathbb{A}$ & $\mathbb{M}$ & $\mathbb{J}$ & $\mathbb{J}$ & $\mathrm{A}$ & $\mathrm{S}$ & $\mathbf{O}$ & $\mathbb{N}$ & $\mathbb{D}$ \\
\hline
\end{tabular}


Spreadwings, unlike most other damselflies, perch with their wings partially open. About 160 species of Lestidae are known worldwide, with 19 or 20 known from North America. Nine species have been found in Massachusetts, all in the genus Lestes.

Spreadwings are recognizable by their relatively large size and habit of perching at an oblique angle (roughly $45^{\circ}$ ), often with wings spread (also at about a $45^{\circ}$ angle; note, however, that teneral individuals often hold their wings closed over the back). Body coloration varies from iridescent green in a few species to pale bluish-gray, to drab black. In larger species, the abdomen is long and slender, while smaller species have stockier abdomens. Mature males typically develop a bluish-gray pruinosity at the tip of the abdomen and on the thorax, and have bright

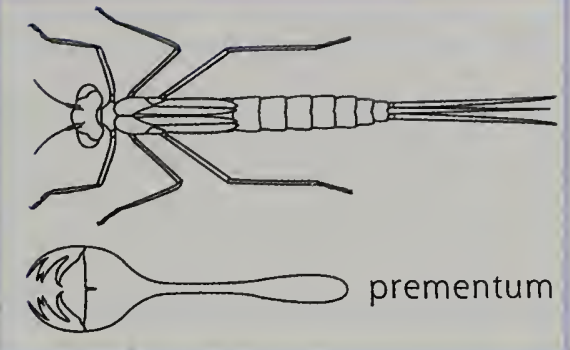

Spreadwing larvae are long and thin, golden brown to green in color, and recognized by their characteristic, stalklike prementum. They are quite mobile, swimming around or climbing in aquatic vegetation. blue eyes. Females are more drab, with varying combinations of brown, gray, and black; they have stockier abdomens than males. All species have pale "shoulder" stripes (more technically called antehumeral stripes), the shape of which can be useful in identification; however, these stripes often become obscure with age. The wings are clear in all of the Lestidae except the Amber-winged Spreadwing (Lestes eurinus). The structure of the male terminal appendages (p. 20) provides the most reliable means of identifying species. Females are rarely identifiable except in the hand, and even then can present difficulties.

Spreadwings are found throughout the state, with some species being common and widespread while others are rare and local. Most are on the wing from mid-June through late August, although a few fly into autumn. They are weak fliers and their flights are low, infrequent, and short in duration and distance. Spreadwings inhabit vegetated still water (lentic) wetlands such as ponds, vernal pools, and marshes, and only rarely are encountered in riverine systems. At favored sites some species can reach exceptional abundance, with adults occasionally numbering into the thousands. Tenerals and young adults can be found in the woods and fields close to the water. When sexually mature, males spend most of the day at breeding sites where they perch on vertical stalks of emergent or shoreline vegetation. Like most odonates, females return to the water only when ready to breed.

Females oviposit endophytically, using the well-developed ovipositors at the end of their abdomens to slice into the stalks of emergent vegetation. In most cases the male remains attached to the female during oviposition. The eggs are laid either above or just below the water surface, those above the water eventually becoming submerged as the plant weakens and dies with the season's passage. Larvae are long and slender, spending much of their time clinging to stalks of aquatic vegetation. The larval stage lasts from a few months to a year. Emergence takes place on vegetation or other surfaces within a foot or so of the water. 
Identifying the nine species of Lestes often requires looking closely at the reproductive structures. The diagrams below show a dorsal view (i.e., looking down from the top) of male abdominal segment 10 (S10) and the terminal appendages. The superior appendages (SA) and inferior appendages (IA) have important characteristics that are described below each illustration. Coloration of S10 and the appendages is not important in identification. Females are not illustrated, refer to the technical manuals (see p. 194).

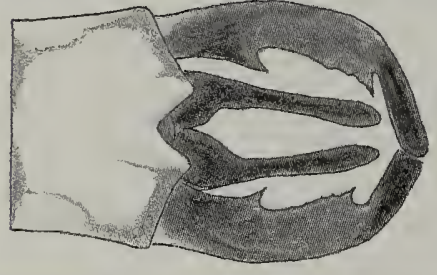

Common Spreadwing, (L. disjunctus): Basal and distal teeth prominent and similar in size. IA nearly as long as SA. p. 21

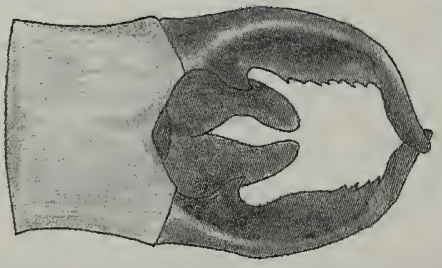

Spotted Spreadwing, (L. congener): IA not longer than $1 / 2$ the length of SA. Basal tooth large, distal tooth indistinct. p. 23

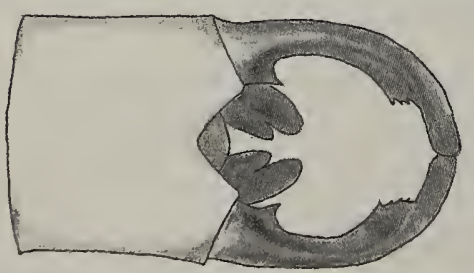

Amber-winged Spreadwing, (L. eurinus): IA very short and stubby. SA smoothly rounded on outer edge. p. 28

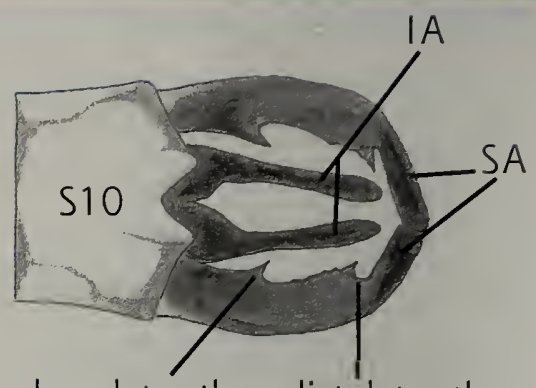

basal tooth distal tooth

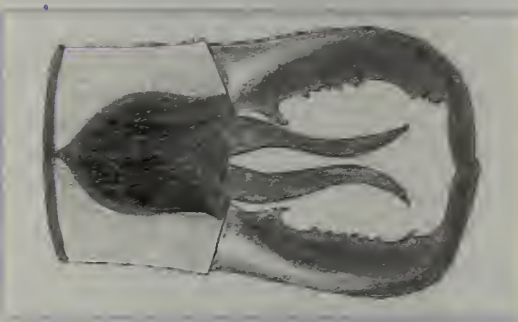

Sweetflag Spreadwing

(L. forcipatus): Basal teeth distinctly larger than distal teeth. p. 22

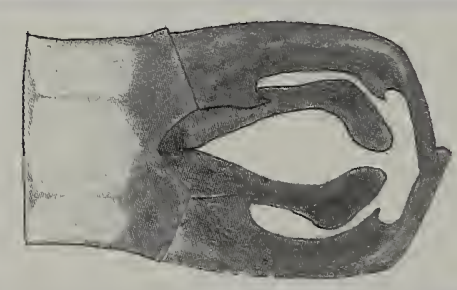

Emerald Spreadwing,

(L. dryas): IA boot shaped. Basal and distal teeth prominent and similar in size. p. 25

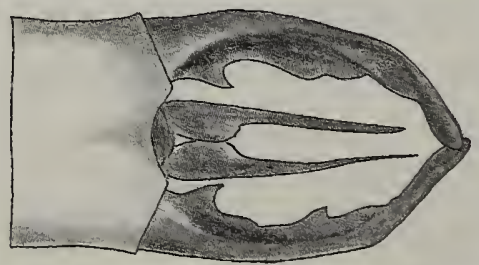

Swamp Spreadwing,

(L. vigilax): IA slender and very long, nearly as long as SA. Distal teeth indistinct. p. 26
Lyre-tipped Spreadwing,

(L. unguiculatus): IA clearly divergent at tips (lyre-shaped). p. 24

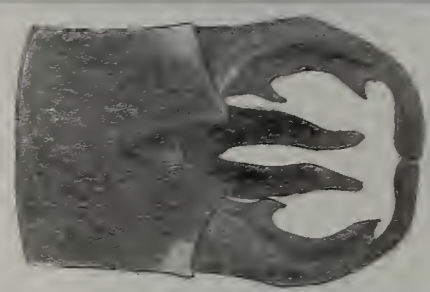

Slender Spread-wing, (L. rectangularis): IA curved downward in side view. p. 29
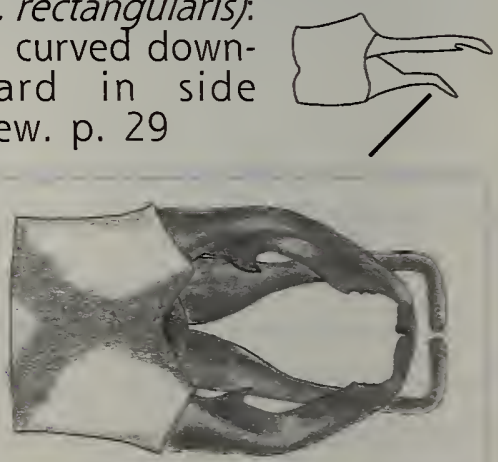

Elegant Spreadwing,

(L. inaequalis): IA distinctly longer than SA, and bent at a right angle near tip. p. 27 

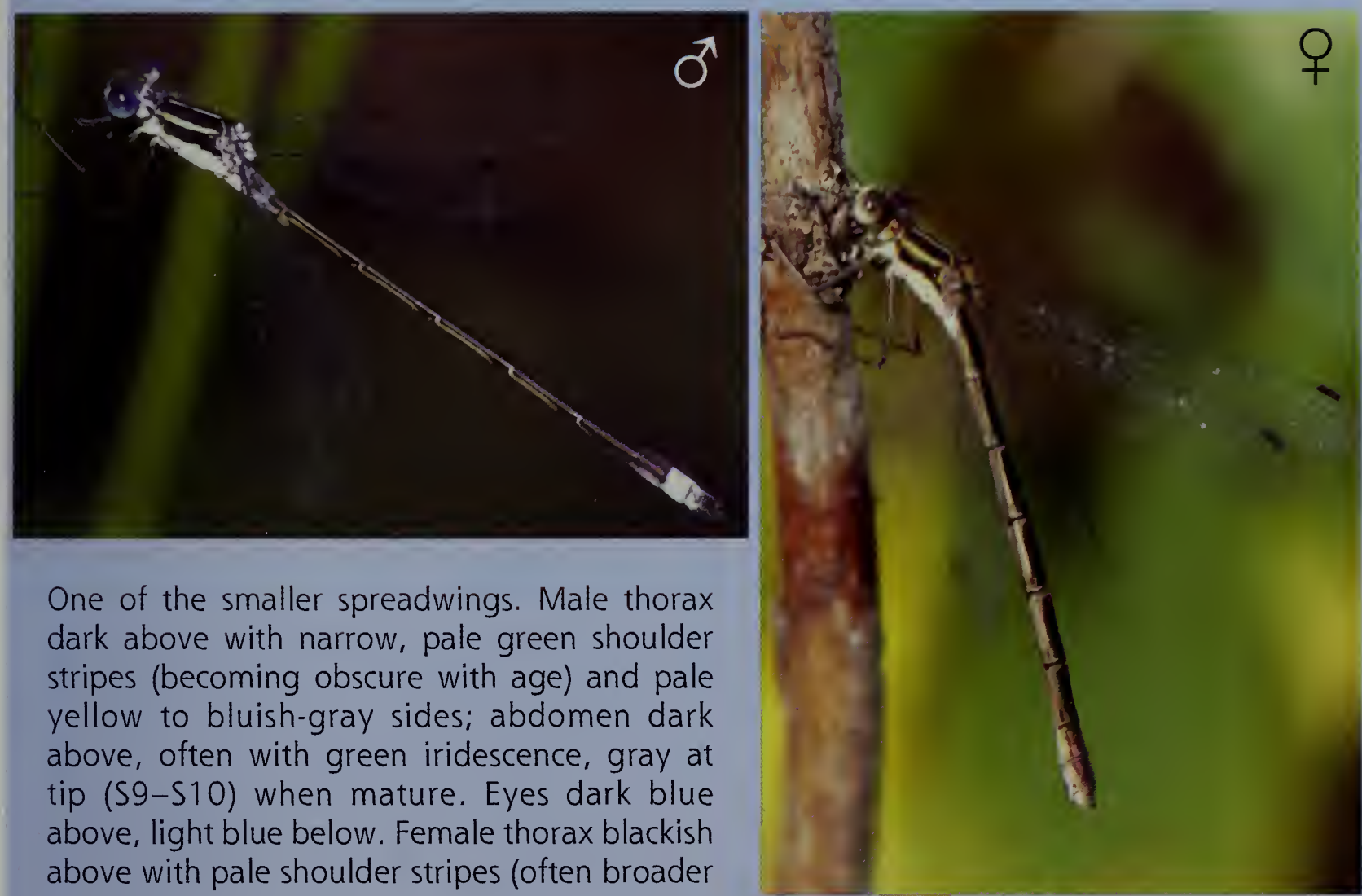

One of the smaller spreadwings. Male thorax dark above with narrow, pale green shoulder stripes (becoming obscure with age) and pale yellow to bluish-gray sides; abdomen dark above, often with green iridescence, gray at tip (S9-S10) when mature. Eyes dark blue above, light blue below. Female thorax blackish above with pale shoulder stripes (often broader than on male) and pale gray or tan sides; abdomen dark iridescent green above and pale brown below. Very similar to the Lyretipped (p. 24) and the Sweetflag (p. 22) spreadwings, and males are best distinguished in the hand by the shape of the terminal appendages ( $p .20)$.

RANGE/STATUS Throughout much of U.S. and Canada. Common throughout MA.

HABITAT A wide range of still-water habitats including vegetated, marshy, and bogbordered ponds, stream backwaters, swamps, and vernal pools.

NOTES Adults perch on emergent vegetation in the wetland or nearby grassy fields, making short, slow flights. They perch in typical Lestes fashion, obliquely with the abdomen lowered and wings partially spread. Females oviposit in tandem in vertical stalks of emergent vegetation, slicing open the stems above the waterline and inserting eggs with the ovipositors.

A southern form ( $L$. disjunctus australis) may be a distinct species. The distal tooth on male terminal appendages of $L$. $d$. australis is less strongly developed than in $L$. $d$. disjunctus. Although not known from MA, it has been recorded in NY and CT and should be looked for in late May and June.

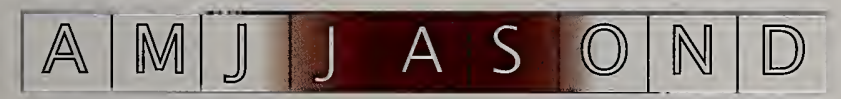


Intermediate in size among the spreadwings, though size variable. Male thorax blackish above with pale shoulder stripes and pale tan to bluish-gray sides, often with a small dark spot on lower sides; abdomen blackish above with pale gray tip (S9S10) when mature. Eyes blue. Female thorax blackish above, with pale shoulder stripes; abdomen blackish above. Quite similar to other spreadwings, but female distinguished in the hand by long ovipositor (extending beyond terminal appendages). Both sexes often have a small, pale brown spot on lower side of thorax, like the Spotted Spreadwing (p. 23). Shoulder stripes of both sexes usually taper abruptly posteriorly. Male very similar to the Common Spreadwing ( $p$. 21) though generally more black above; can be
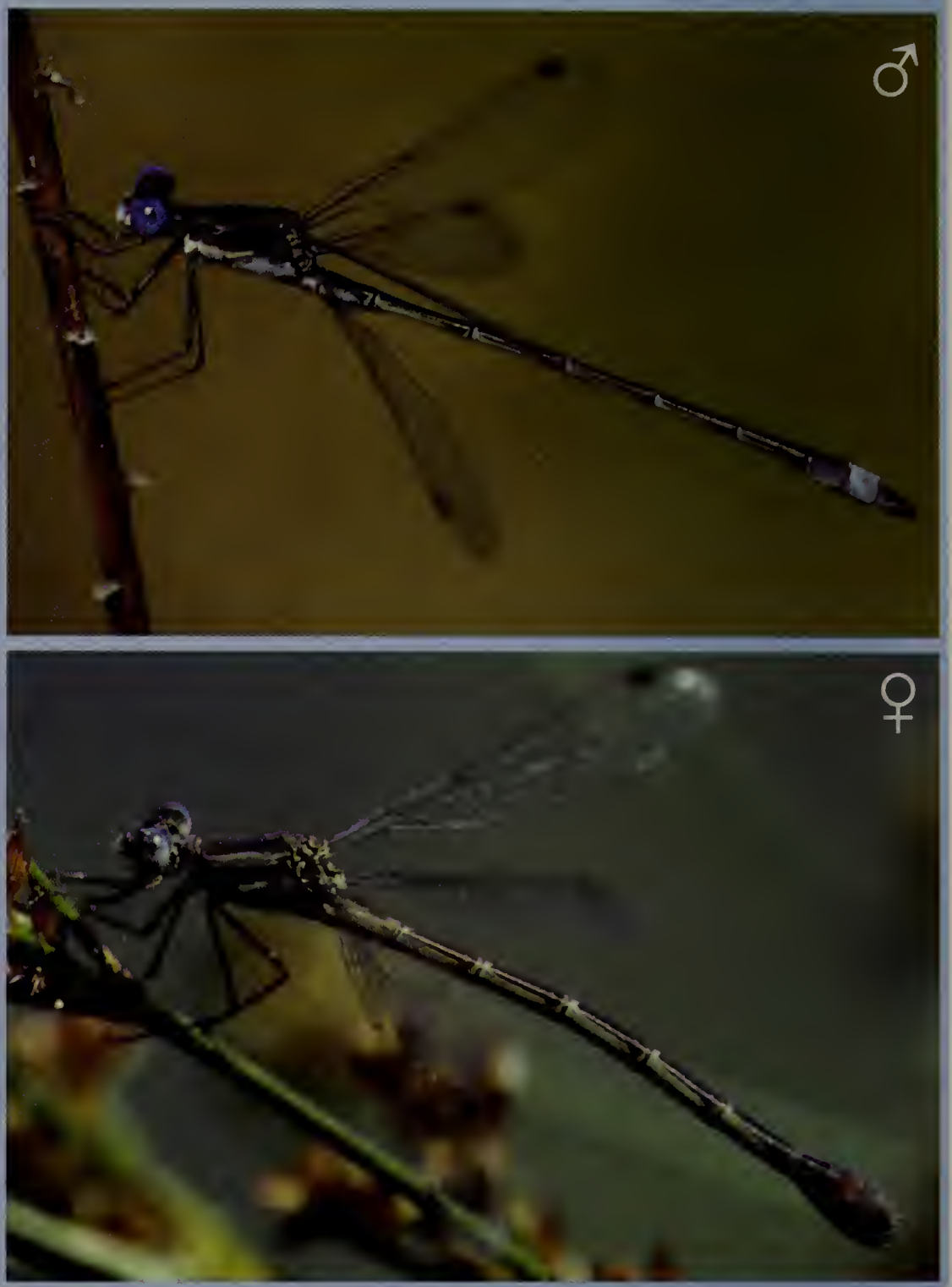
difficult to distinguish even in the hand.

RANGE/STATUS Scattered from the Rocky Mountains to the east coast, extending into Canada. Fairly common at lower elevations throughout MA, most common on the southeast coastal plain.

HABITAT A wide range of still-water habitats including vegetated ponds and pools, boggy ponds, and marshes.

NOTES Adults fly slowly in and out of emergent vegetation along the shore or in nearby grassy fields. They perch frequently in typical Lestes fashion, obliquely with the abdomen lowered and the wings partially spread. Females oviposit in tandem, in emergent vegetation above the waterline or in floating aquatic plants.

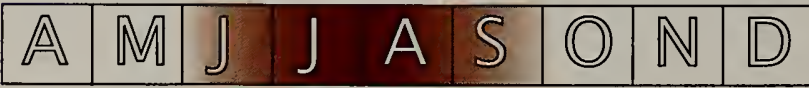


One of the smallest, stockiest spreadwings. Male thorax black above with thin, pale shoulder stripes (which become obscure with age) and pale yellowish to gray sides; dark, elongate spots on the lower side of the thorax (present on both sexes, but very difficult to see except in the hand); abdomen blackish dorsally with blue-gray tip (S9S10). Eyes blue above. Female thorax dark brown above with pale shoulder stripes and pale gray sides; abdomen dark above and pale brown to gray on sides. Similar to other small spreadwings (Common, p. 21: Lyre-tipped, p. 24), but dark spots of lower thorax absent on other species, except the Sweetflag (p. 22), which often has a single, somewhat paler spot on each side.
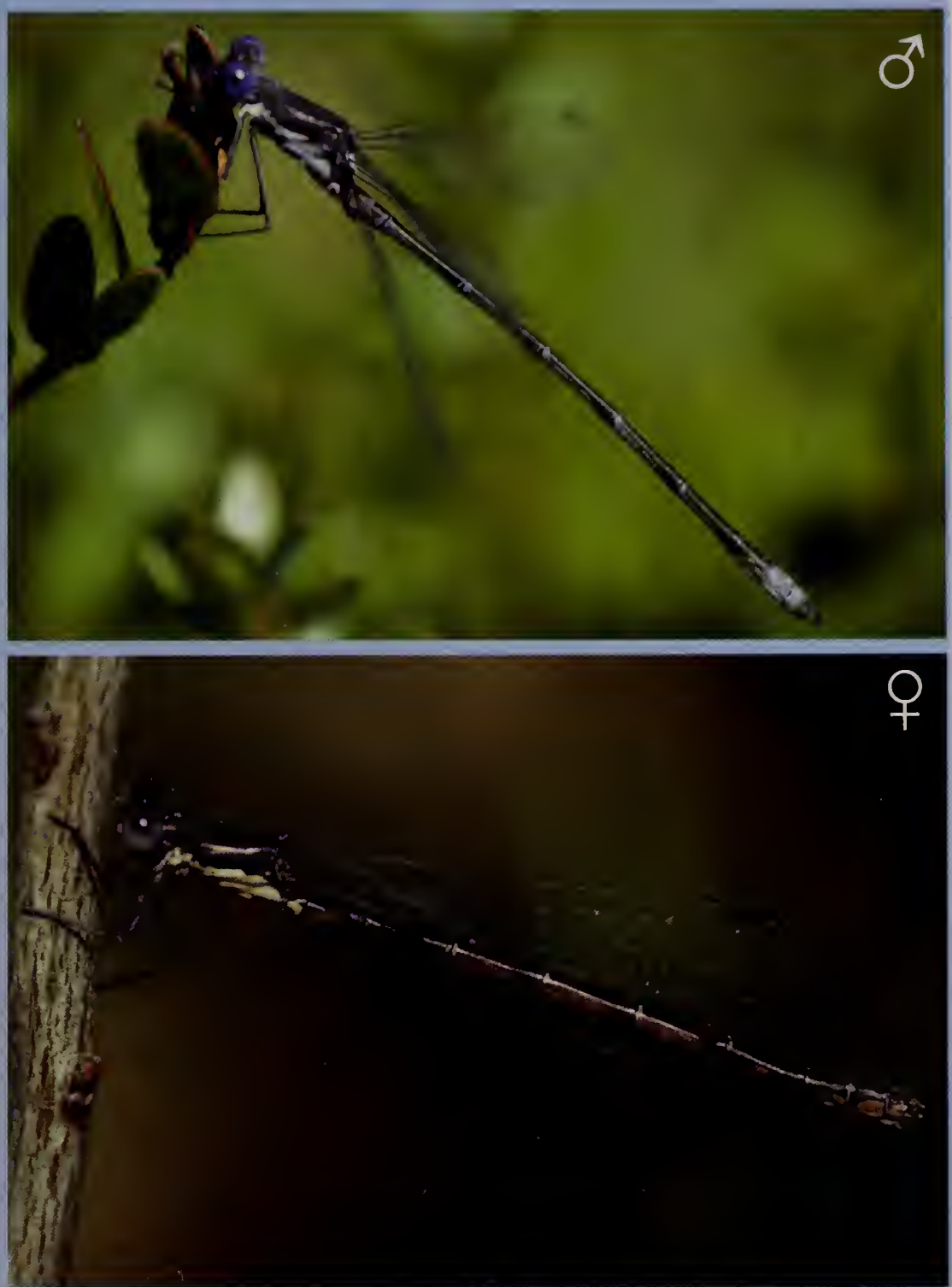

RANGE/STATUS Mid-south through northern U.S. into Canada. Common throughout MA.

HABITAT A wide range of still-water habitats including vegetated, marshy, and bogbordered ponds, stream backwaters, swamps, and vernal pools.

NOTES Adults perch on emergent vegetation in the wetland or nearby grassy fields, making short, slow flights. They perch in typical Lestes fashion, obliquely with the abdomen lowered and wings partially spread. Females oviposit in tandem in vertical stalks of woody and herbaceous emergent vegetation, slicing open the stems above the waterline and inserting eggs with their ovipositors. Spotted Spreadwings have a late flight season, being one of the latest odonates on the wing in the northeast.

$|\mathbb{A}| \mathbb{M} \mid$ I $\mid$ I A A S S O O $|\mathbb{N}| \mathbb{D}$




\section{Lyre-tipped Spreadwing Lestes unguiculatus}

One of the smallest spreadwings. Male thorax dark bronzy above, often becoming pruinose bluegray with age, with pale shoulder stripes and grayish sides; abdomen dark green to blackish above, with pale gray tip (S9-S10) when mature. Female thorax greenish above with pale shoulder stripes and pale tan sides; abdomen green above, pale below. Very similar to the Common Spreadwing (p. 21) and best identified by shape of male terminal appendages (p. 20).

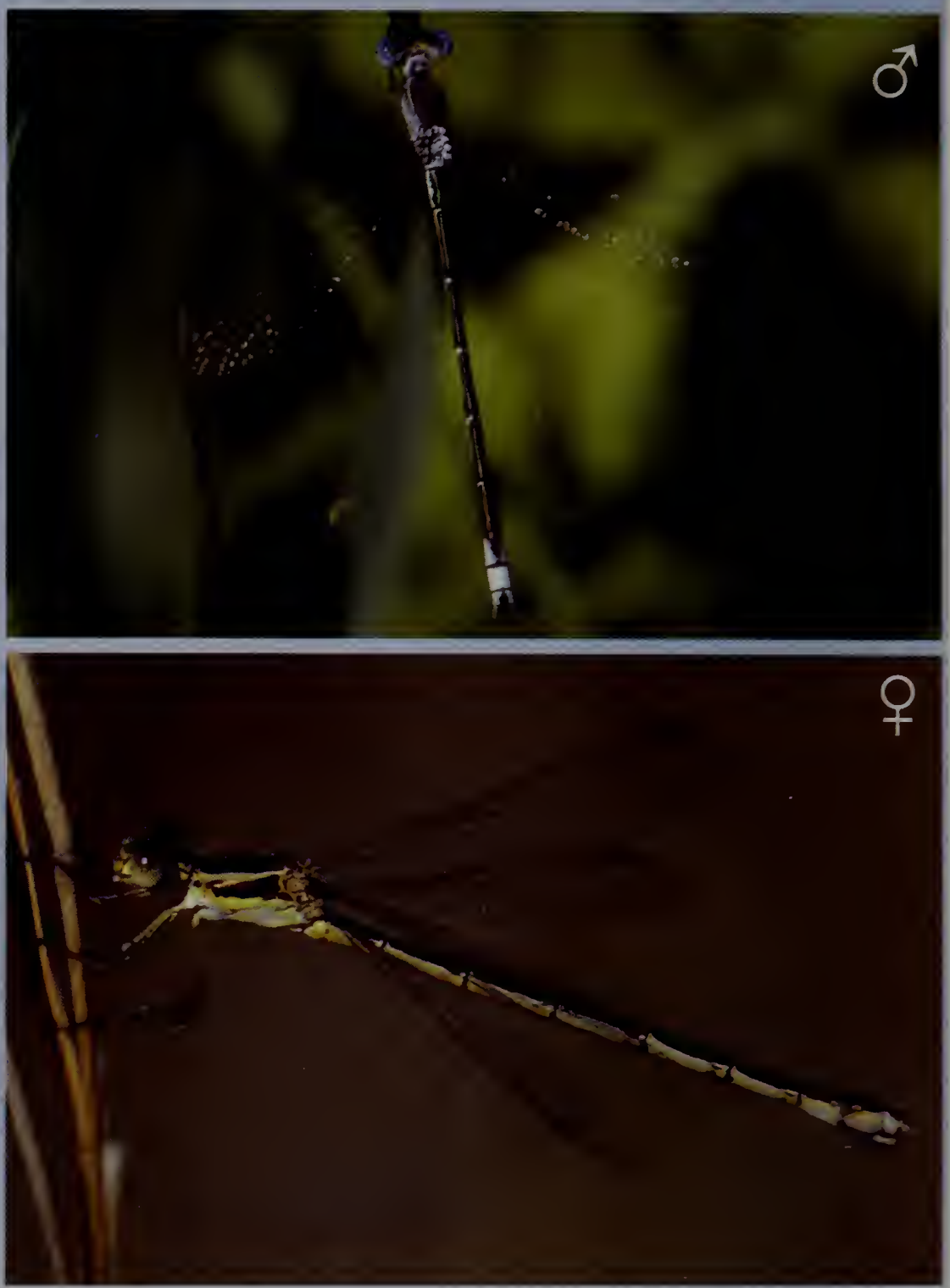

RANGE/STATUS Mid-southern U.S. northward through Canada. Local and uncommon throughout MA. Many of the records are historic, suggesting a population decline. All recent records are from the coastal plain, however this may reflect survey bias.

HABITAT Small, open, vegetated ponds and temporary pools.

NOTES Adults fly slowly in and out of emergent vegetation along the shore and through grassy upland fields. They perch frequently in typical Lestes fashion, obliquely with the abdomen lowered and the wings partially spread. Females oviposit in tandem in stalks of emergent vegetation.

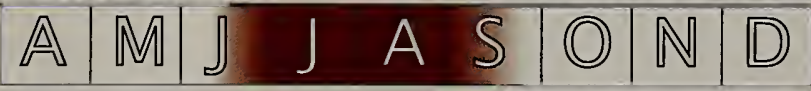


One of the smallest, stockiest spreadwings. Male thorax bright green above, with thin, pale shoulder stripes and pale yellow to blue sides; abdomen green above with pale bluish-gray tip (S9-S10) when mature. Eyes blue above. Similar to other green spreadwings (Elegant, p. 27; Swamp, p. 26), but smaller and stockier and usually brighter green. Female similar to Common Spreadwing (p. 21) and Lyre-tipped Spreadwing (p. 24), but generally much greener dorsally; ovipositor typically extends beyond tip of abdomen (like Sweetflag Spreadwing, p. 22)

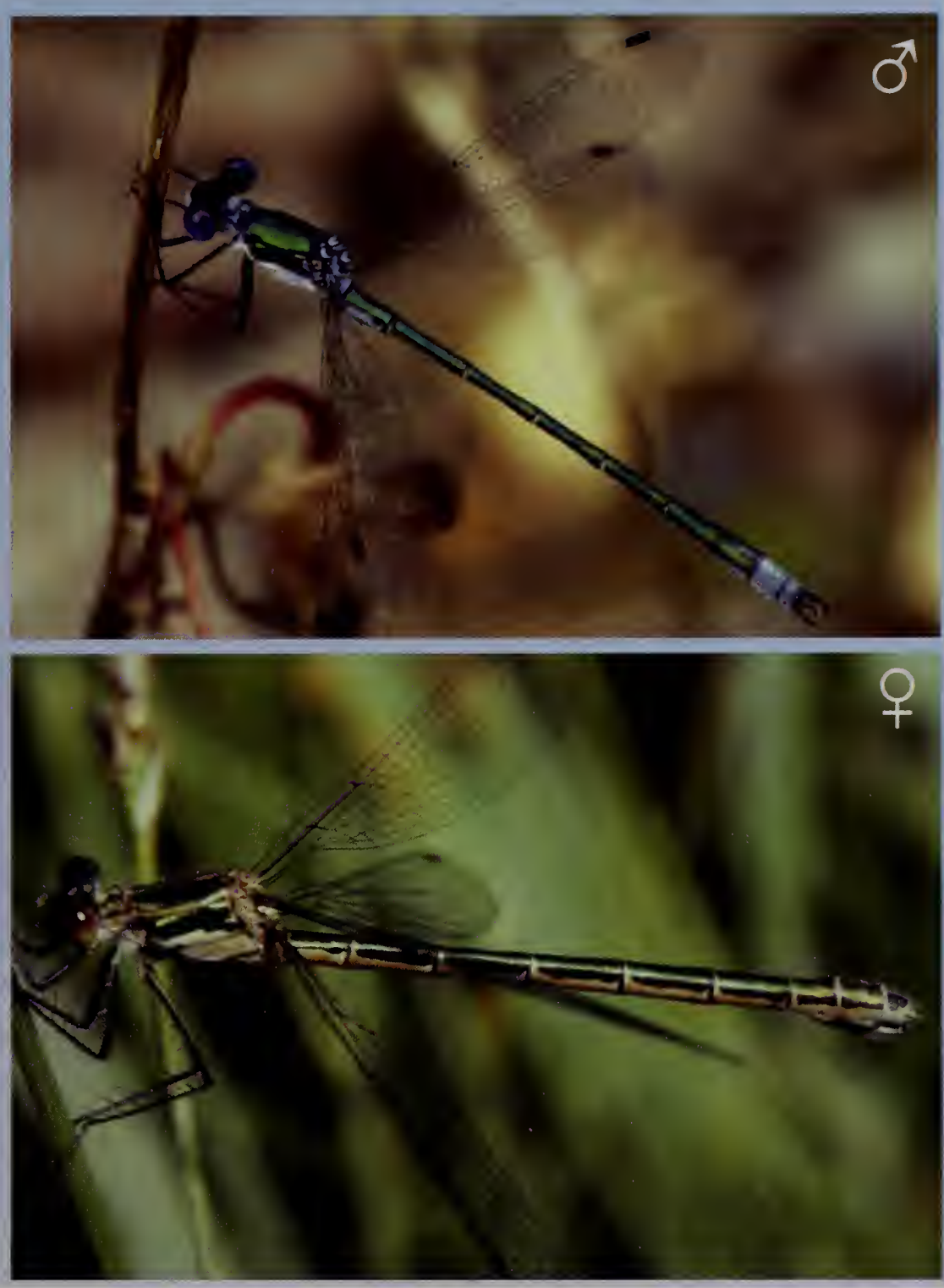

RANGE/STATUS South-central U.S. north through Canada. Uncommon throughout MA; all records from Cape Cod, Martha's Vineyard, and Nantucket are historic. HABITAT A wide range of still-water habitats, often acidic and/or temporary, including vegetated, marshy ponds and pools, and stream backwaters.

NOTES Adults perch on emergent vegetation in the wetland or nearby grassy fields, making short, slow flights. They perch in typical Lestes fashion, obliquely with the abdomen lowered and wings partially spread. Females oviposit in tandem in vertical stalks of emergent vegetation, slicing open the stems above the waterline and inserting eggs with their ovipositors.

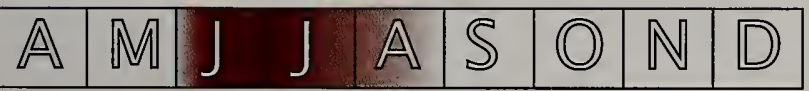


One of the larger spreadwings. Male thorax metallic green above with narrow brown shoulder stripes and dull yellowish sides, becoming pruinose gray with age; abdomen dark green above with pale gray tip (S9-S10) when mature. Eyes blue above. Female thorax green above, with brown shoulder stripes and grayish-yellow sides; abdomen green above, dull brown below. Both sexes very similar to the Elegant Spreadwing ( $p$. 27), but averaging smaller and duller green, with more obvious brown shoulder stripes.

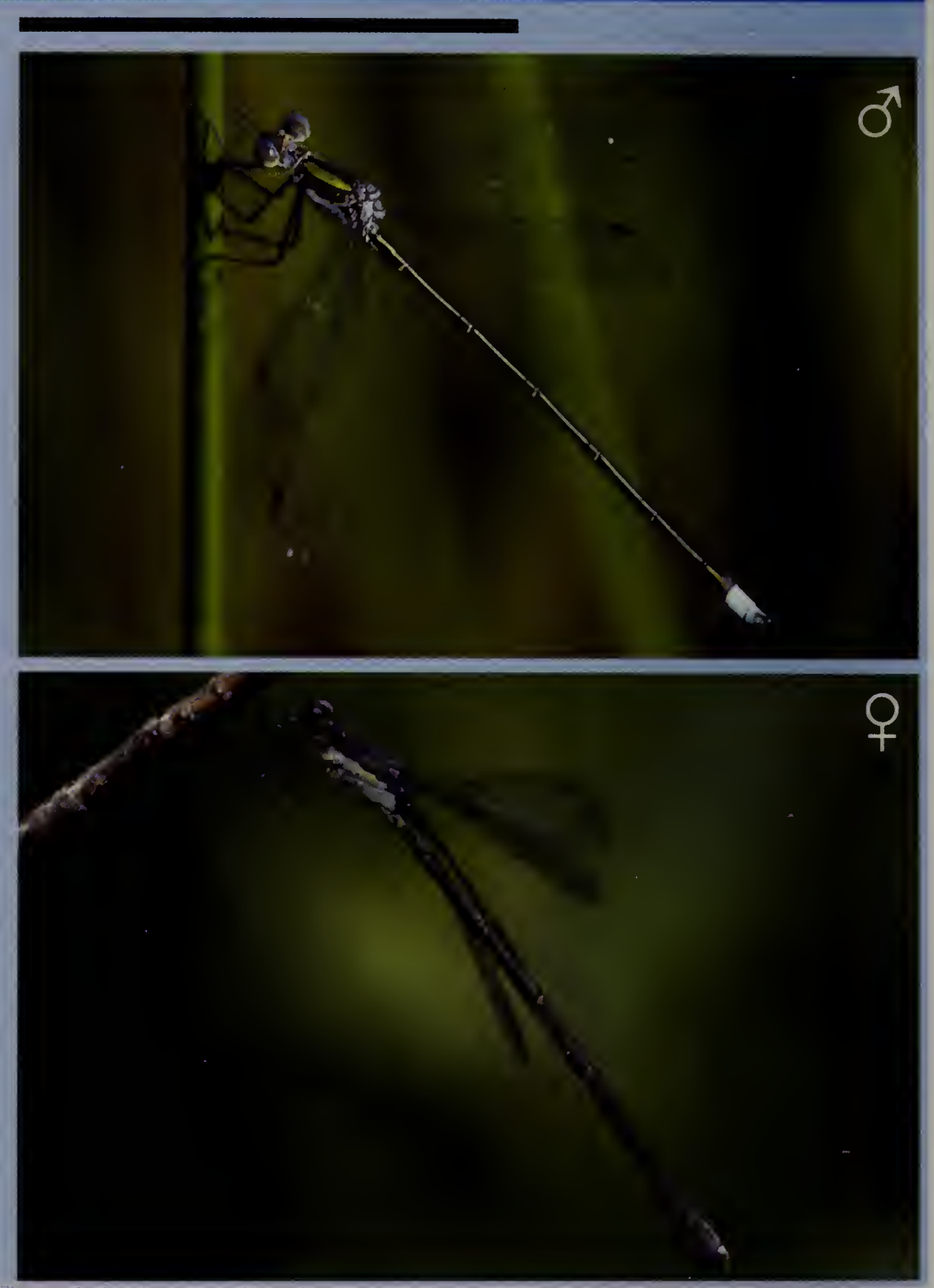

RANGE/STATUS Eastern U.S.; eastern Canada. Common and widespread throughout MA.

HABITAT A wide range of still-water habitats, including vegetated ponds and pools, marshy and bog-bordered ponds, and stream backwaters.

NOTES Adults fly slowly in and out of emergent vegetation along the shore and through grassy upland fields, perching frequently on low vegetation. They perch in typical Lestes fashion, obliquely with the abdomen lowered and the wings partially spread. Females oviposit in tandem in vertical stalks of emergent vegetation, slicing open the stems above the waterline and inserting eggs with their ovipositors.

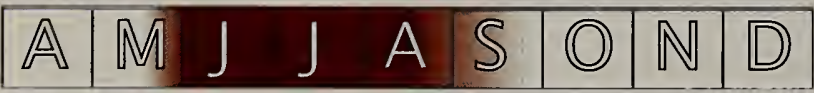


One of the largest spreadwings. Male thorax bright metallic green dorsally, with lemon-yellow sides; abdomen bright green above with a blue-gray tip (\$9-\$10) in mature individuals. Eyes blue above. Long inferior appendages (extending beyond superiors), often visible at close range in the field. Female similar but coloration somewhat duller. Both sexes very similar to the Swamp Spreadwing (p. 26),

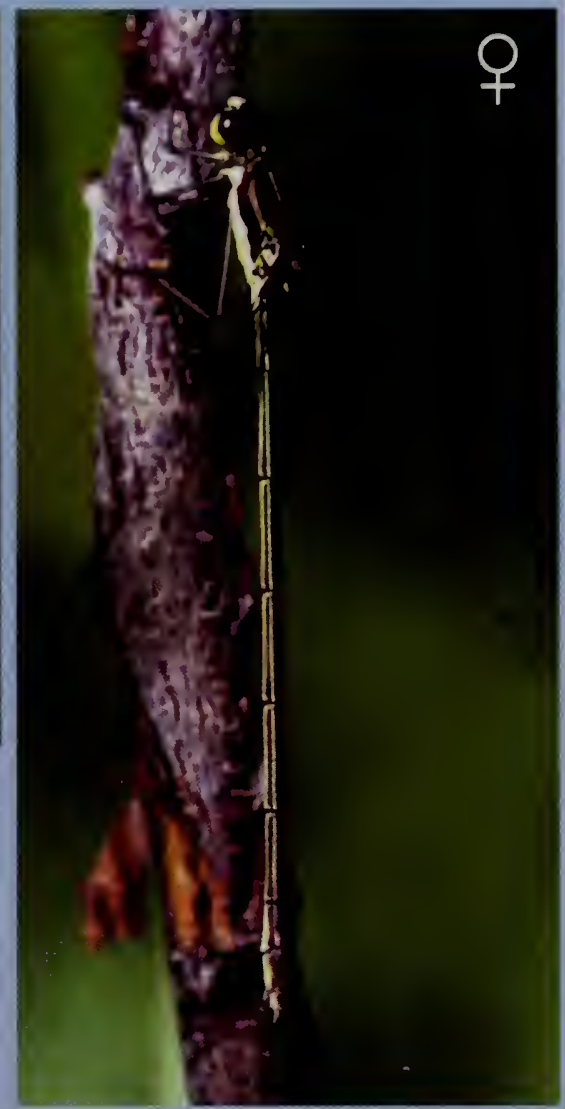
averaging somewhat larger and brighter green above, but with less distinctive brown shoulder stripes; often difficult to distinguish except in the hand. Amber-winged Spreadwing (p. 28) is similar in length but is huskier, less green, has a dark, diagonal streak on sides of thorax, and usually has at least a faint brownish wash in the wings.

RANGE/STATUS Eastern U.S.; eastern Canada. Fairly common throughout MA, though less common on the southeast coastal plain.

HABITAT A variety of still-water habitats including vegetated, marshy ponds and pond-like expansions of streams often with heavily wooded shorelines.

NOTES Adults fly slowly in and out of emergent vegetation, perching frequently in typical Lestes fashion, obliquely with the abdomen lowered and wings partially spread. They also fly low over open water. Females oviposit in tandem in vertical stalks of emergent vegetation and in floating aquatic plants, slicing open the plant tissues and inserting eggs with their ovipositors.

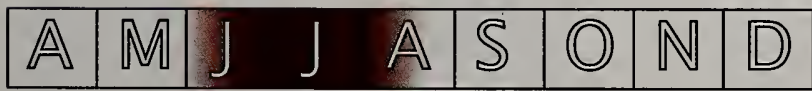


One of the largest spreadwings with varying amounts of amber wash in wings. Male thorax dark green to bluish above, with pale yellow sides and a dark diagonal lateral streak that fades with age; abdomen dark green to blackish above with a pale gray tip (\$9-\$10) when mature. Eyes bright blue above. Wings typically suffused with amber (but occasionally faint). Female thorax bronzy above with pale yellow sides and a dark diagonal lateral streak; abdomen dark green above, pale below. Wings often with little or no amber. Similar in size to the Elegant Spreadwing (p. 27), but stockier with less green coloration and dark lateral streak on thorax. Amber wash in wings is absent in most other spreadwings.

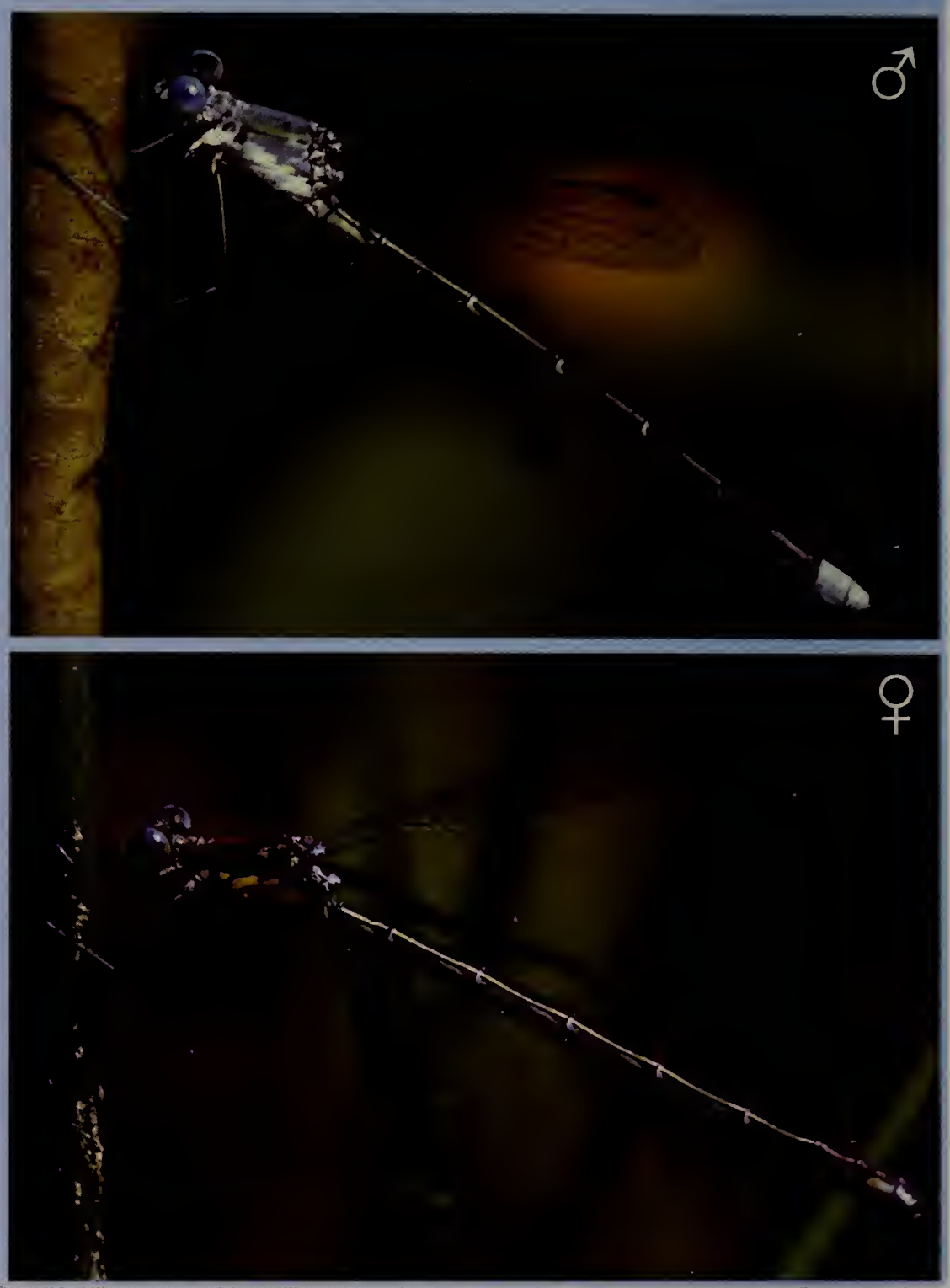

RANGE/STATUS Central to northeastern U.S.; eastern Canada. Uncommon but present throughout MA.

HABITAT A wide range of still-water habitats, most commonly boggy and temporary ponds.

NOTES Adults fly slowly in and out of emergent vegetation along the shore and out over open water. They perch frequently in typical Lestes fashion, obliquely with the abdomen lowered and wings partially spread. Females oviposit in tandem in emergent and floating vegetation. They have one of the earliest flight seasons among the spreadwings.

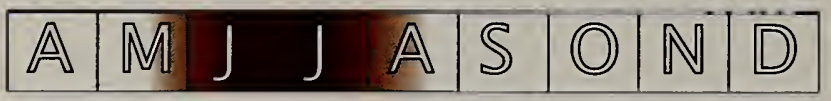


One of the longest spreadwings. Male thorax dark above with pale, often greenish shoulder stripes and lemon-yellow sides; abdomen very long and slender (almost twice the length of folded wings), pale brown but increasingly blackish dorsally toward tip, and lacking pale tip characteristic of other mature male spreadwings. Terminal appendages curved downward in side view. Eyes blue above. Female thorax brown above with pale shoulder stripes and yellow sides; abdomen dark above and stockier than male's (about $11 / 2$ times length of folded wings). Wings in both sexes occasionally tinged with brown.
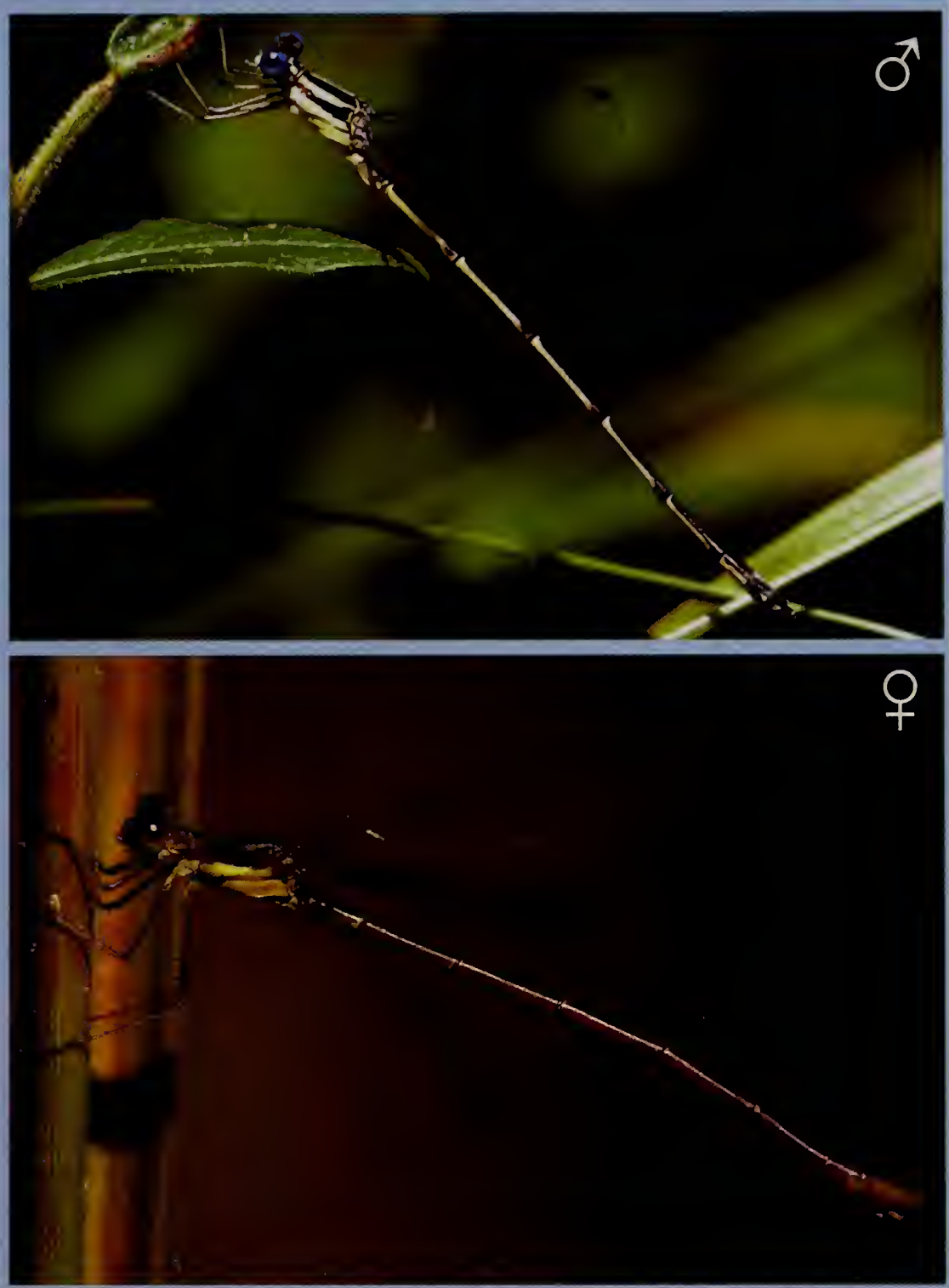

RANGE/STATUS Central to eastern U.S. into central and eastern Canada. Common throughout MA.

HABITAT A wide range of still-water habitats, including vegetated ponds and pools, marshes, and vernal pools.

NOTES Adults perch on emergent vegetation along the shore, often in the shade, flying infrequently. They are often found far from water, perched on low vegetation along trails, roads, and fields. They perch in typical Lestes fashion, obliquely with the abdomen lowered and wings partially spread. Females oviposit alone or in tandem in vertical stalks of emergent vegetation, slicing open the stems and inserting eggs with their ovipositors.

\begin{tabular}{|l|l|l|ll|l|l|l|l|l|}
\hline $\mathbb{A}$ & $\mathbb{M}$ & $J$ & J & A & $S$ & 0 & $\mathbb{N}$ & $\bar{D}$ \\
\hline
\end{tabular}




\section{COENAGRIONIDAE: POND DAMSELS}

Pond damsels are an exceptionally diverse family. Over 1,100 species have been described worldwide, with about 96 species from 13 genera known from North America. There are 35 species in Massachusetts, belonging to seven genera.

Pond damsels occur in a rainbow of colors, blue being most common. Wings are usually clear, though in some species can be dusky or faintly tinged with amber. Identification varies from straightforward to extremely difficult. In the field, many males and some females can be distinguished by the color and pattern of the body, the presence or absence of post-ocular spots ("eyespots"), and the shape and size of the spots. Females of a few species may be dichromatic; in one (homeochromatic) form their

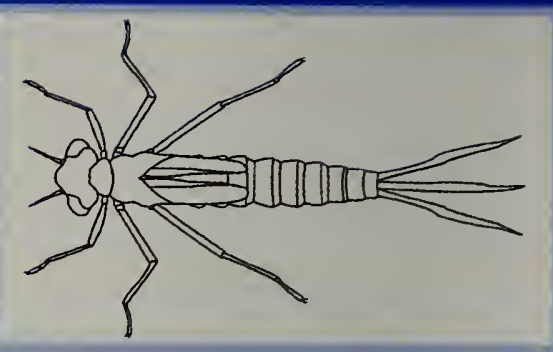

Pond damsel larvae have prominent eyes and short antennae. They tend to be smaller than the larvae of the other damselfly families. They climb on aquatic vegetation, although the species of Argia also sprawl on sand and mud on stream or river bottoms.

\section{color and pattern are similar to the male and in the other}

(heterochromatic) form their color and pattern are different than the male. The structure of the male terminal appendages (p. 31-32) provides the most reliable means of identifying many species.

Pond damsels are found in a wide range of aquatic habitats, with a few even inhabiting brackish wetlands. Some species are habitat specific, such as the coastal plain pond species, while others are generalists, found in a variety of habitats. One generalist, the Eastern Forktail (Ischnura verticalis), is probably the most widespread and common odonate in Massachusetts. Pond damsels are weak fliers and spend most of their time perched horizontally on flat surfaces (e.g., the ground, a rock, or a broad leaf) or horizontally on stalks of vegetation. They are most often found in wetlands, but may be encountered in nearby fields and clearings. They fly throughout the summer, with the earliest species often appearing in late April and the last still on the wing in early October. However, each species generally has a limited flight season, in many cases lasting only a month or so. Most species are active during the day, with the exception of the Vesper Bluet (Enallagma vesperum), which is crepuscular.

Males are generally not territorial, and spend most of the day at water hunting and waiting for receptive females. Females oviposit endophytically or epiphytically, either alone, with the male guarding from a nearby perch, or with the male attached in tandem. In the dancers (Argia), numerous pairs often oviposit synchronously in mats of floating vegetation, creating dense breeding congregations, the males still attached to the females in an upright position. Pond damsel larvae are small and elongate, spending much of their time clinging to stalks of aquatic vegetation or crawling along the undersides of leaves. The larval stage lasts from a few months to a year. Emergence takes place a few inches from the water on emergent vegetation. 
Key to Coenagrionid genera

1a. Tibial spines conspicuously long, more than twice as long as the space between each (a): $\operatorname{Argia}($ p. 64-67)

1b. Tibial spines not conspicuously longer than the space between each (b): 2

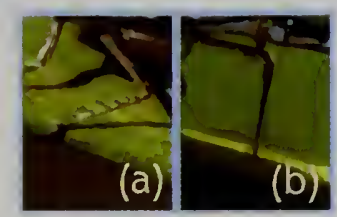

2a. Postocular spots absent (c): 3

2b. Postocular spots present $(\mathrm{d}): 4$

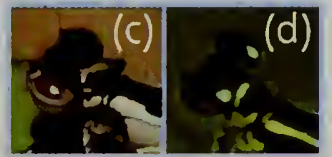

3a. Body blue and black, conspicuous yellow patch on lower thorax: Chromagrion (p. 33)

3b. Body metallic green with last 2 abdominal segments blue: Nehalennia (p. 62-63)

3c. Body red (o) or orange ( $q$ ) and black: Amphiagrion (p. 55)

4. Enallagma, Coenagrion, Ischnura. Male terminal appendages are illustrated below.

\section{MALE TERMinAl APPENDAgES: COENAGRIONIDAE}

The bluets (Enallagma) and similar species are very difficult to identify without examining the male terminal appendages under a hand lens or loupe. Identification of females is extremely difficult and often requires examination under a microscope. Refer to the technical manuals (see p. 194) for female diagnostic characteristics. The following illustrations are organized first by overall coloration of the animal. The species that do not have a blue and black abdomen are on this page, and those with a blue-and-black abdomen are on page 32. Note that the appearance and extent of dorsal and lateral black coloration on $\mathrm{S} 10$ is variable and often NOT a reliable diagnostic character.

\section{ABDOMEN NOT BLUE AND BLACK}

The following Coenagrionids do not have a blue and black abdomen. Body coloration of these species is diagnostic, but terminal appendages should be examined for confirmation.

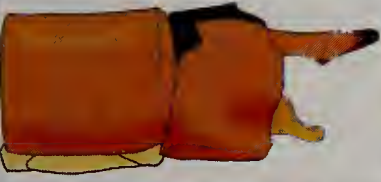

Orange Bluet, (Enallagma signatum): thorax orange; abdomen mostly black, S9 entirely orange. p. 52

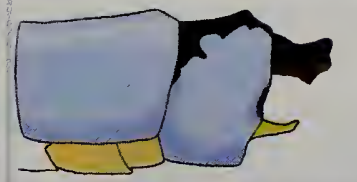

Vesper Bluet, (Enallagma vesperum): thorax bright yellow; abdomen mostly black, 59 entirely blue. p.53
In the following diagrams lateral views of 59 , S10 and the terminal appendages are illustrated. Superior appendages $(S A)$ and inferior appendages (IA) are diagnostic.

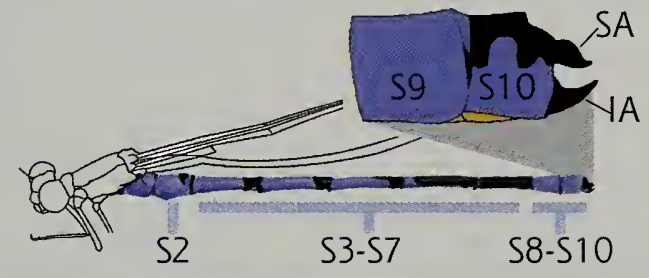




\section{ABDOMEN BLUE AND BLACK}

Most bluets (Enallagma), Coenagrion resolutum and Chromagrion conditum are blue and black. Though S8 and S9 on many are entirely blue, S2-S7 range from either more blue than black to more black than blue. The following terminal appendage illustrations group the species by overall abdomen coloration (more blue at the top of the page to more black at the bottom) and by body size (larger species on the left to smaller species on the right).

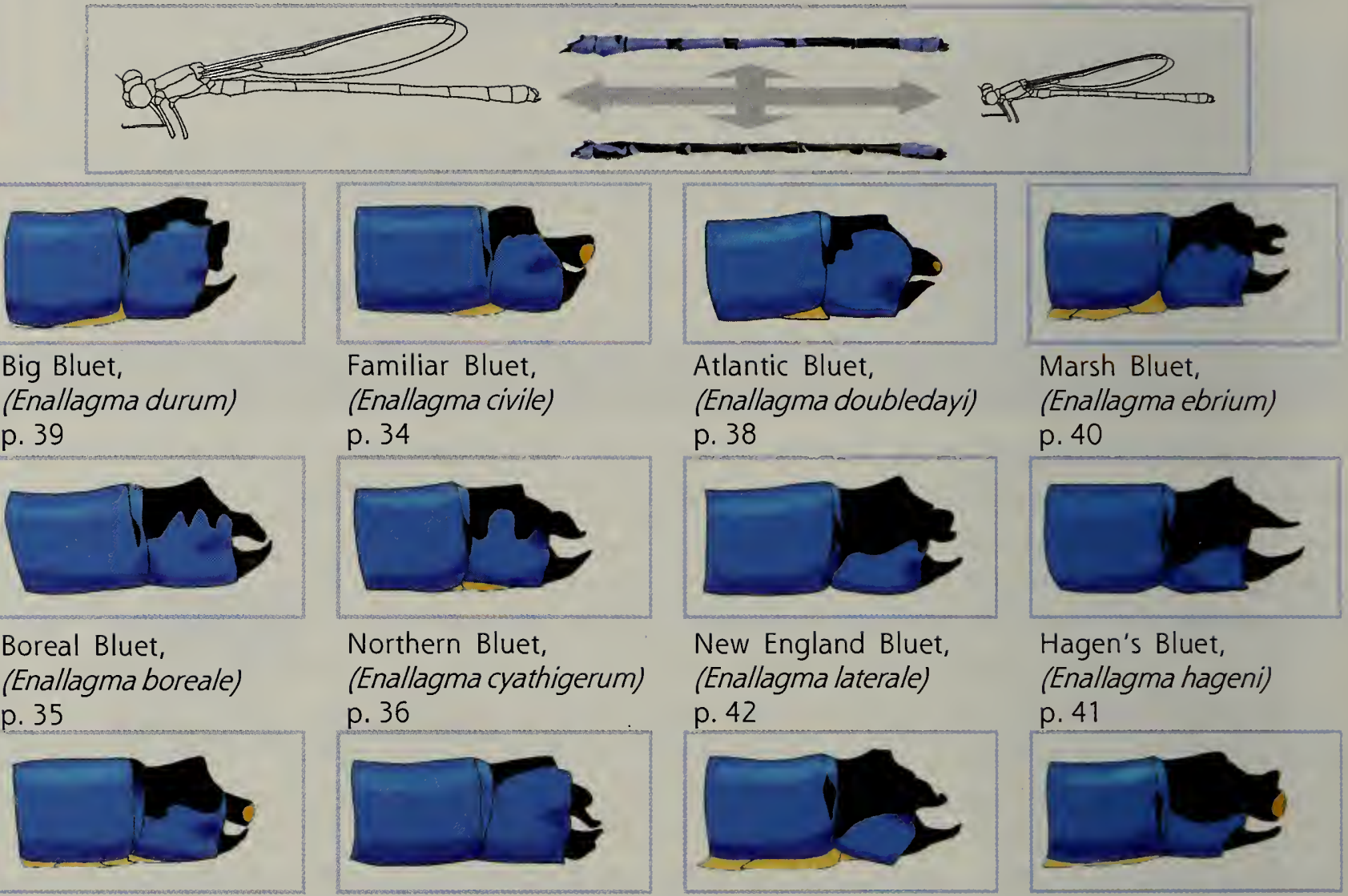

Tule Bluet,

(Enallagma carunculatum) p. 37

Taiga Bluet,

(Coenagrion resolutum)

p. 45

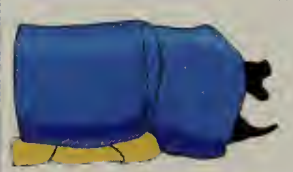

Attenuated Bluet, (Enallagma daeckii) p. 51

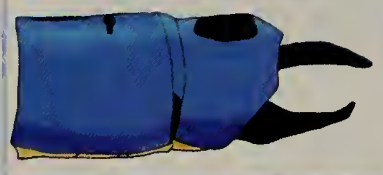

Aurora Damsel, (Chromagrion conditum) p. 33

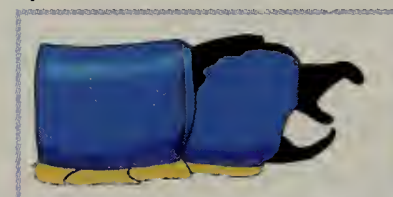

Azure Bluet,

(Enallagma aspersum) p. 50

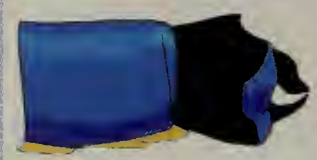

Turquoise Bluet, (Enallagma divagans) p. 48
Pine Barrens Bluet, (Enallagma recurvatum) p. 43

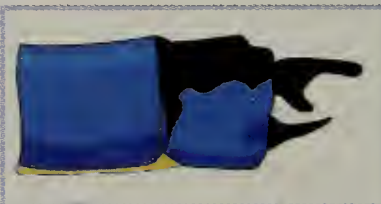

Slender Bluet,

(Enallagma traviatum) p.46

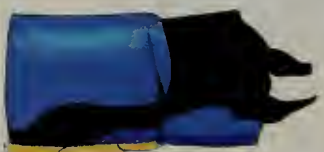

Skimming Bluet, (Enallagma geminatum) p. 49
Little Bluet,

(Enallagma minusculum) p. 44

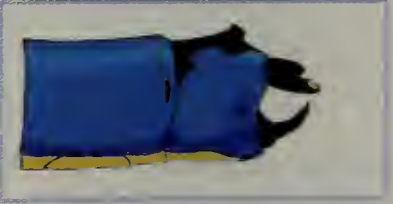

Stream Bluet,

(Enallagma exsulans) p.47 
Resembles a bluet (Enallagma), but typically holds wings partially open like a spreadwing. Male thorax black above, with blue sides and a distinctive yellow patch on lower sides; abdomen mostly black on middle segments (S3-57) with blue rings, S8-\$9 blue with distinctive pattern of thin black markings on top. Eyes blue, no postocular spots. Female similar to male, including distinctive yellow patch on thorax, but light brown to gray where male is blue, and \$8-\$9 black above.

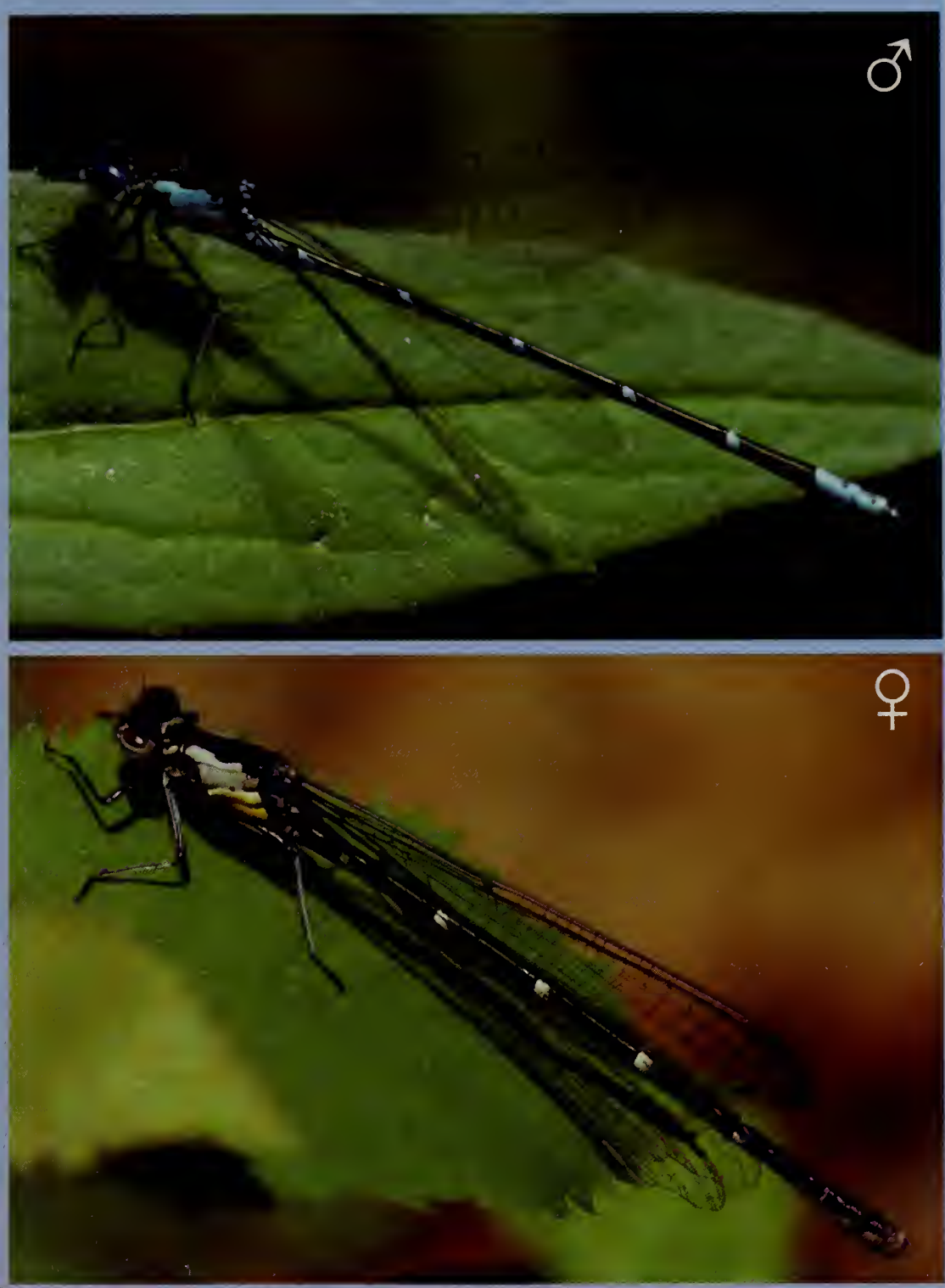

RANGE/STATUS Eastern U.S. Common throughout MA but scarce along southeast coast.

HABITAT Bogs, fens, small streams, and vernal pools.

NOTES Adults spend much of the time perched on low vegetation or on the ground along the shoreline or on roads and trails near water. When perched they are similar to a spreadwing (Lestidae) in habit, with the wings held partially spread. Flights are low and brief. Females oviposit in tandem on floating or submerged plants. 
Typically a large bluet (though size quite variable), with more blue than black on abdomen. Male thorax blue with broad, black mid-dorsal stripe and thinner black shoulder stripes; abdomen mostly blue with black dorsal markings, black most extensive on $56-57$, and entirely blue on 58S9. Postocular spots usually small and rounded or tearshaped. Female thoracic pattern similar to male but pale tan where male is blue, though many become dull blue with age; abdomen mostly black above. Both sexes very similar to Boreal Bluet (p. 35), Northern Bluet ( $p$. 36), Tule Bluet (p. 37), Atlantic Bluet (p. 38), and Big Bluet (p. 39); safely identified only by male terminal appendages. Females often indistinguishable in the field.

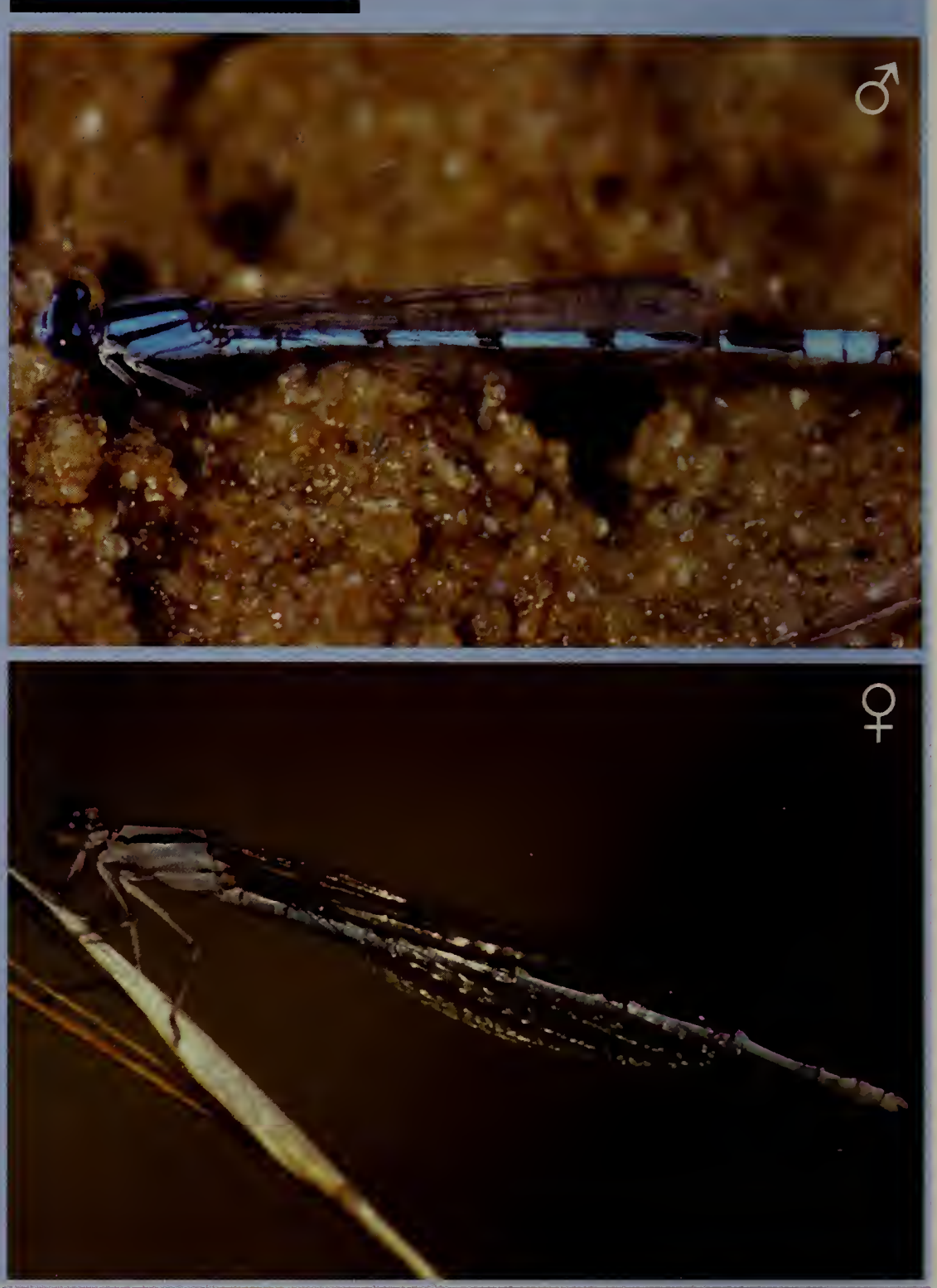

RANGE/STATUS U.S.; southern Canada. Common throughout MA.

HABITAT Large ponds, lakes, and sluggish rivers; sometimes found in brackish or saline wetlands.

NOTES Adults fly low in and out of shoreline and emergent vegetation, perching horizontally on the ground, rocks, logs, and foliage. They hunt in flight, gleaning perched insects from vegetation. Males fly low over open water. Females oviposit in tandem on submerged vegetation, often becoming completely submerged themselves.

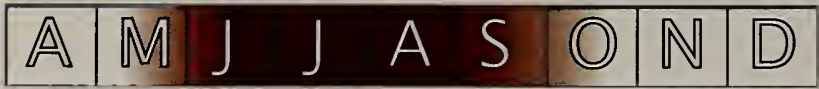


Fairly large bluet with more blue than black on abdomen. Male thorax blue with broad black middorsal stripe and thinner black shoulder stripes; abdomen mostly blue with dorsal black markings, black most extensive on S6-57, and entirely blue on S8-59. Postocular spots typically rounded and fairly large. Female thorax similar to male, but pale grayish-brown where male is blue, often becoming dull blue with age; abdomen mostly black above. Both sexes very similar to Northern Bluet (p. 36) and Familiar Bluet (p. 34); safely identified only by male terminal appendages.
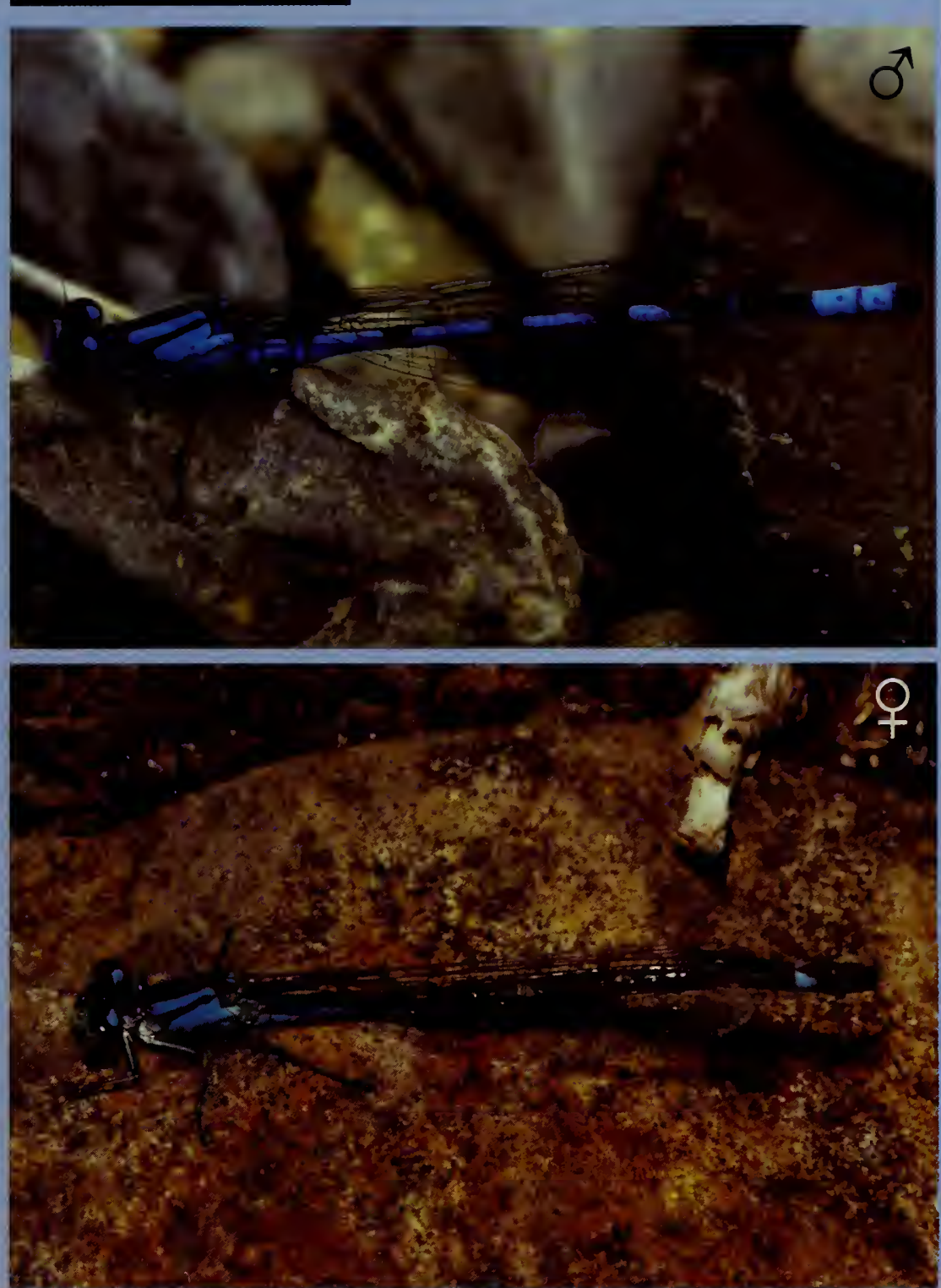

RANGE/STATUS U.S. and Canada. Fairly common in much of MA, but rare along southeast coast.

HABITAT A wide variety of still-water habitats; often vegetated ponds.

NOTES Adults fly low in and out of shoreline vegetation, alighting horizontally or obliquely on foliage. Females oviposit in tandem on floating or submerged vegetation. Like the very similar Northern Bluet (p. 36), this species flies early in the season, reaching peak abundance in June.

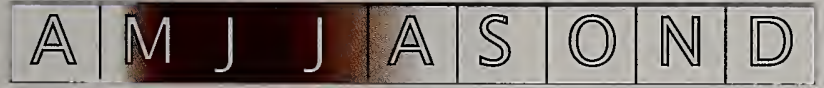


Fairly large bluet with more blue than black on abdomen. Male thorax blue with broad, black mid-dorsal stripe and thinner black shoulder stripes; abdomen mostly blue with black dorsal markings, most extensive on S6--57, entirely blue on S8-59. Postocular spots generally large and rounded. Female thorax similar to male, but pale areas tan to dull blue; abdomen mostly black above, except 58 mostly pale with thin black dorsal line, expanding rearward. Both sexes very similar to Boreal Bluet (p. 35) and Familiar Bluet (p. 34); safely identified only by male terminal appendages.
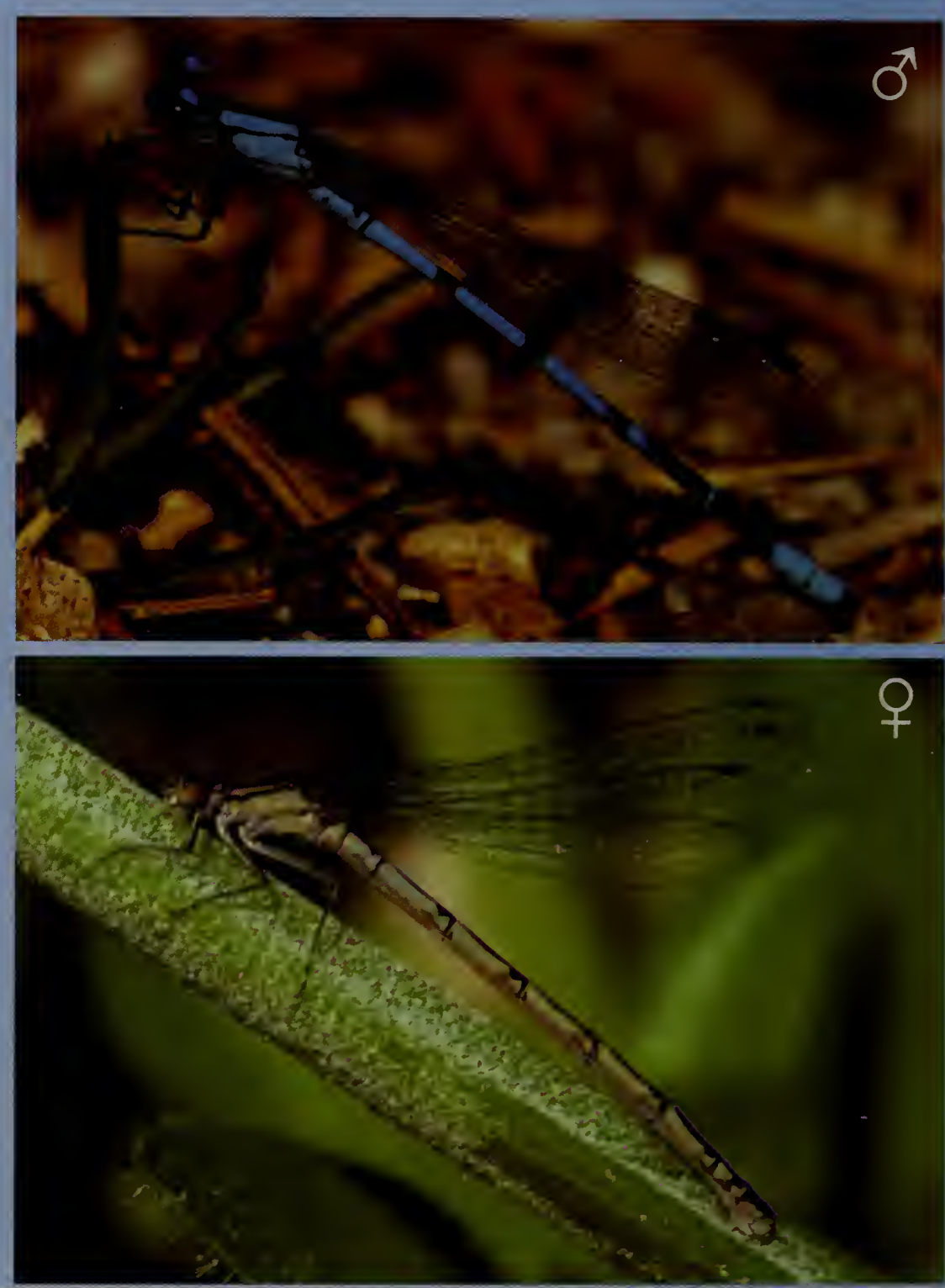

RANGE/STATUS Central U.S. north through Canada. Fairly common throughout MA.

HABITAT A wide range of still-water habitats including vegetated ponds, bogs, and vernal pools; occasionally sluggish streams.

NOTES Adults fly in and out of emergent and shoreline vegetation, alighting horizontally or obliquely on foliage. Females oviposit in tandem in floating and submerged aquatic plants. Like the very similar Boreal Bluet (p. 35), flies early in the season.

The form $E$. cyathigerum vernale may be a distinct species; its status in MA is unclear. Identification requires microscopic examination of the male terminal appendages.

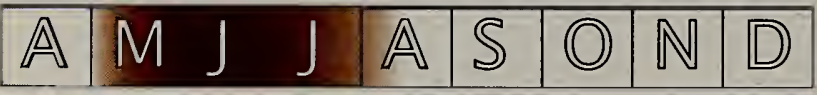


Fairly large bluet with abdomen slightly more black than blue dorsally. Male thorax blue with broad black mid-dorsal stripe and thinner black shoulder stripes; abdomen blue with black dorsal markings on S2-S7 (S457 more black than blue above), 58-59 entirely blue. Postocular spots variable but generally rather small and tearshaped. Female thorax similar to male, but pale areas light brown to bluegray; abdomen mostly black above. Both sexes very similar to Familiar Bluet (p. 34), though male typically with more black on S4-55, imparting a somewhat darker appearance overall. Safely identified only by male terminal appendages.

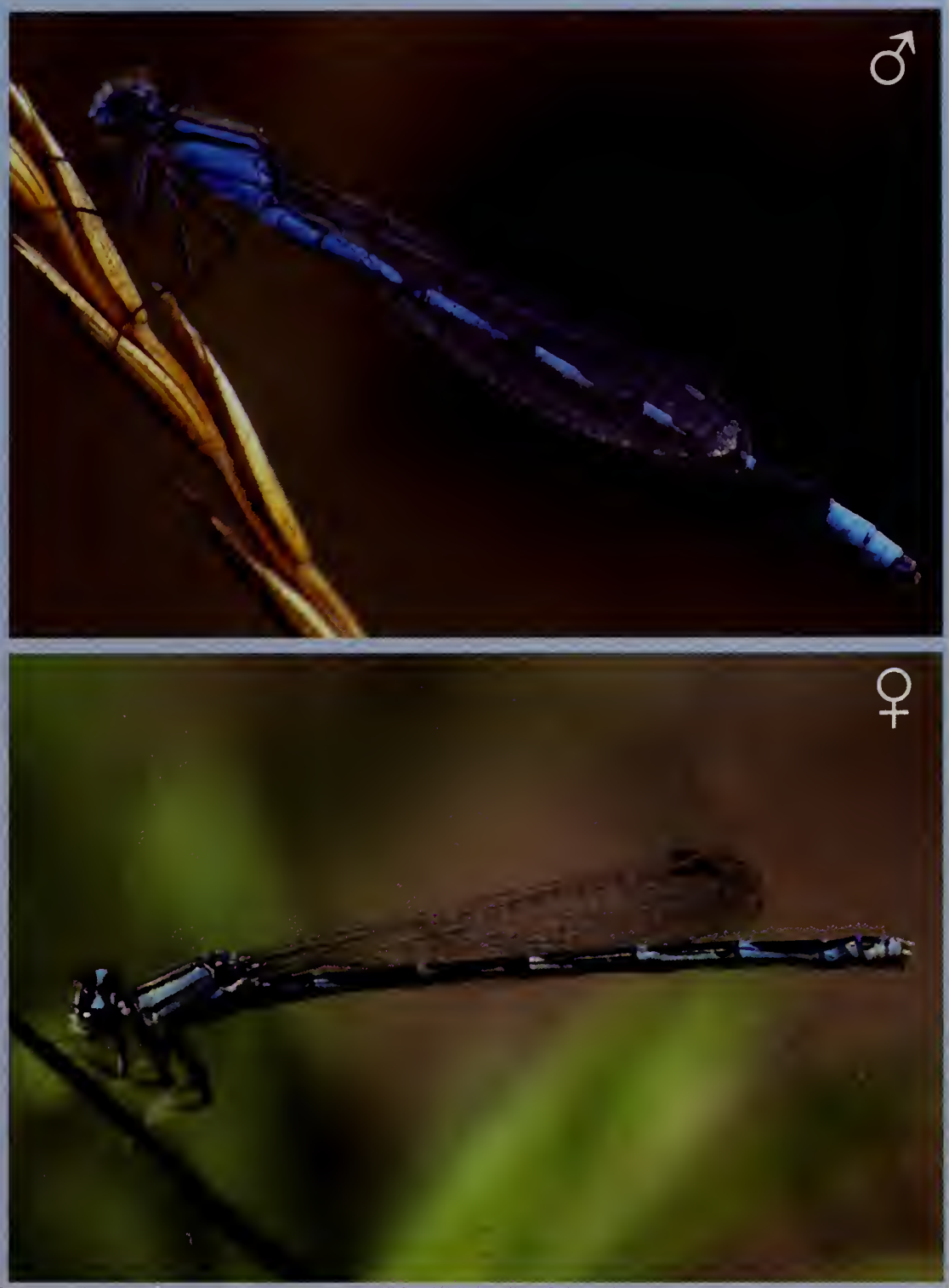

RANGE/STATUS Central U.S. north through southern Canada. Uncommon and local in central and western MA.

HABITAT Ponds and sluggish, mid-sized to large rivers.

NOTES Adults spend much of the time perched horizontally or obliquely on foliage, rocks, and logs, making low, brief flights. Females oviposit in tandem on floating or submerged vegetation.

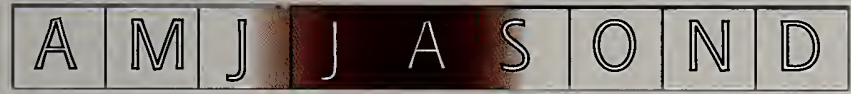


Fairly large bluet with more blue than black on abdomen. Male thorax blue with broad, black mid-dorsal stripe and thinner black shoulder stripes; abdomen mostly blue with black dorsal markings, black most extensive on S6-S7, and 58-59 entirely blue. Postocular spots small and connected by a pale bar across rear of head. Female thorax similar to male but pale areas tan or dull blue; abdomen black above. Both sexes very similar to Familiar Bluet (p. 34), though fused postocular spots usually distinctive. Safely identified only by male terminal appendages. Also similar to Boreal Bluet (p. 35), Northern Bluet (p. 36), and Big Bluet (p. 39).
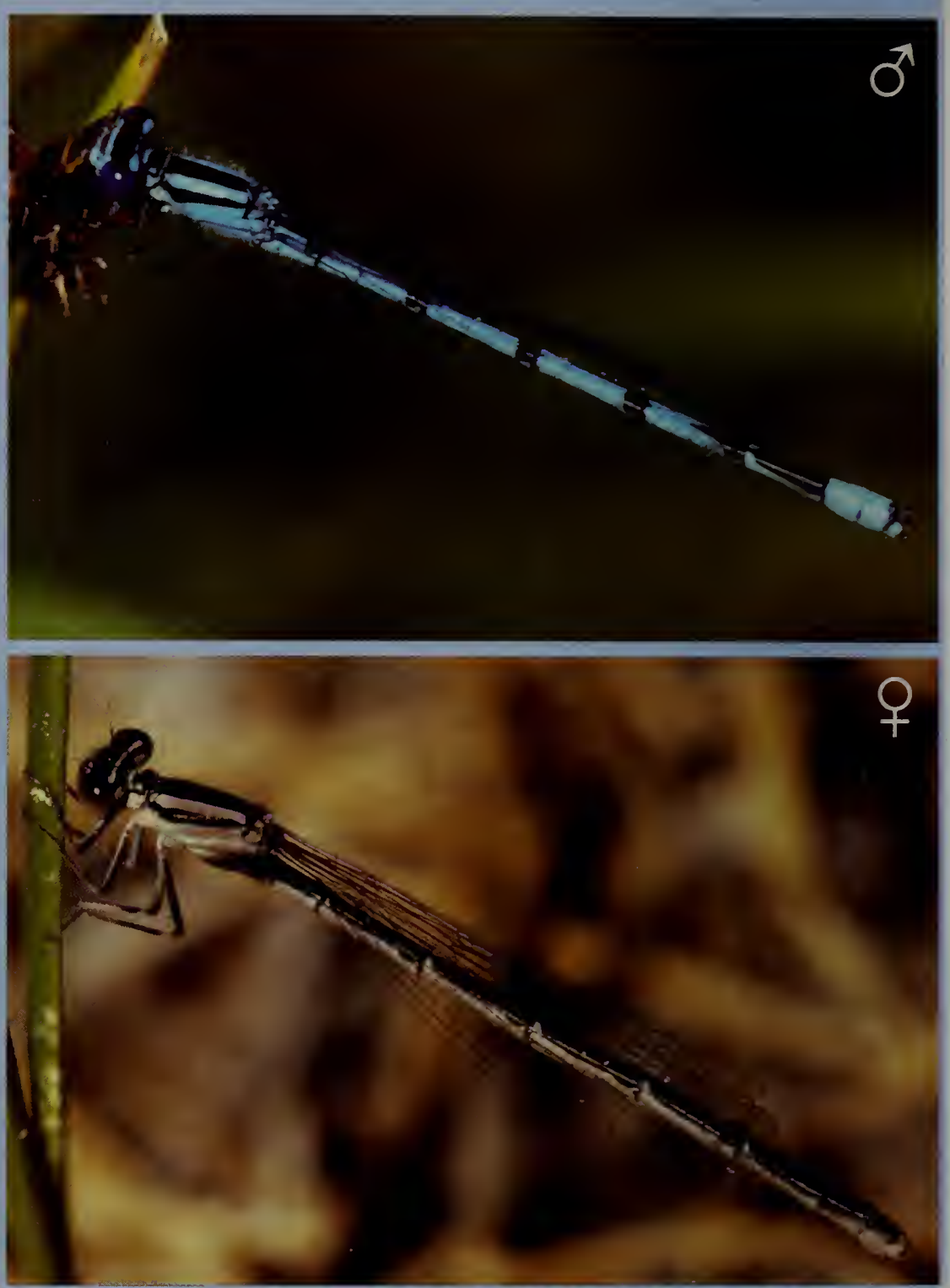

RANGE/STATUS Southeastern U.S., north to MA. Common but local in southeastern MA.

HABITAT Coastal plain ponds.

NOTES Adults fly among emergent shoreline vegetation, often perching on projecting stems. Females oviposit in tandem on horizontal and vertical stems of emergent vegetation. Although the range and flight season overlaps with the Familiar Bluet $(E$. civile) in the southeast, the two species do not seem to occur together, Familiar Bluets typically occurring in less-vegetated ponds. 
Small bluet with more blue than black on abdomen. Male thorax blue with broad, black mid-dorsal stripe and thinner black shoulder stripes; abdomen mostly blue with black dorsal markings, most extensive on 56-57; mostly blue on S8-59. Postocular spots small and tear-shaped. Female thorax similar to male, but pale areas $\tan$ to bluegreen; abdomen extensively black above. Both sexes indistinguishable from Hagen's Bluet ( $p$. 41) without examination of male terminal appendages or female mesostigmal plates on front of thorax. Also very similar to the Familiar Bluet ( $p$. 34), but smaller.

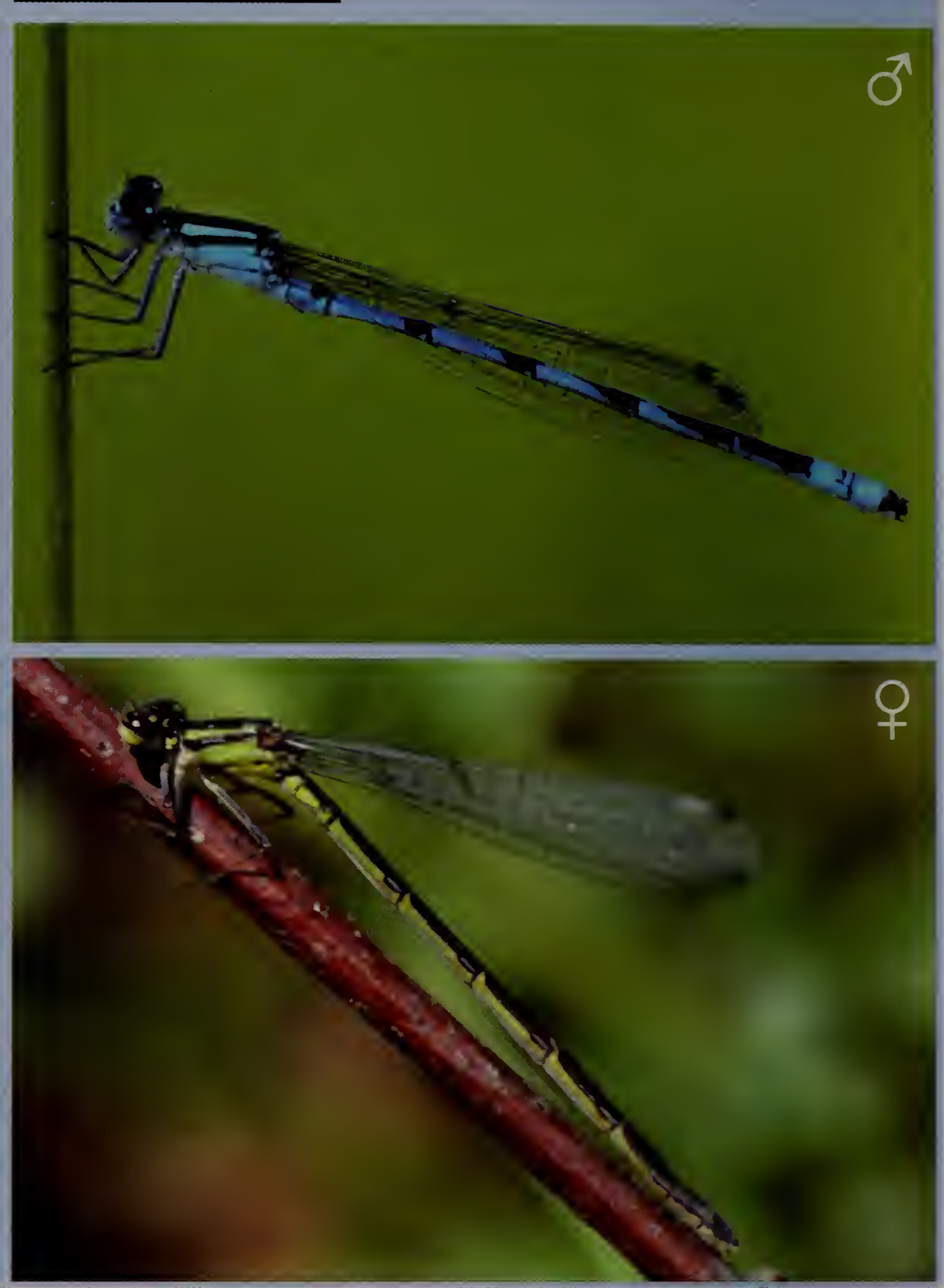

RANGE/STATUS Central to northern U.S.; southern Canada. Common throughout MA but absent from the southeast coastal plain.

HABITAT Grassy wetlands; usually not associated with acidic waters.

NOTES Adults fly slowly through emergent and shoreline vegetation, alighting horizontally or obliquely on foliage. Females oviposit in tandem or alone, often becoming completely submerged. Although this species and the virtually identical Hagen's Bluet (E. hageni) have similar distributions and flight seasons, they typically do not use the same habitat, the latter preferring more acidic conditions. However, they do co-occur at a few sites.

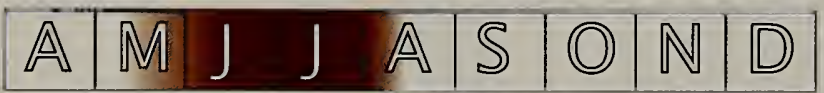


Small bluet with more blue than black on abdomen. Male thorax blue with broad, black mid-dorsal stripe and black shoulder stripes; abdomen mostly blue with black dorsal markings, most extensive on 56-57, mostly blue on 58-59. Postocular spots small and tear-shaped. Female thorax similar to male, but pale areas light brown to bluish or green; abdomen extensively black above. Both sexes indistinguishable from Marsh Bluet (p. 40) without examination of male terminal appendages or female mesostigmal plates on frong of thorax.

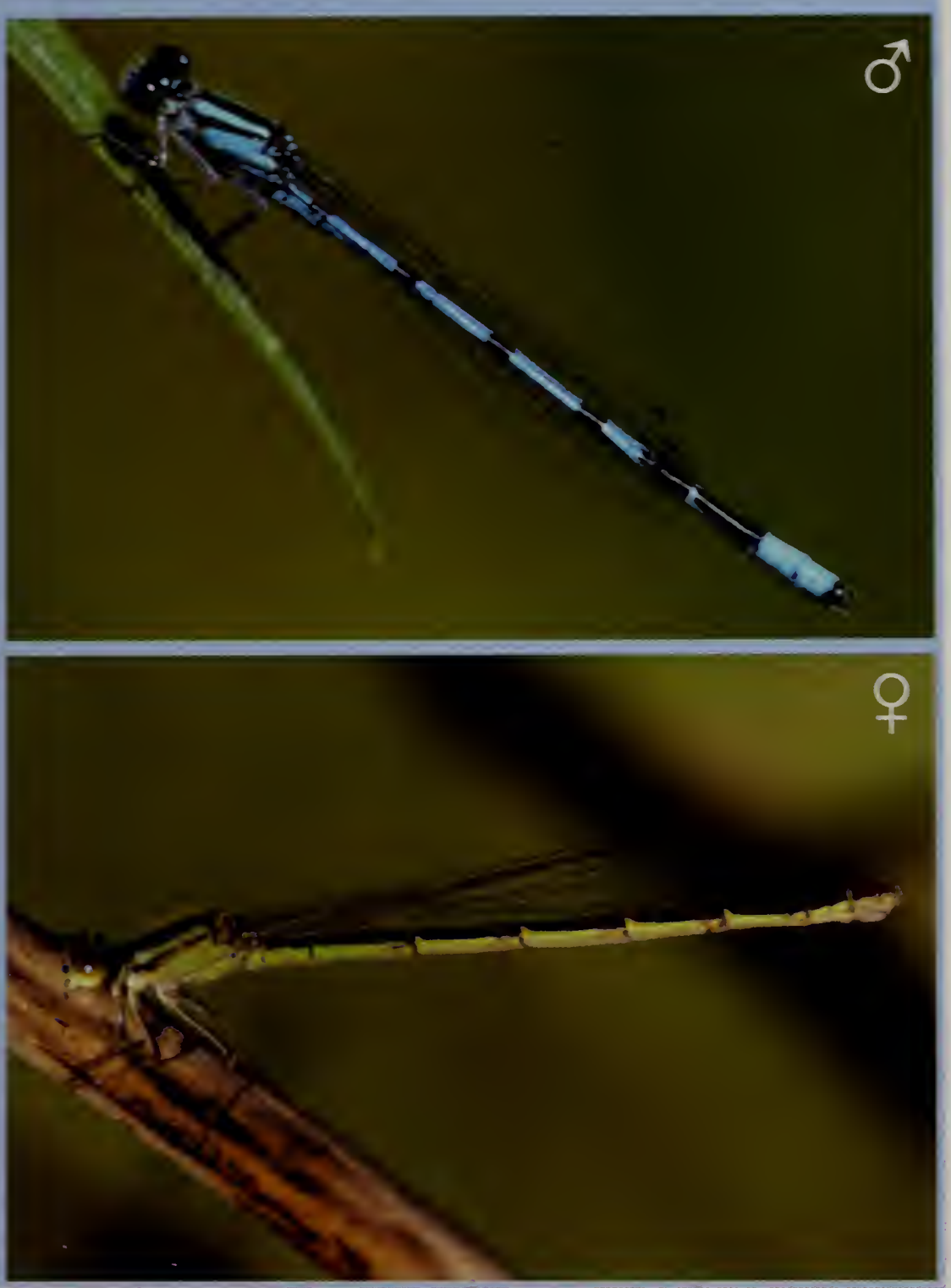

RANGE/STATUS Central to northeastern U.S.; Canada. Common throughout MA but absent from the southeast coastal plain.

HABITAT Vegetated ponds and open bogs, more often in acidic wetlands than Marsh Bluet (E. ebrium).

NOTES Adults fly slowly through emergent and shoreline vegetation, frequently alighting horizontally or obliquely on foliage. Females oviposit in tandem in floating and emergent vegetation.

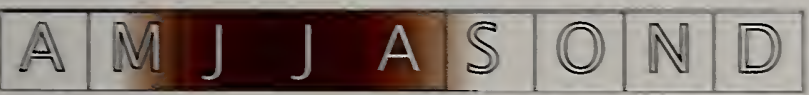


Small bluet with more blue than black on abdomen. Male thorax blue with broad, black mid-dorsal stripe and black shoulder stripes; abdomen mostly blue with black dorsal markings, black most extensive on S6-57; S8S9 mostly blue, with variably sized horizontal black mark on side of $\mathrm{S} 8$. Postocular spots rather small and tear-shaped. Female thorax similar to male, but pale areas tan to blue-gray; abdomen black above. Similar to the Pine Barrens Bluet (p. 43), but males typically less black on S4-S5, with larger black mark on side of S8. Female virtually identical to female Marsh (p. 40) and Hagen's (p.41) Bluets.

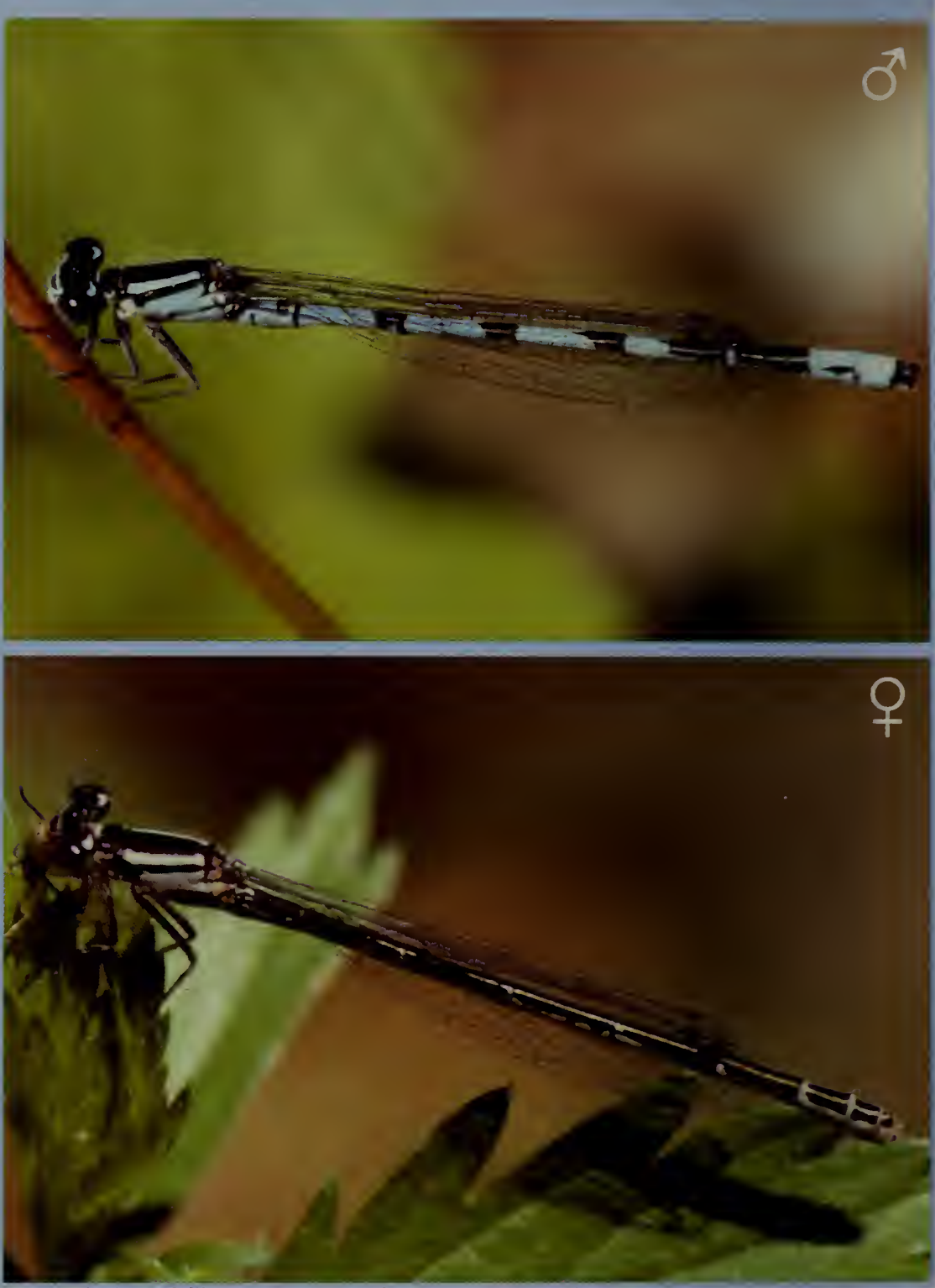

RANGE/STATUS A northeastern endemic found from NJ north to southern ME. It is uncommon to locally common throughout eastern and north-central MA. HABITAT Acidic, sandy ponds (e.g., coastal plain ponds), bog-bordered ponds, and other ponds with ample emergent vegetation.

NOTES Adults fly slowly through emergent and shoreline vegetation and along forest roads and clearings near water, frequently alighting horizontally or obliquely on foliage. Females oviposit in tandem in floating and emergent vegetation.

\begin{tabular}{|l|l|l|l|l|l|l|l|}
\hline $\mathbb{A}$ & $\mathbb{M} J$ & $\mathbb{N}$ & $\mathbb{A}$ & $\mathbb{S}$ & $\mathbb{O}$ & $\mathbb{N}$ & $\mathbb{D}$ \\
\hline
\end{tabular}


Small bluet with more black than blue on middle of abdomen. Male thorax blue with broad, black mid-dorsal stripe and black shoulder stripes; abdomen blue with black markings, black most extensive on S6-S7, about equally blue and black on S4-S5, and 58-59 mostly blue, with small (occasionally absent), horizontal black mark on sides of S8. Postocular spots small and tearshaped. Female thorax similar to male, but pale areas tan to blue-gray; abdomen mostly black above, except 58 partially blue with forwardpointing black triangle. Similar to New England Bluet (p. 42), but usually more black on middle of abdomen and black lateral mark on 58 typically smaller. Female most similar to Skimming Bluet (p. 49), but differs in pattern on $\mathrm{SZ}$.

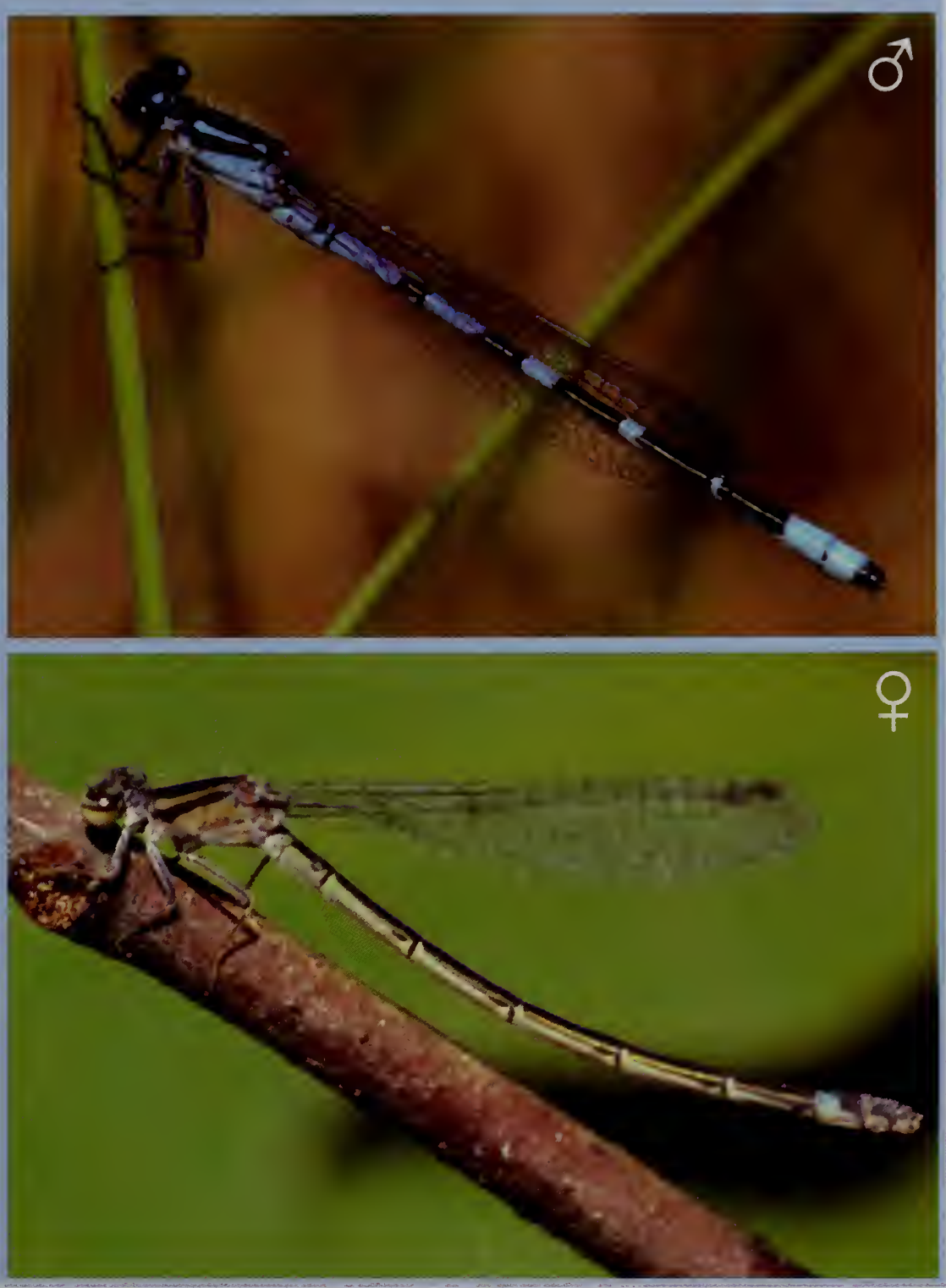

RANGE/STATUS A northeastern endemic found from NJ north to southern ME. It is uncommon and restricted to the southeast coastal plain in MA.

HABITAT Acidic, sandy ponds (e.g., coastal plain ponds).

NOTES Adults fly slowly through emergent and shoreline vegetation and along forest roads and clearings near water, frequently alighting horizontally or obliquely on foliage. Females oviposit in tandem in floating and emergent vegetation.

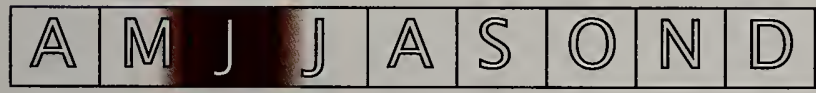


One of the smallest bluets, with about equally blue and black abdomen. Male thorax blue with broad, black mid-dorsal stripe and black shoulder stripes, blue on top of thorax becoming lavender with age; abdomen mostly blue with black dorsal markings, S4S5 half to two-thirds black, S6-S7 mostly black, and S8-59 entirely blue. Female thorax similar to male, but pale areas tan to blue-gray; abdomen black above. Lavender color on male thorax is distinctive. Female very similar to Marsh (p. 40), Hagen's (p. 41) and New England (p. 42) Bluets.

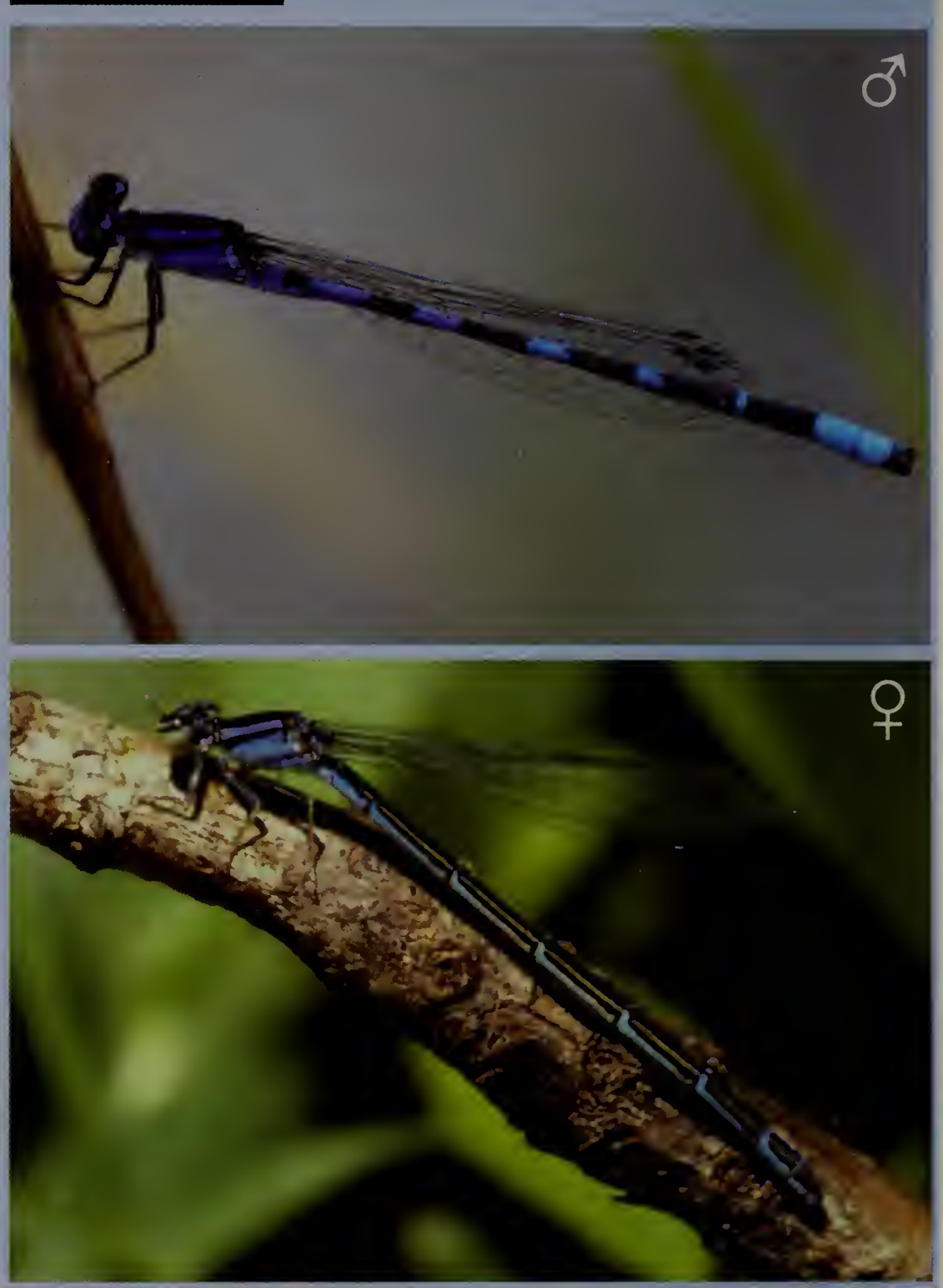

RANGE/STATUS Northeastern U.S.; southeastern Canada. Uncommon in central and eastern MA, more common in the southeast coastal plain.

HABITAT Ponds with sparse emergent or aquatic vegetation and sandy substrate.

NOTES Adults fly slowly through emergent and shoreline vegetation, frequently alighting horizontally or obliquely on foliage. Females oviposit in tandem in floating and emergent vegetation.

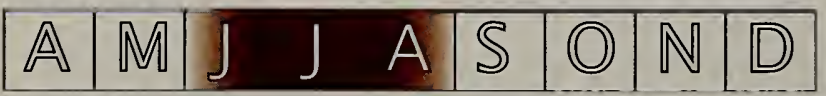


Male thorax blue with broad black mid-dorsal stripe and thinner black shoulder stripes; lower sides of thorax typically tinged with pale green; abdomen blue with black dorsal markings, S3-\$5 about equally blue and black above, S6-57 all black, 58-59 all blue. Postocular spots tearshaped. Female thorax similar to male with pale areas more green; abdomen entirely black above. Male distinguished from other bluets by greenish-blue color and pattern on $\mathrm{S} 2$.

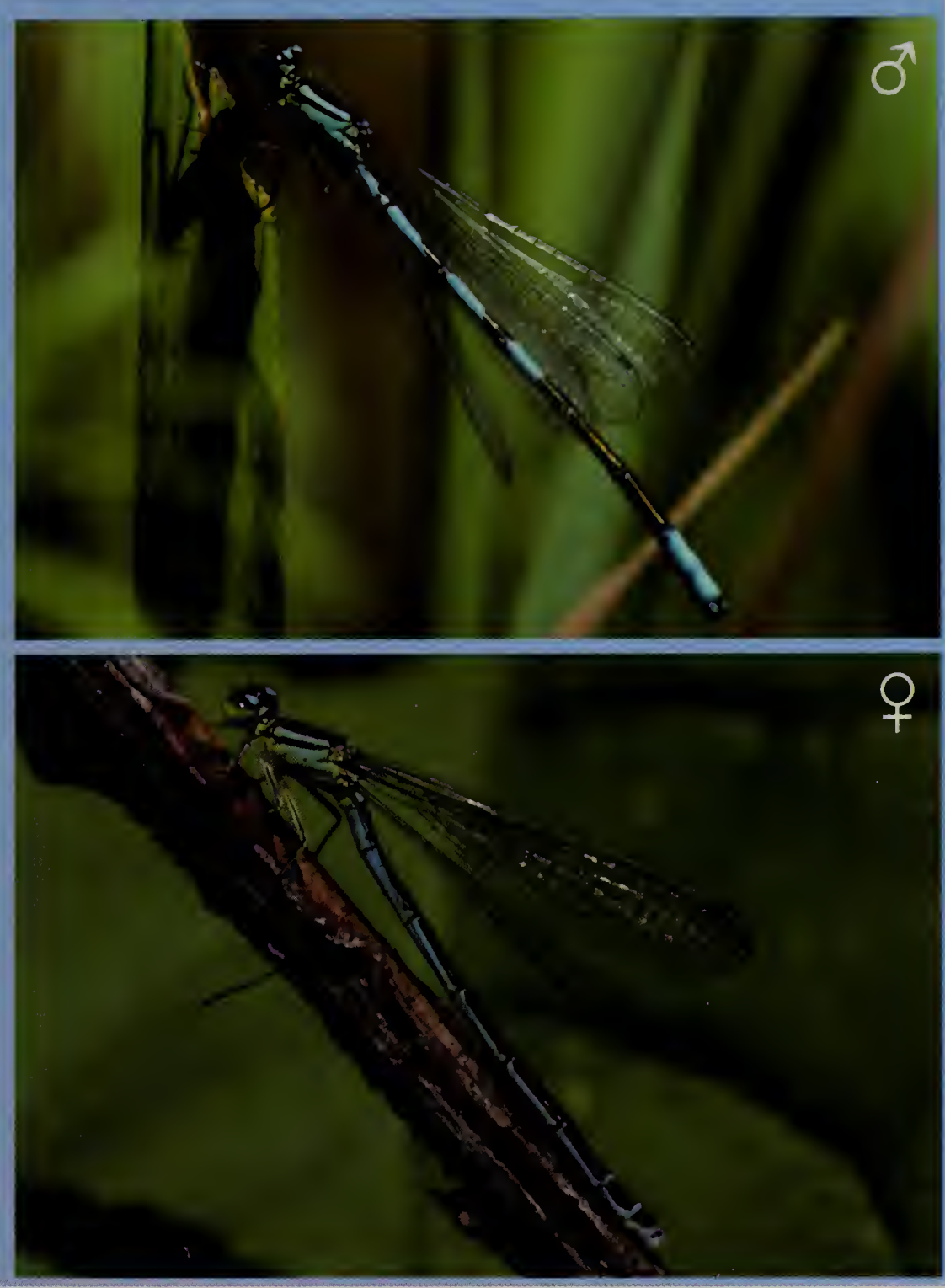

RANGE/STATUS Central to northern U.S.; Canada. Rare in MA, with several records from north-central and northeastern $\mathrm{MA}$ and one anomalous record from Cape Cod.

HABITAT Marshes, bogs, and vegetated ponds.

NOTES Adults perch horizontally on emergent and shoreline vegetation and make low, brief flights. Females oviposit in tandem on emergent or floating vegetation.

\begin{tabular}{|l|l|l|l|l|l|l|l|l|}
\hline $\mathbb{A}$ & $\mathbb{M}$ & $J$ & $J$ & $\mathbb{A}$ & $\mathbb{S}$ & $\mathbb{O}$ & $\mathbb{N}$ & $\mathbb{D}$ \\
\hline
\end{tabular}


Medium-sized bluet with more black than blue on abdomen. Male thorax blue with broad, black mid-dorsal stripe and thick black shoulder stripes; abdomen mostly black on 53-57, but with narrow blue rings on rear of each segment, 58 blue on sides and black above, 59 all blue. Postocular spots small and connected by a pale bar across rear of head. Female thorax similar to male, but pale areas usually dull greenish, and shoulder stripes brown with black edging; abdomen mostly black above, but $\$ 10$ and rear half of 59 pale. Male turquoise Bluet (p. 48) similar, but abdomen lacks conspic-uous blue rings and more blue on 58 . Brown shoulder stripes of female Stream Bluet are dist-inctive.

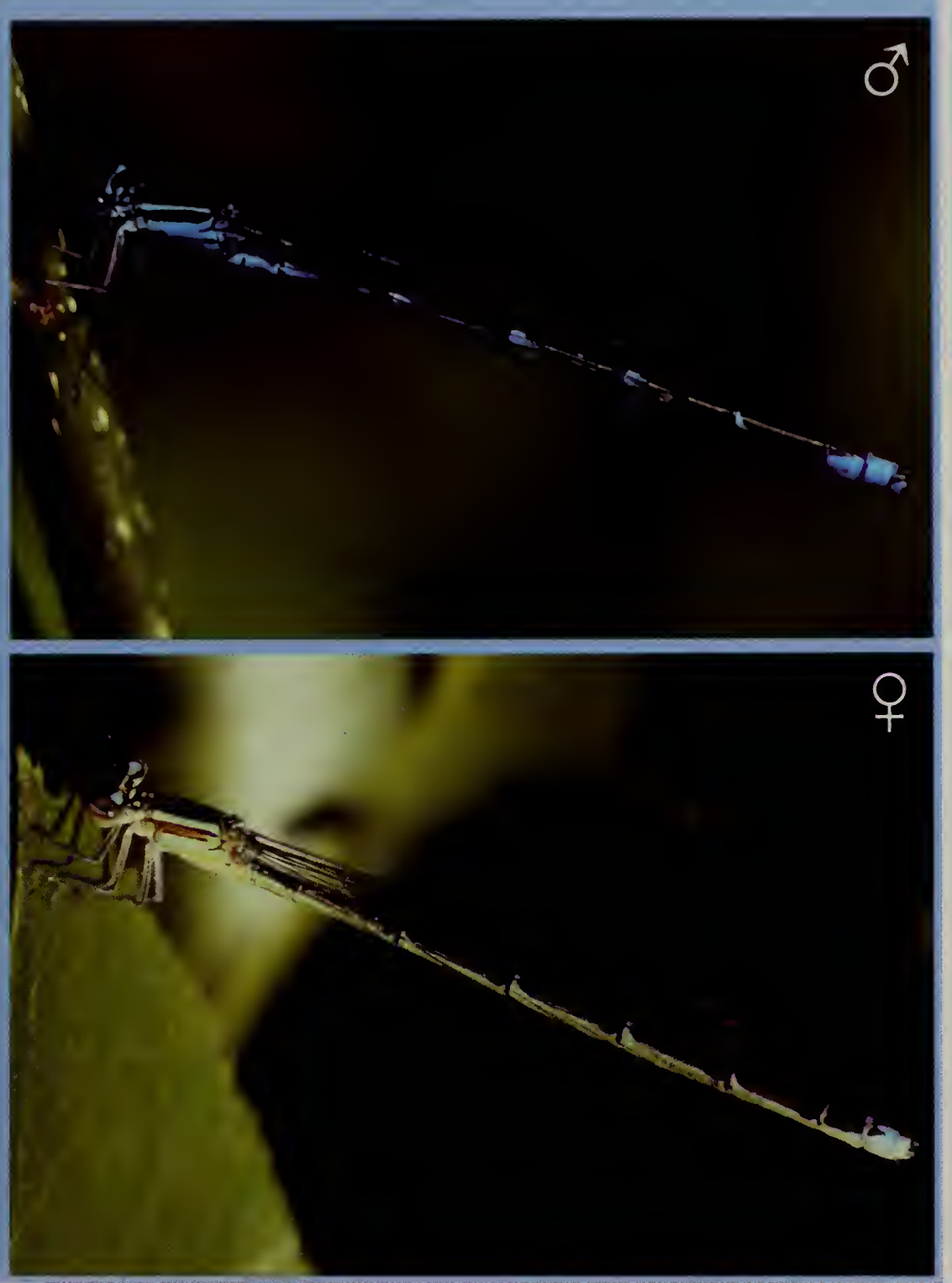

RANGE/STATUS Eastern U.S.; southeastern Canada. Common throughout interior MA, uncommon and local along the southeast coastal plain.

HABITAT Mid-sized to large streams and rivers; occasionally lakes.

NOTES Adults alight horizontally or obliquely on rocks, logs, foliage, and bare ground along the shoreline. They occasionally hover just over the water. Females oviposit in tandem in aquatic vegetation.

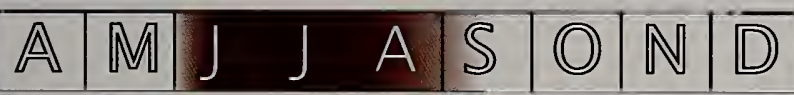


A bluet with mostly black abdomen. Male thorax blue with broad, black mid-dorsal stripe and thinner black shoulder stripes; abdomen mostly black above, except S8-S9 entirely blue. Postocular spots small, tear-shaped, and connected by a pale bar across rear of head. Female thorax similar to male, but pale areas dull blue; abdomen mostly black above, except $\$ 10$ all blue, 59 partially blue posteriorly, and S8 with pale lateral spot on rear. Stream Bluet ( $p$. 47) similar, but with obvious blue rings on abdomen and only 59 blue above. Female distinguished by pattern of S8-S10.

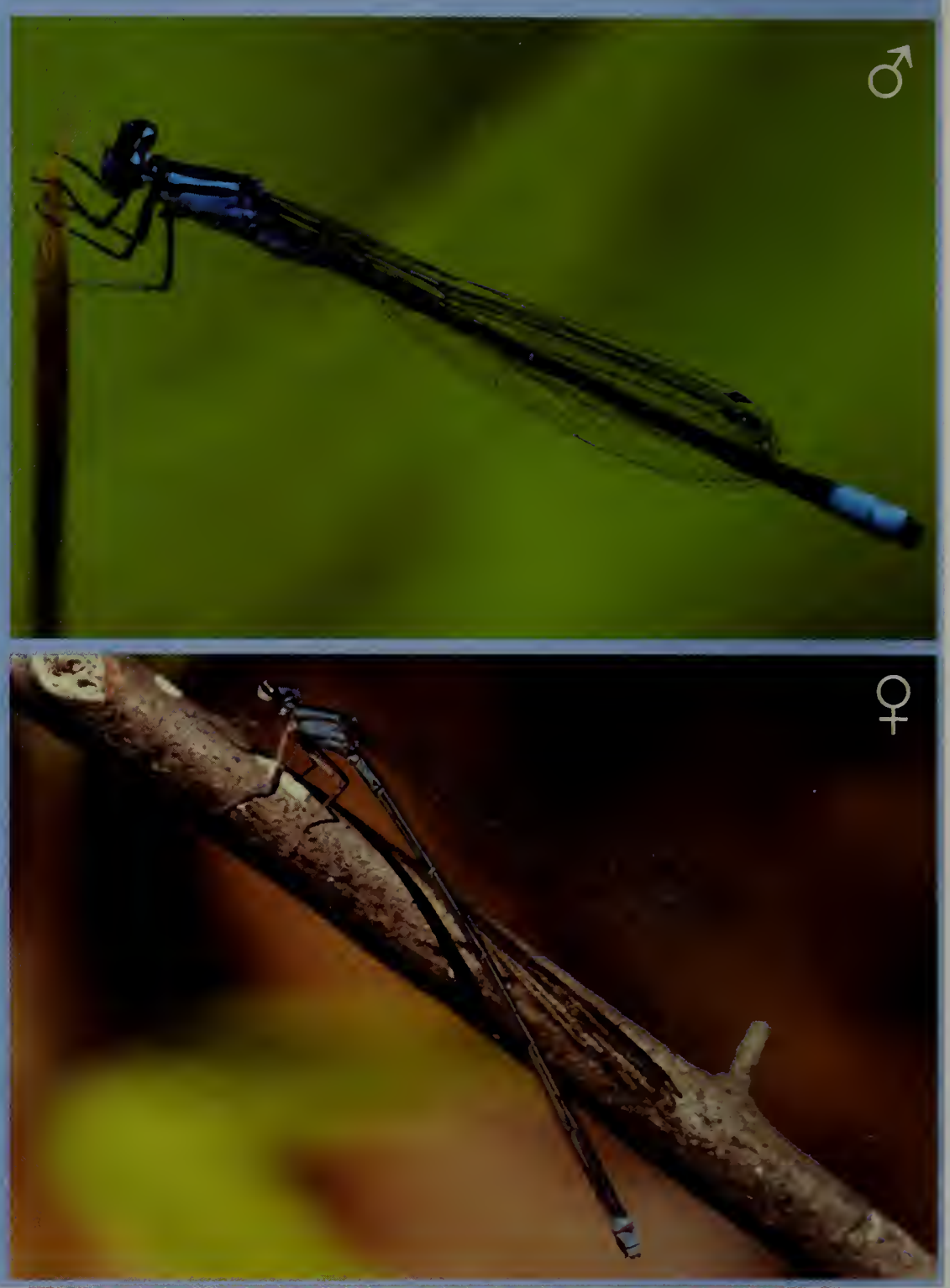

RANGE/STATUS Eastern U.S. Fairly common in eastern and central MA. HABITAT Slow reaches of streams; occasionally well-vegetated ponds and lakes. NOTES Adults fly slowly in and out of emergent and shoreline vegetation, hovering frequently and perching on foliage. Females oviposit in tandem on emergent vegetation; the pair backs down the stem until the female is completely submerged. The male then releases the female and guards the area.

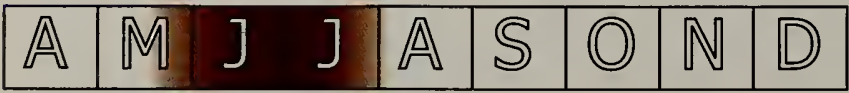


Small bluet with mostly black abdomen. Male thorax blue with broad, black mid-dorsal stripe and black shoulder stripes; abdomen mostly black with narrow blue rings, except \$8-\$9 mostly blue and $S 2$ blue with black diamond above and horizontal black "dash" on side. Postocular spots small and tear-shaped. Female thorax similar to male, but pale areas tan to pale blue; abdomen black above, except large, paired blue ovals on top of 58 . Both sexes distinguished from other bluets by distinctive pattern on $\mathrm{SZ}$.

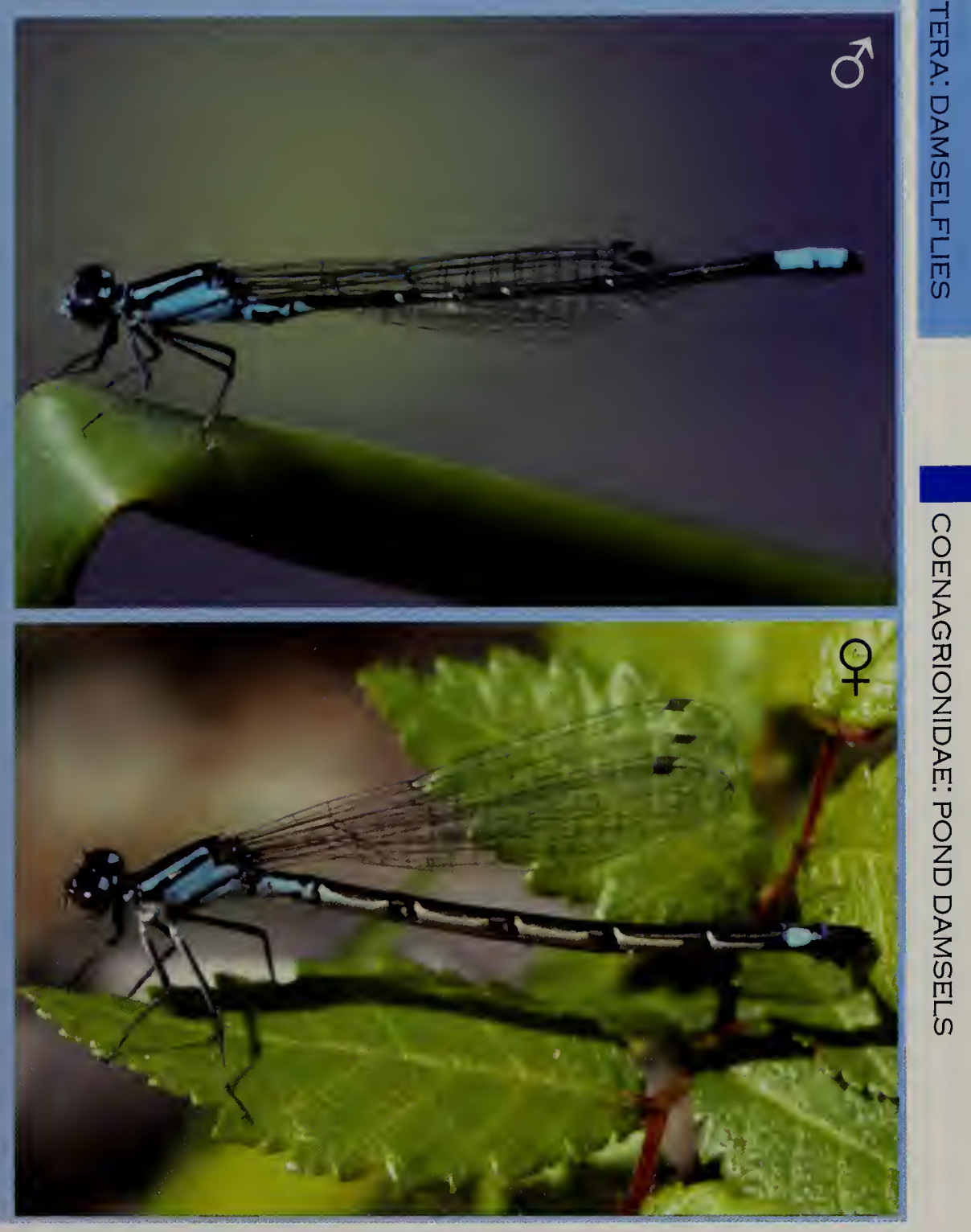

RANGE/STATUS Eastern U.S.; southeastern Canada. Very common throughout MA.

HABITAT A wide range of flowing and still-water habitats including clear streams and well-vegetated ponds and lakes.

NOTES Adults perch horizontally on foliage along the shoreline, or on water lilies. They fly very low, skimming the water's surface. Females oviposit in tandem or alone on aquatic vegetation.

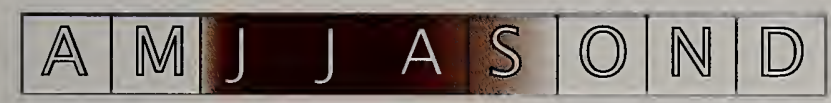


Fairly large bluet, abdomen black in the middle and blue at both ends. Thorax blue with broad black mid-dorsal stripe and thin black shoulder stripes; abdomen mostly black on middle segments (S3-S6), S7 black anteriorly (variable in extent) and blue posteriorly, S8-59 entirely blue. Large, round postocular spots. Female thorax similar to male, except pale areas tan to dull blue; abdomen black above, except 57 mostly pale with a thin black dorsal line, S8 with pair of pale ovals on top. Male abdominal pattern distinctive. Female distinguished by pattern on 57 and 58 .

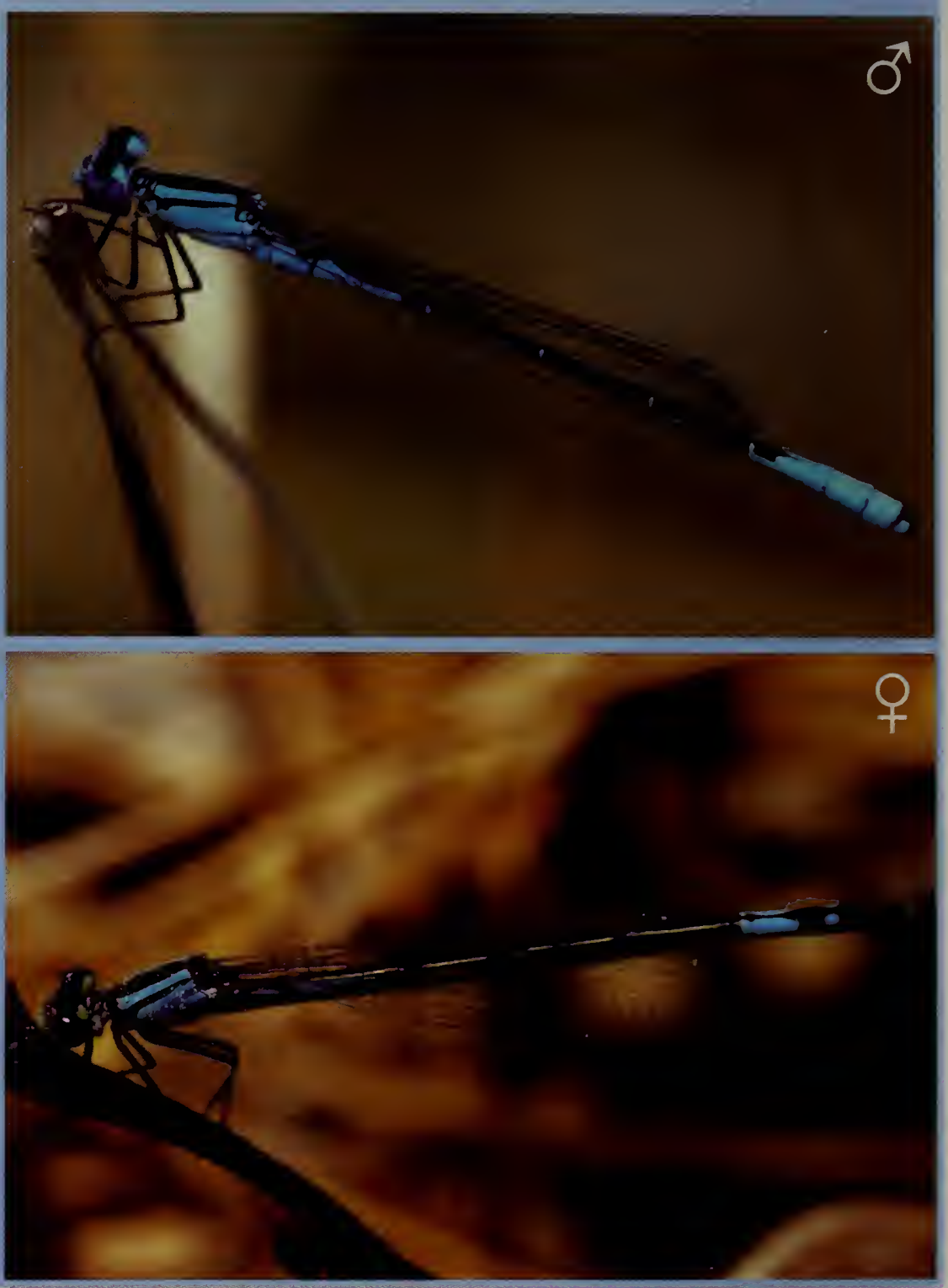

RANGE/STATUS Eastern U.S.; extreme southeastern Canada. Common throughout MA.

HABITAT Vegetated and bog-bordered ponds; vernal pools.

NOTES Adults spend much of the time perched horizontally or obliquely on foliage, occasionally making low, brief flights. Males fly low over open water. Females oviposit in tandem on floating or submerged vegetation.

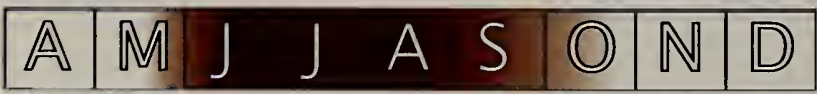


Our largest bluet. Male thorax entirely pale blue, except for very thin black dorsal lines; abdomen mostly blackish, except S8-S10 and posterior $1 / 4$ of 57 all blue. Postocular spots very large, blending into blue eyes, head, and face. Female thorax similar to male but pale areas tan to light blue; abdomen mostly blackish above except S9-\$10 all pale. Near absence of black on thorax and very long. slender abdomen distinguish both sexes of this species from all other northeastern bluets.
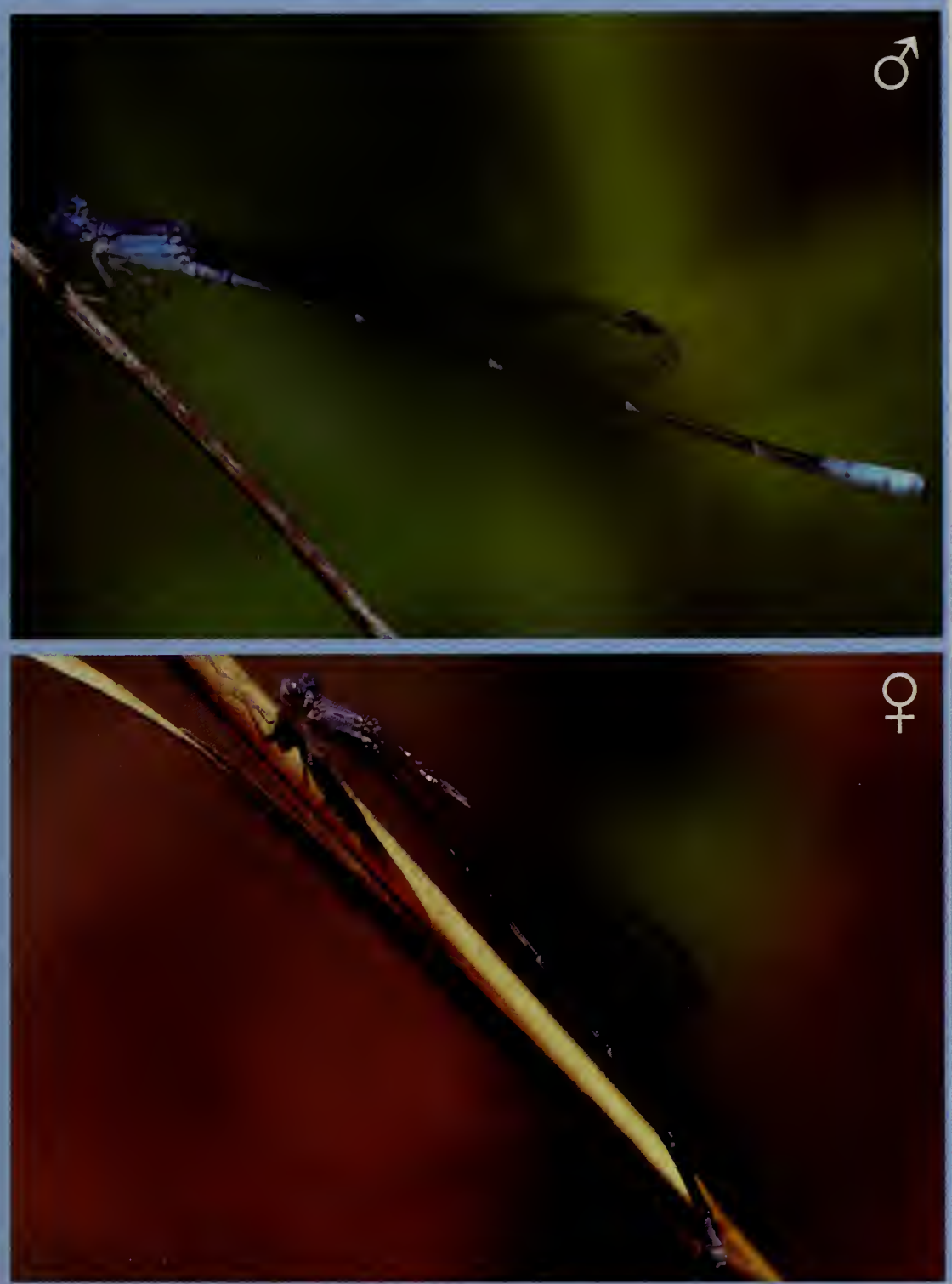

RANGE/STATUS Eastern U.S., north to MA. Rare in MA, found only at a few sites in the southeast.

HABITAT Well-vegetated ponds.

NOTES Adults fly in and out of emergent and shoreline vegetation, alighting on foliage, often in the shade.

\begin{tabular}{|l|l|l|ll|l|l|l|l|}
\hline $\mathbb{A}$ & $\mathbb{M}$ & $\mathbb{J}$ & $\mathrm{J}$ & $\mathrm{A}$ & $\mathbb{S}$ & $\mathbb{O}$ & $\mathbb{N}$ & $\mathbb{D}$ \\
\hline
\end{tabular}




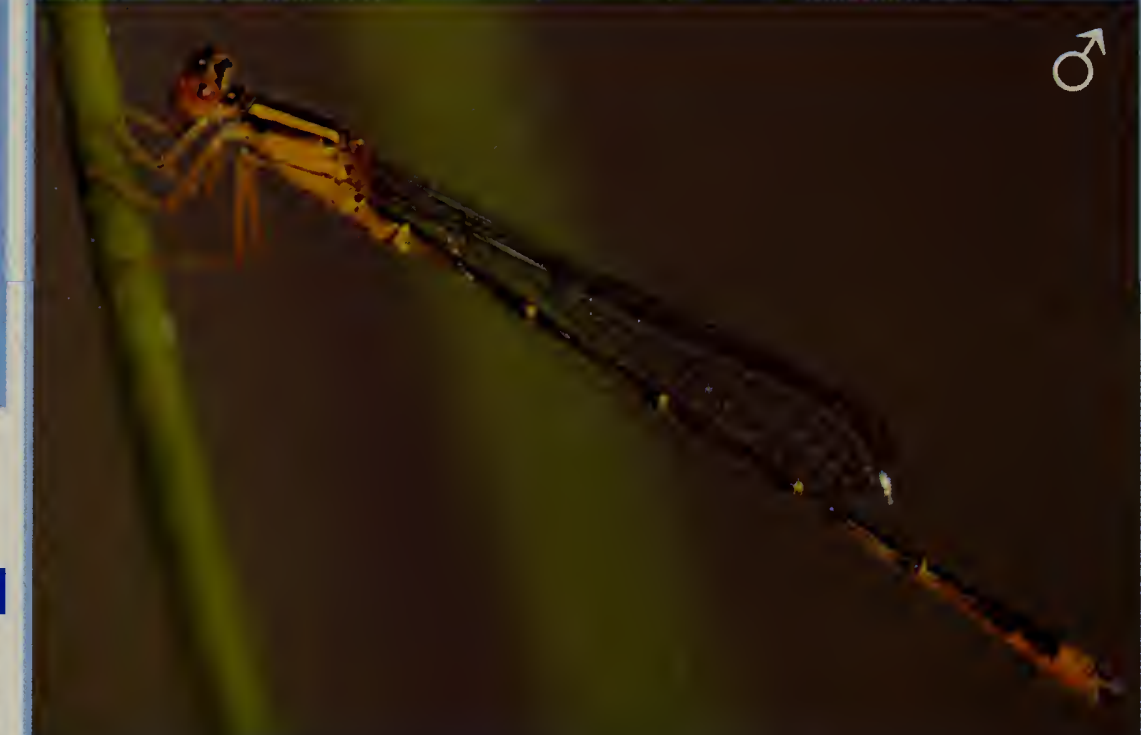

The only orange bluet in the Northeast. Male thorax orange with broad, black mid-dorsal stripe and black shoulder stripes; abdomen mostly black, except 59 entirely orange. Eyes orange; postocular spots small, orange, and connected by an orange bar across rear of head. Stigma dull orange. Female thorax similar to male, but pale areas dull yellow; abdomen mostly black above, except S10 pale. Scarlet

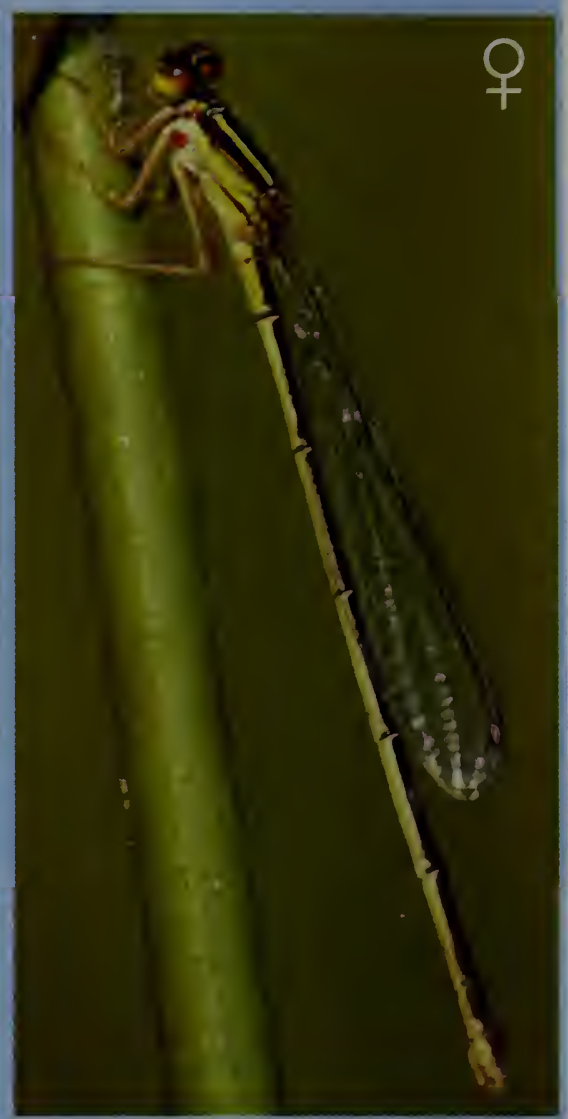
Bluet (p. 54) similar, but male more reddish and S9 black above. Vesper Bluet (p. 53) similar, but male more yellow with thinner shoulder stripe and $\$ 9$ all blue.

RANGE/STATUS Eastern U.S.; southeastern Canada. Common throughout MA. HABITAT A wide range of still-water habitats including stream backwaters.

NOTES Adults fly slowly through emergent and shoreline vegetation, alighting horizontally or obliquely on foliage, rocks, and logs, and skimming the water's surface. They are most active late in the afternoon, and may fly through dusk. Females oviposit in tandem in floating and emergent vegetation.

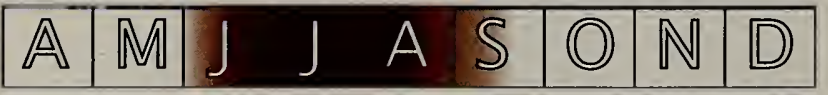


The only bright yellow bluet in the Northeast. Male thorax yellow with broad, black mid-dorsal stripe and thin black shoulder stripes (nearly absent in some individuals); abdomen mostly black above, except S9 entirely blue. Eyes yellowish; postocular spots small, yellow, and connected by a yellow bar across rear of head. Stigma pale yellow. Female thorax similar to male, but pale areas dull yellow; abdomen mostly black above, except S10 pale. Female Orange Bluet ( $p$. 52) very similar, but dark shoulder stripes usually thicker.
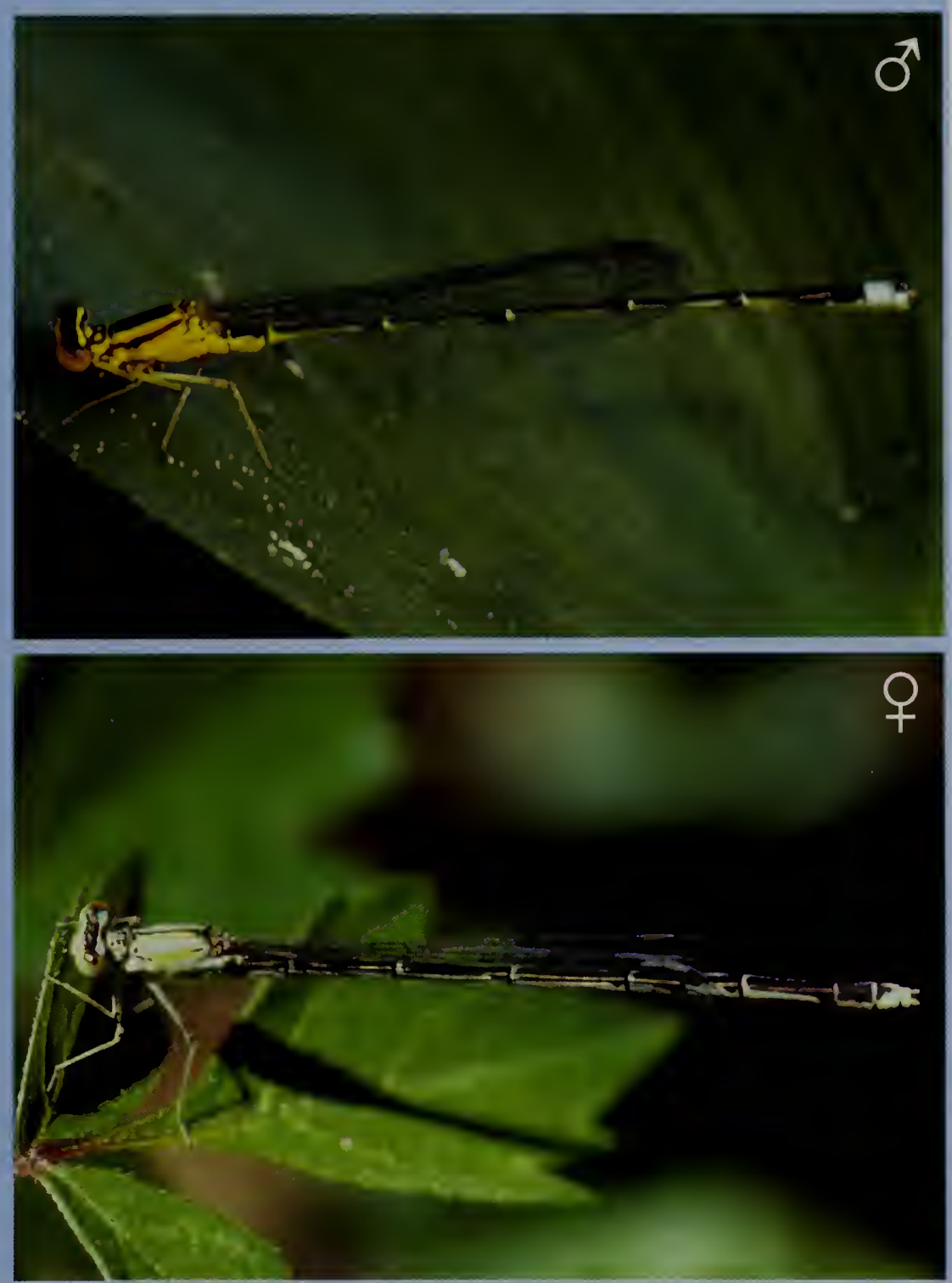

RANGE/STATUS Eastern U.S.; southeastern Canada. Common throughout MA. HABITAT Ponds and lakes with emergent and aquatic vegetation.

NOTES A crepuscular species, most active at dusk and not often encountered at other times of the day. Adults fly slowly through emergent and shoreline vegetation, alighting horizontally or obliquely on foliage, lily pads, rocks, and logs. They fly low over the water. Females oviposit in tandem in floating and emergent vegetation.

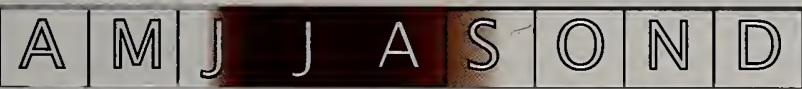



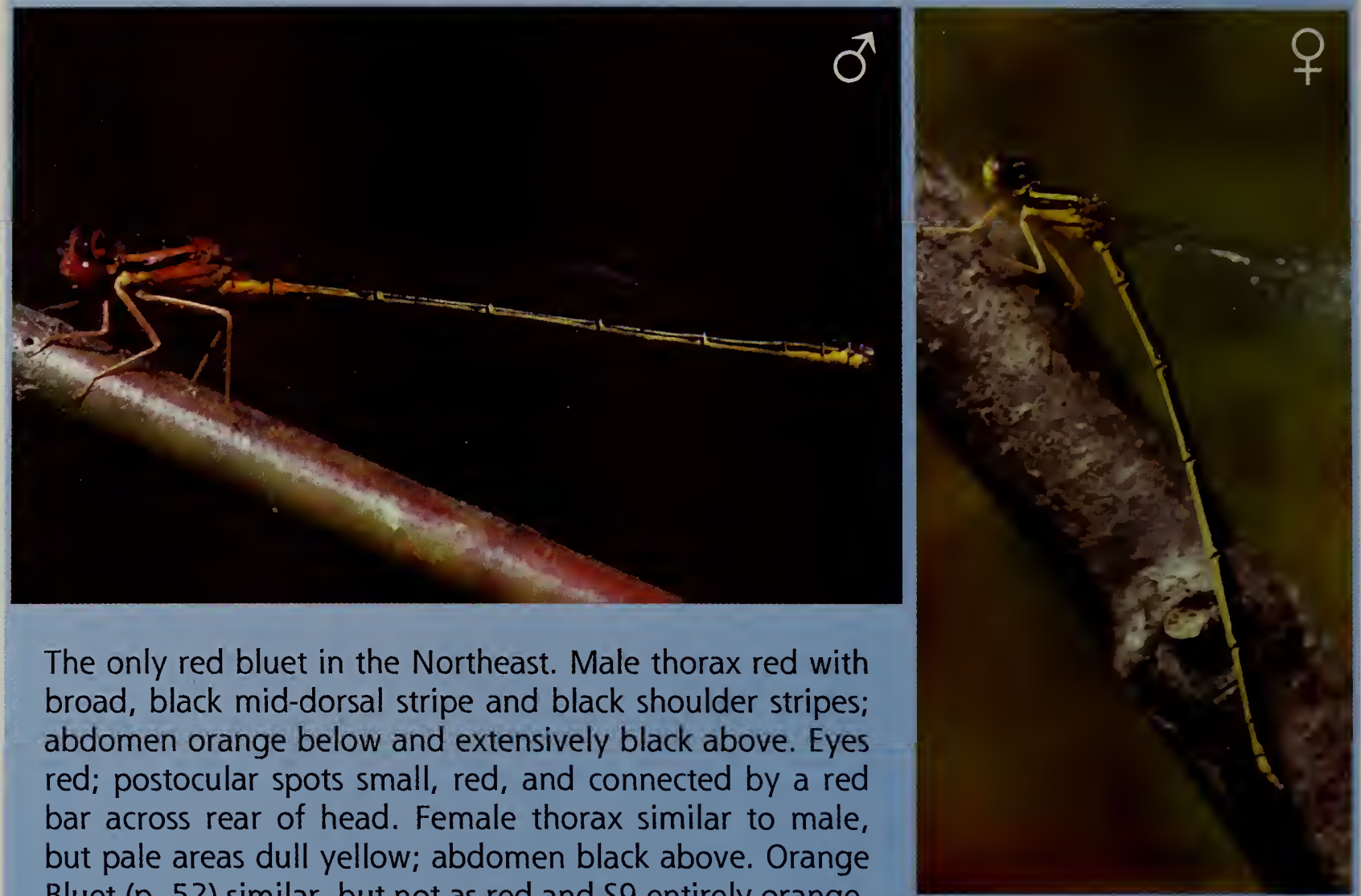

The only red bluet in the Northeast. Male thorax red with broad, black mid-dorsal stripe and black shoulder stripes; abdomen orange below and extensively black above. Eyes red; postocular spots small, red, and connected by a red bar across rear of head. Female thorax similar to male, but pale areas dull yellow; abdomen black above. Orange Bluet (p. 52) similar, but not as red and 59 entirely orange. Eastern Red Damsel (p. 55) is smaller with much less black on abdomen and no postocular spots.

RANGE/STATUS A northeast endemic found from NJ to southern ME. Uncommon and local in MA, primarily in the east.

HABITAT Acidic, sandy ponds (e.g., coastal plain ponds) with floating vegetation, especially water lilies (Nuphar and Nymphaea).

NOTES Adults perch on lily pads or emergent vegetation, flying infrequently and low over the water. Females oviposit in tandem on the undersides of lily pads. They are most often seen out on the water flying low and alighting on lily pads.

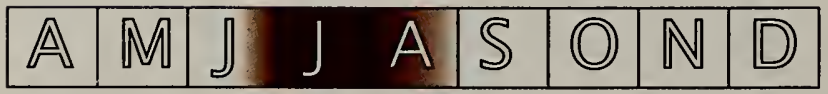


Male thorax black above with pale, reddish-brown sides; abdomen bright red with black marks on S759. Eyes reddish. Female similar but duller brownish-red with no black on thorax. Can be confused with orange (immature) female Eastern Forktail (p. 56), but darker red in color, much less black on top of abdomen, and no postocular spots. Scarlet Bluet (p. 54) larger, entirely dark on top of abdomen, and has postocular spots.

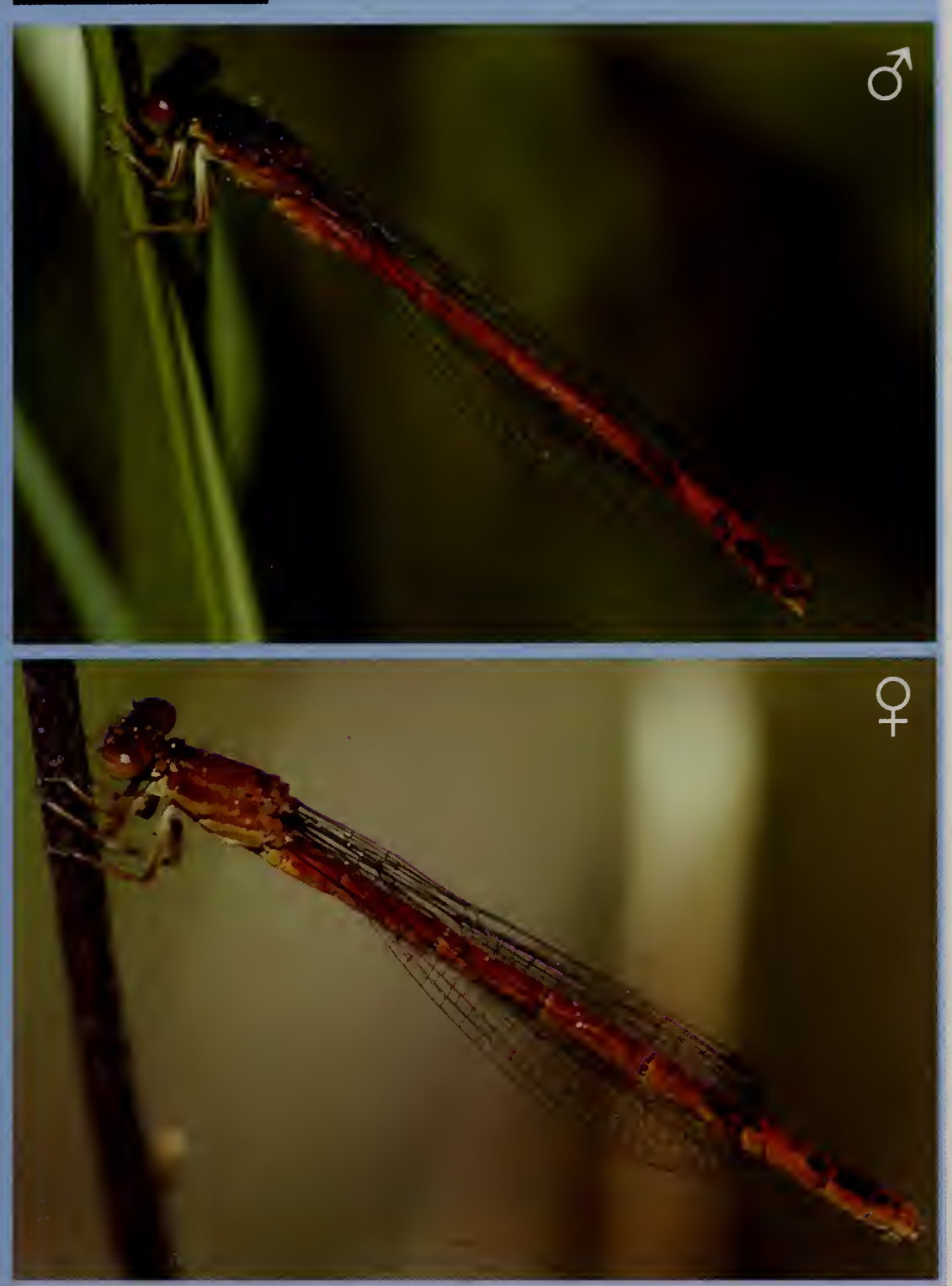

RANGE/STATUS Eastern U.S. Uncommon and local in MA.

HABITAT Spring upwellings and seeps at pond, bog, or stream margins.

NOTES Despite their bright coloration, an inconspicuous and easily overlooked species. Adults spend much of the time perched on emergent vegetation, making occasional short flights through low vegetation, and seldom flying over open water. Females oviposit in tandem on floating and emergent aquatic plants.

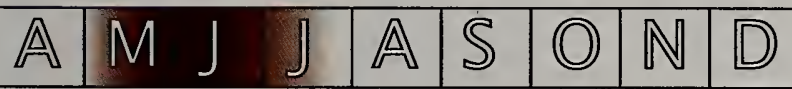


The most common, widespread forktail in the Northeast. Male thorax black above with green shoulder stripes and pale green sides; abdomen mostly black above with thin, pale rings, except mostly blue with black lateral marks on S8-59. Postocular spots small, round, and green. Thorax of young female mostly orange with broad, black mid-dorsal stripe and thin, black shoulder stripes; abdomen orange at base and mostly black above. Postocular spots orange. Older female becomes extensively pruinose bluegray. Rambur's Forktail ( $p$. 57) very similar, but slightly larger, male abdomen blue only on $\mathrm{S} 8$ with no black lateral mark, and postocular spots blue. Orange female Rambur's lacks black shoulder stripe.
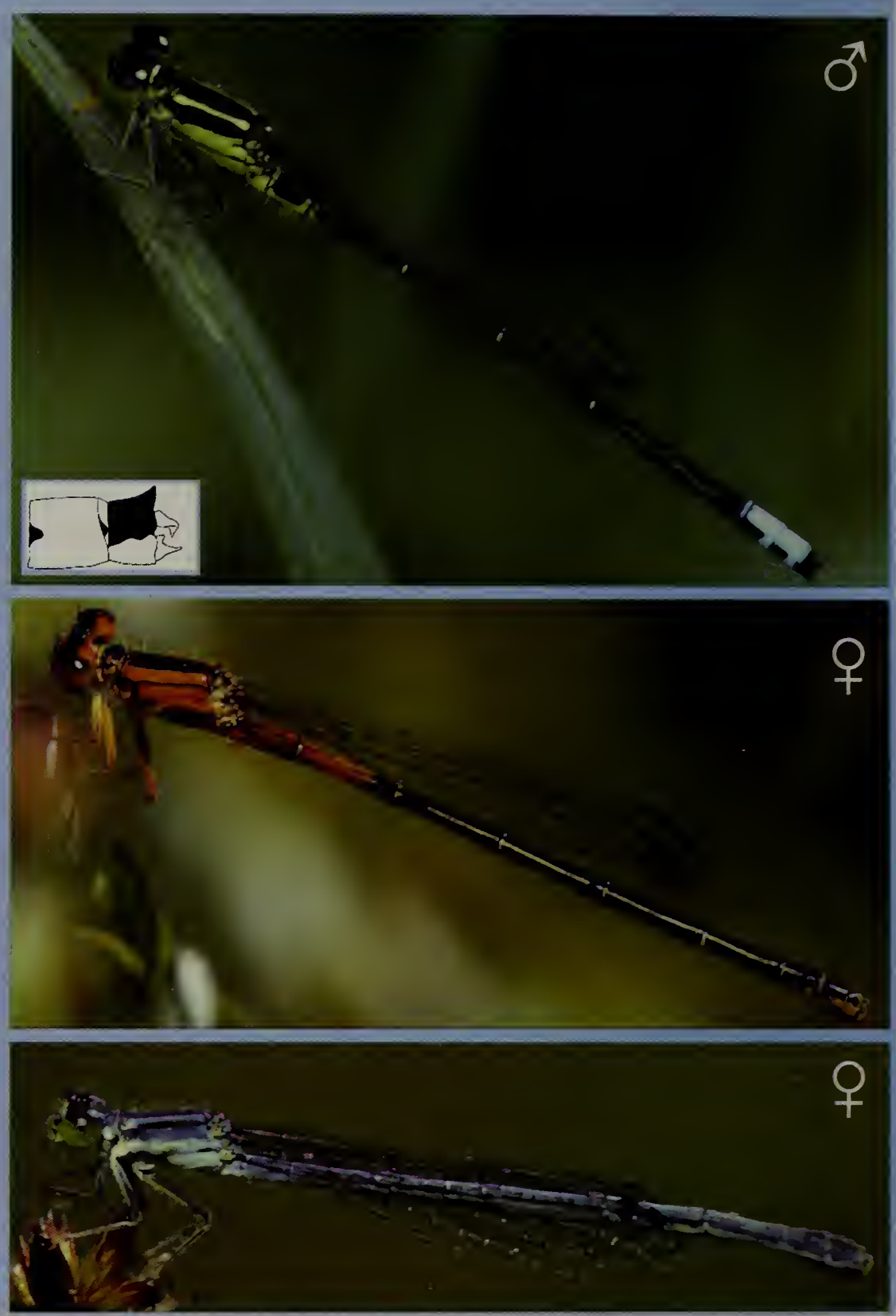

RANGE/STATUS Rocky Mountains east, extending north into southeastern Canada. Very common throughout MA.

HABITAT A wide range of vegetated wetlands including ponds and stream backwaters.

Often found in upland areas among dense vegetation.

NOTES This is one of the most common damselflies in MA and has one of the longest flight periods. Adults fly in and out of shoreline and emergent vegetation, avoiding open water, and either perch horizontally on vegetation or hang vertically from stems. Females oviposit alone in floating and emergent vegetation.

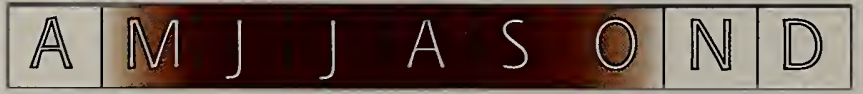


Male thorax black above with green shoulder stripes and pale green sides; abdomen mostly black above, with narrow, pale rings, all blue 58 , and blue on sides of S9-S10 (rarely blue above on 59). Small, round, blue postocular spots. Female occurs in two color forms. Male-like form is patterned like male (including blue S8), though pale areas tend to be more bluish. Orange form has orange thorax, with broad, black middorsal stripe, no shoulder stripes, and orange base of abdomen; remainder of abdomen entirely blackish above. Eastern Forktail ( $p$. 56) very similar, but slightly smaller, male blue above on S8-59, with green postocular spots. Orange female Eastern Forktail has dark shoulder stripes.

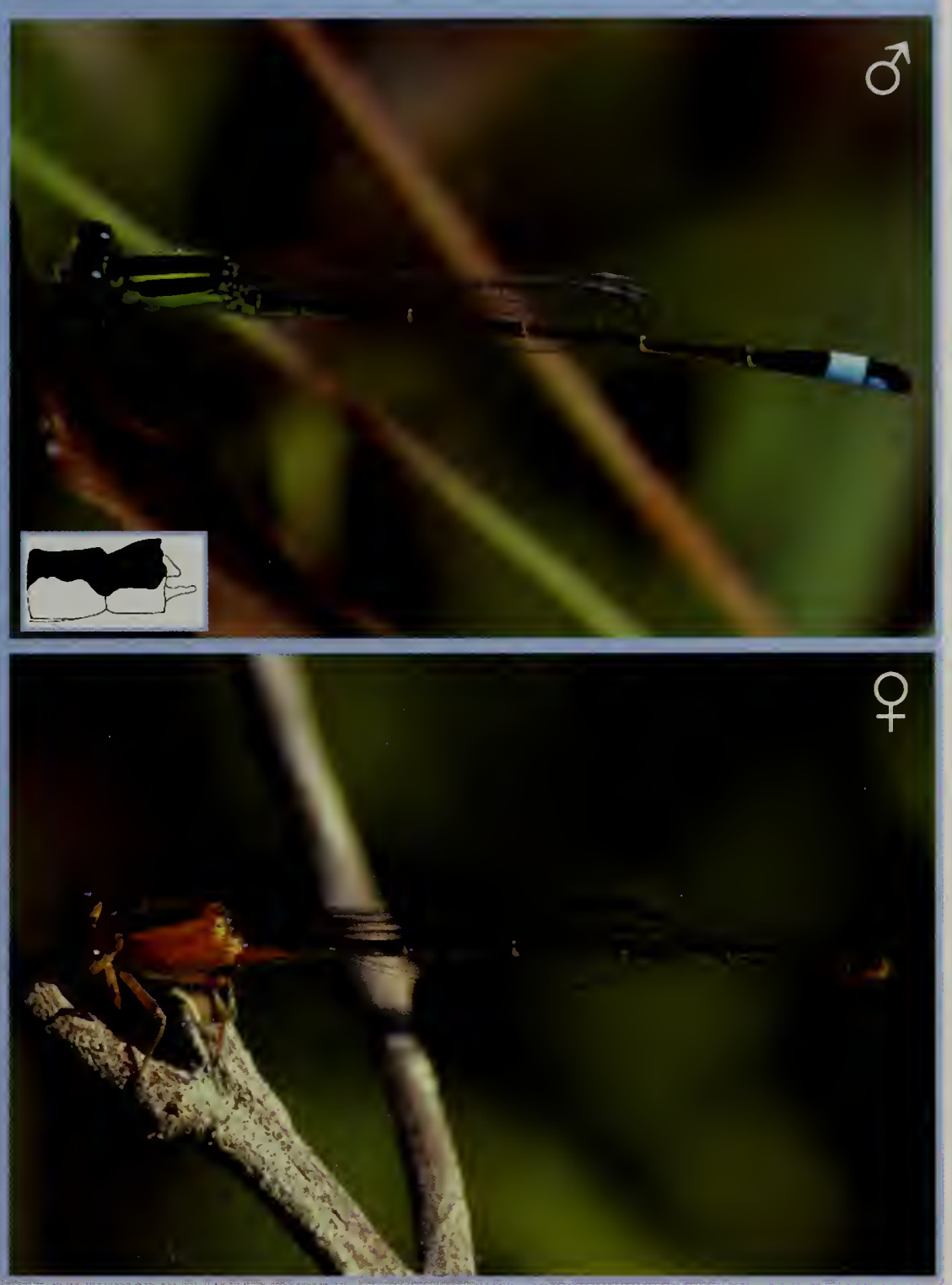

RANGE/STATUS Southern U.S., north along the coast to ME. Rare and local in MA, recorded only from Cape Cod and Martha's Vineyard.

HABITAT Coastal ponds and wetlands, often brackish.

NOTES Adults fly in and out of emergent and shoreline vegetation, perching horizontally or obliquely. Females oviposit alone, curling their abdomen to lay eggs on the underside of vegetation.

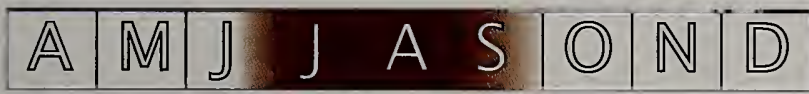


One of the smallest forktails, with a distinctive thoracic pattern. Male thorax black above with broken green shoulder stripes, forming an exclamation point, pale green on sides; abdomen black above, broken by thin, pale rings (very rarely a blue spot on S9). Postocular spots small and round. Female similar to male, but pale areas typically bluish. Older female becomes extensively pruinose bluegray, obscuring distinctive shoulder stripes. Unlike other forktails in our area, female never orange. Eastern Forktail (p. 56) similar but larger, with unbroken shoulder stripes, male with blue on S8-59. Older, pruinose females are very difficult to distinguish.

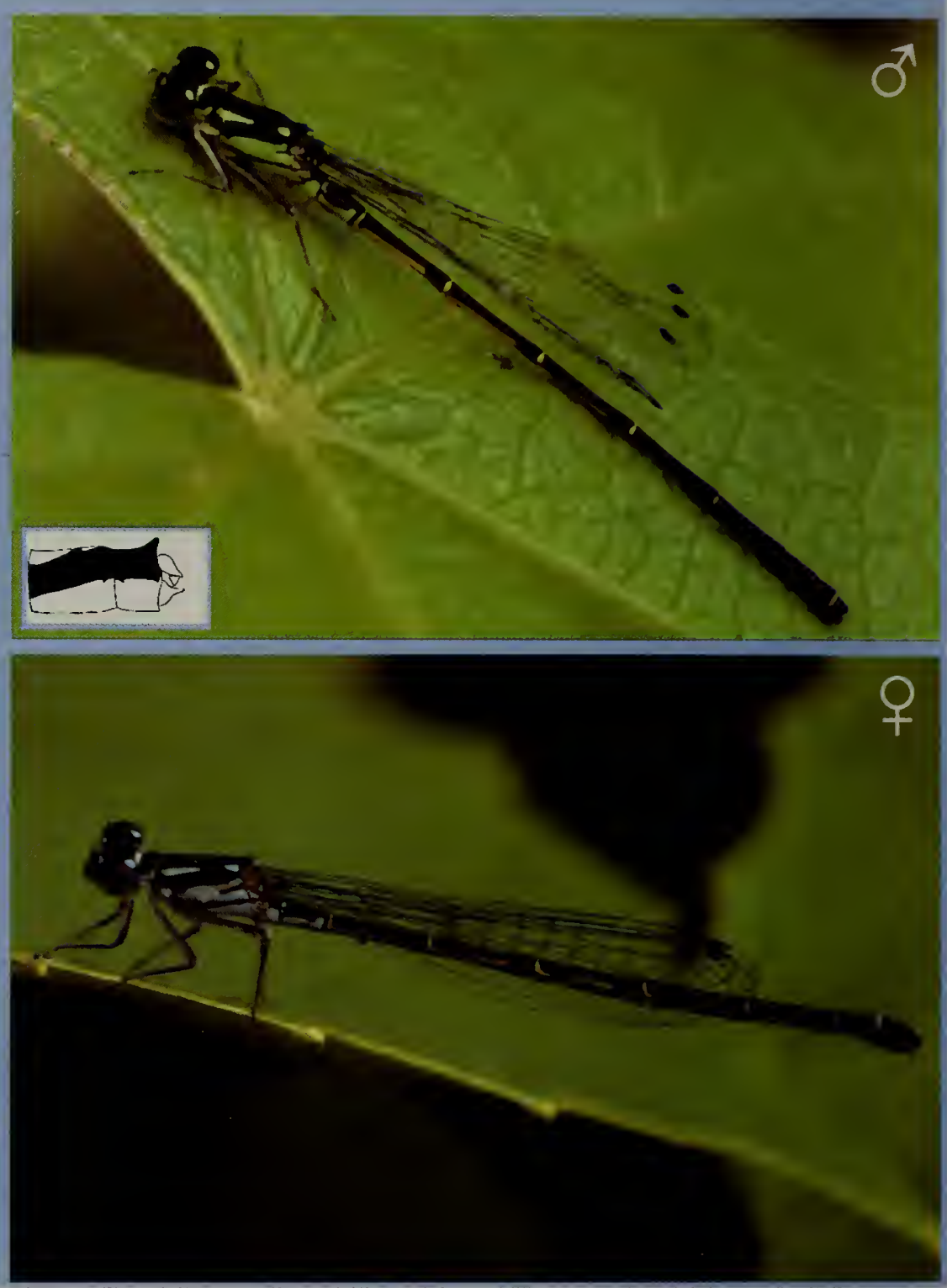

RANGE/STATUS Eastern U.S.; southeastern Canada. Common throughout MA. HABITAT A wide range of vegetated wetlands including ponds, swamps, streams, and vernal pools.

NOTES Adults fly low in and out of emergent and shoreline vegetation, perching horizontally, often remaining in the shade and avoiding open water. Females oviposit in stalks of emergent and floating vegetation, slicing open the stems and inserting eggs with their ovipositors.

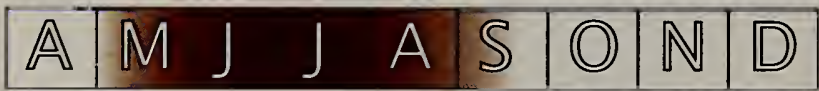


A lanky forktail of southern swamps. Male thorax black above with narrow green shoulder stripes and green sides; abdomen mostly black above, except $\$ 9$ all blue; stigma on forewing fringed with white on outer portion. Thorax of immature female black above with bright orange sides; abdomen mostly orange at base, but black above on S5 - S10. Older female green on sides of thorax and brownish on sides of abdomen. Similar to Eastern Forktail (p. 56), but more elongate and male blue only on S9 (S8 \& 59 blue in Eastern Forktail; only 58 blue in male Rambur's Forktail).

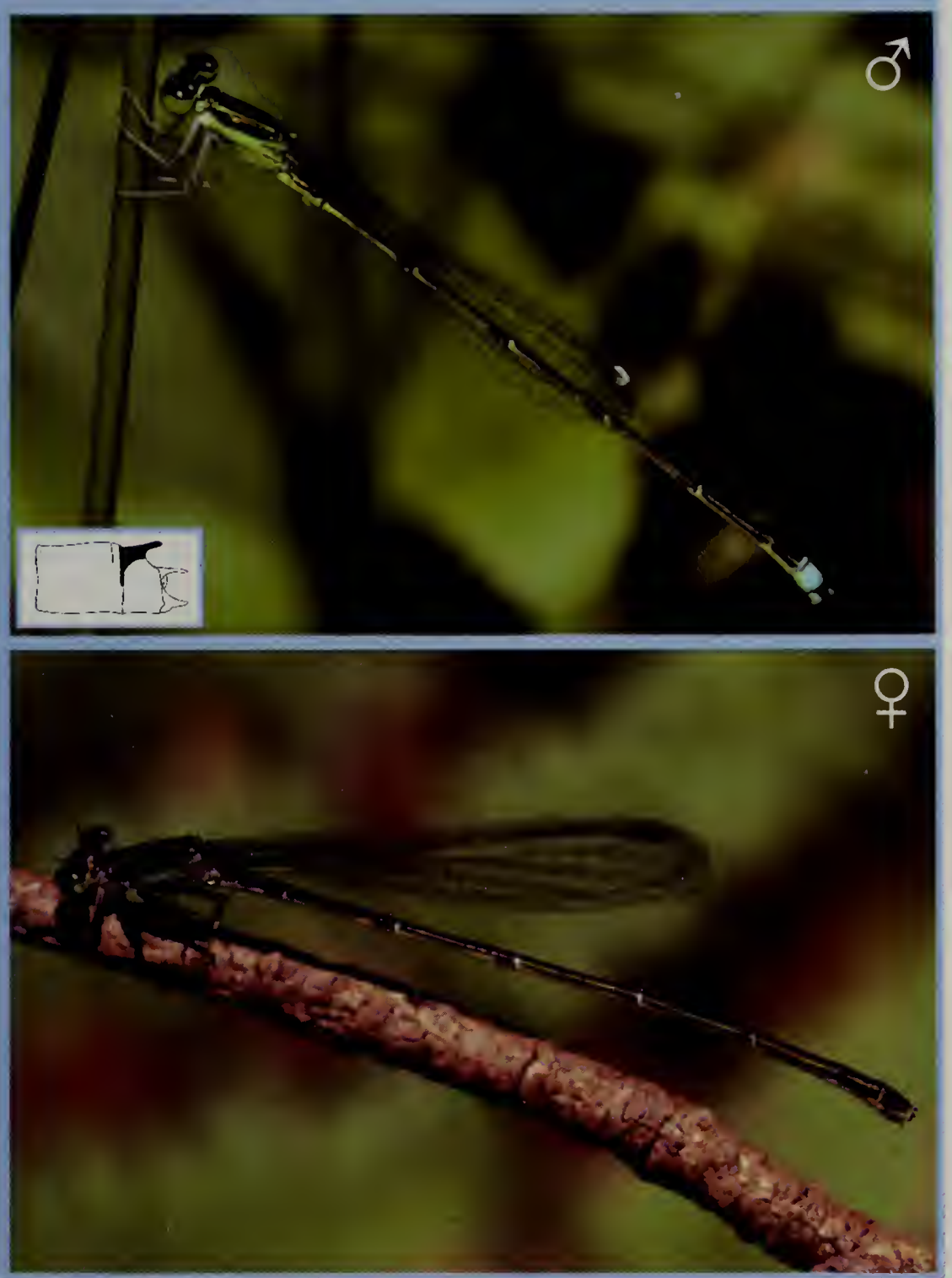

RANGE/STATUS Southern U.S. A vagrant in MA, recorded only once on Cape Cod.

HABITAT Swampy ponds.

NOTES A rather secretive species of shaded southern swamps. Adults fly low in and out of shoreline and emergent vegetation.

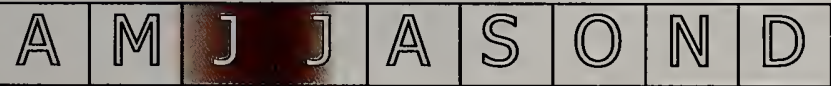


Appears more similar to a bluet than a forktail. Male thorax blue with broad, black mid-dorsal stripe, broad black shoulder stripes, and horizontal black stripe on sides; abdomen mostly black, except blue above on 58 S9 (occasionally S10). Postocular spots large and rounded. Male stigma dark blue on forewing. Female thorax similar to male, except pale areas bright red; abdomen mostly black, except red on S8S10; red areas become pruinose blue-gray with age. Males similar to several bluets, most easily distinguished by combination of very large postocular spots, black horizontal stripe on sides of thorax, abdominal pattern (especially black on sides of 58-59), and characteristic decurved tip of abdomen when perched. Red females similar to male Scarlet Bluet (p. 54), but postocular spots very large and abdomen red above on S8-510.

RANGE/STATUS Eastern U.S. Fairly common in eastern MA, but apparently scarce in the western part of the state.

HABITAT Ponds with lily pads (Nuphar and Nymphaea).

NOTES A southern species that appears to have increased in MA recently. Adults perch on lily pads, occasionally flying from pad to pad. They fly very low, within a couple inches of the water's surface. Females oviposit in lily pads, usually in tandem.

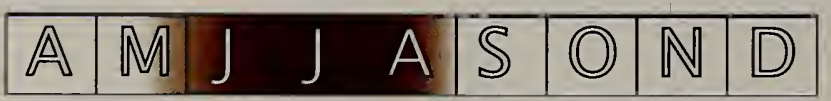




\section{Ischnura hastata}

The smallest damselfly in the Northeast. Male thorax black above with yellow or greenish shoulder stripes and yellow sides; abdomen bright yellow with black triangles above on S3-S7; S8-510 all yellow. Small, yellow "spike" on top of last segment. Tiny, round postocular spots. Stigmas reddish on forewing and black on hind wing. Female thorax orange with broad, black mid-dorsal stripe and very thin black shoulder stripes; abdomen mostly orange on first five segments, mostly black above on S6-59. Pale areas on female become extensively pruinose bluegray with age. Males are distinctive, but older females difficult to distinguish from other forktails.
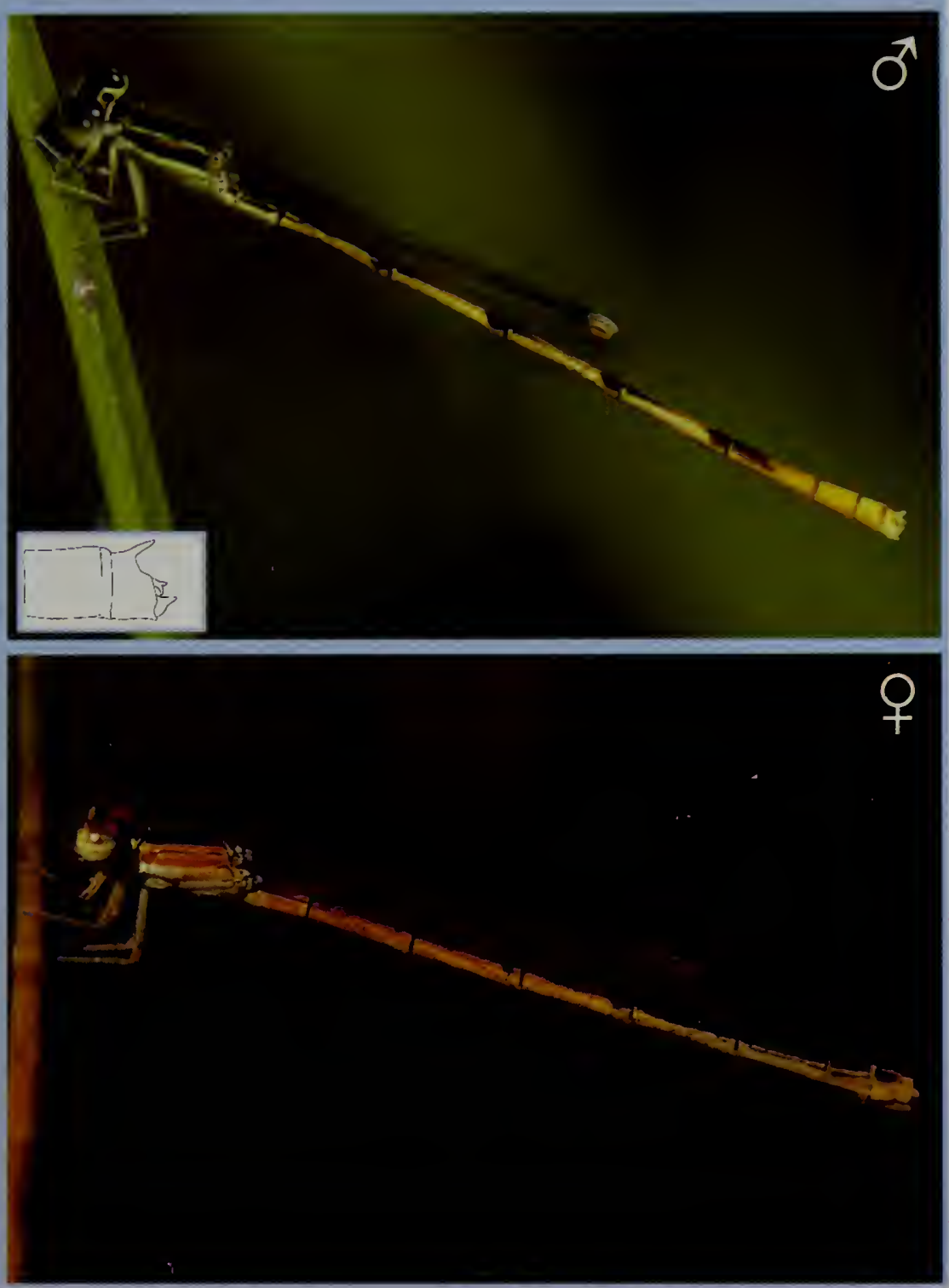

RANGE/STATUS Central to northeastern U.S.; Canadian Great Lakes region. Uncommon and local in MA, recorded from central and eastern MA.

HABITAT Marshy ponds, vernal pools, stream backwaters, and seeps.

NOTES A very inconspicuous and easily overlooked species. Adults fly low in and out of emergent and shoreline vegetation, perching horizontally, and avoiding open water. Females oviposit alone in stalks of emergent vegetation, slicing open the stems with their ovipositors and inserting eggs.

\begin{tabular}{|l|l|l|ll|l|l|}
\hline $\mathbb{A}$ & $\mathbb{M} J$ & J & S & $\mathbb{O}$ & $\mathbb{N}$ & $\mathbb{D}$ \\
\hline
\end{tabular}


A tiny green damselfly. Male thorax bright metallic green above becoming blackish in some individuals, pale green to blue on sides; abdomen dark, iridescent green above, except mostly blue on 58 and entirely blue on S9-S10. No postocular spots, but usually a thin pale blue bar across rear of head. Female similar to male, but 88 (entirely) and S9 (partially) dark green above. Sedge Sprite ( $p$. $63)$ very similar, but male has dark dorsal markings on S8-S10 (similar to female Sphagnum Sprite).

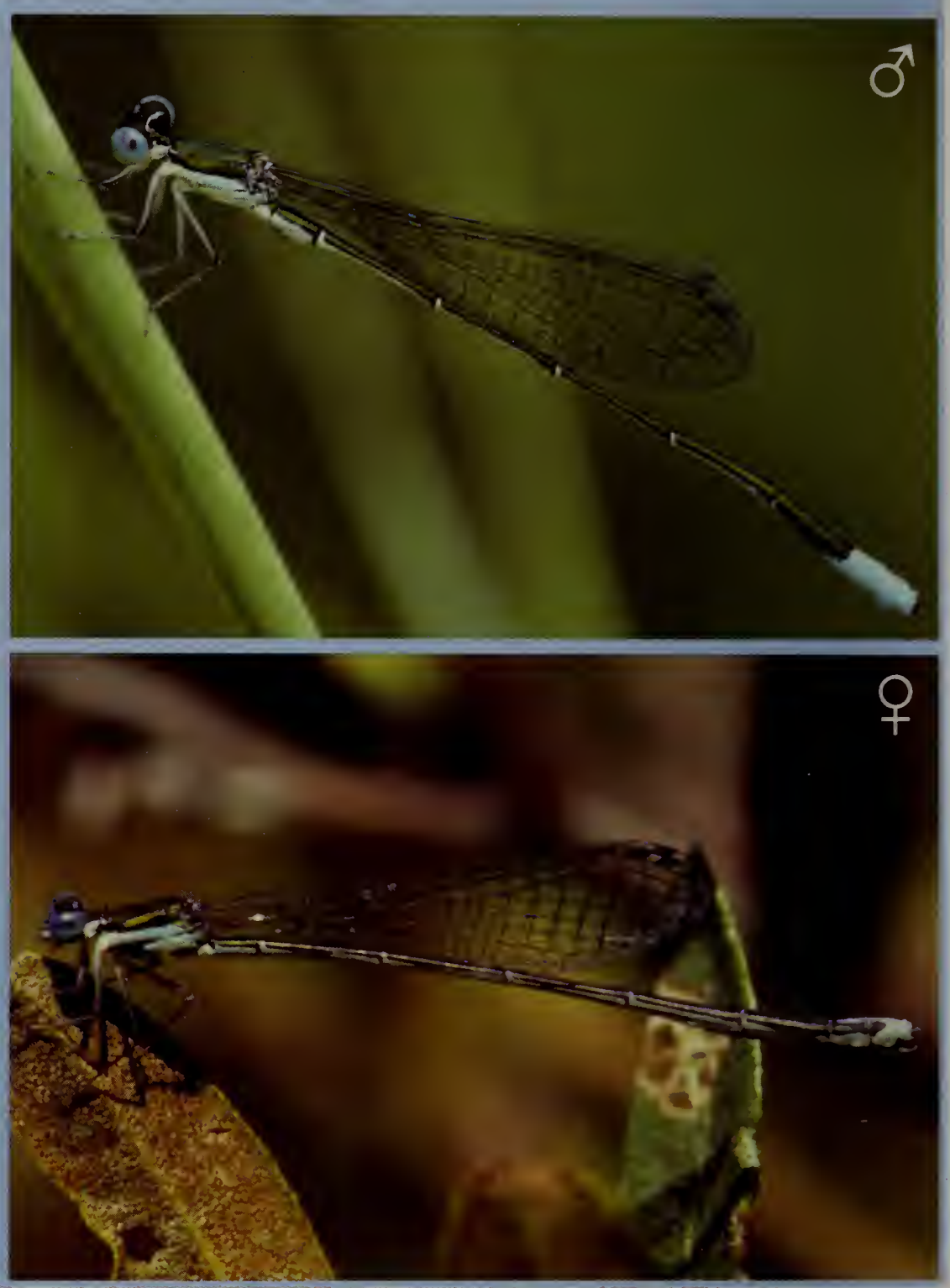

RANGE/STATUS Eastern U.S.; southeastern Canada. Fairly common throughout MA.

HABITAT Sphagnum bogs and fens.

NOTES Adults fly low in and out of emergent and shoreline vegetation, perching horizontally or obliquely on vegetation, and avoiding open water. Aggressive behavior between males has been observed. Females oviposit in tandem in floating vegetation.

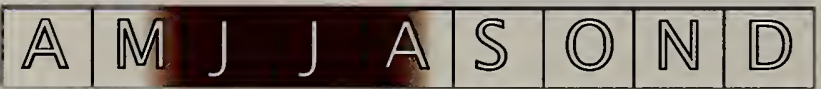


Male thorax bright metallic green above becoming blackish in some individuals, pale yellowish-green to blue on sides; abdomen mostly dark iridescent green, except 58 blue on sides and S9-S10 mostly blue with dark green dorsal spots at base. No postocular spots, but usually a thin pale blue bar across rear of head. Female similar to male, but sides of thorax yellowish and S9-\$10 mostly dark green above.

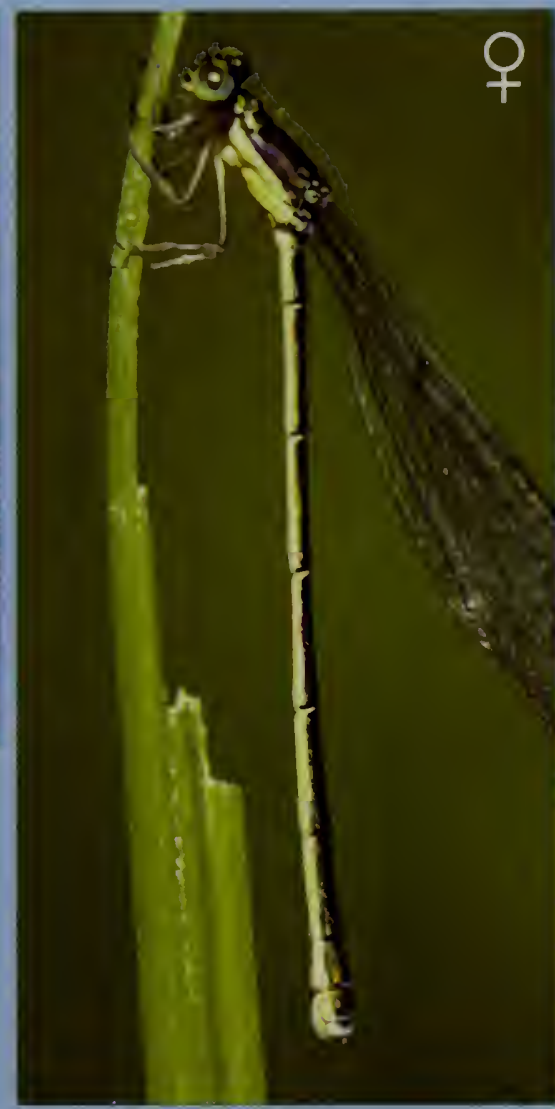

Sphagnum Sprite (p. 62) very similar, but male more blue above on S8-\$10. Female Spahgnum Sprite simiar to male Sedge Sprite.

RANGE/STATUS Central to northern U.S.; southern to central Canada. Common throughout MA, though scarce on the southeast coast.

HABITAT Marshes, sedge fens, grassy ponds, and vernal pools.

NOTES Adults fly low in and out of emergent and shoreline vegetation, perching horizontally or obliquely and avoiding open water. Females oviposit in tandem in stems of floating vegetation.

$\mathbb{A} \mid \mathbb{M} J$ J $A|S| \mathbb{O}|\mathbb{N}| \mathbb{D}$


The only violet damselfly in the Northeast, and the smallest of the dancers (Argia) regionally. Male thorax violet above with narrow black stripes and purple-gray sides; abdomen violet with black markings on S3-S6, mostly black on 57, and mostly blue on S8-S10. Small, dark blue or purple postocular spots, connected with a thin bar. Female thorax dull brownish with a broad black mid-dorsal stripe and thin black shoulder stripes; abdomen dull rusty brown with black streaks and spots on sides (becoming obscure with age). Male coloration is distinctive. Female abdomen paler dorsally than other female dancers.
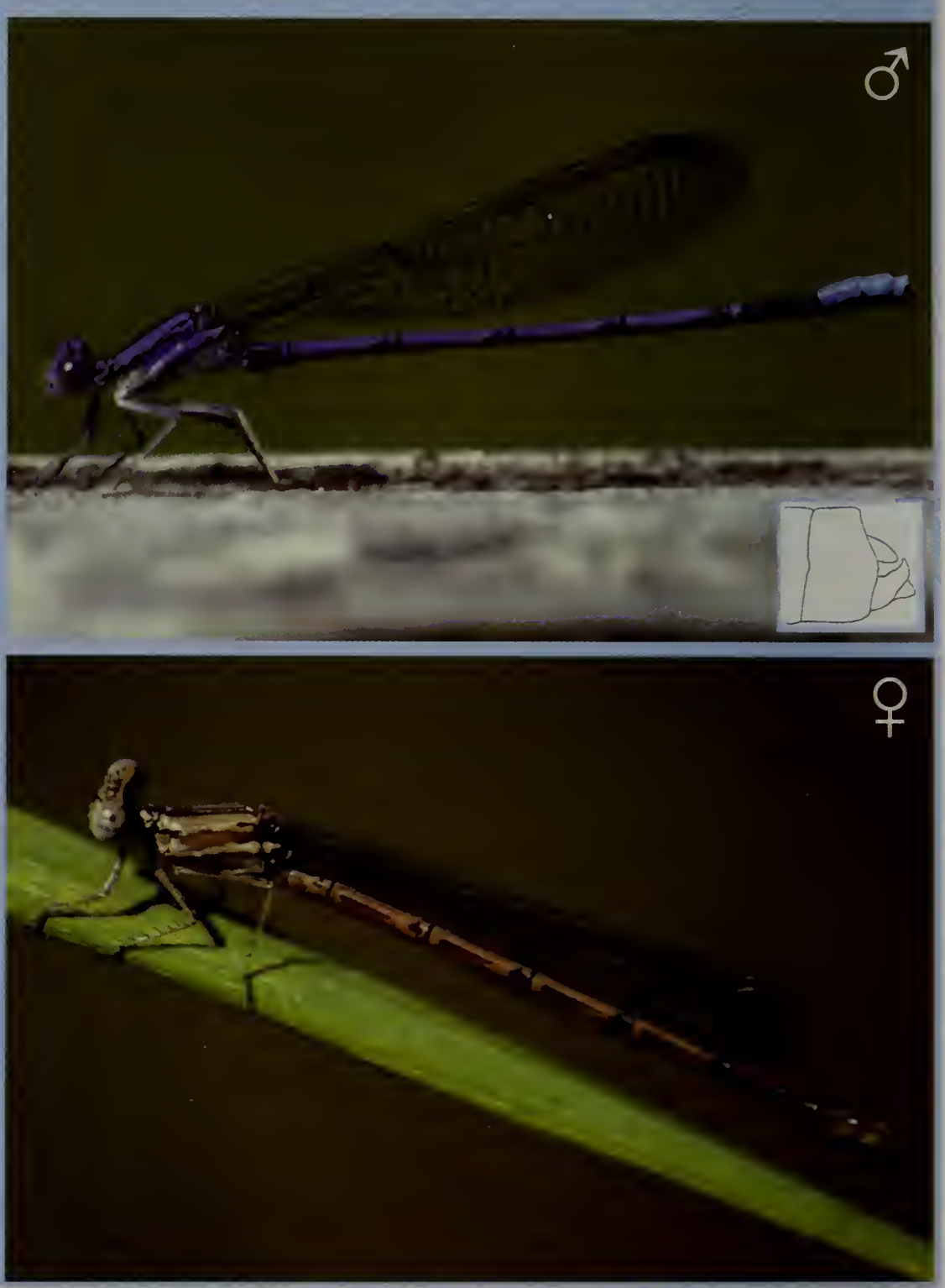

RANGE/STATUS Central to eastern U.S. into southeastern Canada. Common and wide-spread throughout MA.

HABITAT A wide variety of wetlands, but most often vegetated streams and ponds. NOTES Adults fly low in and out of vegetation along the shoreline, perching horizontally on bare ground, rocks, logs, and foliage. Females oviposit in tandem on floating plants and wet logs, sometimes with several breeding pairs close together.

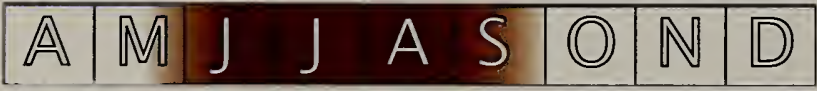


Male thorax black with a dull purplish sheen above, pale sides darkening with age; abdomen mostly black with thin pale rings, and distinctive blue and black pattern on S8-59. Eyes dark blue above; small, round postocular spots. Female thorax pale with broad, dark middorsal stripe and distinctive split black shoulder stripes; abdomen mostly dark with thin pale rings and pale lateral marks on S8-S9. Dark coloration of male is distinctive, as is split shoulder stripe of female.

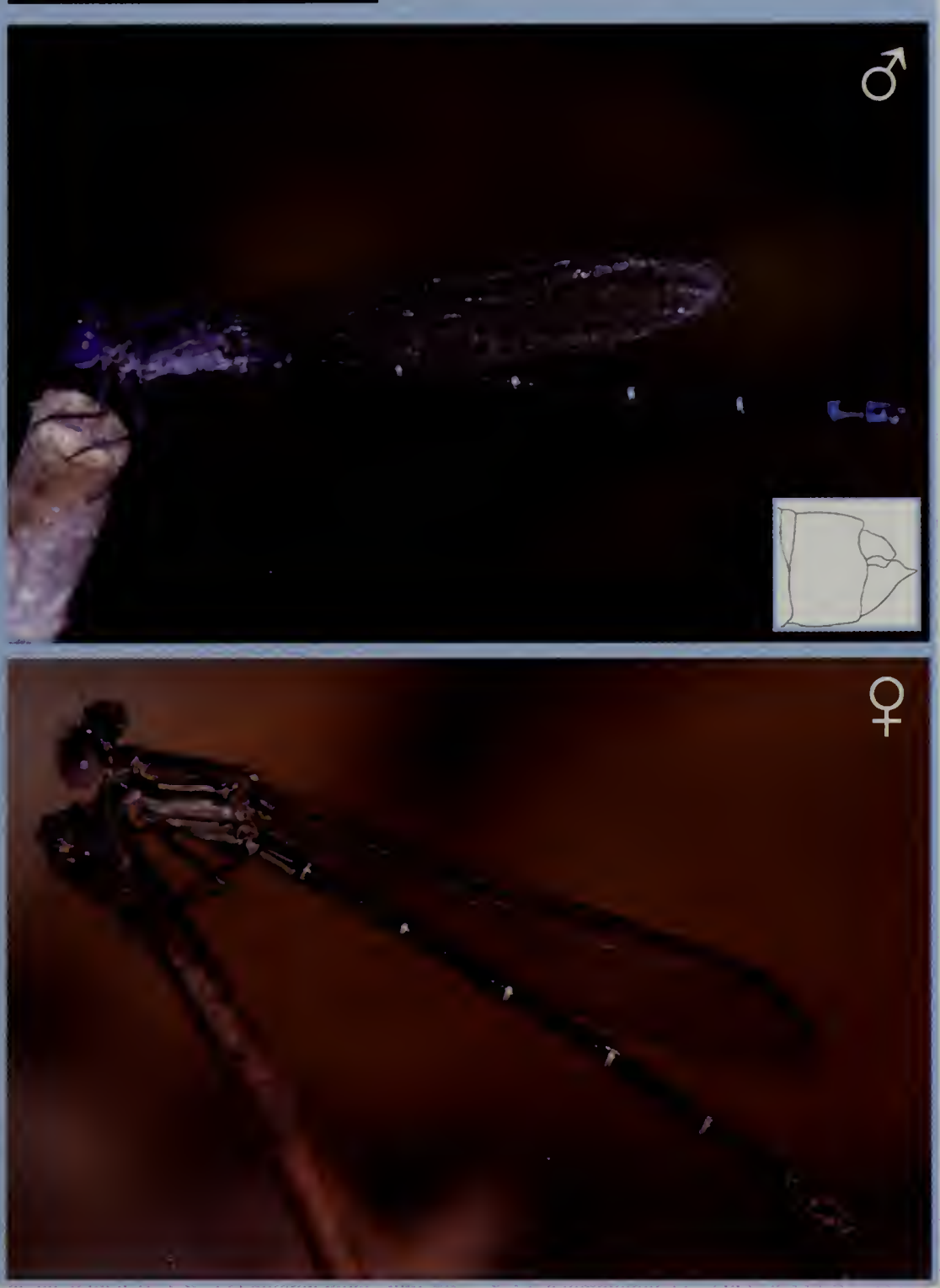

RANGE/STATUS Central and southern U.S. north to southern New England. Uncommon and local in interior MA.

HABITAT Rivers, streams, and poorly vegetated ponds, lakes, and reservoirs.

NOTES Adults fly in and out of shoreline vegetation, perching horizontally on rocks, logs, and foliage, preferring the shade. Females oviposit in tandem with the pair often seeking dense foliage.

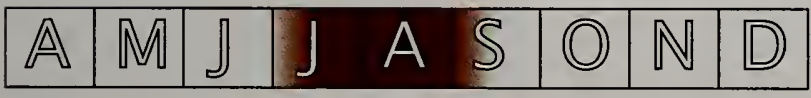


One of the largest dancers. Male thorax powdery gray, with black shoulder stripes becoming obscure with age; abdomen black with thin, pale rings and grayish-white tip (S9S10). Eyes dark, with gray postocular spots and face. No other damselfly is so extensively chalky in coloration. Female thorax either brown or blue, with narrow, dark shoulder stripes; abdomen mostly blackish above, but becoming pale at tip. Very similar to female Bluefronted Dancer (p. 67), but tip of abdomen (S8S10) somewhat paler. Blue female also similar to male Blue-fronted Dancer, but somewhat duller and no blue tip on abdomen.

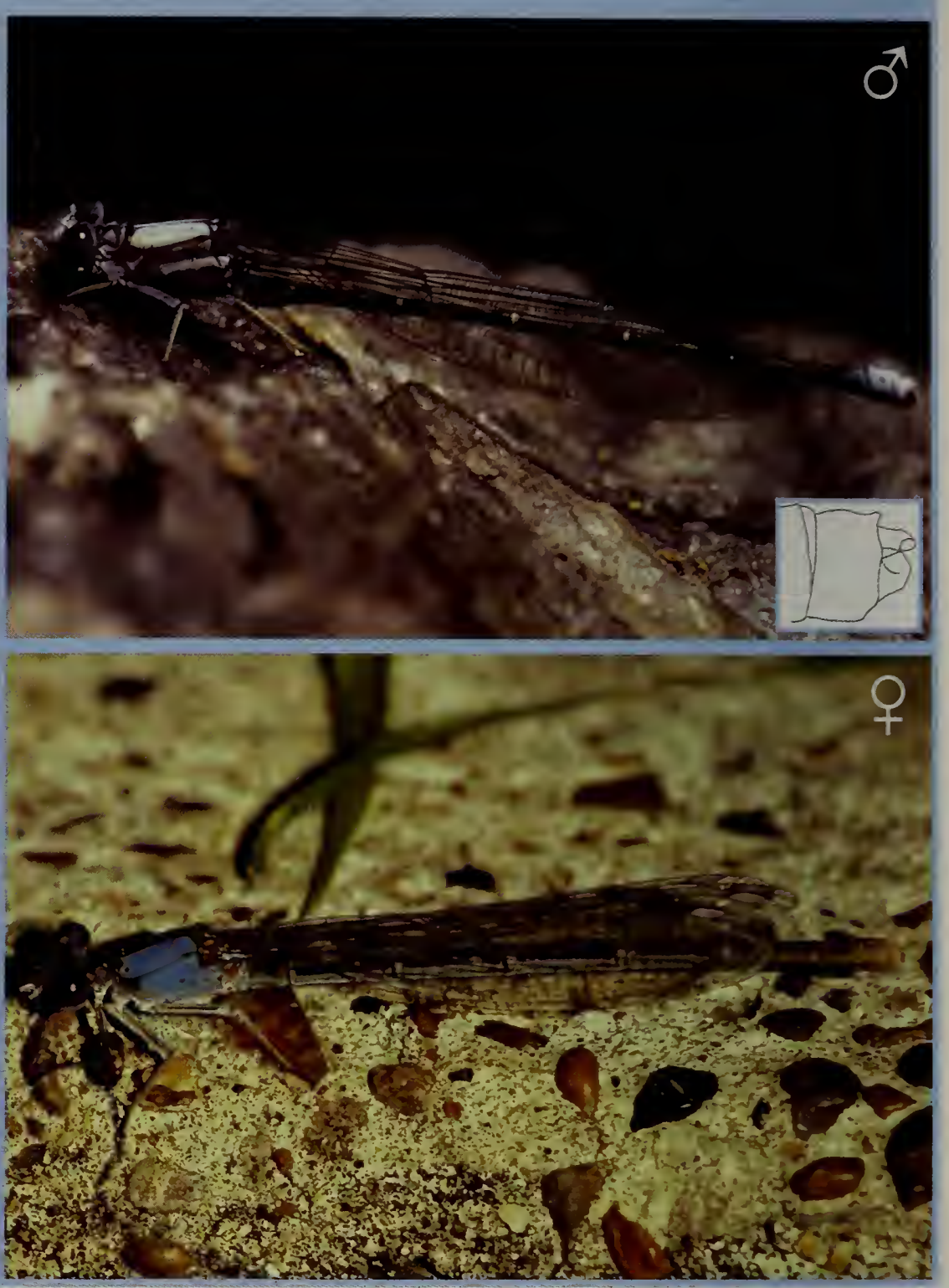

RANGE/STATUS Central to northeastern U.S.; southeastern Canada. Common throughout the interior of MA but scarce on the southeast coastal plain. HABITAT Mid-sized to large rocky rivers; lakes with rocky shores. NOTES Adults perch horizontally on rocks, logs, plants, and sandy stretches of shore, frequently flying over the open water. Females oviposit in tandem in submerged wood or moss-covered rocks, with the pair sometimes staying submerged for more than an hour. Many pairs may oviposit close together, forming dense breeding congregations.

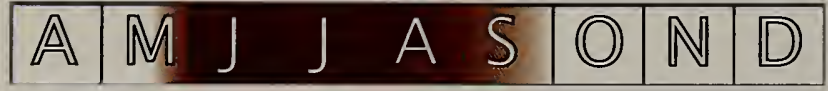


One of the larger dancers in the Northeast. Male thorax brilliant blue on top, with very thin black stripes and blue-gray sides; abdomen black above, with conspicuous blue tip (\$8-S10). Eyes dark blue, with tiny, pale blue postocular spots and blue face. Female occurs in two forms, one mostly brown on the thorax and the other mostly blue; abdomen blackish above in both forms. Male similar to female Powdered Dancer (p. 66), but brighter with blue S8S10. Female similar to Powdered Dancer, but averages darker on tip of abdomen (S8-S10).

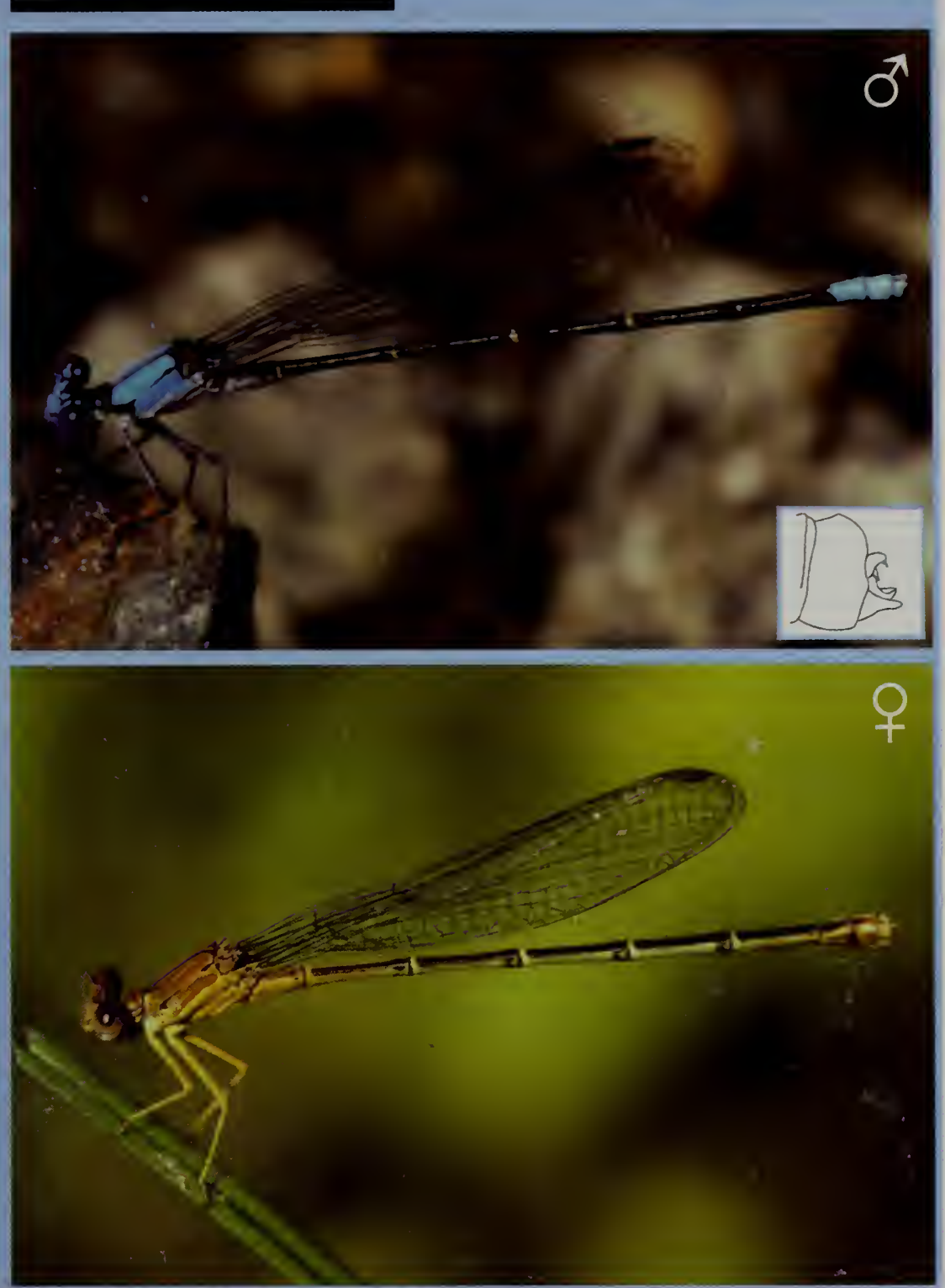

RANGE/STATUS Central through eastern U.S. Uncommon and local in interior MA.

HABITAT Mid-sized to large, sand or mud-bottomed rivers; occasionally lakes and ponds.

NOTES Adults fly in a lilting manner along the shore, often alighting horizontally on bare ground, rocks, logs, or foliage. Males are territorial, and flick their wings and chase away competing males. Females oviposit in tandem on floating plants, sometimes with several breeding pairs close together.

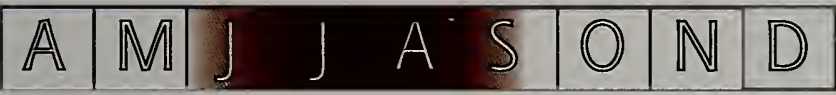


Petaltails are the oldest family of extant dragonflies, with only ten species worldwide. Two species occur in North America, one in the east and one in the west. The Gray Petaltail (Tachopteryx thoreyi), the eastern species, may occur in Massachusetts. It is a large, mottled gray dragonfly that is darner-like in appearance. However, the eyes are well-separated and the stigmas on the wings are long and parallel-sided. Females have a well-developed, bladelike ovipositor. This is the only eastern species whose larvae may not be truly aquatic, developing in mucky, mossy seeps. The extent of the habitat types that are home to the larvae is unknown.

There is a published record of this species based on a specimen reportedly collected in the 1800 's in Massachusetts, however, there are no locality details in that record. The whereabouts of the specimen is unknown, and given the frequent errors and uncertainties in records from that era (especially in labeling), it seems prudent to consider this report hypothetical. However, the species is found in southern New York close to the Massachusetts border, and there is an unverified historic record from southern New Hampshire. The occurrence of this species in Massachusetts is possible as appropriate habitat is present.

\section{Gray Petaltail Tachopteryx thoreyi}

RANGE/STATUS Southeastern U.S. north through southern New England. Potentially in western MA.

HABIT Adults have been found at a variety of habitats throughout its range, including hillside seeps, sandy streams, and small fens. In the northeast, it is thought to most often occur in hillside seeps, however the New Hampshire report describes several adults along a sandy river bed.

NOTES This is a rarely encountered dragonfly in the northeast. It is thought that adults tend to stay close to the natal habitat, spending much of the time perched in sunny spots or hanging vertically from tree trunks. They are not wary and occasionally land on people. Males defend a small territory, and pursue females up into the canopy. Eggs are presumably laid in mossy, wet areas of the seep.

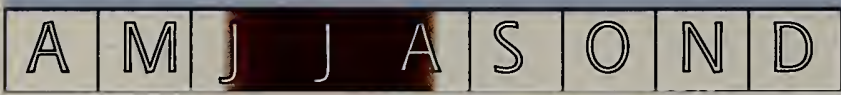

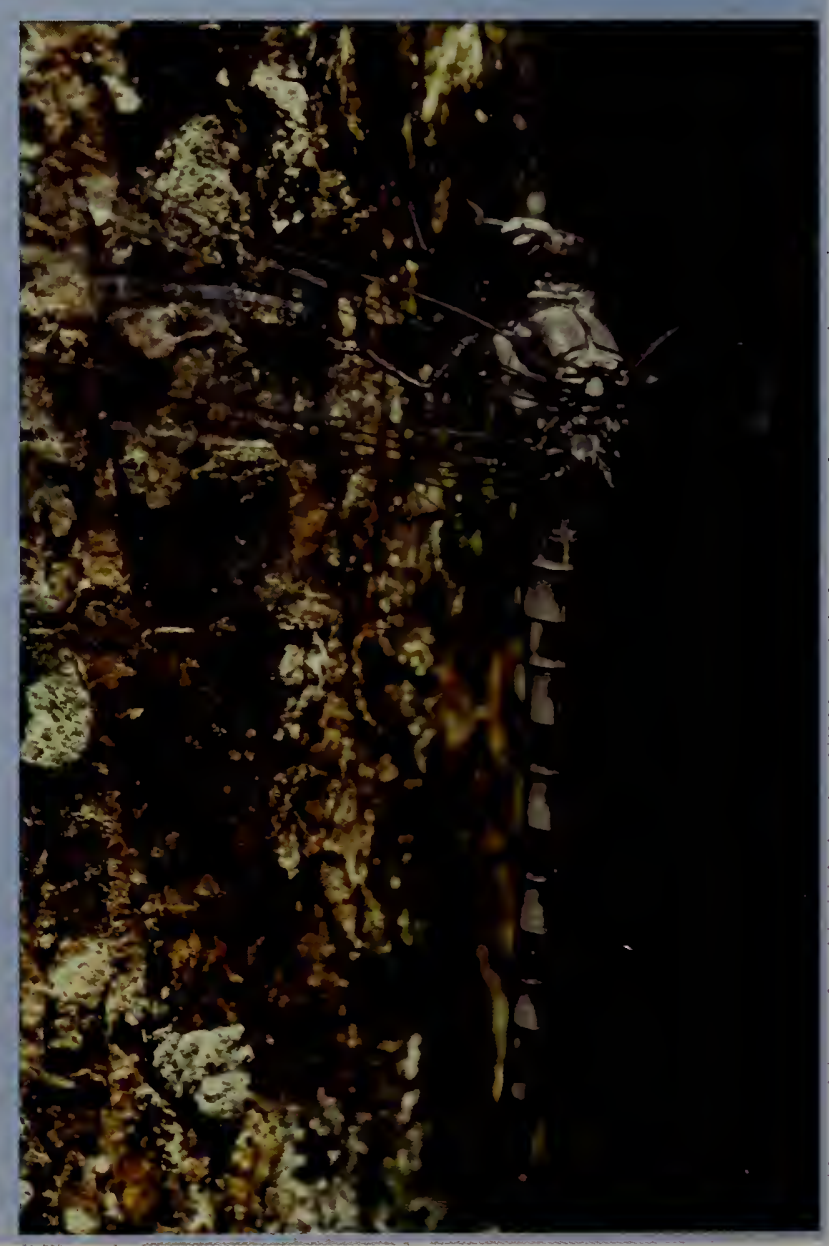




\section{AESHNIDAE: DARNERS}

Darners are large, strong-flying dragonflies, some exceeding three inches in length. Over 430 species are known worldwide, with 39 species recorded from North America. In Massachusetts 20 species have been found, comprising seven genera.

Darners are distinguished by their large eyes that meet in a long seam on the top (vertex) of the head. Some are patterned with blue, green, dull yellow, or tan on the abdomen and have striped thoraxes; others are drab. The two Anax species are bright green on the thorax with blue or red abdomens. Aeshnid wings are typically clear, but in some species, and especially among females, they can be tinged with amber. Females are similar to males, though with stockier abdomens and are often drabber in coloration. Many species can be identified in the hand, using a

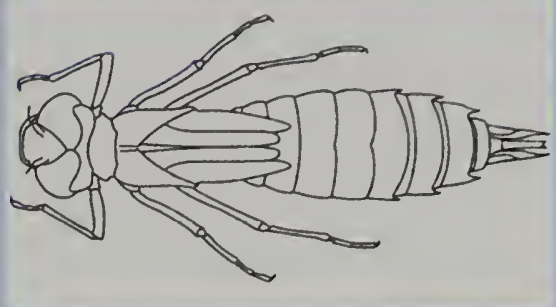

Darner larvae are long, smooth, and slender, with fine, 6- to 7-segmented antennae. They are patterned with speckles and spots, often golden brown to green in color, and climb among aquatic vegetation and detritus. combination of characteristics including thoracic pattern and color (p. 70), abdominal pattern and color, and eye color. A few species can be difficult to differentiate even in the hand and may require a taxonomic key.

Darners inhabit a wide variety of wetlands. A few species fly early, reaching peak abundance in June and disappearing by mid-July; these species tend to have short flight seasons. The majority of darners reach a peak abundance in August. The Common Green Darner (Anax junius) has by far the longest flight season of any odonate in the Northeast, with the first individuals (migrants from the south) typically appearing in mid-April, and the last often lingering through November. Darners perch vertically, heads up, either by hanging from branches or clinging flat against tree trunks. A few perch low in grasses or small shrubs, but most perch high in trees where they are difficult to find. Most species hunt over upland fields, dirt roads, and hilltops, often in mixed species swarms, and often far from where they emerged. Feeding activity is most common late in the day, and extends until well after sunset.

Males spend long periods patrolling at breeding sites, in most species a few feet over the water's surface, searching for females and driving off competing males. Females oviposit endophytically in aquatic vegetation or wet, decaying wood by slicing into the substrate with the long ovipositors on the underside of the abdomen. In most species the female oviposits alone, but in the Common Green Darner the pair often remains in tandem while the female lays eggs. Larvae are long and cylindrical, and spend much of their time crawling among and clinging to stalks of aquatic vegetation, or hiding under rocks and woody debris. The larval stage lasts from one to three or more years. Emergence takes place close to the water, usually on stalks of emergent vegetation, where the exuviae may be found. 
Mosaic darners (Aeshna) can be identified by examining the lateral thoracic patterns. In most species there is a distinct front or anterior lateral stripe (ALS) and a rear or posterior lateral stripe (PLS). LS shape is less variable than their color and therefore is more useful for identification. Characteristics that are important in identification are described below each illustration.

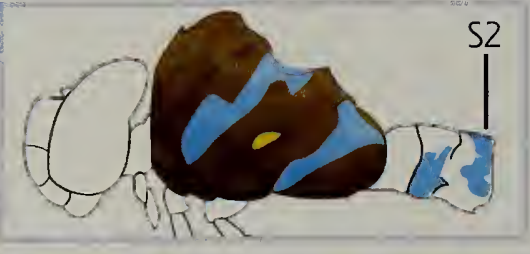

Canada Darner, (A. canadensis): ALS deeply indented on leading edge; dorsal flag. Yellow midlateral spot. Blue on $\mathrm{S} 2$ shallowly cleft. p. 76

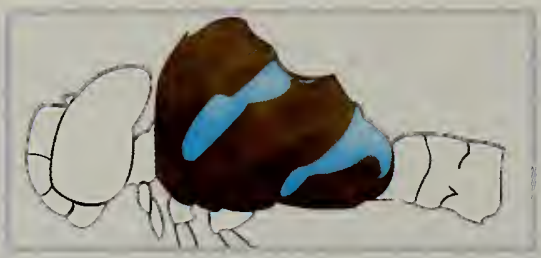

Lance-tipped Darner, (A. constricta): ALS shallowly indented; dorsal flag small or lacking. PLS thick dorsally with rearward pointing extension. p. 78

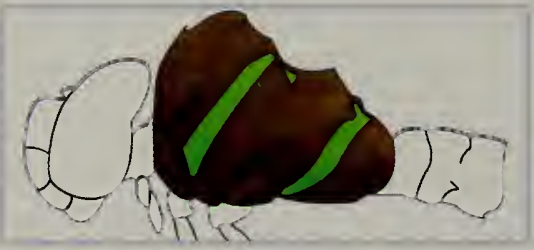

Shadow Darner, (A umbrosa): LS narrow and straight, thinly outlined in black. Flag on ALS narrow at base but broad and blunt distally. p. 74

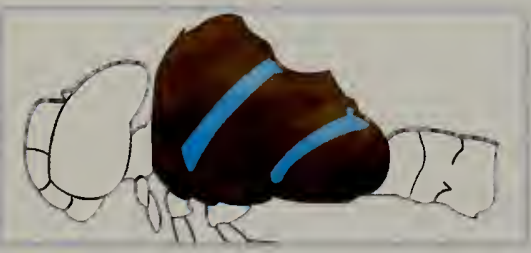

Spatterdock Darner, (A. mutata): LS relatively straight and thin, little or no flag on ALS; PLS with little or no dorsal expansion. Eyes, face bright blue. p. 82

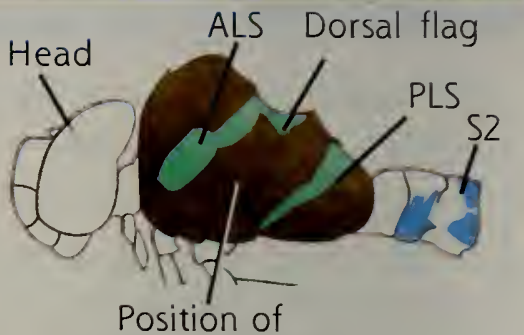

mid-lateral spot

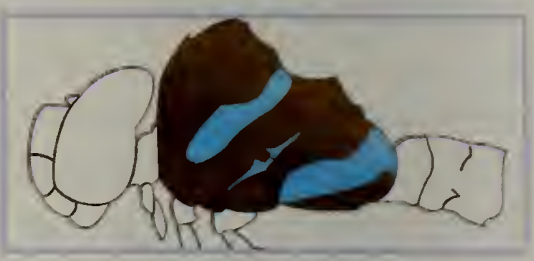

Lake Darner, (A. eremita): Similar to canadensis. ALS not as deeply indented and often lacks flag; PLS thicker; usually 1-3 blue midlateral spots. p. 79

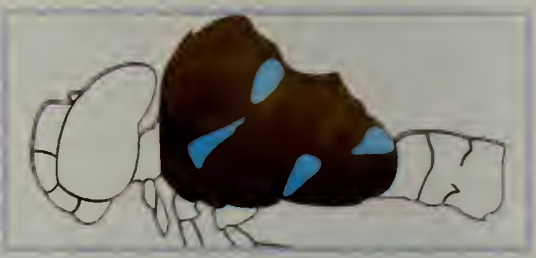

Variable Darner, (A. interrupta): LS broken into elongate, blue/ green spots. p. 81 elongate, yellow to blue midlateral spots. p. 80

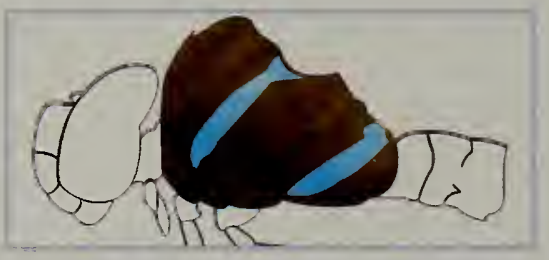

Black-tipped Darner, $(A$. tuberculifera): LS straight and relatively uniform in width; short, pointed flag on ALS. p. 75

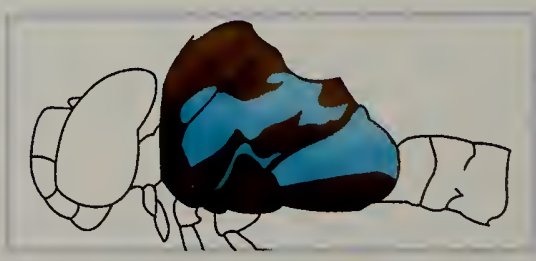

Mottled Darner, (A. clepsydra): LS expanded into very broad, irregularly-shaped patches with additional spots, creating mottled pattern. p. 83

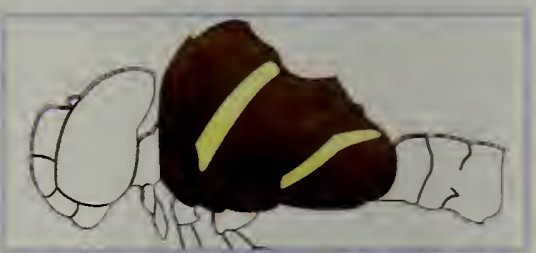

Springtime Darner, (Basiaeschna janata): LS narrow, relatively straight, and yellow or white with no blackish outline. p. 71

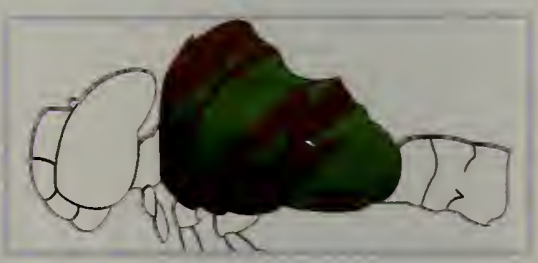

Harlequin Darner, (Gomphaeschna furcilata): Mottled yellow or greenish pattern on sides; no distinct LS. p. 85 

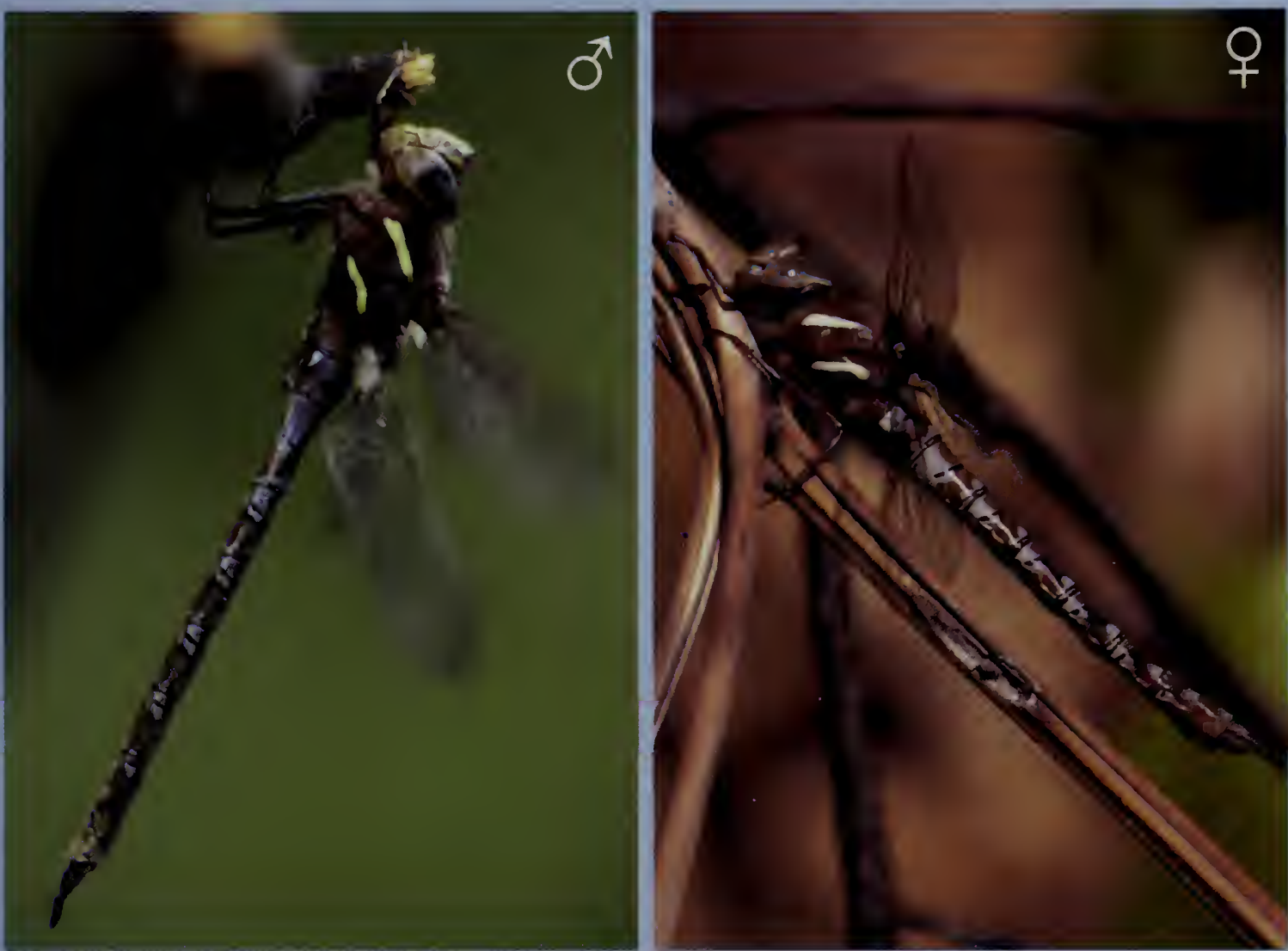

Male thorax brown with thin, pale dorsal stripes and two narrow, straight, pale yellow to ivory lateral stripes; abdomen brown with blue spots and markings on all segments. Eyes brown to dark blue. Wings with small dark patches at base. Female similar, but abdominal spots often greenish and wings often tinged brown. The mosaic darners (genus Aeshna) are similar, but generally larger, lack dark basal spots on wings, and fly later in the season (except Spatterdock Darner).

RANGE/STATUS Eastern U.S.; southeastern Canada. Common throughout MA. HABITAT Rivers and streams; well-oxygenated lakes and ponds with little aquatic vegetation.

NOTES Adults fly over open fields and water from early in the day through dusk. Flight is similar to that of the spotted darners' (Boyeria spp.) zigzagging, but faster and higher. Like the Common Green Darner (Anax junius) and the Lance-tipped Darner (Aeshna constricta), commonly perches near the ground in brush and grasses. They also hang vertically from tree trunks. Males patrol along the shoreline, scouting and defending breeding sites. Females oviposit in aquatic vegetation, submerging their abdomens and laying eggs endophytically under the waterline.

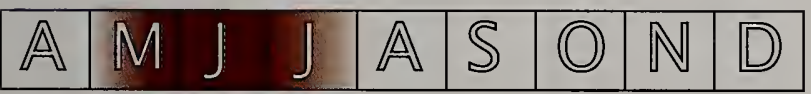



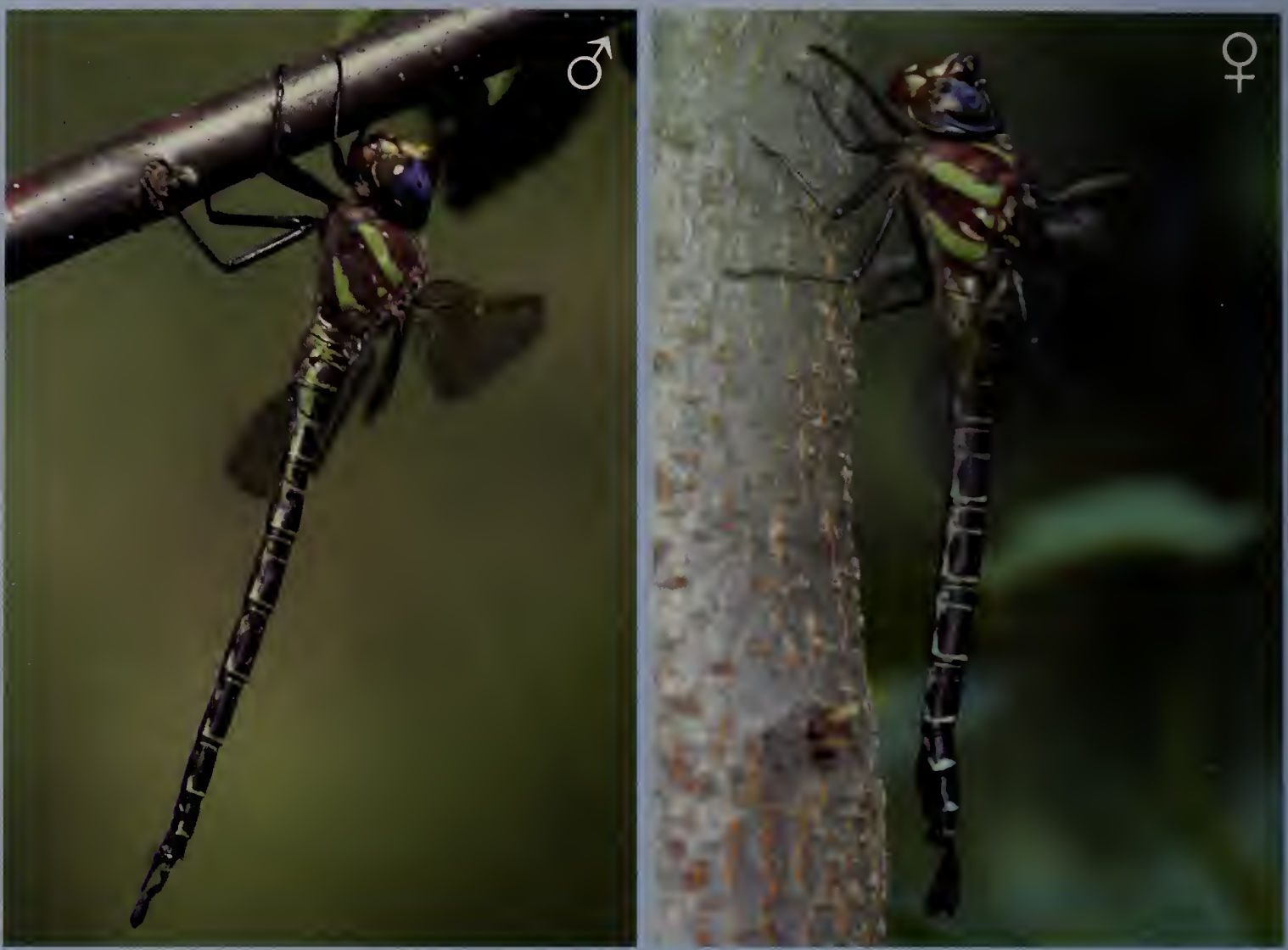

One of the largest dragonflies in MA. Male thorax brown with green dorsal stripes, two broad, green lateral stripes, and a small green triangle between wing bases; abdomen dark brown with narrow green rings. Eyes blue. Wings often with dusky tips and tinged with amber or light brown. Female similar. The green-ringed abdomen is distinctive among northeast darners.

RANGE/STATUS Eastern U.S. Generally uncommon in MA, most regularly seen in eastern portions; rarely, large incursions from the south occur during the early summer. HABITAT Shady ponds, swamps, and slow streams.

NOTES Adults fly high over fields and clearings, and form late afternoon feeding swarms, and occasionally enter buildings. They hang vertically from branches and tree trunks, often high in trees. Males do not patrol at breeding sites. Females oviposit in mud, dry pond bottoms, and stems up to several feet above the waterline. This species is occasionally seen in Atlantic coast migratory swarms.

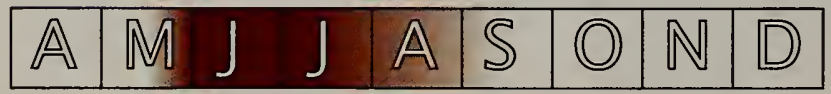



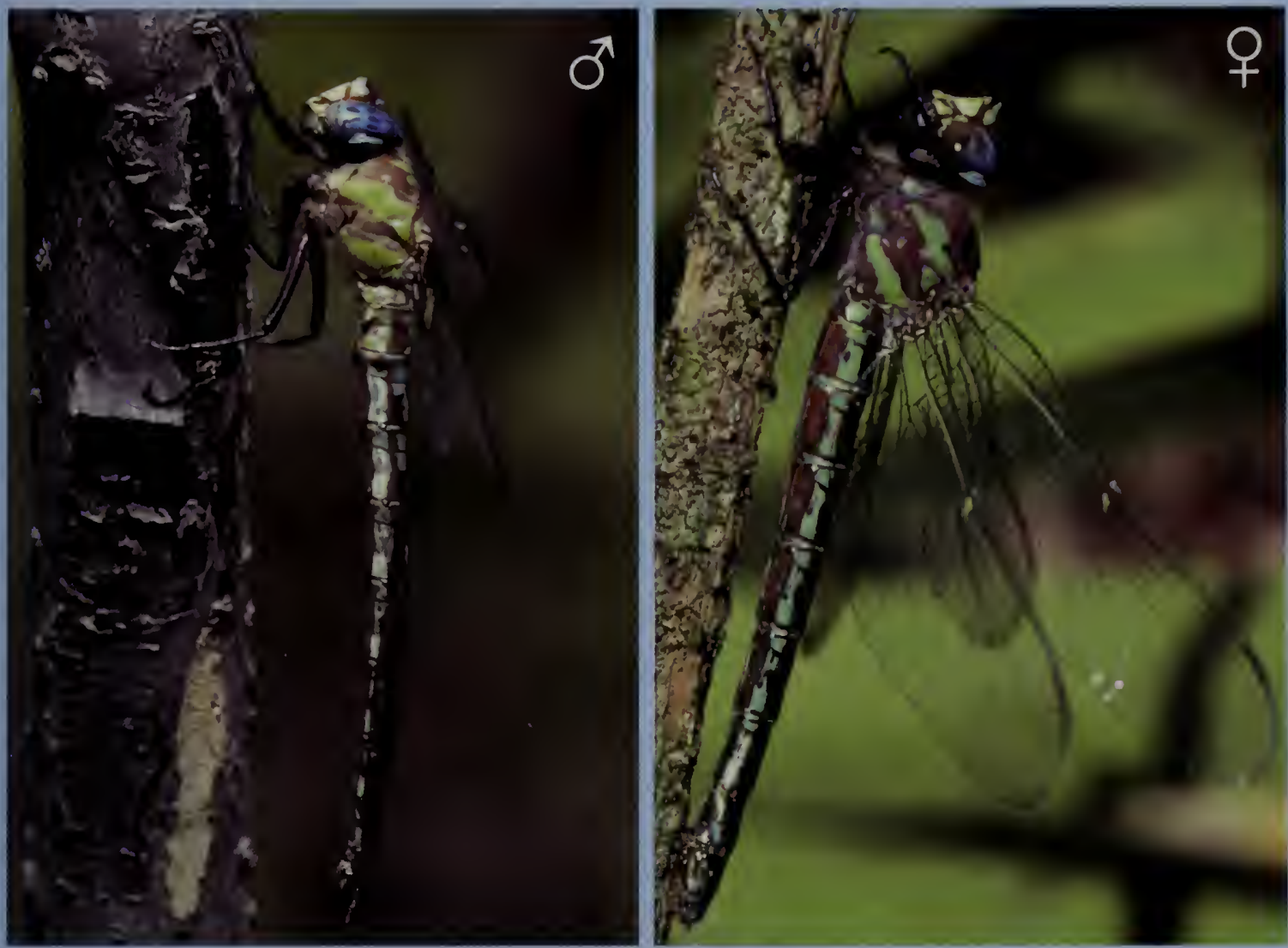

Male thorax brown with thick, green dorsal stripes (shaped like the number 7) and broad, blue-green lateral stripes; abdomen distinctly tapered and brown with prominent bluel green dorsal and lateral spots and patches. Eyes blue. Projecting "forehead." Female similar, but abdomen thicker. Similar to some mosaic darners (Aeshna spp.), but stockier with very thick lateral thoracic stripes and projecting "forehead," and has earlier flight season.

RANGE/STATUS Eastern U.S.; southeastern Canada. Near the northern extent of its range in MA. Uncommon and most often found in eastern MA.

HABITAT Ponds, slow streams, and coves of lakes.

NOTES Adults hunt in forests and do not join swarms. They frequently prey on other dragonflies and damselflies. They perch vertically on tree trunks and vegetation. Males patrol slowly above the water, zigzagging back and forth, without hovering. Females oviposit in water-soaked logs and submerged vegetation.

\begin{tabular}{|l|l|l|l|l|l|l|l|l|}
\hline $\mathbb{A}$ & $\mathbb{M}$ & $\mathbf{J}$ & $\mathbb{J}$ & $\mathbb{A}$ & $\mathbb{S}$ & $\mathbb{O}$ & $\mathbb{N}$ & $\mathbb{D}$ \\
\hline
\end{tabular}



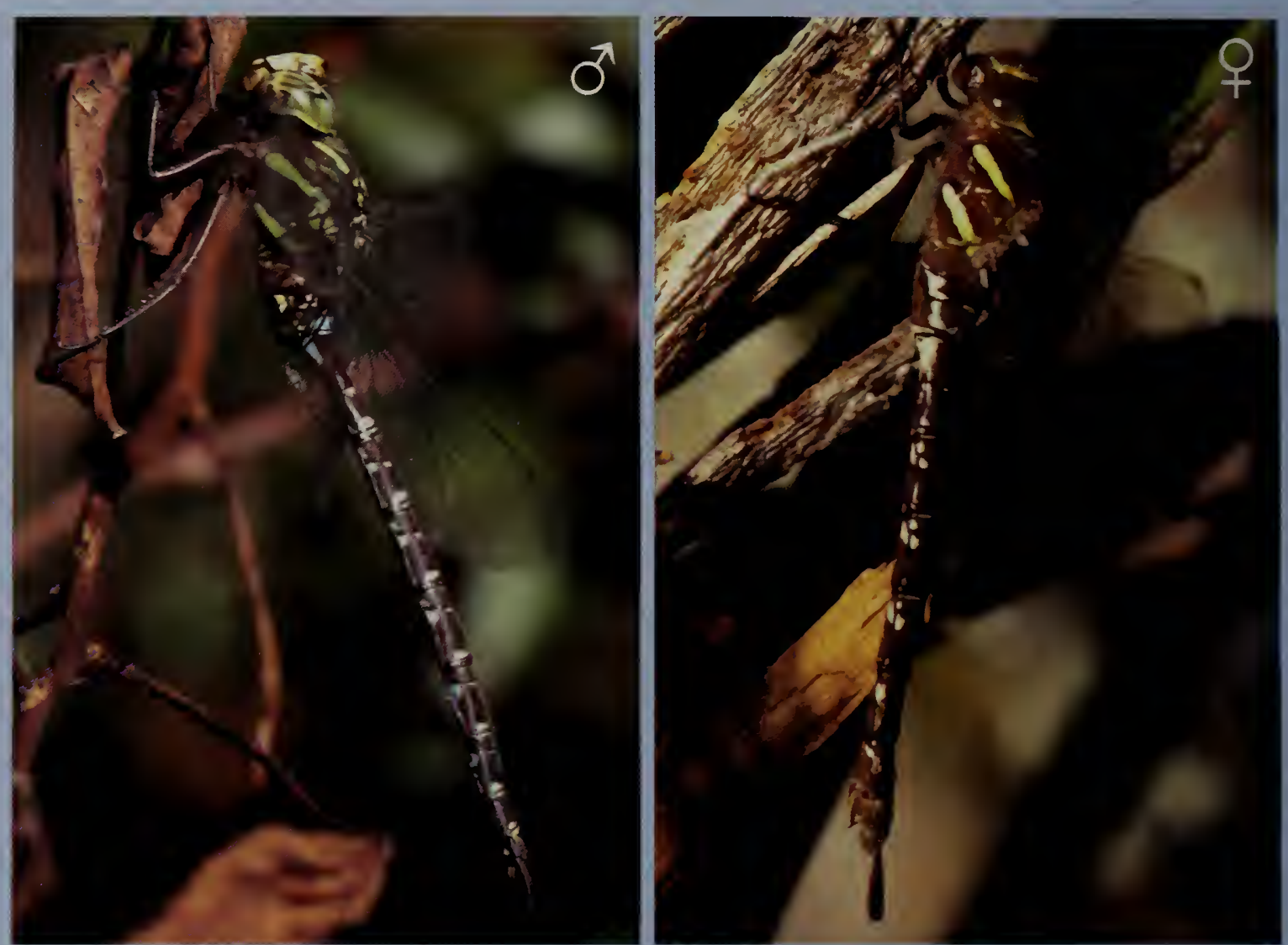

Male thorax brown with blue to greenish-yellow dorsal stripes and two blue to greenishyellow lateral stripes; lateral stripes relatively straight and narrowly outlined in black; abdomen brown with blue markings, except S10 occasionally all dark; pale abdominal markings smaller and often duller than in other Aeshna. Eyes dull, grayish-blue to greenish. Female similar, but pale areas duller blue, green, or yellow, wings often tinged with brown. Black-tipped Darner (p. 75) similar, but lateral thoracic stripes not outlined in black, male terminal appendages not paddle-shaped with "spike."

RANGE/STATUS Mid-U.S. north to mid-Canada. Common throughout MA. HABITAT Primarily small forested streams, but also beaver ponds, bogs, swamps, and fens.

NOTES This is a crepuscular, shade-loving species. Adults forage along shaded forest edges and may feed in swarms with other darners at dusk. They hang vertically from vegetation. At breeding sites, males fly long beats that are punctuated by short periods of hovering as they patrol along the shoreline. Females oviposit in wet, decaying wood. This is one of the very few species that fly into early November. 

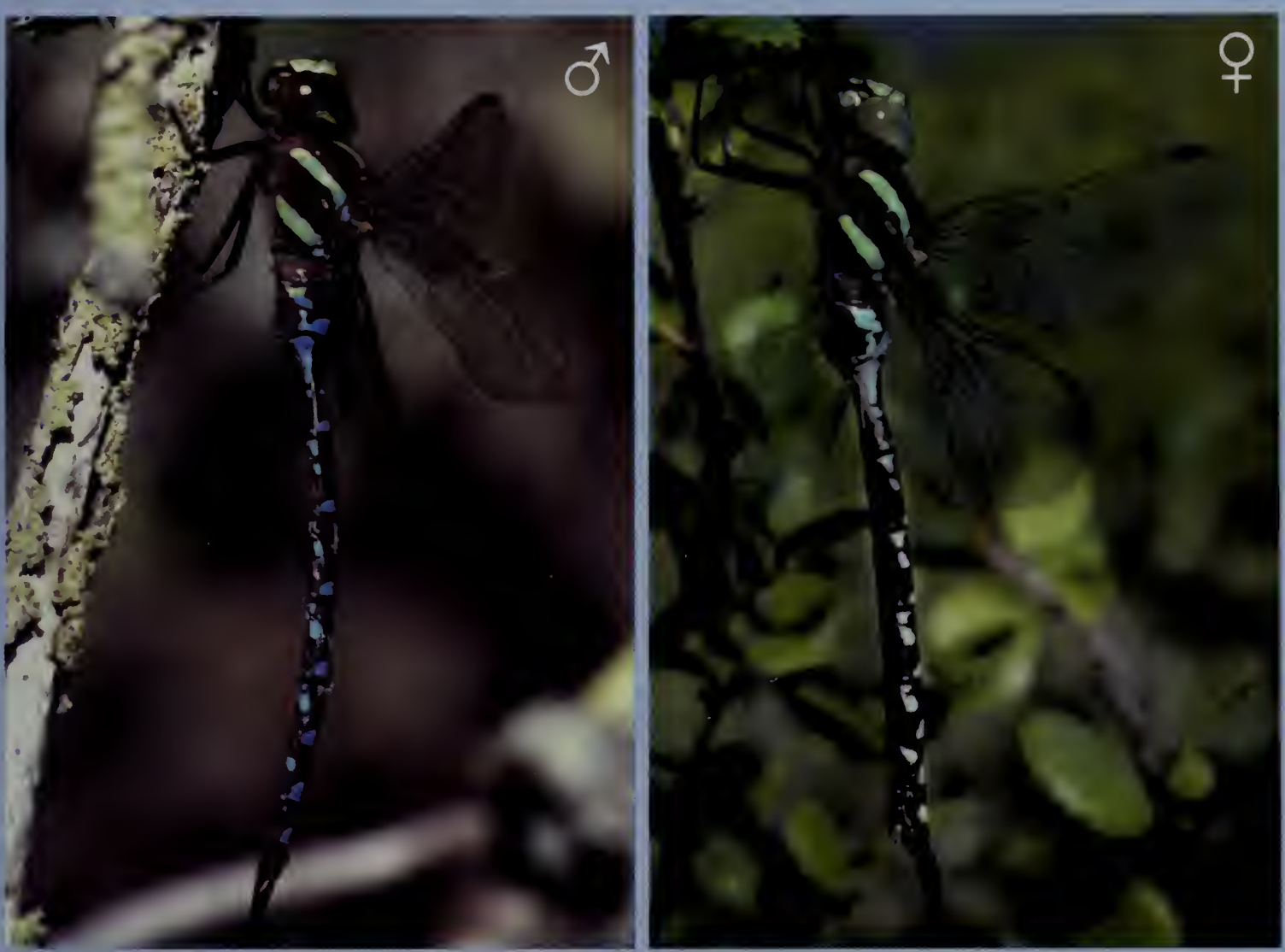

Male thorax brown with blue to bluish-green dorsal stripes and two green to blue lateral stripes; lateral stripes relatively straight and parallel-sided; abdomen brown with blue markings, except $\$ 10$ all dark. Eyes dull blue-gray to greenish. Female similar, but pale areas often green to greenish-yellow and wings occasionally tinted with amber. Shadow Darner (p. 74) similar, but lateral thoracic stripes outlined in black and male terminal appendages paddle-shaped and "spiked."

RANGE/STATUS Northeastern U.S. and southeastern Canada; northwestern U.S. and southwestern Canada. Locally common throughout MA.

HABITAT Ponds and lakes with emergent vegetation, bog-bordered ponds, and marshy streams.

NOTES Adults hunt along forest edges, dirt roads, and in clearings. They may join evening feeding swarms. Males patrol along the shoreline, usually at a height of 4-6 ft., over emergent vegetation and the water, scouting and defending breeding sites. Females oviposit in emergent vegetation above and below the waterline, or in the mud of dry pond beds.

\section{$\mathbb{A}|\mathbb{M}| 』|J| A S|O| \mathbb{N} \mid \mathbb{D}$}



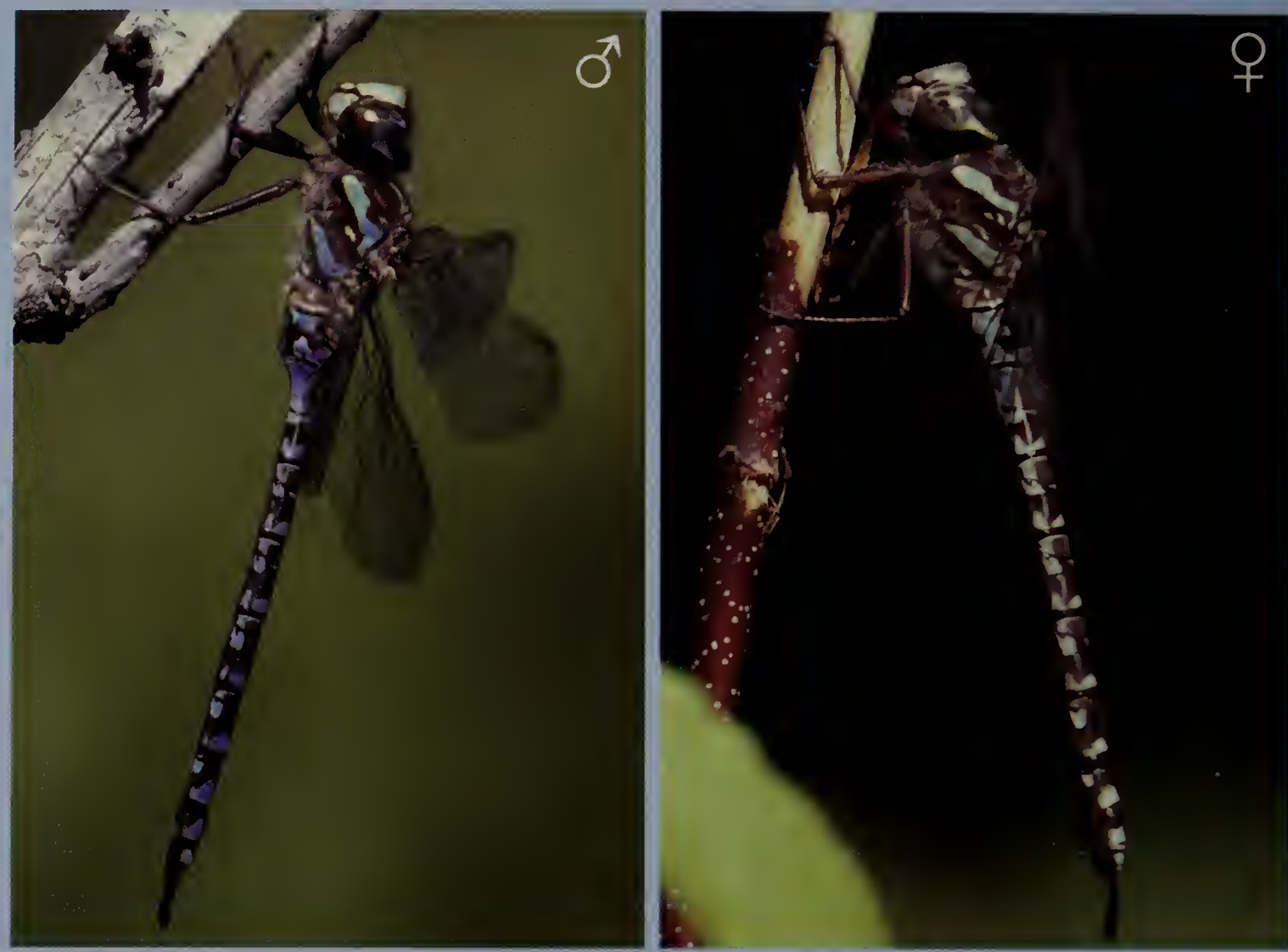

Male thorax brown with blue or greenish-blue dorsal stripes and two blue to green lateral stripes; the front lateral stripe deeply indented on leading edge; abdomen brown with blue markings on all segments. Eyes dull bluish-gray to greenish. Females similar, but pale areas green or greenish-yellow; wings occasionally amber-tinted. Very similar to several other Aeshna. Green-striped Darner (p. 77) nearly identical, but often distinguishable by a combination of subtle differences in shape and coloration of lateral stripes and spots (p. 70), pattern on sides of S2, and face pattern (darker "lips" of Canada). Lake Darner (p. 79) slightly larger, with subtly different shape of lateral thoracic stripes and a black crossline on face. Lance-tipped Darner (p. 78) differs in shape of male abdominal appendages and shape of lateral thoracic stripes (p. 70).

RANGE/STATUS Northern U.S. and southern Canada. Very common in MA.

HABITAT Grassy marshes, fens, flooded beaver ponds, bog-bordered lakes with floating vegetation, and sluggish marsh-bordered streams.

NOTES Adults hunt along forest edges, in sunny clearings, and in late afternoon feeding swarms. They hang vertically at rest. At breeding sites, males patrol over emergent vegetation scouting for females and defending against other males. They typically fly at a height of 2 $4 \mathrm{ft}$., hovering frequently and regularly drop down into openings in the vegetation. Females oviposit in emergent vegetation, just below the waterline.

\begin{tabular}{|l|l|l|llll|l|l|}
\hline $\mathbb{A}$ & $\mathbb{M}$ & $\mathbb{J}$ & J & A & $S$ & 0 & $\mathbb{N}$ & $\mathbb{D}$ \\
\hline
\end{tabular}



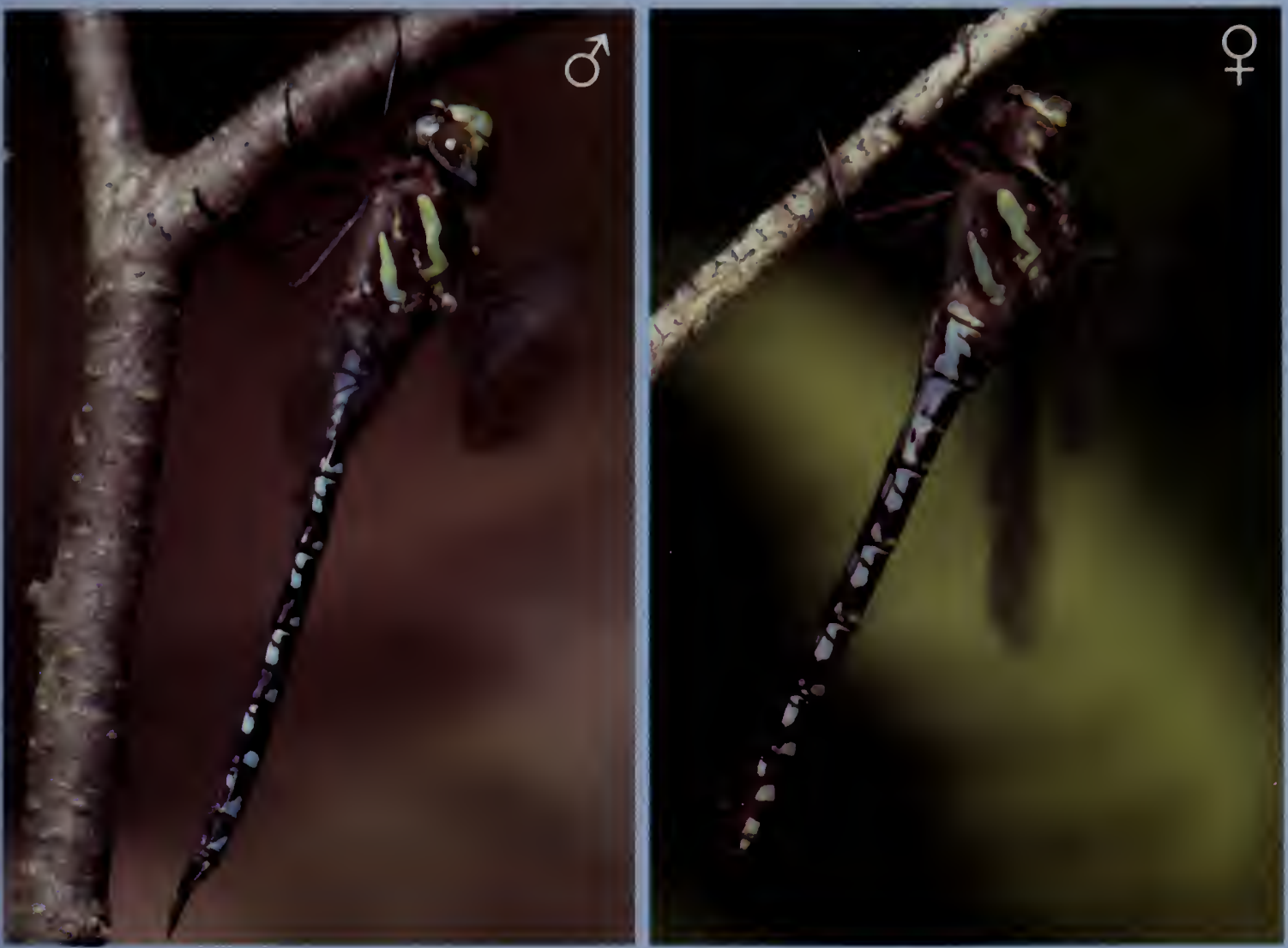

Male thorax brown with broad, green to bluish-green dorsal stripes and two green lateral stripes, front lateral stripe deeply indented on leading edge; abdomen brown with blue markings on all segments. Eyes dull blue-gray to greenish. Female similar, but pale areas often green or greenish-yellow. Distinguished from Canada Darner (p. 76) by subtle differences in pattern of thorax, S2, and face (paler "lips"). Also similar to Lance-tipped Darner (p. 78) and Lake Darner (p. 79).

RANGE/STATUS Northeastern U.S.; southeastern Canada. Locally common in MA.

HABITAT Bogs, fens, wet meadows, and marsh-bordered ponds.

NOTES Adults fly until dusk, feeding in sunny clearings, along forest edges, and in early-evening feeding swarms. They hang vertically from tree trunks or branches. Males patrol shorelines, scouting and defending breeding sites.

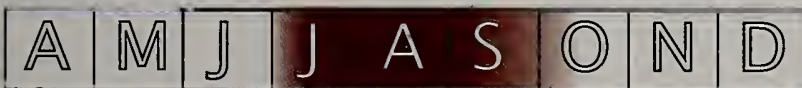




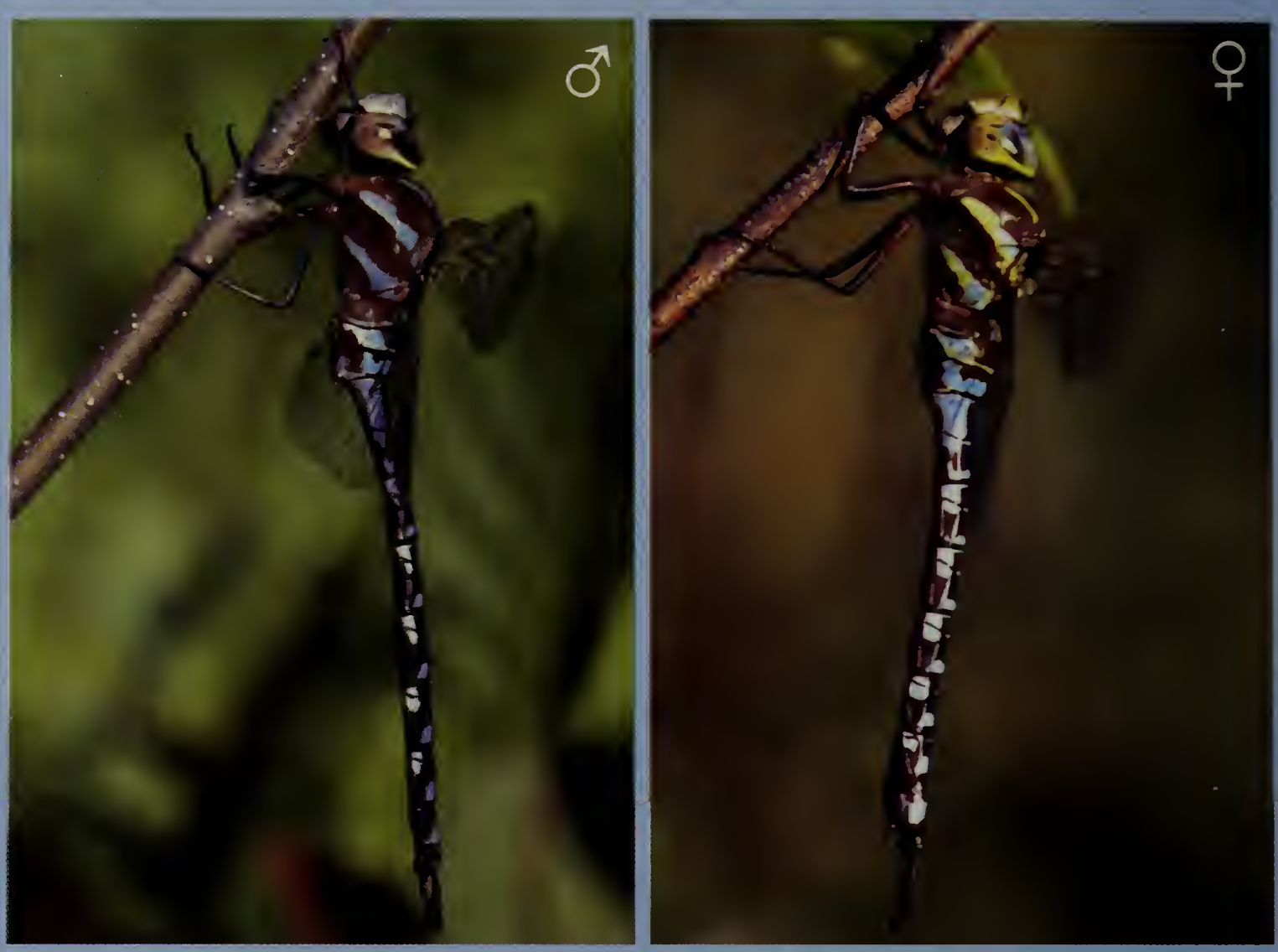

Male thorax brown with green to bluish-green dorsal stripes and two blue or green lateral stripes; abdomen brown with blue markings on all segments; terminal appendages paddleshaped with "spiked" tips. Eyes dull blue-gray to greenish-yellow. Female similar, but pale areas blue-green to yellowish, S10 all dark, and wings often tinted with amber. Very similar to Canada Darner (p. 76), Green-striped Darner (p. 77), and Lake Darner (p. 79), but lateral thoracic pattern subtly different (p. 70), male terminal appendages "spiked," female 59 longer with pale patch extending down to lower sides, and female terminal appendages more pointed at tip than other species.

RANGE/STATUS Mid to northern U.S. and southern Canada. Common in MA but scarce or absent from higher elevations, and very rare on Cape Cod.

HABITAT Slow streams in open marshes, small ponds with emergent vegetation, temporary ponds, and occasionally bogs.

NOTES Adults fly over grassy fields, open marshes, and join late afternoon feeding swarms. One of three darners, and the only Aeshna, that commonly perches in grasses and low weeds. They occasionally hang vertically from tree trunks and large shrubs. Females oviposit in emergent vegetation, probably along open streams in marshes, well above the waterline, in plants such as sweet flag and cattails.

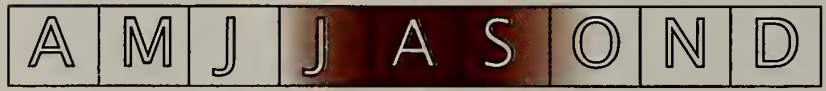



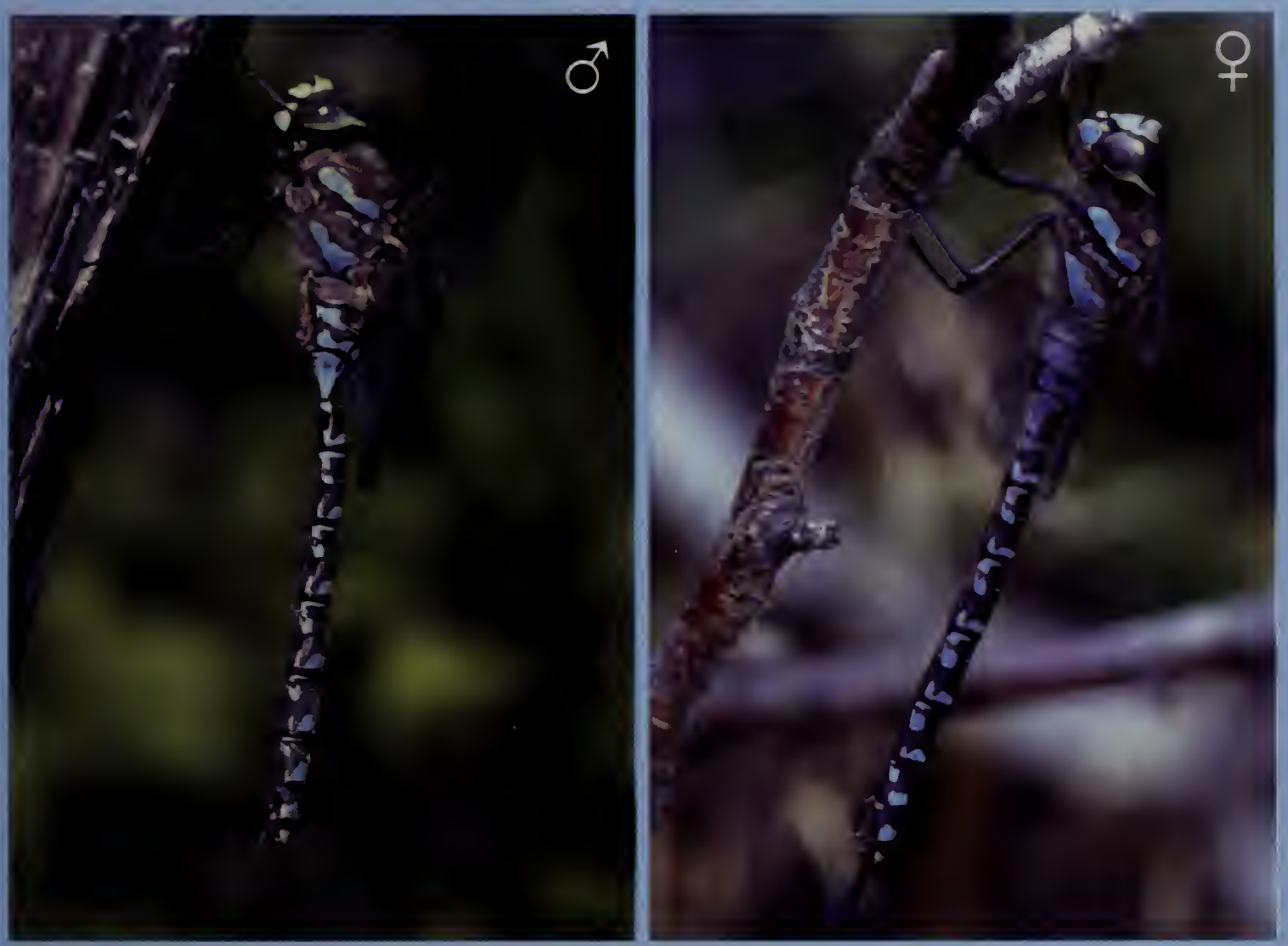

Male thorax brown with blue to bluish-green dorsal stripes and two bluish lateral stripes; abdomen brown with blue markings on all segments. Eyes dull blue-gray to greenish. Face with black "lips" and black bar across upper portion. Female similar, but pale areas duller blue to greenish-yellow. Very similar to Canada Darner (p. 76), Green-striped Darner (p. 77), and Lance-tipped Darner (p. 78), but usually distinguishable by shape of lateral thoracic stripes (no horizontal "flag" on anterior lateral stripe and top half of postericr lateral stripe broader, p. 70).

RANGE/STATUS Northern U.S. and Canada. At the extreme southern extent of its range and rare in MA, found only at higher elevations in the north-central and western parts of the Commonwealth.

HABITAT Bog and marsh-bordered lakes, fens, ponds, and slow streams. NOTES Adults hunt along forest edges. They are active from dawn past dusk, and will even fly in light rain. They hang vertically from tree trunks or branches. Males patrol over the water, with abdomen slightly arched, but are not territorial. Females oviposit in various floating and emergent plants, just below the waterline.

\begin{tabular}{|l|l|l|lll|l|l|l|}
\hline $\mathbb{A}$ & $\mathbb{M}$ & $\mathbb{J}$ & $J$ & $A$ & $S$ & $O$ & $\mathbb{N}$ & $\mathbb{D}$ \\
\hline
\end{tabular}



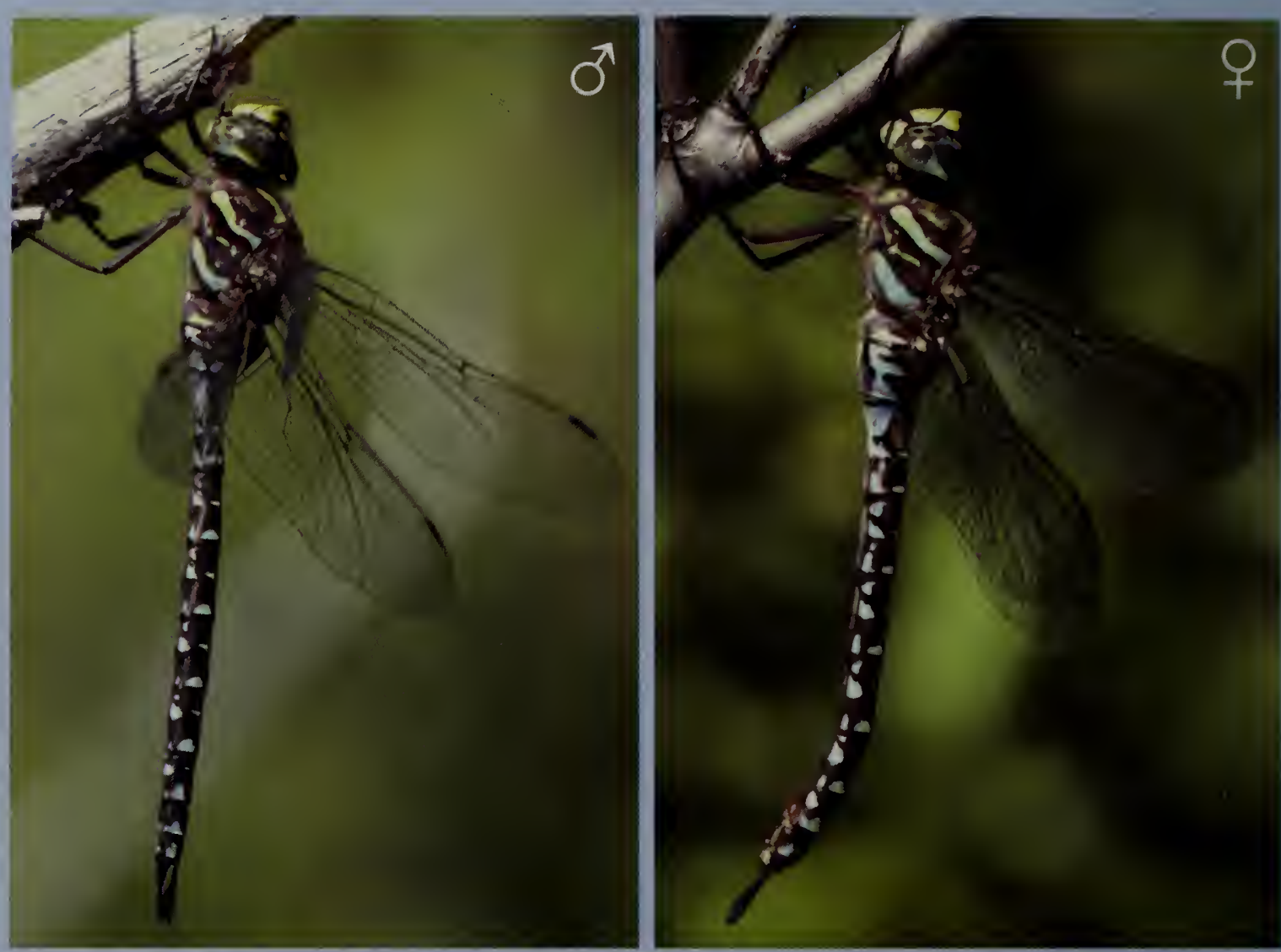

Male thorax brown with green to bluish-green dorsal stripes and two narrow, green to blue lateral stripes; lateral stripes typically blue-green above and yellowish below, bent forward, and separated by an irregularly-shaped streak; abdomen brown with greenishblue markings on all segments. Eyes dull blue-gray to greenish. Face has dark crossline. Female similar, but pale areas often green or yellow; wings occasionally tinted with amber. Similar to Canada Darner (p. 76), Green-striped Darner (p. 77), and Lance-tipped Darner (p. 78), but slightly smaller with black crossline on face and thinner lateral thoracic stripes.

RANGE/STATUS A boreal species found in the northeastern U.S. and Canada. Rare in MA; known from only a couple of sites in north-central MA. HABITAT Sphagnum bogs and deep fens with wet sphagnum.

NOTES Adults hunt in open areas through dusk. Males patrol low over wetter areas of bogs and fens. Not known to join feeding swarms. Females oviposit in soupy patches of sphagnum or on edges of bog pools.

\begin{tabular}{|l|l|l|l|ll|l|l|l|}
\hline $\mathbb{A}$ & $\mathbb{M}$ & $\mathbb{N}$ & $\mathbb{N}$ & $\mathrm{A}$ & $\mathbf{S}$ & $\mathrm{O}$ & $\mathbb{N}$ & $\mathbb{D}$ \\
\hline
\end{tabular}



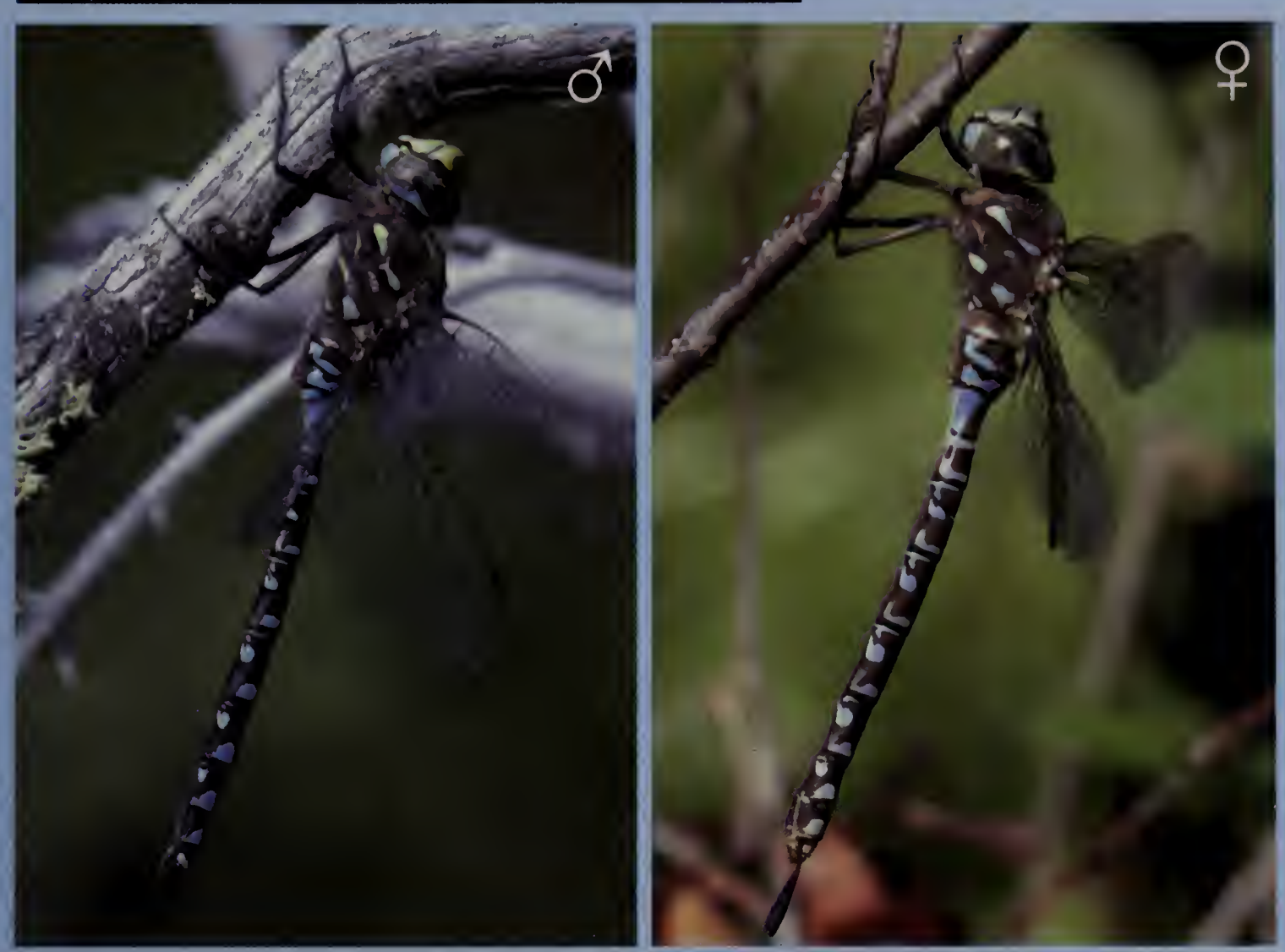

Male thorax brown with thin, green to bluish-green dorsal and lateral stripes, lateral thoracic stripes broken; abdomen brown with blue markings on all segments. Eyes dull blue-gray to greenish. Black crossline on face. Female similar, but pale areas often green or yellowish; wings occasionally tinged with brown. The broken lateral thoracic stripes are diagnostic.

RANGE/STATUS Northern U.S.; Canada. Near the southern extent of its range in $\mathrm{MA}$; fairly common in north-central and western portions of the state.

HABITAT Bogs and marshes with open water, slow streams.

NOTES Adults hunt along roads, over fields, and in evening feeding swarms and seem especially numerous around hill tops. They perch vertically on tree trunks and other vegetation. At breeding sites, they fly swiftly in a straight line, the flight punctuated by periods of hovering. The males patrol along the shoreline, scouting and defending breeding sites. Females oviposit in stalks of aquatic vegetation below the waterline.

\begin{tabular}{|l|l|l|lll|l|l|l|}
\hline $\mathbb{A}$ & $\mathbb{M}$ & $\mathbb{J}$ & J & A & $S$ & $\mathrm{O}$ & $\mathbb{N}$ & $\mathbb{D}$ \\
\hline
\end{tabular}



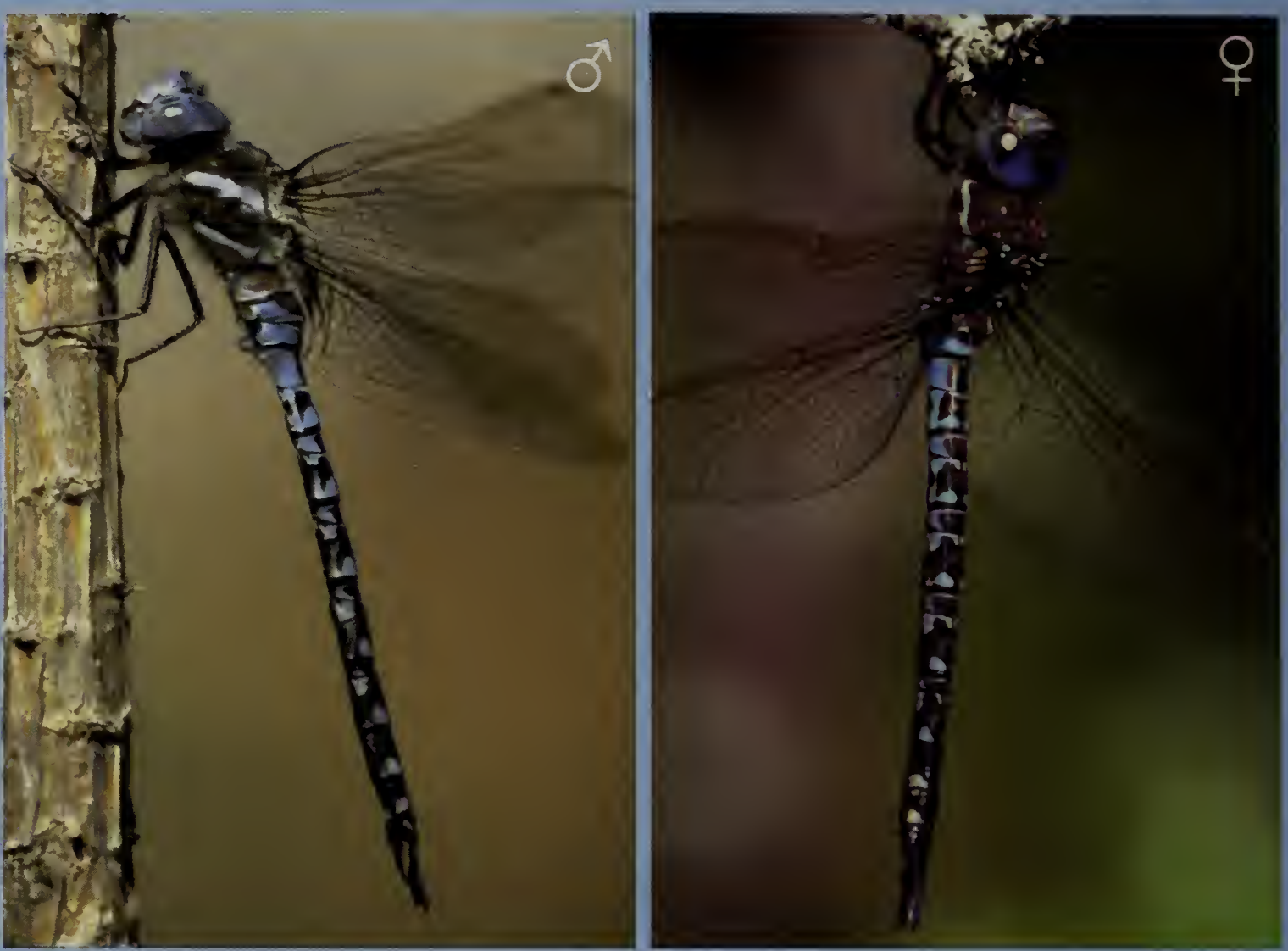

Male thorax brown with blue dorsal stripes and two relatively straight and thin, blue lateral stripes; abdomen brown with blue markings on all segments. Eyes bright blue. Female similar, though thoracic markings generally duller. Bright blue eyes and early flight season distinguish this species from other Aeshna. Cyrano Darner (p. 73) also has blue eyes and an early flight season, but is huskier with thick green thoracic stripes.

RANGE/STATUS Uncommon and local in the northeastern U.S. and southern Ontario. Uncommon in MA; found mainly in eastern and central MA.

HABITAT Vegetated ponds and pools, open marshes and bogs, often with spatterdock (yellow water lily, Nuphar variegatum).

NOTES Adults hunt along forest edges and dirt roads. They hang vertically from tree trunks and branches. Males patrol over the water and along the shoreline, searching for females and pursuing competing males. Females oviposit on the undersides of spatterdock leaves, in other aquatic and emergent vegetation, and in shoreline mud.

The nearly identical Blue-eyed Darner (Aeshna multicolor), a species common in the western U.S. and Canada, has been recorded once in MA in 1943. There are no other records of the species in the eastern U.S., and it seems unlikely to occur in MA again.

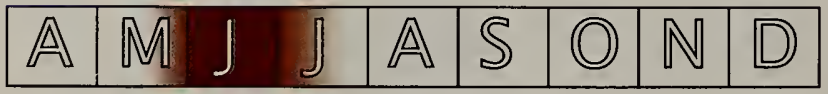



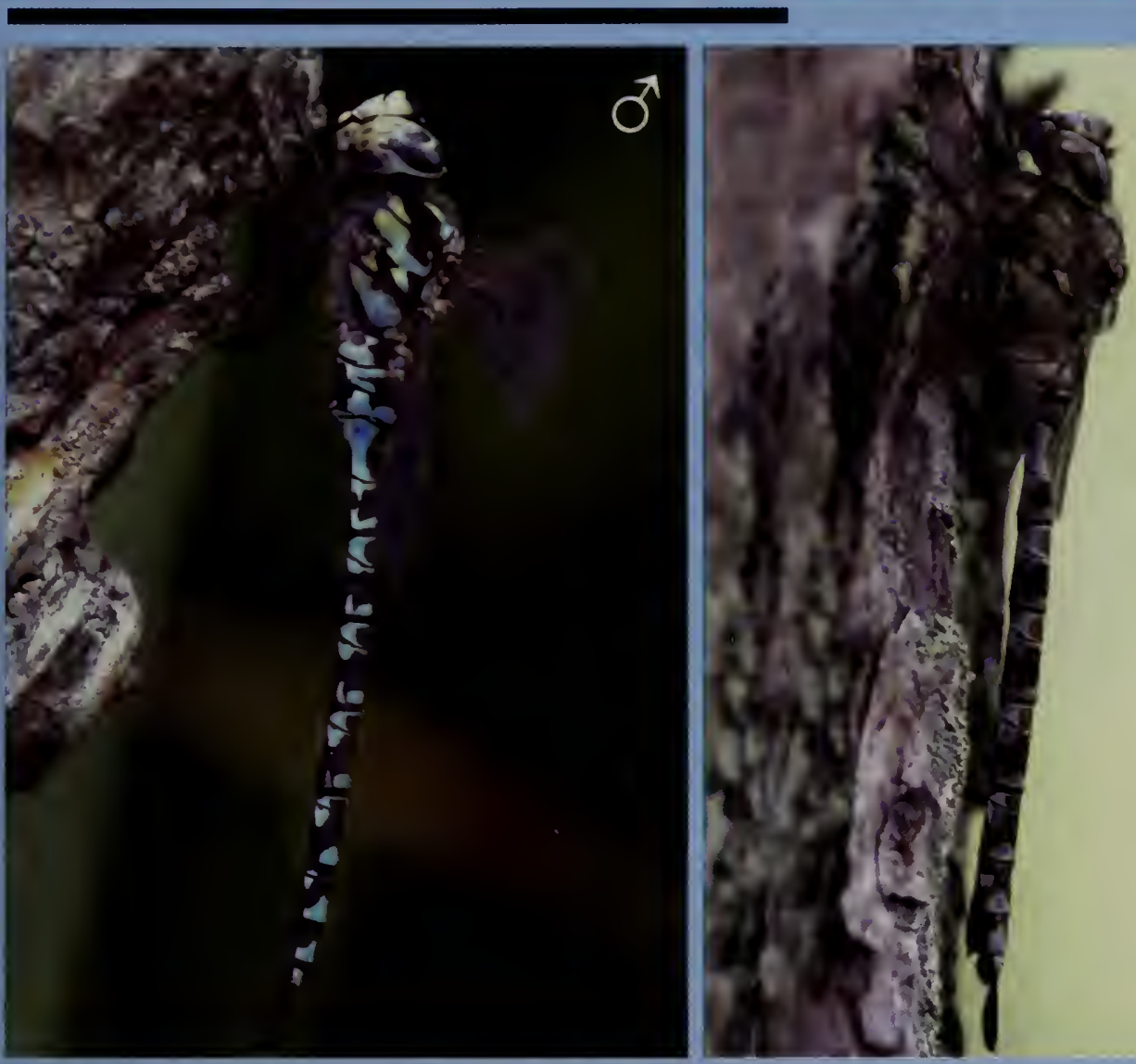

Male thorax brown with green to bluish dorsal stripes and mottled green to greenish-blue lateral pattern (sides of thorax more blue than brown); abdomen brown with blue to greenish markings on all segments. Eyes bluish-gray to greenish. Female similar to male but pale markings often more green. The only Aeshna with a mottled lateral thoracic pattern. Cyrano Darner (p. 73) similar but larger and huskier, with a protruding "forehead," blue eyes, and flies earlier in the season.

RANGE/STATUS Northeastern U.S.; southeastern Canada. Fairly common but rather local in MA.

HABITAT Marshes and bogs with open water, coastal plain ponds, small lakes, and bays of larger lakes.

NOTES Adults hunt in open forest and sunny clearings. They perch vertically on tree trunks. Males patrol near the shoreline over emergent vegetation, scouting and defending breeding sites from mid-morning to late afternoon. Females oviposit in emergent vegetation just below the waterline.

\begin{tabular}{|l|l|l|l|ll|l|l|l|}
\hline $\mathbb{A}$ & $\mathbb{M}$ & $\mathbb{1}$ & $\mathbb{J}$ & $\mathrm{A}$ & $\mathrm{S}$ & $\mathrm{O}$ & $\mathbb{N}$ & $\mathbb{D}$ \\
\hline
\end{tabular}



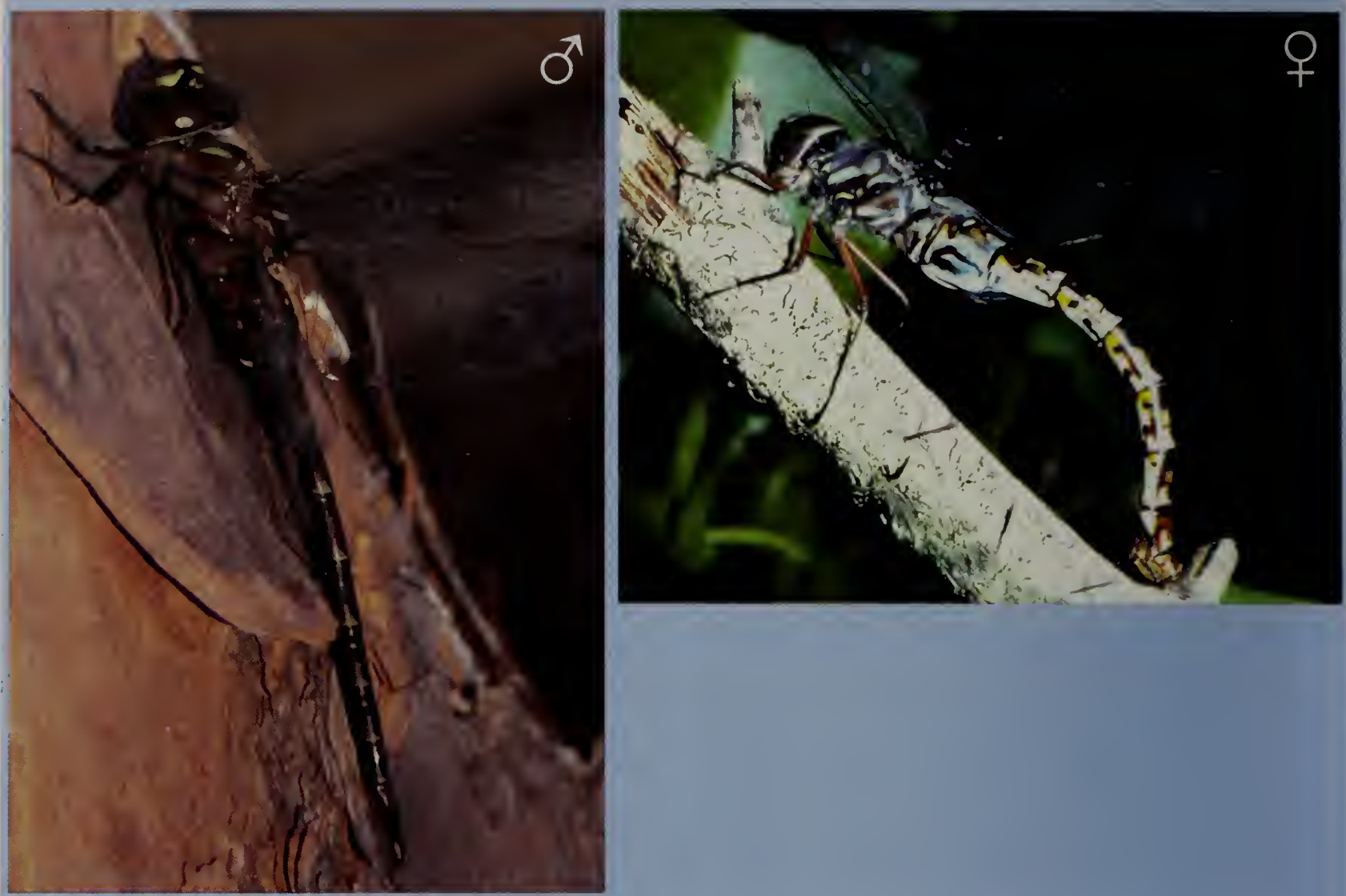

Male thorax brown with pale dorsal stripes and mottled pale lateral pattern; abdomen brown with complex pattern of dull greenish spots. Eyes dark gray (immature) to dull green. Female similar but more drab, occasionally with brownish tint on outer wings. Very similar to Harlequin Darner (p. 85) but drabber with dark abdominal markings paler and less extensive; hind wings wider; the two are safely separable only in the hand.

RANGE/STATUS Eastern U.S. Near the northern edge of its range and rare in MA. Recorded at just a few sites in eastern MA.

HABITAT Sphagnum bogs, swamps, and fens.

NOTES Adults hunt along forest edges and may form feeding swarms, especially males. They perch on tree trunks, hang vertically from branches, and occasionally perch on the ground. Females oviposit in wet wood above the waterline. Although not known to migrate, small numbers have been recorded among other migrating dragonflies in coastal MA. The flight season averages somewhat later than the similar Harlequin Darner.

\begin{tabular}{|l|l|l|l|l|l|l|l|l|}
\hline $\mathbb{A}$ & $\mathbb{M}$ & $\mathbb{J}$ & $\mathbb{D}$ & $\mathbb{A}$ & $\mathbb{S}$ & $\mathbb{O}$ & $\mathbb{N}$ & $\mathbb{D}$ \\
\hline
\end{tabular}




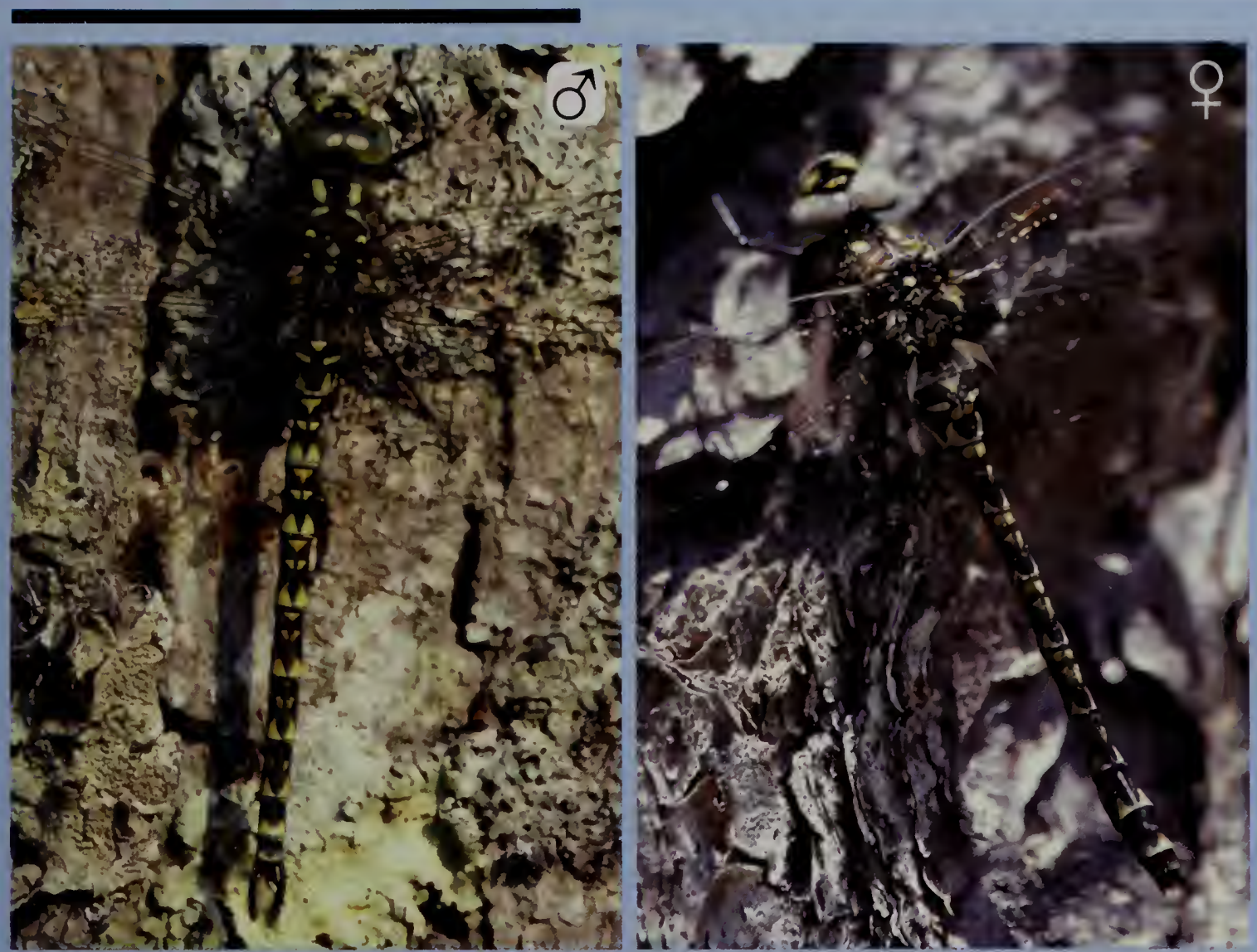

One of the smallest darners. Male thorax brown with green dorsal stripes and mottled, pale green lateral pattern; abdomen brown with complex pattern of dull greenish spots. Eyes dark gray (immature) to green. Female similar but stockier, with pale areas more yellowish and often with brownish tint on outer wings. Very similar to Taper-tailed Darner (p. 86), separable only in the hand.

RANGE/STATUS Eastern U.S.; southeastern Canada. Locally common in MA, especially inland.

HABITAT Sphagnum bogs, swamps, and fens.

NOTES Adults hunt along forest edges and may form feeding swarms, especially males. They fly long beats at varying heights, punctuated by rather lengthy periods of hovering. While hovering they often change directions, occasionally rotating 360 degrees. They perch on tree trunks, hang vertically from branches, and occasionally perch on the ground. Males patrol over wetlands, often hovering for long periods. Females oviposit in emergent vegetation or rotten wood, above the waterline.

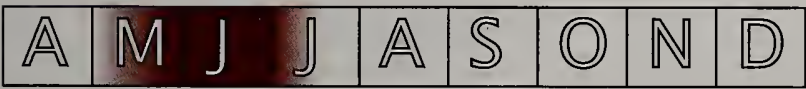



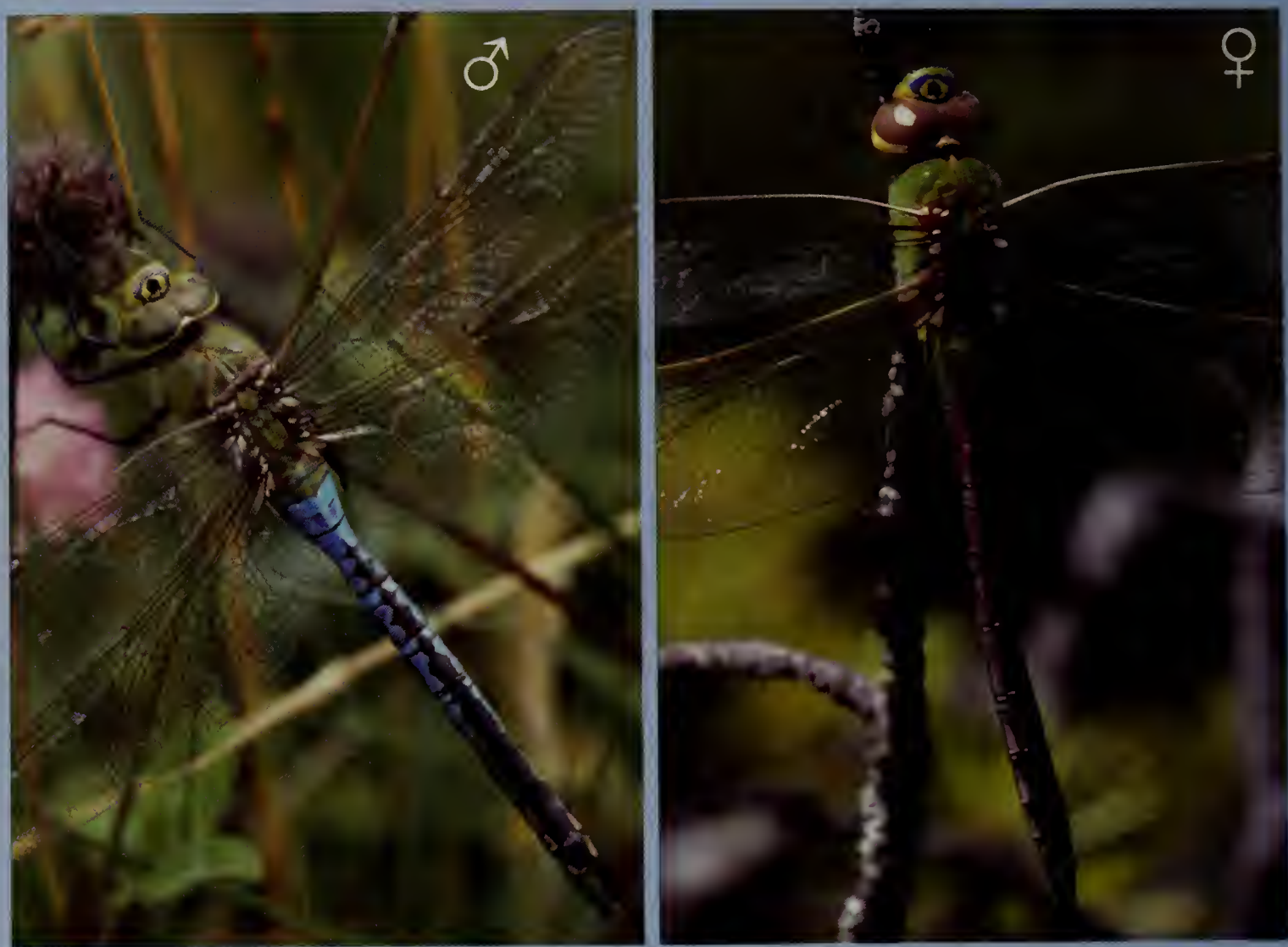

One of only two darners in the Northeast with an entirely green thorax. Male thorax bright green without distinct markings; abdomen blue (becoming purple when cool), brightest at base, with dark dorsal stripe that broadens distally. Eyes dull greenish-yellow to brown. "Bulls-eye" pattern on "forehead." Female thorax green, often grayish-green on sides; abdomen rusty brown to purple, with dark dorsal stripe. Eyes brown. Wings in both sexes have yellow leading edges and are often tinted with amber, especially in females. Immatures are quite reddish on the abdomen and can be confused with the Comet Darner (p. 87), but are smaller, duller, and have "bulls-eye" on "forehead."

RANGE/STATUS Widespread in the U.S. and southern Canada. Common throughout MA.

HABITAT A wide variety of wetlands, including well-vegetated ponds and lakes.

NOTES Adults fly from early morning until dusk, often joining late afternoon feeding swarms. One of three darner species that perch low in grasses and weeds. Males patrol shorelines, clashing with other males and searching for females. This is the only darner that often lays eggs in tandem; the female submerges her abdomen and oviposits in aquatic and emergent vegetation. Migrants from the south are some of the first dragonflies seen in the spring. Southbound swarms in early fall may have thousands of individuals.

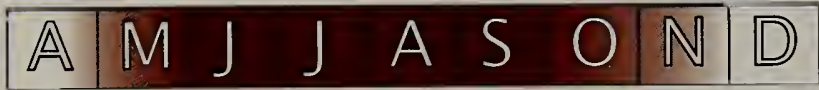



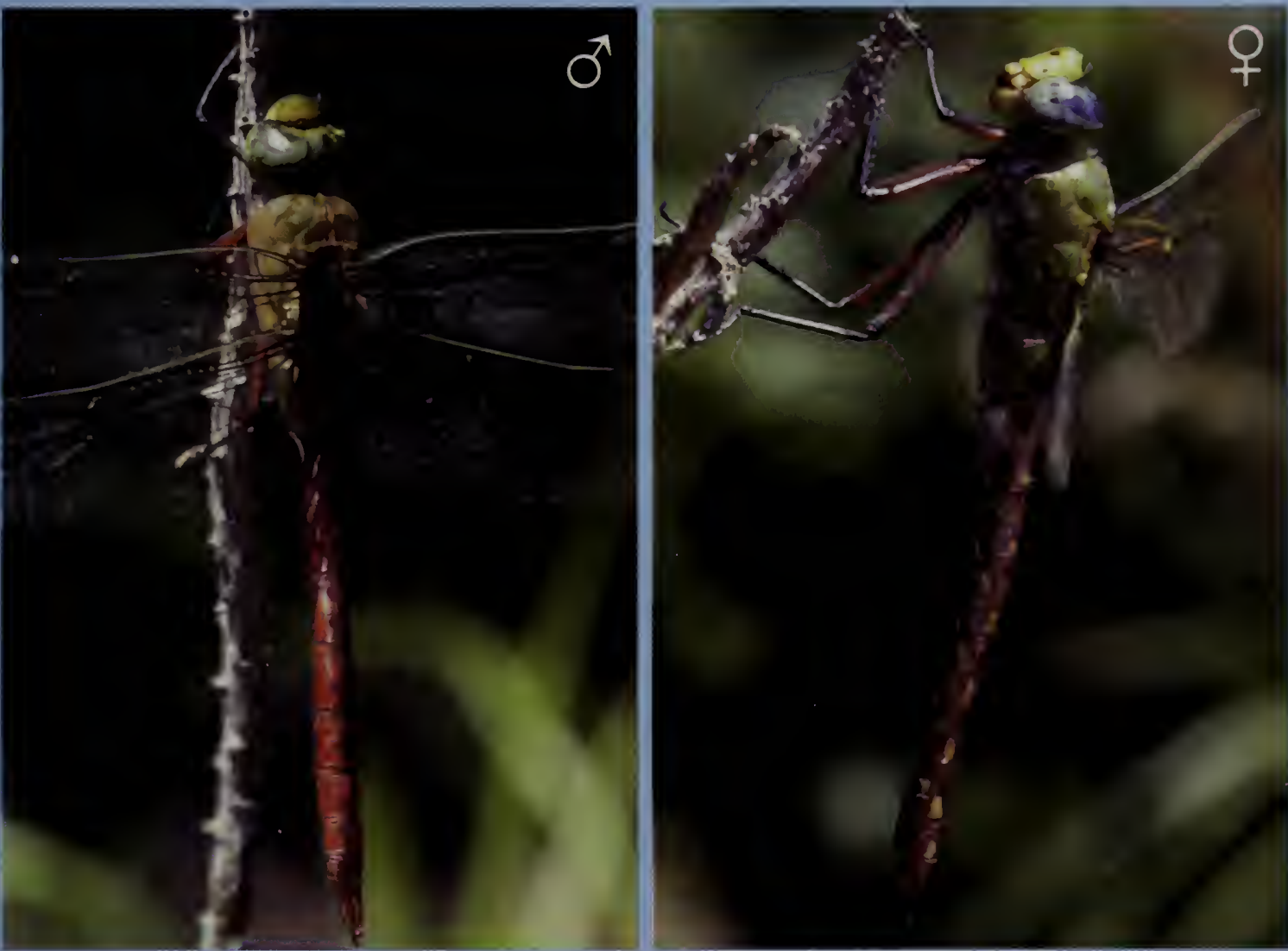

Male thorax bright green without obvious markings; abdomen bright red. Eyes dark greenish. Green "forehead" lacks "bulls-eye." Legs reddish at base. Leading edge of wings green. Female thorax entirely green; abdomen dull, rusty-red with paler dorsolateral markings; eyes blue. Bright red abdomen of male, blue eyes of female, and lack of "bullseye" on "forehead" in both sexes distinguish this species from immatures of Common Green Darner.

RANGE/STATUS An uncommon species found in the eastern U.S., scattered north along the Atlantic coast to southern New England, rarely to Nova Scotia. In MA most often seen on the coastal plain where it is uncommon.

HABITAT Grassy ponds and coastal plain ponds.

NOTES This is a very fast-flying, spectacular dragonfly that cruises along pond shores and over open water, usually at heights of 4-8 ft. It does not join feeding swarms. Males patrol lengthy beats along the shoreline, clashing with other dragonflies and searching for females. Females oviposit in emergent and aquatic vegetation.

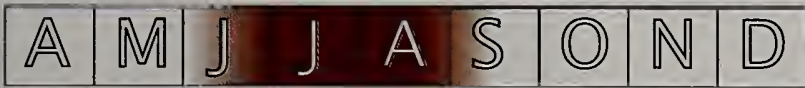



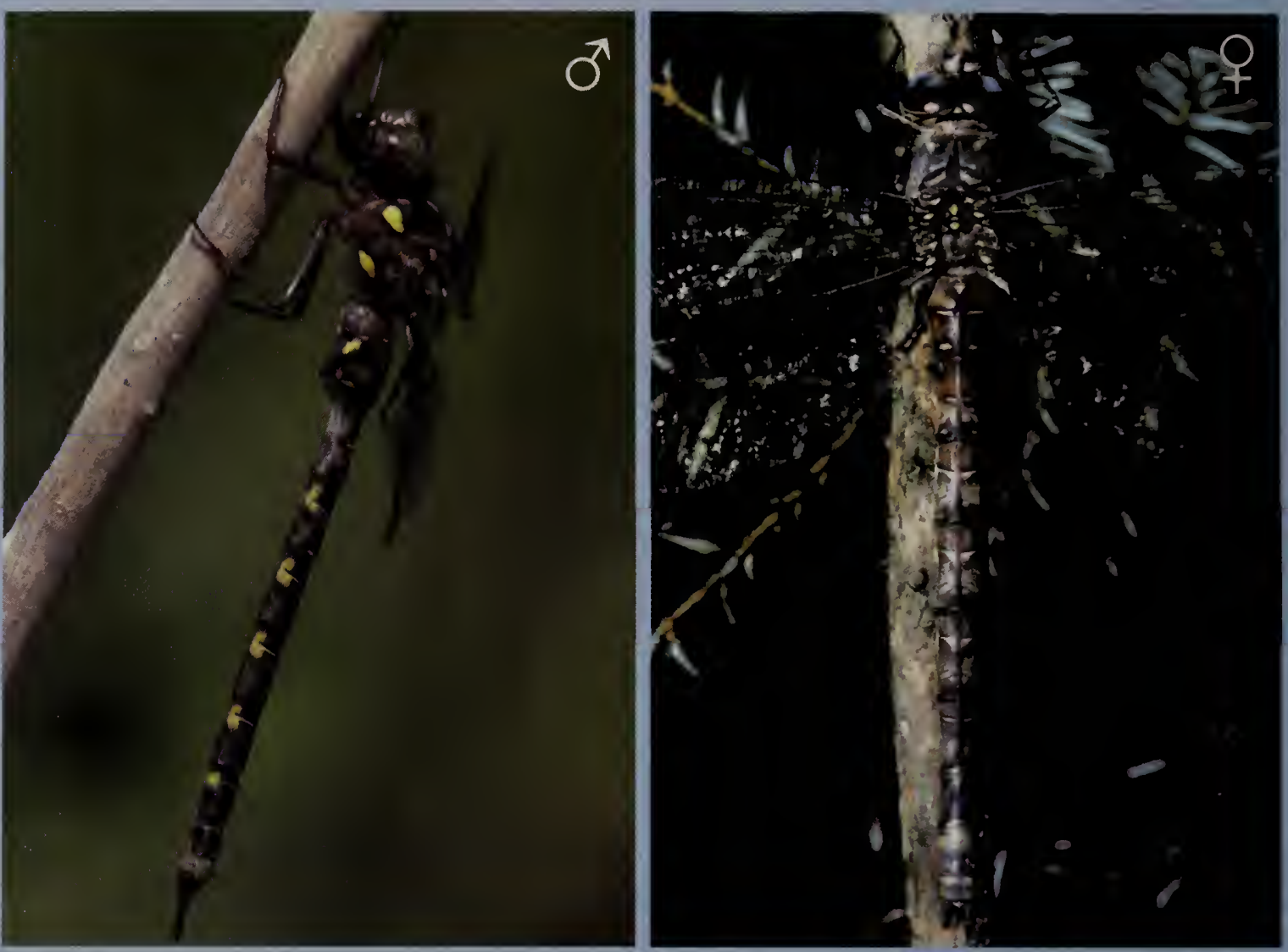

Male thorax dark grayish-brown with short, thin, greenish dorsal stripes and two round yellow lateral spots; abdomen brown with yellowish lateral spots on S4-S9. Eyes brown to dark green. Wing tips tinted brown. Female similar. Fawn Darner (p. 89) very similar but paler brown overall, with smaller abdominal spots and more brown at base of wings.

RANGE/STATUS Northeastern U.S.; southeastern Canada extending west to the Great Lakes. An uncommon species in MA, found in northwestern portions of the state.

HABITAT Swiftly-flowing, rocky forest streams and rivers; rocky-shored lakes.

NOTES This is a semi-crepuscular, shade-loving species that is not often seen in the open. Males patrol short beats low over streams, with zigzagging flights, investigating everything in their paths. They have been observed patrolling early in the morning. Adults rest in trees, particularly conifers. Females oviposit in wet wood and aquatic vegetation.

\begin{tabular}{|l|l|l|l|l|l|l|l|l|}
\hline $\mathbb{A}$ & $\mathbb{M}$ & $\mathbb{J}$ & $\mathcal{J}$ & $A$ & $S$ & $O$ & $\mathbb{N}$ & $\mathbb{D}$ \\
\hline
\end{tabular}



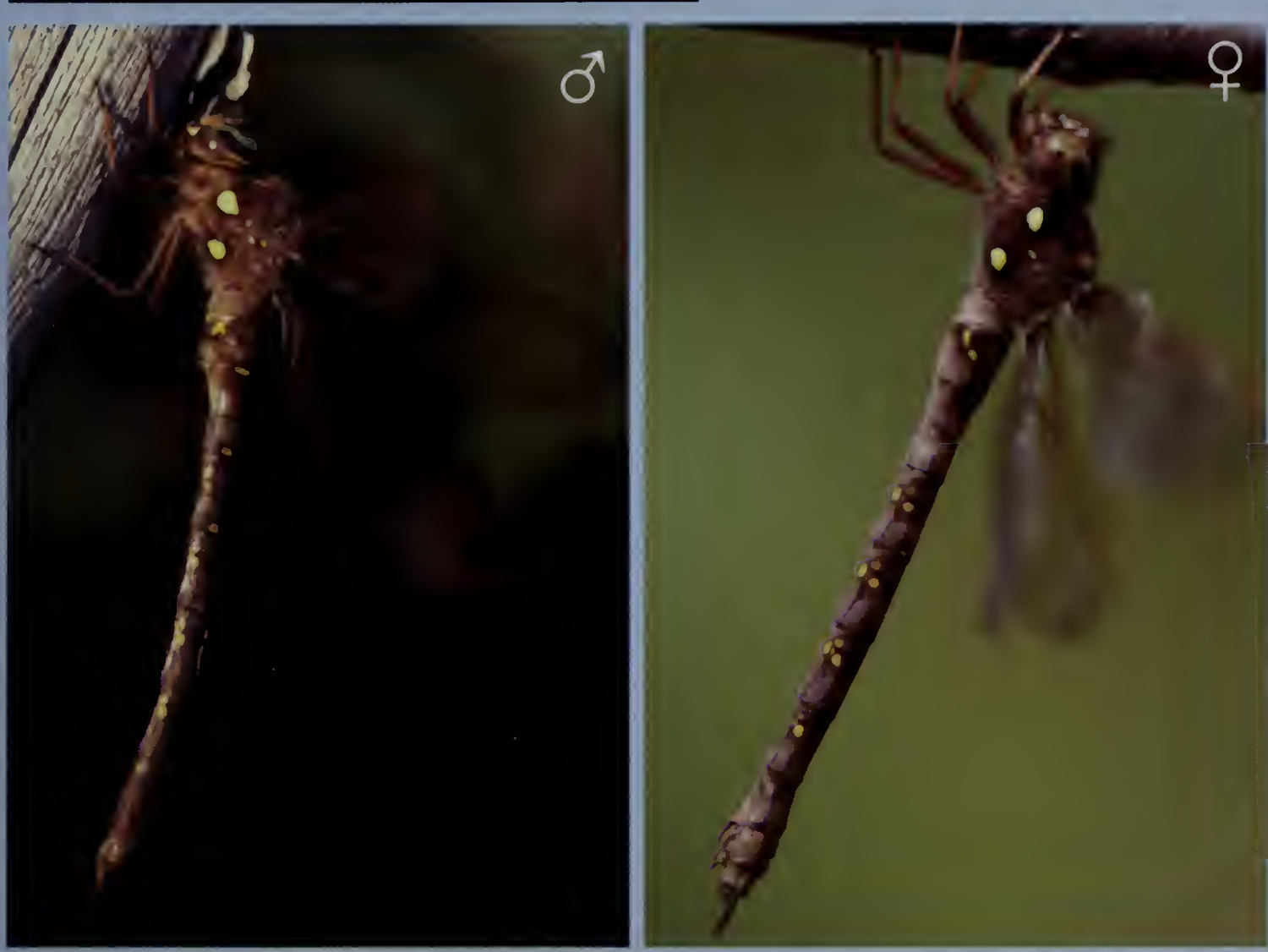

Male thorax brown with short, thin, yellowish (often indistinct) dorsal stripes and two round yellow lateral spots; abdomen brown with yellow lateral spots on S4-S8 (occasionally 59). Eyes brown to dark green. Wings often tinted brown. Female similar. Ocellated Darner (p. 88) very similar, but more gray overall, abdominal spots larger, dorsal thoracic stripes brighter, and dark basal wing spots smaller or lacking.

RANGE/STATUS Eastern U.S.; southeastern Canada. A common species that is found throughout MA.

HABITAT Moderately-flowing shaded, forest streams and rivers; occasionally lakes. NOTES This is a semi-crepuscular, shade-loving species that is not often seen in the open. Males patrol short beats low over streams, with zigzagging flights. Like the Ocellated Darner (B. grafiana), they investigate everything in their paths. Adults rest in trees, particularly conifers. Females oviposit in wet wood near the waterline and in aquatic and emergent vegetation.

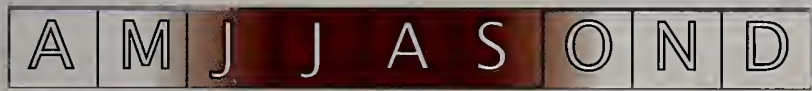




\section{GOMPHIDAE: CLUBTAILS}

Clubtails are an extremely diverse and variable group of dragonflies. There are over 1,000 described species worldwide. Nearly 100 species occur in North America and 27, comprising nine genera, occur in Massachusetts.

Clubtails range in size from some of the smallest odonates, little more than an inch in length, to some of the largest, measuring a robust three inches or more. They are named for a club-like expansion near the tip of the abdomen, though this feature is highly variable and essentially absent in some species. Unlike other dragonflies (with the exception of the Gray Petaltail, p. 68), the eyes of clubtails are widely separated on the head. Most clubtails are marked with shades of yellow, green, brown, and black; red and blue coloration is essentially absent. Most species have

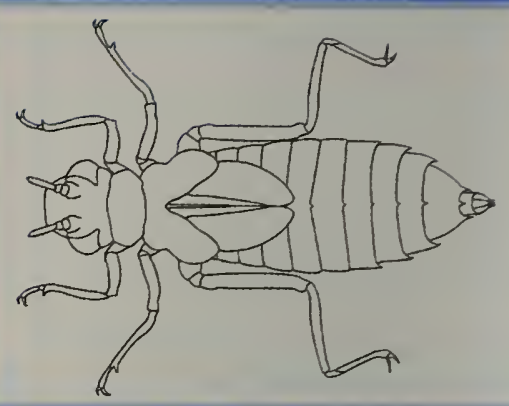

Clubtail larvae are robust, with a wedge shaped head and thick 4-segmented antennae. They are burrowers, hiding just under sediment, and are dark in color, ranging from a deep golden brown to green.

clear wings. Females are similar in coloration to the males, differing primarily in their stockier abdomens and shorter and more divergent terminal appendages. Sexually immature individuals of both sexes are often more brightly colored than older individuals. Identification of gomphid species is often difficult, although some species can be identified by sight in the field. While it's often possible to place an individual into a genus or sub-genus based upon features such as size, color and pattern of the thorax and abdomen, size of the "club," and eye color, specific identification in most cases requires in-hand examination of male terminal appendages (p. 91-92) and/or male hamules, or female vulvar lamina (refer to Needham et al., 2000).

Most clubtails are lotic (riverine) species, though a few species inhabit ponds and lakes. Some are widely distributed across Massachusetts, while others have precise habitat requirements and are rare and local in distribution, such as those found only along the Connecticut River. The majority of clubtails fly during June, but a few fly in mid-summer and the hanging clubtails (Stylurus spp.) are most abundant in August and early September. Most species have rather short flight seasons, averaging just a month to six weeks, rarely exceeding two months. Clubtails spend most of their time perched. They fly rather infrequently, though the males of a few species may make lengthy patrols at breeding sites. Most species perch horizontally on the ground or on rocks or logs. The hanging clubtails perch high in trees on the surfaces of leaves. Immature adults can often be found in fields, power line cuts, along dirt roads, or on hilltops, where they spend their time feeding prior to reaching breeding condition.

Females oviposit alone while in flight, tapping the tips of their abdomens to the water's surface to release the eggs. Larvae are robust, and either burrow into the substrate (many Gomphus) or kick up sand and silt to cover themselves (Ophiogomphus spp.). One striking exception is the larva of the Dragonhunter (Hagenius brevistylus), which is flattened and discoidal in shape and can be found lurking under loose bark on submerged trees or other debris. Emergence takes place close to the water, often on sandbars, bridge abutments, or tree trunks. Exuviae may be found in numbers just after emergence. 
Identification of the clubtails is complex and best begun by placing an individual into one of the nine Massachusetts genera based on visual characteristics such as overall size, color and pattern on the body, size of the "club" (swelling of terminal segments) and eye color. Identification of species in the genera Hagenius, Dromogomphus, Lanthus, Progomphus, Stylogomphus, and Stylurus can usually be made without examination of the terminal appendages, and these species are not illustrated here. However, the remaining three genera are more difficult and often require examination of the male terminal appendages for positive identification.

The diagrams below show a dorsal view (i.e., looking down from the top) of male abdominal segment 10 (S10) and the terminal appendages. Lateral (side) views are presented where useful or necessary for diagnosis. In these diagrams, the superior appendages (SA) are medium gray; inferior appendages (IA) are dark gray.

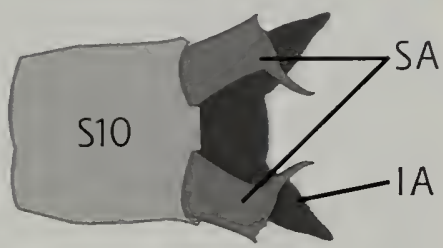
For identification of females, refer to technical manuals (e.g., Needham, et. al., 2000).

Pond clubtails (Arigomphus): Grayish-green thorax with poorly defined dark stripes, poorly developed club, large head, and yellow terminal appendages. Inhabit ponds and stagnant river backwaters.

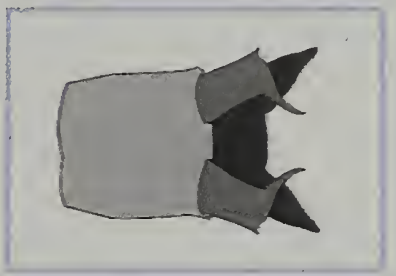

Lilypad Clubtail (A. furcifer), p. 110

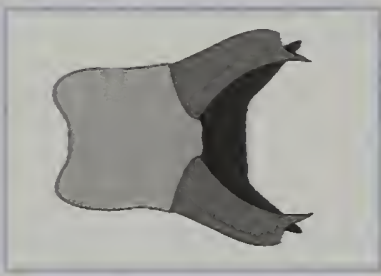

Unicorn Clubtail (A. villosipes), p. 111

Snaketails (Ophiogomphus): The snaketails are readily recognized by their bright green thorax (but beware of the female Eastern Pond Hawk, p. 155). They are small to medium-sized and rather stocky, with short legs and only moderately developed clubs. The abdomen is typically marked with prominent yellow dorsal spots, the shape of which can be useful in identification. Most inhabit swiftly flowing streams.

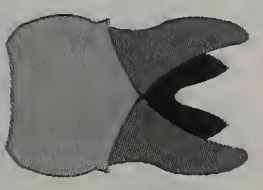

Rusty Snaketail

(O. rupinsulensis), p. 119

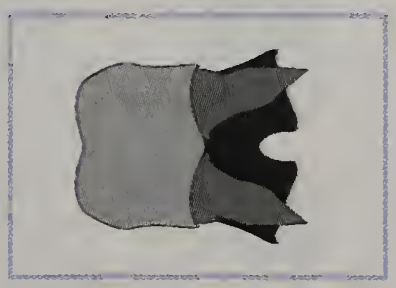

Riffle Snaketail

(O. carolus), p. 117

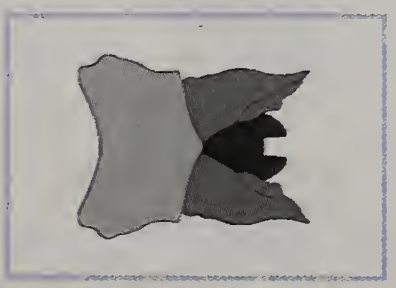

Brook Snaketail

(O. aspersus), p. 116

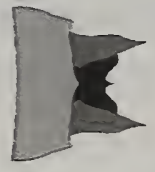

Pygmy Snaketai! (O. howei), p. 115

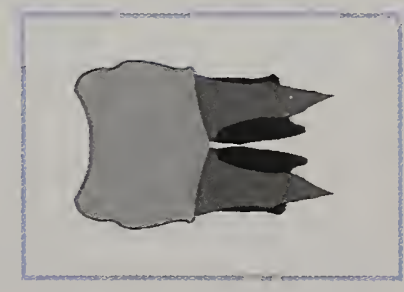

Maine Snaketail (O. mainensis), p. 118 
Common clubtails in the genus Gomphus can be divided into the following 3 subgenera that are useful for identification. All species have pale dorsal thoracic markings that, when viewed from the front, look like two inverted 7s facing each other.

The six Gomphus in the Phanogomphussubgenus are medium-sized and rather slender with small to moderate-sized clubs. They all have yellow on the sides of the club (S8 and S9) and yellow dorsal markings on the abdomen that are helpful in distinguishing species.

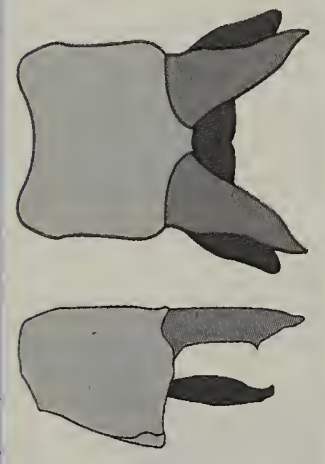

Rapids Clubtail

(G. quadricolor), p. 99

The two Gomphus in the Hylogomphussubgenus are small and stocky with black legs, mostly black abdomens, and poorly developed clubs. They are most easily distinguished by face pattern and the extent of yellow on the sides of the club ( 58 and 59 ).

The three Gomphurus are characterized by their large overall size, broad club, large thorax, and small head. Face pattern and relative amount of yellow color on the sides of the club ( 58 and 59) can be useful in identification.

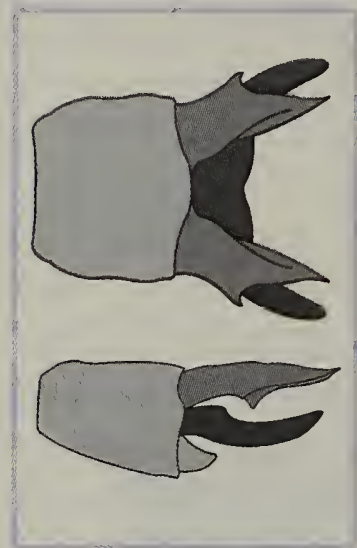

Dusky Clubtail

(G. spicatus), p. 96

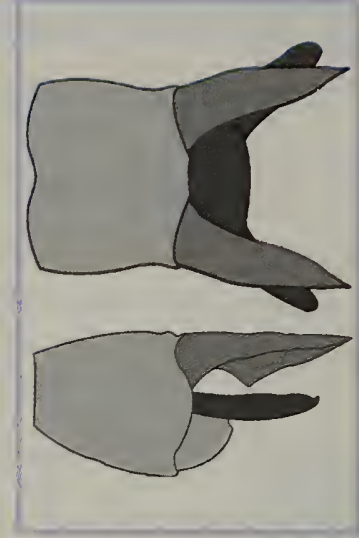

Lancet Clubtail

(G. exilis), p. 94

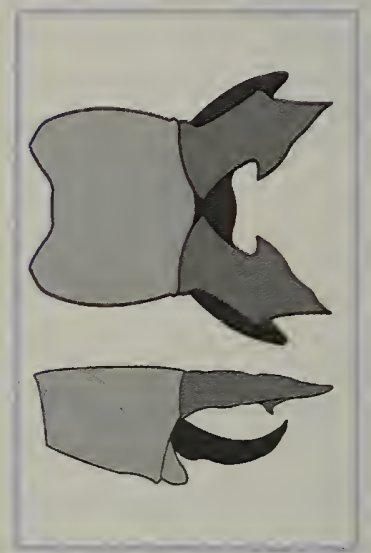

Harpoon Clubtail

(G. descriptus), p. 98

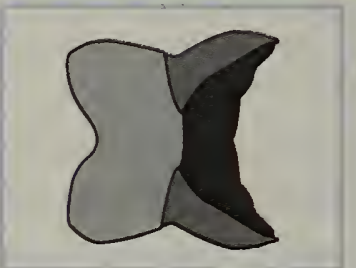

Spine-crowned Clubtail (G. abbreviatus), p. 100

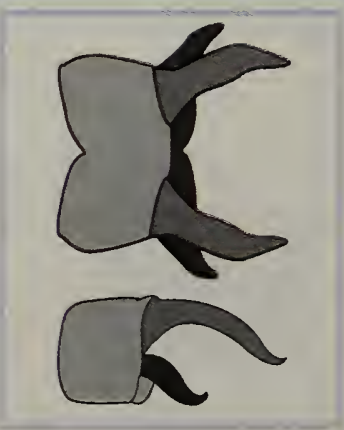

Midland Clubtail

(G. fraternus), p. 105

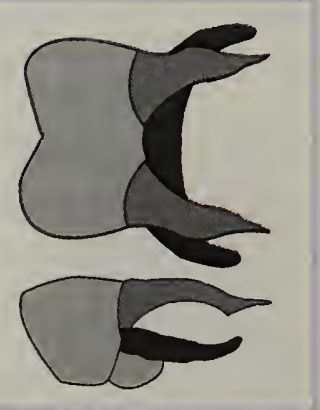

Cobra Clubtail

(G. vastus), p. 103

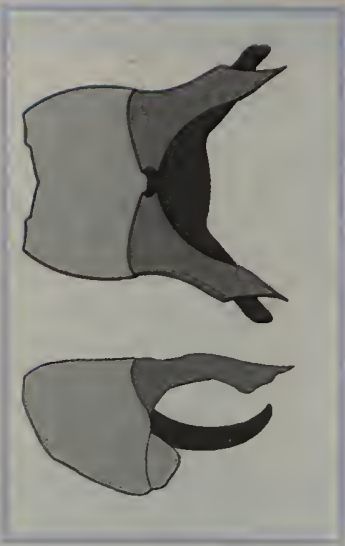

Ashy Clubtail

(G. lividus), p. 95

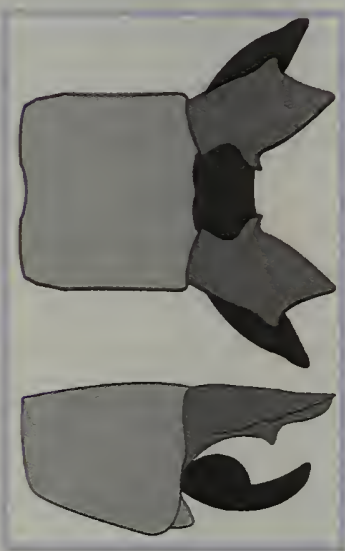

Beaverpond Clubtail (G. borealis), p. 97

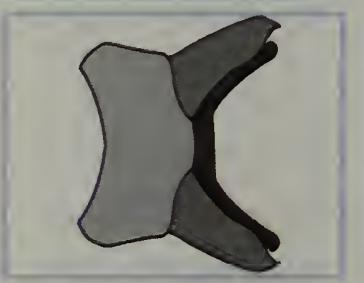

Mustached Clubtail (G. adelphus), p. 101

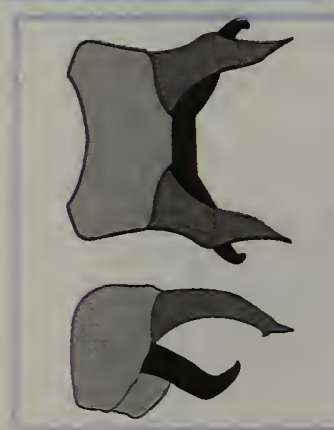

Skillet Clubtail

(G. ventricosus), p. 104 
The largest of the clubtails, with a poorly developed club and relatively small head. Male thorax black, boldly patterned with thin yellow dorsal stripes, a yellow collar, and two thick yellow lateral stripes; abdomen black with almost no club, 51-58 (occasionally S9) with yellow dorsal stripes, S8S9 with large, irregular, yellow lateral spots; terminal appendages short and stocky. Eyes green. Legs black. Female similar but more extensively yellow on sides of abdomen. Combination of very large size, poorly developed club, and thoracic pattern distinguish this species from all other clubtails.
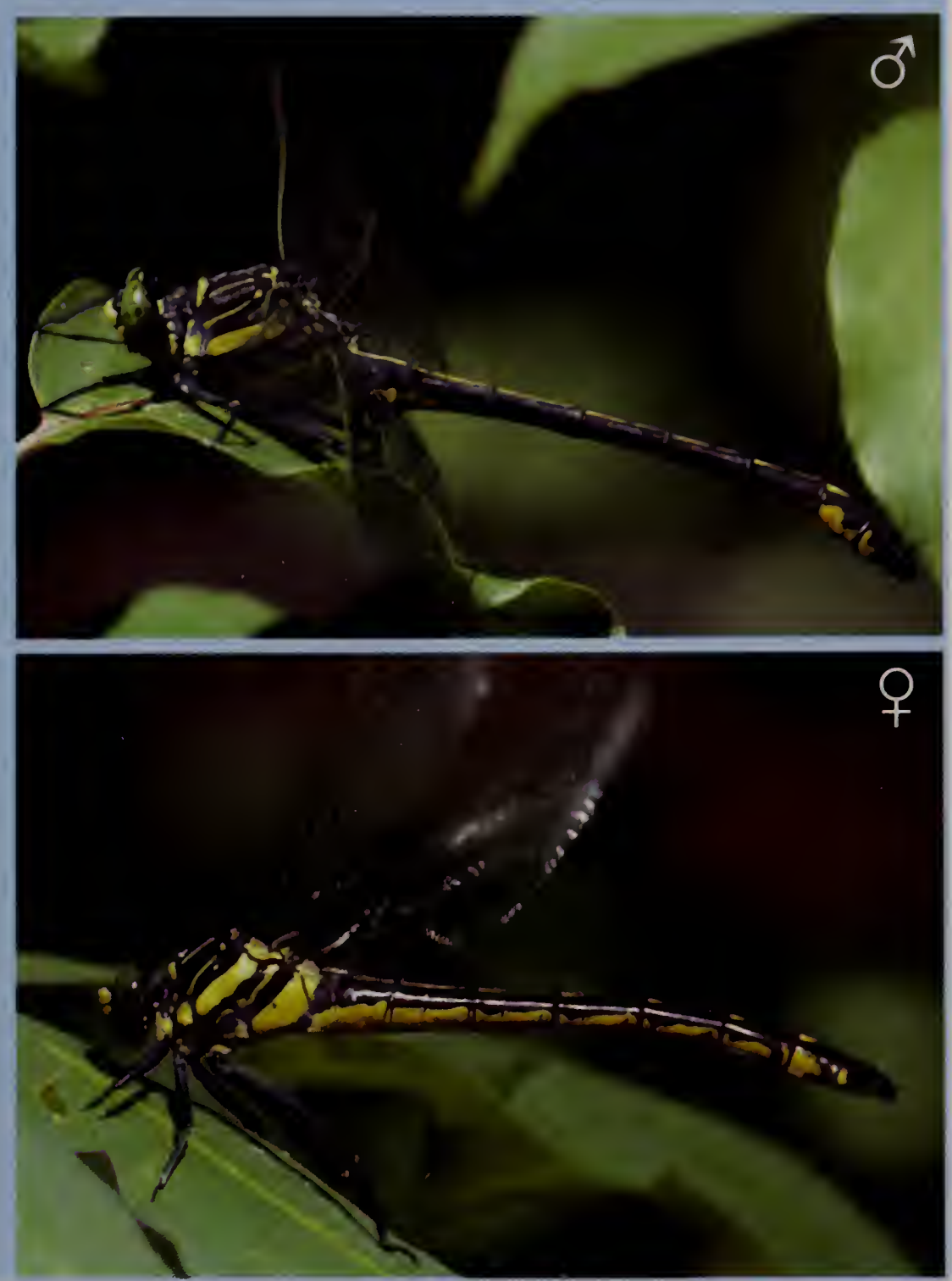

RANGE/STATUS Central to eastern U.S.; southeastern Canada. Fairly common throughout interior MA but not found on the southeast coastal plain.

HABITAT Slow to moderately-flowing, forested rivers and streams; occasionally bays and channels of lakes.

NOTES This impressive dragonfly is the largest clubtail in North America. Its primary prey is other dragonflies. Away from water adults hunt along forest edges, slowly flying a few feet above the ground and perching on rocks and vegetation. At the water males fly long patrols a few feet over the water with the abdomen curved downward, and perch on vegetation or rocks along the water's edge. Females oviposit by hovering near the shore and splashing down, or by flying long patrols punctuated by dropping down and tapping their abdomen on the water, washing eggs off of the tip of the abdomen.

\begin{tabular}{l|l|lll|l|l|l|l|}
\hline $\mathbb{A}$ & $\mathbb{M}$ & $J$ & $J$ & $A$ & $S$ & $\mathbb{O}$ & $\mathbb{N}$ & $\mathbb{D}$ \\
\hline
\end{tabular}


One of the Phanogomphus clubtails with a poorly developed club. Male thorax brown with yellow dorsal stripes and two yellow lateral stripes; abdomen slender with almost no club, dark brown with yellow dorsal streaks and lateral spots on all segments (though 59 occasionally all dark above), 58-59 extensively yellow on lower sides; terminal appendages dark. Eyes gray-blue. Legs brown, paler basally. Female abdomen thicker with no club and more extensively yellow on sides. Very similar to other species in the Phanogomphus group (pp. 9499); this is the only species in the group that typically has pale dorsal markings on all abdominal segments (though this is somwhat variable). Safely identified only through examination of reproductive structures.
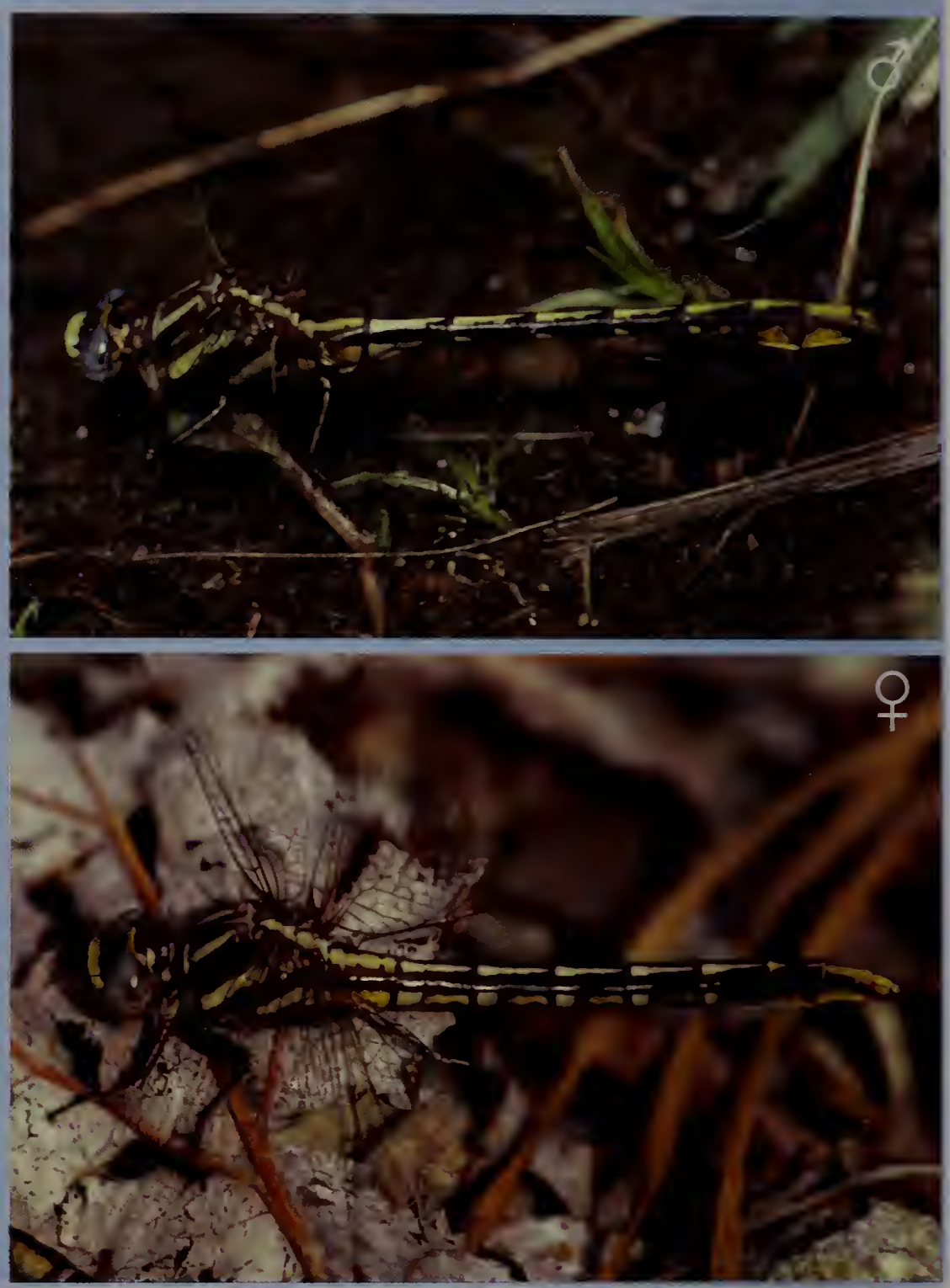

RANGE/STATUS Eastern U.S.; southeastern Canada. Common throughout MA; one of the most widespread clubtails in the state.

HABITAT Slow streams and rivers, marshy river backwaters, and a variety of ponds. NOTES Away from water, adults hunt along open roads and in fields, often perching on the ground or rocks. Males perch on rocks, leaves or the ground at the shore making brief patrolling flights low over water. When flushed they often fly off in a roller-coaster pattern of dips and climbs (a habit shared by some other species in the Phanogomphus group). Females oviposit by flying low and tapping their abdomens on the water.

\section{\begin{tabular}{|l|l|l|l|l|l|l|l|}
\hline $\mathbb{A}$ & $\mathbf{M}$ & $\mathcal{A}$ & $\mathbb{S}$ & $\mathbb{O}$ & $\mathbb{N}$ & $\mathbb{D}$
\end{tabular}}


One of the Phanogomphus clubtails with a poorly developed club, and one of the dullest of the group. Male thorax dark brown with yellow to gray-green dorsal stripes and two dull yellow to gray-green lateral stripes; abdomen slender with almost no club, dark brown with yellow dorsal stripes on $51-58$, stripes becoming progressively shorter posteriorly, S9 varies from dull yellow to brown dorsally, 510 usually dark above, S8-59 streaked with yellow on lower edge; terminal appendages dark. Eyes dull gray-blue. Legs pale brown basally. Female similar. Very similar to other species in the Phanogomphus group (pp. 9499), especially the Dusky Clubtail (p. 96).
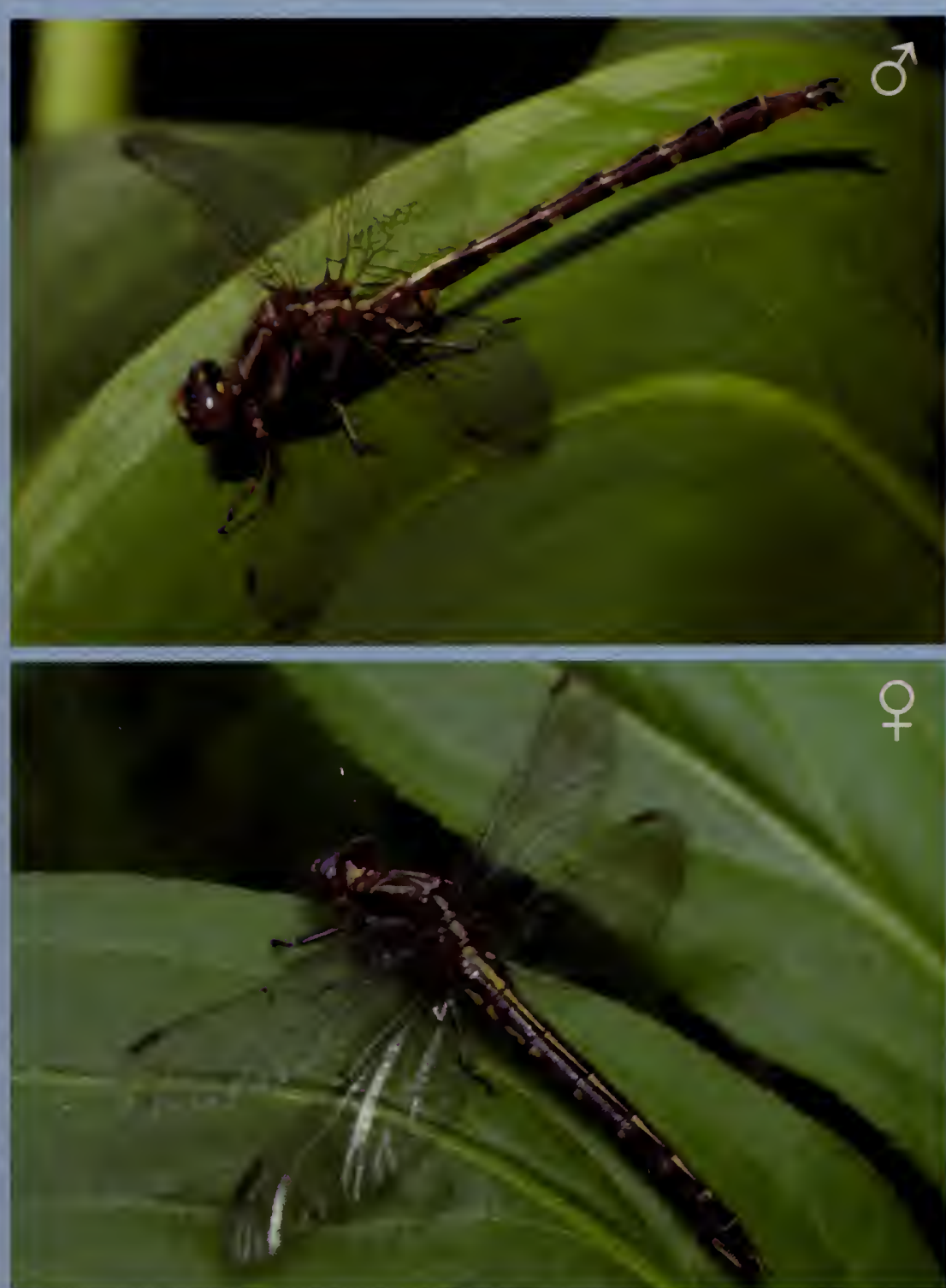

RANGE/STATUS Eastern U.S.; southeastern Canada. Fairly common in interior MA.

HABITAT Slowly-flowing, small streams to swiftly-flowing, large rivers, with sandy substrate and emergent vegetation.

NOTES Adults hunt near ground level in forest clearings and fields. They fly along the water's edge, occasionally gliding, and perch on leaves. When flushed, males often fly off with an undulating, roller-coaster like flight. Females oviposit in flight by tapping their abdomens on the surface of the water.

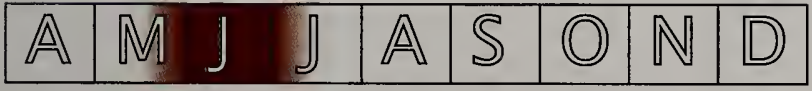


One of the drabbest of the Phanogomphus clubtails. Male thorax dark brown with yellow to gray-green dorsal stripes and two yellow to gray-green lateral stripes; abdomen slender with almost no club, black with yellow dorsal streaks on S1-58, the streaks becoming progressively shorter posteriorly, $\quad 59-510$ usually all dark above, S8S9 with yellow patch on lower sides; terminal appendages dark. Eyes dull gray-blue. Legs pale on tarsus. Female much more extensively yellow on sides of abdomen. Very similar to other species in the Phanogomphus group (pp. 94-99), especially the Ashy Clubtail (p. 95), and safely identified only in the hand.

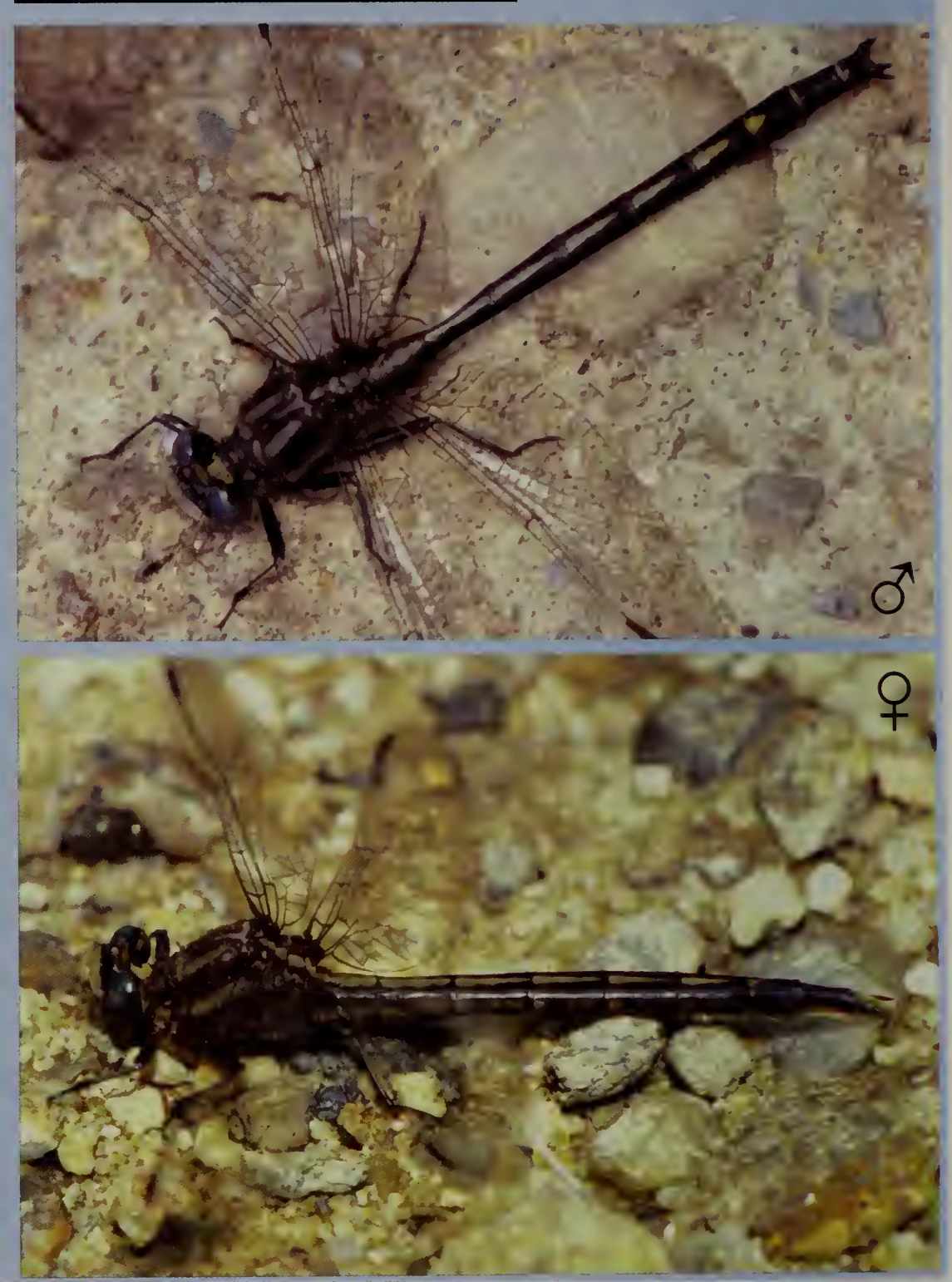

RANGE/STATUS Northeastern U.S.; southeastern Canada. Common in central and western MA.

HABITAT Still water. Bog-and marsh-bordered ponds and slow streams.

NOTES Adults fly low, near the ground. Like other species in the subgenus Phanogomphus, they sometimes fly in an up-and-down, roller-coaster pattern. They perch on the ground, low vegetation, and rocks. Females oviposit by flying low over the water and tapping the surface with the tips of their abdomens.

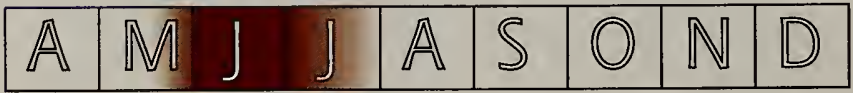


The most distinctly marked of the Phanogomphus clubtails. Male thorax blackish with very broad, yellow to gray-green dorsal stripes forming a broken " $U$ ", extensively yellow to gray-green sides; abdomen slender with slight club, black with yellow dorsal stripes on S1-S7, stripes becoming progressively shorter posteriorly, 58 either all black above or with small yellow dorsal spot, S9-510 black above, narrow yellow streaks along lower edges of club (58-59); terminal appendages dark. Eyes gray-blue to green. Legs black. Female more extensively yellow on top and sides of abdomen, wings occasionally tinged with amber. Very similar to other species in the Phanogomphus group (pp. 94-99), but pale thoracic markings more extensive.

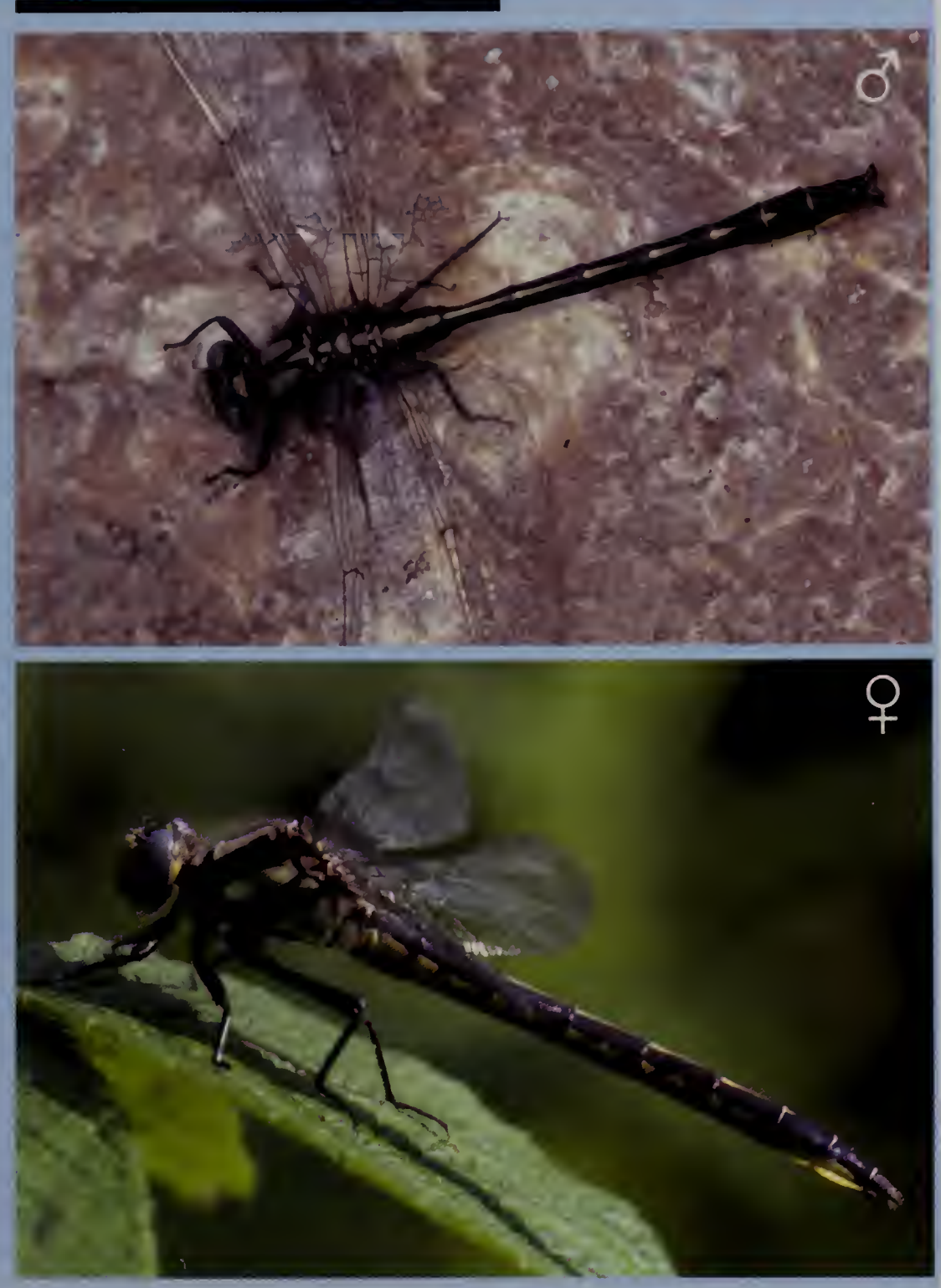

RANGE/STATUS Northeastern U.S.; southeastern Canada. This species is uncommon in MA, found only in the north-central and western parts of the state.

HABITAT A variety of northern (boreal) wetlands including beaver ponds, slow streams, bogs, and fens.

NOTES Males perch along the shore, making periodic patrols low over the water. Adults hunt in upland meadows, and perch on rocks and grasses. Populations of this species may have increased recently in response to expanding habitat created by a burgeoning beaver population in MA.

\begin{tabular}{|l|l|l|l|l|l|l|l|}
\hline $\mathbb{A}$ & $\mathbb{M} J$ & $J$ & $\mathbb{A}$ & $\mathbb{S}$ & $\mathbb{O}$ & $\mathbb{N}$ & $\mathbb{D}$ \\
\hline
\end{tabular}


One of the Phanogomphus clubtails with a poorly developed club. Male thorax dark brown with thick, yellow to gray-green dorsal stripes forming a broken "U", broad yellow to gray-green lateral stripes and patches; abdomen slender with almost no club, black with thin yellow dorsal streaks on S1-S7, streaks becoming progressively shorter posteriorly, S8S10 all dark above with yellow on lower edges; terminal appendages dark. Eyes dull green. Legs black (except female hind leg streaked with green). Female more extensively yellow on top and sides of abdomen. Wings occasionally tinged with brown in both sexes. Very similar to other species in the Phanogomphus group (pp. 9499), especially the Beaverpond Clubtail (p. 97).

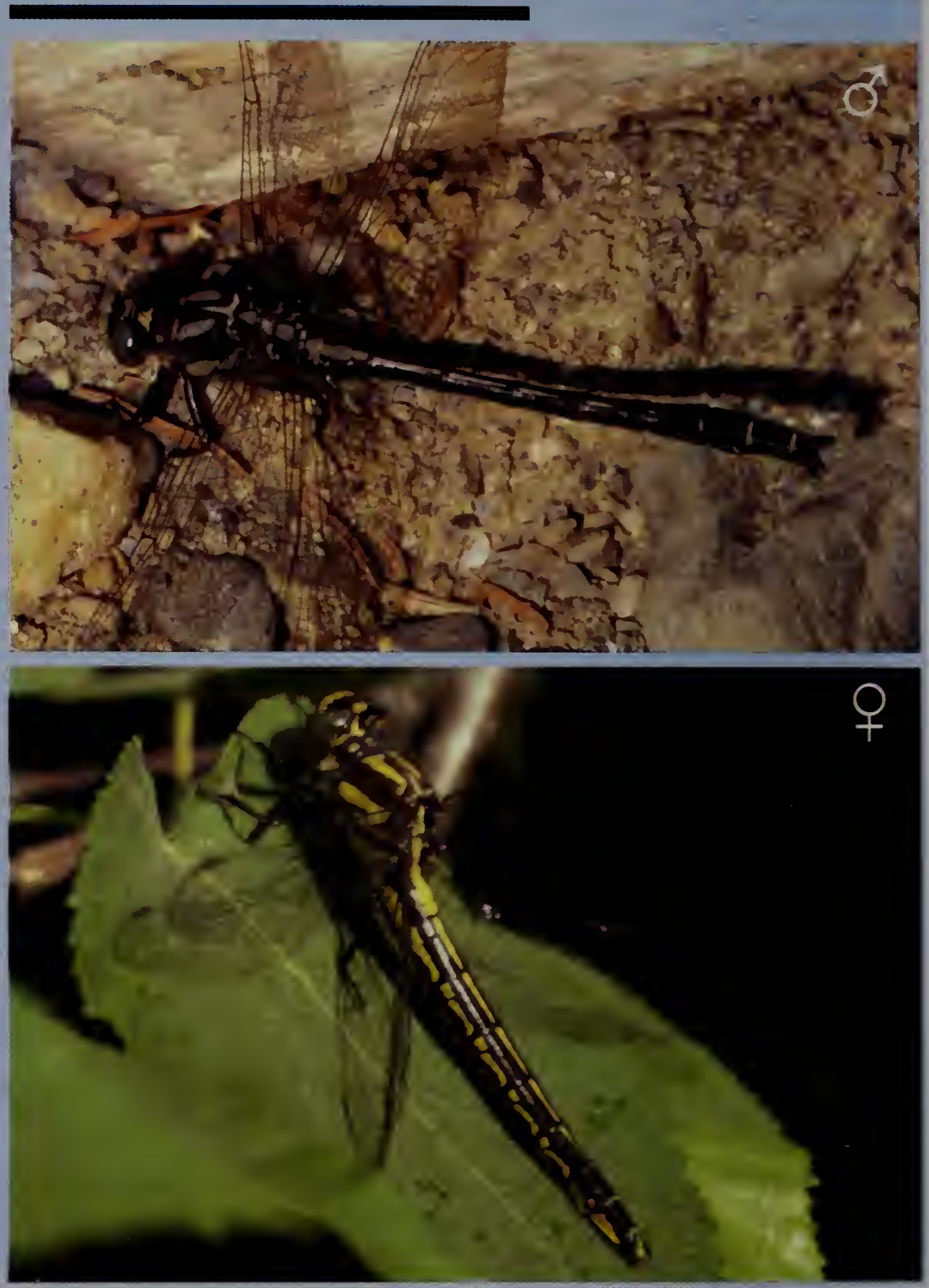

RANGE/STATUS Northeastern U.S.; southeastern Canada. Rare in MA, recorded only in the western part of the state.

HABITAT Swift, rocky or sand-bottomed streams and rivers.

NOTES Adults hunt along forest edges and in fields, perching on leaves or on the ground. Males fly low over the water, especially over riffles, and perch on rocks or overhanging leaves.

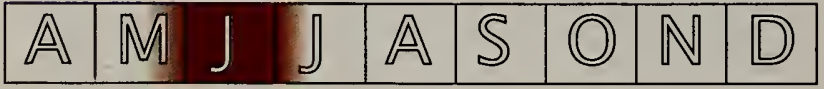


One of the smallest and most brightly marked of the Phanogomphus clubtails. Male thorax blackish with yellow to gray-green dorsal stripes, yellow to gray-green lateral stripes; abdomen slender with narrow club, black with thin yellow dorsal streaks on 51-57, streaks becoming progressively shorter posteriorly, S8-S10 dark above (rarely with small yellow spot on 58 or \$10), 58-59 with yellow patches on lower sides; terminal appendages dark. Eyes blue-green. Legs black. Female has more yellow spotting on abdomen. Very similar to other species in the Phanogomphus group (pp. 94-99), but male can be distinguished by more prominent club, less yellow on top of abdomen, and entirely black legs.

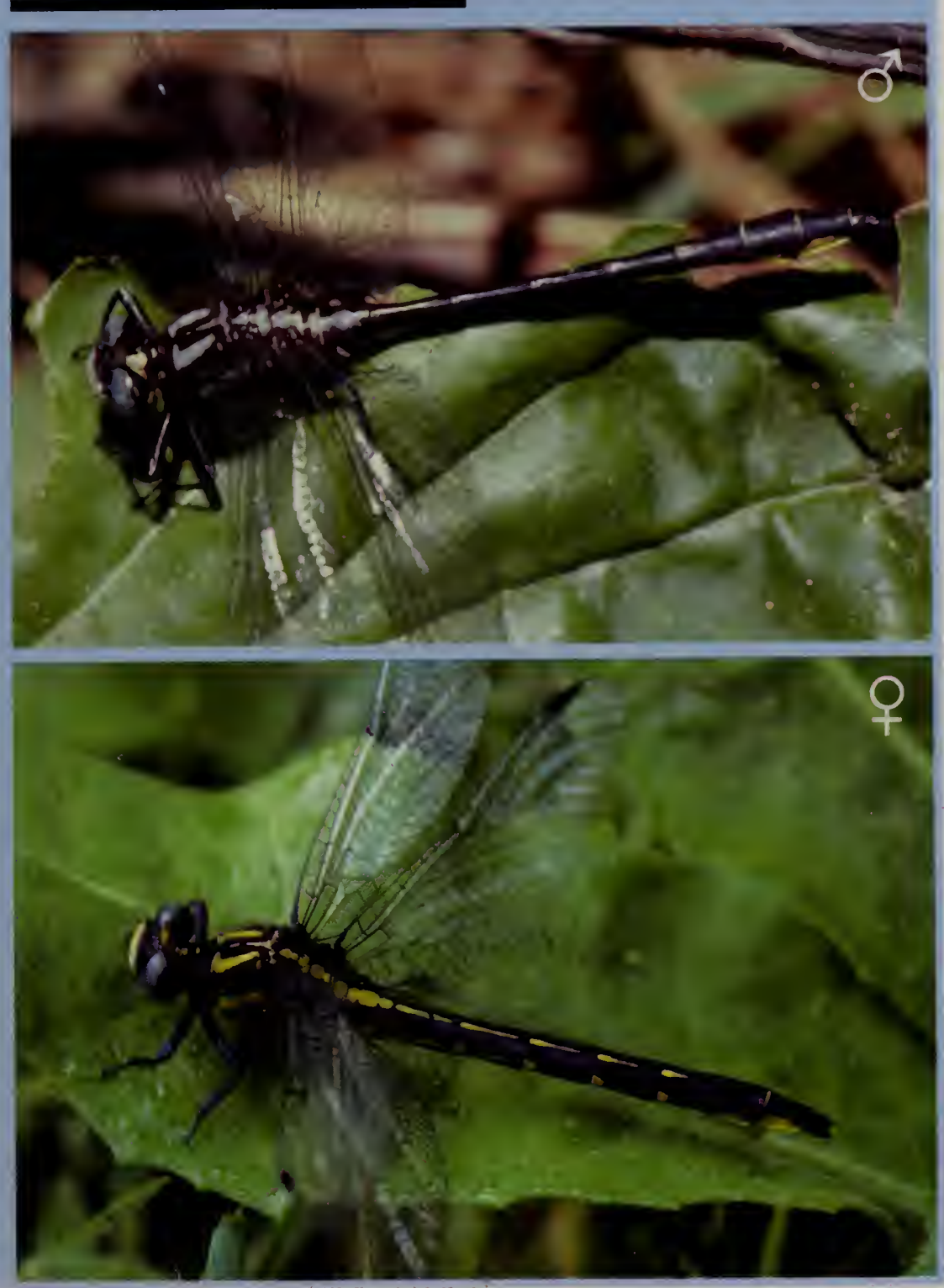

RANGE/STATUS Eastern U.S., extending into Canadian Great Lakes region. Recorded only a few times in central MA.

HABITAT Large streams and rivers with rapids and riffles; occasionally mud-bottomed rivers.

NOTES Adults fly along the river's edge and are often seen near rapids where females oviposit, or in fields and clearings. They perch on leaves and broad grasses away from the water, or on boulders and rocks in the river.

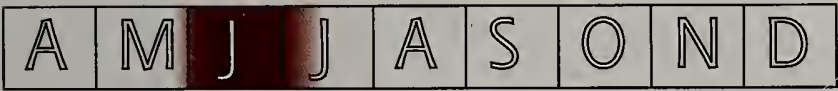


One of the smallest and stockiest clubtails; in the Hylogomphus group. Male thorax dark brown with broad yellow dorsal stripes forming a thick broken "U", extensively yellow to gray-green sides; abdomen black with $\mathrm{S} 1$ 53 extensively yellow above, S4-S7 with yellow dorsal spots anteriorly, and 58-59 dark above with large, bright yellow lateral spots; terminal appendages black. Eyes gray-blue to green. Face yellow, without dark stripes. Legs black. Female similar, but with less developed club and more yellow on sides of abdomen. Mustached Clubtail (p. 101) very similar, but face striped black and male club mostly dark.

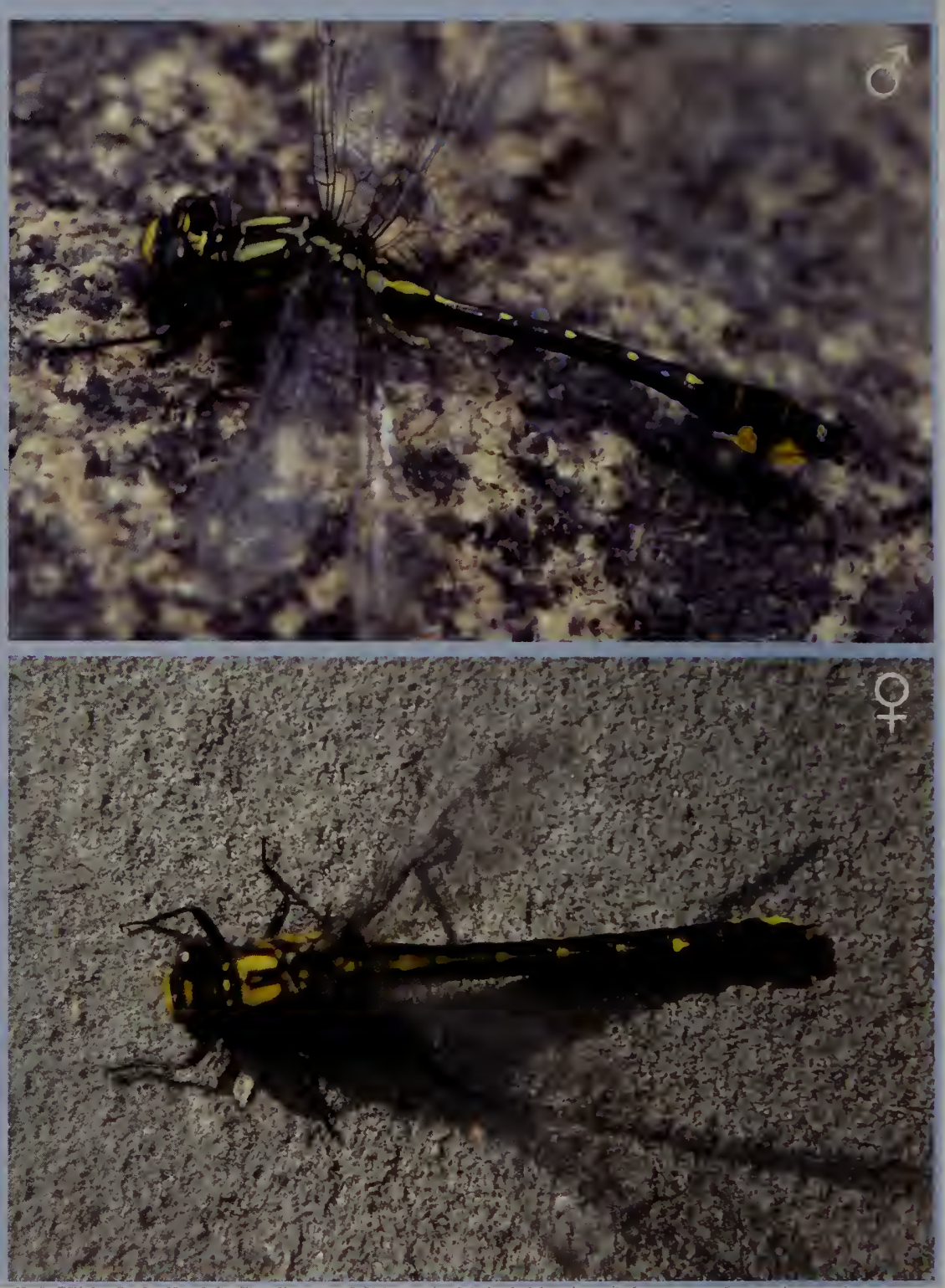

RANGE/STATUS Found in a narrow band along the northeastern seaboard. Rather rare, recorded only in central and eastern MA.

HABITAT Clean, sandy or rocky streams; rivers with muck deposits.

NOTES Adults fly along river edges, perching on leaves. Males hover above riffles and perch on rocks. This species is most active in the afternoon and occasionally found on hill tops.

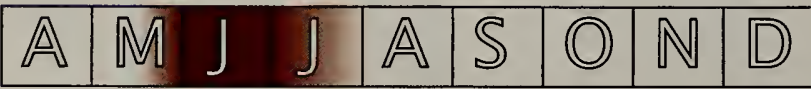


One of the smaller and stockier clubtails; in the Hylogomphus group. Male thorax blackish with broad yellow to dull green dorsal stripes forming a broken "U", extensively yellow to gray-green sides; abdomen black with yellow dorsal streaks on S1-S3, small yellow dorsal spots anteriorly on S4-S7, S8S10 dark above with little yellow on sides of club; terminal appendages black. Eyes green. Face yellow with prominent black cross-streaks. Legs black. Female similar but with less developed club and more extensive yellow markings on top and sides of abdomen. Spinecrowned Clubtail (p. 100) very similar, but face unstreaked and more yellow on sides of male club.
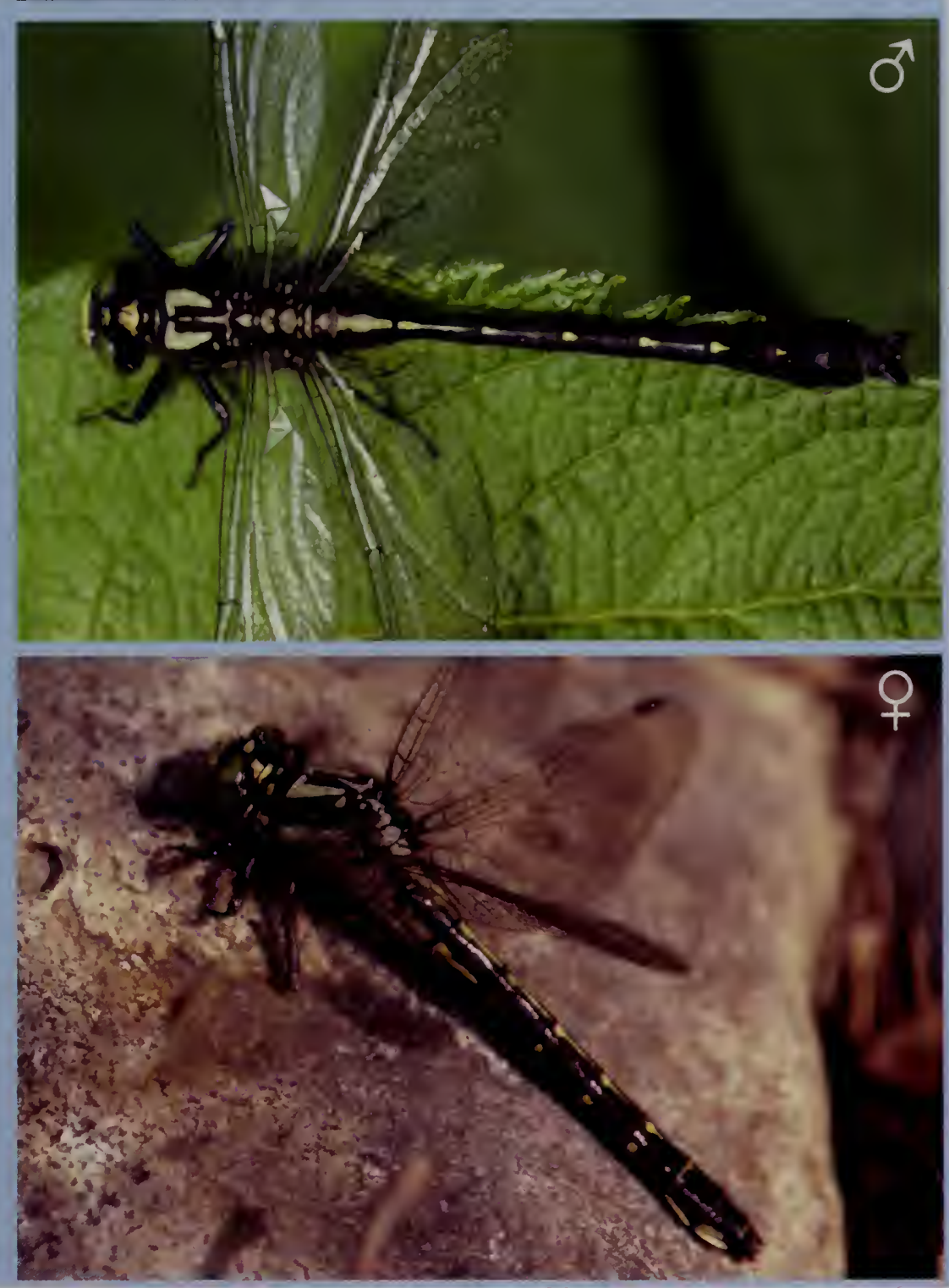

RANGE/STATUS Northeastern U.S.; southeastern Canada. A fairly common species found primarily in central and western MA.

HABITAT Clear, rocky, swiftly-flowing rivers and streams.

NOTES Adults fly low over the water, males hovering over riffles with their abdomens slightly arched. They perch on rocks and leaves.

\begin{tabular}{|l|l|l|l|l|l|l|l|l|}
\hline $\mathbb{A}$ & $\mathbb{M}$ & $J$ & $J$ & $\mathbb{A}$ & $\mathbb{S}$ & $\mathbb{O}$ & $\mathbb{N}$ & $\mathbb{D}$ \\
\hline
\end{tabular}


A rather large species with moderate club. Male thorax mostly pale yellow to dull green with broad, dark shoulder stripes; abdomen dark with nearly full-length, yellow dorsal streaks on S1-57, yellow triangles dorsally (variable in extent) on S8-59, yellow above on 510 , and limited yellow on sides of club. Eyes green. Legs black; very long hind legs with prominent spines. Female similar though abdomen somewhat thicker, less clubbed, and more yellow on sides. Distinguished from most other clubtails by more extensively pale thoracic sides, darker sides of club, and longer hind legs.

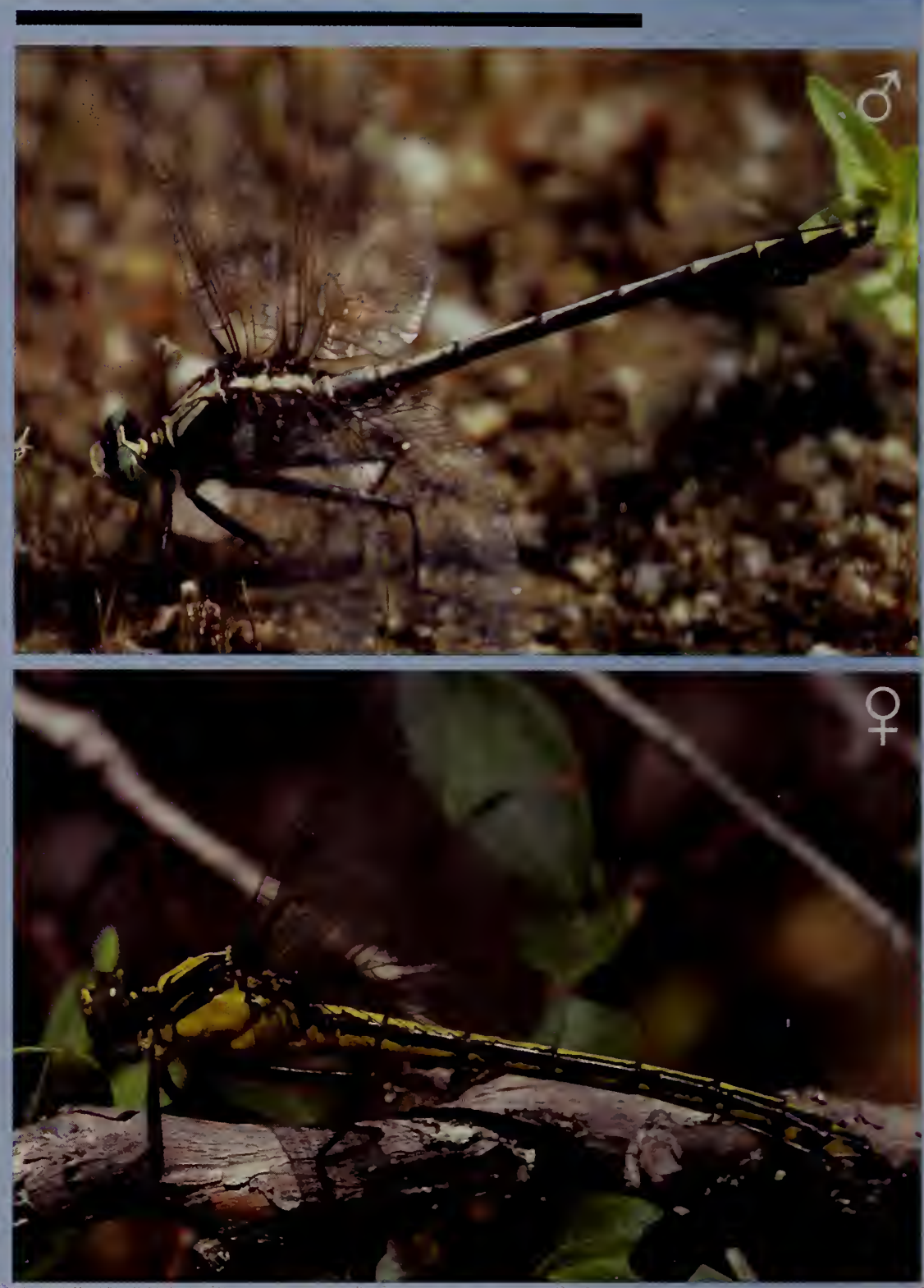

RANGE/STATUS Eastern U.S.; southeastern Canada. Common throughout MA. HABITAT Slow streams and rivers; large lakes with rocky shores.

NOTES Adults hunt in forests and along forest edges. They perch in shade on leaves or on the ground. Males patrol a few feet over the water, often far from shore, hovering occasionally and flying with their abdomens slightly upturned. They will land on slow moving boats or canoes. Females oviposit by flying rapidly low over the water, occasionally tapping the surface to release eggs. This species seems more tolerant of degraded water conditions than most clubtails.

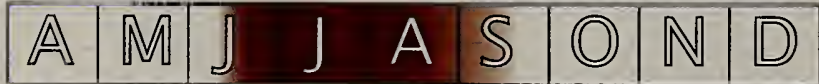


One of the Gomphurus clubtails with a welldeveloped club (as wide as thorax). Male thorax dark brown with yellow to gray-green dorsal stripes forming a "W," connected to thin, pale shoulder stripes, and extensively yellow to gray-green sides interrupted by thin dark diagonal streaks; abdomen black with thin, yellow dorsal streaks on S3-S7 (thickest on S7), 58 dark above with yellow lateral spot at base, 59 black above with large yellow patch on sides, S10 all black. Eyes green. Face pale with black crossstripes. Wings occasionally tinted yellow at base. Legs black. Female similar, though abdomen thicker with less developed (though still prominent) club. Very similar to the Skillet Clubtail (p. 104) and Midland Clubtail ( $\mathrm{p}$. 105), but distinguished from both by dark facial
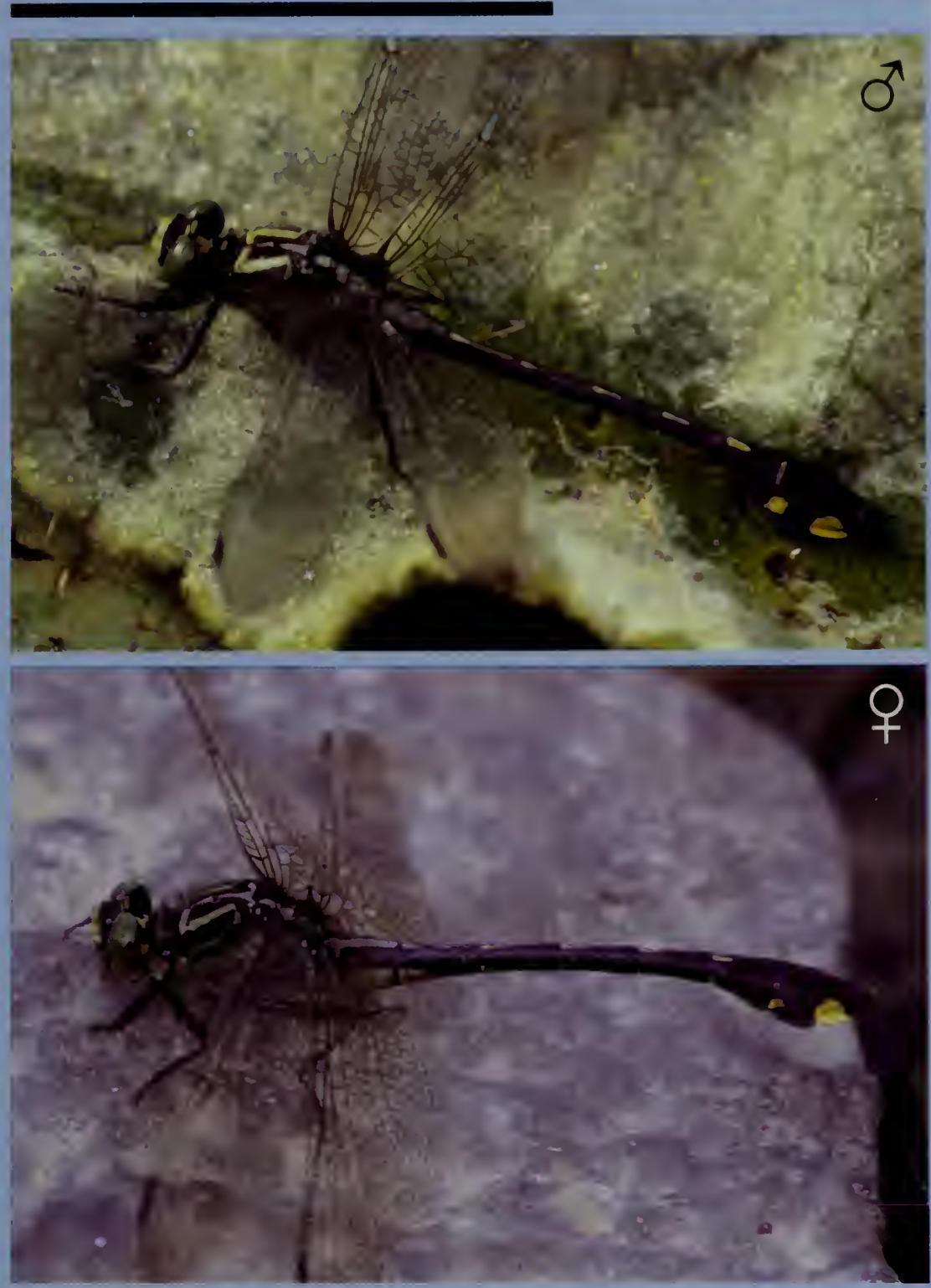
cross streaks and thinner dorsal thoracic stripes.

RANGE/STATUS Eastern U.S., barely extending into southeastern Canada. Very local in MA; known only from the Merrimack River, where its current status is uncertain, and from the Connecticut River, where it is common.

HABITAT Medium to large, mud-bottomed rivers; sometimes large streams and lakes. NOTES Adults perch in vegetation or on the ground along the shoreline or on sand and gravel bars. They can occasionally be found in meadows and openings away from water. Males fly long patrols with abdomen upturned, a few feet over the river, periodically hovering and clashing with other males. Females oviposit in flight by tapping their abdomens to the surface of the water.

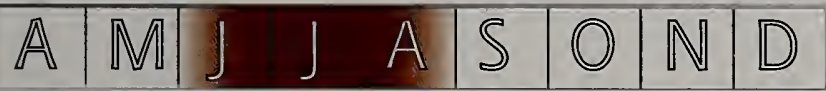




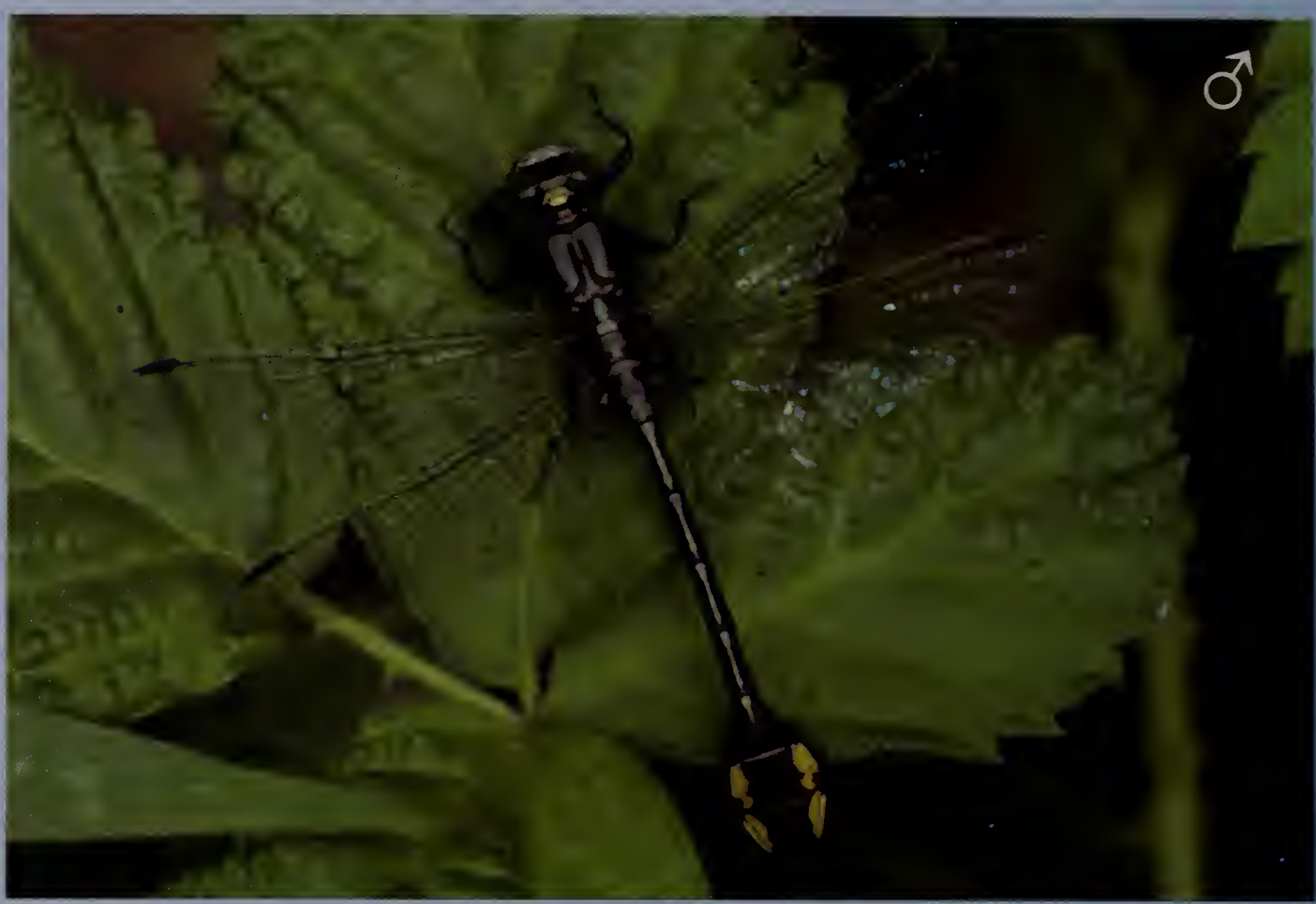

The smallest of the Gomphurus clubtails, but with the most prominent club (wider than thorax). Male thorax dark brown with yellow to gray-green dorsal stripes forming a thick "W", sides mostly yellow to gray-green, lacking dark diagonal streaks; abdomen black with thin, yellow dorsal streaks on S3-57, 58-59 dark above with wide yellow lateral spots (often connected), and S10 and appendages all black. Eyes green. Legs black. Female similar, though abdomen thicker with less developed (though still prominent) club. Very similar to the Cobra Clubtail (p. 103) and Midland Clubtail (p. 105), but smaller with no dark lateral thoracic streaks and much larger (and often connected) lateral spots on S8-S9.

RANGE/STATUS Northeastern U.S.; southeastern Canada. Rare in MA; recorded only from the Connecticut, Housatonic, and Merrimack watersheds.

HABITAT Medium to large rivers, often with mud bottoms.

NOTES Males fly short patrols over the water. Adults perch low on vegetation or on the ground along the shore and can occasionally be found in clearings away from the water.

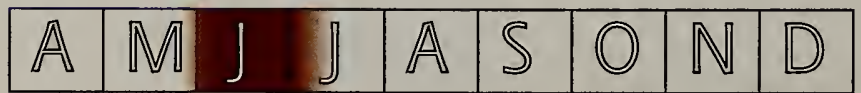


One of the Gomphurus clubtails with a welldeveloped club. Male thorax dark brown with thick, yellow to gray-green dorsal stripes forming a fat "U", sides mostly yellow to gray-green, interrupted by dark diagonal streaks; abdomen black with thin, yellow dorsal streaks on S3-57, S8 with small yellow dorsal spot at base and large lateral spot (extending down to lower edge), 59 dark above with large yellow lateral spot, S10 all black. Eyes green. Face dull yellow. Legs black (except hind leg of female occasionally pale). Female similar, though abdomen thicker with slightly narrower (though still prominent) club. Very similar to the Cobra Clubtail (p. 103) and Skiliet Clubtail (p. 104), but distinguished from both by dorsal spot on 58 , from former by unmarked face, and from latter by
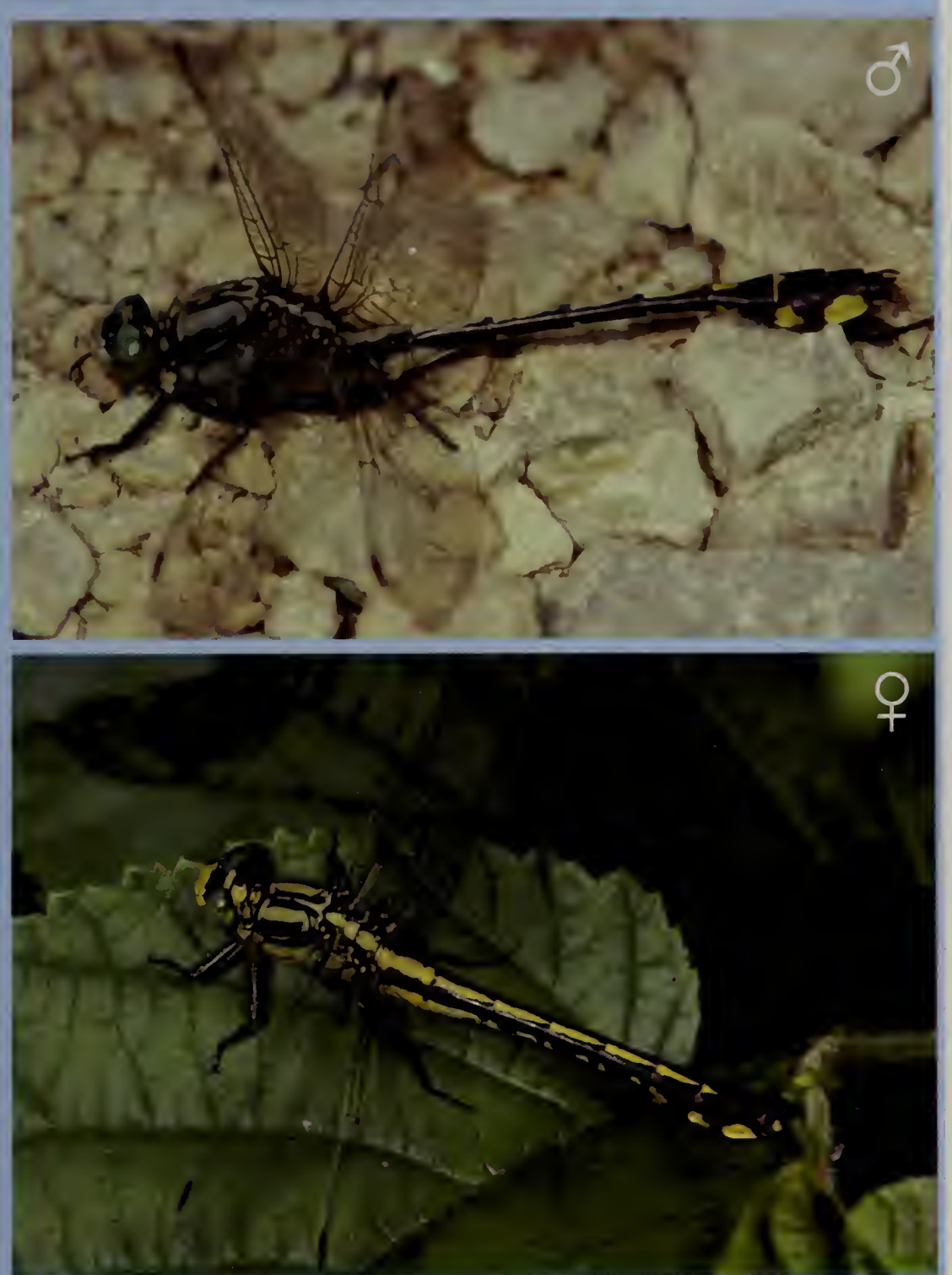
smaller lateral spots on S8-59.

RANGE/STATUS Northeastern U.S.; southeastern Canada. Very rare in MA, recorded only from a limited stretch of the Connecticut River.

HABITAT Medium to large, mud-and sand-bottomed rivers; large lakes with emergent vegetation.

NOTES Adults fly along the edges of rivers, perching on the banks or leaves. Their flight is swift and long, and a few feet above the water's surface. They often rest on sunny rocks and sandbars. Females may oviposit in rapids or in turbulent shallows of lakes.

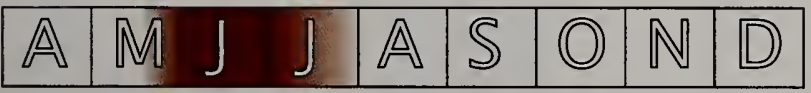


Male thorax dark brown with a yellow to graygreen T-shaped collar, dorsal stripes, and yellow to gray-green sides with narrow brown lateral stripes; abdomen black with well developed club, \$4-\$9 with yellow dorsal spots, small yellow lateral spot on 57, prominent yellow lateral spots on S8S9; dark terminal appendages. Eyes green. Face with dark streaks. Legs black with some pale on hind legs. Female similar but abdomen thicker with more extensive yellow lateral markings. Similar to the Arrow Clubtail (p. 107), but smaller, sides of thorax paler, and 59 not elongate.

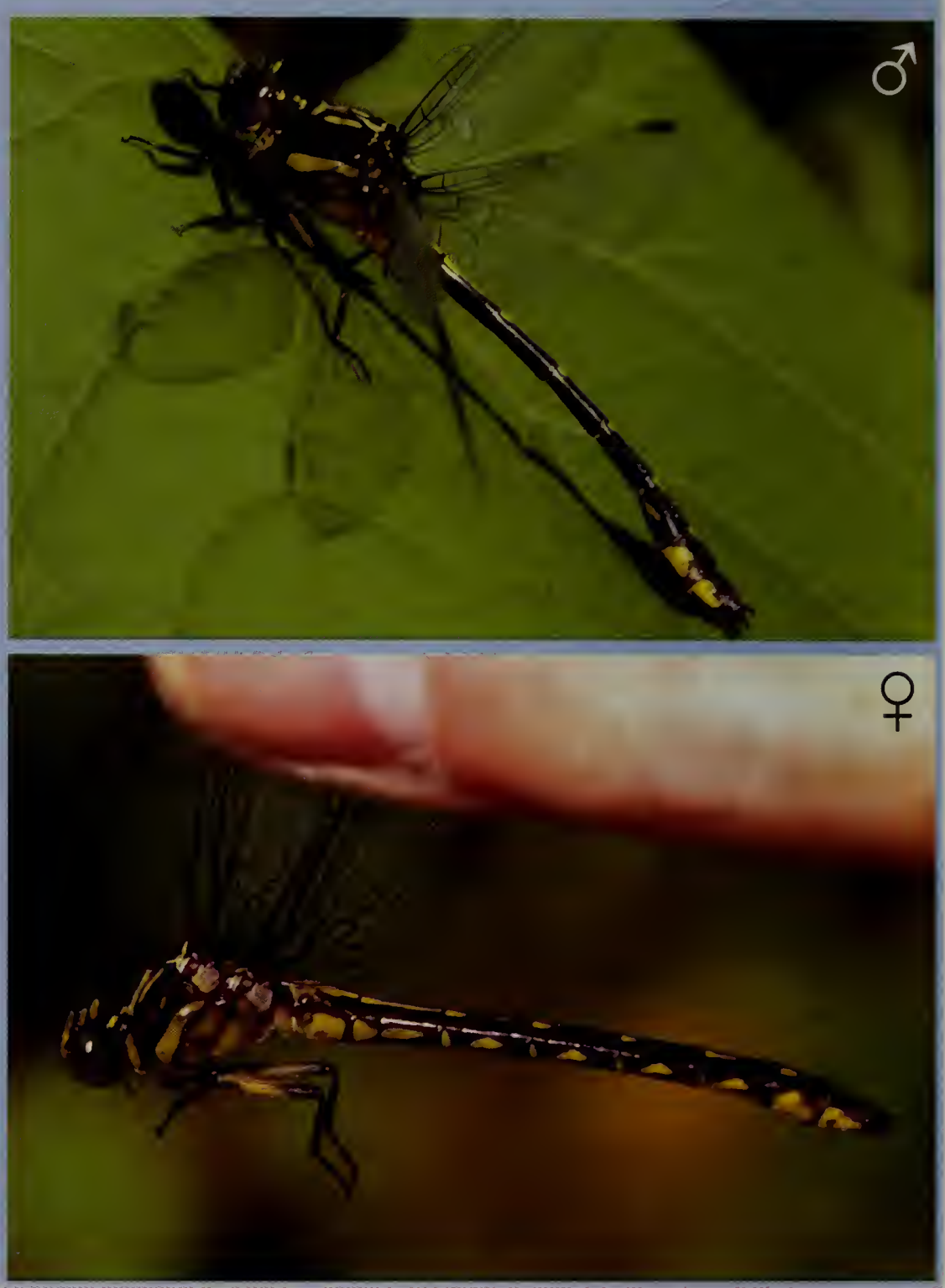

RANGE/STATUS Eastern U.S.; southeastern Canada. Rare in MA, recorded only from the Connecticut River.

HABITAT Medium to large rivers with sand, gravel, or mud bottoms.

NOTES Adults hunt in the trees along the shoreline, and apparently spend most of the time high in the canopy. Males make patrols over the water from mid-morning to dusk. A scarce, poorly-known species throughout its range.

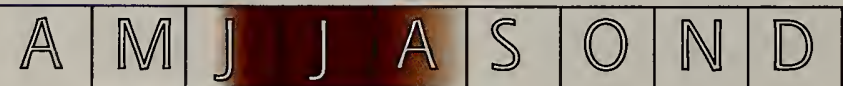



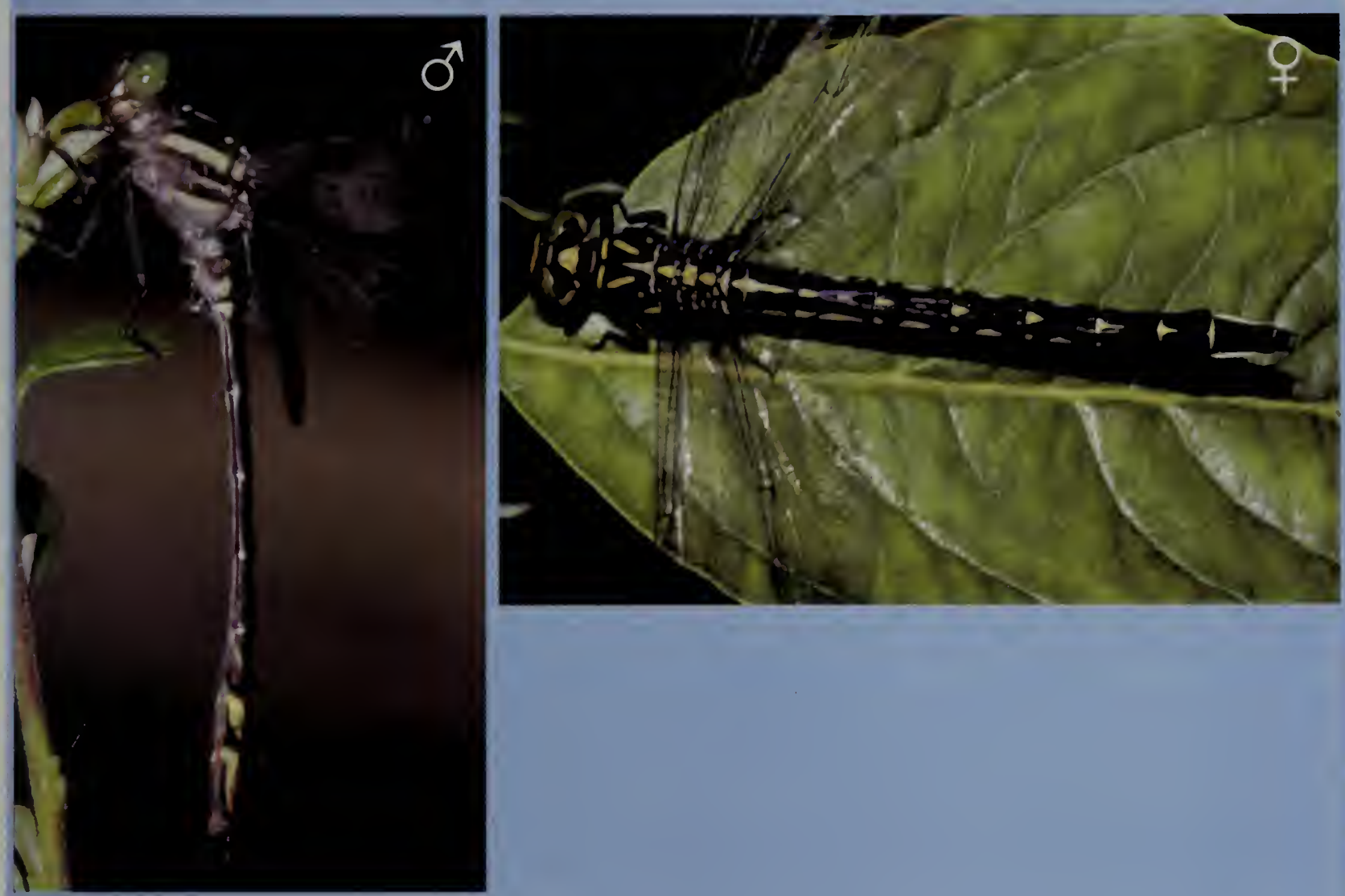

One of the longest, most spindly clubtails. Male thorax dark brown to black with thin yellow to gray-green dorsal stripes, thin pale collar, and pale lateral stripes; abdomen long with slender club, 59 longer than 58 , dark brown with yellow dorsal spots at base of S3-S8, small yellow lateral spot on S7, large yellow lateral anterior spots on S8-S9. Eyes green. Face dark. Legs black. Female similar, but abdomen thicker, not clubbed, and more extensively marked with yellow.

RANGE/STATUS Northeastern U.S.; southeastern Canada. Uncommon in MA, found in only a handful of inland sites, including the Connecticut River.

HABITAT Mud-and sand-bottomed rivers; occasionally streams and lakes.

NOTES Adults perch on leaves and brush, apparently spending most of the time high in tree tops. Males make swift, straight patrols over the water and are most active from mid-afternoon through dusk.

$\mathbb{A}|\mathbb{M}| J \mid J$ A S $|O| \mathbb{N} \mid \mathbb{D}$


One of the most robust and distinctly marked clubtails. Male thorax dark brown with slender yellow dorsal stripes, a thin yellow collar, and yellow to gray-green lateral stripes; abdomen black with well developed club, S3-S7 with prominent yellow basal rings, 57-58 with short, rearward pointing, yellow dorsal streaks, S8-S9 with yellow lateral patches, and appendages dark. Eyes green. Face pale with black stripes. Legs dark. Female similar but abdomen thicker, not clubbed, with more yellow on sides. No other large clubtail has a ringed abdomen.
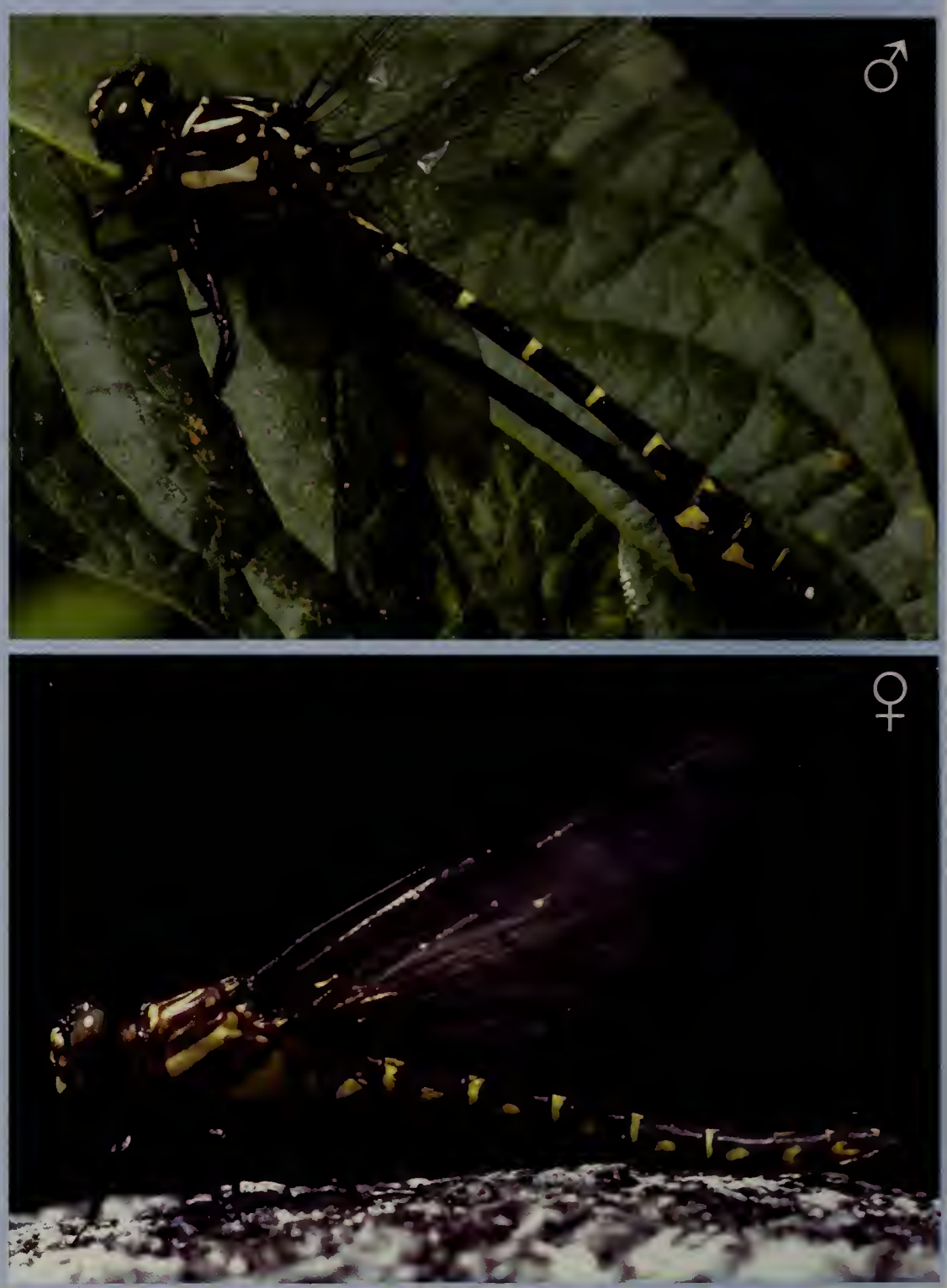

RANGE/STATUS Northeastern U.S.; southeastern Canada. Uncommon, recorded only from a handful of rivers and streams in central and western MA.

HABITAT Sand-bottomed streams and small rivers with riffles.

NOTES Adults hunt in forest clearings and along forest edges though they apparently spend much of their time perched high in the canopy. Males perch on rocks and leaves along rivers and make quick patrols over the water. They are most active from midafternoon until dusk.

\begin{tabular}{|l|l|l|l|ll|l|l|l|}
\hline $\mathbb{A}$ & $\mathbb{M}$ & $\mathbb{J}$ & $\mathcal{J}$ & $A$ & $S$ & $O$ & $\mathbb{N}$ & $\mathbb{D}$ \\
\hline
\end{tabular}


The only clubtail in the Northeast with dark basal wing markings. Male thorax dark brown with yellow dorsal stripes forming a thin "W" pattern, thin shoulder stripe, and yellow lateral stripes; abdomen brown and moderately clubbed, S3-S7 with broad, yellow dorsal triangles or squares, yellow lateral patches (often indistinct) on $57-$ S9; terminal appendages yellow. Eyes grayishgreen. Legs short and dark brown. Wings with yellow leading edges and small brown basal spots. Female similar but abdomen thicker with more yellow on sides. The combination of basal wing spots and yellow appendages distinguishes this species from all other clubtails.

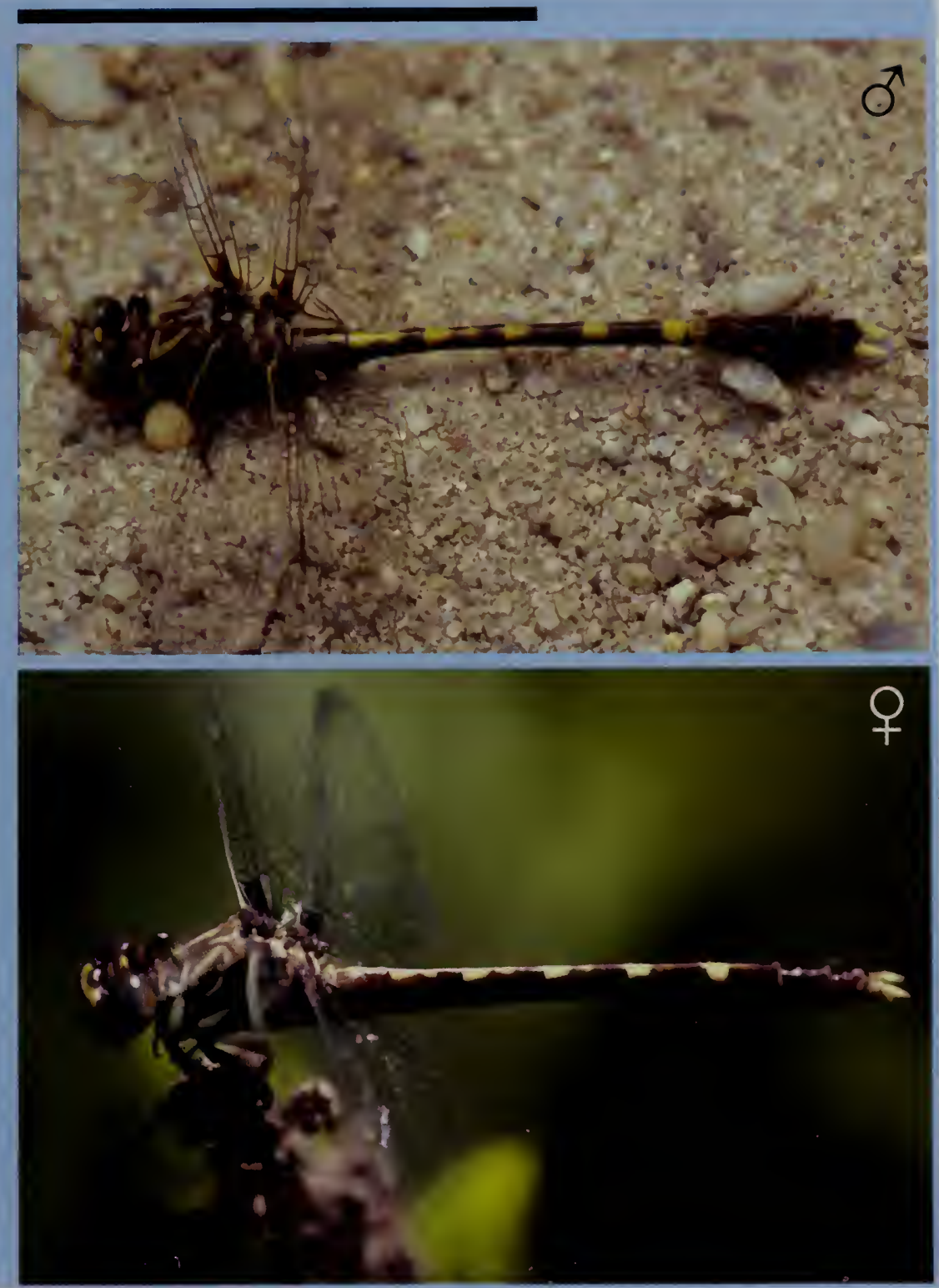

RANGE/STATUS Central to eastern U.S. extending into the Canadian Great Lakes region. A fairly common species in southeastern MA. HABITAT Sandy-bottomed ponds, lakes, and streams.

NOTES Adults perch in vegetation or on the ground. At breeding sites males perch on sandy ground and make swift patrols, sometimes hovering, very low over the water. Females oviposit by either tapping their abdomens to the water, or releasing eggs a foot or so above the water.

A|MIIJ AISTOIND


Male thorax brown with broad green dorsal stripes (forming "W" pattern) and mostly grayish-green sides; abdomen only slightly clubbed and blackish with yellow dorsal streaks on S1-S7, a short dorsal streak on 58 , rusty on sides of S8-59, yellow above on S10; yellow appendages. Eyes pale blue. Face plain, dull yellow. Legs black. Female similar but with more yellow on abdomen. Very similar to Unicorn Clubtail (p. 111), but eyes typically more blue, male abdomen less clubbed, and legs all black.

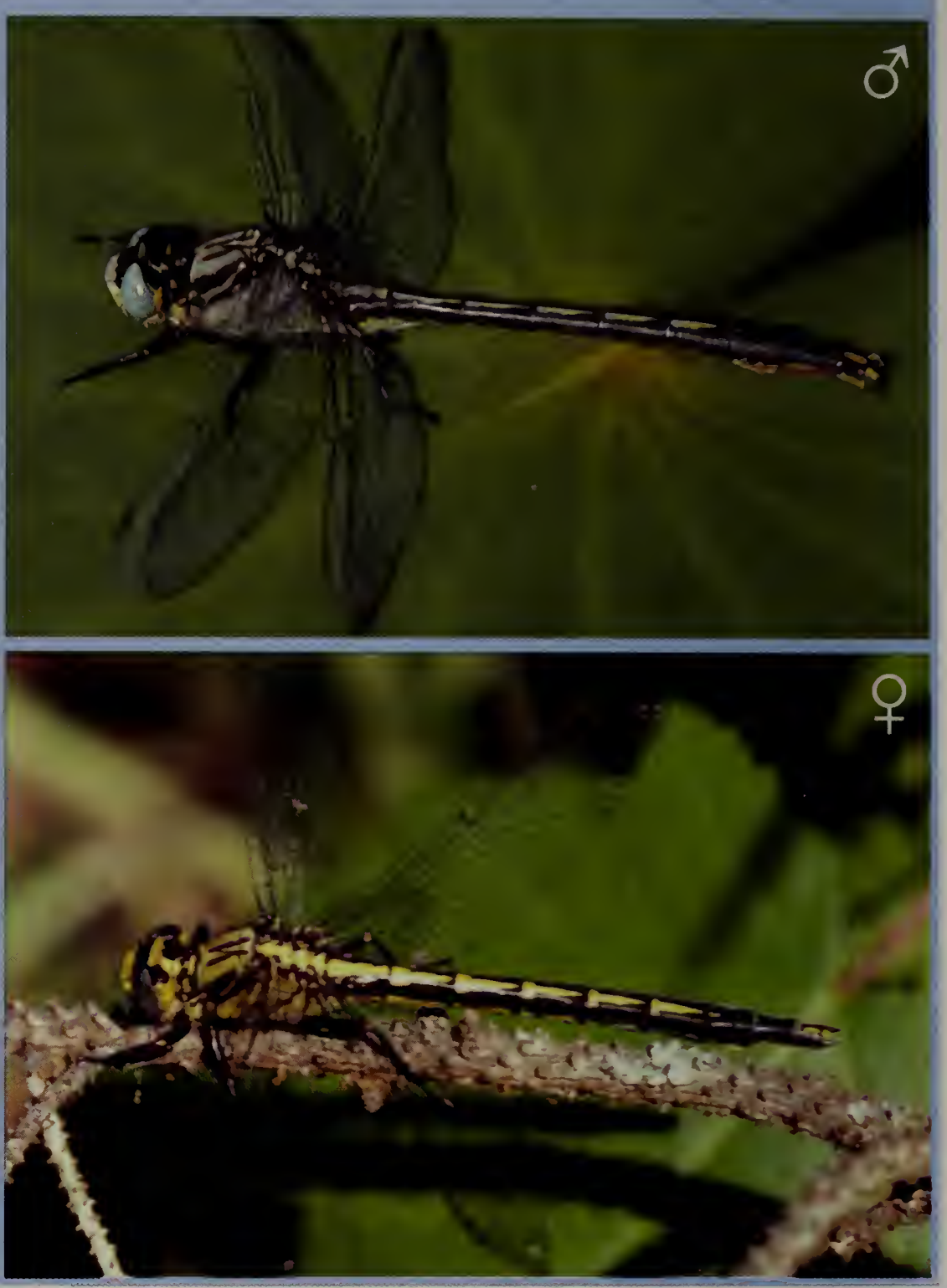

RANGE/STATUS Northeastern U.S.; southeastern Canada. Somewhat uncommon throughout MA, absent from the southeast coastal plain.

HABITAT Still water with floating and aquatic vegetation, bog-bordered ponds and lakes, and slow streams.

NOTES Adults hunt along forest edges, perching on the ground, rocks, and occasionally broad-leaved vegetation. At breeding sites males perch along the shore and on floating vegetation, such as lily pads. Females oviposit by tapping their abdomens to the water.

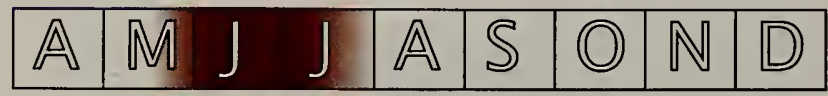




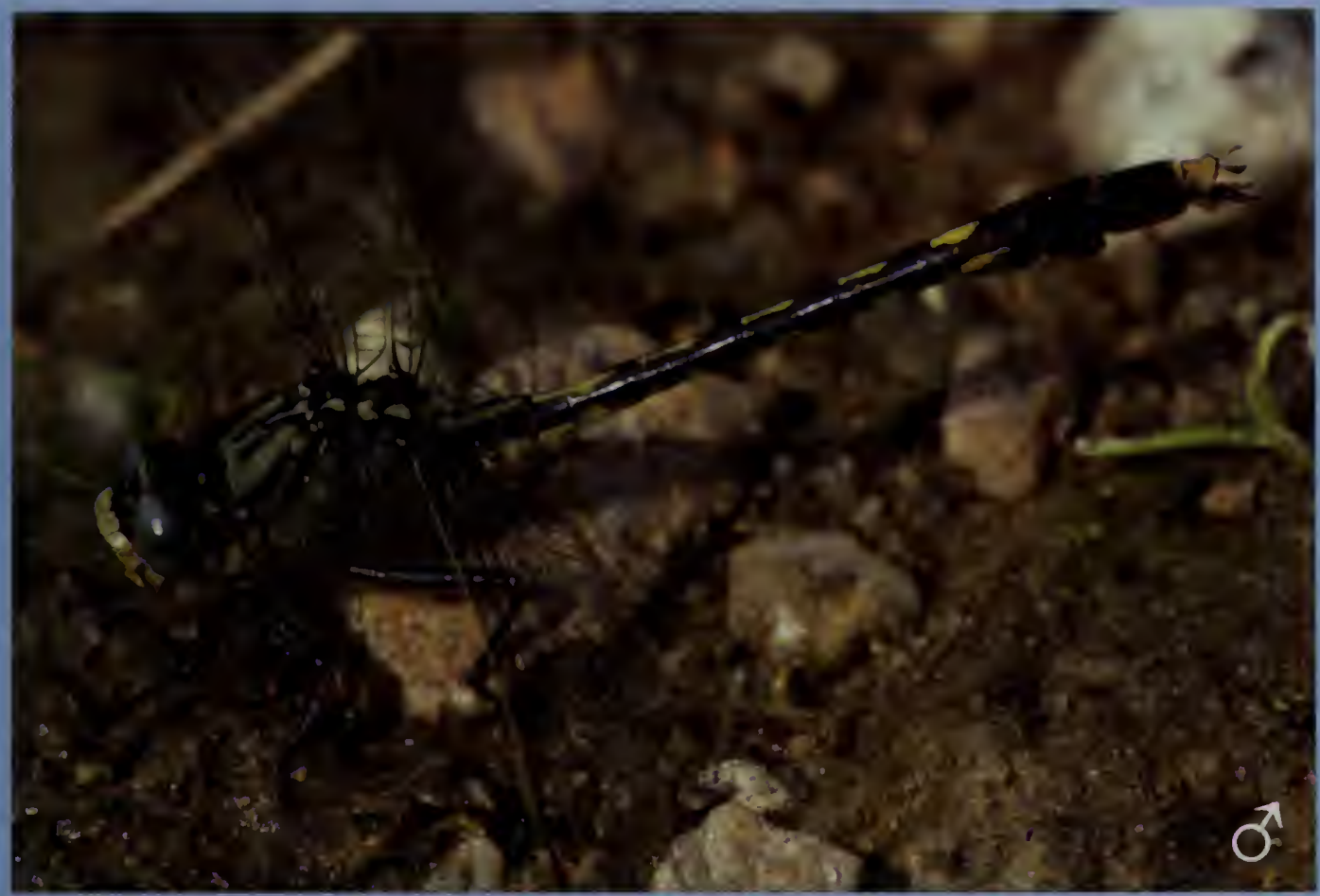

Male thorax brown with broad green dorsal stripes (forming "W" pattern) and mostly grayish-green sides; abdomen only slightly clubbed and blackish with yellow dorsal streaks on S1-S7 (occasionally a small dorsal spot on S8 and/or S9), rusty on sides of S8-S9, and mostly yellow on $\$ 10$ and appendages. Eyes blue-green. Face plain, dull yellow. Legs mostly black with pale yellow streak on tibia. Female similar but with more yellow on sides of abdomen. Very similar to Lilypad Clubtail (p. 110), but eyes more green, male abdomen more clubbed, and legs with pale streaks.

RANGE/STATUS Central to northeastern U.S. Fairly common throughout MA, but absent from the southeast coastal plain.

HABITAT Muddy-bottomed lakes, ponds, slow streams, and stagnant waters.

NOTES Males perch on the shore or low vegetation. They make low patrols with their abdomens turned slightly upward. Females oviposit by flying slowly above the water and tapping their abdomens to the surface to release eggs. This species seems more tolerant of degraded habitats than most other clubtails.

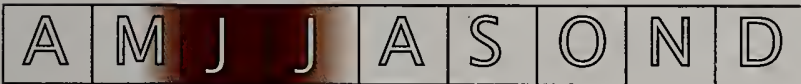


One of the smallest clubtails. Male thorax black with short yellow to gray-green dorsal stripes, broken yellow collar, sides extensively gray-green with dark brown "H" pattern; abdomen slender with poorly developed club, mostly black except S1-S3 with yellow dorsal markings, S3-58 with small lateral spots, S7-59 with narrow yellow posterior rings; terminal appendages black. Eyes dull green. Face pale with dark cross-streaking. Female similar but abdomen with very thin, yellow dorsal streaks on S1-S7. Southern Pygmy Clubtail (p. 113) very similar, but dark lateral thoracic markings less extensive. Least Clubtail (p. 114) has more pale markings on abdomen and pale terminal appendages.
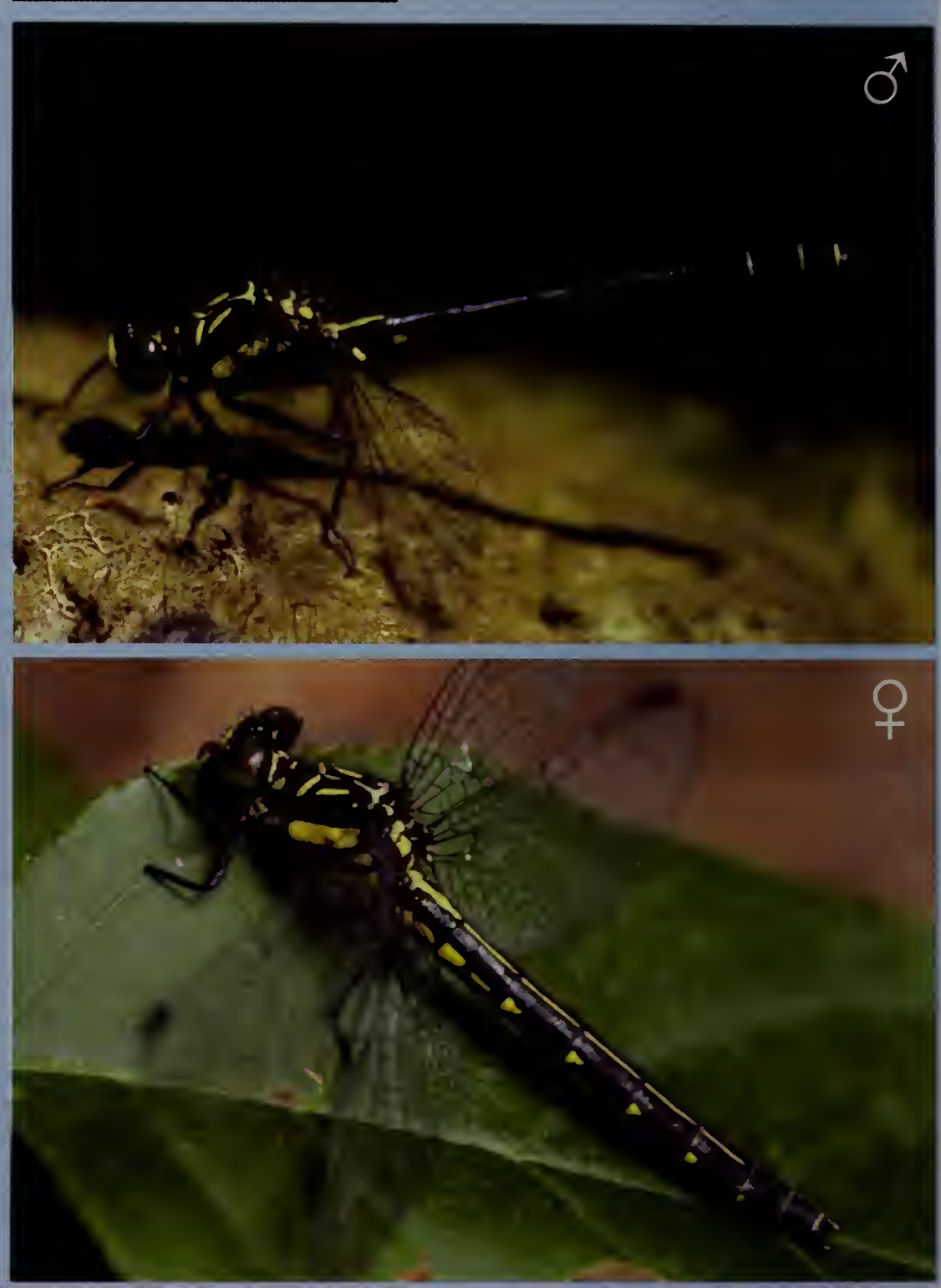

RANGE/STATUS Northeastern U.S.; southeastern Canada. Rare, documented only at higher elevations in western MA.

HABITAT Small, rocky, forested streams.

NOTES Adults perch on leaves in sunny clearings. At the water they perch on sunny rocks near riffles.

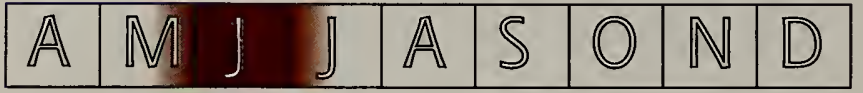


One of the smallest clubtails. Male thorax black with short yellow to gray-green dorsal stripes, broken yellow collar, and sides extensively graygreen with one complete and one partial dark lateral stripe; abdomen slender with poorly developed club, black except S1-53 with yellow dorsal markings, S3-58 with small lateral spots, 57-59 with narrow, yellow posterior rings; terminal appendages black. Eyes dull green. Face pale with dark cross-streaks. Female similar but abdomen with yellow dorsal streaks on S1-S7. Northern Pygmy Clubtail (p. 112) very similar, but dark lateral thoracic markings more extensive. Least Clubtail (p. 114) has more pale markings on abdomen and pale terminal appendages.

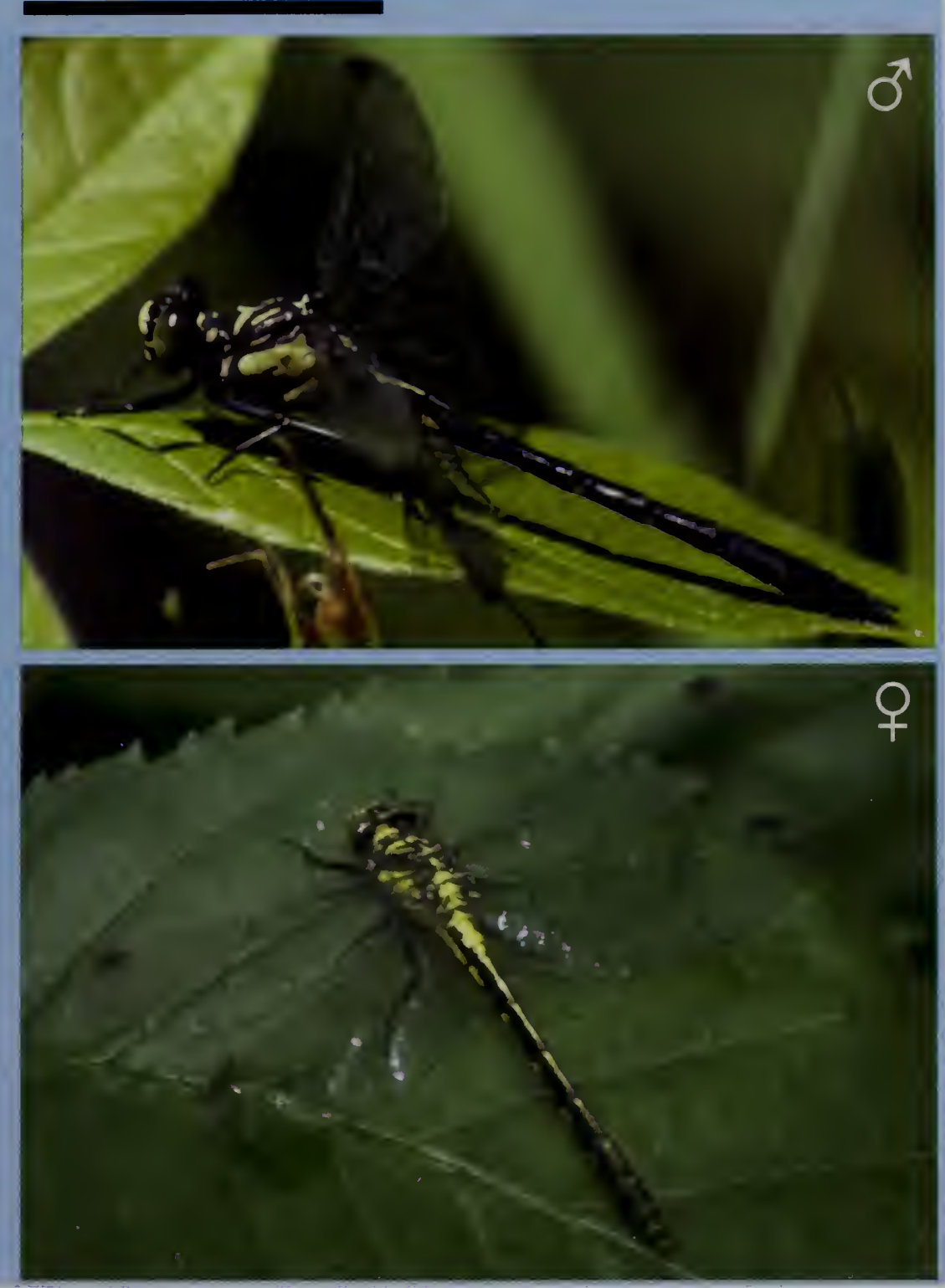

RANGE/STATUS A narrow belt through the northeastern U.S. Uncommon, found at lower elevations in eastern and central MA.

HABITAT Very small, rocky or gravelly forested streams, often semi-permanent. Typically found at smaller, more shaded streams than the Northern Pygmy Clubtail ( $L$. parvulus).

NOTES Adults hunt in clearings and perch on foliage. Near the water, males perch close to riffles. They are less wary than most clubtails.

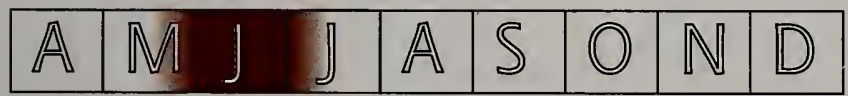


One of the smallest clubtails. Male thorax black with narrow yellow dorsal stripes, yellow collar stripe, and alternating dark and pale lateral stripes; abdomen slender with poorly developed club, black with yellow basal rings (often broken) on S4-S7, yellow lateral spots on S8-59; terminal appendages white. Eyes green. Face pale with black streaks. Female similar but yellow on abdomen more extensive. Very similar to both the Northern Pygmy Clubtail (p. 112) and Southern Pygmy Clubtail (p. 113), but terminal appendages pale (both sexes), middle abdominal segments ringed, and lateral thoracic markings thinner and more intricate.

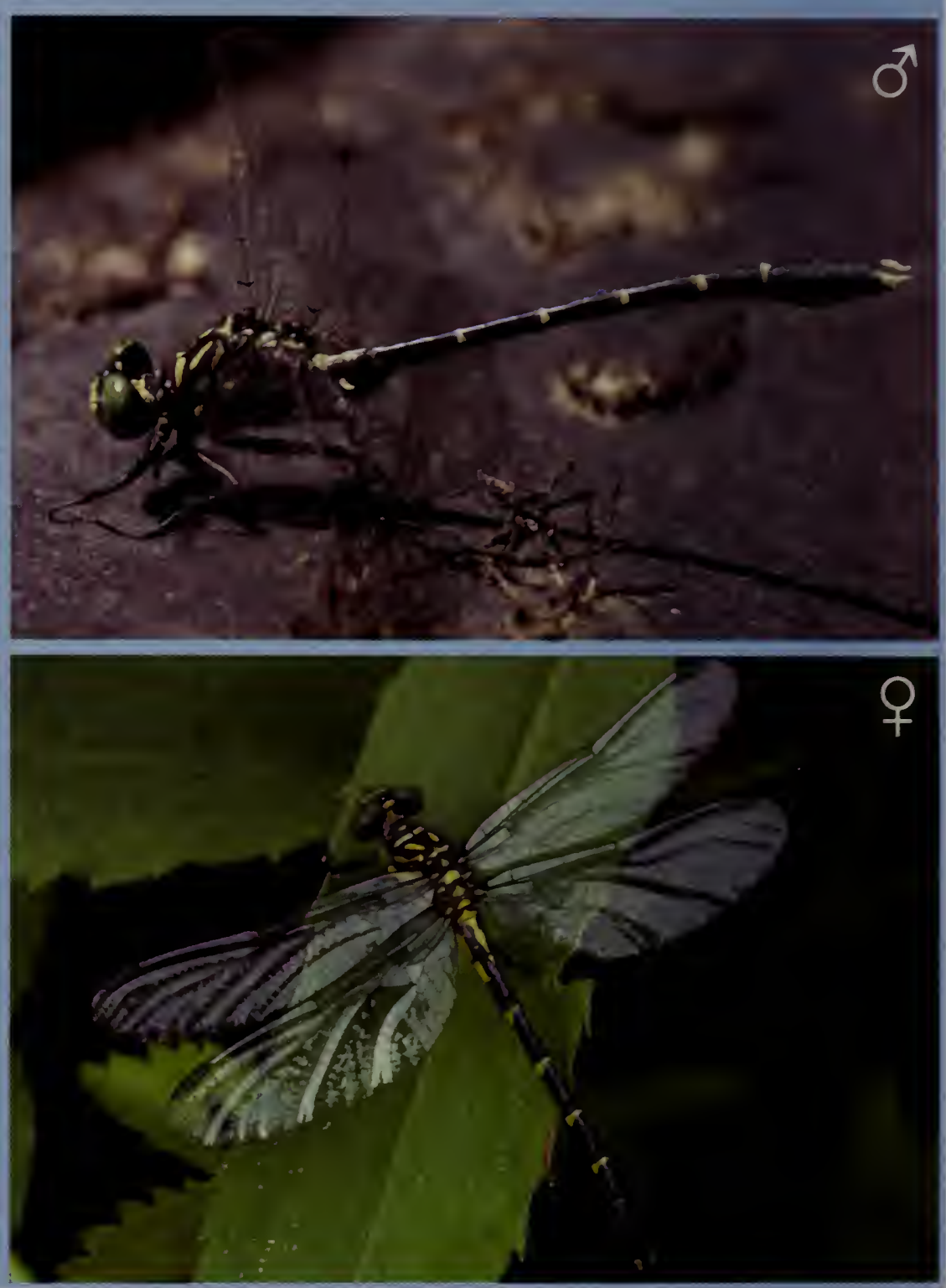

RANGE/STATUS Central to eastern U.S.; southeastern Canada. A fairly common species in interior MA, but absent from the southeast coastal plain.

HABITAT Riffles along rocky or sandy streams.

NOTES Adults hunt among the trees. Males fly above riffles, perching on rocks and sandbars. 
A small, bright green clubtail with amber hind wing patches. The smallest and one of the most poorly known snaketails. Male thorax bright green with dark mid-dorsal stripe, paired dark shoulder stripes, and thin, dark lateral stripes; abdomen blackish with prominent club, pointed yellow dorsal markings and lateral spots on all segments; dull yellowish terminal appendages. Hind wings washed with amber on basal third. Eyes and face green. Legs black. Female similar but abdomen thicker with more extensive yellow markings. Combination of small size, bright green coloration, and amber on wings is distinctive.

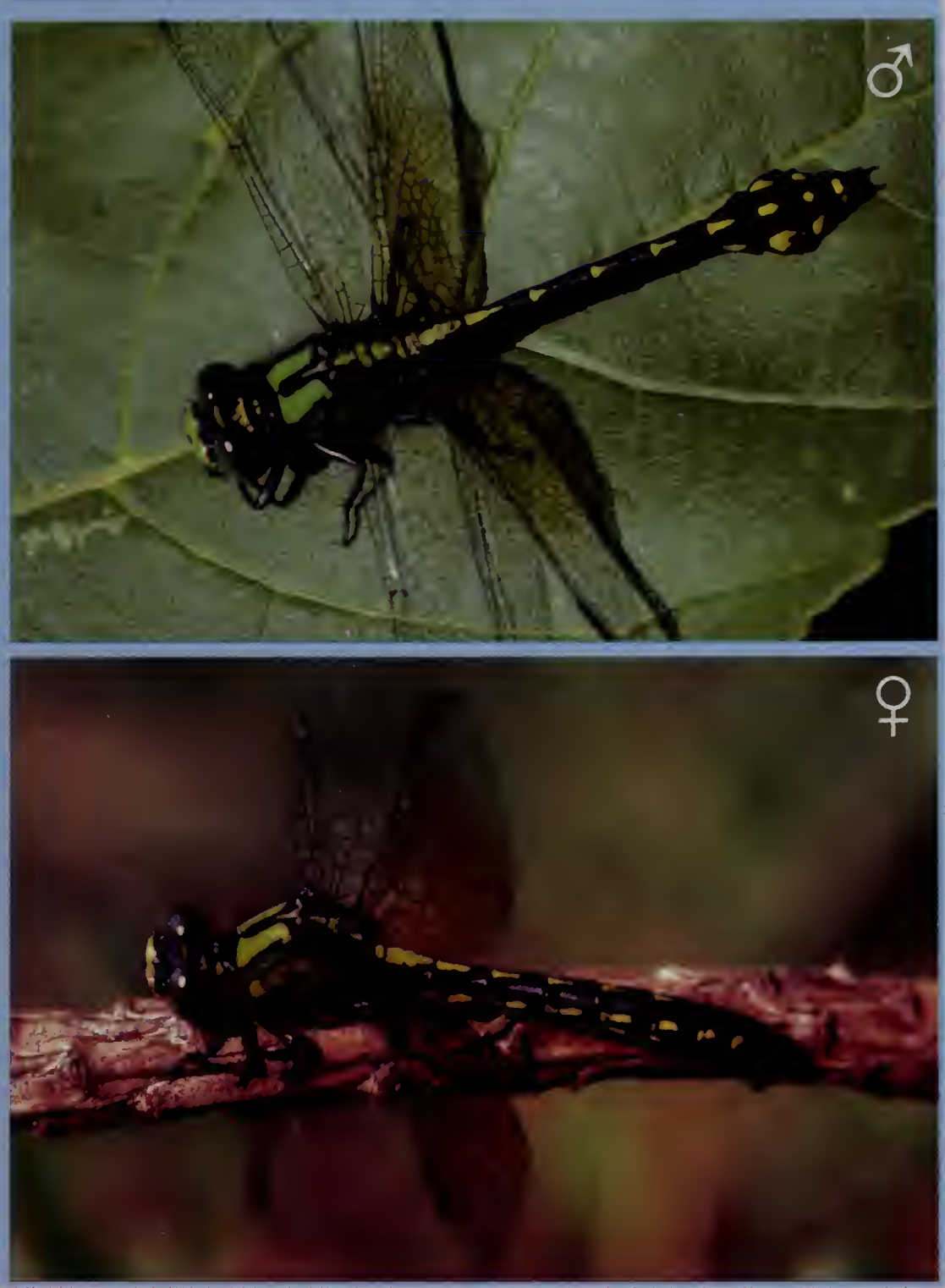

RANGE/STATUS Northeastern U.S., including the Great Lakes region. The type specimen of this species was collected near the Connecticut River in MA in 1928. However, there have been no MA records since, and whether a population still exists in the Connecticut River Valley is not known.

HABITAT Large, clear, gravel- and sand-bottomed rivers.

NOTES Adults hunt in the canopy along rivers or in nearby fields. Males make short patrols with fast bounding flights over riffles.

\begin{tabular}{|l|l|l|l|l|l|l|l|}
\hline $\mathbb{A}$ & $\mathbb{M} J$ & $\mathbb{N}$ & $\mathbb{A}$ & $\mathbb{S}$ & $\mathbb{O}$ & $\mathbb{N}$ & $\mathbb{D}$ \\
\hline
\end{tabular}


Male thorax bright green with dark brown middorsal stripe, paired, thin shoulder stripes, and single thin dark lateral stripe; abdomen black with moderately sized club and prominent yellow dorsal markings on all segments, those on S2-58 daggershaped and those on S9S10 rounded, lateral yellow spots on all segments, those on 58-59 large and prominent; terminal appendages yellowish. Eyes green. Face green and unmarked. Legs often with pale stripe on tibia. Female similar but abdomen thicker. Very similar to Riffle Snaketail (p. 117) and Maine Snaketail (p. 118); safely identified only in the hand.

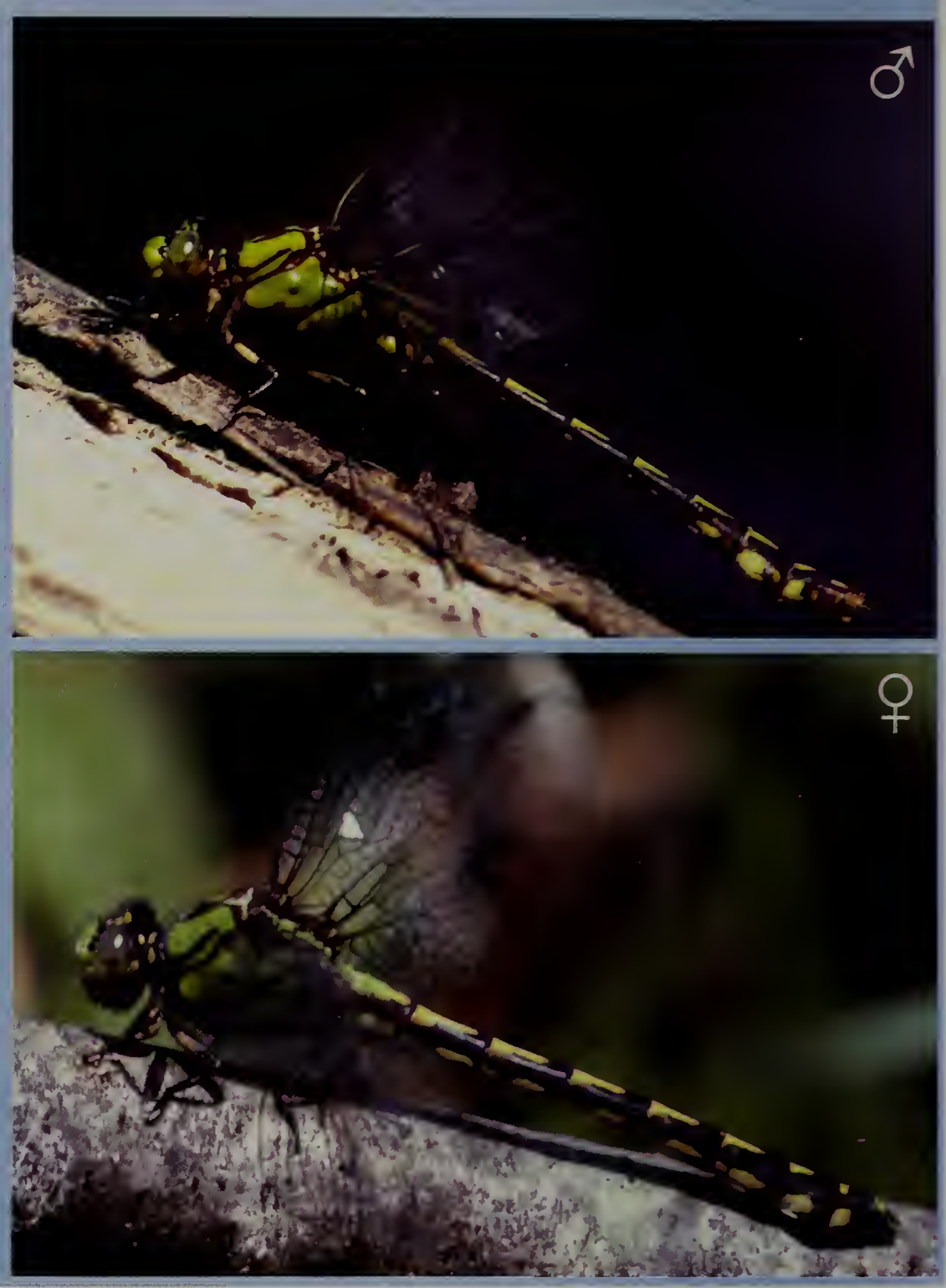

RANGE/STATUS Spottily distributed across the northeastern U.S. and Great Lakes region. An uncommon species found only in interior MA.

HABITAT Open, sand-bottomed streams and rivers with gravelly or rocky riffles. NOTES Adults hunt in forest clearings and fields. Males patrol along rivers, perching on rocks and sandbars and in overhanging trees. Females oviposit near riffles, flying swiftly and striking the water with the tips of their abdomens.

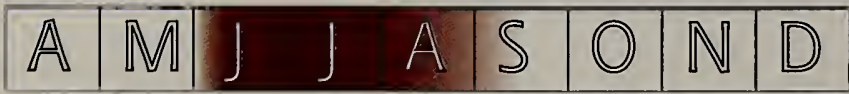


Male thorax bright green with broad, dark middorsal stripe, thick brown shoulder stripes, and a dark lateral stripe; abdomen black with moderately sized club, prominent yellow dorsal markings on all segments, those on S3-S7 thick and dagger-shaped with a noticeable constriction, on S8 rectangular, and on S9-\$10 rounded, lateral yellow spots on all segments, those on S8--59 large and prominent; terminal appendages dull yellowish. Eyes green. Face green and unmarked. Legs black, occasionally with pale stripe on tibia. Female similar but abdomen thicker. Very similar to Brook Snaketail (p. 116) and Maine Snaketail (p. 118); safely identified only in the hand.

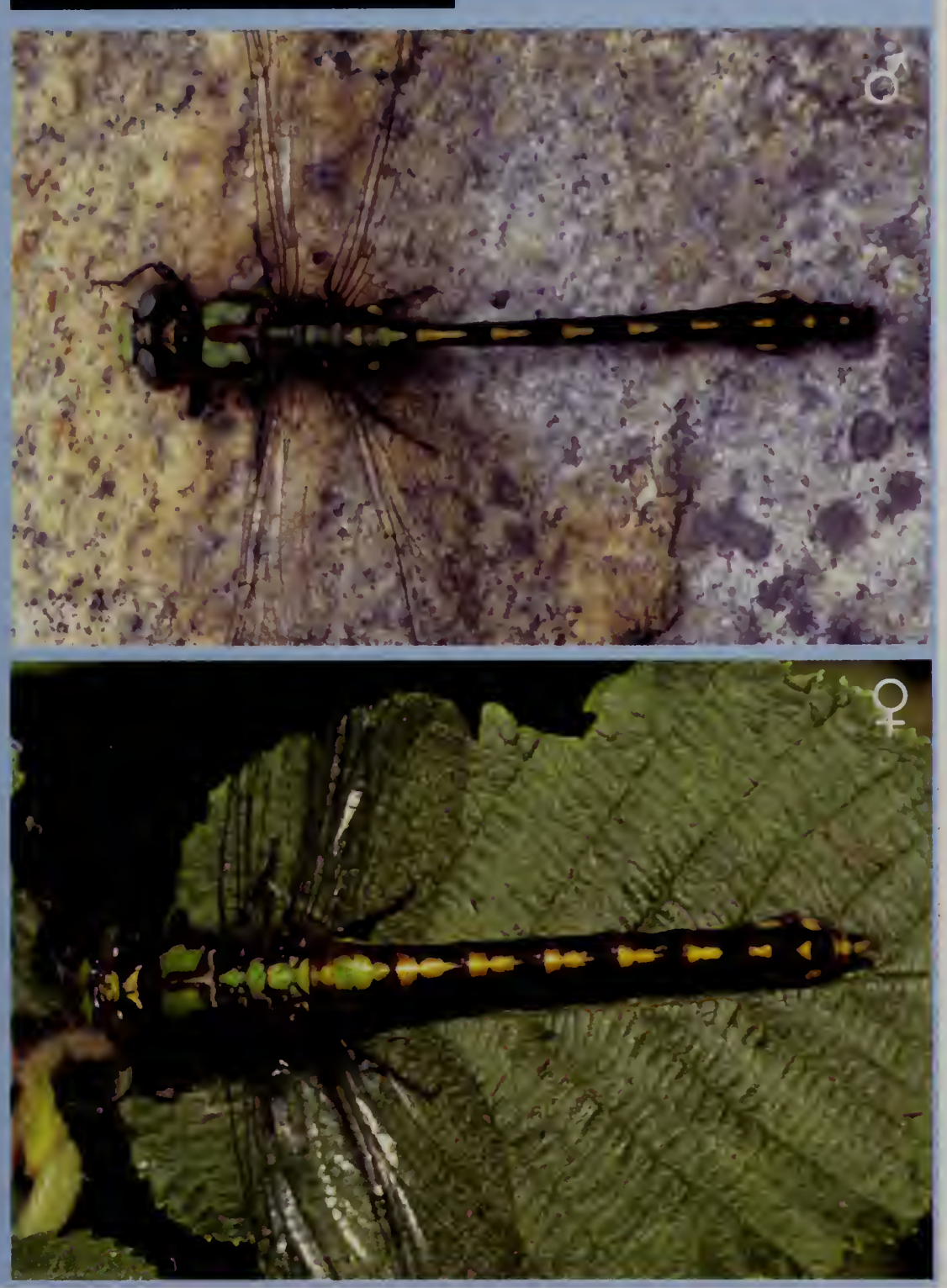

RANGE/STATUS Northeastern U.S. and southeastern Canada. Uncommon in MA, known only from the north-central and western parts of the state.

HABITAT Swiftly flowing, sandy or rocky streams and rivers.

NOTES Adults hunt in forest clearings away from the water, perching on broad leaves, tips of herbaceous vegetation, and occasionally on the ground. Near water they fly fast and low near riffles and rapids, and perch in overhanging trees, on exposed rocks in the water, and on the ground along the shore.

\begin{tabular}{|l|l|l|l|l|l|l|l|}
\hline $\mathbb{A}$ & $\mathbb{M}$ & $\mathbf{J}$ & $\mathrm{A}$ & $\mathbb{A}$ & $\mathbb{S}$ & $\mathbb{N}$ & $\mathbb{D}$ \\
\hline
\end{tabular}


Male thorax bright green with broad, dark middorsal stripe, thick brown shoulder stripes, and dark lateral stripe; abdomen black with moderately sized club, 53-57 with narrow yellow, daggershaped dorsal streaks, S8S10 usually black above, but occasionally with short streaks or spots, large lateral spots on S8-59; terminal appendages dull yellowish. Eyes green. Face green and unmarked. Legs mostly black. Female similar but abdomen thicker with more yellow on sides. Very similar Brook Snaketail (p. 116) and Riffle Snaketail ( $p$. 117), but dorsal abdominal markings thinner and usually absent on S8-59.

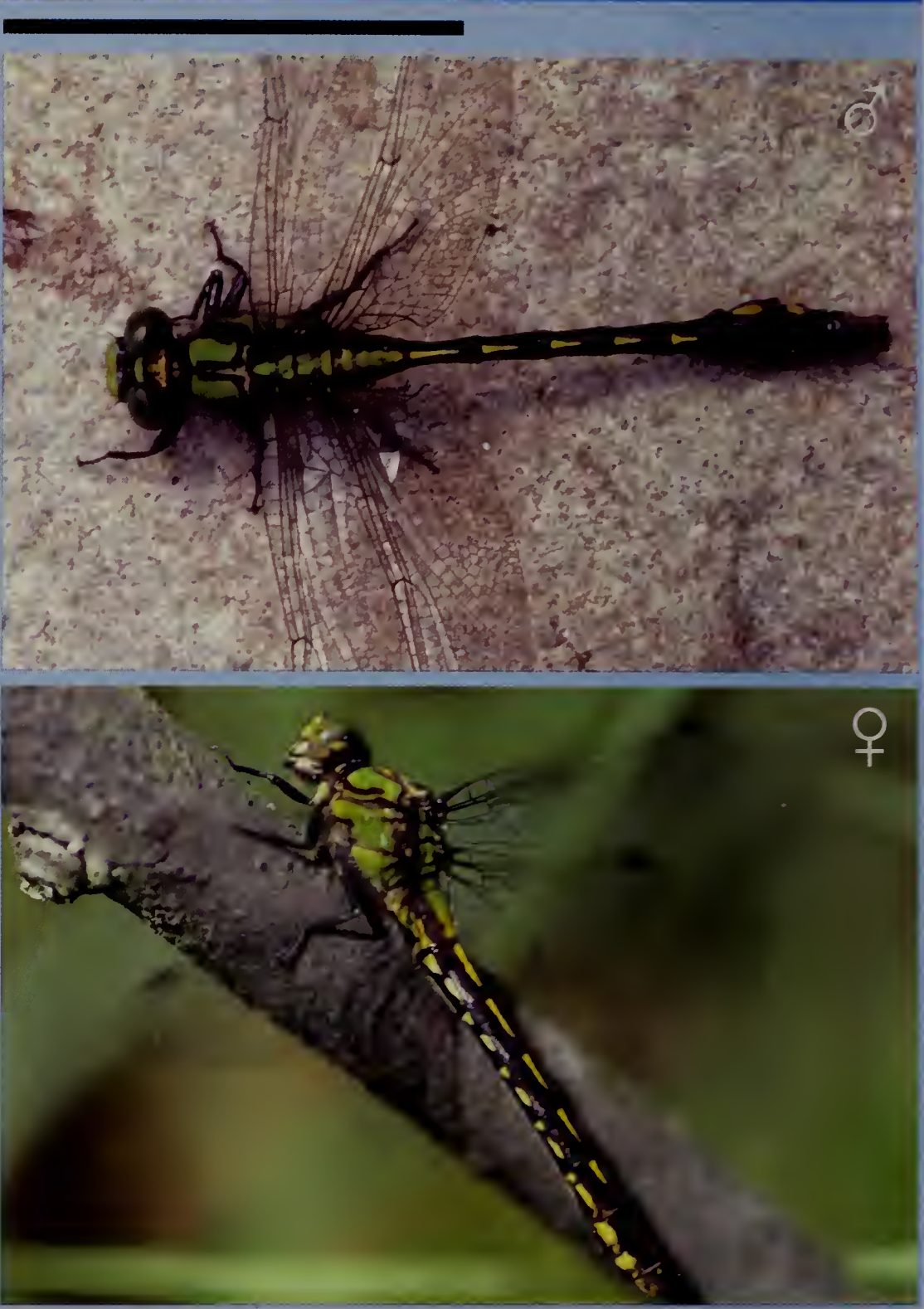

RANGE/STATUS A narrow band along the northeastern U.S., extending into southeastern Canada. An uncommon species found in central and western MA. HABITAT Clear, rocky streams.

NOTES Adults hunt in fields and clearings. Males perch on rocks in streams or on foliage along the shore.

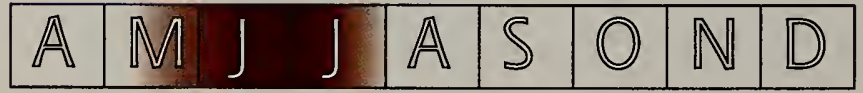


Male thorax bright green with thin, pale brown middorsal stripe, narrow brown shoulder stripes, and faint lateral stripe; abdomen rusty brown with moderately sized club, dull blackish patches on 53-59, dull yellow dorsal and lateral spots on S8-S10; terminal appendages dull yellowish. Eyes green to blue-green. Face green and unmarked. Legs pale at base. Female similar but abdomen thicker. Rusty-brown abdomen and faint thoracic pattern distinctive among the snaketails.

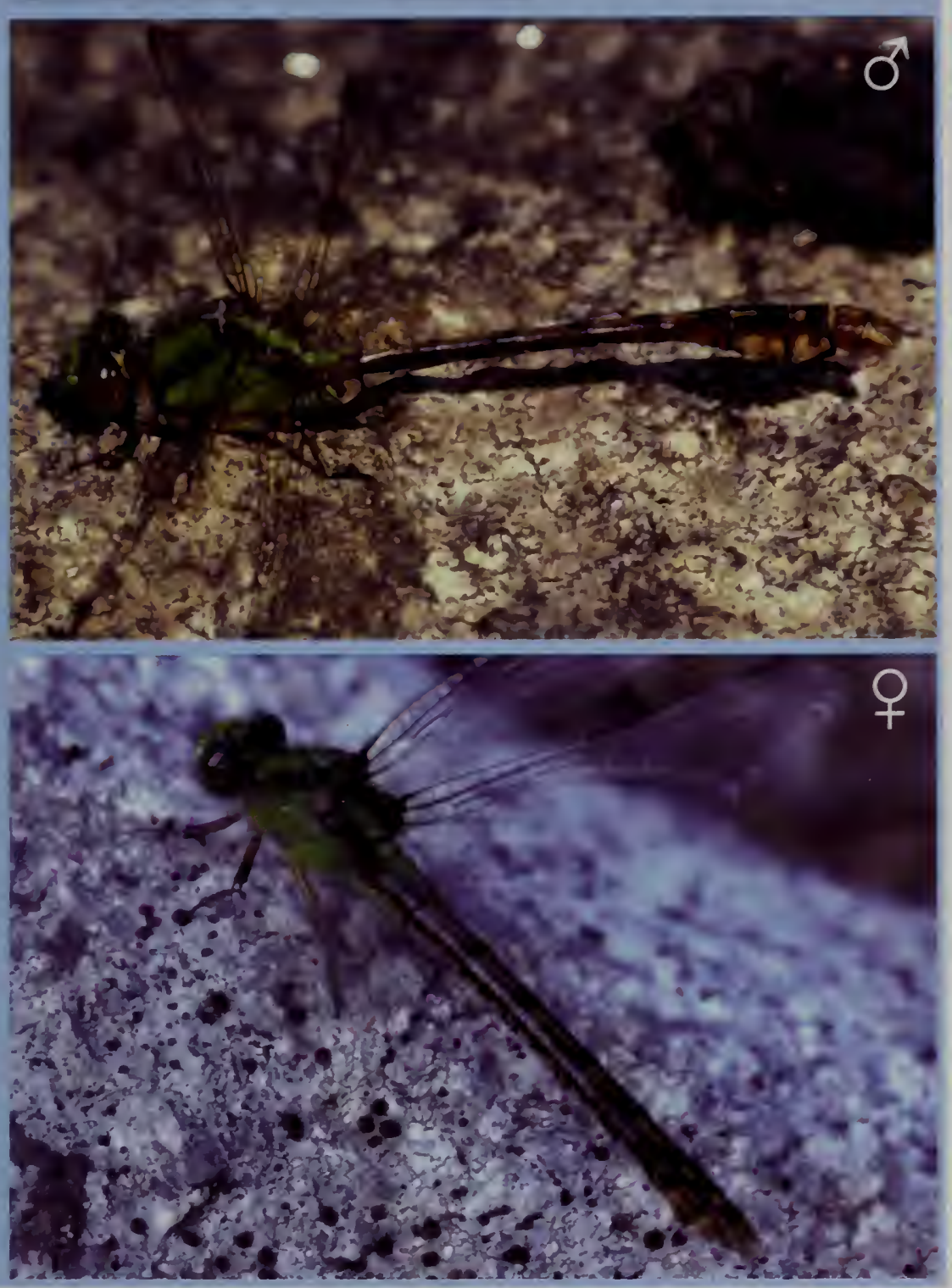

RANGE/STATUS Northeastern U.S.; south-central to southeastern Canada. An uncommon species found in northeastern, central, and western MA.

HABITAT Swiftly to moderately flowing large streams and rivers. Apparently more tolerant of silt than other snaketails (Ophiogomphus spp.).

NOTES Adults hunt in fields and forest openings near water, also visiting hill tops. They perch on branches and other protruding vegetation and may also perch on the ground or on rocks near the water. Males fly low over riffles and rapids, making erratic patrols. Active until late in the day.

\begin{tabular}{|l|l|ll|l|l|l|l|l|}
\hline $\mathbb{A}$ & $\mathbb{M}$ & $\mathbf{J}$ & $\mathrm{J}$ & $\mathbb{A}$ & $\mathbb{S}$ & $\mathbb{O}$ & $\mathbb{N}$ & $\mathbb{D}$ \\
\hline
\end{tabular}




\section{CORDULEGASTRIDAE: SPIKETAILS}

Spiketails are very large, brown or black dragonflies with bold yellow markings. At least 35 species are known worldwide, with eight species in North America, all in the genus Cordulegaster. Three species occur in Massachusetts.

Spiketails range in length from about $2 \frac{1}{2}$ to 3 inches and are superficially similar to darners (Aeshnidae, p. 69). However they behave quite differently, and their eyes, though large, do not meet in a seam but rather barely touch at one point. The eyes are bright green or bluish-green. The three Massachusetts species are dark brown to blackish with two yellow stripes on the sides of the thorax, yellow stripes or spots on top of the thorax, and yellow markings on the abdomen that can be used to distinguish the species. The wings are clear. Females are identical to males in pattern and coloration, but have thicker abdomens and prominent ovipositors on the underside of the eighth

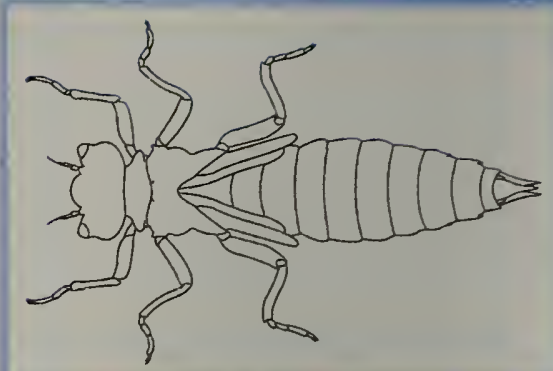

Spiketail larvae are robust and hairy, golden brown in color with short, fine antennae, and a mask-like labium. They use their hind legs to kick up sediment, burrowing down backwards into the muck until just their eyes and antennae remain visible.

\section{abdominal segment. The long ovipositor extends beyond the tip of the abdomen, giving the} family their common name "spiketails". Identification is fairly straightforward, based on the distinctive abdominal patterns.

Spiketails inhabit streams or seeps where there is at least a slight water flow. They are most common in June and early July. Adults hunt in fields and woodland clearings, and perch obliquely (at about a $45^{\circ}$ angle) on vertical or overhanging stems, usually low (1-3 ft.) to the ground. They do not form feeding swarms. Males patrol up and down streams, low over the water, searching for females and prey.

Females oviposit alone, hovering in a vertical (head-up) position and rapidly punching their long ovipositor into shoreline mud in a sewing machine like fashion. Larvae are hairy and sub-cylindrical (slightly dorso-laterally flattened) in shape, and are found in pools below riffles or rapids, lurking just below the substrate. The larvae burrow into loose sand and substrate or kick sand and silt up over their bodies, disguising themselves as they lie in wait for prey. The larval stage is thought to last from 2 to 5 years. 


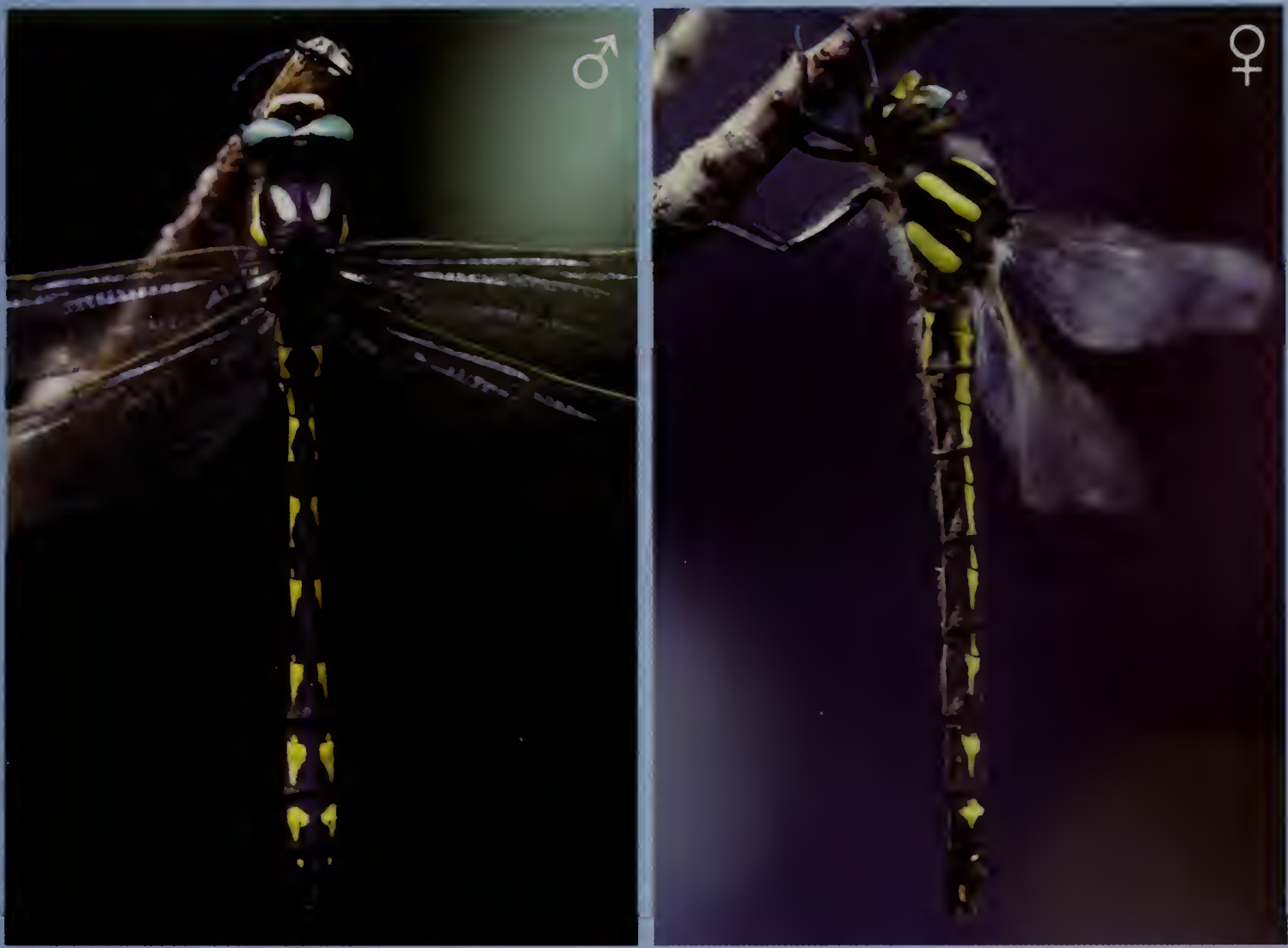

The smallest of the three MA spiketails. Male thorax blackish with two yellow dorsal stripes and two broad yellow lateral stripes; abdomen black, with yellow lateral spots on S1-S9, those on S3-S8 dagger-shaped. Eyes green. Female similar but with thicker abdomen and prominent ovipositor. Similar to Twin-spotted Spiketail (p. 122) and Arrowhead Spiketail (p. 123), but abdominal pattern distinct and female ovipositor shorter.

RANGE Northeastern U.S.; southeastern Canada. Fairly common throughout MA, but absent from most of the southeast coastal plain.

HABITAT Small marshy streams and seeps.

NOTES Adults feed in forest clearings near streams. They perch at an oblique angle, low to the ground on twigs and vegetation along the forest or water's edge. Males patrol along streams or seeps at a height of about one foot. Females oviposit by hovering over shallow water and driving their abdomens into the shallows again and again like a sewing machine needle.

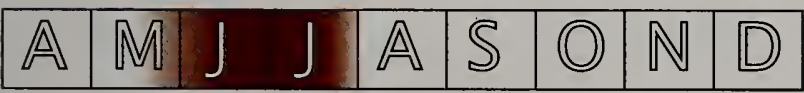



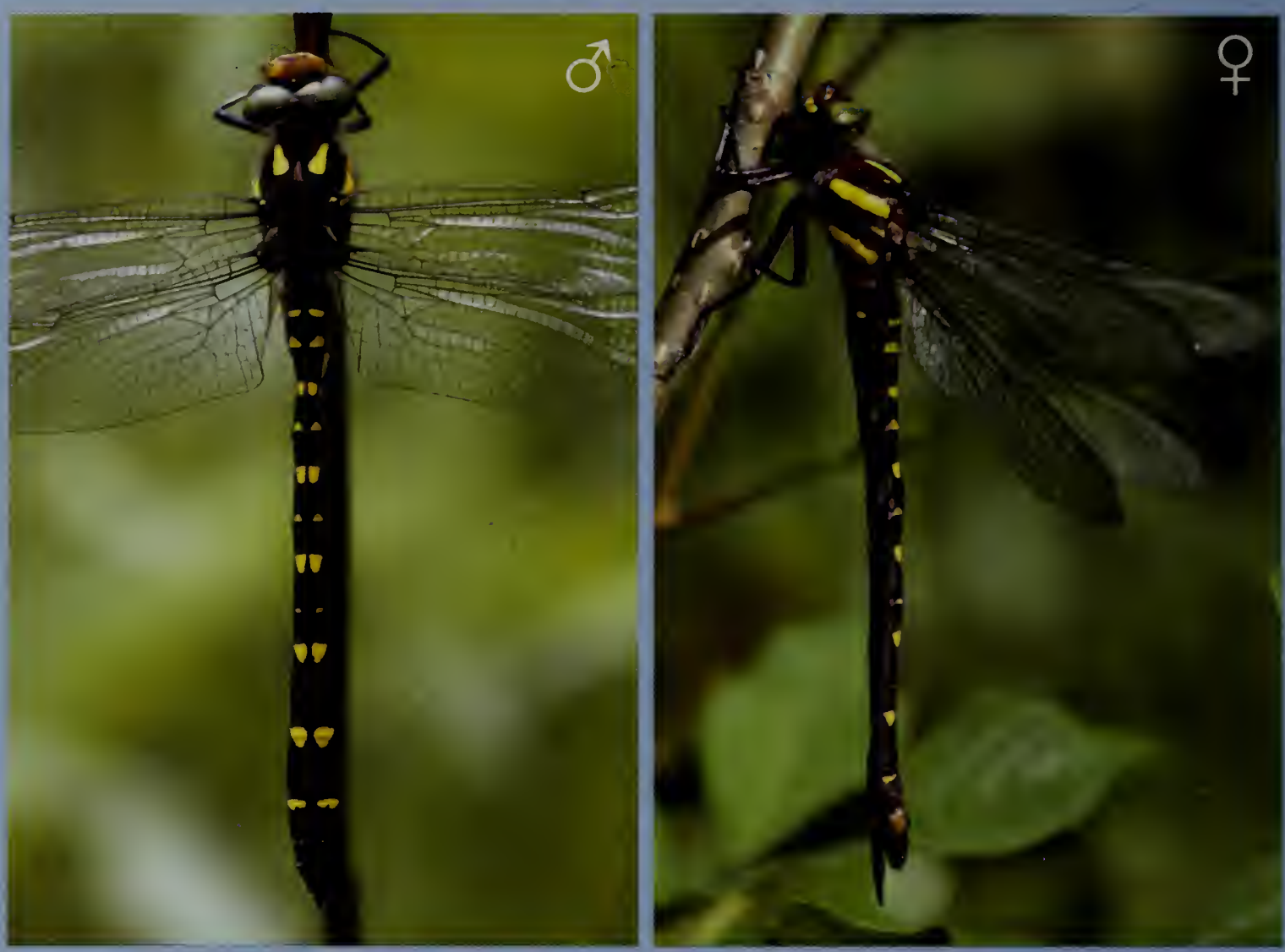

The only MA spiketail with rounded abdominal markings. Male thorax blackish with two yellow dorsal stripes and two broad yellow lateral stripes; abdomen black and slightly clubbed, with paired, round yellow dorso-lateral spots on S3-58. Eyes green. Female similar but abdomen thicker and not clubbed, with very long ovipositor. Similar to the Delta-spotted Spiketail (p. 121) and Arrowhead Spiketail (p. 123), but abdominal pattern distinctive and female ovipositor longer.

RANGE Eastern U.S.; southeastern Canada. Common throughout interior MA, but absent from the southeast coastal plain.

HABITAT Rocky forest streams and small, fast rivers.

NOTES Adults feed in forest clearings and along edges, stopping to perch at oblique angles from twigs and vegetation, usually within $3 \mathrm{ft}$. of the ground. Males patrol a few inches to a foot above water, flying long beats up and down rivers. Females oviposit by hovering over shallow water and driving their abdomens into the shallows again and again like a sewing machine needle.

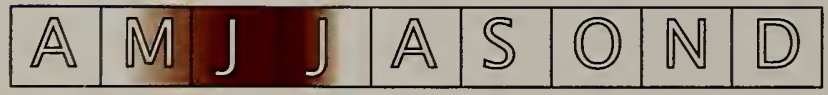




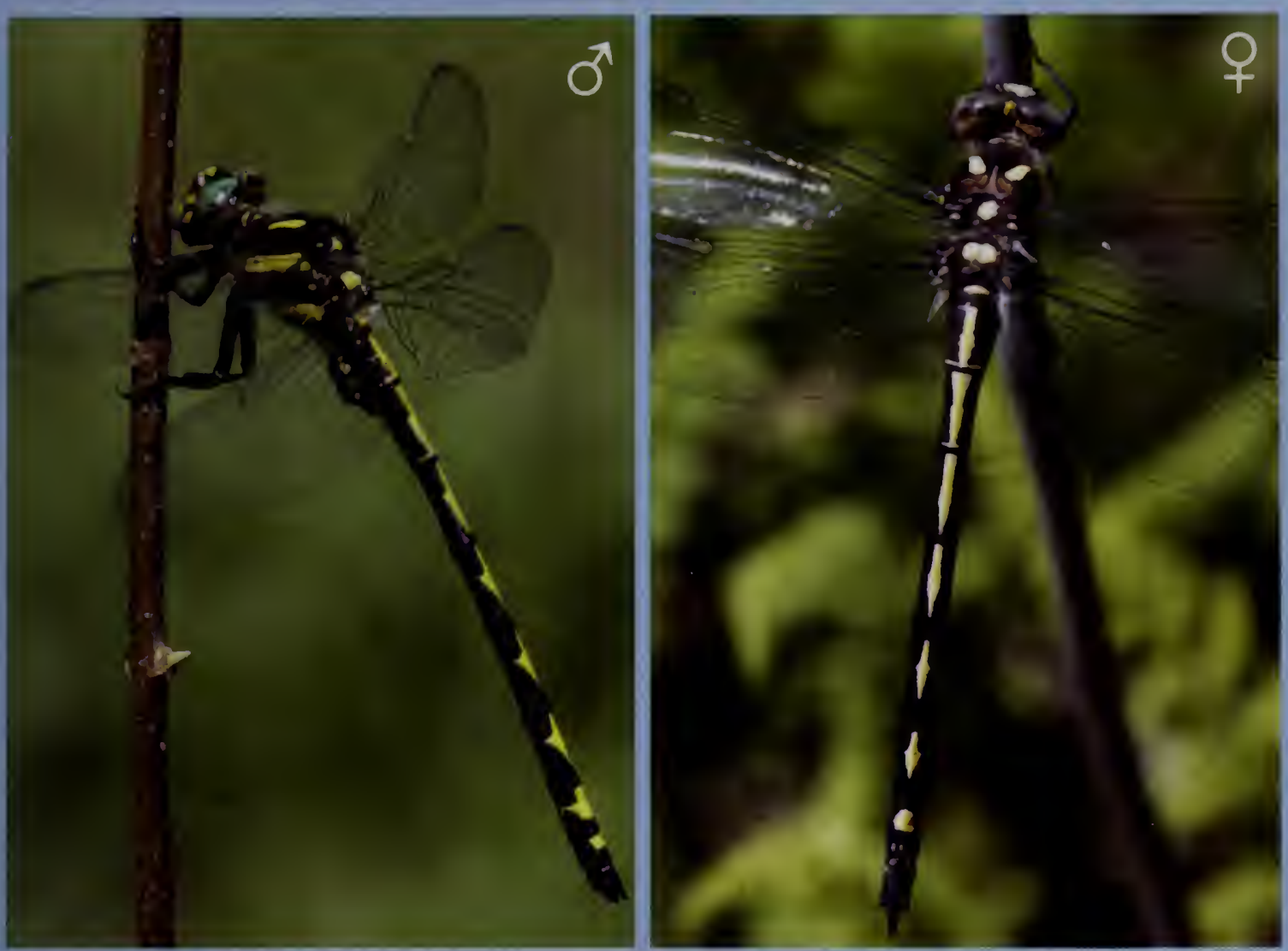

The largest of the three MA spiketails, with a distinctive abdominal pattern. Male thorax blackish with two yellow dorsal stripes and two broad yellow lateral stripes; abdomen black with yellow dorsal spots on S1-S9, those on \$4-\$8 arrowhead-shaped. Eyes green. Female similar but with thicker abdomen and prominent ovipositor. Similar to the Deltaspotted Spiketail (p. 121) and Twin-spotted Spiketail (p. 122), but abdominal pattern distinct.

RANGE Eastern U.S.; southeastern Canada. Uncommon and local in central and eastern MA.

HABITAT Semi-permanent streams and seeps.

NOTES Adults feed in forest clearings and perch low to the ground at an oblique angle on twigs and vegetation. Males make patrols along streams at a height of $1-3 \mathrm{ft}$. Females oviposit by hovering over shallow water and driving their abdomens into the shallows again and again like a sewing machine needle.

\begin{tabular}{|l|l|l|l|l|l|l|l|l|}
\hline $\mathbb{A}$ & $\mathbb{M}$ & $\mathrm{J}$ & $\mathbb{J}$ & $\mathbb{A}$ & $\mathbb{S}$ & $\mathbb{O}$ & $\mathbb{N}$ & $\mathbb{D}$ \\
\hline
\end{tabular}




\section{MACROMIIDAE: CRUISERS}

Cruisers are fairly large, brown to black dragonflies with yellow markings. There are at least 150 species worldwide, with nine species and two genera in North America. In Massachusetts, two species (of two genera) occur. The Massachusetts species are both widely distributed across the state.

Cruisers are brown to black in color and easily identified as a group by a single yellow stripe on the side of the thorax. They also have yellow bars and/or stripes on top of their thoraxes, a yellow cross-stripe on their faces, and yellow markings on their abdomens. Species in the genus Macromia have brilliant green eyes when mature. Cruisers are similar to spiketails (Cordulegastridae, p. 120) in general appearance, but their eyes meet in a seam on top of the head, they have just one pale lateral stripe on the thorax, and a yellow cross-stripe on the face. Body color, abdominal pattern, and eye color readily distinguish the two Massachusetts species.

Cruisers inhabit rivers, ponds, and lakes where the males patrol at low to moderate heights over the water. They perch either obliquely or vertically from vegetation. The Stream Cruiser (Didymops transversa) usually perches within 2-3 ft. of the ground, while the Illinois River Cruiser

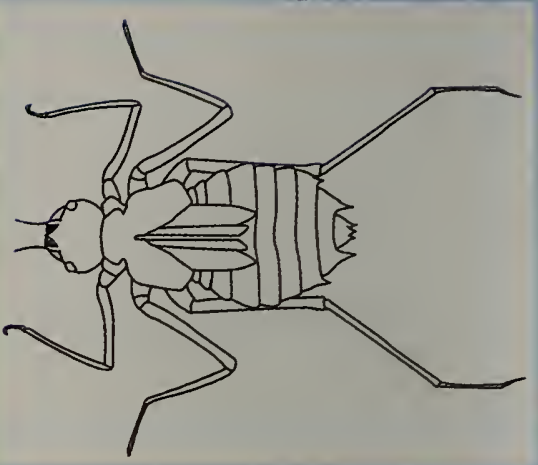

Cruiser larvae are very distinctive with their spiderlike shape. They have a flat abdomen, sprawling, long legs, a triangular horn protruding from between their eyes, and a mask-like labium. They are sprawlers in habit, lying in wait in the shallow reaches of lake bottoms or the slow sections of streams and rivers. They become covered with a fine layer of sediment, further camouflaging their golden brown form, as they lay in wait for prey.

(Macromia illinoiensis) often perches high in trees. Both species feed along woodland edges, over clearings, and along dirt roads. Females oviposit by flying rapidly low over the water and tapping the surface frequently with the tips of their abdomens to release their eggs, which then drop to the bottom. Larvae sprawl on the substrate and are very broad and flattened with very long legs, giving them a spider-like appearance. Emergence takes place many feet from the water (in some cases over a hundred feet), and the exuviae may be found on rocks, bridge abutments, docks, trees and even buildings. 

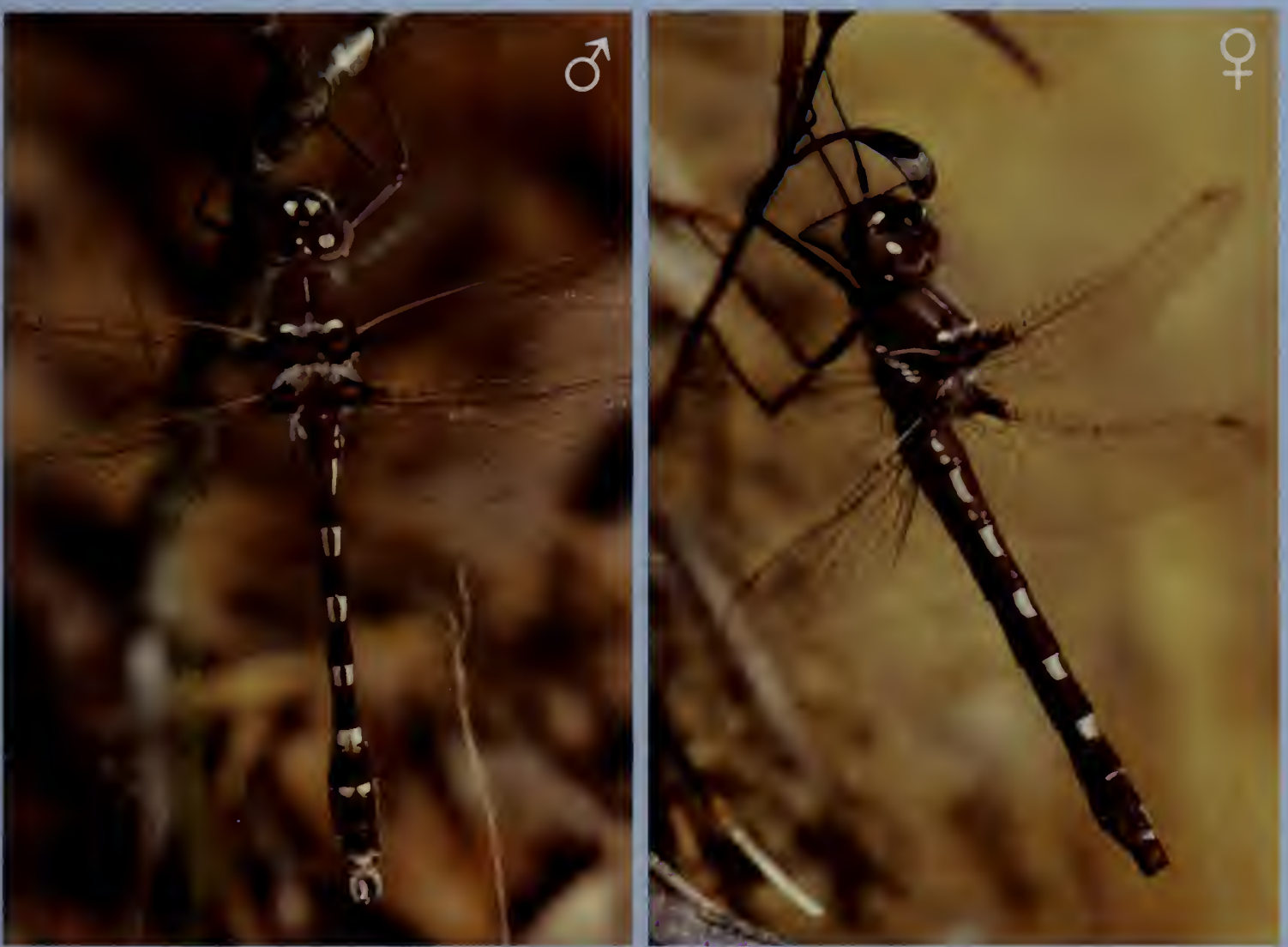

Somewhat clubtail-like in appearance, but behavior very different. Male thorax brown with pale yellow dorsal crossbar at base of wings and a single ivory lateral stripe; abdomen brown and slightly clubbed, with paired, ivory dorsal spots on S2-57, those on S7-S8 fused; terminal appendages dull yellow. Eyes brown to dull olive-green. Face dark with two yellow cross-stripes. Wings with small, dark brown basal patches and, when young, yellow leading edges; occasionally tinted brown. Female similar but stockier and abdomen not clubbed.

RANGE Eastern U.S.; southeastern Canada. Common throughout MA. HABITAT Sand-bottomed streams and rivers with a slow to medium current, large ponds, and lakes.

NOTES Adults hunt low over fields and dirt roads, flying in and out of vegetation. They perch obliquely from branches and grasses, usually 1-3 ft. above the ground. Males patrol along the water's edge at moderate heights. Females oviposit by striking their abdomens on the surface of the water, often near the shore.

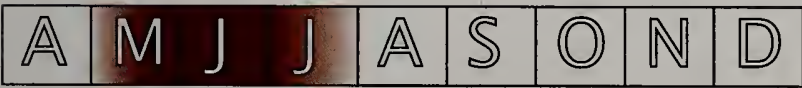



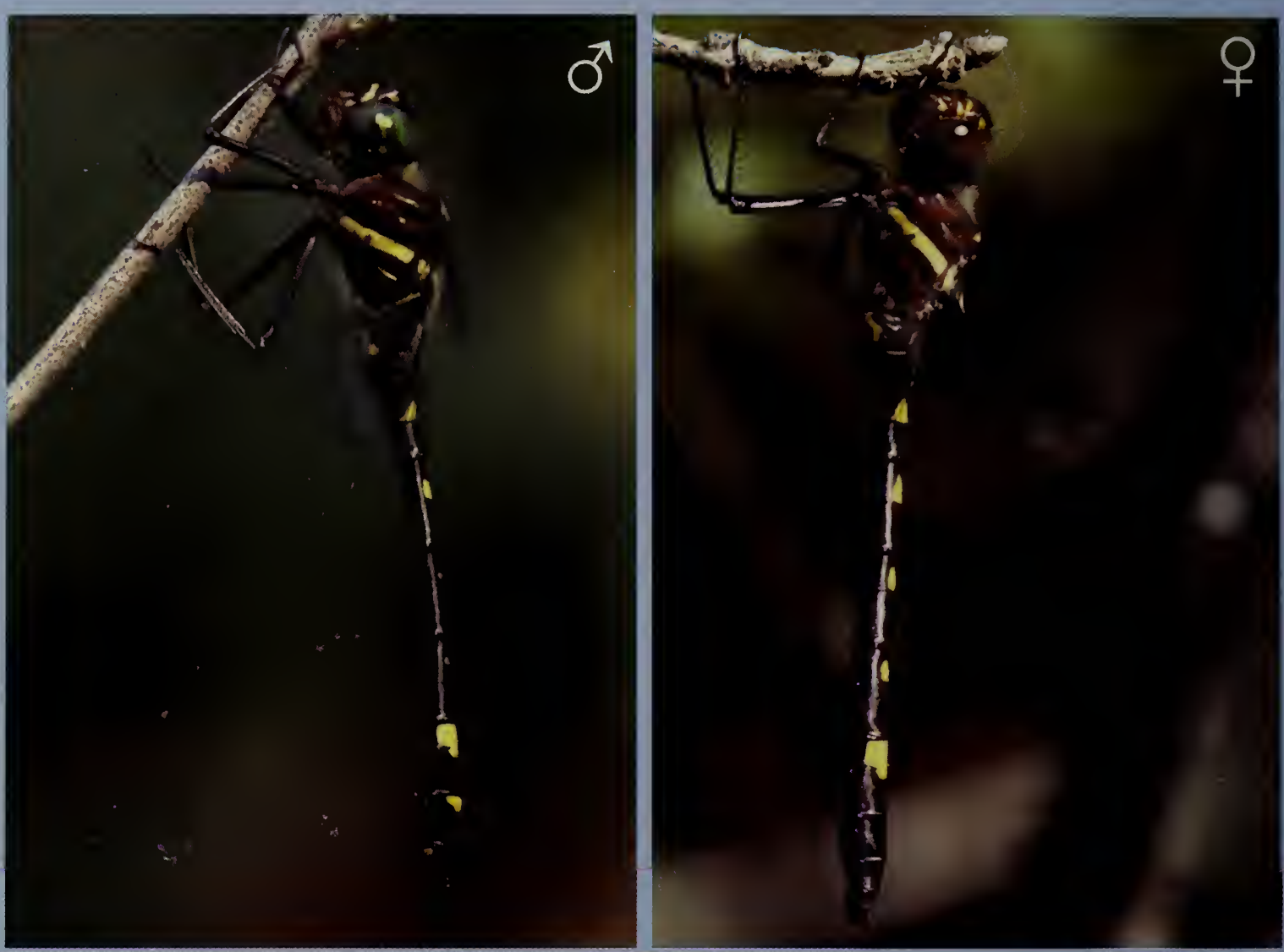

Our only species with bright green eyes combined with a single lateral thoracic stripe. Male thorax dark brown with short, pale dorsal streaks (often obscured) and a single yellow lateral stripe; abdomen black and slightly clubbed, with prominent yellow dorsal spot on 57 and smaller dorsal spots on S2, S3, and occasionally S8. Eyes bright green when mature. Face dark with two yellow cross-stripes. Female similar but abdomen thicker and not clubbed, yellow dorsal markings more extensive, and eyes less green.

RANGE Eastern U.S.; southeastern Canada. Fairly common throughout MA. HABITAT Rivers and lakes.

NOTES Adults hunt along forest edges and dirt roads flying at a height of 3-6 ft. When hunting along roads they often patrol back and forth following a beat of a few hundred feet. They sometimes can be seen high overhead in late-afternoon feeding swarms. Males patrol low along the water's edge. Females oviposit by striking their abdomens on the surface of the water, often near the shore.

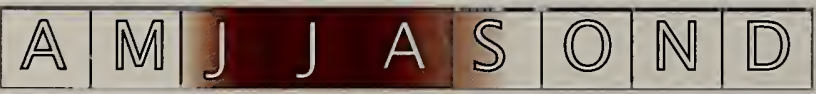




\section{CORDULIIDAE: EMERALDS}

Emeralds are a diverse group of dragonflies. Over 200 species have been described worldwide. About 50 species in seven genera are known in North America, and 22 of these have been found in Massachusetts. The family is essentially northern in distribution and includes a few species that are found as far north as any odonate.

Emeralds range in length from about $1 \frac{1}{2}$ to nearly 3 inches. Their bodies are brown to blackish, often with pale yellow or white markings. In mature individuals of many species the eyes are bright, iridescent green. The wings are generally clear, though in baskettails (Epitheca spp.) are variably marked with dark patches or spots. Females are very similar to males in most species, but with duller eyes and thicker abdomens. Although genera can often be recognized in the field with experience, identification to species is very difficult, typically requiring in-hand examination of subtle body markings, male terminal appendages (p. 128) or the female subgenital plate (refer to Needham et al., 2000).

Members of the Emerald family inhabit a wide variety of wetlands, including bogs, ponds, lakes, and rivers, though

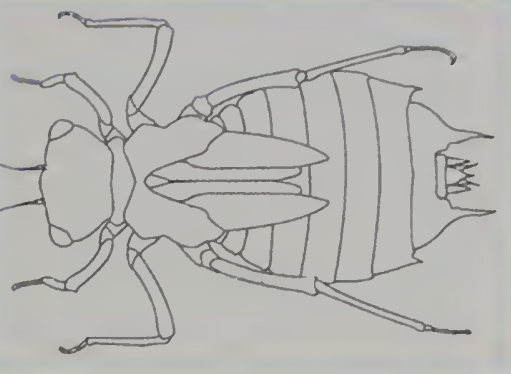

Emerald larvae have long spines or bumps down the back and long spines on the tip of their abdomens. They have a wedge shaped head and masklike labium, with the long legs of an insect that sprawls on the bottom or climbs through aquatic vegetation. The sprawlers, those that lie in wait on the bottom, are often dark and hairy, and those that climb among vegetation are smooth and patterned with golden brown and greens. Very similar to skimmer larvae. many species have very specific habitat requirements. Emeralds are on the wing during the spring and summer, with baskettails (Epitheca spp.), Ulher's Sundragons, and especially boghaunters (Williamsonia spp.) having some of the earliest flight seasons of any odonates. Although not particularly secretive, many have inconspicuous habits, which combined with their drab appearance makes them difficult to find. The shadowdragons (Neurocordulia spp.) and striped emeralds (Somatochlora spp.) are among the most elusive odonates; shadowdragons are only active for a brief period at dusk, apparently spending the remainder of the day high in treetops. Emeralds perch either vertically or obliquely from vegetation. Many species (especially the baskettails and striped emeralds) spend long periods on the wing and will join mixed-species feeding swarms over upland fields and clearings, often late in the day.

Males patrol over breeding sites at low to moderate heights. Females exhibit a wide range of ovipositing behaviors, though all oviposit alone. Some oviposit by flying low over the water, tapping the surface repeatedly to release eggs. Others lay eggs in wet mud or shallow water at the edges of wetlands, inserting their well-developed ovipositors into the substrate. Female baskettails have a unique method of oviposition, in which all the eggs are connected in a chain which the female carries balled up under the tip of the abdomen until finding an appropriate site, at which point the ball is released into the water where it unwinds. Emerald larvae are spider-like and are hairy or patterned with brown and green. They crawl amongst submerged root clumps and vegetation. Emergence often takes place many feet from the water on rocks, sides of buildings, emergent vegetation, and tree trunks. 


\section{TERMINAL APPENDAGES: SOMATOCHLORA}

Identification of the 11 species of striped emeralds (genus Somatochlora) in Massachusetts is difficult and rarely possible without examination of the male terminal appendages or the female vulvar lamina. Other features that can be useful are overall size and thoracic pattern. Most species have yellow lateral spots on the thorax, the size and shape of which can provide clues to identification (see the species accounts). Male appendages are illustrated below; for female identification refer to the technical manuals (e.g., Needham, et al., 2000).

The diagrams below show a lateral (side) view of male abdominal segment 10 (S10) and the terminal appendages. With the exception of the Coppery Emerald, the coloration of the terminal appendages is not important in identification; in these illustrations S10 is light gray, superior appendages (SA) medium gray, and inferior

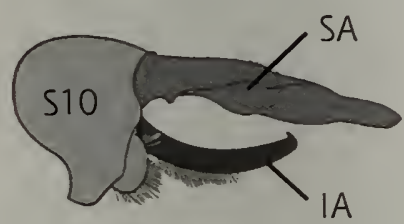
appendages (IA) dark gray. Illustrations are generally grouped with the largest animals above, smaller below.

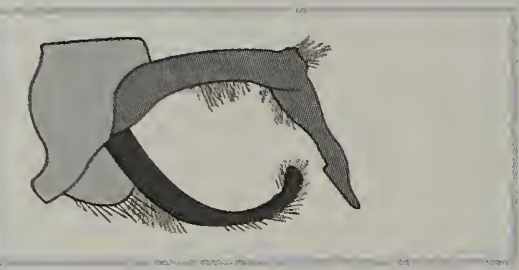

Clamp-tipped Emerald

Somatochlora tenebrosa, p. 130
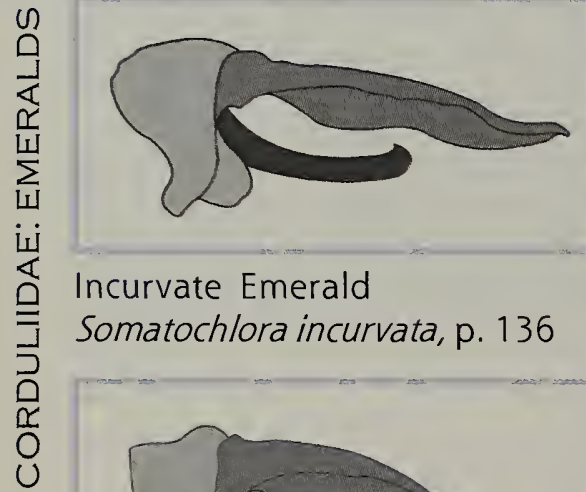

Incurvate Emerald Somatochlora incurvata, p. 136

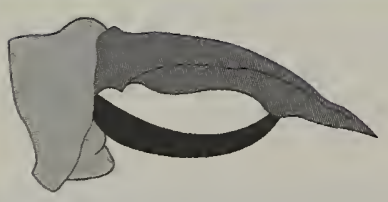

Forcipate Emerald Somatochlora forcipata, p. 135

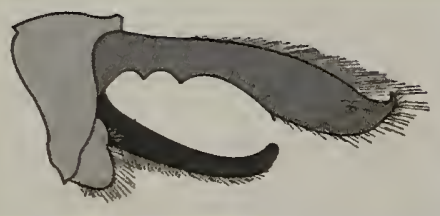

Brush-tipped Emerald Somatochlora walshii, p. 129

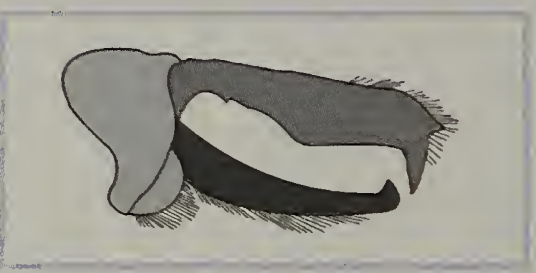

Mocha Emerald

Somatochlora linearis, p. 133

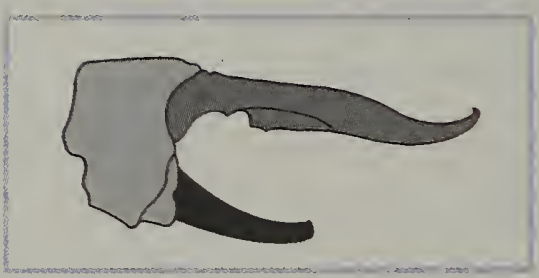

Ski-tailed Emerald

Somatochlora elongata, p. 132

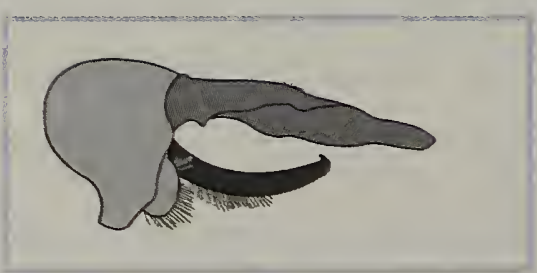

Kennedy's Emerald

Somatochlora kennedyi, p. 134

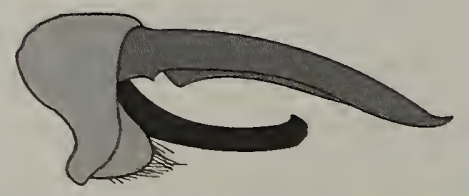

Ocellated Emerald

Somatochlora minor, p. 139

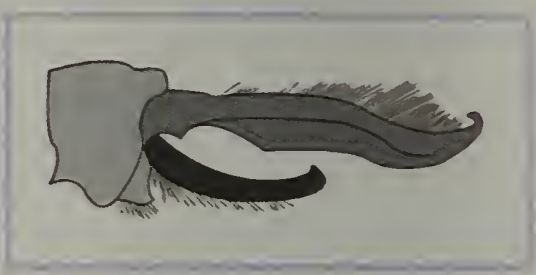

Williamson's Emerald Somatochlora williamsoni, p. 131

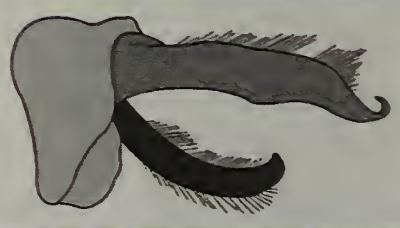

Lake Emerald Somatochlora cingulata, p. 137

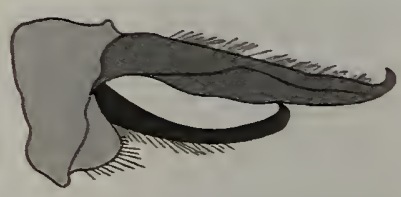

Coppery Emerald Somatochlora georgiana, p. 138 


\section{Brush-tipped Emerald Somatochlora walshii}
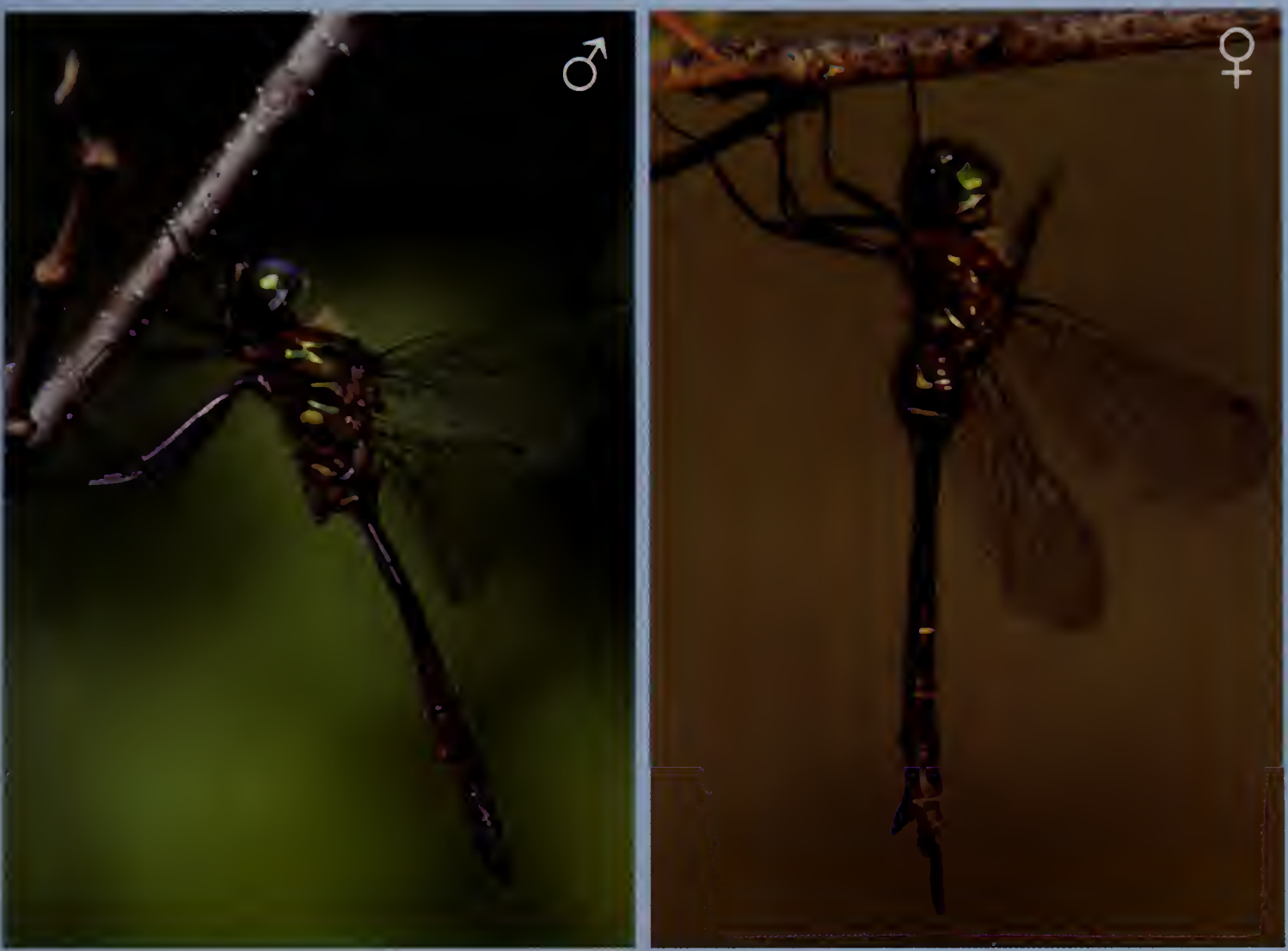

One of the smallest striped emeralds in MA. Male thorax blackish with dull greenish iridescence and two yellow lateral markings, the anterior mark elongate, forming a short stripe, the posterior shorter, more rounded and brighter (both marks fade with age); abdomen rather short and black with yellow lateral spot on 52 , pale basal ring on 53 , and small yellowish lateral spots on S5-S7 (occasionally S4 or S8) which fade with age. Eyes bright green when mature. Male superior appendages blunt distally and hairy (p. 128). Female similar, but wings occasionally tinged amber; ovipositor dark and obliquely triangular in shape. Similar to other small striped emeralds and safely identified only in the hand.

RANGE/STATUS Northeastern and northwestern U.S.; southern Canada. Fairly common throughout MA but not recorded from the southeast coastal plain. HABITAT Slow, clear streams running through bogs, fens, and marshes.

NOTES Adults forage along forest edges, often joining late afternoon feeding swarms. Males patrol along streams, flying at a height of about $3 \mathrm{ft}$. with abdomens slightly arched, hovering and darting frequently. Females oviposit by repeatedly dipping the tips of their abdomens into the water near emergent vegetation.

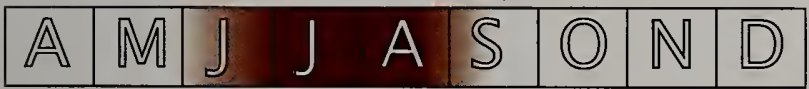



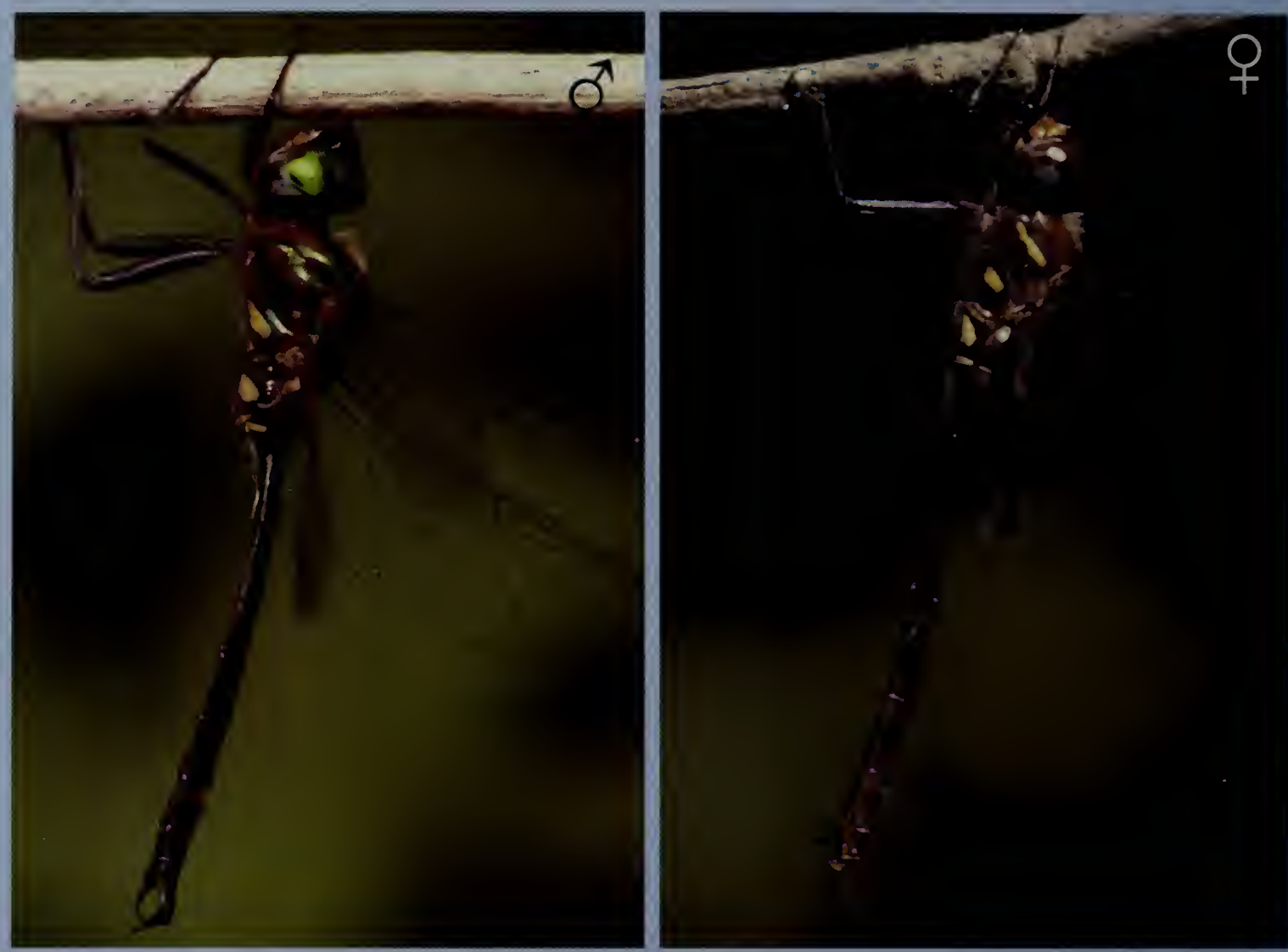

One of the larger emeralds in MA. Male thorax blackish with dull greenish iridescence and two yellow lateral stripes, the posterior stripe shorter and more ovate; both marks fade with age; abdomen black with pale lateral spot on S2 and a pale basal ring on S3. Eyes bright green when mature. Male appendages distinctly clamp-shaped in side view, with dorsal spike on superiors (p. 128). Female similar but abdomen stockier, occasionally with faint spots on S5-S8, with thorn-shaped ovipositor nearly perpendicular to abdomen (angled slightly rearward) and wings occasionally tinged with amber. Similar to other large striped emeralds, but male appendages distinctive and often visible in the field.

RANGE/STATUS Eastern U.S.; narrow band along the eastern Canadian border. Fairly common throughout most of MA (the most widespread Somatochlora in the state), but rather rare to absent on Cape Cod and the islands.

HABITAT Boggy wetlands and shaded forest streams.

NOTES Adults hunt along forest edges (often in the shade) and over fields flying at varying heights. They are most active in the early morning and late evening. They perch in the shade on vegetation, hanging vertically, high in trees. Males patrol streams at a height of $2-3 \mathrm{ft}$., staying in the shade and hovering frequently. Females oviposit by tapping their abdomens on the water near rocks and vegetation or in mud along the shoreline.

\begin{tabular}{|l|l|l|l|l|l|l|l|l|}
\hline $\mathbb{A}$ & $\mathbb{M}$ & $\mathbb{N}$ & $\mathrm{J}$ & $\mathrm{A}$ & $\mathrm{S}$ & $\mathrm{O}$ & $\mathbb{N}$ & $\mathbb{D}$ \\
\hline
\end{tabular}



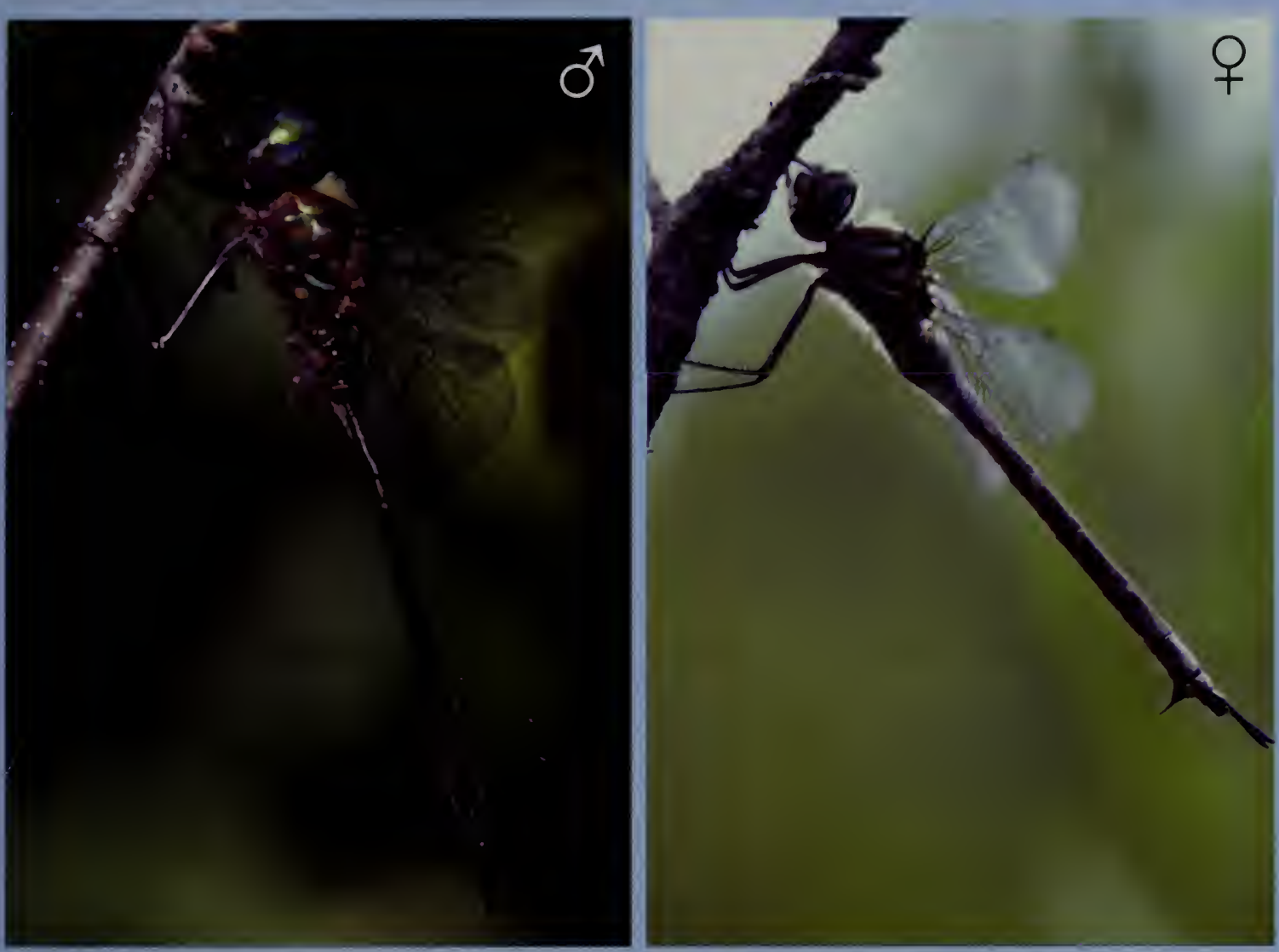

One of the larger emeralds in MA. Male thorax blackish with dull greenish iridescence and two yellow lateral marks, the anterior mark elongate and forming a stripe, the posterior shorter and more rounded; both marks darken with age; abdomen black with yellow lateral spot on S2, pale basal ring on S3, and faint pale lateral spots on S6-S8 which darken with age. Eyes bright green when mature. Male superior appendages recurved at tip and hairy. Female similar but wings occasionally tinted with amber, abdomen thicker with pale lateral spots on S4-S8; ovipositor thorn-shaped and perpendicular to abdomen. Very similar to other large striped emeralds and positively identified only in the hand. Female is especially similar to the Clamp-tipped Emerald (p. 130).

RANGE/STATUS Northeastern U.S. south through the Appalachian Mountains; southeastern Canada. Fairly common throughout MA but absent from the southeast coastal plain.

HABITAT Shady streams and bog-bordered ponds.

NOTES Adults feed in forest clearings, sometimes joining late afternoon feeding swarms. They have been observed flying at heights of 30-50 ft. Males patrol along streams, just above the water in shade or much higher over open water. Females oviposit by tapping their abdomens into mud and mosses along the waterline.

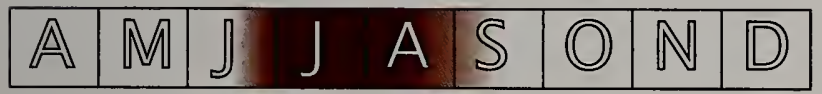



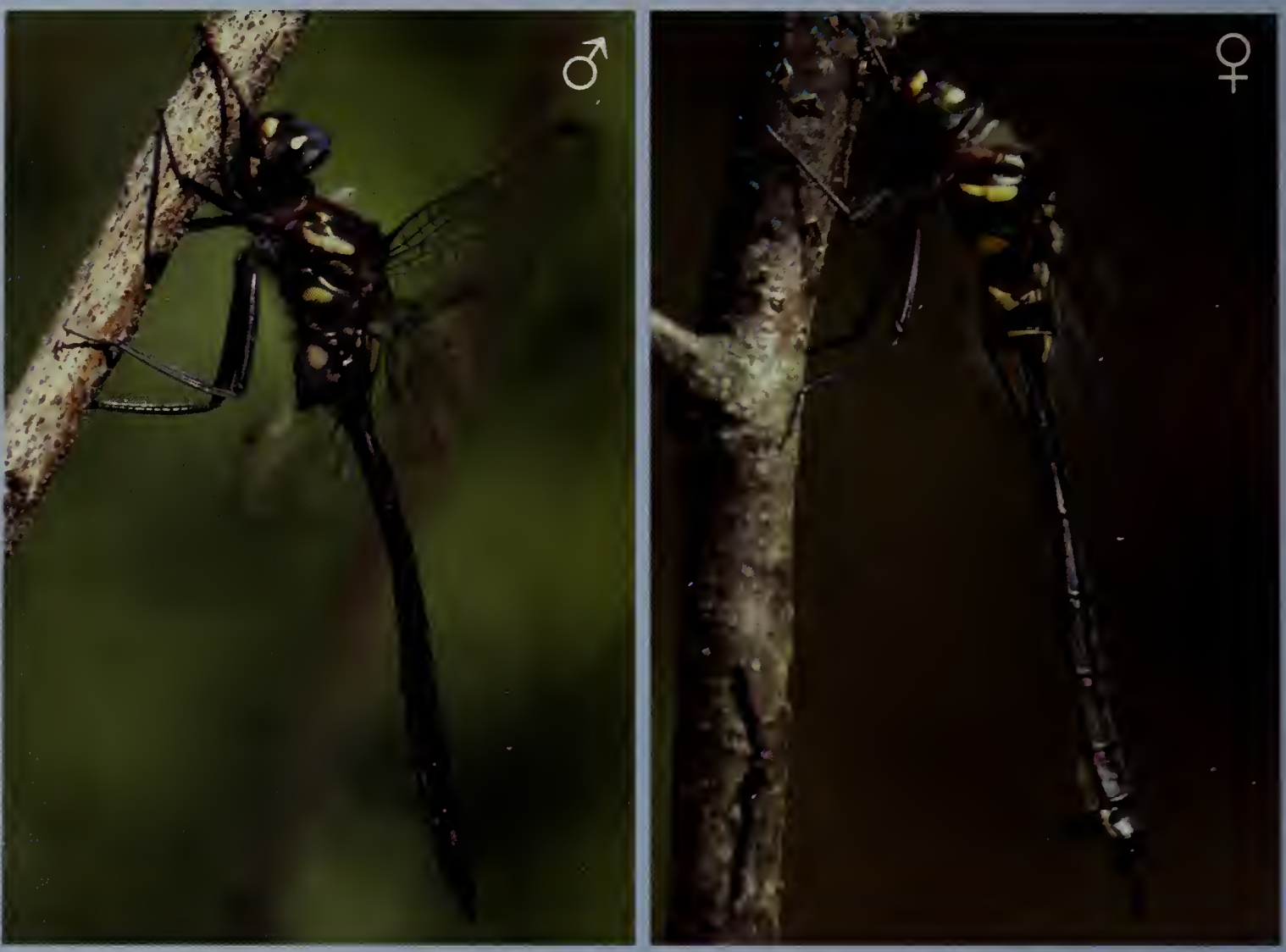

One of the larger emeralds in MA. Male thorax blackish with dull greenish iridescence and two yellow lateral marks, the anterior mark elongate forming a stripe, the posterior shorter and more rounded; both marks fade with age; abdomen long and slender, basally constricted, black with yellow lateral spot on $\$ 2$ and pale basal ring on $\$ 3$. Eyes bright green when mature. Male superior appendages curve upward at tips (p. 128): Wings occasionally washed with pale amber. Female similar, but abdomen thicker with triangular ovipositor protruding at a right angle to the tip of abdomen. Very similar to other large striped emeralds, especially the Clamp-tipped Emerald (p. 130) and Williamson's Emerald (p. 131). Female's thick, triangular ovipositor is distinctive.

RANGE/STATUS Northeastern U.S. south through the Appalachian Mountains; southeastern Canada. Uncommon in north-central and western MA. HABITAT Very small, shaded streams and outlets of beaver ponds. NOTES Adults forage high in forest clearings. Males patrol along shorelines, frequently hovering, and occasionally perching on low vegetation. Females oviposit by striking the tip of their abdomens onto the water's surface near the shore or in mosses just above the waterline.

\begin{tabular}{|l|l|l|ll|l|l|l|l|}
\hline $\mathbb{A}$ & $\mathbb{M}$ & $\mathbb{J}$ & J & A & $\mathbb{S}$ & $\mathbf{O}$ & $\mathbb{N}$ & $\mathbb{D}$ \\
\hline
\end{tabular}




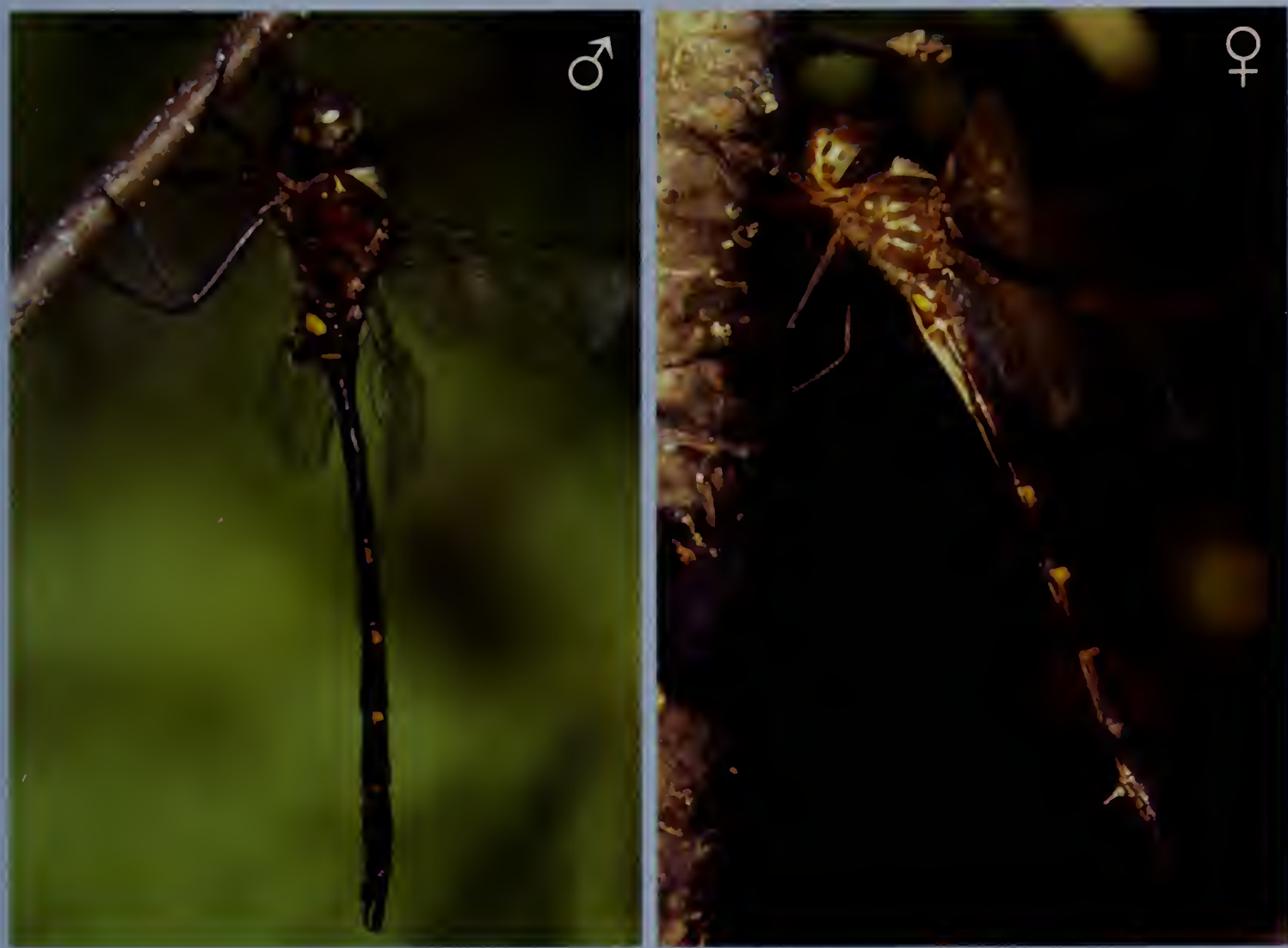

One of the largest and drabbest emeralds in MA. Male thorax dark brown with dull greenish iridescence, no pale lateral markings; abdomen long and slender, basally constricted, black with yellow lateral spot on S2, pale basal ring on S3, and pale lateral spots on S3-58 that fade with age. Eyes bright green when mature. Wings occasionally suffused with brown. Male superior appendages with distinct, small distal spike (p. 128). Female similar but abdomen thicker with more prominent, pale lateral markings; wings often with extensive amber; ovipositor thorn-shaped and perpendicular to abdomen. Usually distinguishable from other striped emeralds by large size, amber wash on wings, and lack of pale thoracic markings.

RANGE/STATUS Eastern U.S. Uncommon, found in eastern MA but absent from the southeast coastal plain.

HABITAT Small, shaded streams.

NOTES Adults hunt in fields and forest openings, usually flying at a height of $6-10 \mathrm{ft}$.

They are most active in the morning and evening. Females oviposit as they fly along stream banks, inserting their abdomens into mud.

\begin{tabular}{|l|l|l|l|l|l|l|l|l|}
\hline $\mathbb{A}$ & $\mathbb{M}$ & $\mathbb{N}$ & $J$ & $A$ & $\mathbb{S}$ & $\mathbb{O}$ & $\mathbb{N}$ & $\mathbb{D}$ \\
\hline
\end{tabular}



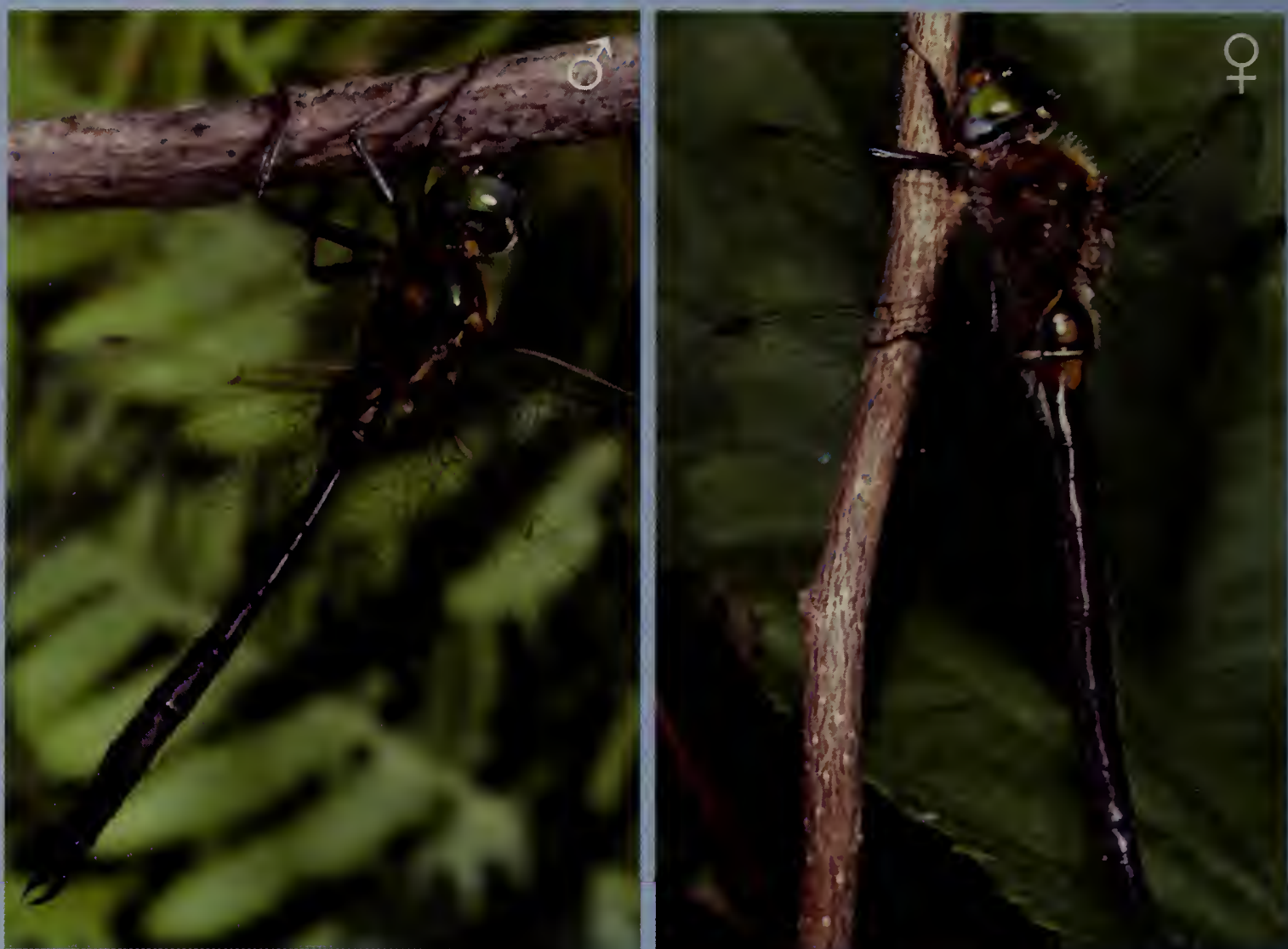

One of the drabbest of the striped emeralds. Male thorax blackish with dull greenish iridescence and no obvious pale marks; abdomen long and slender, basally constricted, black with pale lateral spot on $\$ 2$ and pale basal ring on 53 . Eyes bright green when mature. Male superior appendages curve down in side view (p. 128). Female similar but abdomen thicker, with yellowish ovipositor parallel to abdomen. Very similar to other striped emeralds but generally lacking pale lateral marks.

RANGE/STATUS Northeastern U.S.; Canada. Rare, recorded only from a few sites in central and eastern MA.

HABITAT Bogs, fens and swamps, often with flowing water.

NOTES Adults hunt in forest openings and over roads and streams, occasionally perching on low vegetation. Males patrol over open water, flying at a height of $2-3 \mathrm{ft}$. Females oviposit by tapping the tips of their abdomens into the water, releasing the eggs.

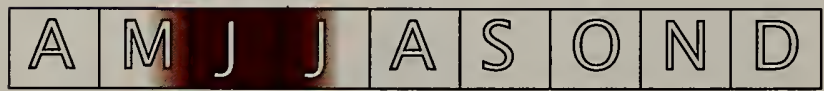


A medium-sized, slender striped emerald. Male thorax blackish with dull greenish iridescence and two yellow lateral ovals, the anterior more elongate (both marks fade with age); abdomen long and slender, basally constricted, black with yellow lateral spot on 52 , pale basal ring on 53 , and dull yellowish lateral spots on S5-S7 (occasionally S8). Eyes bright green when mature. Male superior appendages arched down in side view (p. 128). Female similar but abdomen stockier with pale lateral marks on S3-S7; ovipositor dull yellowish, relatively short, and lies flat against abdomen. Very similar to other striped emeralds and identifiable only in the hand.

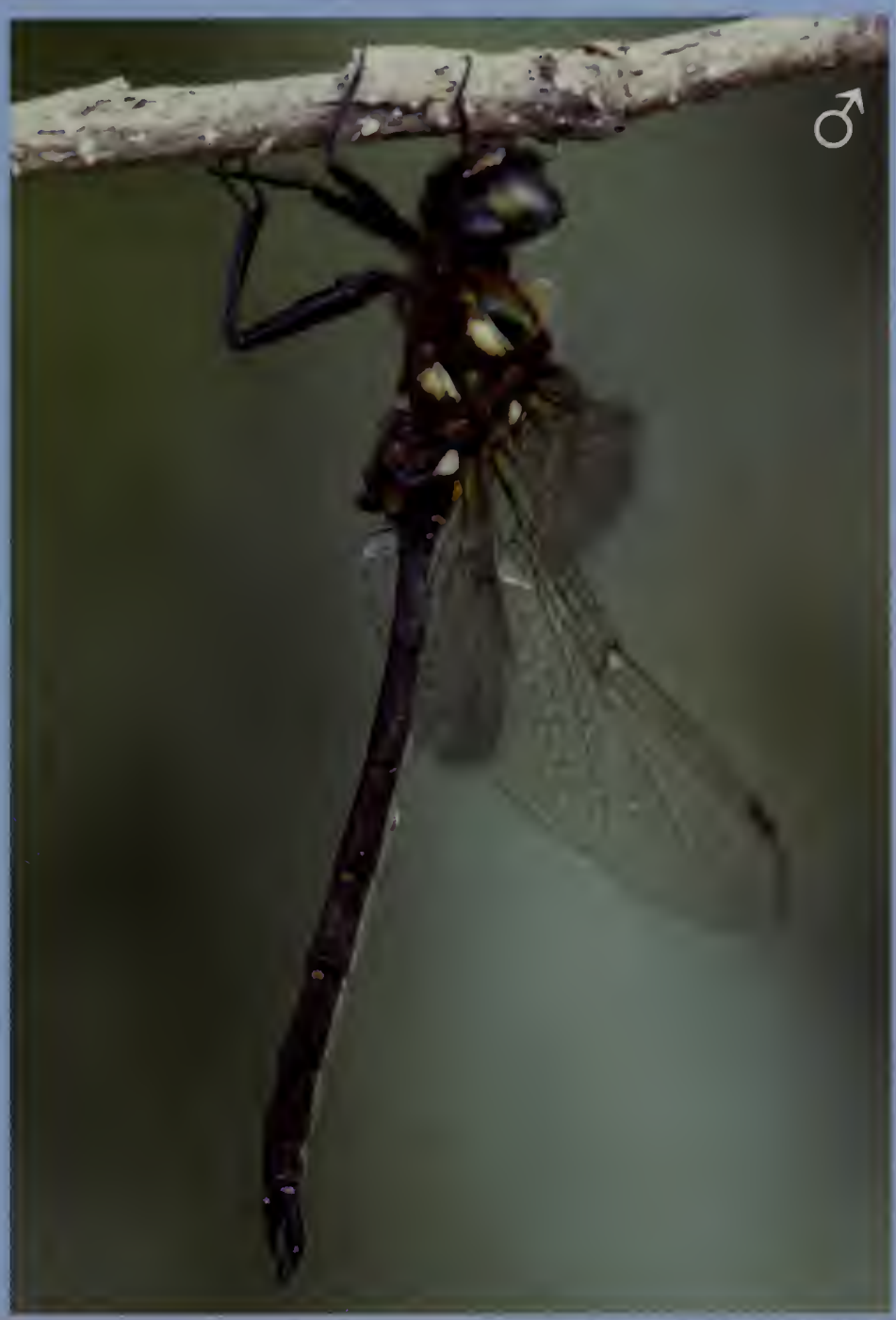

RANGE/STATUS Northeastern U.S. south through the Appalachian Mountains; southeastern Canada. Rare, recorded from a handful of sites in north-central and western MA.

HABITAT Bogs and small forested streams.

NOTES Adults forage in forest openings and along roads, often flying rather low. They perch by hanging from branches, often high in trees. Males patrol along streams. Females have been observed ovipositing by tapping the tips of their abdomens into pockets of water along stream banks.

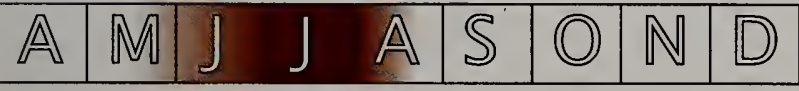



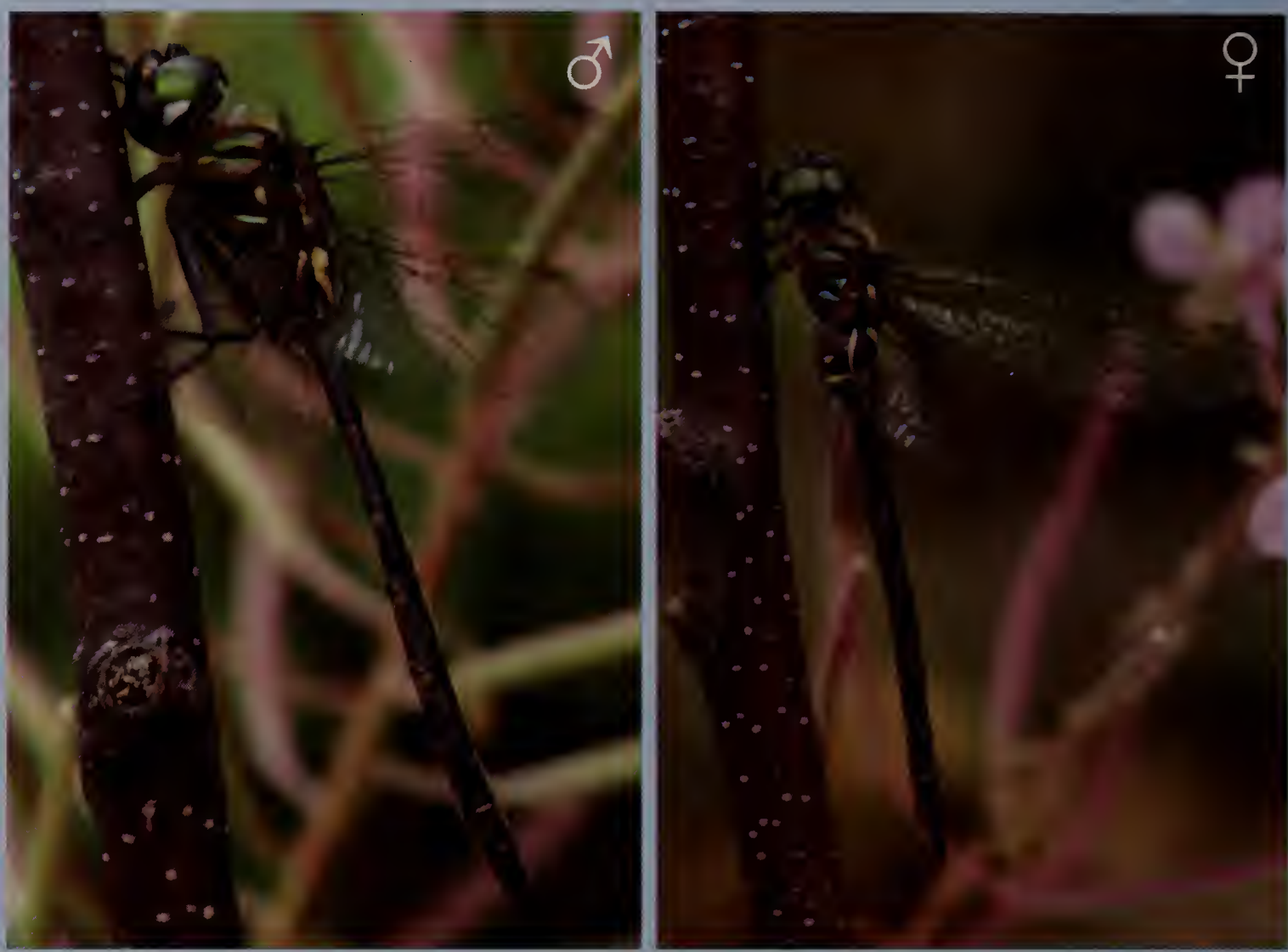

One of the larger emeralds in MA. Male thorax blackish with dull greenish iridescence and two indistinct lateral spots, the anterior spot more elongate, the posterior spot shorter and more rounded (both fade with age); abdomen long and slender, basally constricted, black with yellow lateral spot on S2, pale basal ring on S3, and diffuse, pale lateral spots on S4-S8. Eyes bright green when mature. Male superior appendages curved down in side view (p. 128). Female similar but abdomen thicker, with yellowish ovipositor parallel to abdomen. Very similar to other large striped emeralds and generally identifiable only in the hand.

RANGE/STATUS Northeastern U.S.; narrow band along southeastern Canadian border. Rare and known only from a few sites in north-central MA.

HABITAT Sphagnum bogs.

NOTES Adults forage high in forest clearings, sometimes joining late afternoon feeding swarms. Males fly over open bogs, stopping to hover at small pools. Females oviposit in Sphagnum pools by dipping the tips of their abdomens into the water, releasing the eggs.

\begin{tabular}{|l|l|l|lll|l|l|l|}
\hline $\mathbb{A}$ & $\mathbb{M}$ & $\mathbb{J}$ & $\mathrm{J}$ & $\mathrm{A}$ & $\mathbb{S}$ & $\mathbb{O}$ & $\mathbb{N}$ & $\mathbb{D}$ \\
\hline
\end{tabular}


A rather large and stocky striped emerald. Male thorax blackish with dull greenish iridescence, lacking any yellowish marks; abdomen black with prominent, white basal rings on all segments. Eyes bright green when mature. Female similar; lacks an ovipositor. The ringed abdomen is unique among Somatochlora in southern New England.

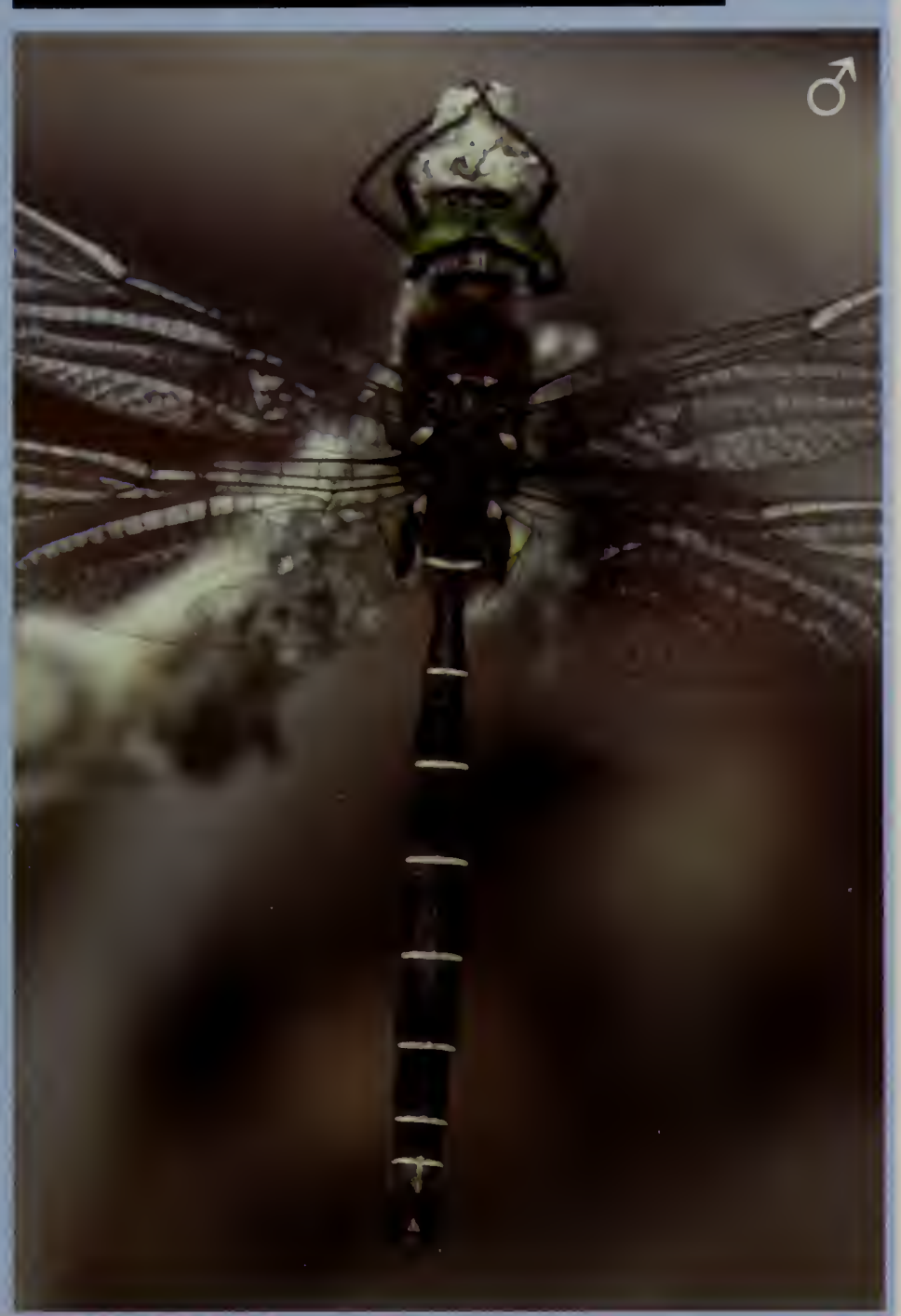

RANGE/STATUS Northeastern U.S; eastern to west-central Canada. Recorded only once in northwestern MA, on Mt. Greylock in 1973.

HABITAT Shallow lakes and sluggish reaches of rivers and streams.

NOTES Adults forage high overhead or low along the edges of woodland roads and clearings. Males fly over open water and are not territorial.

\begin{tabular}{|l|l|l|ll|l|l|l|l|}
\hline $\mathbb{A}$ & $\mathbb{M}$ & $\mathbb{J}$ & $\mathfrak{J}$ & $\mathbb{A}$ & $\mathbb{S}$ & $\mathbb{O}$ & $\mathbb{N}$ & $\mathbb{D}$ \\
\hline
\end{tabular}


Very unlike other Somatochlora, somewhat similar in size and coloration to a female meadowhawk (Sympetrum). Male thorax brown with two pale lateral stripes that fade with age; abdomen slender and rusty brown with no obvious marks. Eyes reddish-brown (never green). Female similar, but abdomen thicker with triangular ovipositor perpendicular to abdomen. Coloration distinguishes this species from all others in the genus.

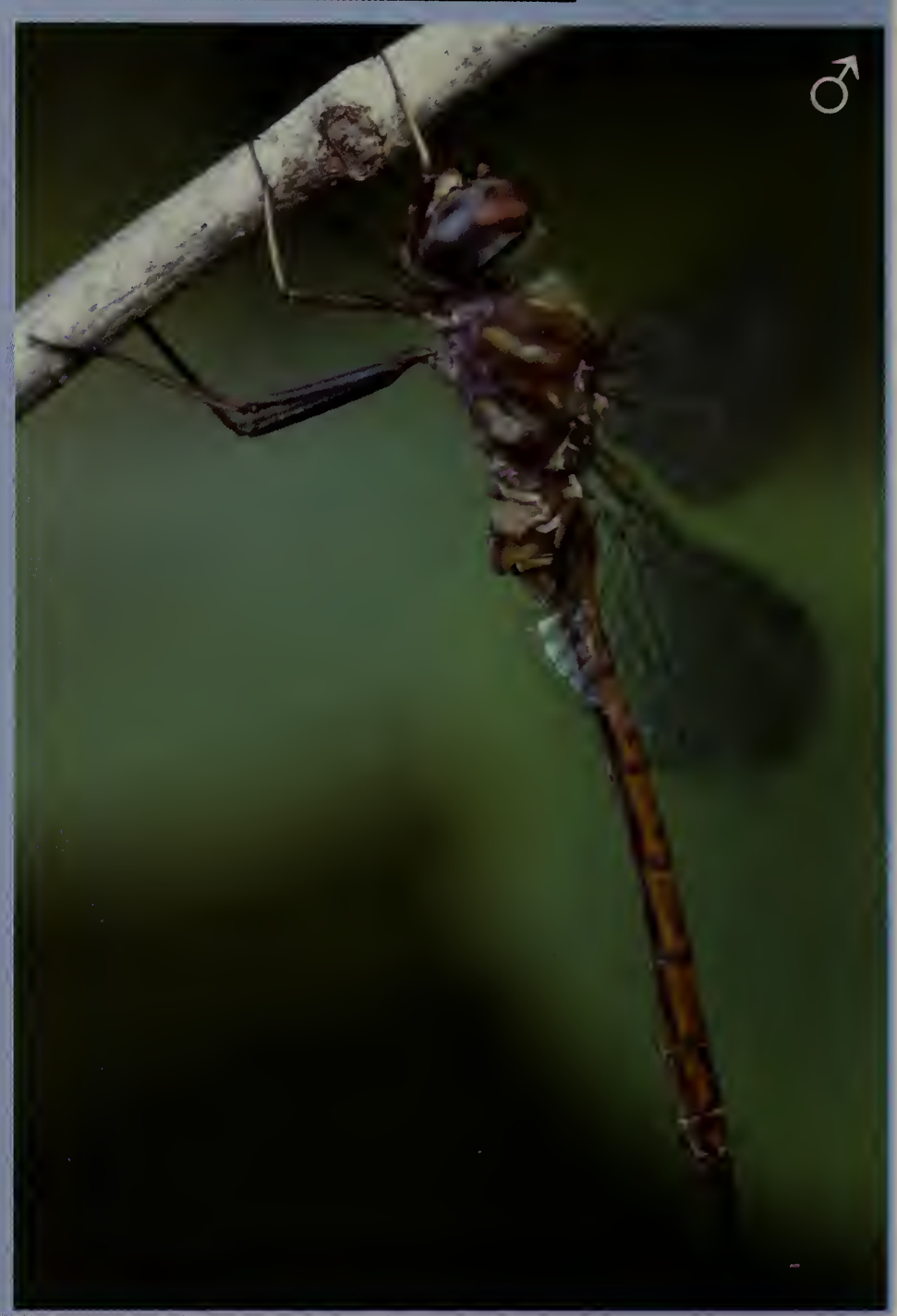

RANGE/STATUS Eastern seaboard of U.S., from LA to NH. Rare, recorded only from a few sites in eastern MA.

HABITAT Acidic, swampy, or forested streams.

NOTES Adults hunt in forest openings and in the forest canopy. They sometimes join feeding swarms and may also glean prey by flying along forest edges and nabbing insects off of the tips of branches. Males patrol stream banks.

\begin{tabular}{|l|l|l|l|l|l|l|l|l|}
\hline $\mathbb{A}$ & $\mathbb{M}$ & $\mathbb{J}$ & $\mathbb{J}$ & $A$ & $\mathbb{S}$ & $O$ & $\mathbb{N}$ & $\mathbb{D}$ \\
\hline
\end{tabular}



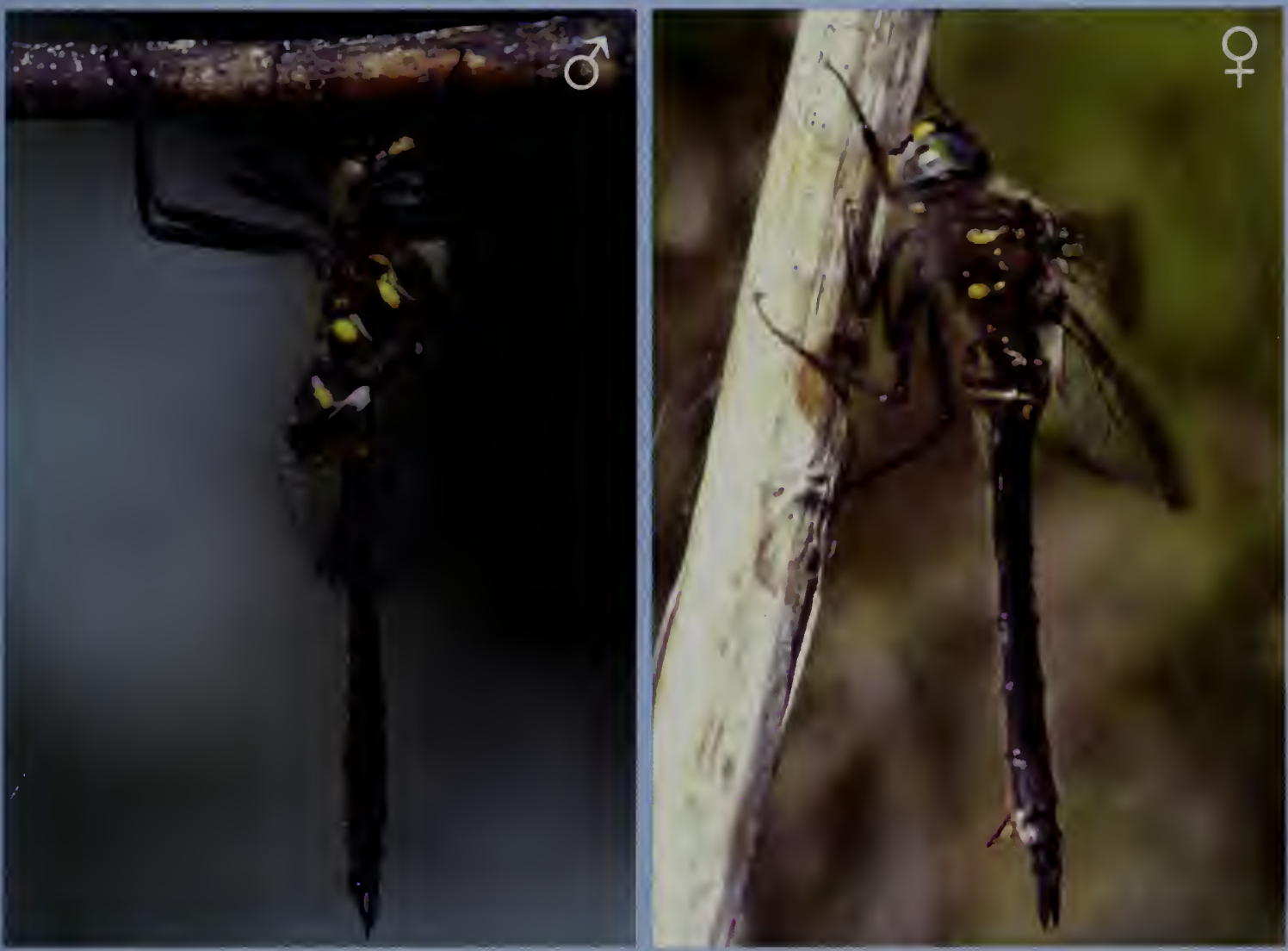

One of the smallest of the striped emeralds. Male thorax blackish with dull greenish iridescence and two yellow, oval lateral spots; abdomen short and entirely black except for yellow lateral spots on S2 \& S3, and a pale basal ring on S3. Eyes bright green when mature. Female similar, but wings often heavily tinged with amber; ovipositor dull yellowbrown and spout-like. Similar to other small striped emeralds, especially Brush-tipped Emerald (p. 129), though lateral thoracic stripes more rounded.

RANGE/STATUS Northern U.S.; Canada. One record from north-central MA in the early 1980's.

HABITAT Clear, small forest streams.

NOTES Adults hunt in shady forest openings at a height of $4-5 \mathrm{ft}$. They perch in the shade on low vegetation and twigs. Males patrol streams at a height of about a foot, staying in the shade and hovering occasionally. Females oviposit by tapping their abdomens on the water near rocks and vegetation or in moss along the shoreline.

\begin{tabular}{|l|l|l|l|l|l|l|l|l|}
\hline $\mathbb{A}$ & $\mathbb{M}$ & $\mathbf{J}$ & $\mathrm{J}$ & $\mathbb{A}$ & $\mathbb{S}$ & $\mathbf{O}$ & $\mathbb{N}$ & $\mathbb{D}$ \\
\hline
\end{tabular}


Male thorax brown and hairy, with elongate yellowish lateral spot (fades with age); abdomen dark brown with pale yellowish lateral patches. Eyes dull bluegreen in mature males, brown in immature males and females. "Forehead" often with black "T" spot (occasionally absent). Hind wings often with large, triangular, dark basal patch; however, some have only small basal wing spots. Female similar but abdomen thicker. Darkwinged individuals distinctive but clearwinged form very similar to Beaverpond Baskettail (p. 141) and Spiny Baskettail (p. 142). These two species are slightly larger, mature males have greener eyes, and females often have a brown wash in the wings.
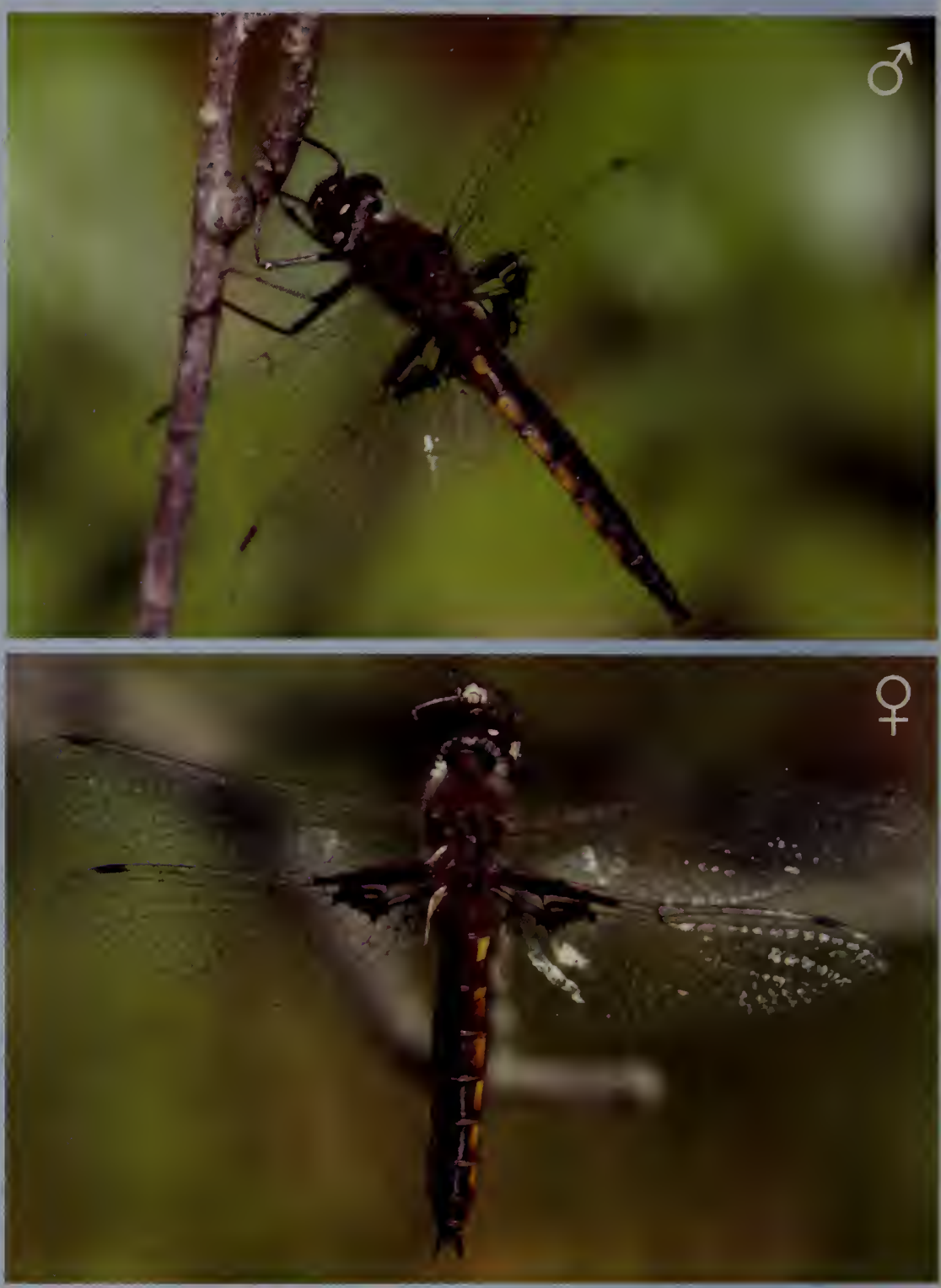

RANGE/STATUS Eastern U.S.; southeastern Canada. Apparently common, but status in MA is uncertain due to confusion with the very similar (conspecific?) Mantled Baskettail (E. semiaquea).

HABITAT Marshy wetlands, lakes, ponds, and slow streams.

NOTES Adults hunt in sunny forest openings, fields, and over the water, flying swiftly and erratically at a height of 4-10 ft. and occasionally forming swarms. They perch obliquely on stems of low vegetation. Males patrol over wetlands, hovering frequently.

The Mantled Baskettail of the southeastern U.S. is virtually identical, inseparable in the field, and of uncertain taxonomic distinction. Recent evidence suggests this form may occur in southern New England.

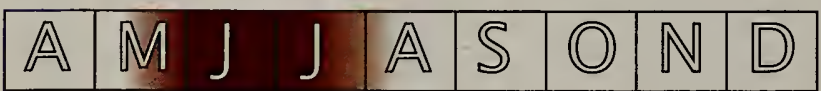



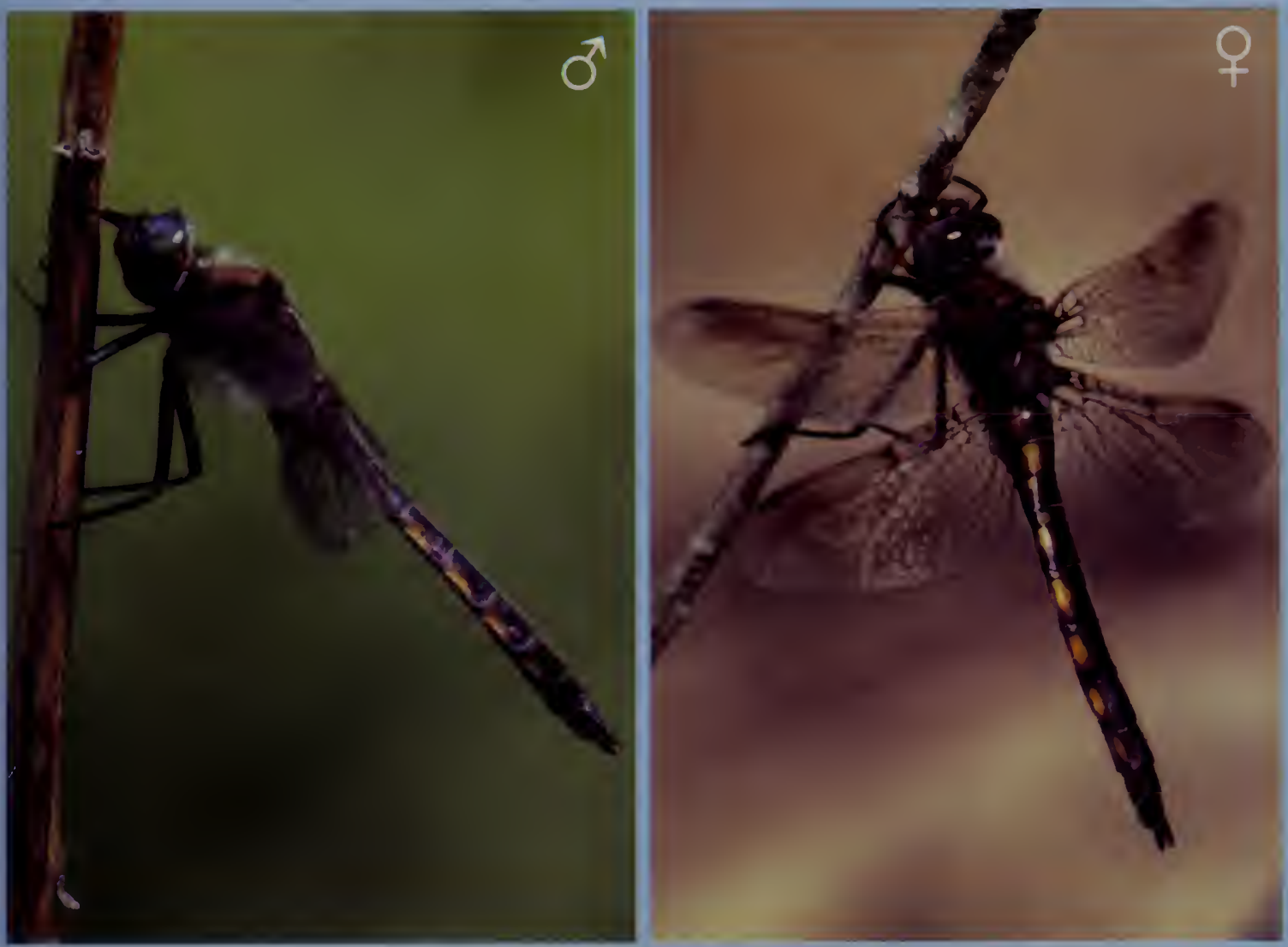

Male thorax brown and hairy with elongate, yellowish lateral spot that fades with age; abdomen dark brown with pale yellowish lateral patches. Eyes dull green in mature male, brownish in immature male and female. "Forehead" lacks "T" spot. Wings with small, dark basal spots, often washed with amber. Female similar but wings often heavily washed with dark amber. Common Baskettail (p. 140) very similar but slightly smaller, often with broad, dark basal wing patch; male lacks dorsal spike on appendages; female wings lack amber. Spiny Baskettail (p. 142) very similar, but with dark "T" spot on "forehead," male with ventral spike on superior appendages; female generally lacks amber wash on wings; usually separable only in the hand.

RANGE/STATUS Northern U.S.; southern Canada. Common throughout most of MA but absent from the southeast coastal plain.

HABITAT Beaver ponds and bogs with open water.

NOTES Adults hunt in sunny forest openings and may form feeding swarms. They perch obliquely from twigs and stems, or on flat leaves of bushes and small trees. Males patrol small territories over wetlands, hovering frequently. Females oviposit by producing long strings of eggs, forming balls at the tips of their abdomens. They then tap the tips of their abdomens on the surface of the water, releasing the eggs. The flight season averages somewhat earlier than other baskettails.

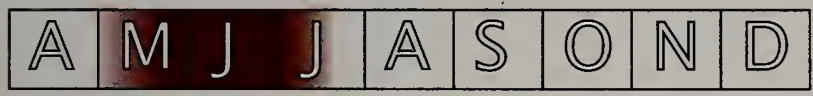


Male thorax brown and hairy with elongate yellowish lateral spot (fades with age); abdomen dark brown with pale yellowish lateral patches. Eyes dull bluegreen in mature male, brown in immature male and female. "Forehead" with black "T" spot. Wings with small, dark basal spots. Male superior appendages with small, ventral spike approximately $1 / 3$ from base. Female similar but wings often washed with brown, especially on outer portions. Female appendages as long as $S 9+\$ 10$. Beaverpond Baskettail ( $p$. 141) very similar but lacks "T" spot on "forehead," male superior appendages with distal dorsal spike; female appendages somewhat shorter (less than $59+510$ ).

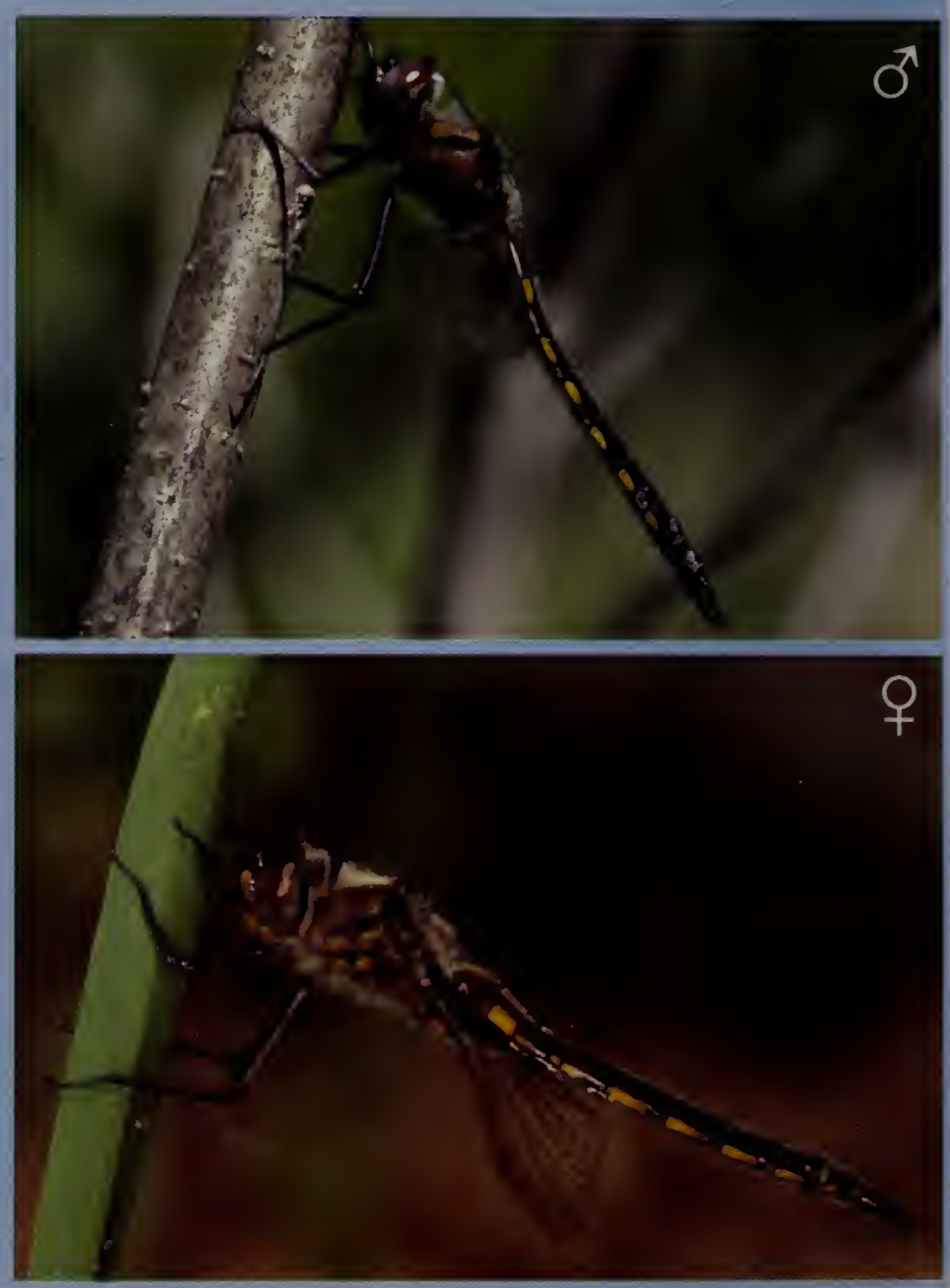

RANGE/STATUS Northern U.S.; southern Canada. Uncommon in MA and absent from the southeast coastal plain.

HABITAT Bogs and boggy wetlands, marshes, and slow streams.

NOTES Adults forage along forest edges and over woodland roads. Males patrol over wetlands, hovering frequently. Females oviposit by producing long strings of eggs, forming balls at the tips of their abdomens. They then tap the tips on the surface of the water to release the eggs.

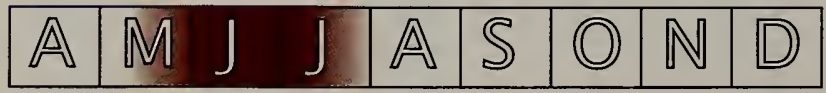


Much larger than other baskettails. Male thorax dark brown and hairy; abdomen dark brown with thin, pale rings. Eyes green in mature male, brownish in immature male and female. Wing marks extensive but variable; typically with a broad, dark basal bar on leading edges, a large, irregularly shaped patch at the nodus, and dark tips, wrapping around the trailing edges. Female similar. Size, shape, and behavior darner-like, but wing pattern distinctive. Twelve-spotted Skimmer (p. 164) and female Common Whitetail (p. 163) have similar wing patterns but are small, with shorter, stockier abdomens, and behave very differently. A large, slender dragonfly with conspicuous wing markings patrolling high over head will be this species.

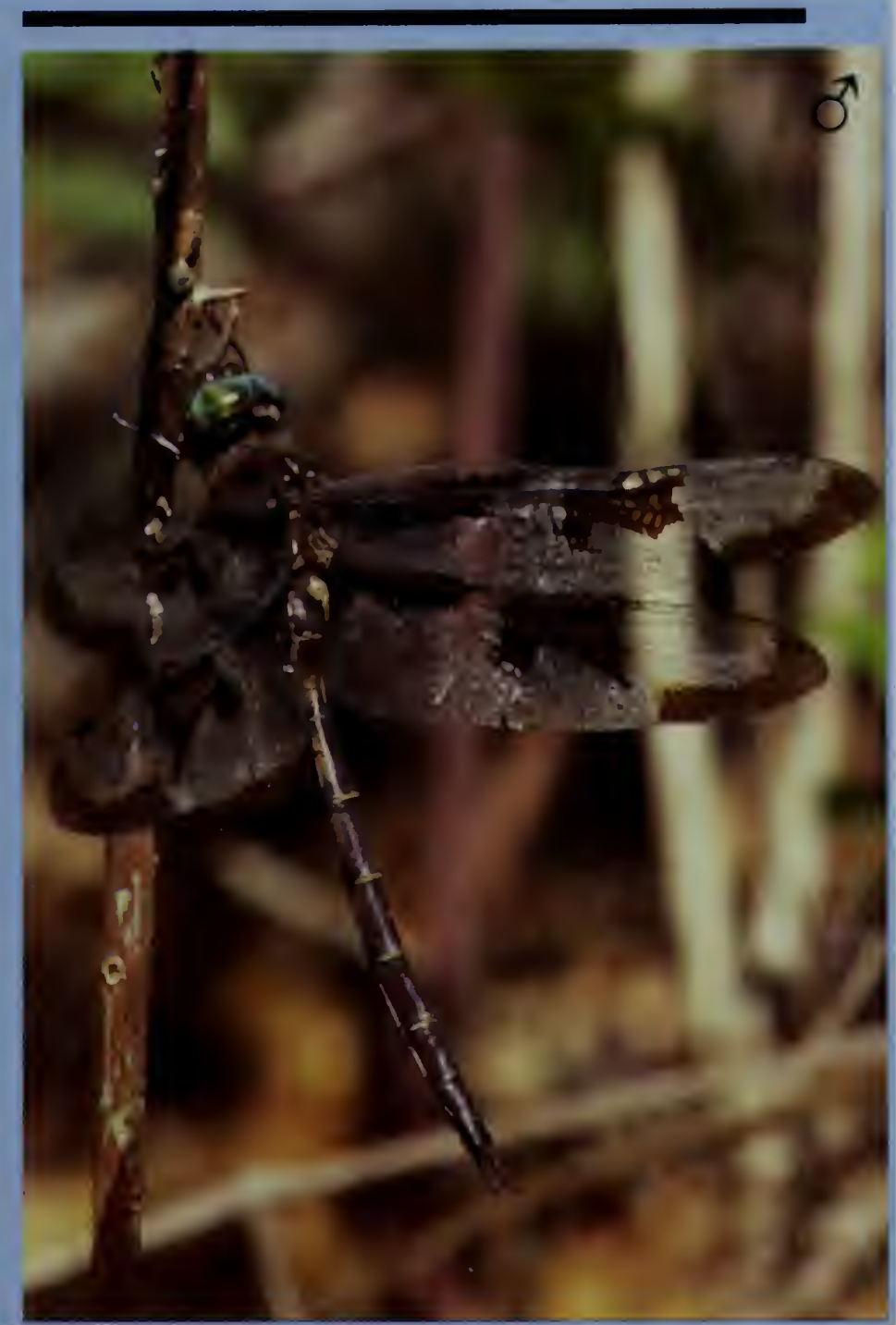

RANGE/STATUS Central to eastern U.S.; southeastern Canada. Common throughout MA.

HABITAT Ponds, lakes, and quiet rivers.

NOTES Adults hunt along forest edges, roads, and in fields. They forage at the tops of trees, and form feeding swarms high overhead in the late afternoon. On warm sunny days they are also active very early in the morning. They perch by hanging vertically under twigs and branches with the abdomen curled upward. Males patrol over water, flying at a height of 3-6 ft. Females oviposit by producing long strings of eggs, forming balls at the tips of their abdomens. They then tap the tips of their abdomens on the surface of the water to release the eggs. Most often seen ovipositing in the early evening.

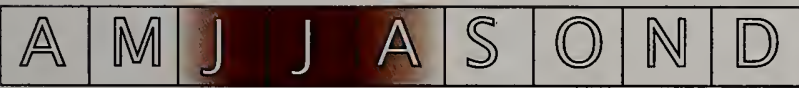




\section{Uhler's Sundragon Helocordulia uhleri}
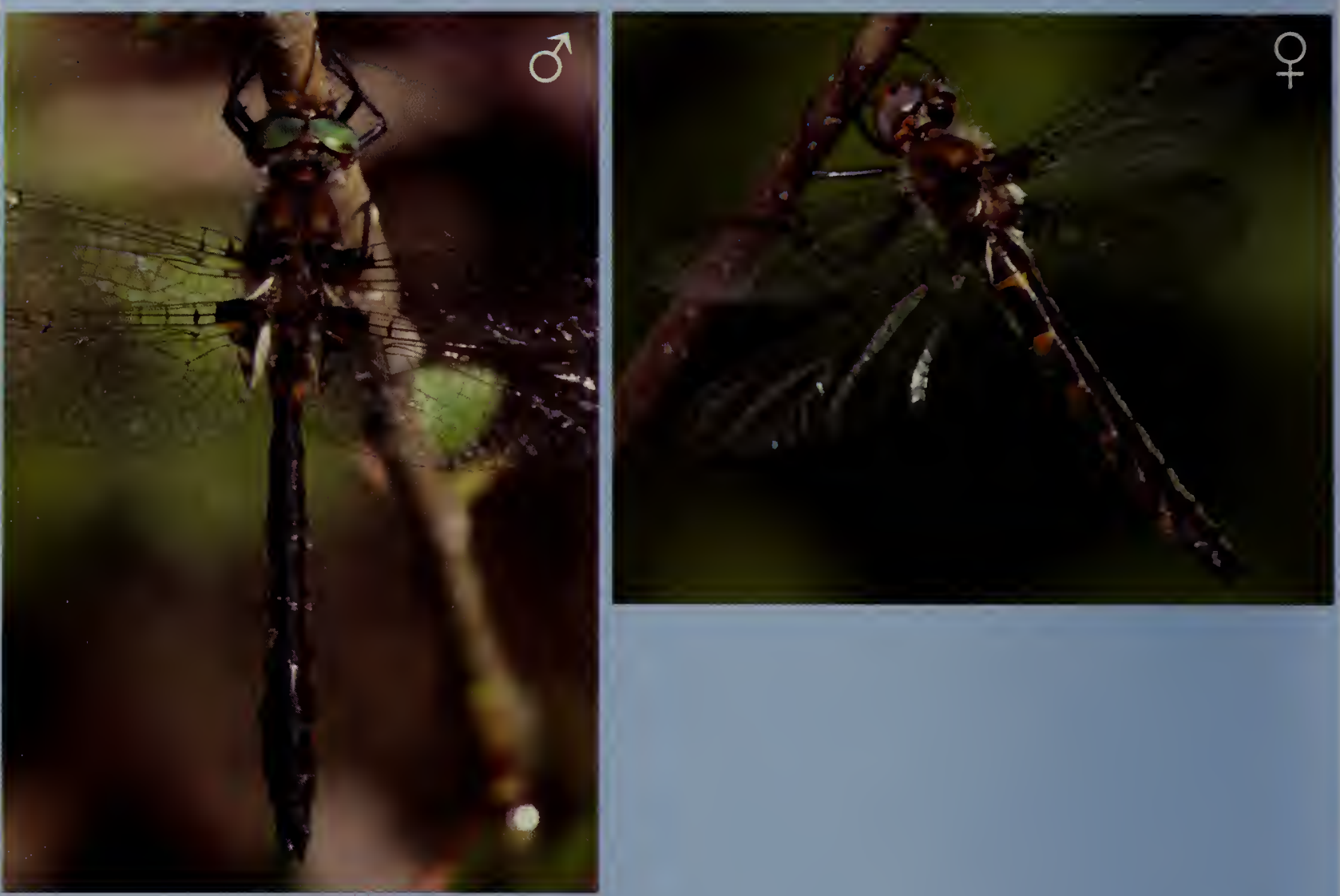

Male thorax dark, bronzy brown and hairy, with iridescent greenish highlights; abdomen black and swollen distally, with orange basal ring on 53, and 54-58 with dull orange lateral spots. Eyes green when mature. Face yellowish. Wings with dark basal spots, small amber patches, dark, prominent crossveins on leading edge of wings basally, and occasionally a brownish wash. Female similar but abdomen thicker and lateral spots larger. Amber patches at base of wings and darkened crossveins distinguish this species from other small emeralds.

RANGE/STATUS South-central to northeastern U.S.; southeastern Canada. Uncommon in MA and absent from the southeast coastal plain.

HABITAT Clean, rapid streams and large lakes.

NOTES Adults forage along forest edges. They perch obliquely on twigs and stems near the ground. Males patrol low over water and along shorelines with a fast, erratic flight and occasional hovering. They are often active late in the day.

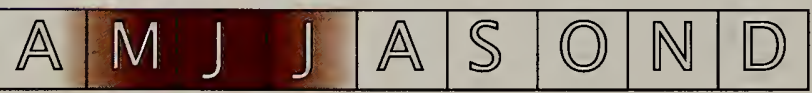



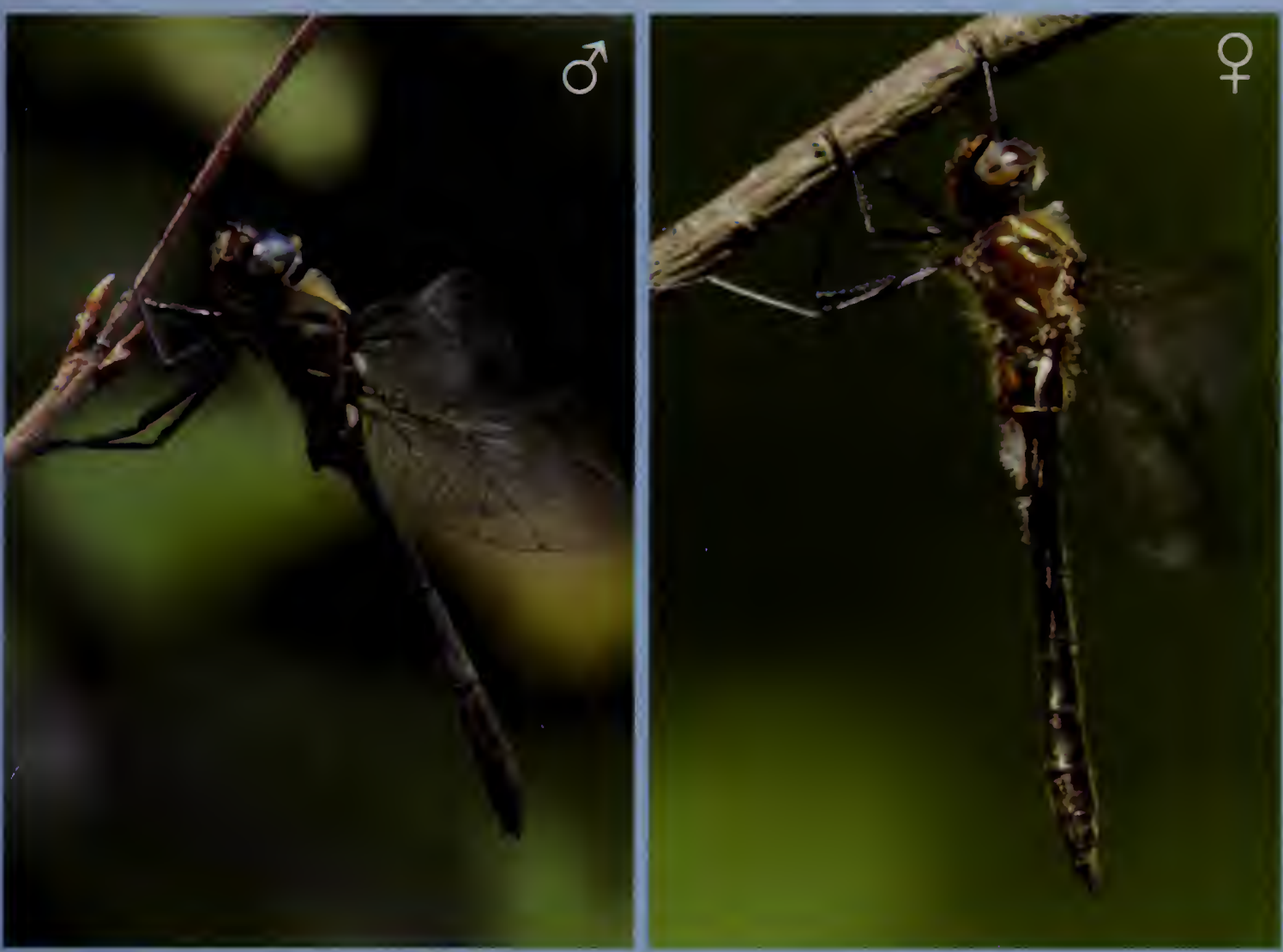

Male thorax dark, bronzy brown and hairy, with iridescent green highlights; abdomen black and slightly swollen on $56-\$ 8$, with dull yellowish-brown marks along lower sides of $51-52$ and a narrow yellow ring at the joint of S2-S3. Eyes bright green when mature. Face dusky and "forehead" dark iridescent green. Female similar but abdomen stockier, with white on lower sides of S3-S4 and duller eyes. Very similar to other small emeralds. Male Racket-tailed Emerald (p. 147) is smaller and has more prominently clubbed abdomen. Male Petite Emerald (p. 146) is smaller and has dull brownish-orange lateral basal spot on S3. Male Uhler's Sundragon (p. 144) has yellow face, dark basal wing spots, and pale lateral spots on S4-S8.

RANGE/STATUS Northern U.S.; Canada. Common throughout interior MA but absent from the southeast coastal plain.

HABITAT Vegetated ponds and lakes, beaver ponds, open boggy ponds and fens. NOTES Adults hunt along forest edges, flying in and out of sunny patches. They occasionally perch on vegetation, hanging under twigs or resting on flat leaves. Males patrol short beats, flying a few feet above the water near the shore, hovering frequently. Females oviposit by flying quickly over the water and tapping the tips of their abdomens onto the surface to release eggs.

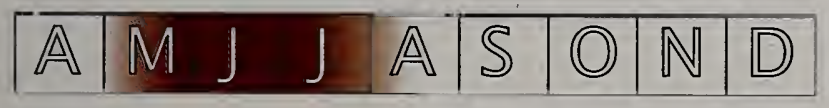



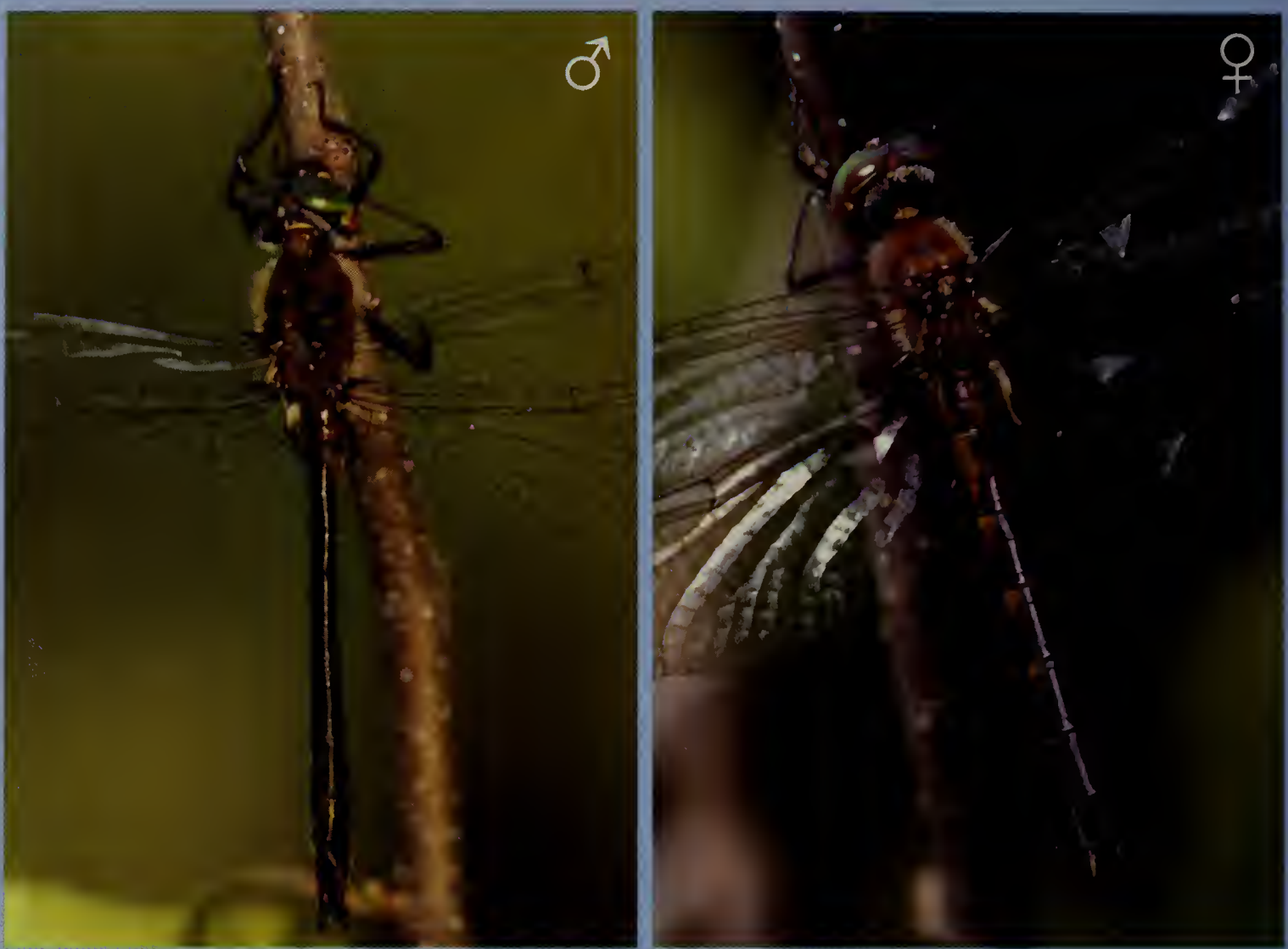

One of the smallest of the emeralds. Male thorax dark, bronzy brown with iridescent green highlights; abdomen black and slightly clubbed, with pale brown lateral spots on S2-S3. Eyes bright green when mature. Top of face and "forehead" dark, iridescent green. Female similar but abdomen stockier with pale lateral spots on S4-S7. Rackettailed Emerald (p. 147) very similar but slightly larger and abdomen more clubbed; female abdomen also clubbed and without pale spots on S4-S7.

RANGE/STATUS A narrow band along the northeastern U.S. into southeastern Canada. Uncommon and local throughout MA.

HABITAT Bogs and swamps; generally more acidic wetlands than the Racket-tailed Emerald (D. libera).

NOTES Adults hunt in forest openings and fields. They occasionally perch on vegetation, hanging under twigs or resting on flat leaves. Males patrol over emergent and shoreline vegetation. Females oviposit by tapping the tips of their abdomens on the surface of the water to release eggs.

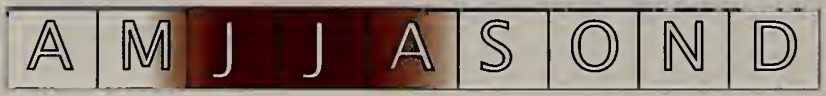



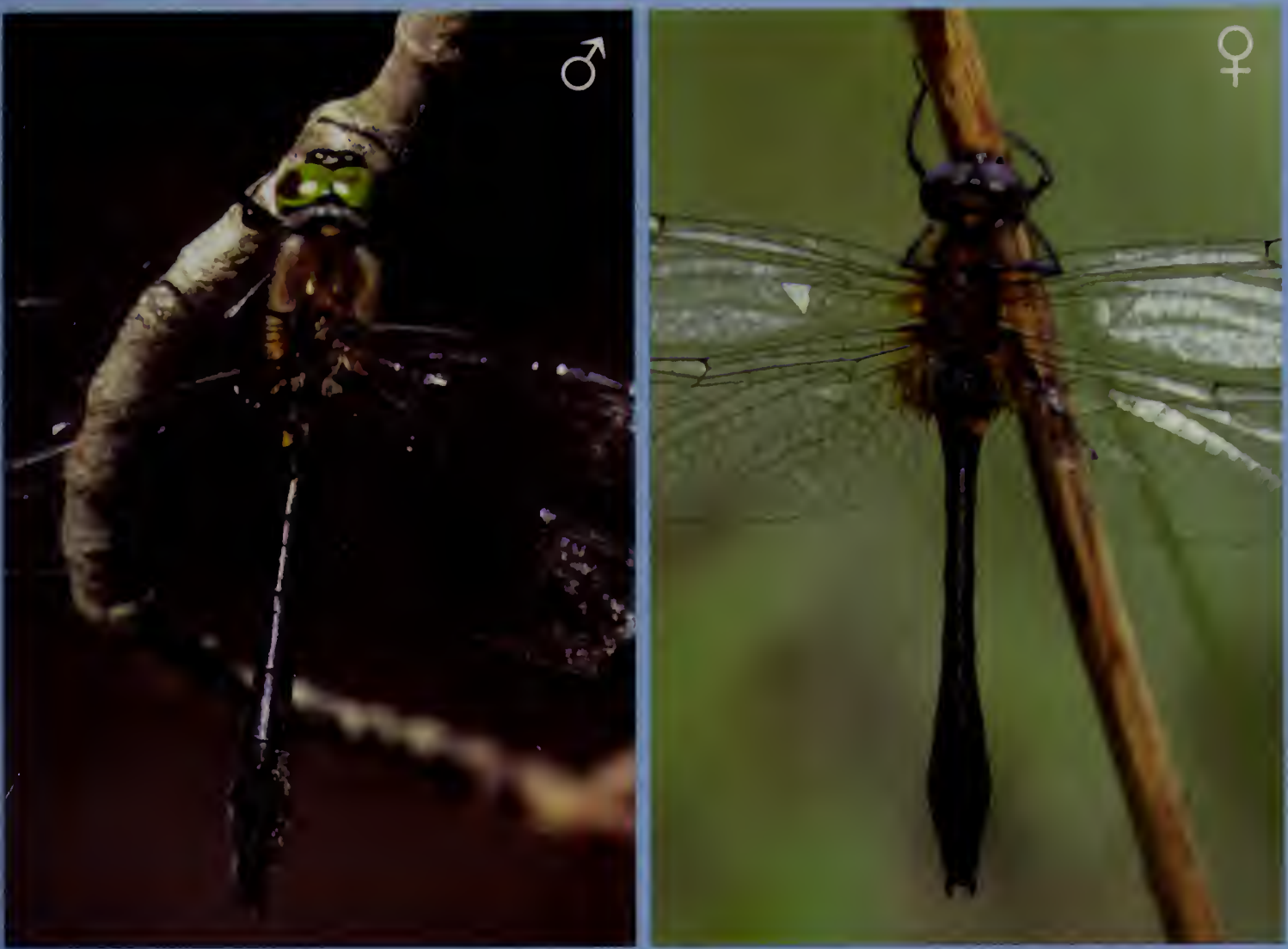

Male thorax dark, bronzy brown with iridescent greenish highlights; abdomen entirely black and prominently clubbed, with dull orange-brown patches on S2-S3. Eyes bright green when mature. Top of face and "forehead" dark iridescent green. Wings occasionally tinted with amber at base. Female similar but abdomen slightly less clubbed. Petite Emerald (p. 146) very similar but slightly smaller and abdomen less clubbed; female abdomen has pale lateral spots on $54-57$.

RANGE/STATUS Northeastern U.S.; southeastern Canada. Fairly common throughout MA but absent from the southeast coastal plain.

HABITAT Bogs, marshes, and ponds; usually less acidic wetlands than the Petite Emerald (D. lepida).

NOTES Adults hunt along forest edges, flying in and out of sunny patches and occasionally occur in feeding swarms late in the day. They occasionally perch on vegetation, hanging under twigs or resting on flat leaves. Males patrol over open wetlands at a height of 3-5 ft., flying slowly with their abdomens arched upward. Females oviposit by tapping the tips of their abdomens onto the water's surface to release eggs.

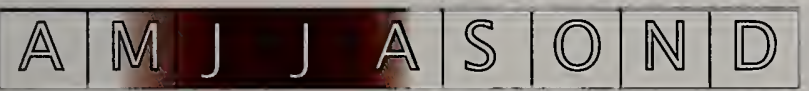


Male thorax dark brown and hairy with a yellowish lateral spot; abdomen brown with pale lateral spots. Eyes brown. Wings with dark basal patch, small dark spot at nodus, dark crossveins on the leading edges of the wings basally, orange stigma, and often heavily suffused with dark amber. Female similar. The Stygian Shadowdragon (p. 149) very similar but lateral abdominal marks larger and brighter and wings clear except for basal patches.

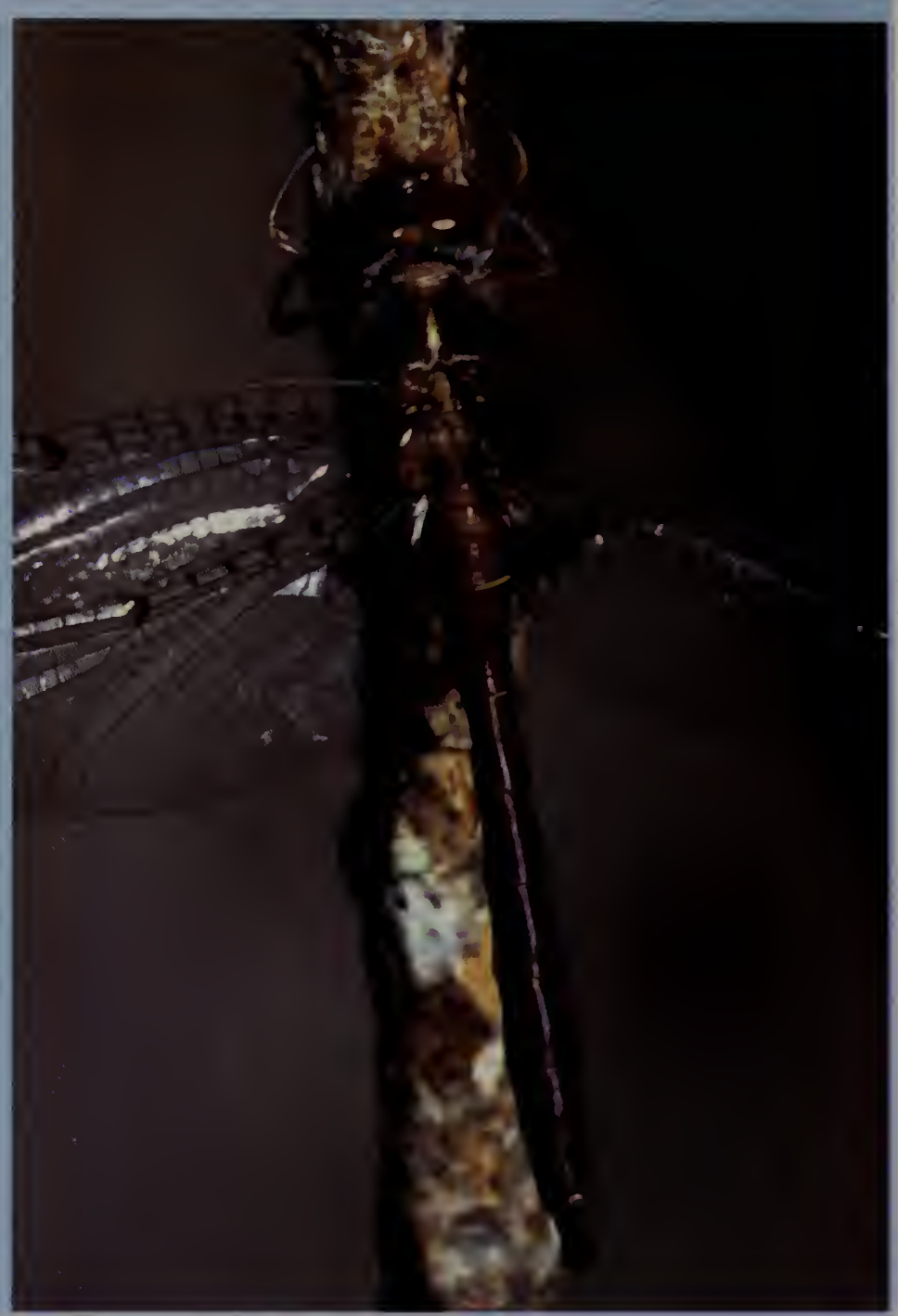

RANGE/STATUS Eastern U.S. Rare, recorded only in central and eastern MA. A crepuscular species, it may be easily overlooked and more common than thought.

HABITAT Rivers, lakes, and reservoirs.

NOTES This crepuscular species spends the day hanging from twigs and branches in the shade, apparently high in the trees as they are very rarely seen before dusk. Adults forage close to shorelines and over open water, flying very low and erratically for a brief period from sunset until dark. Mating and egg laying also occur at this time. The presence of this species is most easily confirmed by locating their exuviae on bridge abutments, retaining walls, dams, steep embankments, or tree trunks.

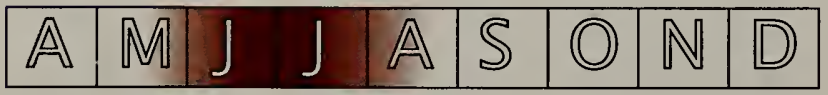


Male thorax dark brown and hairy with a dull yellowish lateral spot; abdomen brown with dull yellow lateral patches. Eyes brown. Wings with small, dark basal patch and orange stigma. Female similar. Umber Shadowdragon (p. 148) similar but sides of abdomen duller and wings have more prominent crossveins on leading edges.

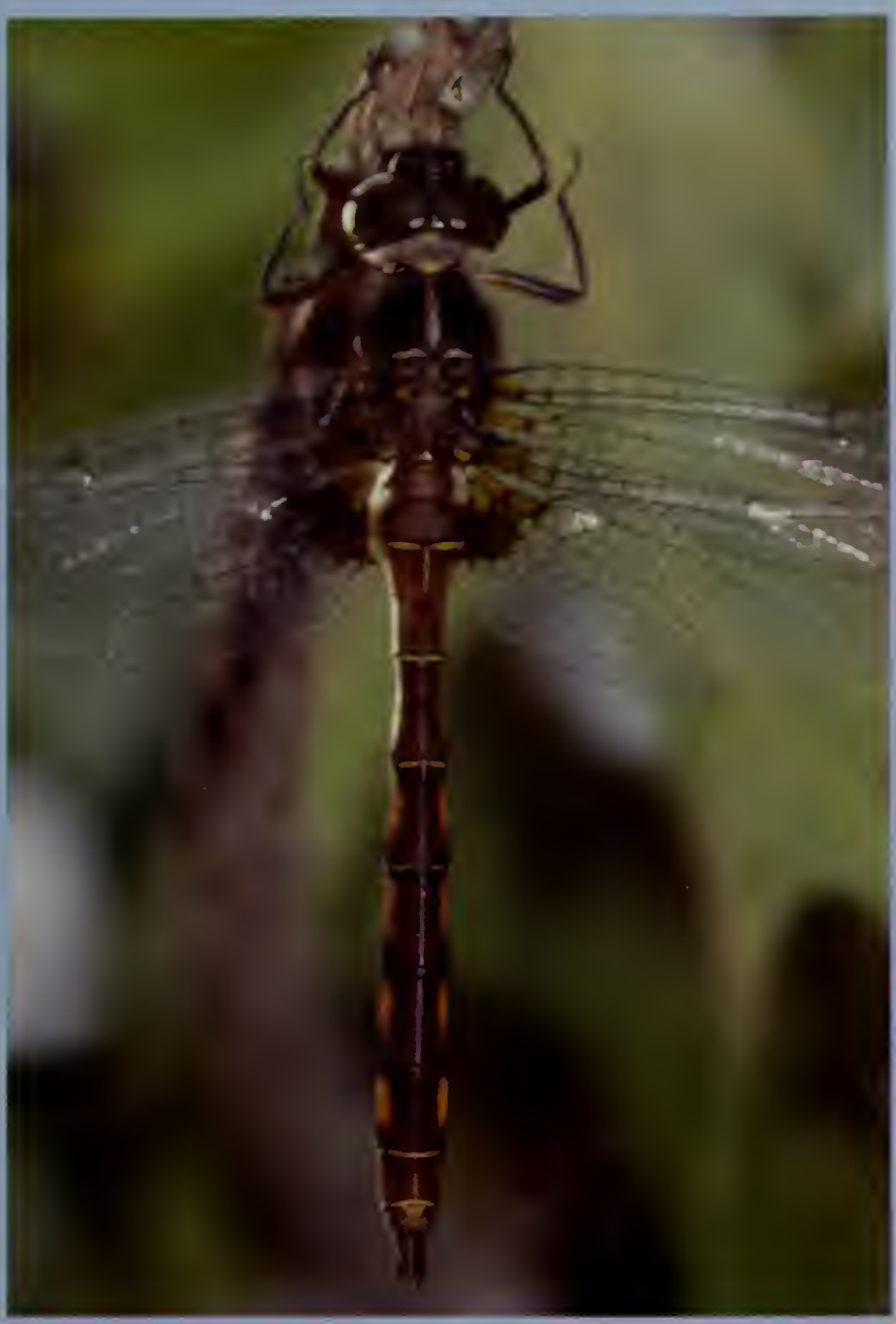

RANGE/STATUS Northeastern U.S.; narrow band along border of southeastern Canada. Rare in MA, recorded from only a few sites along the Connecticut River. A crepuscular species, it may be easily overlooked and more common than thought. HABITAT Large rivers and lakes, often with rocky shores.

NOTES This crepuscular species spends the day hanging from twigs and branches in the shade apparently very high in the canopy, as they are very rarely seen before dusk. Adults forage close to shorelines and over open water, flying very low and erratically for a brief period from sunset until dark. Mating and egg laying also take place during this time. The larvae emerge on bridge abutments, revetments, steep banks, and tree trunks, and the presence of exuviae provides the easiest means to confirm this species' occurrence.

\begin{tabular}{|l|l|l|l|l|l|l|l|l|}
\hline $\mathbb{A}$ & $\mathbb{M}$ & $J$ & $\mathrm{~J}$ & $\mathbb{A}$ & $\mathbb{S}$ & $\mathbb{O}$ & $\mathbb{N}$ & $\mathbb{D}$ \\
\hline
\end{tabular}


Male thorax blackish and unmarked; abdomen black with narrow white rings on $52-54$. Eyes green in mature males. Wings clear. Face dark. Female similar but eyes gray. Ringed Boghaunter ( $p$. 151) similar but with orange rings on $52-59$ and paler face. Whitefaces (Leucorrhinia spp.) similar in size, behavior, and habitat, but with white face and yellow or red marks on the body.

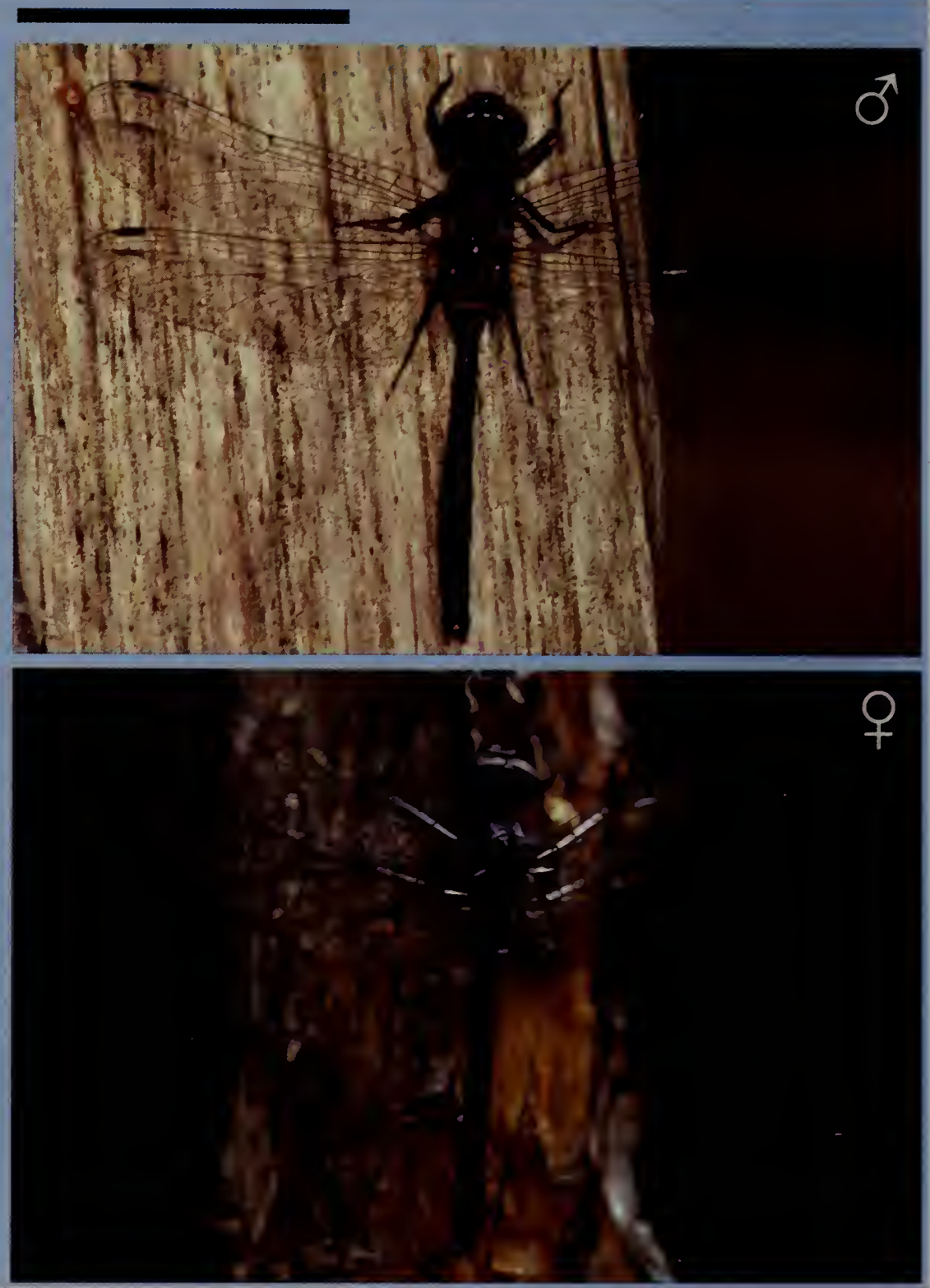

RANGE/STATUS Northeastern U.S.; southeastern Canada. Rare, known only from a handful of sites in north-central MA.

HABITAT Sphagnum bogs and swamps with open pools.

NOTES Adults frequent sunny patches in or near wetlands, perching low on tree trunks, brush, and the ground. They are not active flyers. Males make brief patrols low over open pools. Females oviposit in small pools and wet depressions in the sphagnum mat. Both species of boghaunters (Williamsonia spp.) are considered to be glacial relicts that may have been more common during the colder period after the glacier retreated and before the temperate forests extended north.

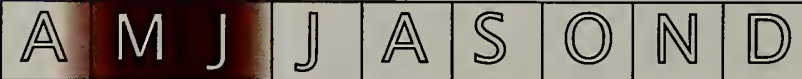


Male thorax dark brown and unmarked; abdomen black with prominent orange dorsal rings on S259. Eyes blue-gray. Face pale orange-brown. Female similar, but abdomen thicker. Ebony Boghaunter similar but lacks orange rings on S559, face darker, and eyes green in mature males. Whitefaces (Leucorrhinia spp.) similar in size, behavior, and habitats, but have white faces and yellow, or red markings on body.

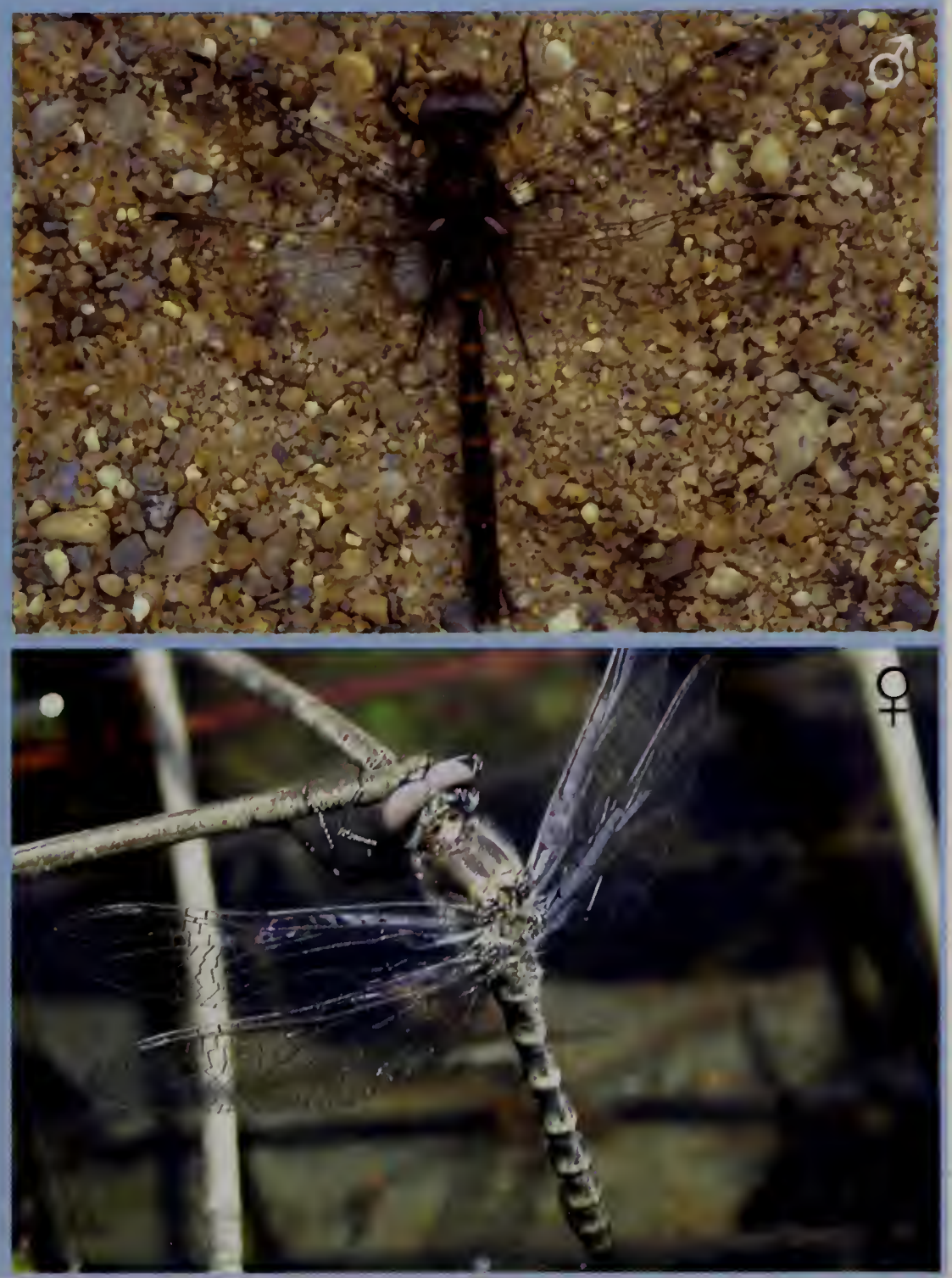

RANGE/STATUS Spottily distributed in the northeastern U.S. and Great Lakes Region. Rare, known only from north-central and eastern MA.

HABITAT Sphagnum bogs with open pools.

NOTES Adults frequent sunny patches, including sun-dappled roadsides. They fly low, landing often in sunny spots and on light-colored tree trunks. They are not active flyers and are seldom encountered in wetlands. Both species of boghaunters (Williamsonia spp.) are considered to be glacial relicts that may have been more common during the colder period after the glacier retreated and before the temperate forests extended north.

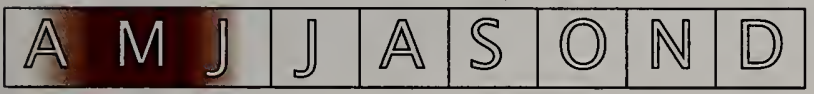




\section{LIBELLULIDAE: SKIMMERS}

Skimmers comprise the largest and most diverse family of odonates worldwide, with over 1,000 described species. Of the 105 species and 26 genera in North America, 41 species in 11 genera have been recorded in Massachusetts.

Skimmers range in size from very small, barely an inch or so, to fairly large, approaching $2 \frac{1}{2}$ inches in length. They are extremely diverse in both color and pattern, some rivaling butterflies with their bold and bright coloration. In some species the wings are prominently colored and patterned as well as the body. The eyes are very large and meet in a seam along the top of the head. Identification of most species is possible in the field based on a combination of body, eye and wing color and pattern. Females and immature males often look very different from adult males, which can lead to confusion for the novice. Some species develop a blue-gray, waxy pruinosity on the body as an individual matures. In a few groups, most notably the meadowhawks (Sympetrum spp.), some species can be identified only by in-hand examination of morphological characteristics, and even then identification can be difficult because of unresolved taxonomic issues.

Skimmers inhabit a wide variety of wetlands, though most species are scarce to absent in riverine systems. They are most common at well-vegetated ponds, where as many as a dozen or more species can co-occur. Adults tend to wander far from water, maturing and feeding in fields and clearings. The majority are summer fliers, but the whitefaces (Leucorrhinia spp.) are among the first dragonflies on the wing in the spring, while some of the meadowhawks (Sympetrum spp.) remain active into the late fall. Most species are perchers, spending much of their time perched horizontally or obliquely on vegetation, logs, rocks, or, in a few species, flat on the ground. Some "tee-up" horizontally on the tops of small shrubs or stiff grasses, pivoting in the breeze like small flags. Several species, primarily the gliders (Pantala spp.) and saddlebags (Tramea spp.), spend long periods on the wing; many of these species are also migratory and are occasionally seen in large numbers along the coast in spring and fall. Skimmers are typically the most numerous and conspicuous odonates at wetlands, and many species routinely frequent upland fields and clearings far from water.

Males of many species are territorial, defending short stretches of shoreline from other males. In a few species, the males perform flight displays in unison with competing males. Females oviposit in the water by tapping the surface with the tips of their abdomens. They may oviposit alone, with the male guarding nearby, or with the male still attached in tandem. Larvae are cylindrical and elongate; they live on the bottom, crawling amongst debris. Exuviae are often found on emergent vegetation, rocks, or logs just above the waterline. 
Male thorax brown with two large yellow lateral spots; abdomen orangebrown with very thin yellow rings; terminal appendages whitish. Eyes reddish-brown. Wings entirely orange, with dark reddish-orange stigmas. Female body similar but abdomen more brown and wings generally clear with a variably-sized brown spot proximally and a brown band distally. The combination of small size and wing pattern is distinctive among northeastern dragonflies.

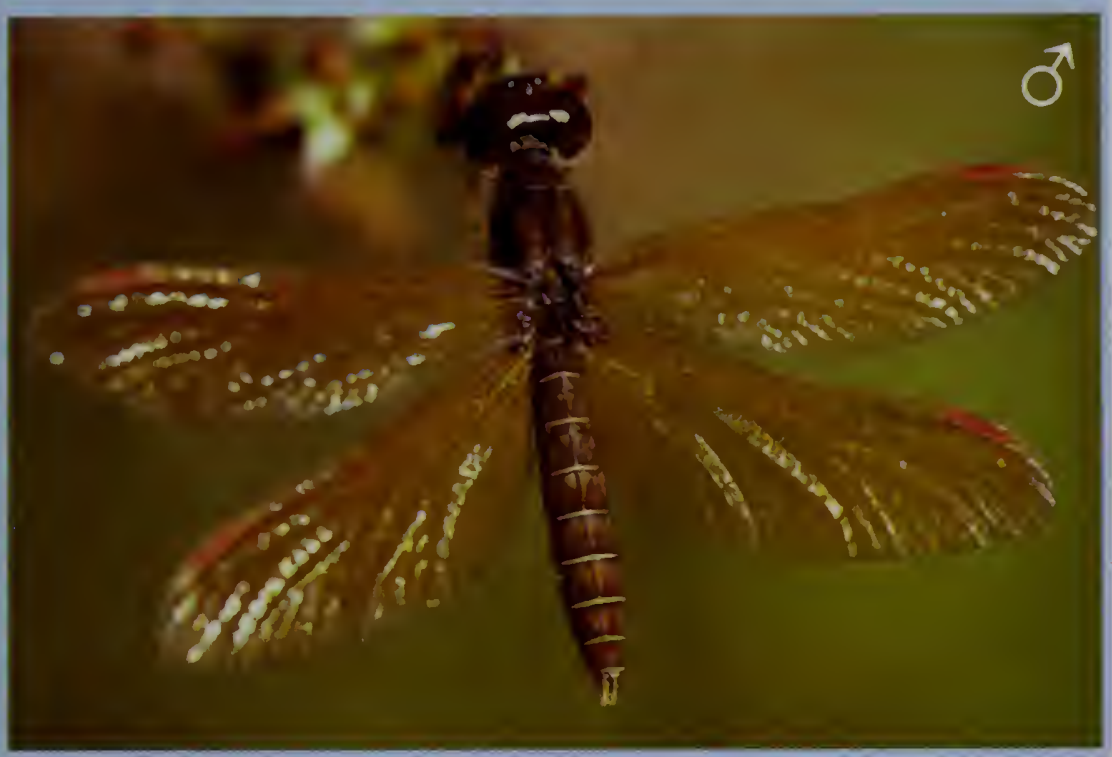

RANGE/STATUS Central and eastern U.S. Common throughout MA, though scarce at higher elevations.

HABITAT A variety of wetlands including vegetated ponds, lakes, and slow streams; often seen alighting on pickerel weed (Pontederia cordata).

NOTES Adults fly low, in and out of vegetation along shorelines or over water. They perch horizontally on the tips of emergent vegetation. This species is a wasp mimic; when perched they pump their abdomen and wings up and down in a wasp-like fashion. Males patrol small territories over water with emergent vegetation, flying with their abdomen raised. Females oviposit on emergent vegetation, and fly with their abdomens and hind wings tilted sharply upwards.

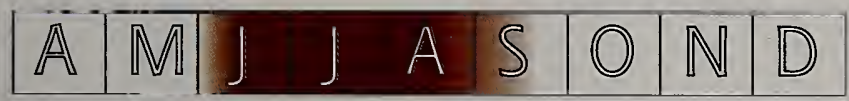


Male thorax brown with thin yellow dorsal bars and stripes, and yellow lateral stripes; abdomen pruinose blue-gray when mature, with black tip (S8-S10). Eyes green. Face white. Hind wings have amber basal patches with black streaks; wings often tinted with brown distally. Female and immature male thorax similar; abdomen mostly black with yellow sides on basal segments and distinctive paired yellow dorsal streaks on S3-S8 (fade with age). Eyes rusty brown. Female hind wings lack black basal streaks. The combination of striped thorax and black-tipped, blue abdomen of the male is distinctive, as is the paired dorsal streaks on the abdomen of immature males and females.

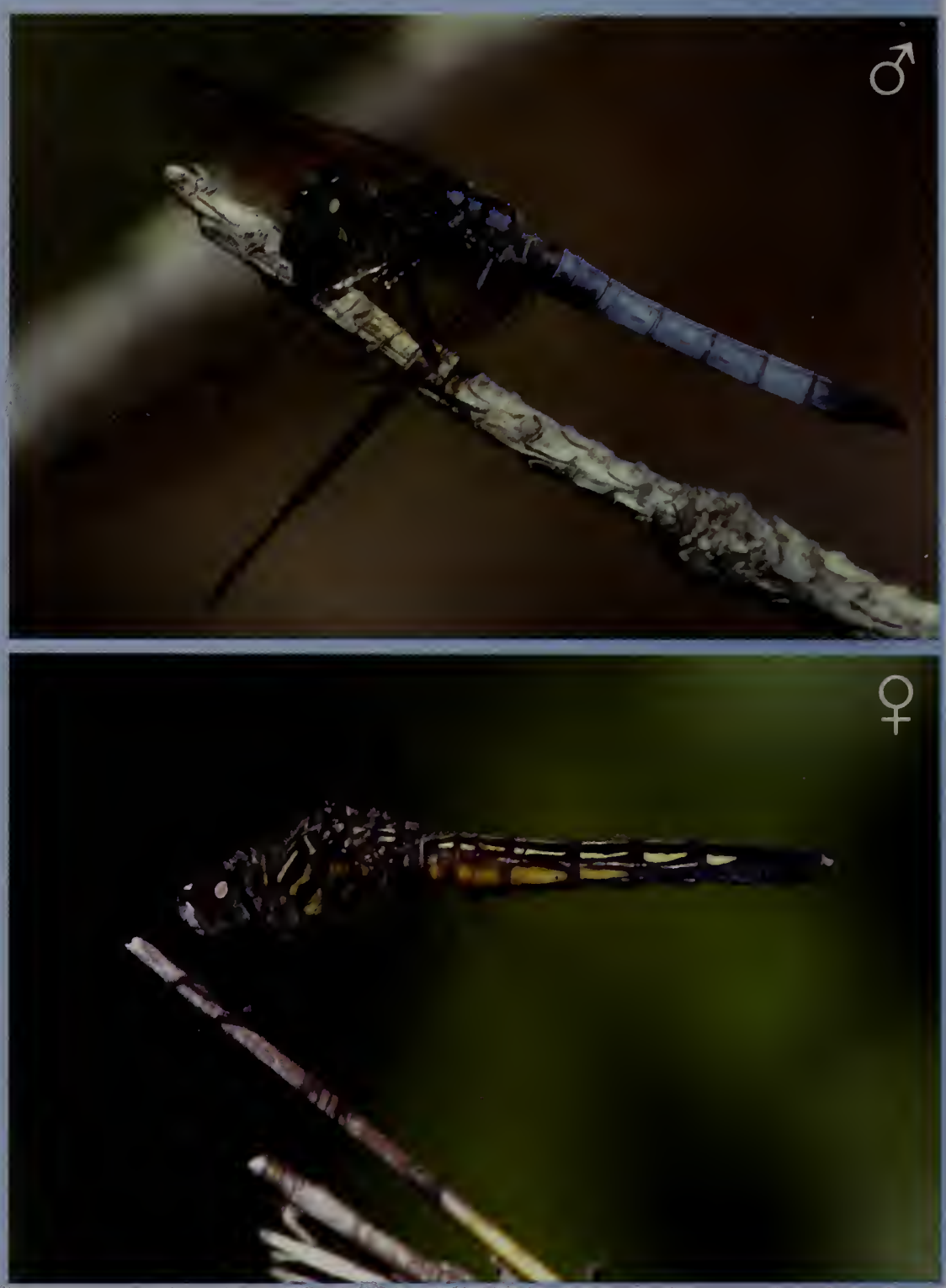

RANGE/STATUS Throughout the U.S. except the Rocky Mountain states; scattered localities along the southeastern Canadian border. Common to abundant throughout MA, especially at lower elevations.

HABITAT A variety of wetlands, but most common in well-vegetated ponds. Apparently tolerant of polluted waters.

NOTES Adults often forage along shorelines, perching horizontally on vegetation often with their wings cocked downward. Males make short patrols over water, clashing with other males and hovering frequently. Females oviposit in flight, hovering and dipping the tips of their abdomens into the water, often with males hovering or perching nearby. This species occasionally participates in Atlantic Coast migrations. 
Mature male thorax and abdomen entirely pruinose blue; immature male thorax bright green. Eyes blackish. Face green. Wings clear with brownish stigmas. Superior appendages yellow-white. Female thorax entirely bright green; abdomen yellowish green with black dorsal patches on S4-S6, mostly black on S7-59, with white terminal appendages. Eyes grayish green. Face green. Male is the only entirely blue skimmer with green face and pale terminal appendages. Female and immature can be confused only with the rarer snaketails ( $p$. 115119), but are larger, with differently patterned and unclubbed abdomen, and eyes that meet on top of the head.

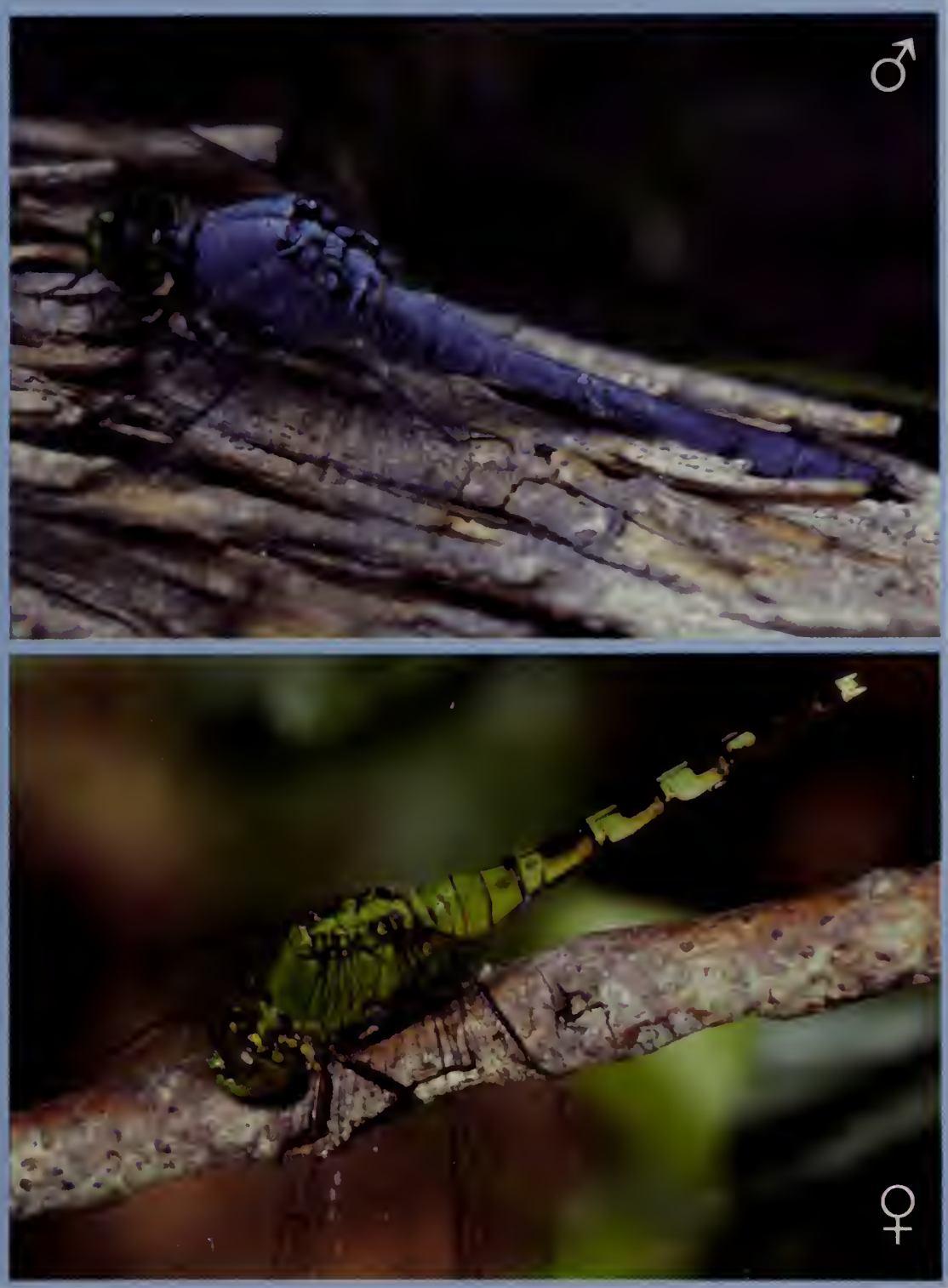

RANGE/STATUS Central to eastern U.S.; Canadian Great Lakes region. Common in MA; one of the most widespread and frequently seen dragonflies in the state. HABITAT Vegetated ponds, lakes, and slow streams.

NOTES Adults are voracious hunters, foraging on low vegetation and near the ground. They fly near water, in fields, along roads, and other open areas, and perch horizontally on logs, rocks, leaves, and the ground, or obliquely on vegetation. Males patrol small territories over floating vegetation; competing males fly characteristic loop-de-loops, alternately passing below then in front of each other. Females oviposit in flight, hovering low over the water and repeatedly dipping their abdomens into the water to release the eggs, while the male guards nearby.

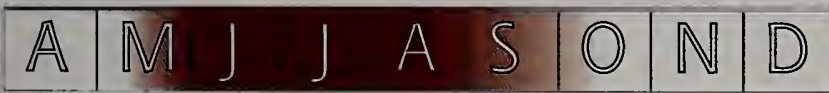


Male thorax and abdomen entirely dark blue. Eyes and face blackish. Wings with small dark basal streaks, amber streak along leading edge, and stigmas strikingly white and black. Female and immature male thorax dark brown above with broad, white mid-dorsal stripe and pale yellow sides and a single brown lateral stripe; abdomen yellow with broad black dorsal stripe and lateral stripes. Female wing tips dusky. No other dragonfly in the Northeast has white stigmas.
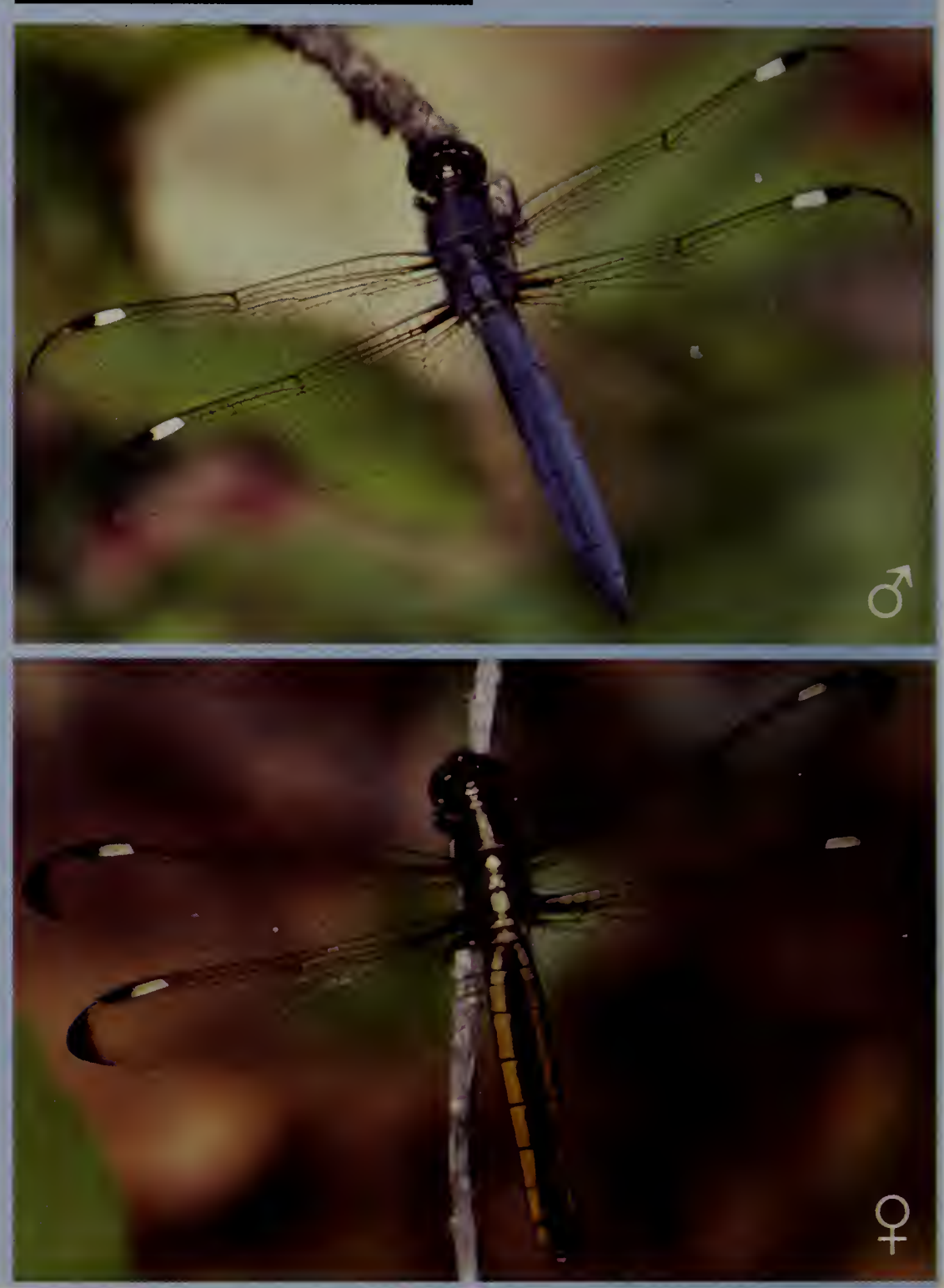

RANGE/STATUS Eastern U.S. Common throughout MA.

HABITAT Vegetated ponds, lakes, and slow streams.

NOTES Adults forage in fields and clearings near water. They perch horizontally on weed tips or obliquely on plant stems. Males are territorial near or over the water. Females oviposit in flight by dipping the tips of their abdomens into the water.

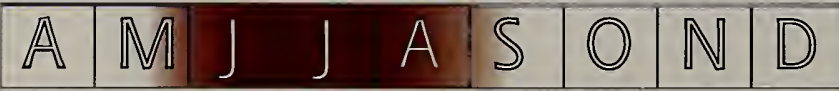


Male thorax and abdomen entirely dark blue, often appearing blackish. Eyes and face black. Wings mostly clear with black stigma and dusky tips; occasionally with thin dark bar on outer leading edge of wing and/or dark basal streaks. Female and immature male thorax brown above with broad, pale mid-dorsal stripe and large ivory patches on sides; abdomen yellowish with broad black dorsal stripe. Female abdomen with prominent flange on lower sides of 58 . Female wings often with broad, dark tips. Face brown. Male is distinctive. Female Great Blue Skimmer very similar but has white face; other female skimmers distinguished by wing pattern.
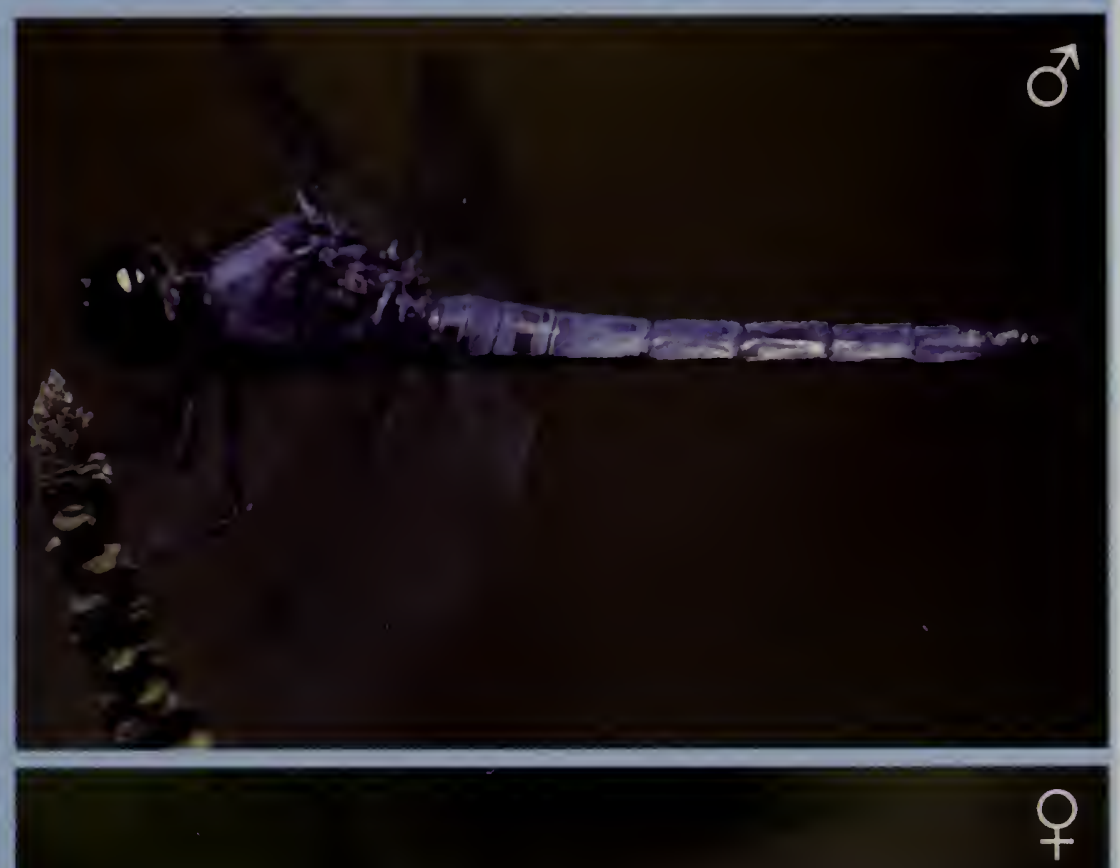

RANGE/STATUS Central to eastern U.S.; southeastern Canada. Common throughout $\mathrm{MA}$; one of the most widespread dragonfly species in the state.

HABITAT Ponds, lakes, and slow streams.

NOTES Adults forage along forest edges. They perch horizontally on twigs or obliquely from plant stems, occasionally also on logs or rocks. Males are territorial, perching on stems along shorelines. They clash frequently with other males, performing horizontal loop-de-loops around each other.

$\overline{\mathbb{A}} \mid \mathbb{M} J$ J A S $|O| \mathbb{N} \mid \mathbb{D}$


Male thorax and abdomen entirely pale blue. Eyes bluish-green. Face chalky white. Wings with narrow black basal bar, black spot at nodus, black stigma, dark tips, and occasionally a black bar between nodus and stigma. Female and immature male thorax brown with broad pale mid-dorsal stripe and mostly pale sides; abdomen yellow with fulllength, black dorsal stripe and a flange on lower edge of S8. Eyes rusty brown. Older females become entirely grayishbrown. Male Eastern Pondhawk (p. 155) similar but smaller, face green, terminal appendages white, and lacks black wing marks. Female Slaty Skimmer (p. 157) similar but face darker.

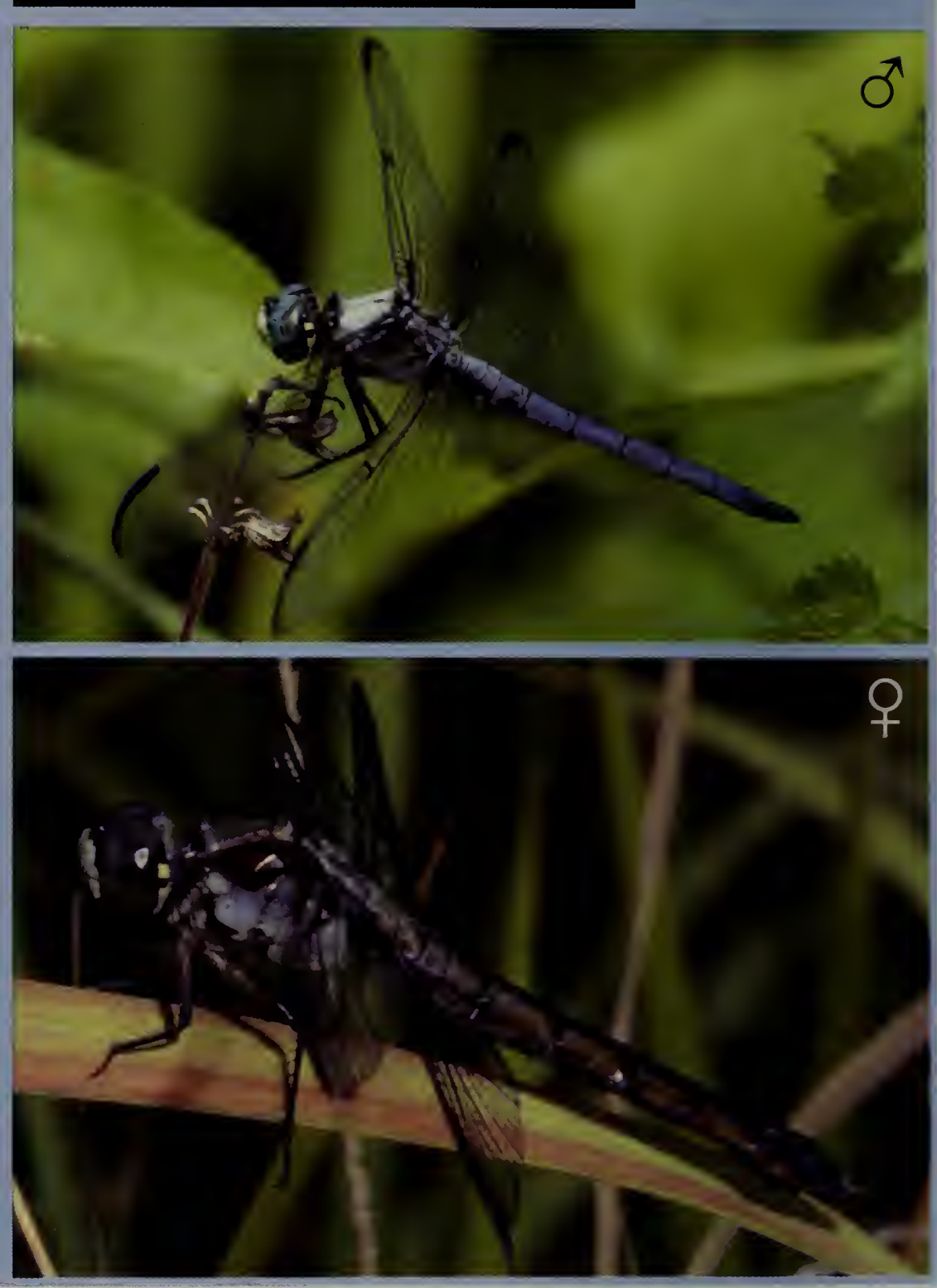

RANGE/STATUS Southeastern U.S. A species recorded only sporadically in south and northeastern MA.

HABITAT Swampy pools and streams.

NOTES Adults forage in fields and along forest edges, perching obliquely or horizontally on plant stems. Males are territorial near shorelines. Females oviposit in flight by tapping the tips of their abdomens to the water's surface, often with males hovering nearby. Small numbers are sometimes seen in Atlantic Coast migrations. Occasional northward incursions bring this species into southern New England.

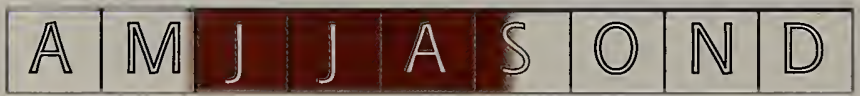




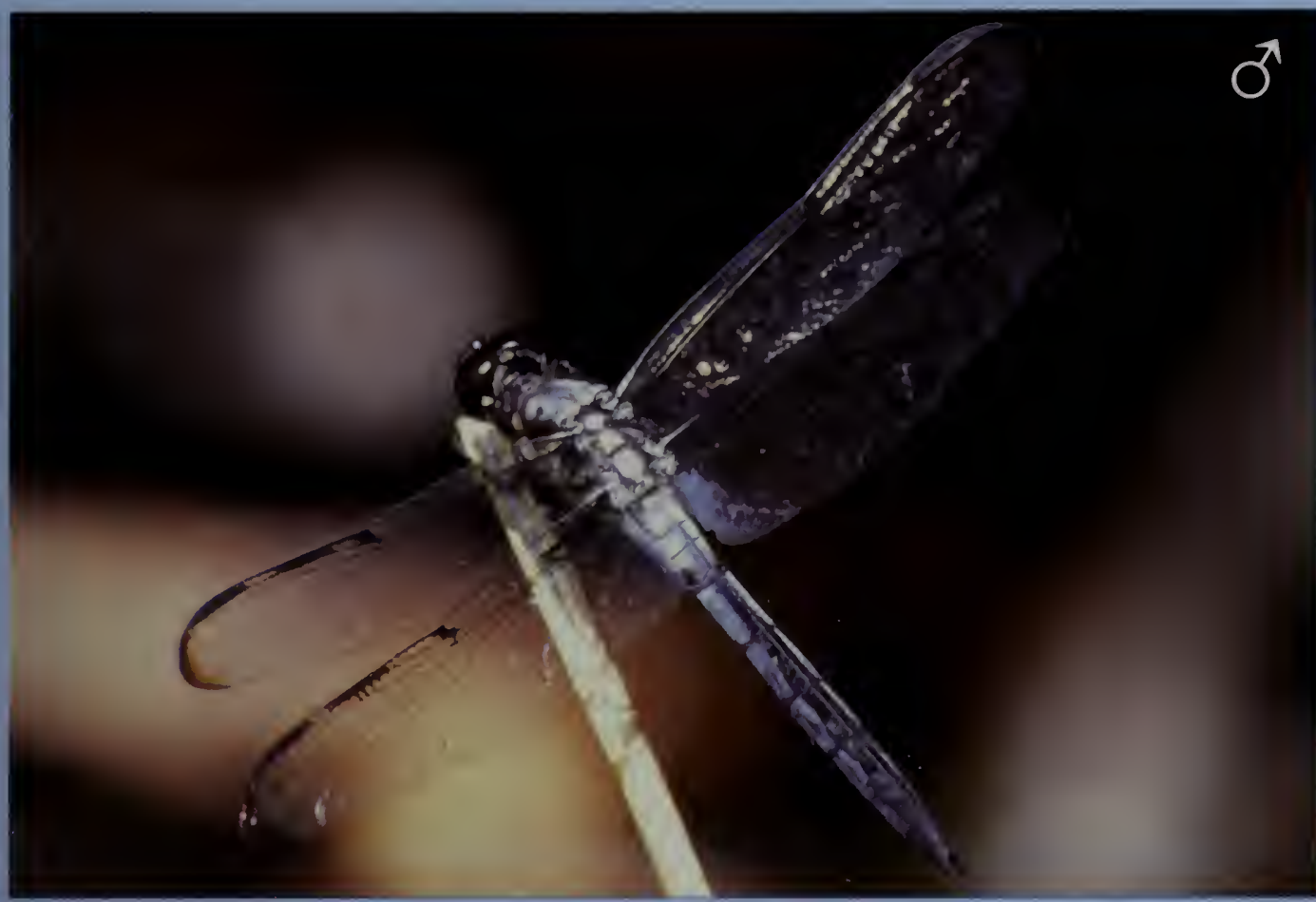

A large, blackish and gray dragonfly of the southeastern U.S. Male thorax pruinose gray above and on sides; abdomen blackish, becoming pruinose gray on the basal three segments. Wings have narrow dark streak at base, black spot at nodus, dark streak on leading edge between nodus and stigma, narrow black band wrapping around tip, and pruinose gray patch at base of hind wing. Eyes dark. Female and immature male thorax brown with broad, pale mid-dorsal stripe and extensively pale sides; abdomen yellow with full-length, black dorsal stripe; wings similar to male, but lack gray patch. Older females become dusky grayish-brown. Similar to Slaty Skimmer (p. 157) and Great Blue Skimmer (p. 158), but males more gray (less blue) on body and dark wing marks more extensive (especially bar between nodus and stigma), with gray patch at base of hind wing.

RANGE/STATUS Southeastern U.S., north to MA. Two records from MA, both males: one in Eastham in 1996, and one in Bourne in 2001.

HABITAT Vegetated ponds and vernal pools.

NOTES Adults perch at various heights on the tips of emergent vegetation, up to the tops of trees. Males patrol over open pools in wetlands. Small numbers of this species occasionally wander north along the Atlantic Coast.

\begin{tabular}{|l|l|l|ll|l|l|l|l|}
\hline $\mathbb{A}$ & $\mathbb{M}$ & $\mathrm{J}$ & $\mathrm{J}$ & $\mathrm{A}$ & $\mathrm{S}$ & $\mathrm{O}$ & $\mathbb{N}$ & $\mathbb{D}$ \\
\hline
\end{tabular}


Male thorax blue above, dark brown on sides; abdomen blue. Eyes dark brown to black. Wings with dark basal streaks, longer and thicker on the hind wings; stigma brown. Female and immature male thorax dark brown with pale dorsal stripes; abdomen brick red with connected, forwardpointing black triangles on top of S3-S9. Older female becomes drab gray/blue. White Corporal (p. 161) similar but male abdomen whiter and without blue on thorax; female abdomen paler with black dorsal stripe (no triangles).

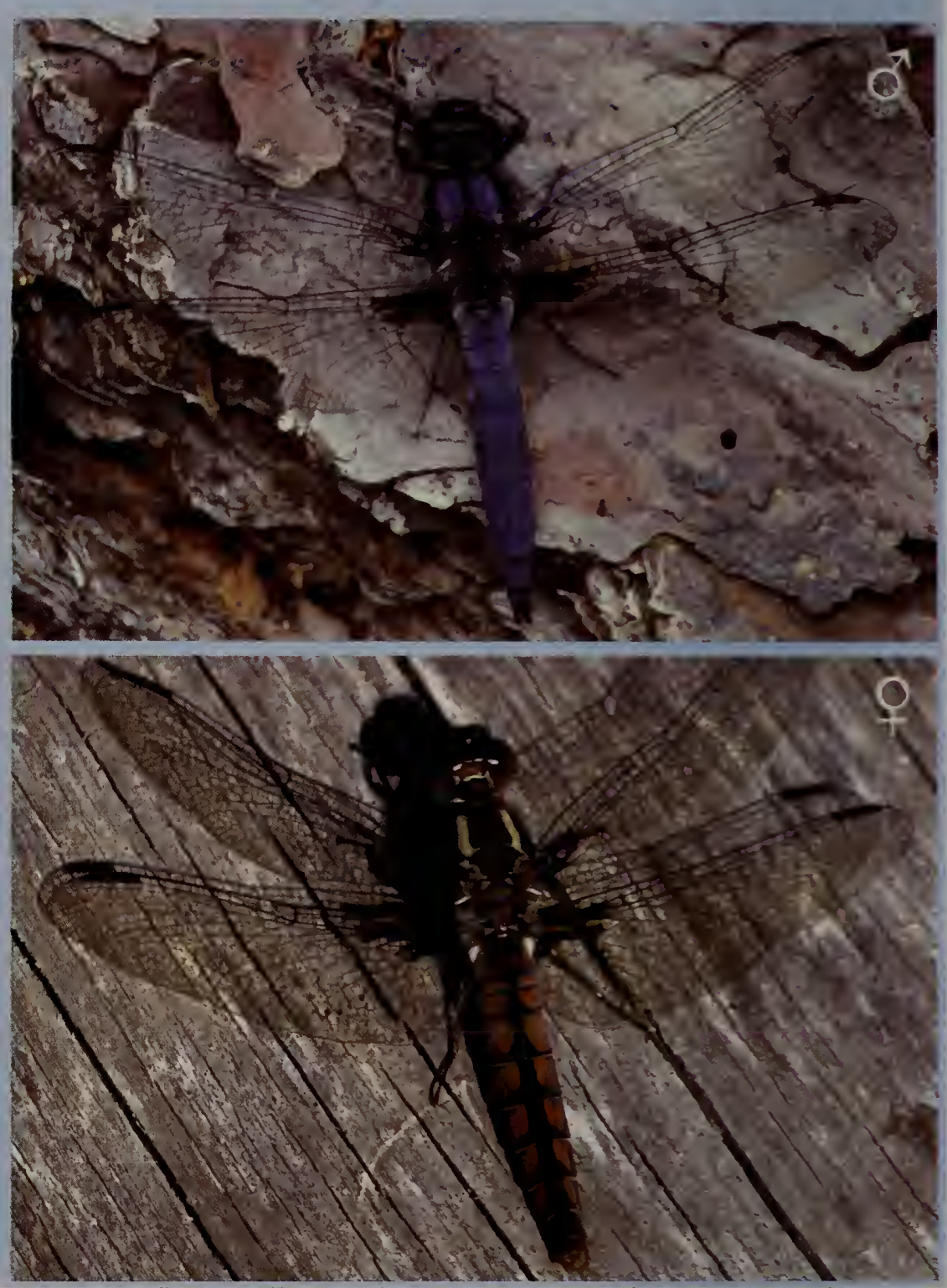

RANGE/STATUS Southeastern U.S., north to MA. A locally common species of the coastal plain.

HABITAT Coastal plain ponds.

NOTES Adults forage in fields and clearings near water. They perch horizontally on the ground or logs, or vertically on tree trunks. Males are territorial, flying low over open water and clashing frequently with other males. Females oviposit in flight by dipping the tips of their abdomens into the water, washing off the eggs.

\begin{tabular}{|l|l|l|l|l|l|l|l|}
\hline $\mathbb{A}$ & $\mathbb{N} J \mathbf{A}$ & $\mathbb{A}$ & $\mathbb{S}$ & $\mathbb{O}$ & $\mathbb{N}$ & $\mathbb{D}$ \\
\hline
\end{tabular}


Male thorax dark brown with pale shoulder stripes (fade with age); abdomen mostly pale, pruinose white. Eyes dark brown. Wings with small dark basal patch, larger on hind wing. Female and immature male thorax dark brown with pale dorsal stripes; abdomen pale rusty with black dorsal stripe. Older female can look like a drab male. Blue Corporal (p. 160) similar but dark basal wing marks split into distinct bars, male thorax blue on top and abdomen darker blue; female abdomen darker with black dorsal triangles. Chalk-fronted Corporal (p. 162) wings have smaller basal spots; male has gray top of thorax and only basal half of abdomen whitish; female has wider black dorsal abdominal stripe.
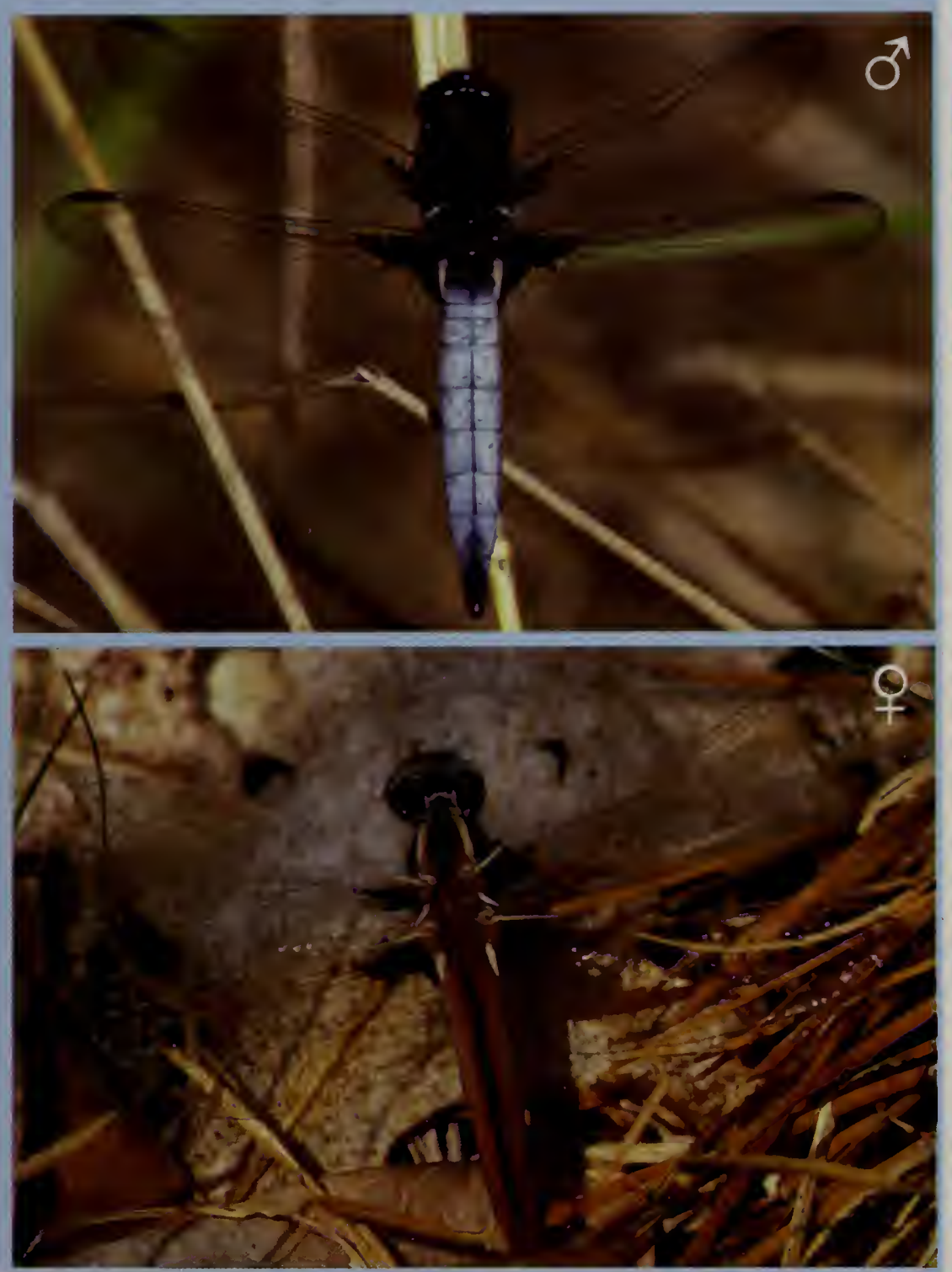

RANGE/STATUS A narrow band along the northeastern coastal plain, extending into southeastern Canada. Fairly common throughout MA.

HABITAT Vegetated and bog-bordered ponds and lakes.

NOTES Adults forage in fields and clearings near water. They perch on floating vegetation and logs, the ground, or on tree trunks. Males are territorial and make frequent forays low over water.

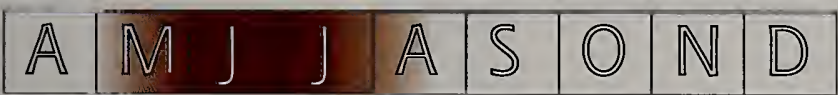


Male thorax grayish-white above and dark brown on sides; abdomen blackish with chalky gray pruinosity on basal half ( $\mathbf{S 2}-\mathbf{S 4}$ or S5). Wings with small dark basal patch, larger on hind wings. Female and immature male thorax dark brown with pale dorsal stripes; abdomen rusty brown with black dorsal stripe. Older female becomes drab with dull pruinosity on abdomen. White Corporal (p. 161) similar but basal wing patch larger, male lacks white on thorax and abdomen more extensively grayish-white; female abdomen paler with slightly thicker black dorsal stripe.

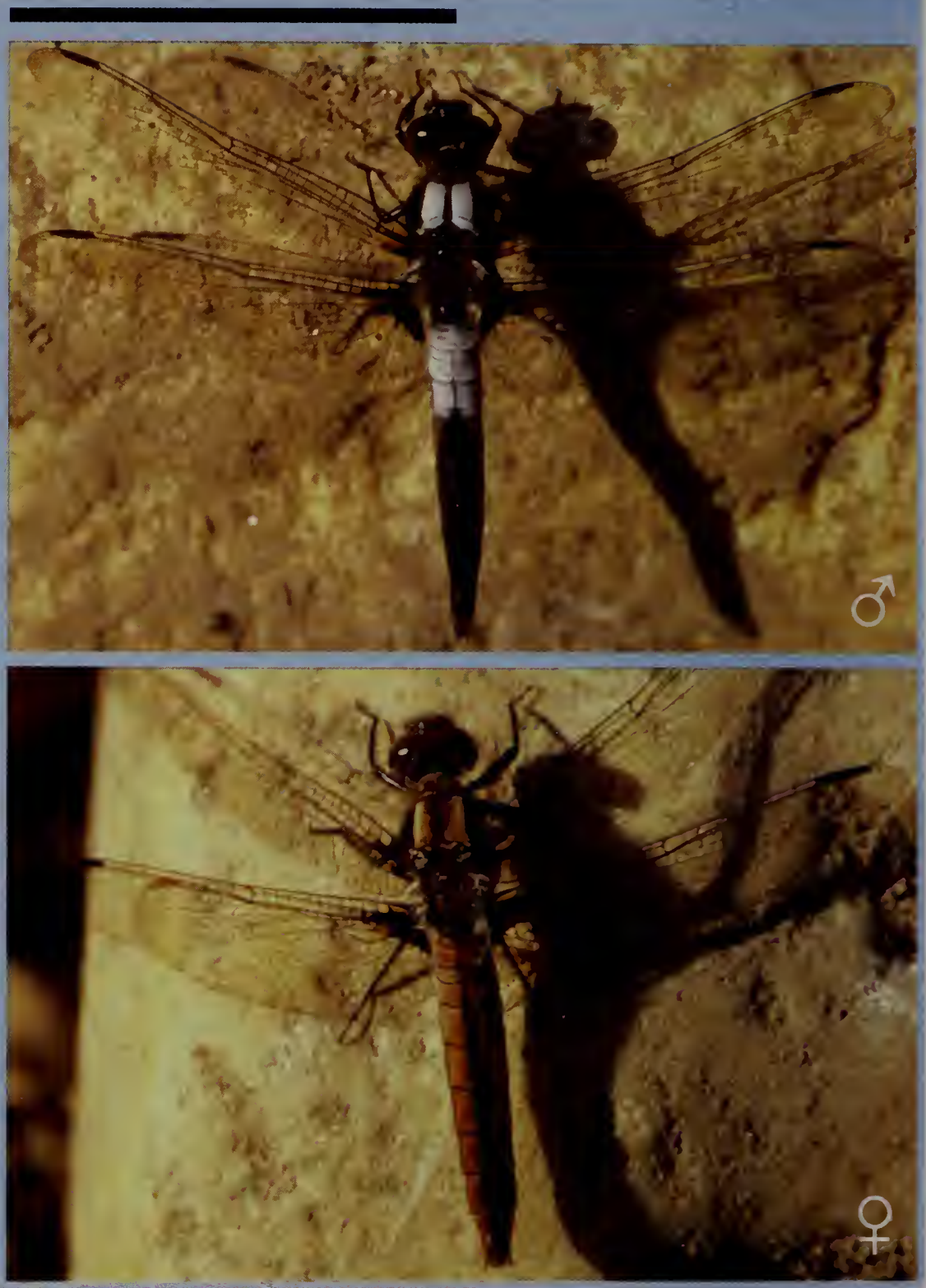

RANGE/STATUS A narrow band across the northern U.S. and southern Canada. Common to abundant throughout interior MA, but absent from the southeast coastal plain.

HABITAT Boggy and marsh-bordered ponds and lakes.

NOTES Adults forage near the ground and bushes in sunny forest openings. They perch horizontally on the ground, logs or rocks, and occasionally on plant stems. Males will perch near shorelines or on floating vegetation, flying low, swift patrols over open water, chasing each other and occasionally hovering.

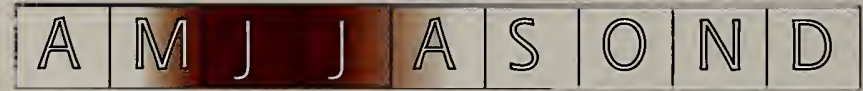


Male thorax dark brown with two pale lateral stripes that fade with age; abdomen stocky and entirely pruinose white. Eyes dark brown. Wings with elongate basal patch on leading edge and broad black band across middle third. Female and immature male thorax brown with two yellow lateral stripes; abdomen brown with broken, angled, yellowish lateral patches. Female wings with elongate basal patch, large irregularly shaped patch at nodus, and broad black tip. Mature male unmistakable. Female Twelve-spotted Skimmer (p. 164) wing pattern similar, but abdomen not as chunky, yellow on sides of abdomen continuous (not broken).
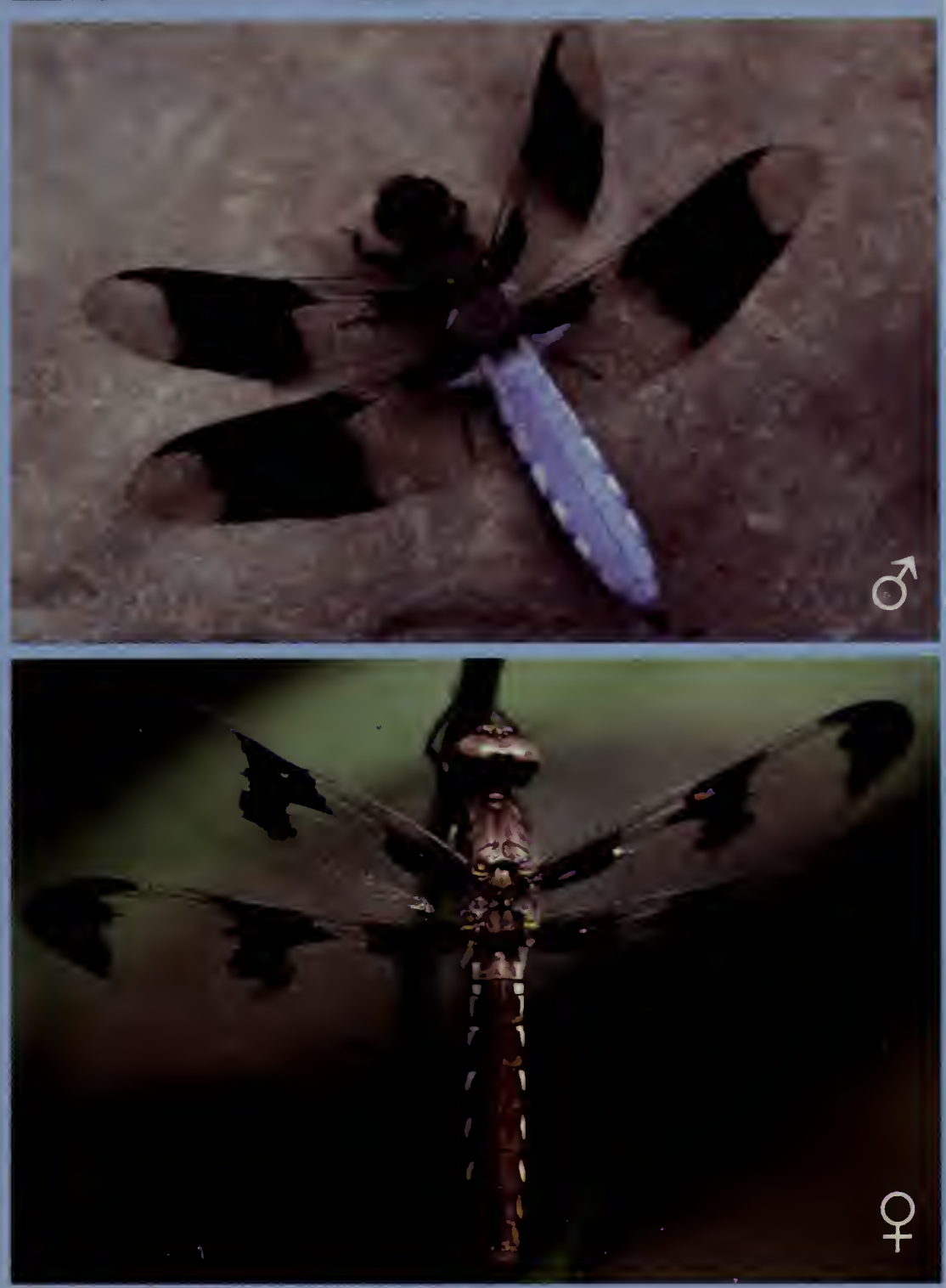

RANGE/STATUS U.S.; southern Canada. Common throughout MA; one of the most widespread and abundant dragonflies in the state.

HABITAT A variety of wetlands including ponds, slow-moving, muddy-bottomed rivers and streams, and marshes; apparently tolerant of degraded habitats.

NOTES Adults stray far from water, foraging in fields and forest openings and perching horizontally on the ground or obliquely on low vegetation. Males defend small territories and raise their abdomens aggressively in flight when clashing with other males. Females oviposit in flight, tapping the tips of their abdomens to the water's surface to release the eggs. Males often hover nearby during oviposition.

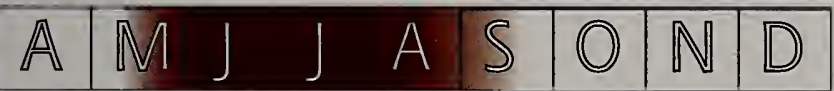


Male thorax brown with two yellow lateral stripes that fade with age: abdomen becomes predominantly pruinose gray. Eyes dark reddish-brown. Wings with elongate, black basal patch, black patch at the nodus, and black tip; older males develop pruinose white patches between the black patches. Female and immature male similar, but abdomen brown with fulllength, yellow lateral stripes and wings without white patches. Female has flange on lower edge of S8. Female Common Whitetail (p. 163) has similar wing pattern, but abdomen stockier and lateral yellow marks broken.
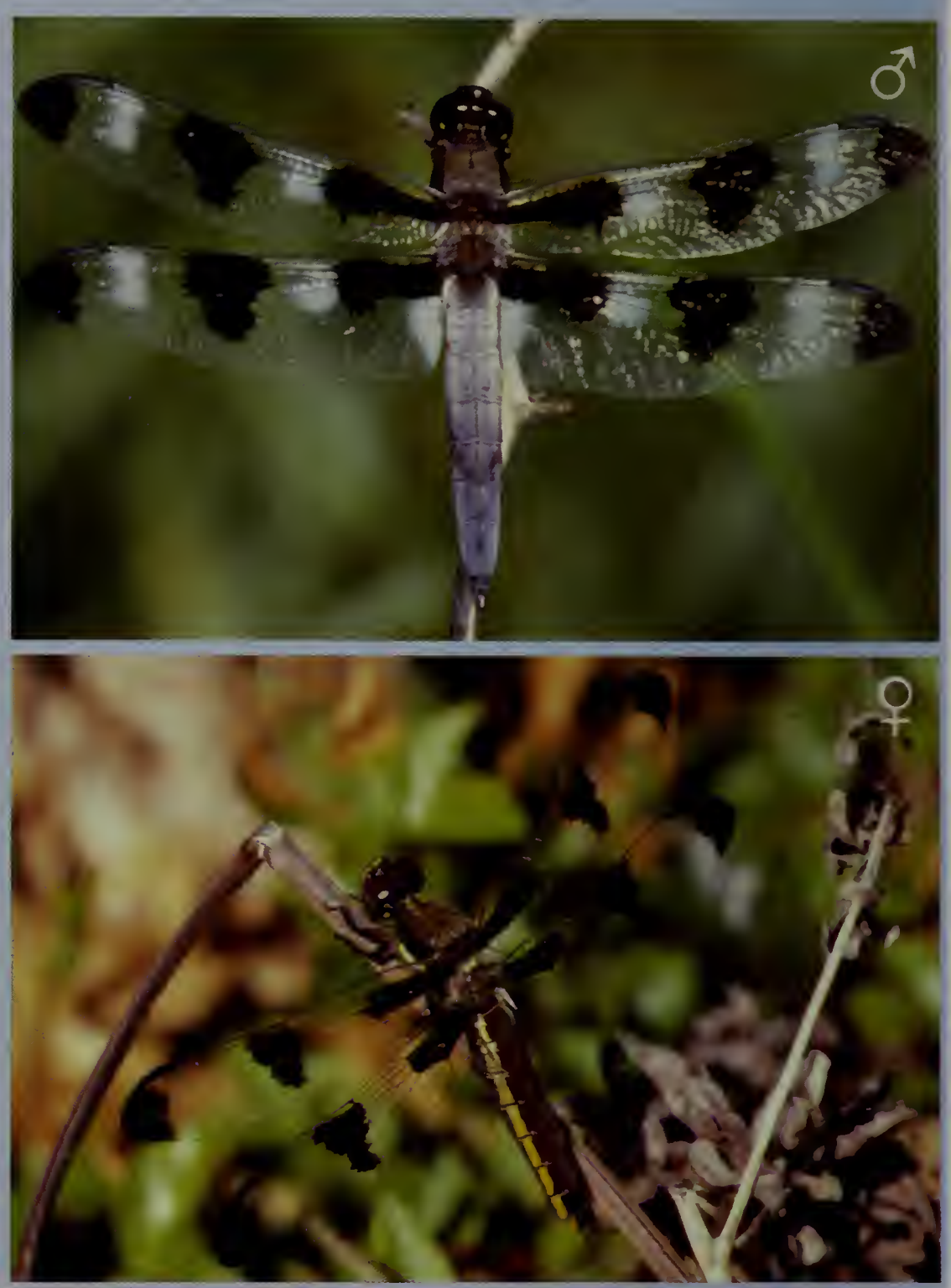

RANGE/STATUS U.S.; southern Canada. Common throughout MA. HABITAT Ponds, slow streams, and lakes; occasionally marshes or bogs.

NOTES Adults forage in fields, perching horizontally or obliquely on stem tips. Males perch near shore in sunny spots on emergent vegetation. They are territorial and patrol over water, loop-de-looping with competing males. Small numbers of this species occasionally take part in Atlantic Coast migrations.

\begin{tabular}{|l|l|l|l|l|l|l|l|}
\hline $\mathbb{A}$ & $\mathbb{M}$ & $J$ & $\mathrm{~A}$ & $\mathrm{~S}$ & $\mathrm{O}$ & $\mathbb{N}$ & $\mathbb{D}$ \\
\hline
\end{tabular}


Male thorax blackish, becoming pruinose gray above; abdomen mostly pruinose gray. Eyes dark brown. Wings dark brown to black over basal third with pruinose white bands outside the black. Female and immature male thorax dark brown with broad, pale mid-dorsal stripe; abdomen yellow with broad, black dorsal stripe. Wings similar to male but lack white patches. Male Common Whitetail (p. 163) similar, but dark bands in middle of wing and white wing patches lacking.
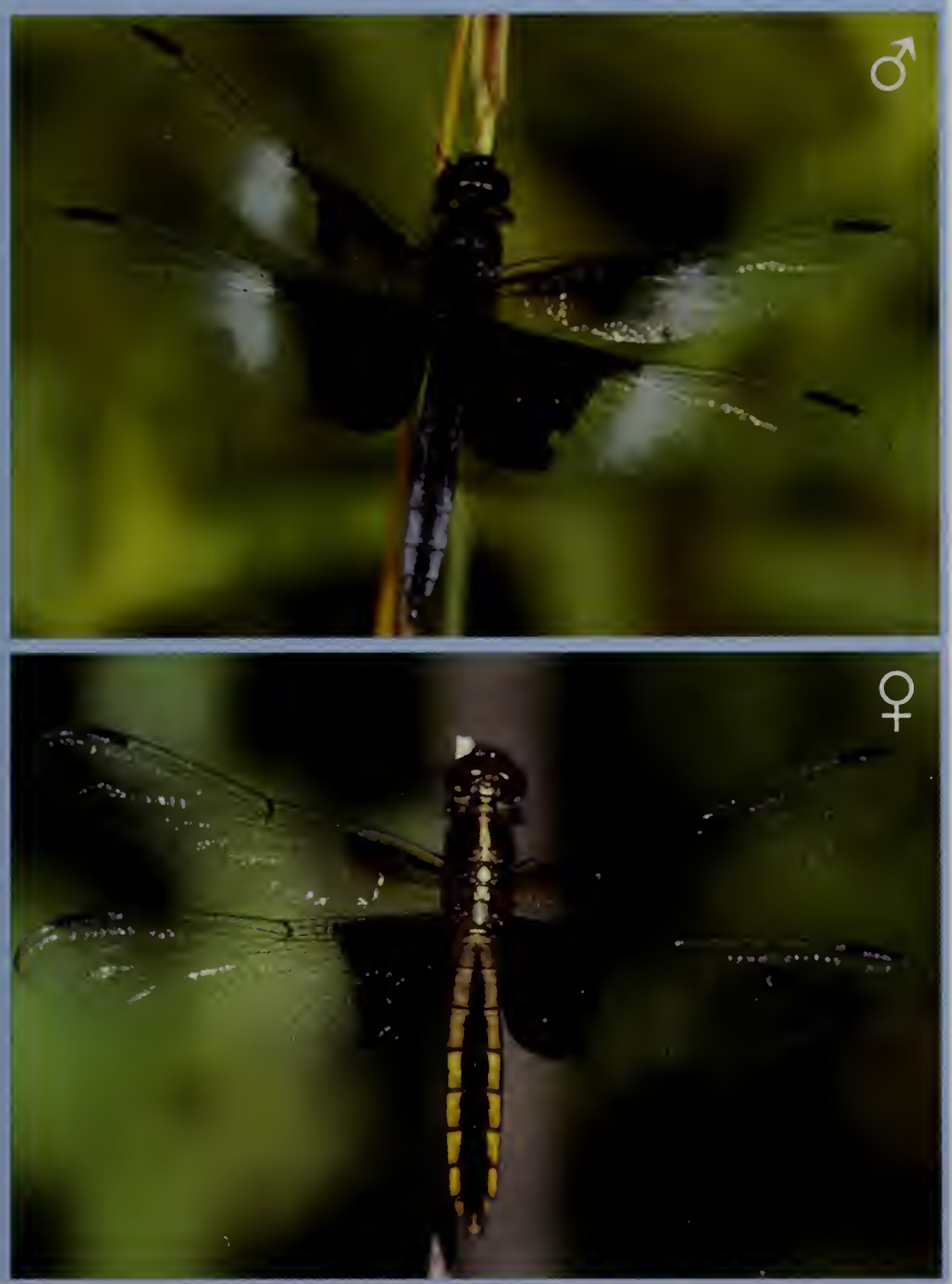

RANGE/STATUS Much of the U.S., extending into southwestern and southeastern Canada. Common throughout much of MA, but rare to absent on Cape Cod and the offshore islands.

HABITAT Ponds, lakes, marshes, and stream backwaters.

NOTES Adults forage in open fields, often far from water. They perch obliquely on plant stems. Males defend small territories at breeding sites; at high densities dominant males are most successful at mating. Females oviposit in flight, dipping the tips of their abdomens to release eggs.

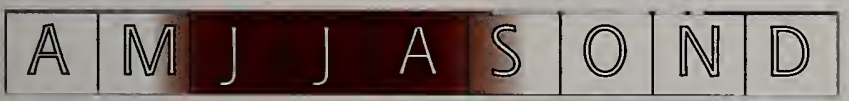


Male thorax orangebrown above with paler sides; abdomen bright orange with black dorsal stripe. Eyes reddishbrown. Face orange. Wings suffused with orange; stigma redorange. Female and immature male thorax brown with broad white mid-dorsal stripe and pale sides; pale areas of abdomen yellow and wings tinged yellow. Needham's Skimmer ( $p$. 167) very similar, but male more red, tibia of hind leg pale brown, and inner leading edge of wing dark brown (except in older males).

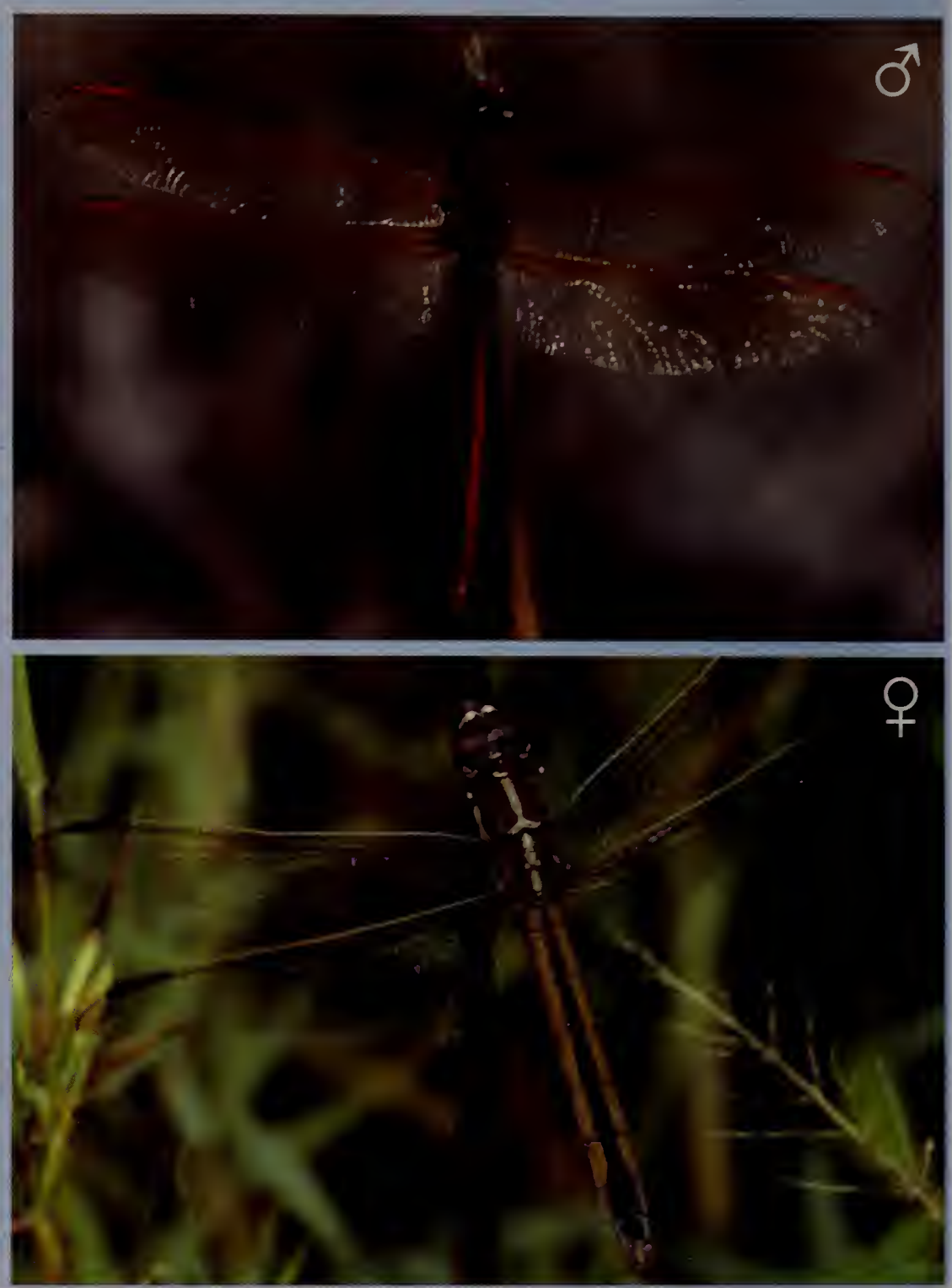

RANGE/STATUS Southeastern U.S., north to MA. Uncommon and local in MA, restricted to the southeast coastal plain.

HABITAT Coastal plain ponds.

NOTES Adults forage in fields and clearings near water, making sorties from the tops of stems where they perch horizontally or obliquely. Males defend territories along the shore or over open water, frequently clashing with other males. Females oviposit in flight by dipping the tips of their abdomens into the water, washing off the eggs.

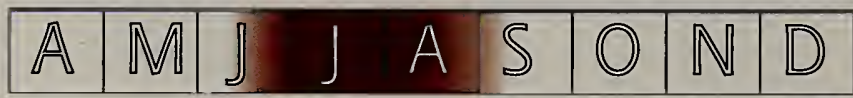


Male thorax reddishbrown; abdomen bright reddish-orange with black dorsal stripe. Eyes reddishbrown. Face red. Anterior portion of wings redorange, except leading edge usually brown basally; stigma reddish. Tibia of hind legs pale brown. Female and immature male thorax brown above with broad, pale mid-dorsal stripe and pale sides; pale areas of abdomen yellow; face yellow; front half of wings tinged yellow. Goldenwinged Skimmer (p. 166) very similar but male abdomen less red, leading edge of wing orangel yellow basally, posterior half of wings suffused with orange/yellow, and tibia of hind legs black. Older male often difficult to distinguish in the field.

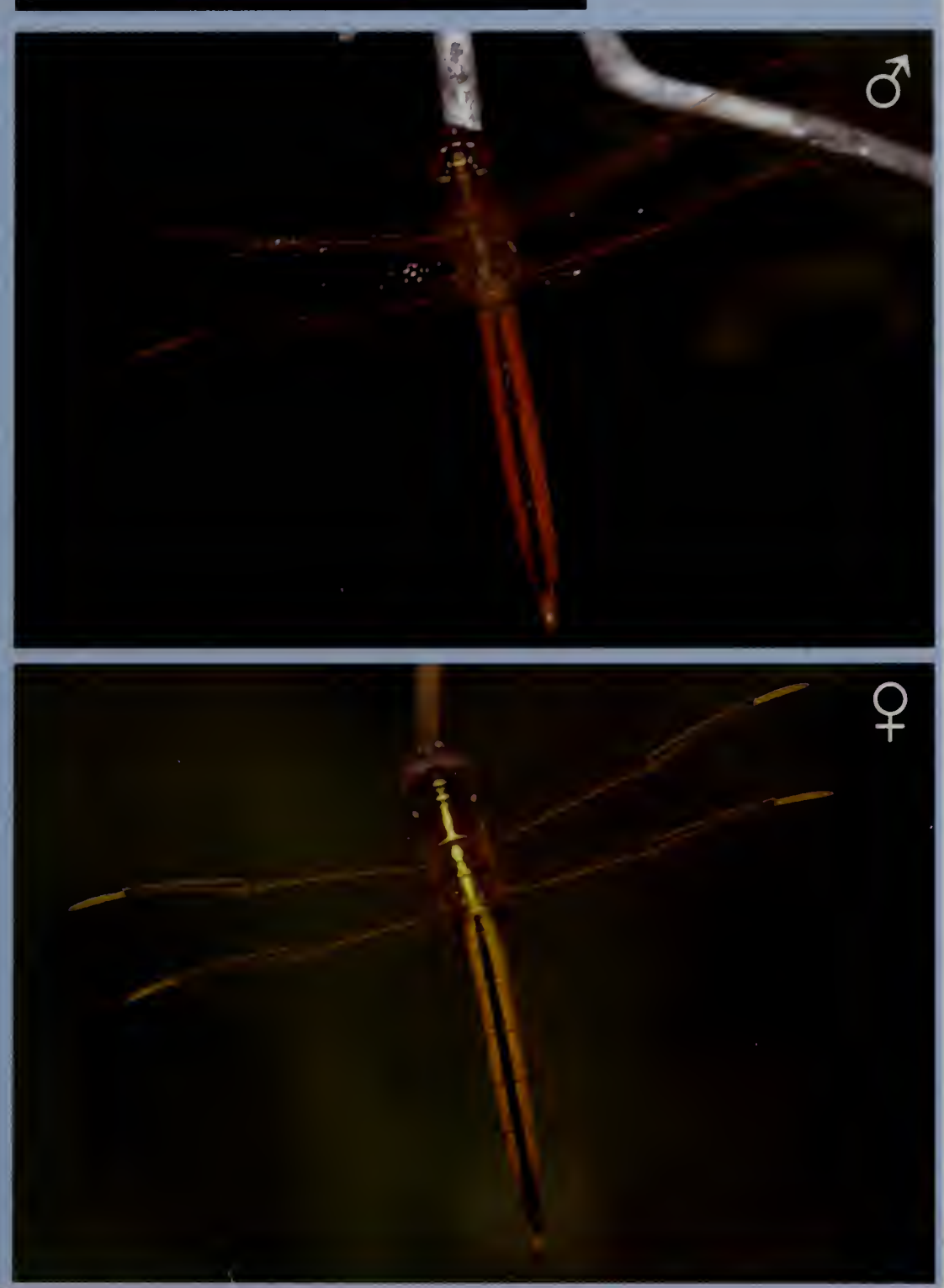

RANGE/STATUS A narrow band along the Gulf Coast from TX to FL, and the Atlantic Coast from FL to NH. An uncommon species in MA, found primarily along the coast.

HABITAT Ponds, lakes, and brackish wetlands.

NOTES Adults forage in marshes along the coast. Males are territorial, and perch horizontally or obliquely from emergent or shoreline vegetation.

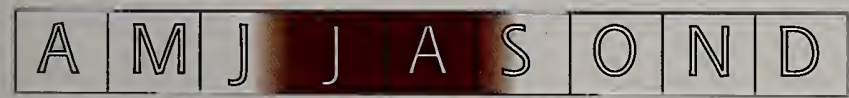


Male thorax rusty brown with two pale lateral stripes; abdomen orange, brightest on sides, with diffuse gray dorsal marks on S3-S5 and black dorsal marks on S6-S10. Eyes rusty brown. Wings amber at base, along leading edge, and at tip, with large brown spot at nodus, brown band near tip. elongate dark streak at base of hind wing, and orange-brown stigma. Females similar but orange coloration duller. Halloween Pennant (p. 171) similar but smaller, with wings entirely suffused with orange and brown patches more extensive.

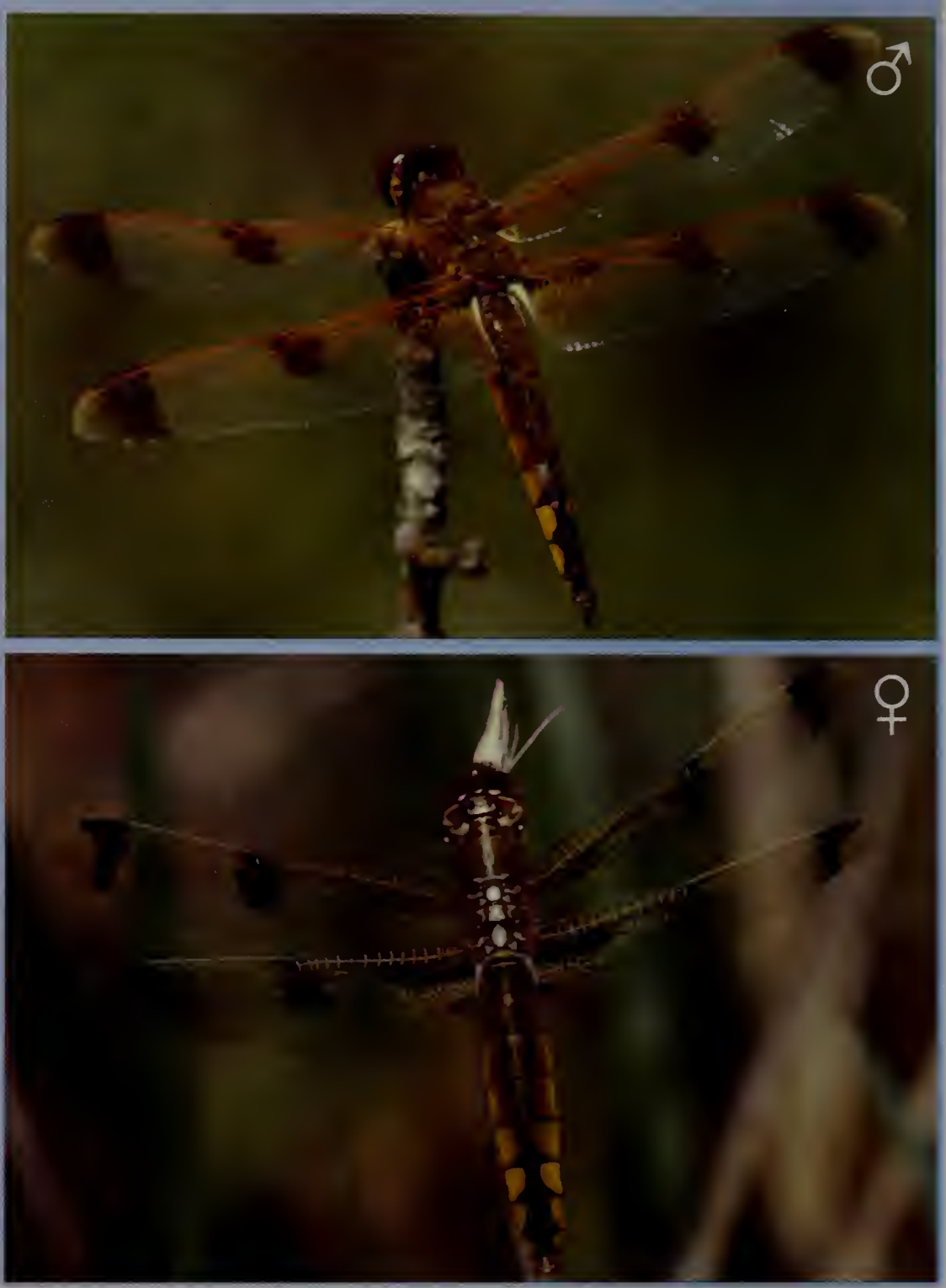

RANGE/STATUS Eastern U.S., extending north into Nova Scotia. Fairly common in eastern MA, scarce inland.

HABITAT Grassy ponds, vernal pools, bog-bordered ponds, and slow streams.

NOTES Adults forage in fields and clearings, perching horizontally or obliquely on plant stems. They are often seen in upland areas far from water. Males are territorial, clashing frequently with other males. They occasionally make migratory movements along the Atlantic Coast. Immigrants from the south apparently account for at least a portion of the population in MA.

\begin{tabular}{|l|l|l|l|l|l|l|l|}
\hline $\mathbb{A}$ & $\mathbb{M} J$ & $\mathbb{A}$ & $\mathbb{S}$ & $\mathbb{O}$ & $\mathbb{N}$ & $\mathbb{D}$ \\
\hline
\end{tabular}


Male thorax brown and hairy with yellow lateral spots; abdomen mostly brown on $51-56$, mostly black on S7-S10, with yellow lateral stripes. Eyes brown. Wings have amber leading edge, black spot at nodus, black stigma; triangular black basal patch on hind wings. Females similar but abdomen thicker. Wing pattern and half brown/ half black abdomen are distinctive.
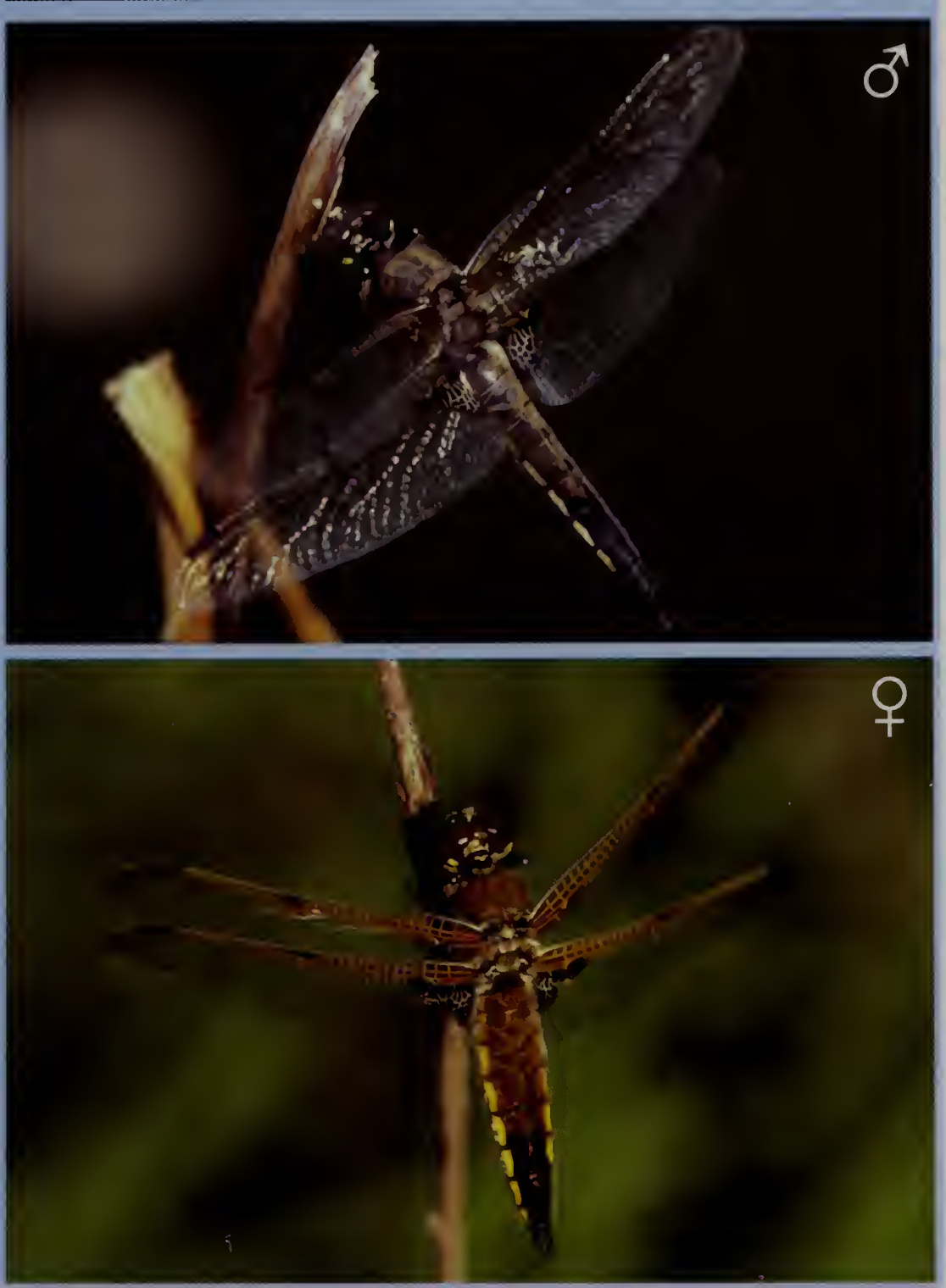

RANGE/STATUS Central to northerr U.S.; Canada. Common throughout interior MA, scarcer on the southeast coastal plain.

HABITAT Bog-bordered ponds, fens, and acidic, marshy streams.

NOTES Adults stray from water to forage in fields and clearings. They perch obliquely or horizontally on vegetation. Females oviposit in flight, tapping the tips of their abdomens to the water's surface to release the eggs. Males often hover nearby during oviposition.

$|\bar{A}| \mathbb{M} J \mathcal{A}|\mathbb{A}| S|O| \mathbb{N}|\bar{D}|$


The reddest of the pennants. Male thorax dark red; abdomen black with red, posteriorlypointing triangles on top of S3-S7, red on sides of S1-S4; terminal appendages reddish. Eyes reddishbrown. Distinctive wing pattern (though somewhat variable): stigmas reddish; wing tips dark brown (clear on some individuals), dark brown spots (variable in size) between nodus and stigma, reddish-brown venation on leading edges, large, reddishbrown patch occupying basal quarter of hind wing. Female and immature male similar but yellow where mature males are red (including stigmas). Halloween Pennant ( $p$. 171) similar, but wings amber without large basal hind wing patch, outer wings banded (not spotted), and mature male more orange.

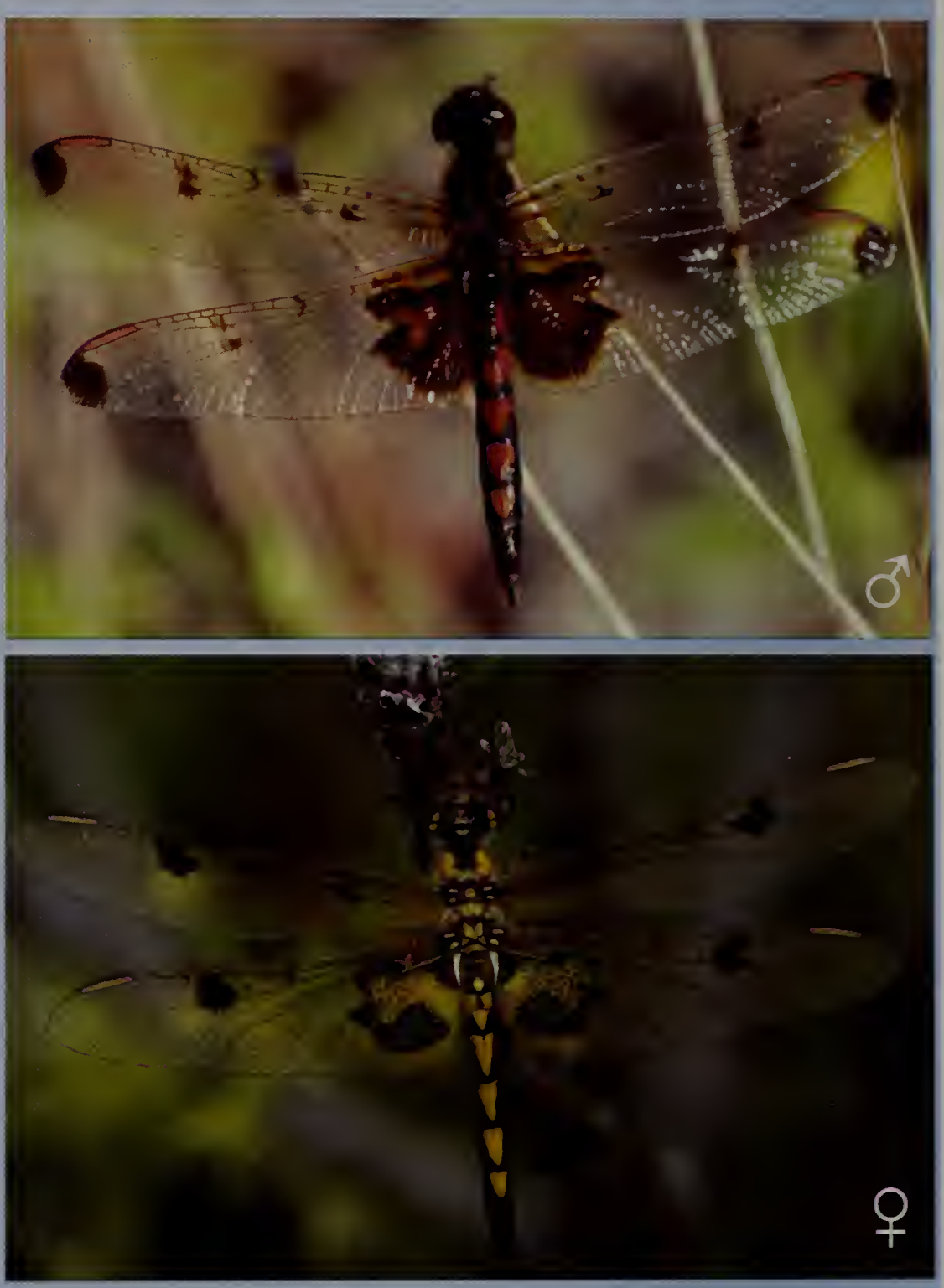

RANGE/STATUS Central to eastern U.S.; narrow band along the southeastern Canadian border. Common and widespread throughout MA.

HABITAT Vegetated ponds, lakes, bogs, and slow streams.

NOTES Adults forage in open fields and along shorelines, perching on the tips of grasses and other vegetation. Males wait for females near the shore, chasing off other males. They also fly low over water. Females oviposit in tandem, most often in the morning, dipping the tips of their abdomens into the water to release the eggs.

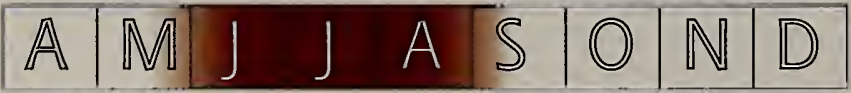


Orange coloration of male distinct among the pennants. Male thorax dark rusty orange; abdomen black with orange dorsal marks on S3-S7; orange terminal appendages. Eyes reddishbrown. Wings amber with dark brown bands crossing outer portion, dark brown bands (occasionally broken) at mid-wing, large brown basal spot, and reddish stigmas; wing tips occasionally dusky. Female and immature male similar, but pale areas on body yellow rather than orange. Flight rather bouncy and butterfly-like. Calico Pennant (p. 170) similar but with large, basal hind wing patch and spotted (not banded) outer wings.

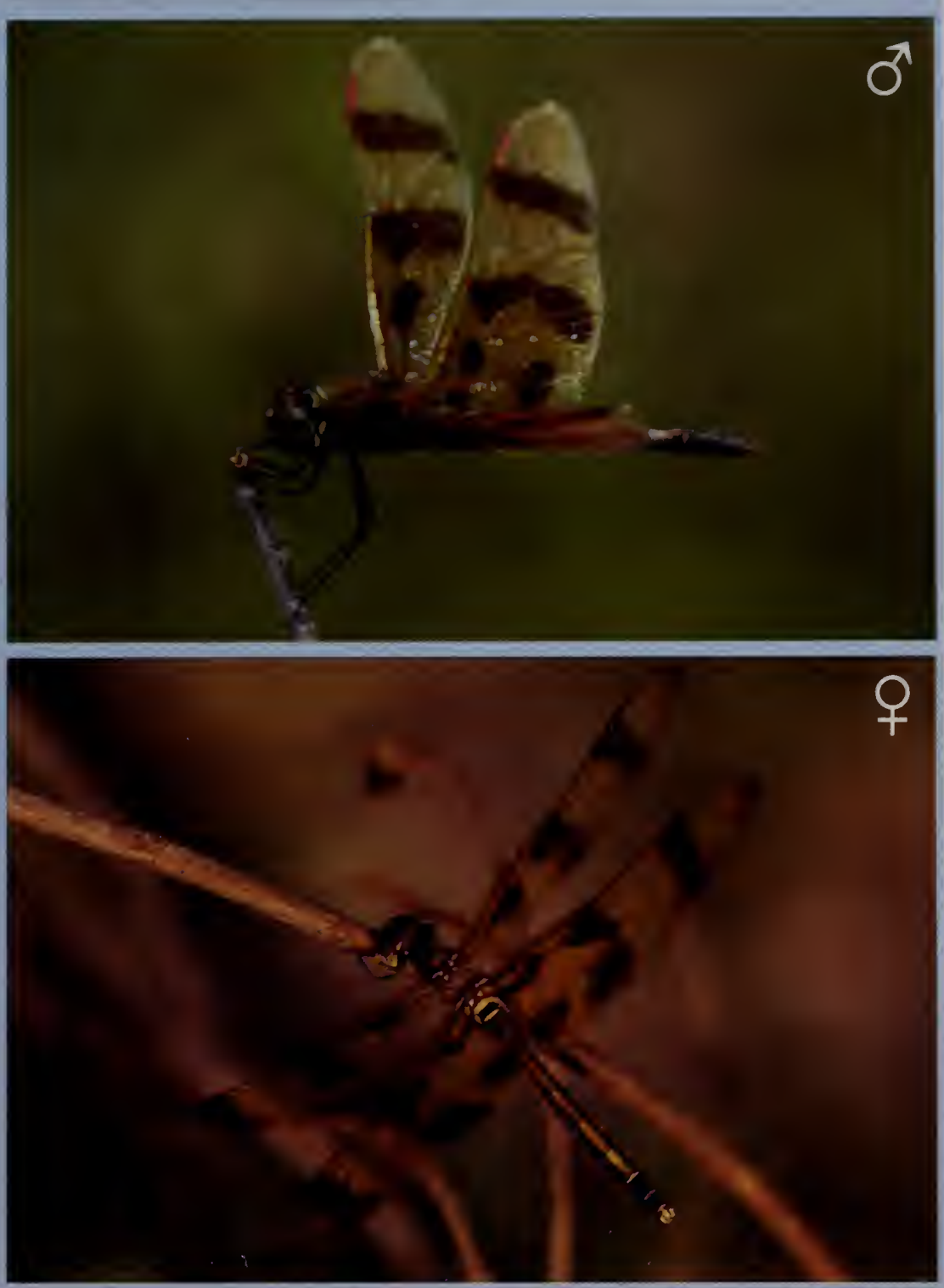

RANGE/STATUS Central to eastern U.S.; narrow band along the southeastern Canadian border. Common in MA, primarily at lower elevations.

HABITAT Vegetated ponds, lakes, and slow streams.

NOTES Adults forage in open fields, often far from water, and along shorelines, fluttering like butterflies and perching on the tips of grasses and other vegetation, often with wings cocked upward. Males are not territorial, but wait for females near the water. Females oviposit in tandem, most often in the morning, dipping the tips of their abdomens into the water to release the eggs.

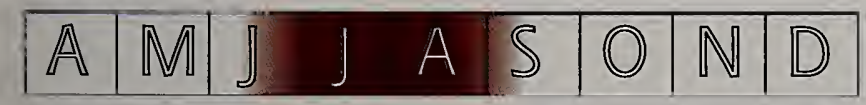


The only mostly black pennant with extensive wing marks. Male thorax blackish and hairy; abdomen entirely dark, blackish-blue. Eyes black. Wing pattern variable, but typically with large black basal bars on leading edge, large black spots between nodus and stigma, small basal hind wing spots, black tips (occasionally lacking), and blackish stigmas. Female and immature male thorax boldly patterned with yellow and black marks, fading with age; abdomen black with yellow dorsal spots on S3-S7; wings similar to male but often with clear tips and yellow basal venation. Eyes chestnut. Martha's Pennant (p. 173) similar, but wing marks limited to basal patch.
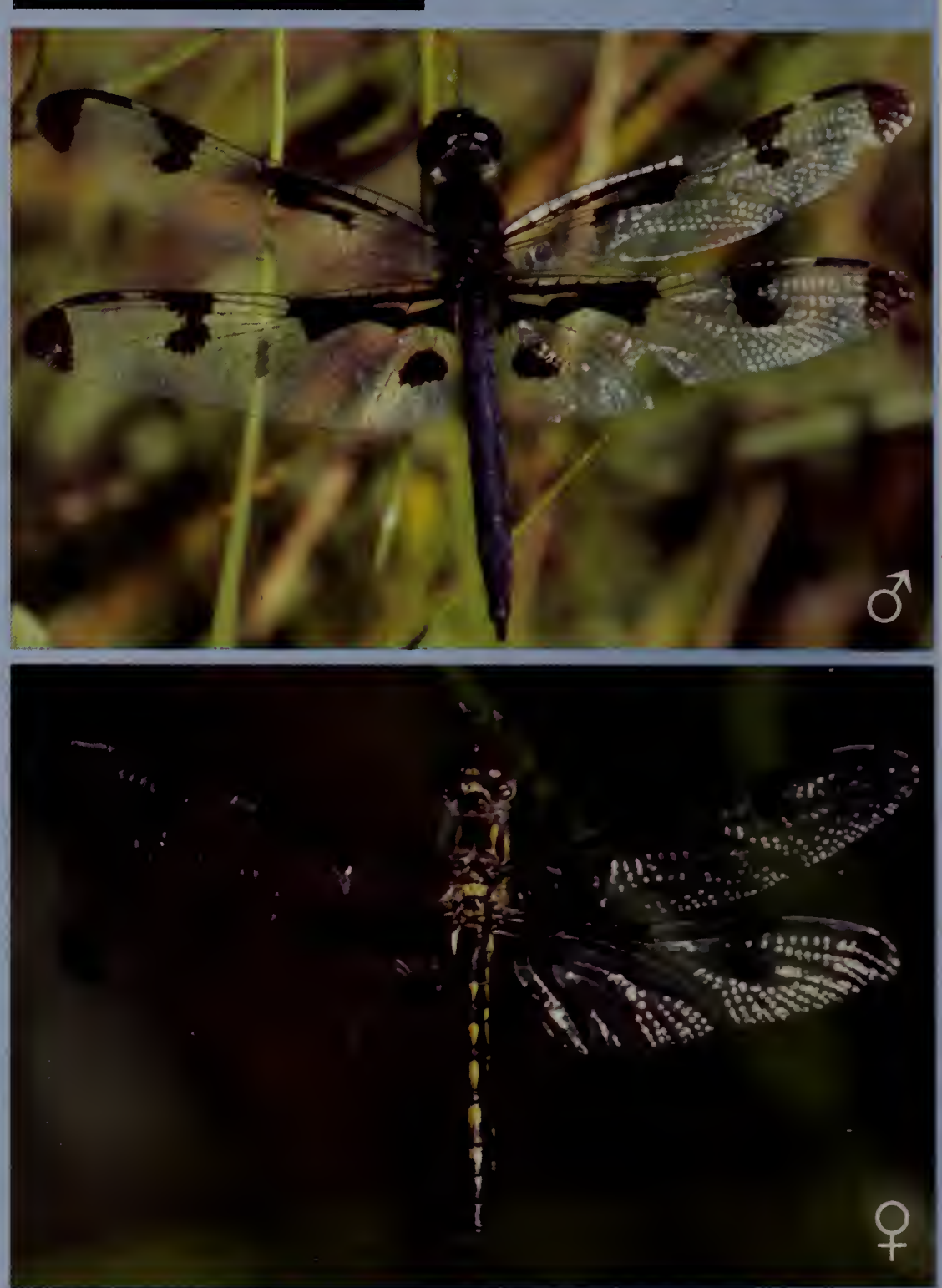

RANGE/STATUS Central to northeastern U.S. Uncommon in central and eastern MA.

HABITAT Ponds, lakes, and reservoirs.

NOTES Adults forage from the tops of tall bushes and trees and perch on the tops of tall bushes near shorelines. Males are not territorial, but wait for females near the water. Females oviposit in tandem, most often in the morning, dipping the tips of their abdomens into the water to release the eggs

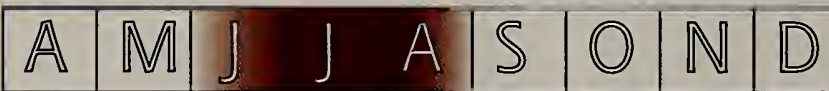


The only blackish pennant with clear outer wings. Male thorax black and hairy; abdomen dark bluish-black. Wings clear except for black basal patches on hind wing, and brownish stigma. Eyes black. Female and immature male thorax dark with yellowish marks, abdomen dark with yellow dorsal spots on S3-S7; often has yellow venation and amber wash at base of hind wing. Banded Pennant (p. 172) similar but wings much more extensively marked. Black Saddlebags (p. 191) similar but much larger, with broader wings and larger dark basal hind wing patch.

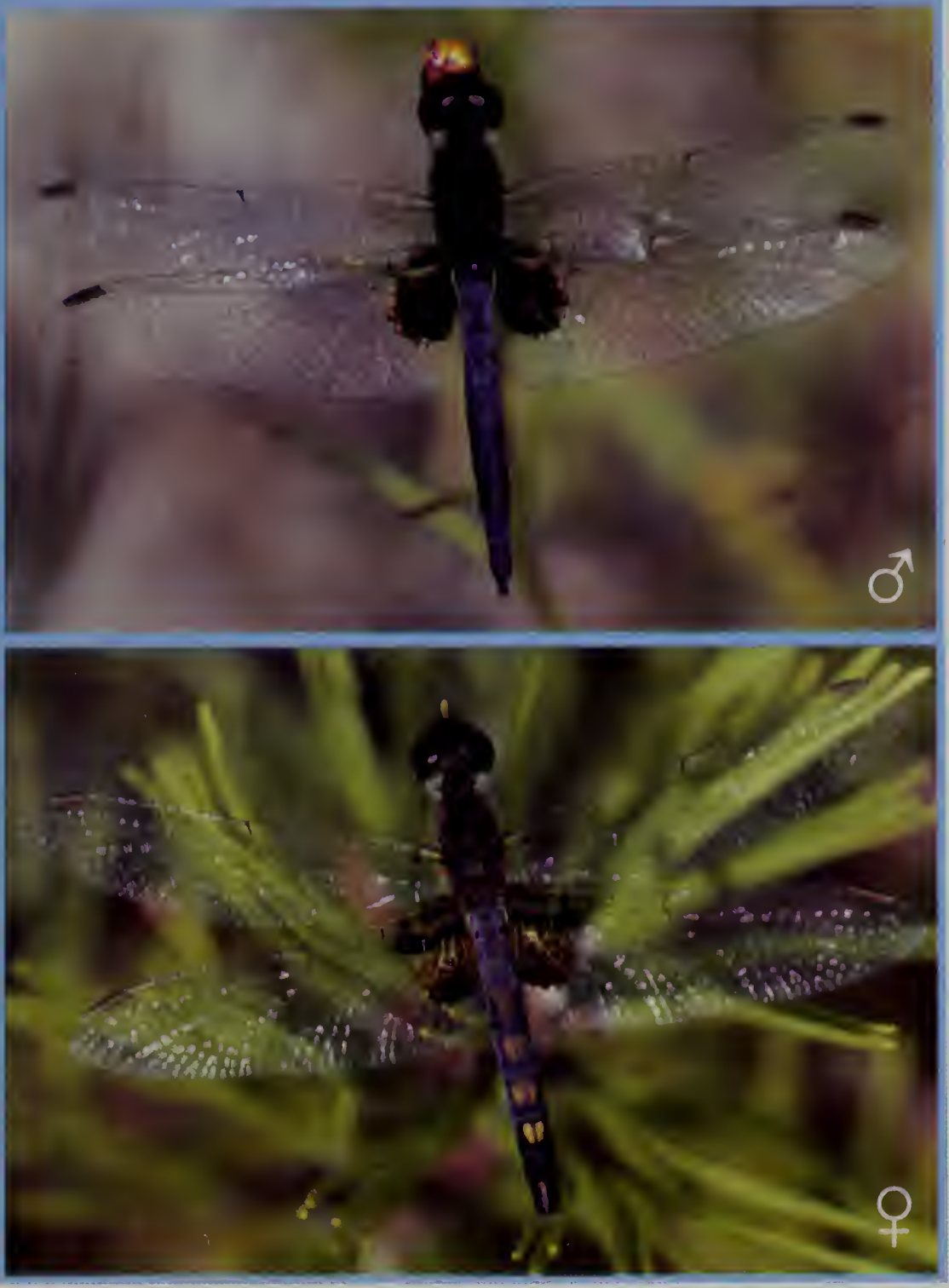

RANGE/STATUS A narrow band along the northeastern coastal plain. An uncommon species found in south-central MA and the southeast coastal plain. HABITAT Vegetated ponds and lakes.

NOTES Adults forage in open fields and along shorelines, perching on the tips of grasses and other vegetation. Males patrol over emergent vegetation, flying at a height of $2-4 \mathrm{ft}$., and are most active in the morning. Females oviposit in tandem, most often in the morning, dipping the tips of their abdomens into the water to release the eggs.

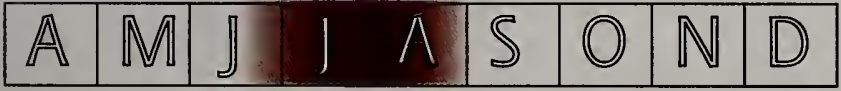


The smallest dragonfly in North America. Male thorax and abdomen powdery blue; abdomen slightly clubbed. Eyes rusty brown. Immature male blackish on thorax and abdomen. Female thorax dark brown with yellow dorsal stripes and lateral spots; abdomen black with yellow dorsal bars, broadest on basal segments (giving a bee-like appearance). Female wings have large amber basal patch. Both sexes typically perch with wings drooped downward. Extremely small size is distinctive.
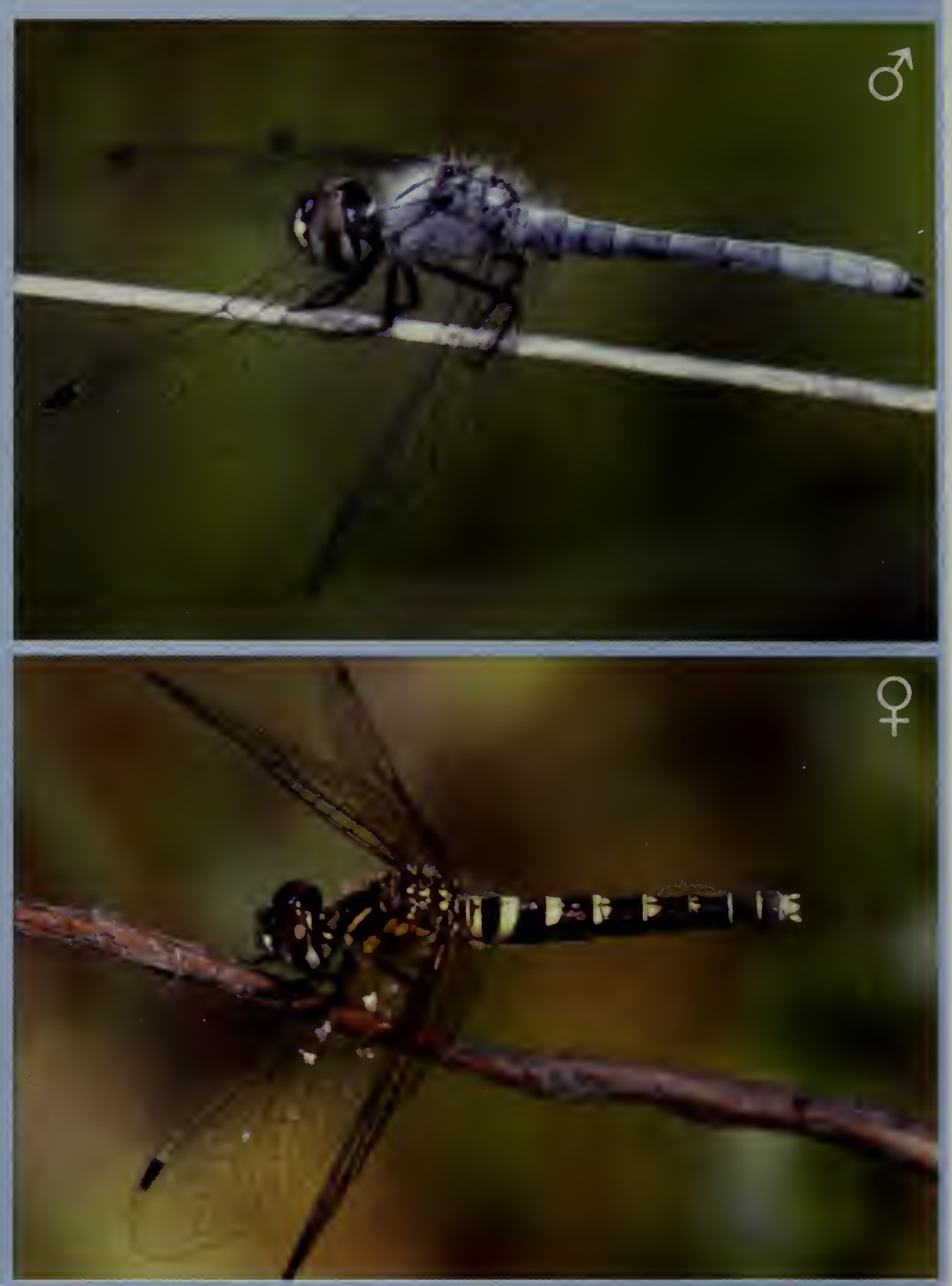

RANGE/STATUS Eastern U.S.; a narrow band along the southeastern Canadian border. Fairly common but local in appropriate habitat in MA, scarce in the southeast coastal plain.

HABITAT Bogs and seeps.

NOTES Adults forage inconspicuously a few inches above bog mats, flying in and out of vegetation and perching horizontally or obliquely on vegetation, often with wings drooped downward. In flight females resemble bees. Females oviposit in open pools within bogs, often with males hovering nearby.

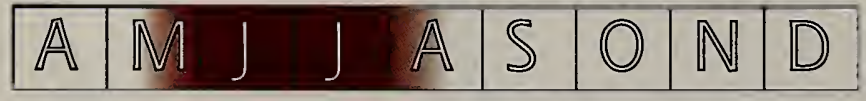


Male thorax dark navy blue to black; abdomen slender and black with dull orange lateral spots on S3-S7 (fade with age). Eyes dark brown. Face blackish. Female and immature male thorax intricately patterned in narrow orange and black "tiger" stripes; abdomen mostly orange above on \$1-S7 and black below. Wings of some females have large amber patch at mid-point and amber at base. Older female becomes all dark and similar to male. Both sexes often hold the wings cocked downward. Male Slaty Skimmer (p. 157) similar but much larger and does not occur in saline habitats. Female Blue Dasher (p. 154) larger with paired yellow dorsal streaks on abdomen.
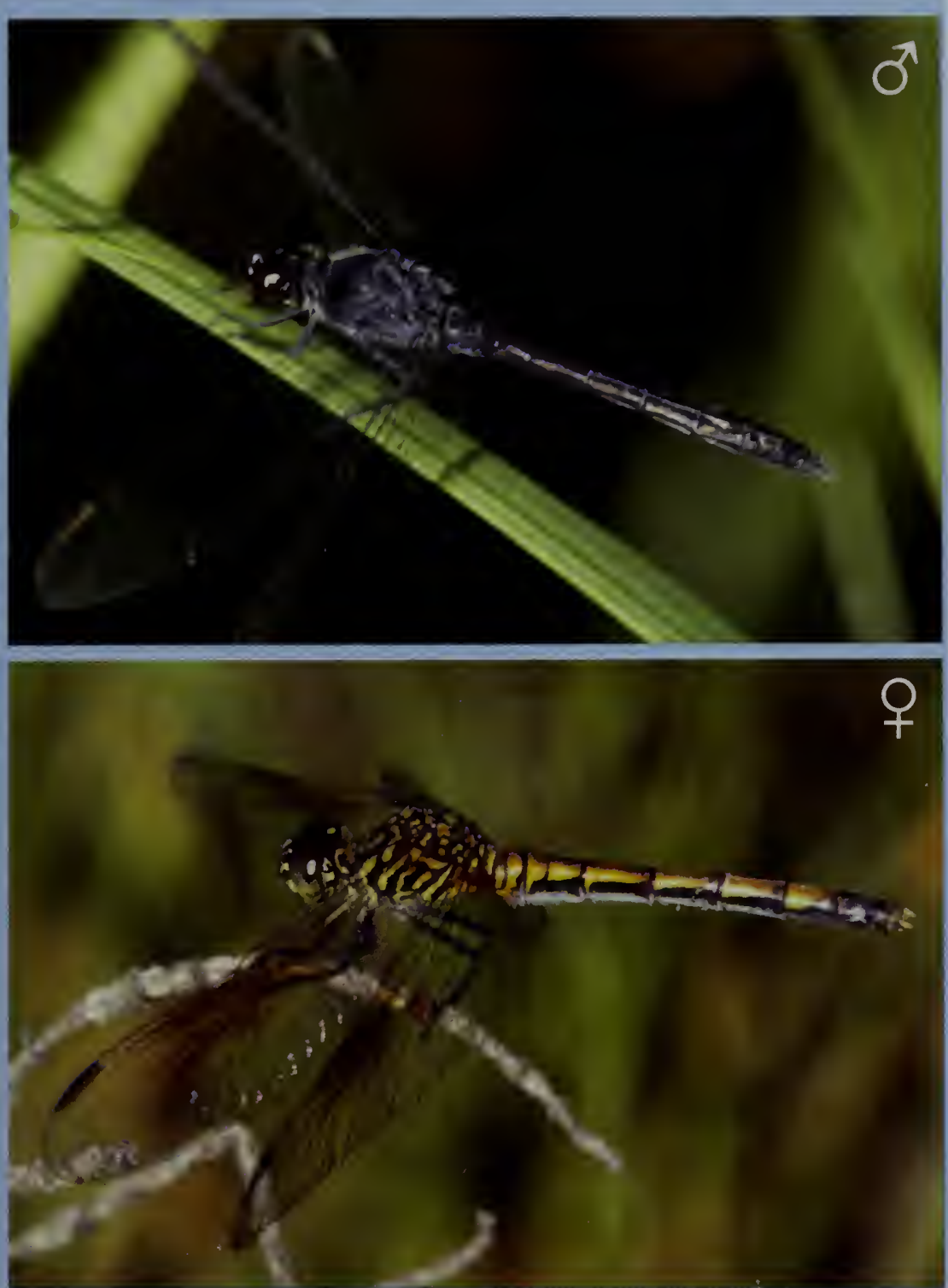

RANGE/STATUS Salt marshes and mangrove swamps along the eastern shore of the U.S.; saline lakes in the southwestern U.S. Common to abundant in the salt marshes along the MA coast.

HABITAT Salt marshes.

NOTES This is the only small dragonfly occurring in salt water habitats. Adults forage over marshes, perching among and on the tips of marsh grasses. Males defend small territories around pools and tidal creeks. Females oviposit in tandem on algal mats. Even where numerous, their small size, coloration, and low, weak flights make them inconspicuous.

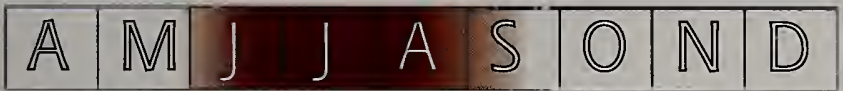


Male thorax reddish brown; abdomen bright red with black, usually triangular, marks on lower sides, often black dorsal spots on S8-S9. Eyes dark reddish-black. Face usually pale brownish. Wings mostly clear, with rusty brown stigma and small amber basal patch. Legs all black. Female and immature male abdomen yellow, becoming drab olive-brown or dull reddish in older females. Indistinguishable in the field from the Cherry-faced Meadowhawk (p. 177) and some White-faced Meadowhawks (p. 178).

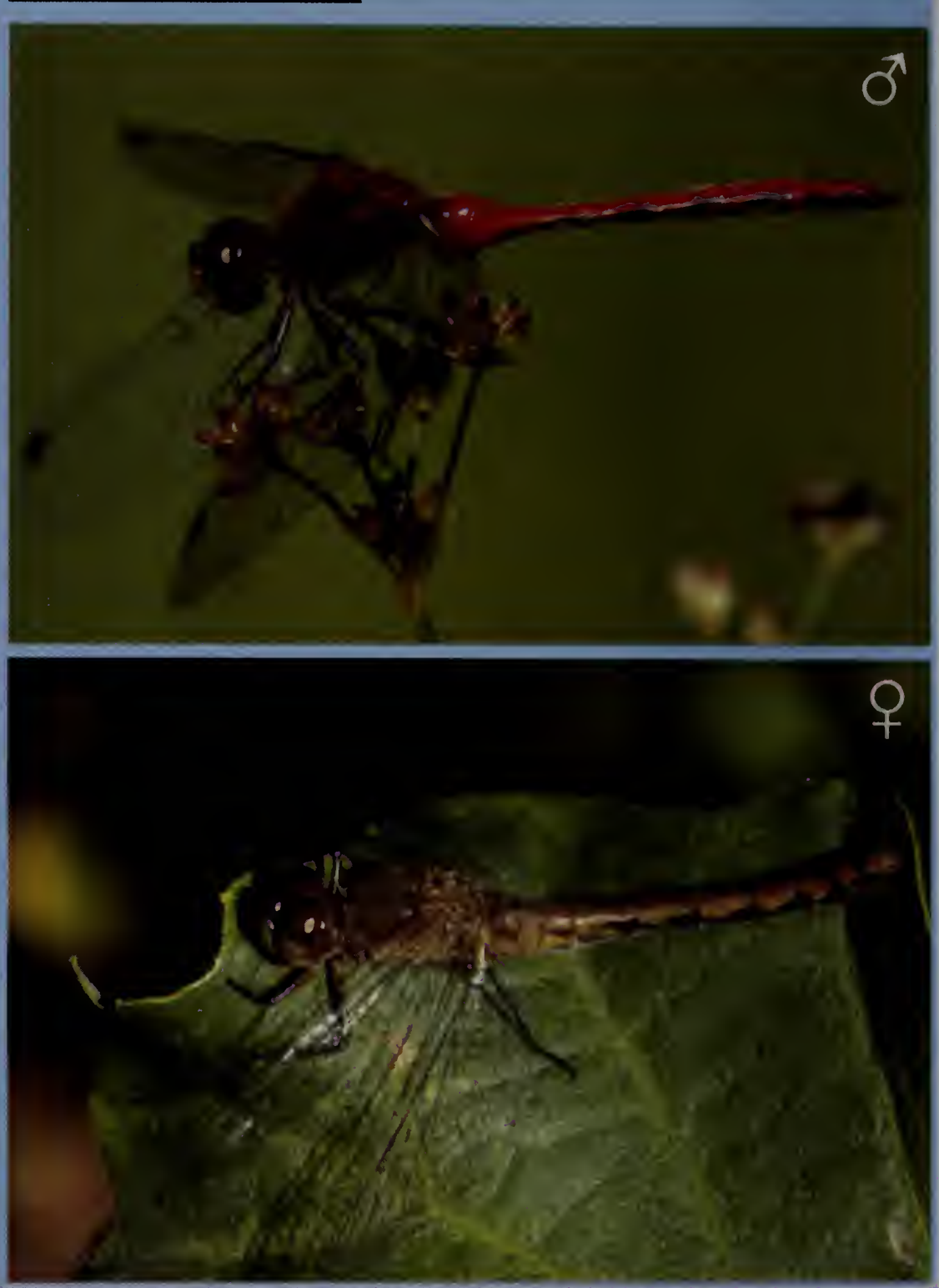

RANGE/STATUS Central to eastern U.S.; southeastern Canada. Common in coastal MA, but apparently rare elsewhere; confusion with Cherry-faced Meadowhawk (Sympetrum internum) makes delineation of range difficult.

HABITAT A variety of wetlands including temporary ponds, bogs, and slow streams. NOTES Adults forage in fields, clearings, and backyards, often far from water. They fly low, perching horizontally on vegetation, rocks, and brush. Males are territorial near wetlands. Females oviposit in flight, sometimes with males hovering nearby.

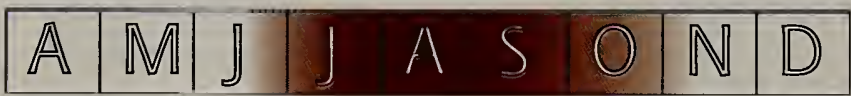




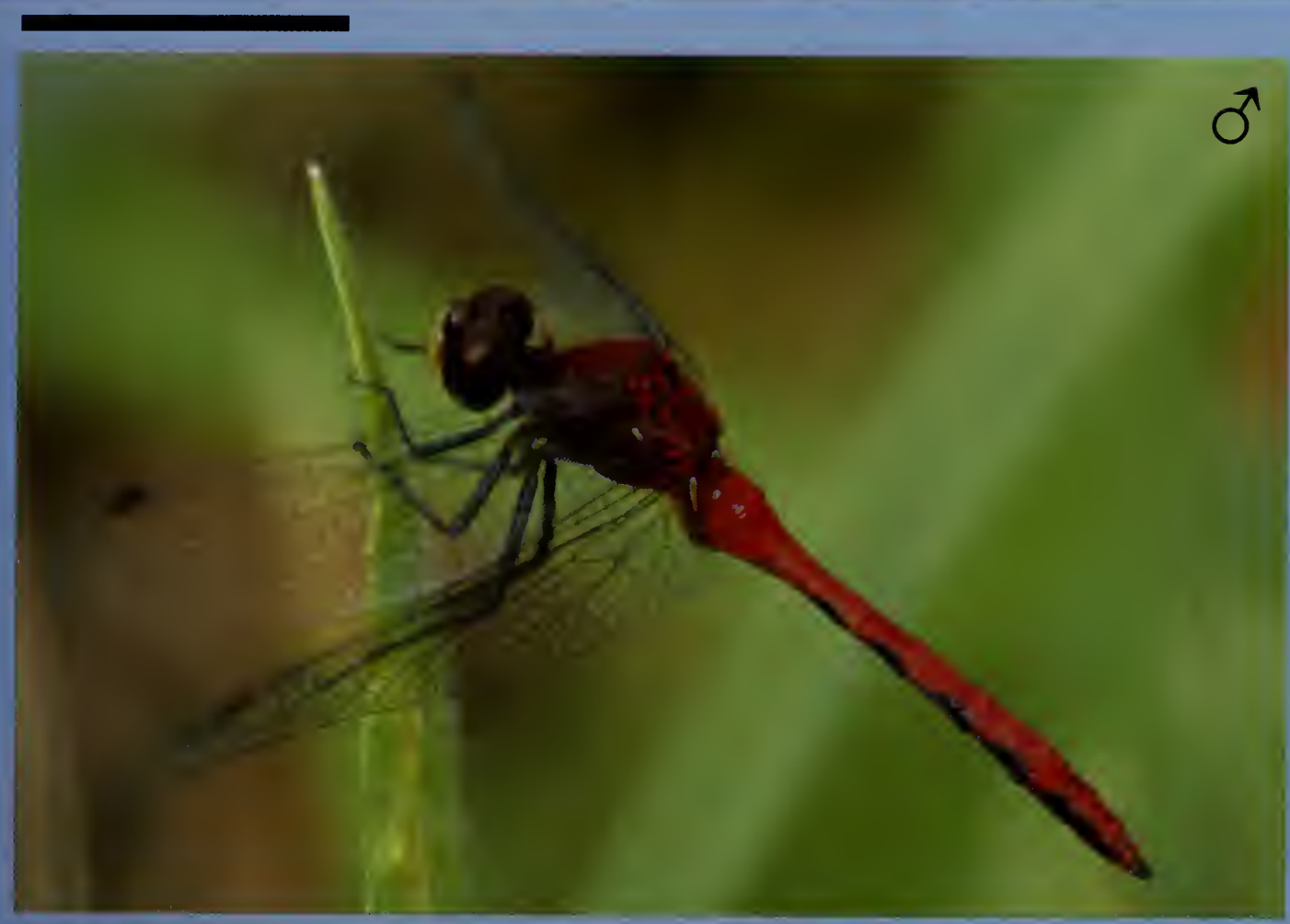

Male thorax reddish-brown; abdomen bright red with black, usually triangular, marks on lower sides, often black dorsal spots on S8-S9. Eyes dark reddish-black. Face usually pale brownish or dull ivory, rarely tinged reddish in southern New England. Wings mostly clear, with rusty brown stigma and small amber basal patch. Legs black. Female and immature male abdomen yellow, becoming drab olive-brown or dull reddish in older females. Indistinguishable in the field from the Ruby Meadowhawk (p. 176), and some White-faced Meadowhawks (p. 178).

RANGE/STATUS Central to northern U.S.; southern to central Canada. Common throughout central and western MA and apparently rare in the southeast; however, the taxonomy of this complex is unclear and the distribution of the three forms uncertain. Jane's Meadowhawk (Sympetrum janeae) was described in 1993, distinguished from others in the Ruby/Cherry-faced/White-faced complex by subtle morphological features. According to this treatment, southern New England populations are Jane's Meadowhawk, with Cherry-faced Meadowhawk not occurring at all in southern New England. However, the validity of $S$. janeae is still debated and, pending further study, we have chosen to retain the traditional taxonomy.

HABITAT Ponds, lakes, marshes, and slow streams.

NOTES Adults forage low over wet meadows and wetlands and perch horizontally on rocks and vegetation. Oviposition occurs in tandem, with females dropping eggs over water and onto wet ground near the water's edge.

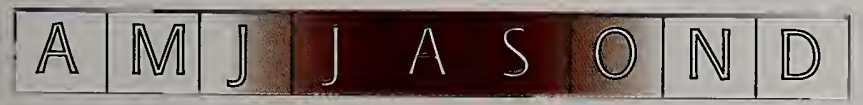


Male thorax reddishbrown; abdomen bright red with black, usually triangular, marks on lower sides, and often black dorsal spots on S8-59. Eyes dark reddish-black. Face white when mature. Wings mostly clear, with rusty brown stigma and small amber basal patch. Legs black. Female and immature male abdomen yellow, becoming drab olive-brown or dull reddish in older females. White face of mature male distinctive, but otherwise indistinguishable in the field from the Cherry-faced Meadowhawk (p. 177) or Ruby Meadowhawk (p. 176). Hudsonian Whiteface (p. 183) similar but more extensively black on abdomen, with dark basal wing patches, and flies earlier in the season.
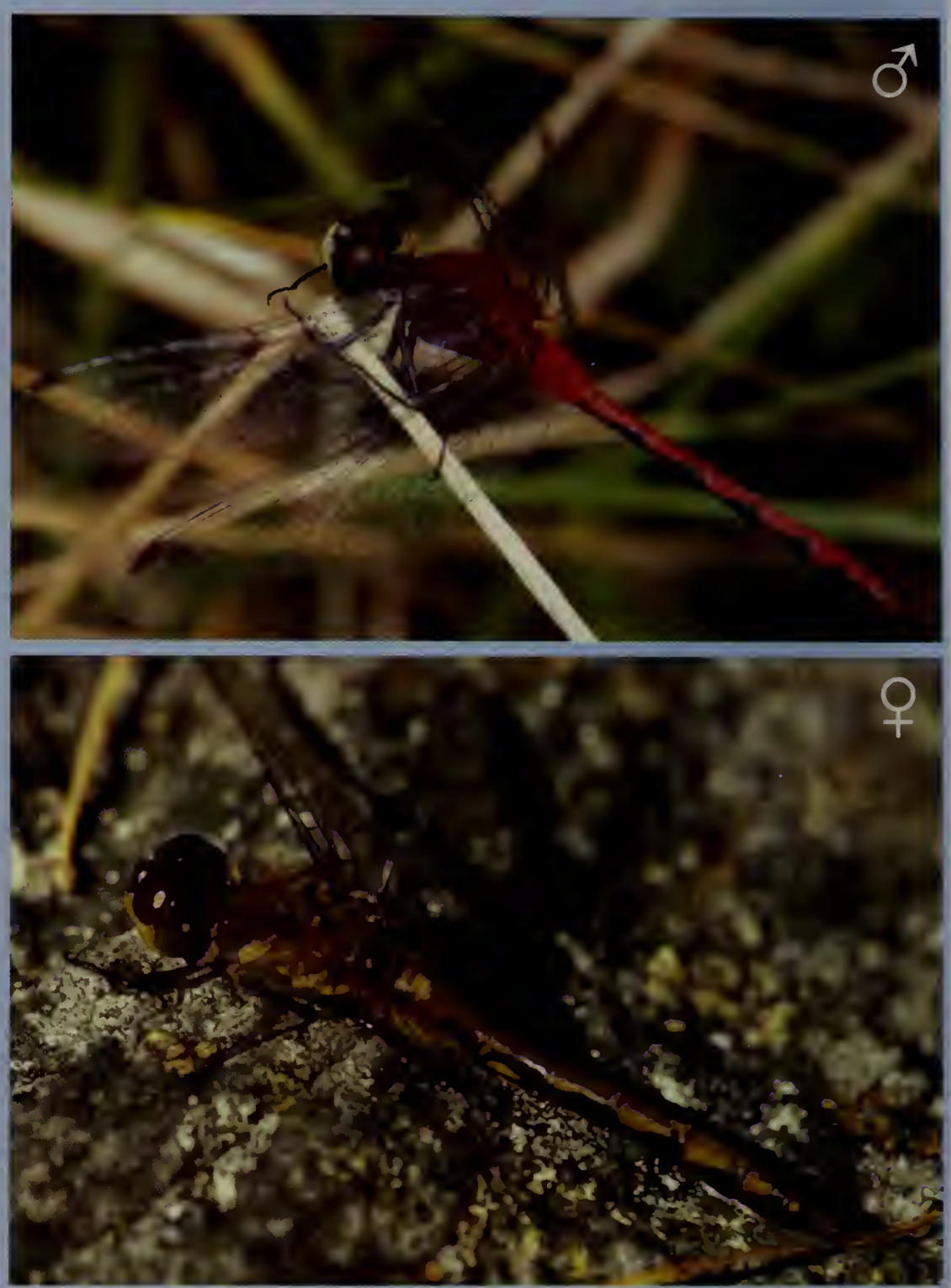

RANGE/STATUS Central to northern U.S.; southern to central Canada. Rare in $\mathrm{MA}$, recorded only from central MA and historically from the southeast coastal plain; apparently once much more common.

HABITAT A variety of wetlands including temporary ponds, bogs, and slow streams. NOTES Adults forage in fields and clearings, often far from water. They fly low, perching horizontally on vegetation, rocks, and brush. Males are territorial near wetlands. Females oviposit in flight, sometimes with males hovering nearby.

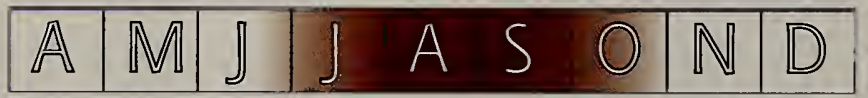


Male thorax rusty brown; abdomen red with black marks along lower edge and occasionally small black dorsal markings on S8-59. Eyes dark reddishbrown. Face reddish. Wings clear with small amber basal patch and reddish stigma. Legs brown. Female and immature male abdomen yellow, legs dull yellowish; older females often become dull red. Female with distinctive triangular ovipositor on underside of S8. Lack of black on legs and (usually) less black on sides of abdomen distinguish this species from the Ruby Meadowhawk ( $p$. 176), Cherry-faced Meadowhawk (p. 177), and White-faced Meadowhawk (p. 178). Saffronwinged Meadowhawk ( $p$. 180) larger, with amber leading edge on wings (except some older males) and some black on legs.
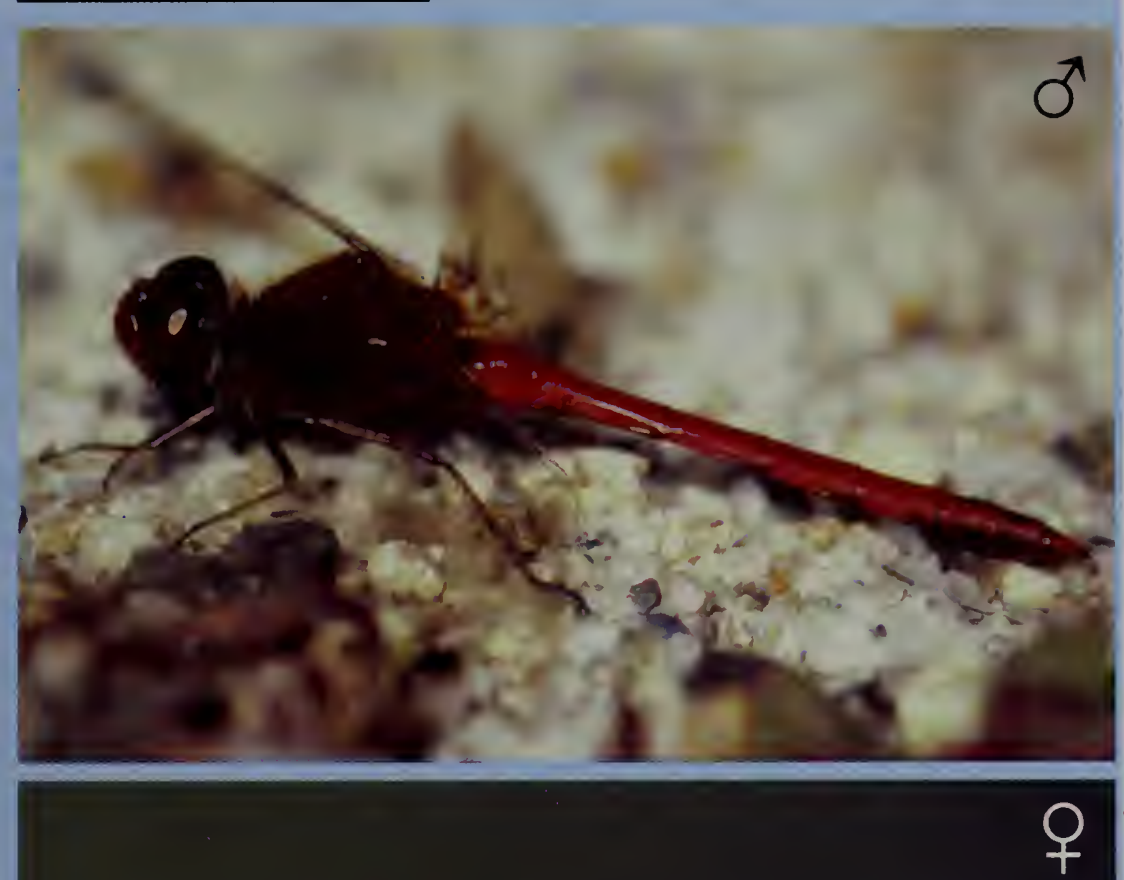

RANGE/STATUS Much of the U.S., extending into southeastern and southwestern Canada. Common throughout MA.

HABITAT Ponds, lakes, marshes, and temporary pools.

NOTES Adults often forage over fields and clearings far from water. They perch horizontally on rocks and low vegetation, occasionally vertically on tree trunks and on cool days will even land on light colored clothing. Females oviposit in tandem, the pair dipping down to the water and the female tapping the surface with the abdomen, releasing the eggs. Mass movements of adults have been observed in the fall. The last odonate on the wing, with adults regularly seen into November and (rarely) early December.

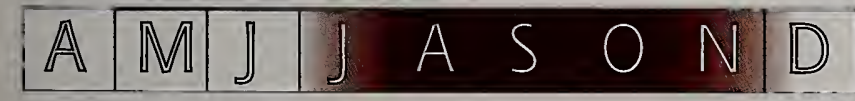


Male thorax rusty brown; abdomen red with black marks along lower edge and (usually) dark dorsal marks on 58-S9; terminal appendages pale reddish. Eyes dark. Face dull reddish. Wings with amber veins anteriorly that fade with age and very small amber basal patch. Legs mostly black but often pale at base. Female and immature male abdomen and stigmas yellow; older females become brown or reddish. Males are duller red than other meadowhawks, and the other species lack amber on leading edge of wings and most have more black on sides of abdomen.
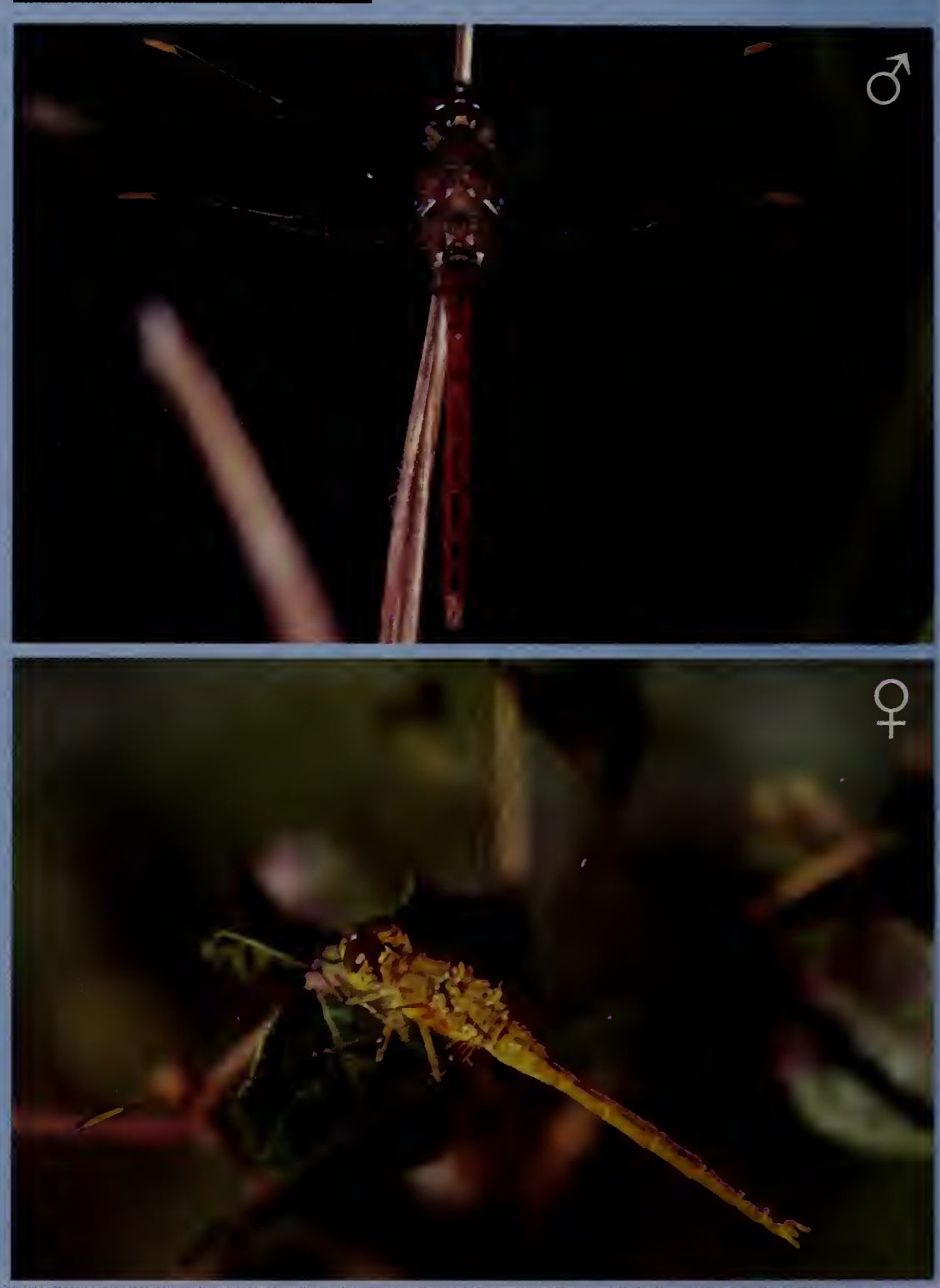

RANGE/STATUS Central to northern U.S., extending into southern Canada. Uncommon and local throughout MA, most numerous on the southeast coastal plain. HABITAT Ponds and lakes; acidic and brackish wetlands.

NOTES Adults forage in fields and clearings, often far from water, perching horizontally on low vegetation or on the ground. At breeding sites, males make brief patrols over water. Oviposition occurs in tandem, the pair dipping down and the female touching the water's surface with the tip of the abdomen to release eggs. This species is more tolerant of brackish conditions than other meadowhawks.

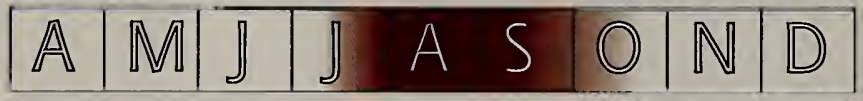


The smallest of the meadowhawks. Male thorax reddish-brown; abdomen bright red with black, usually triangular, marks on lower sides, often black dorsal spots on S859. Eyes dark reddishblack. Face usually pale brownish. Wings mostly clear, with broad amber basal band, most prominent on hind wings, and reddish-brown stigma. Legs black. Female and immature male abdomen yellow, becoming olivebrown or dull red in older female. The broad amber wing bands are distinctive among meadowhawks.

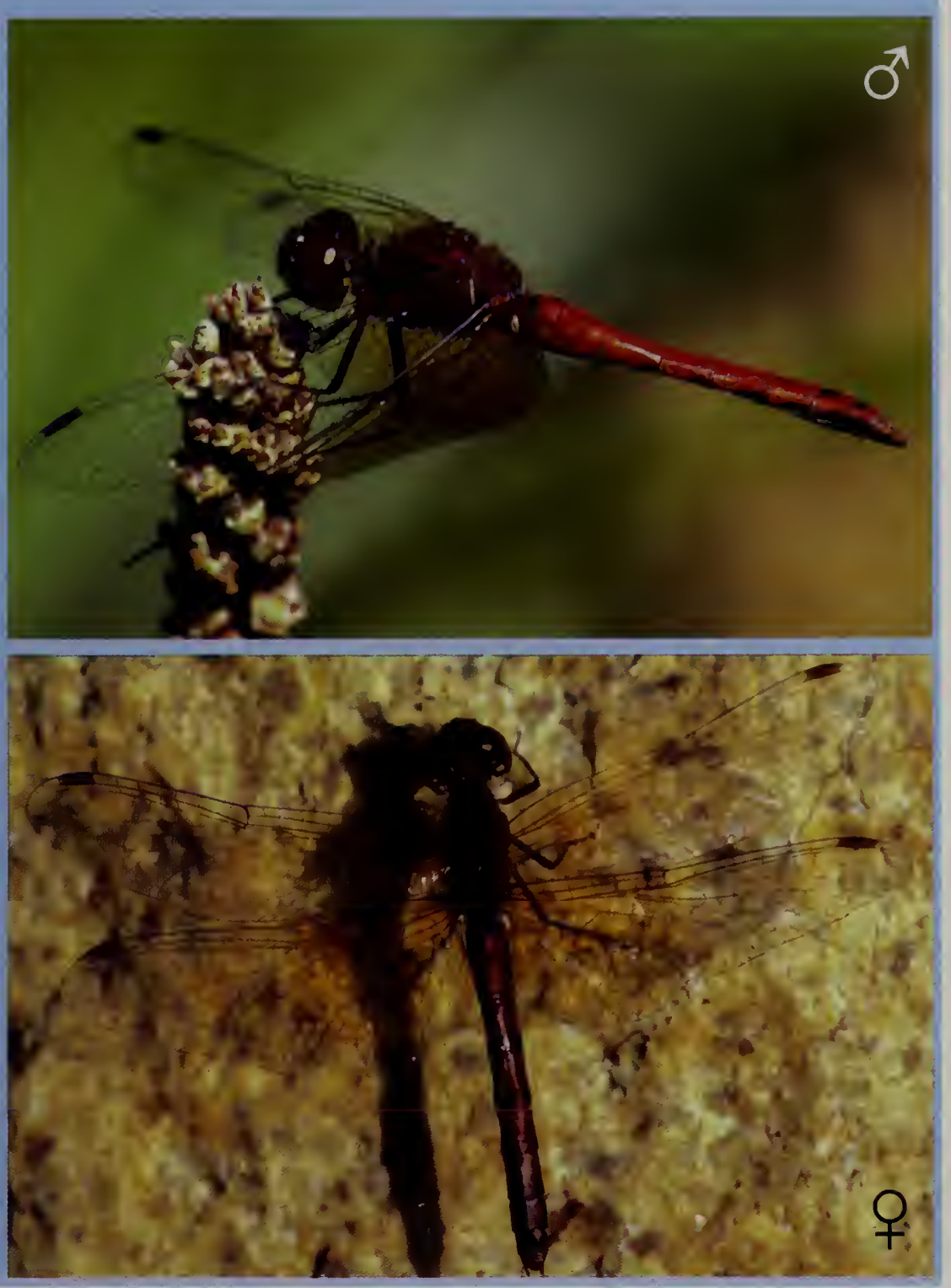

RANGE/STATUS Central U.S. north into southern Canada. Fairly common throughout interior MA, but less so on the coastal plain.

HABITAT Marshes, marsh-bordered ponds and rivers, bogs, and fens.

NOTES Adults forage over fields and clearings, sometimes far from water. They perch horizontally on rocks and low vegetation. Females oviposit in tandem, the pair dipping down to touch the water's surface with the female's abdomen.

$|\mathbb{A}| \mathbb{M} \mid \bar{J} J$ A S S O $|\mathbb{N}| \mathbb{D}$


A brightly patterned species, unlike other meadowhawks. Male thorax brown with two white or yellow lateral stripes that fade to spots with age; abdomen mostly red with gray dorsal patches on S3-57, black dorsally on 58-59, and white lateral patches on S2-S8 outlined in black. Wings suffused with yellow on leading edges; distal half of stigma yellow. Face red and eyes grayish. Female and immature male similar but abdomen yellow where male is red, and face dull tan. Abdominal pattern is distinctive in both sexes.

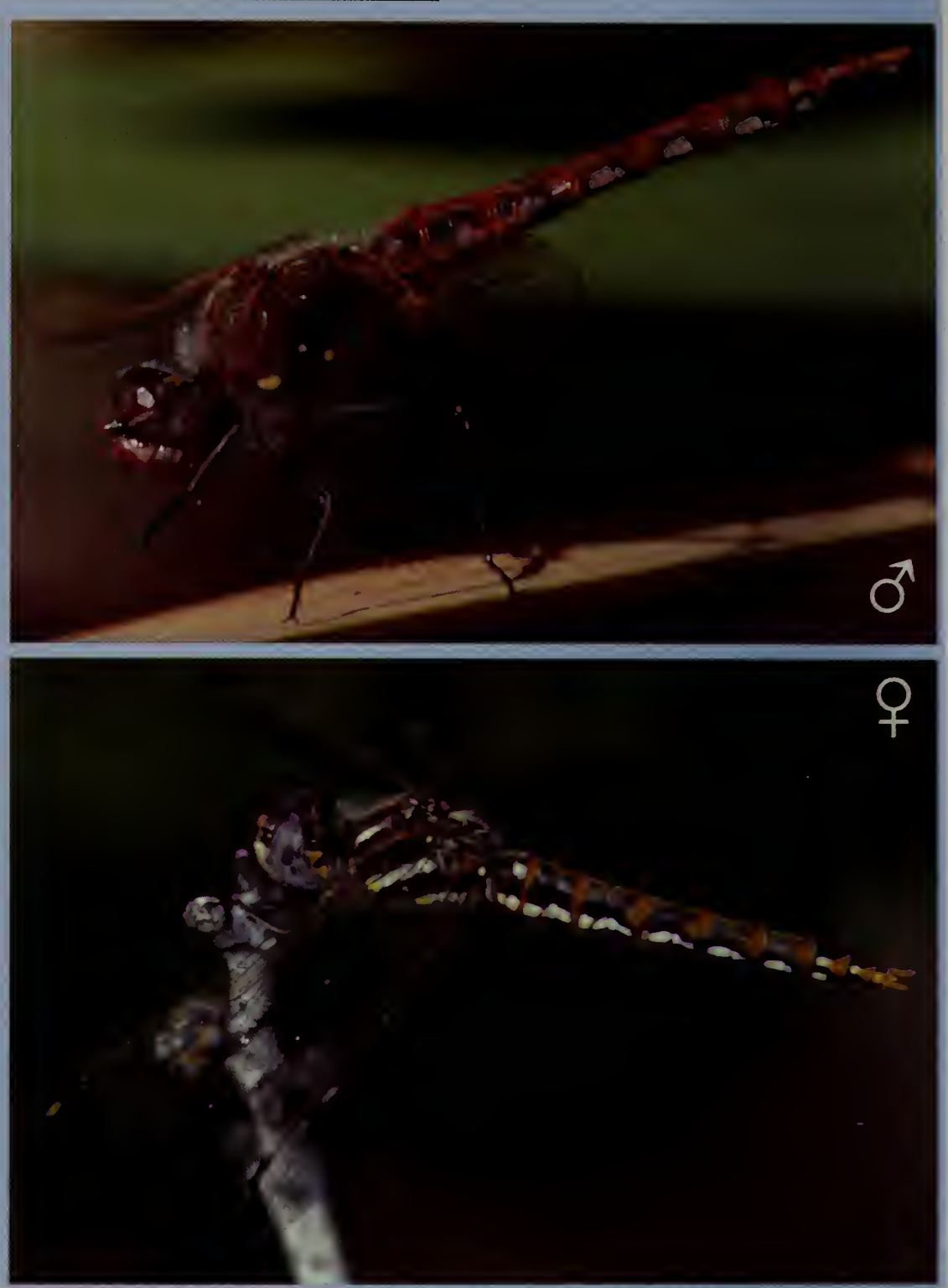

RANGE/STATUS Western U.S. and southwestern Canada, occasionally wandering eastward. A regular vagrant on the East Coast but very rare north of NJ. Has been recorded in MA only three times.

HABITAT A variety of wetlands including ponds, temporary pools, slow streams, and saline lakes.

NOTES Adults forage in fields and openings, even parking lots, and perch horizontally on the ground or low vegetation. Males defend territories over water. Females oviposit in tandem. This is a migratory species, with large movements along the Pacific Coast.

Others occasionally stray eastward toward the Atlantic.

\begin{tabular}{|l|l|lll|l|l|l|l|}
\hline $\mathbb{A}$ & $\mathbb{M}$ & $\mathrm{J}$ & $\mathrm{J}$ & $\mathrm{A}$ & $\mathrm{S}$ & $\mathrm{O}$ & $\mathbb{N}$ & $\mathbb{D}$ \\
\hline
\end{tabular}


Male thorax and abdomen black with bright yellow spot on S7. Eyes black. Face white. Female and immature male thorax dark brown with yellow marks; abdomen blackish with yellow dorsal spots and streaks on S2-S7, spot on 57 usually wider than those on 54-56; yellow marks fade with age. Eyes dark brown. Hind wings have small dark basal patches. Mature male unmistakable; female similar to other whitefaces, especially the Hudsonian Whiteface (p. 183), but spot on 57 more rectangular, and wider than spots on S5-S6.

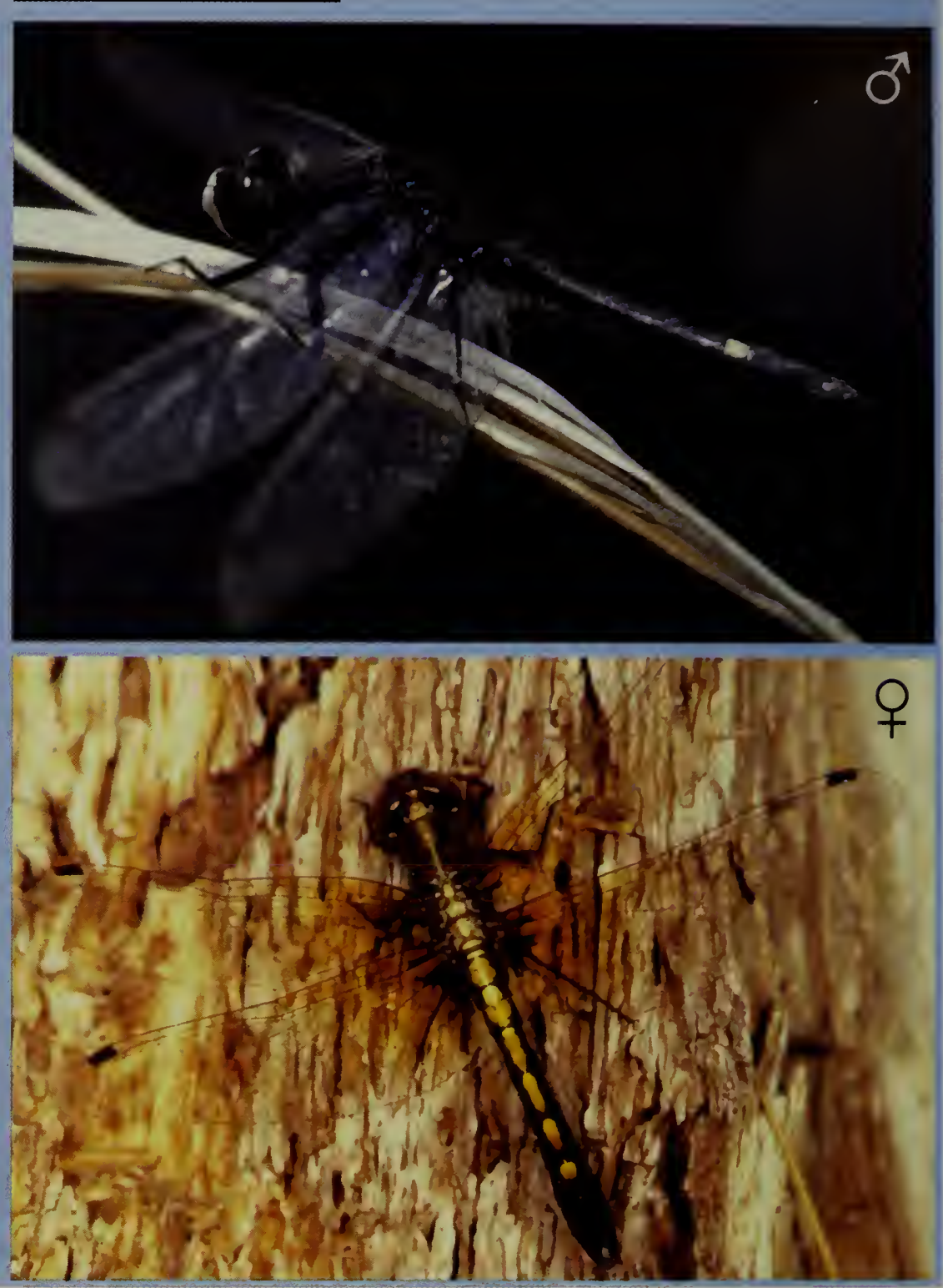

RANGE/STATUS Central to northern U.S.; southern Canada. Common and widespread throughout MA.

HABITAT Vegetated and bog-bordered ponds and lakes.

NOTES Adults forage in or near wetlands. They perch horizontally on the ground, low bushes, and floating vegetation, especially lily pads. Males sometimes maintain small territories. Females oviposit in flight by tapping their abdomens to the water's surface, often with males hovering nearby. This species seems fairly tolerant of degraded conditions.

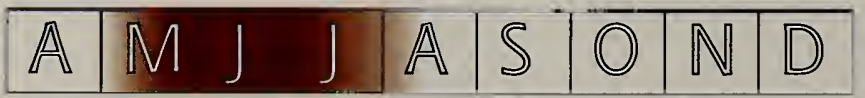


One of the smallest and least colorful of the whitefaces. Male thorax entirely blackish; abdomen black with white pruinosity on S2-S4. Eyes black. Face white. Hind wings have small dark basal spots. Female and immature male thorax dark brown with yellow lateral patches; abdomen mostly yellow on $52-53$. otherwise black with yellow dorsal spots on S3S7, spots becoming smaller and narrower posteriorly, on 57 typically a thin short streak. Wings have amber wash around dark basal spots. Older female can become somewhat male-like. Red-waisted Whiteface (p. 187) very similar but larger with longer and more slender abdomen, male with a hint of red coloration between the wings; female lacks amber at base of wings.

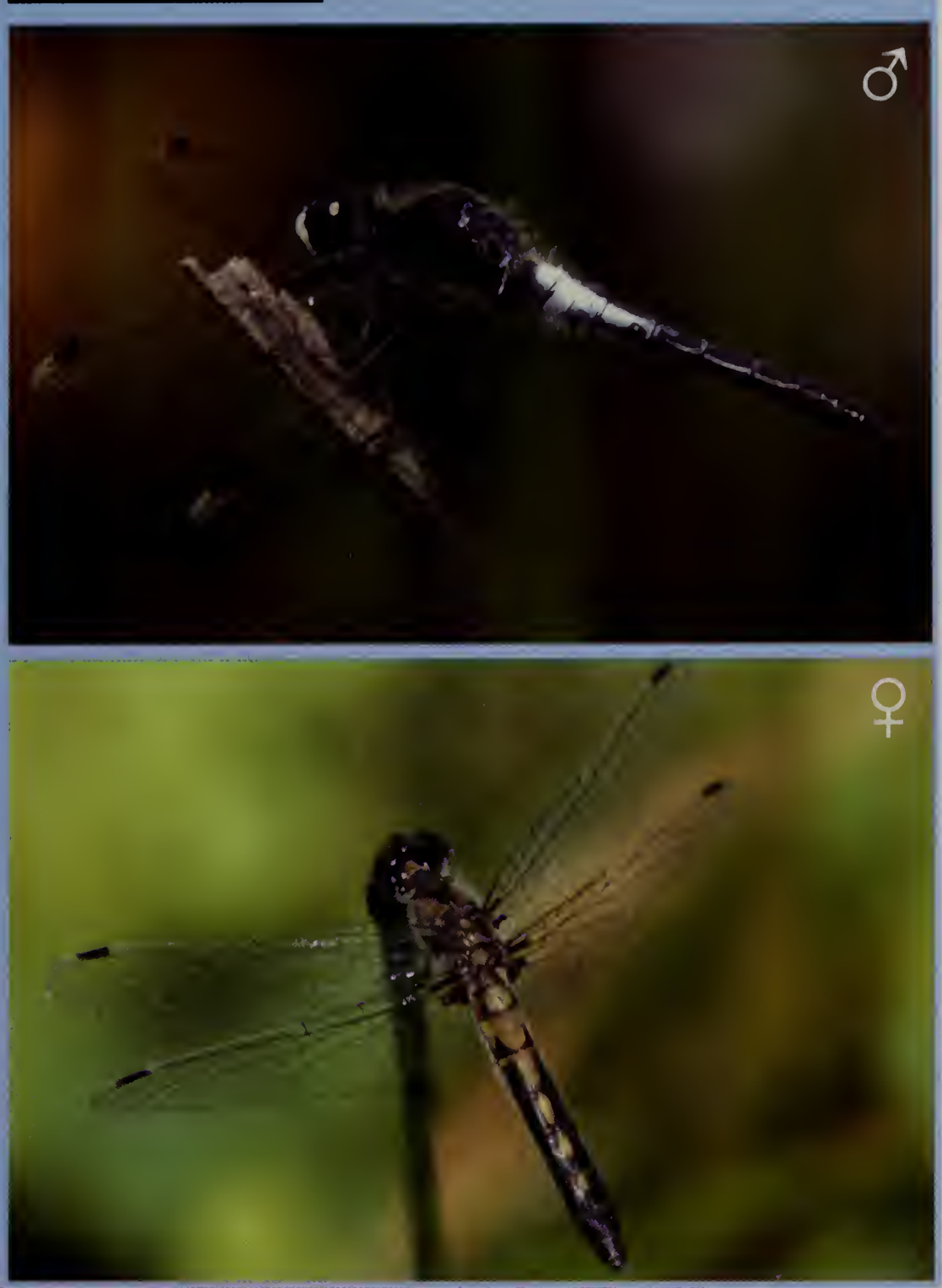

RANGE/STATUS Northeastern U.S. and southeastern Canada, from the Great Lakes region to the east coast and north to Nova Scotia. Common throughout interior MA, scarce on the southeast coastal plain.

HABITAT Bog and marsh-bordered ponds and lakes.

NOTES Adults hunt in or near wetlands, flying low and perching on the tips of grasses and brush. Males defend small territories along the shore or over floating vegetation. Females oviposit in flight by tapping their abdomens to the water's surface, often with males hovering nearby.

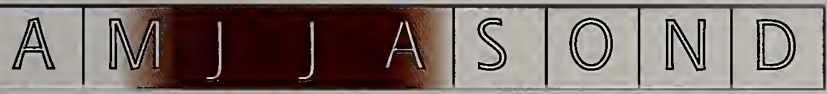


One of the largest of the whitefaces. Male thorax red dorsally and black on the sides; abdomen bright red at base (\$2-S3), otherwise all black. Face white. Eyes blackish. Hind wings have small dark basal patch. Female and immature male thorax black with broad yellow shoulder stripes and yellow lateral marks; abdomen black with narrow yellow dorsal spots on S3-S7. Yellow marks turn red on some older females. Eyes dark reddish-brown. Redwaisted Whiteface ( $p$. 187) similar but male less red with pruinose base of abdomen; female indistinguishable, except in the hand.
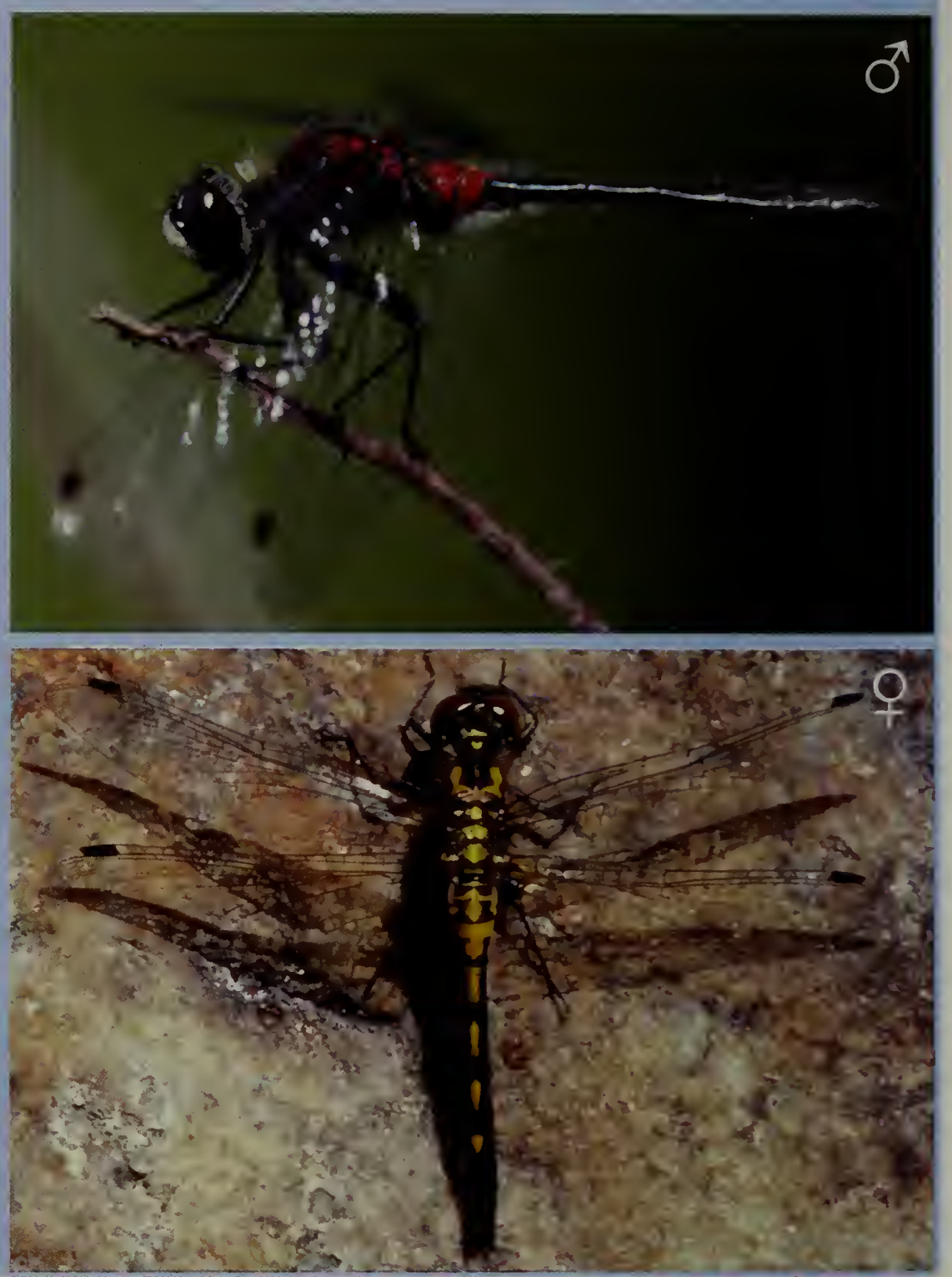

RANGE/STATUS Northern U.S.; southern Canada. Uncommon in MA, recorded primarily from the western and central parts of the state.

HABITAT Bog-bordered ponds, vegetated ponds and lakes.

NOTES Adults forage in or near wetlands. They perch horizontally on the ground, low bushes, and floating vegetation. Males are territorial. Females oviposit in flight by tapping their abdomens to the water's surface, often with males hovering nearby.

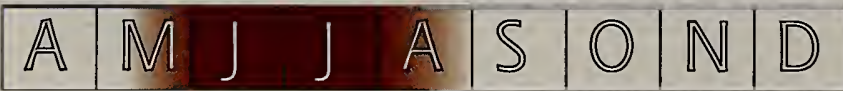


One of the largest whitefaces. Male thorax blackish with red dorsal coloration, especially between wings; abdomen black with white pruinosity on S2-S4 (occasionally S5S6). Eyes blackish. Face white. Hind wings have small dark basal patch. Female and immature male thorax dark brown with yellow marks; abdomen black with yellow dorsal spots and streaks on S2-S7; yellow marks fade with age and may become reddish in older females. Mature male very similar to Frosted Whiteface ( $p$. 185), but larger and usually with red on thorax between wings. Females not separable from the Crimson-ringed Whiteface (p. 186) except in the hand.

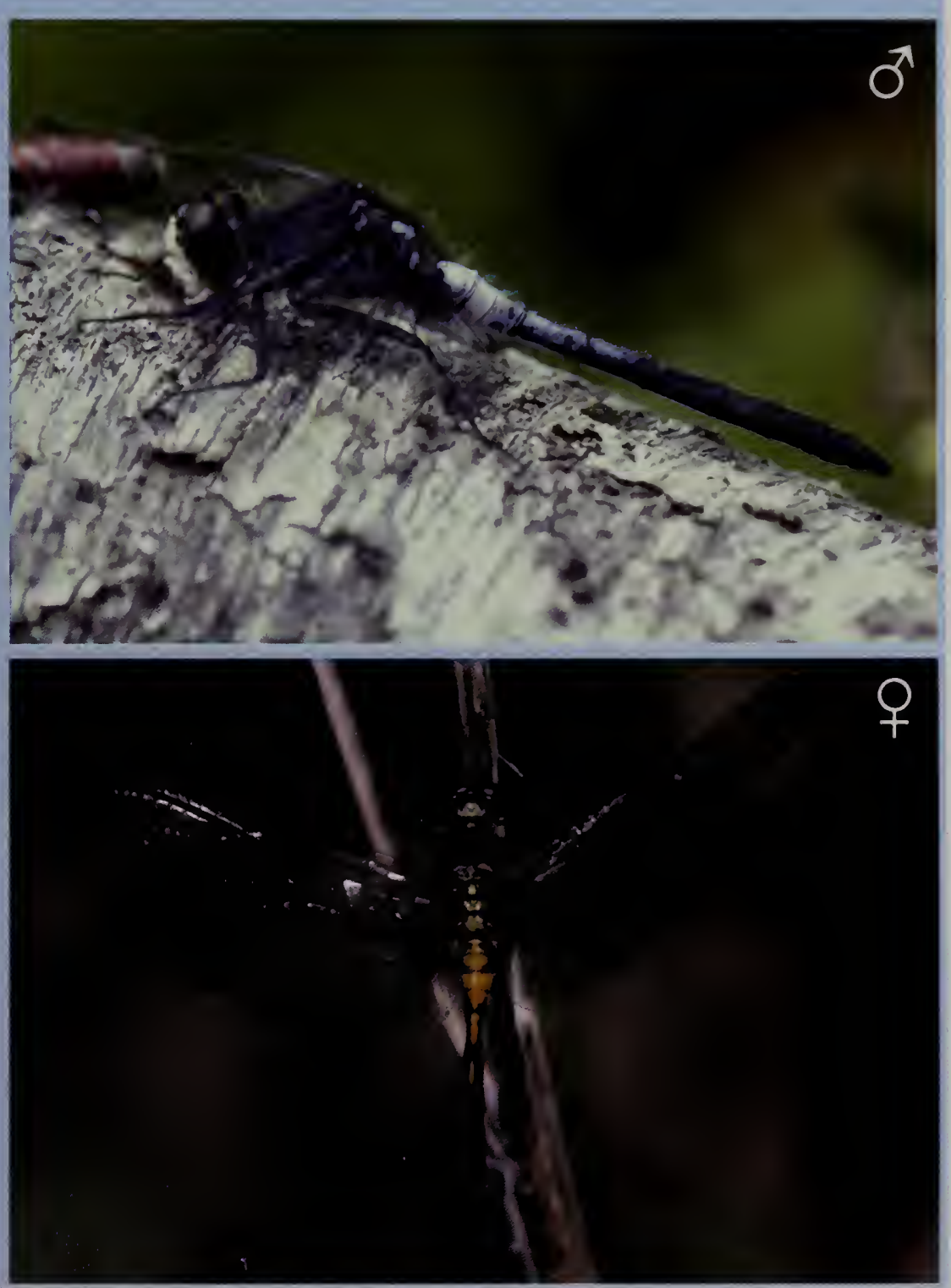

RANGE/STATUS Northern U.S.; Canada. Uncommon in MA, found only in the central and western parts of the state.

HABITAT Bog and marsh-bordered ponds and lakes, open fens.

NOTES Adults forage in forest openings near wetlands, flying low and perching horizontally on twigs and grasses. Males defend small territories. Females oviposit in flight by tapping their abdomens to the water's surface, often with males hovering nearby.

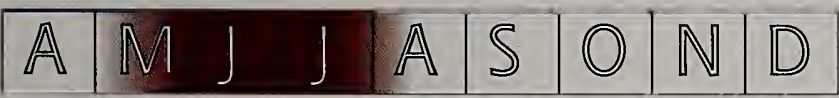




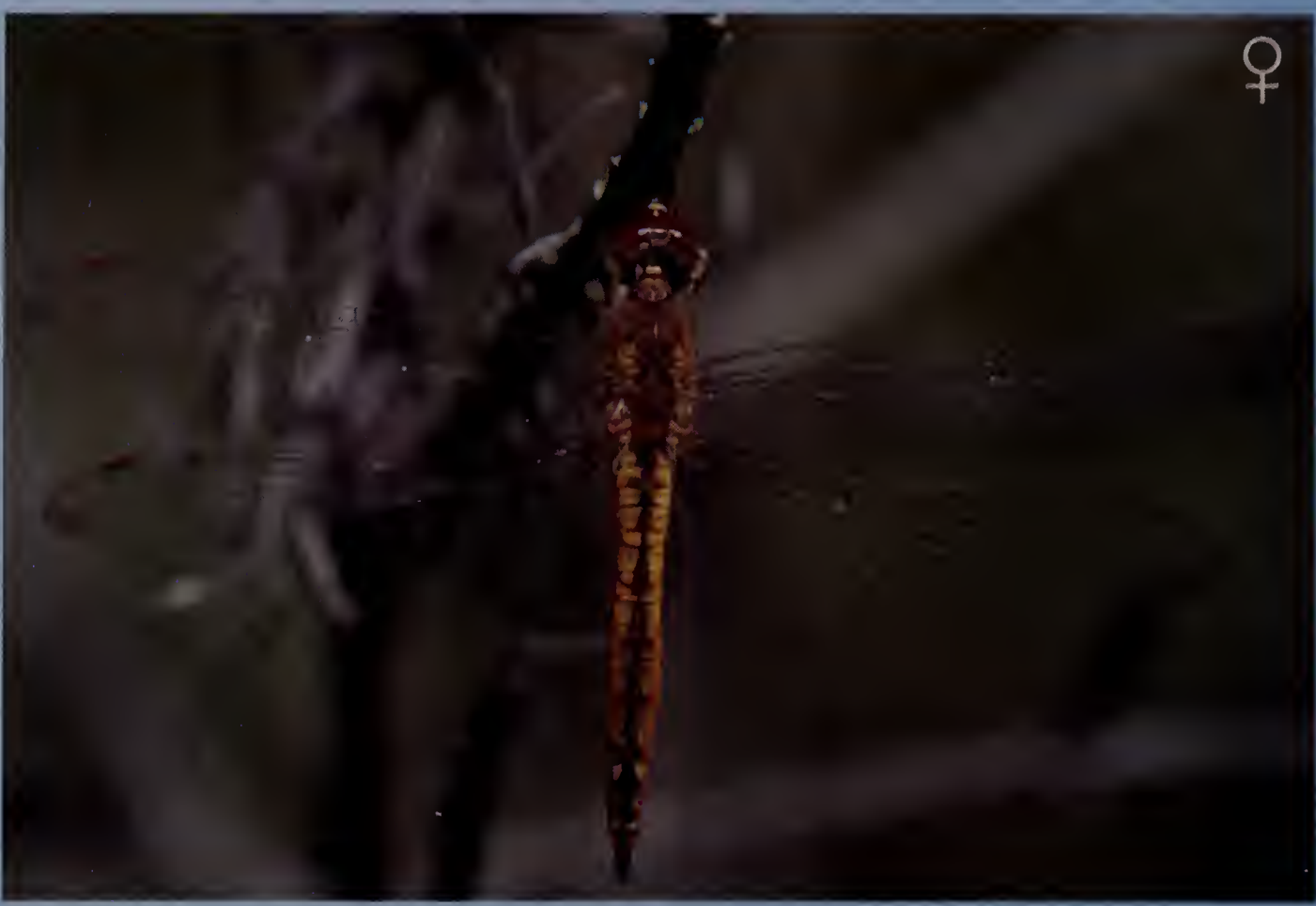

Male thorax dull brown with pale grayish sides; abdomen yellow-orange with dark dorsal marks, darkest on the posterior segments. Eyes reddish. Face yellow. Hind wings broad and clear, with orange stigma and often an amber wash on tip. Female and immature male similar but abdomen more yellow. Spot-winged Glider (p. 189) similar, but lacks yellow on abdomen and has dark basal hind wing spot. Other skimmers with mostly yellow abdomen have narrower wings, more rounded abdomen, and different behavior.

RANGE/STATUS Throughout most of U.S.; southeastern Canada. Fairly common throughout MA, especially near the coast.

HABITAT Temporary pools and puddles.

NOTES Adults glide along over fields and clearings, sometimes in feeding swarms. They perch vertically or obliquely on vegetation, typically near the ground. Some migrate north in the spring, lay eggs, and the adults from the next generation migrate south in the late summer or fall. Females oviposit in small, temporary pools, even puddles, and have been seen attempting to lay eggs on the shiny hoods and roofs of automobiles. They are wanderers, sometimes seen hundreds of miles out to sea, and are the only truly cosmopolitan dragonfly, found on every continent except Antarctica.

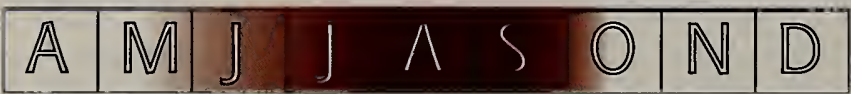


Male thorax dull brown with pale mottled grayish sides; abdomen dull, rusty brown with diffuse mottled pattern. Eyes chestnut. Face red. Wings broad with brown basal spot on hind wing (often hard to see) and reddish-brown stigma. Female and immature male similar but face yellow and abdominal pattern more distinct. Wandering Glider (p. 188) similar, but abdomen yellow or orange and lacks basal spot on hind wing.
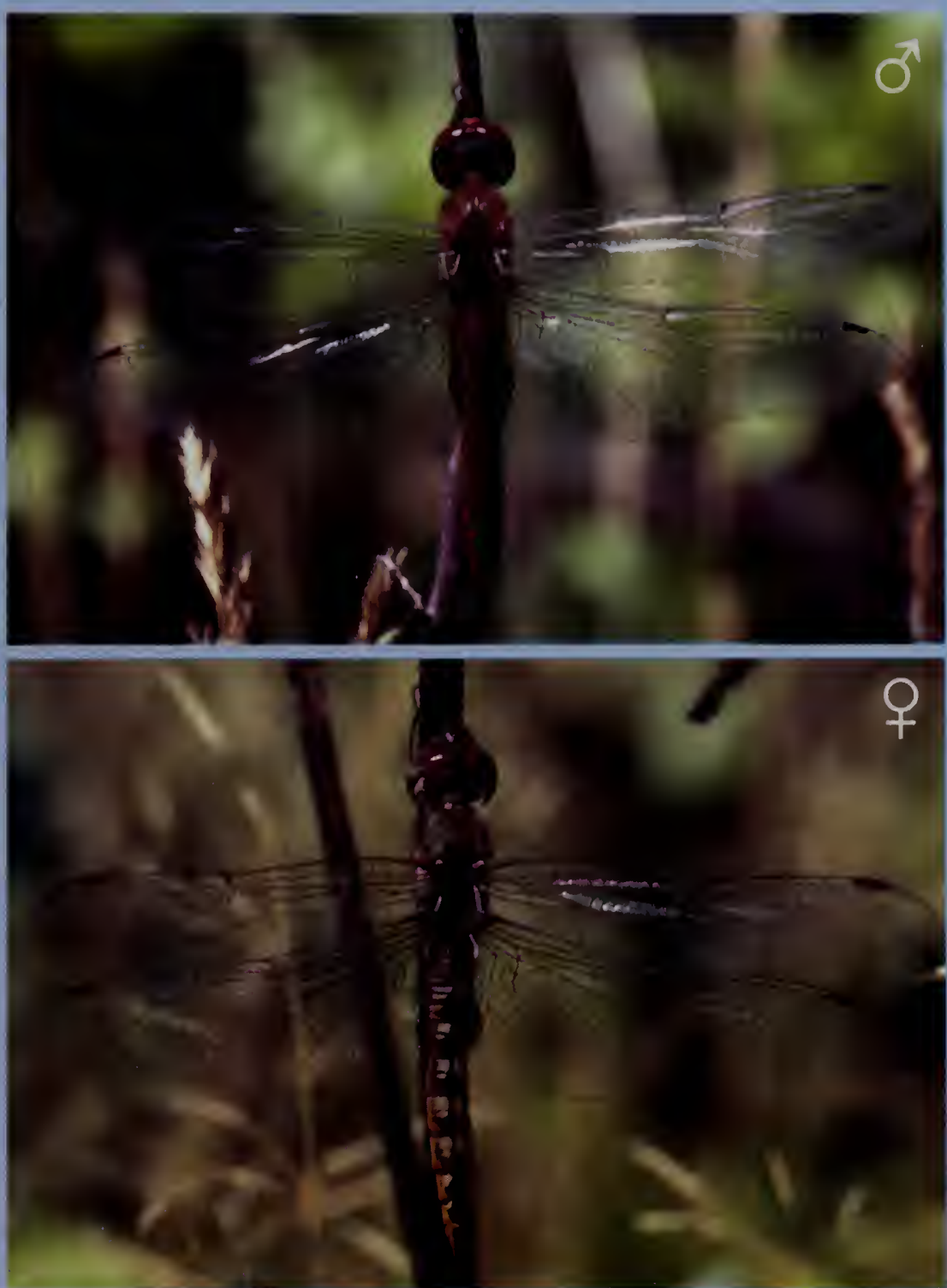

RANGE/STATUS Throughout much of U.S.; Canadian Great Lakes Region. Fairly common throughout $\mathrm{MA}$, occasionally abundant along the coast.

HABITAT Temporary pools and puddles.

NOTES Adults glide over fields and clearings, sometimes in feeding swarms. They perch vertically or obliquely on vegetation a few feet above the ground. Adults are wanderers, often seen far from water. Some migrate north in the spring, lay eggs, and the next generation migrates south in the late summer or fall. Unlike the Wandering Glider ( $P$. flavescens), they are most common in early summer.

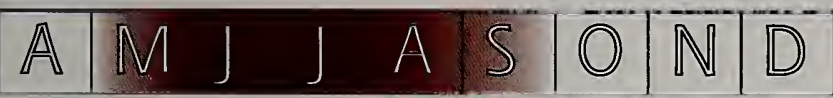




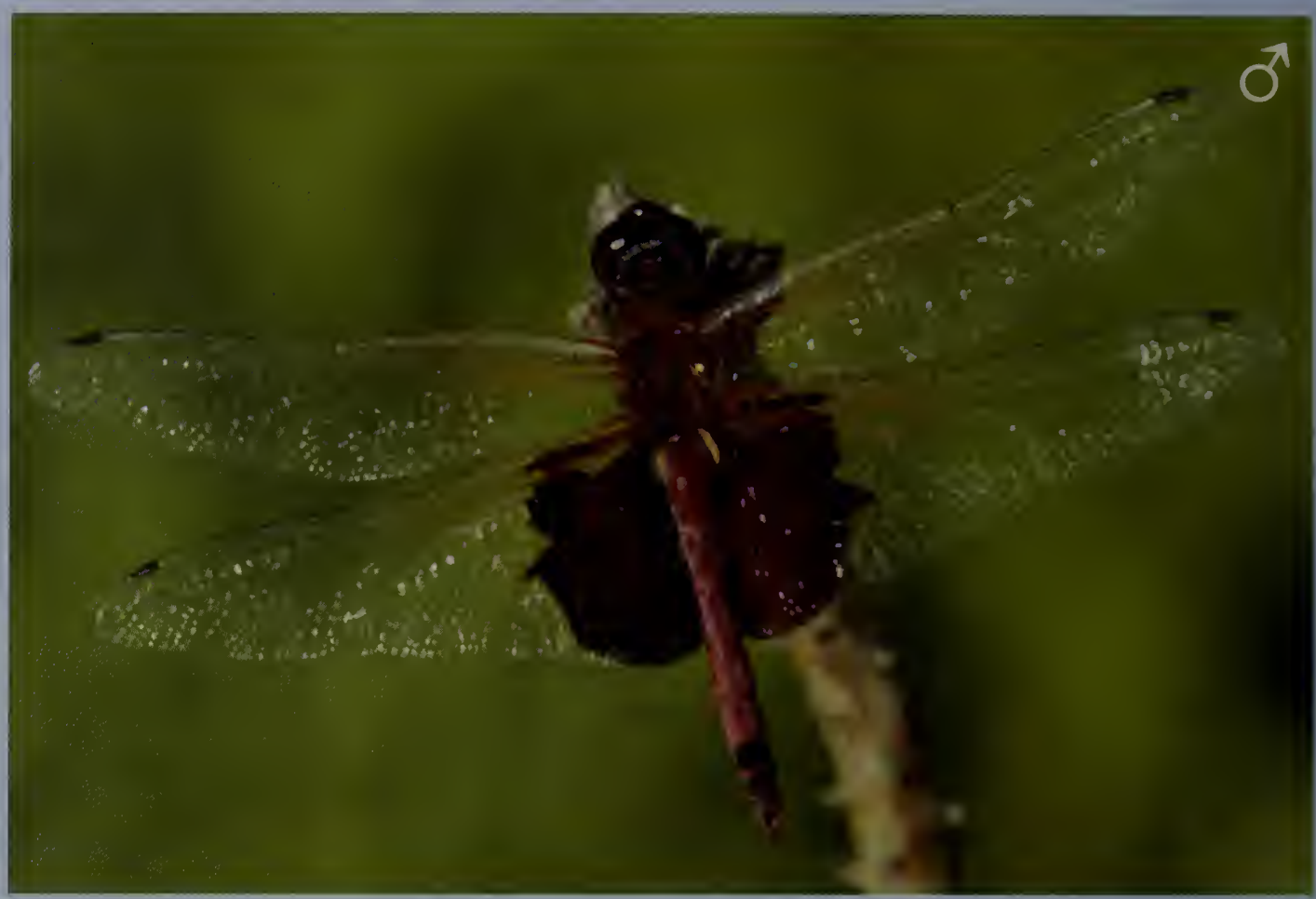

Male thorax rusty brown; abdomen bright red with black dorsal patches on S8-59. Eyes dark reddish-brown. "Forehead" metallic violet. Hind wings very broad with large red basal patch; forewing with reddish basal venation; stigma red. Female and immature male similar, but reddish-brown where male is red. Male Calico Pennant (p. 170) much smaller, with outer wing marks and more black than red on abdomen. Striped Saddlebags (p. 192), a very rare vagrant in the Northeast, has lateral stripes on thorax and narrower "saddle."

RANGE/STATUS South-central to eastern U.S. extending into Nova Scotia. Uncommon in MA, occurring primarily in the southeast coastal plain, with scattered records in south-central $M A$.

HABITAT Coastal plain ponds, temporary pools.

NOTES Adults fly along shorelines and over fields and clearings in a leisurely manner, alternating between gliding and flapping, usually at a height of 4-8 ft. Males patrol large expanses of wetlands, and are most active in the morning. Females oviposit either alone or in tandem, with the males periodically releasing the females as they drop down to tap the tips of their abdomen to the water's surface to release eggs. This is a migratory species, occasionally seen along the coast in summer and early fall. 


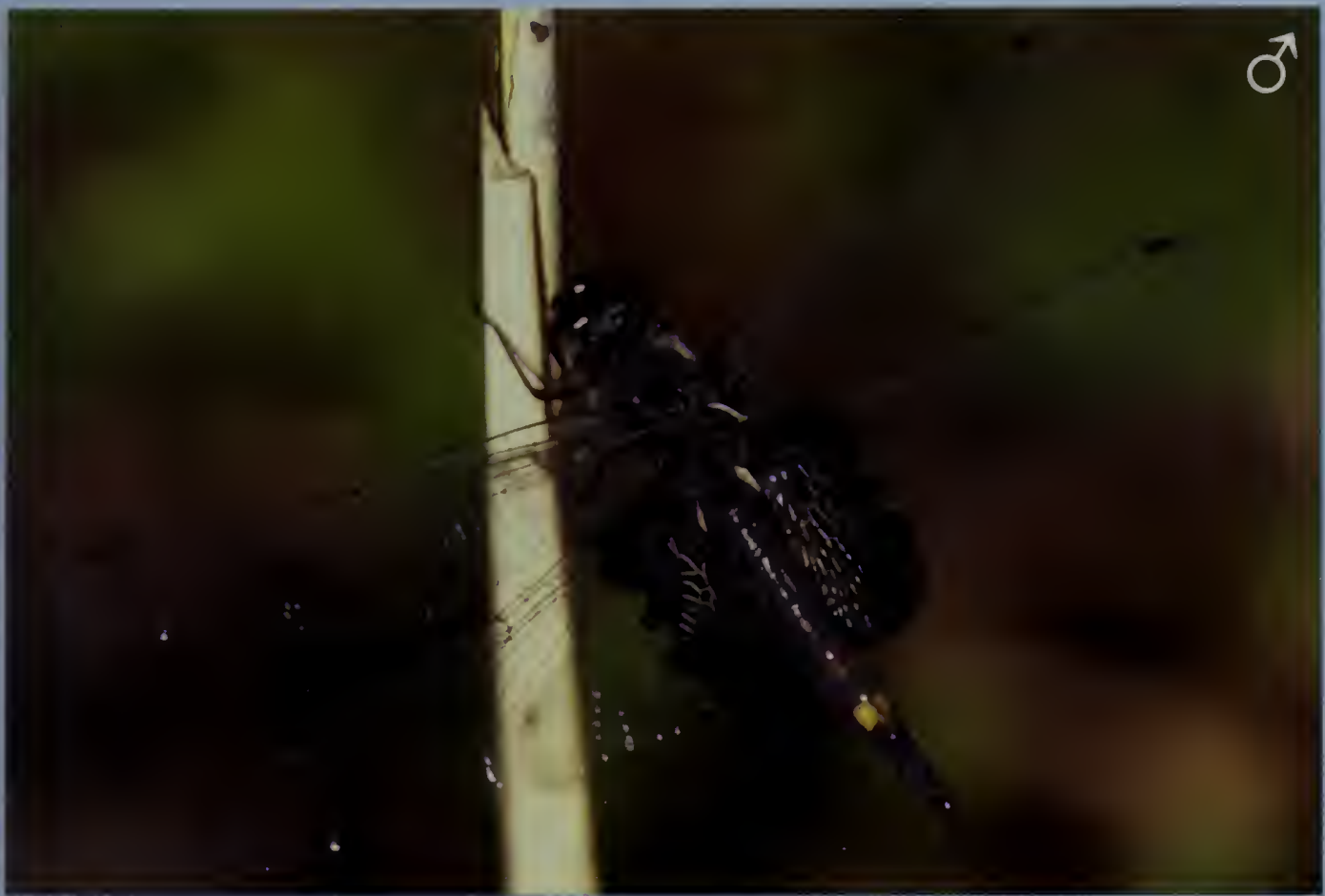

Male thorax and abdomen black with yellowish dorsal spots on S3-S7 that darken with age, those on 57 persisting the longest. Face and eyes black. Hind wings very broad with large black basal patch; forewings with short basal bars; stigma dark brown. Female and immature male similar. An unmistakable species, though in poor light the Carolina Saddlebags (p. 190) can look similarly dark.

RANGE/STATUS U.S.; Canadian Great Lakes region. Fairly common throughout MA, though scarce at higher elevations.

HABITAT Ponds, lakes, marshes, and temporary pools.

NOTES Adults fly along shorelines and over fields and clearings in a leisurely manner, alternating between gliding and flapping, usually at a height of 4-8 ft. Males patrol large expanses of wetlands. Females oviposit either alone or in tandem, with the males periodically releasing the female as they drop down to tap the tips of their abdomens to the water's surface to release eggs. This is a migratory species, often seen along the coastline or mountain ridges in summer and early fall. 
A large, bright red dragonfly with large reddish brown wing patches. Male thorax rusty brown with pale gray or whitish lateral stripes; abdomen bright red, except mostly black on 58-59. Eyes dark reddish-brown. Hind wing very broad, with large reddishbrown basal patch; forewing with reddish basal venation; stigma red. Female and immature male similar, but reddish-brown where male is red. Carolina Saddlebags ( $p$. 190) similar but without lateral stripes on thorax and with a broader "saddle."

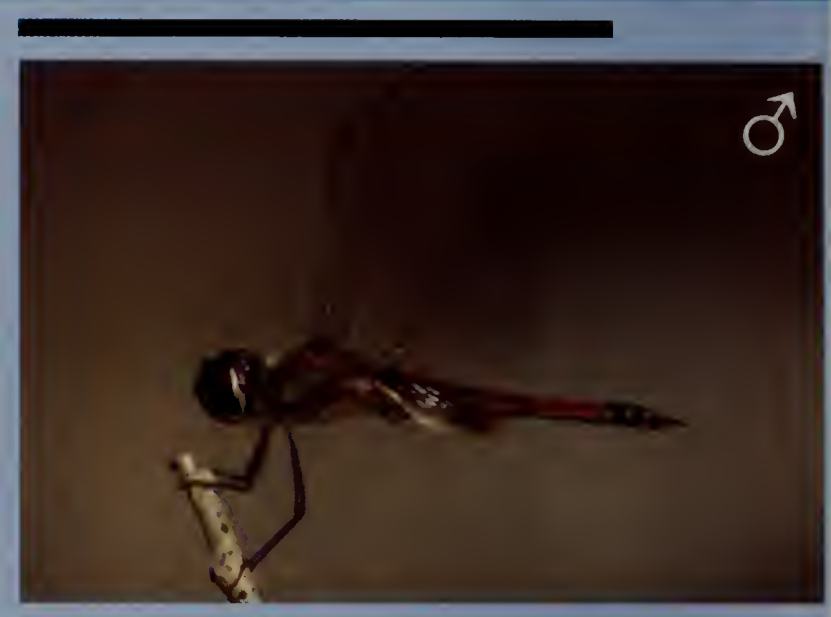

RANGE/STATUS Southern tip of TX and FL. A tropical species that occasionally wanders northward. There are two records from Massachusetts: a sight record from Eastham in 1997, and a specimen collected in Ipswich in 1999.

HABITAT Ponds and slow streams.

NOTES Adults forage over fields. Males patrol along shorelines, perching on emergent vegetation. In $\mathrm{MA}$, most likely along the coast.

\section{Vermilion Saddlebags Tramea abdominalis}

A tropical species that is a rare vagrant in the north. A large, bright red dragonfly with large red wing patches. Male thorax rusty brown; abdomen bright red with black dorsal patches on S8-S9. Eyes dark reddishbrown. Hind wing very broad with red basal patch; forewing with reddish basal venation; stigma red. Female and immature male similar, but reddish-brown where male is red. Striped Saddlebags (above) similar, but with pale lateral stripes on thorax. Carolina Saddlebags (p. 190) has broader, more

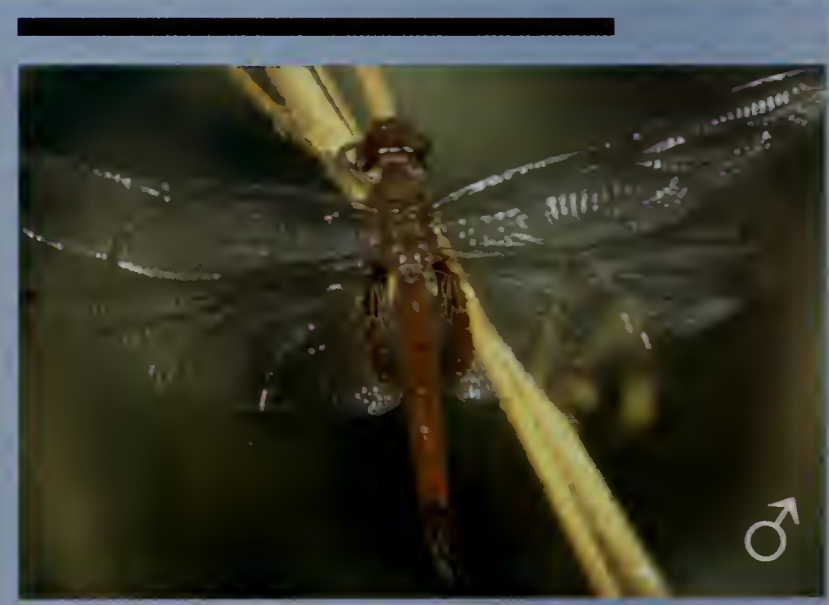
irregularly shaped "saddle."

RANGE/STATUS Southern tip of TX and FL. A tropical species recorded only once north of FL: an 1800's specimen from Nantucket 


\section{GLOSSARY}

ANISOPTERA (the dragonflies) a sub-order of Odonata, characterized by (among other features) having hind wings wider at the base than the front wings

ANTERIOR in front, opposite of posterior

APICAL at or near the tip (apex) of a structure

BASAL at or closest to the body

CERCUS (plural cerci) appendage at the end of the $10^{\text {th }}$ abdominal segment

CREPUSCULAR active at dusk

DISTAL furthest away from the body (opposite of proximal)

DORSAL upper surface; opposite of ventral

ECLOSION emergence of the adult from the skin of the last larval stage; emergence of the larva from the egg

EMERGENCE eclosion of the winged adult from the last larval stage

ENDOPHYTIC method of oviposition in which eggs are inserted into plant tissue, such as stems or leaves EPIPHYTIC method of oviposition in which the eggs are laid directly onto plant tissue or other substrates EPIPROCT dorsal projection from the $10^{\text {th }}$ abdominal segment

EXOPHYTIC method of oviposition in which eggs are either dropped or laid into the water and are not placed on or in plant tissue

EXUVIAE (always plural) the shed skin (cuticle) from the molt from the previous larval instar, often refers to the shed skin from the last larval stage

FEMUR segment of the leg which is proximal to the thorax (the "thigh")

HAMULE either of the two pairs of forked appendages located ventrally on the second abdominal segment of the adult male, part of the secondary genitalia

INFERIOR APPENDAGE ventral appendages at end of $10^{\text {th }}$ abdominal segment

LATERAL on the side

LARVA (plural larvae) immature stage of an insect, between egg and adult, also called nymph or naiad LENTIC still water

LOTIC flowing water

NODUS stout cross-vein near the middle of the leading edge of the wing

OVIPOSITION the act of laying eggs

OVIPOSITOR tubular or valved structure at the end of the female abdomen through which eggs are laid

PARAPROCT One of the two lobes formed by the ventrolateral parts of the epiproct

PHARATE ADULT an adult fully formed, but not yet emerged, from the larval skin (exuviae)

POSTERIOR hindmost, opposite of anterior

POSTOCULAR SPOTS colored spots on the rear of the head behind the eyes

PROXIMAL nearest the body or base of a given part (opposite of distal)

PRUINOSITY a bluish-white bloom on the body of some adult dragonfly species

STIGMA (PTEROSTIGMA) a thickened, opaque spot on the leading edge of the wing near the wing tip

SUPERIOR APPENDAGES dorsal appendages at end of $10^{\text {th }}$ abdominal segment

TANDEM reproductive behavior in which the male and female are linked, the male grasping the female behind her head with his terminal appendages

TARSUS segment of the leg farthest from the body, bearing the claws (the "foot")

TENERAL an adult, just after emergence from the larval stage, when the flight muscles are not fully developed and the exoskeleton is soft, pale, and the wings pearlescent

TIBIA section of the leg between the femur and tarsus (the "calf")

TERMINAL APPENDAGES appendages at the end of the $10^{\text {th }}$ abdominal segment

VENTRAL underside; opposite of dorsal

VULVAR LAMINA the pair of finger or scoop like projections on the underside of the 9 th abdominal segment in females of the Gomphidae, Corduliidae, and Libellulidae. Vulvar lamina are used in oviposition. ZYGOPTERA (the damselflies) sub-order of Odonata, characterized by (among other features) having hindwings and forewings similar in shape 


\section{REFERENCES}

Arnett, R.H. Jr. 2000. American Insects: A Handbook of Insects of America North of Mexico, Second Ed. CRC Press. 1024 pp.

Cannings, R.A. 2002. Introducing the Dragonflies of British Columbia and the Yukon. Royal British Columbia Museum. 96 pp.

Carpenter, V. 1991. Dragonflies and Damselflies of Cape Cod. Cape Cod Museum of Natural History. Brewster, MA. 79 pp.

Corbet, P.S. 1999. Dragonflies: Behavior and Ecology of Odonata. Comstock Publishing Associates

(Cornell Univ. Press). 829 pp.

Curry, J.R. 2001. Dragonflies of Indiana. Indiana Academy of Science. 303 pp.

Glotzhober, R.C. and D. McShaffery (Ed.). 2002. The Dragonflies and Damselflies of Ohio. Ohio Biological Survey Bulletin New Series. Vol. 14, No. 2. 364 pp.

Dunkle, S.W. 1989. Dragonflies of the Florida Peninsula, Bermuda and the Bahamas. Scientific Publishers. 154 pp.

Dunkle, S.W. 1990. Damselflies of Florida, Bermuda and the Bahamas. Scientific Publishers. 148 pp.

Dunkle, S.W. 2000. Dragonflies Through Binoculars. Oxford Univ. Press. 352 pp.

Legler, K., D. Legler, and D. Westover. 1998. Color Guide to Common Dragonflies of Wisconsin. Sauk City, WI .

NatureServe. 2003. www.natureserve.org.

Needham, J.G., M.S. Westfall, Jr., and M.L. May. 2000. Dragonflies of North America. Scientific Publishers. 650 pp.

Nikula, B., J. Sones, D. Stokes, and L. Stokes. 2002. Beginner's Guide to Dragonflies. Donald and Lillian Stokes. $159 \mathrm{pp}$.

Rosche, L. 2002. Dragonflies and Damselflies of Northeast Ohio. Cleveland Museum of Natural History. $94 \mathrm{pp}$.

Walker, E.M. 1953. The Odonata of Canada and Alaska, Vol I. Univ. Toronto Press. 292 pp.

Walker, E.M. 1958. The Odonata of Canada and Alaska, Vol II. Univ. Toronto Press. 318 pp.

Walker, E.M. and P.S. Corbet. 1975. The Odonata of Canada and Alaska, Vol III. Univ. Toronto Press. 308 pp.

Westfall, M.J., Jr. and M.L. May. 1996. Damselflies of North America. Scientific Publishers. 649 pp.

A complete bibliography of New England Odonata is available online at www.odenews.net 


\section{INDEX AND CHECKLIST}

Both common and scientific names are indexed for the species in this book. Use the circles to the right of each column to maintain a record of species observed.

\begin{tabular}{|lrl} 
AESHNIDAE & 69 & \\
Aeshna & & \\
canadensis & 76 & $\mathrm{O}$ \\
clepsydra & 83 & $\mathrm{O}$ \\
constricta & 78 & $\mathrm{O}$ \\
eremita & 79 & $\mathrm{O}$ \\
interrupta & 81 & $\mathrm{O}$ \\
multicolor & 82 & $\mathrm{O}$ \\
mutata E & 82 & $\mathrm{O}$ \\
subarctica T & 80 & $\mathrm{O}$ \\
tuberculifera & 75 & $\mathrm{O}$ \\
umbrosa & 74 & $\mathrm{O}$ \\
verticalis & 77 & $\mathrm{O}$ \\
Amberwing, Eastern & 153 & $\mathrm{O}$ \\
Amphiagrion saucium & 55 & $\mathrm{O}$ \\
Anaax & & \\
junius & 86 & $\mathrm{O}$ \\
longipes SC & 87 & $\mathrm{O}$ \\
Argia & & \\
apicalis & 67 & $\mathrm{O}$ \\
fumipennis & 64 & $\mathrm{O}$ \\
moesta & 66 & $\mathrm{O}$ \\
translata & 65 & $\mathrm{O}$ \\
Arigomphus & & \\
furcifer & 110 & $\mathrm{O}$ \\
villosipes & 111 & $\mathrm{O}$ \\
Basiaeschna janata & 71 & $\mathrm{O}$ \\
Baskettail & & \\
Beaverpond & 141 & $\mathrm{O}$ \\
Common & 140 & $\mathrm{O}$ \\
Mantled & 140 & $\mathrm{O}$ \\
Prince & 143 & $\mathrm{O}$ \\
Spiny & 142 & $\mathrm{O}$ \\
Bluet & & \\
Atlantic & 38 & $\mathrm{O}$ \\
Attenuated SC & 51 & $\mathrm{O}$ \\
Azure & 50 & $\mathrm{O}$ \\
Big & 39 & $\mathrm{O}$ \\
Boreal & 35 & $\mathrm{O}$ \\
Familiar & 34 & $\mathrm{O}$ \\
Hagen's & 41 & $\mathrm{O}$ \\
Little & 44 & $\mathrm{O}$ \\
Marsh & 40 & $\mathrm{O}$ \\
New England SC & 42 & $\mathrm{O}$ \\
Northern & 36 & $\mathrm{O}$ \\
Orange & 52 & $\mathrm{O}$ \\
Pine Barrens $\mathrm{T}$ & 43 & $\mathrm{O}$ \\
Scarlet T & 54 & $\mathrm{O}$ \\
& &
\end{tabular}

\begin{tabular}{|c|c|c|}
\hline Bluet (continued) & & \\
\hline Skimming & 49 & \\
\hline Slender & 46 & \\
\hline Stream & 47 & \\
\hline Taiga & 45 & \\
\hline Tule SC & 37 & \\
\hline Turquoise & 48 & \\
\hline Vesper & 53 & \\
\hline Boyeria & & \\
\hline grafiana SC & 88 & \\
\hline vinosa & 89 & \\
\hline Boghaunter & & \\
\hline Ebony $\mathrm{E}$ & 150 & \\
\hline Ringed $E$ & 151 & \\
\hline Broad-winged Damsels & 13 & \\
\hline CALOPTERYGIDAE & 13 & \\
\hline Calopteryx & & \\
\hline aequabilis & 16 & \\
\hline amata & 15 & \\
\hline dimidiata & 17 & \\
\hline maculata & 14 & \\
\hline Celithemis & & \\
\hline elisa & 170 & \\
\hline eponina & 171 & \\
\hline fasciata & 172 & \\
\hline martha & 173 & \\
\hline Chromagrion conditum & 33 & \\
\hline Clubtail & & \\
\hline Arrow $\mathrm{T}$ & 107 & \\
\hline Ashy & 95 & \\
\hline Beaverpond SC & 97 & \\
\hline Cobra SC & 103 & \\
\hline Dusky & 96 & \\
\hline Harpoon E & 98 & \\
\hline Lancet & 94 & \\
\hline Least & 114 & \\
\hline Lilypad & 110 & \\
\hline Midland E & 105 & \\
\hline Mustached & 101 & \\
\hline Pygmy, Northern & 112 & \\
\hline Pygmy, Southern & 113 & \\
\hline Rapids $T$ & 99 & \\
\hline Riverine $\mathrm{E}$ & 106 & \\
\hline Skillet SC & 104 & \\
\hline Spine-crowned E & 100 & \\
\hline Unicorn & 111 & \\
\hline Zebra E & 108 & \\
\hline abtails & 9 & \\
\hline
\end{tabular}

\begin{tabular}{|lrr} 
Cocnagrion resolutum & 45 & 0 \\
COENAGRIONIDAE & 30 & \\
CORDULEGASTRIDAE & 120 & \\
Cordulegaster & & \\
diastatops & 121 & 0 \\
maculata & 122 & 0 \\
obliqua & 123 & 0 \\
Cordulia shurtleffii & 145 & 0 \\
CORDULIIDAE & 127 & \\
Corporal & & \\
$\quad$ Blue & 160 & 0 \\
Chalk-fronted & 162 & 0 \\
White & 161 & 0 \\
Cruiser & & \\
Illinois River & 126 & 0 \\
Stream & 125 & 0 \\
Cruisers & 124 & \\
Damsel & & \\
Aurora & 33 & 0 \\
Eastern Red & 55 & 0 \\
Dancer & & \\
Blue-fronted & 67 & 0 \\
Dusky & 65 & 0 \\
Powdered & 66 & 0 \\
Variable & 64 & 0 \\
Dar &
\end{tabular}

Darner

Black-tipped 75

Blue-eyed $\quad 82$

Canada $\quad 76$

Comet SC $\quad 87$

Common Green 86

Cyrano 73

Fawn

Green-striped

Harlequin

Lake

Lance-tipped

Mottled

Ocellated SC

Shadow

Spatterdock E

Springtime

Subarctic T

Swamp

Taper-tailed

Variable

Darners

Thoracic stripes
50

O

76

870

860

890

77

85

79

78

83

88

74

82

71

80

72

84

81

69

70

If you encounter a state-listed species (Endangered, Threatened, or Special Concern), please fill out a Rare Animal Observation Form, available at www.state.ma.us/dfwele/dfw/nhesp. 
Dasher, Blue

Didymops transversa

Dorocordulia

$$
\text { lepida }
$$

libera

Dragonhunter

Dragonlet, Seaside

Dromogomphus spinosus

Emerald

$$
\text { American }
$$

Brush-tipped

Clamp-tipped

Coppery E

Forcipate SC

Incurvate $T$

Kennedy's E

Lake SC

Mocha SC

Ocellated

Petite

Racket-tailed

Ski-tailed SC

Williamson's

Emeralds

Enallagma

aspersum

boreale

carunculatum SC

cyathigerum

civile

daeckii SC

divagans

doubledayi

durum

ebrium

exulans

geminatum

hageni

laterale SC

minusculum

pictum $\mathrm{T}$

recurvatum $\mathrm{T}$

signatum

traviatum

vesperum

Epiaeschna heros

Epitheca

canis

cynosura

princeps

semiaquea

spinigera

Erythemis simplicicollis
1540

125

$146 \mathrm{O}$

$147 \mathrm{O}$

930

$175 \mathrm{O}$

$102 \mathrm{O}$

$145 \mathrm{O}$

1290

$130 \quad \mathrm{O}$

$138 \quad \mathrm{O}$

$135 \mathrm{O}$

$136 \mathrm{O}$

$134 \mathrm{O}$

$137 \mathrm{O}$

$133 \mathrm{O}$

$139 \mathrm{O}$

$146 \mathrm{O}$

$147 \mathrm{O}$

$132 \mathrm{O}$

$131 \mathrm{O}$

127

$50 \quad \mathrm{O}$

$35 \mathrm{O}$

370

$36 \mathrm{O}$

$34 \quad 0$

510

$48 \mathrm{O}$

$38 \quad \mathrm{O}$

390

$40 \quad \mathrm{O}$

$47 \mathrm{O}$

$49 \mathrm{O}$

$41 \mathrm{O}$

$42 \mathrm{O}$

$44 \mathrm{O}$

540

$43 \mathrm{O}$

520

$46 \mathrm{O}$

$53 \mathrm{O}$

$72 \mathrm{O}$

$141 \mathrm{O}$

$140 \quad \mathrm{O}$

$143 \mathrm{O}$

$140 \mathrm{O}$

$142 \mathrm{O}$

$155 \mathrm{O}$

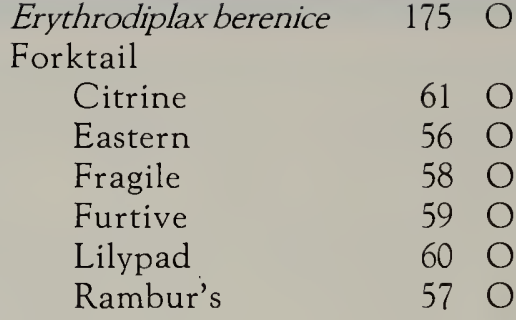

Glider

Spot-winged $\quad 189 \quad 0$

Wandering

Gomphaeschna

antilope

furcillata

GOMPHIDAE

Gomphus

abbreviatus E $\quad 100 \quad \mathrm{O}$

adelphus

borealis SC

descriptus $\mathrm{E}$

exilis

fraternus $\mathrm{E}$

lividus

quadricolor T

spicatus

vastus $\mathrm{SC}$

ventricosus SC

Hagenius brevistylus

Helocordulia uhleri

Hetaerina americana

Ischnura

hastata

kellicotti

posita

prognata

ramburii

verticalis

Jewelwing

Ebony

River

Sparkling

Superb

Lanthus

parvulus

vernalis

LESTIDAE

Lestes

congener

disjunctus

dryas

eurinus

forcipatus
$188 \mathrm{O}$

$84 \mathrm{O}$

$85 \mathrm{O}$

90

100

$97 \mathrm{O}$

980

94. $\mathrm{O}$

1050

$95 \mathrm{O}$

$99 \mathrm{O}$

$96 \mathrm{O}$

$103 \mathrm{O}$

$104 \mathrm{O}$

930

$144 \mathrm{O}$

180

610

600

$58 \mathrm{O}$

590

$57 \quad 0$

$56 \mathrm{O}$

$14 \mathrm{O}$

160

170

$15 \mathrm{O}$

1120

$113 \mathrm{O}$

19

230

210

250

$28 \mathrm{O}$

220
Lestes (continued)

inaequalis

rectangularis

$27 \mathrm{O}$

290

240

260

Leucorrhinia

unguiculatus

vigilax

1850

frigida

glacialis

$186 \mathrm{O}$

hudsonica

$183 \mathrm{O}$

intacta

$184 \mathrm{O}$

proxima

187

Libellula

auripennis

$166 \mathrm{O}$

axilena

1590

cyanea

1560

deplanata

$160 \quad 0$

exusta

1610

incesta

$157 \mathrm{O}$

julia

luctuosa

1620

1650

lydia

needhami

1630

pulchella

1670

quadrimaculata

1640

semifasciata

1690

vibrans

LIBELLULIDAE

1680

1580

MACROMIIDAE

152

Macromia illinoiensis

124

126

Meadowhawk

Band-winged

181

Cherry-faced

177

Jane's

Ruby

177

Saffron-winged

176

Variegated

180

182

White-faced

Yellow-legged

178

1790

Nannothemis bella

$174 \quad 0$

Nasiaeschna pentacantha

730

Nehalennia

gracilis

irene

620

630

Neurocordulia

obsoleta SC

yamaskanensis SC

148

1490

Ophiogomphus

aspersus SC

1160

carolus T

$117 \bigcirc$

howei

1150

mainensis

1180

rupinsulensis 


\begin{tabular}{|c|c|c|c|c|c|c|c|}
\hline $\begin{array}{l}\text { Pachydiplax longipennis } \\
\text { Pantala }\end{array}$ & 154 & $\mathrm{O}$ & $\begin{array}{l}\text { Snaketail } \\
\text { Brook SC }\end{array}$ & 116 & $\mathrm{O}$ & $\begin{array}{l}\text { Stylogomphus albistylus } \\
\text { Stylurus }\end{array}$ & 114 \\
\hline flavescens & 188 & $\mathrm{O}$ & Maine & 118 & $\mathrm{O}$ & amnicola $\mathrm{E}$ & 106 \\
\hline hymenaea & 189 & $\mathrm{O}$ & Pygmy & 115 & $\mathrm{O}$ & scudderi $\mathrm{E}$ & 108 \\
\hline Pennant & & & Riffle T & 117 & $\mathrm{O}$ & spiniceps $\mathrm{T}$ & 107 \\
\hline Banded & 172 & $\mathrm{O}$ & Rusty & 119 & $\mathrm{O}$ & Sundragon, Uhler's & 144 \\
\hline Calico & 170 & $\mathrm{O}$ & Somatochlora & & & Sympetrum & \\
\hline Halloween & 171 & $\mathrm{O}$ & cingulata SC & 137 & $\mathrm{O}$ & corruptum & 182 \\
\hline Martha's & 173 & $\mathrm{O}$ & elongata SC & 132 & $\mathrm{O}$ & costiferum & 180 \\
\hline Perithemis tenera & 153 & $\mathrm{O}$ & forcipata SC & 135 & $\mathrm{O}$ & internum & 177 \\
\hline Petaltail, Gray & 68 & $\mathrm{O}$ & georgiana $\mathrm{E}$ & 138 & $\mathrm{O}$ & janeae & 177 \\
\hline PETALURIDAE & 68 & & incurvata $\mathrm{T}$ & 136 & $\mathrm{O}$ & obtrusum & 178 \\
\hline Pondhawk, Eastern & 155 & $\mathrm{O}$ & kennedyi E & 134 & $\mathrm{O}$ & rubicundulum & 176 \\
\hline Pond Damsels & 30 & & linearis SC & 133 & $\mathrm{O}$ & semicinctum & 181 \\
\hline Progomphus obscurus & 109 & $\mathrm{O}$ & minor & 139 & $\mathrm{O}$ & vicinum & 179 \\
\hline Rubyspot, American & 18 & $\mathrm{O}$ & tenebrosa & 130 & $\mathrm{O}$ & Tachopteryx thoreyi & 68 \\
\hline Saddlebags & & & walshii & 129 & $\mathrm{O}$ & Terminal Appendages & \\
\hline Black & 191 & $\mathrm{O}$ & williamsoni & 131 & $\mathrm{O}$ & Coenagrionidae & 31 \\
\hline Carolina & 190 & $\mathrm{O}$ & Spiketail & & & Lestidae (Lestes spp.) & ) 20 \\
\hline Striped & 192 & $\mathrm{O}$ & Arrowhead & 123 & $\mathrm{O}$ & Gomphidae & 91 \\
\hline Vermilion & 192 & $\mathrm{O}$ & Delta-spotted & 121 & $\mathrm{O}$ & Somatochlora & 128 \\
\hline Sanddragon, Common & 109 & $\mathrm{O}$ & Twin-spotted & 122 & $\mathrm{O}$ & Tramea & \\
\hline Shadowdragon & & & Spiketails & 120 & & abdominalis & 192 \\
\hline Umber SC & 148 & $\mathrm{O}$ & Spinyleg & & & calverti & 192 \\
\hline Stygian SC & 149 & $\mathrm{O}$ & Black-shouldered & 102 & $\mathrm{O}$ & carolina & 190 \\
\hline Skimmer & & & Spreadwings & 19 & & lacerata & 191 \\
\hline Bar-winged & 159 & $\mathrm{O}$ & Spreadwing & & & Whiteface & \\
\hline Elfin & 174 & $\mathrm{O}$ & Amber-winged & 28 & $\mathrm{O}$ & Crimson-ringed & 186 \\
\hline Four-spotted & 169 & $\mathrm{O}$ & Common & 21 & $\mathrm{O}$ & Dot-tailed & 184 \\
\hline Golden-winged & 166 & $\mathrm{O}$ & Elegant & 27 & $\mathrm{O}$ & Frosted & 185 \\
\hline Great Blue & 158 & $\mathrm{O}$ & Emerald & 25 & $\mathrm{O}$ & Hudsonian & 183 \\
\hline Needham's & 167 & $\mathrm{O}$ & Lyre-tipped & 24 & $\mathrm{O}$ & Red-waisted & 187 \\
\hline Painted & 168 & $\mathrm{O}$ & Slender & 29 & $\mathrm{O}$ & Whitetail, Common & 163 \\
\hline Slaty & 157 & $\mathrm{O}$ & Spotted & 23 & $\mathrm{O}$ & Williamsonia & \\
\hline Spangled & 156 & 0 & Swamp & 26 & $\mathrm{O}$ & fletcheri E & 150 \\
\hline Twelve-spotted & 164 & $\mathrm{O}$ & Sweetflag & 22 & $\mathrm{O}$ & lintneri $\mathrm{E}$ & 151 \\
\hline Widow & 165 & $\mathrm{O}$ & Sprite & & & & \\
\hline Skimmers & 152 & & Sedge & 63 & $\mathrm{O}$ & & \\
\hline & & & Sphagnum & 62 & $\mathrm{O}$ & & \\
\hline
\end{tabular}

\section{About the authors}

Blair Nikula has been studying and photographing dragonflies for the past decade. He coedits the dragonfly newsletter Ode News, and maintains the Ode News website, www.odenews.net. Blair is a member of the MA Natural Heritage \& Endangered Species Advisory Committee.

Jennifer L. Loose is an Invertebrate Zoologist with the MA Natural Heritage \& Endangered Species Program. She has been involved in research on the Odonata for several years and has helped direct NHESP's Odonate scientific programs.

Matthew R. Burne was the Vernal Pool Ecologist with the MA Natural Heritage \& Endangered Species Program from 1995-2003. He currently does wetlands consulting and freelance graphic design and scientific illustration. 
Across Massachusetts, dragonflies and damselflies can be seen flying over streams, rivers, lakes, and fields. Their dramatic colors and expert flying skills draw our attention and attract us to their rich diversity. The 166 species that occur in Massachusetts are an excellent subject for nature study, as well as an important part of the state's natural heritage in need of conservation.

This field guide is a valuable tool for those interested in learning about and working toward conserving the diverse odonate fauna of Massachusetts. Included are:

- Detailed accounts of all species recorded in Massachusetts;

- Illustrations of diagnostic characteristics for different species groups;

- Phenology diagrams illustrating flight periods in the state;

- Useful information on range, habitat, and behavior for all species.

This field guide is a product of the Living Waters project, the freshwater conservation initiative of the Massachusetts Division of Fisheries $\mathcal{E}$ Wildlife's Natural Heritage $\mathcal{E}$ Endangered Species Program. Living Waters is a statewide effort to identify and map habitats critical to the long-term conservation of Massachusetts' rare and endangered aquatic species, as well as the diversity of aquatic systems upon which these species depend.

\section{Help Save Endangered Wildlife!
Please contribute to the Massachusetts \\ Help Save Endangered Wildlife!
Please contribute to the Massachusetts}
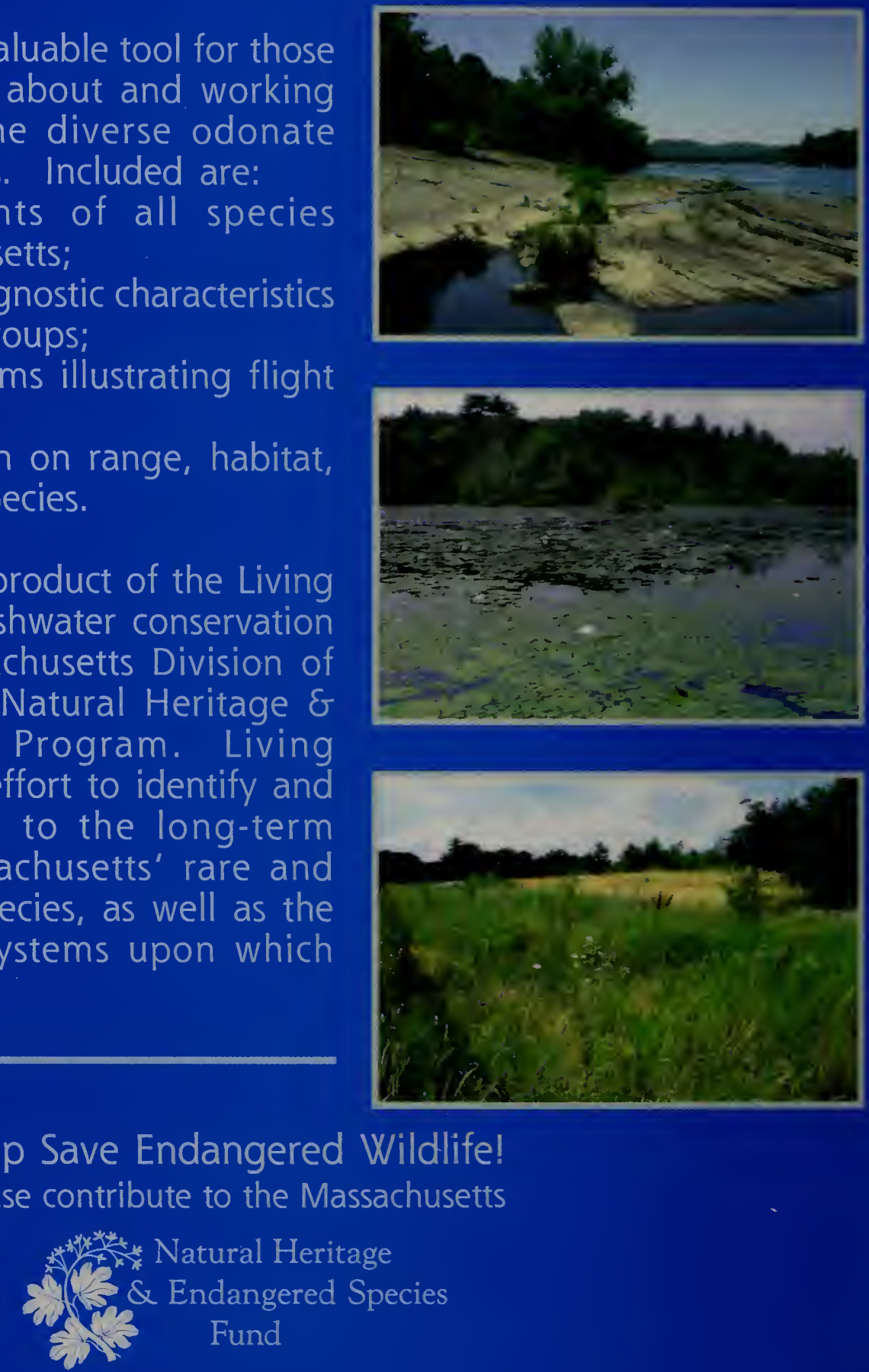

To learn more about the Natural Heritage $\&$ Endangered Species Program, visit our web site at: www.state.ma.us/dfwele/dfw/nhesp. 